\title{
From end-of-pipe technology to clean technology : effects of environmental regulation on technological change in the chlor-alkali Industry in Japan and Western Europe
}

Citation for published version (APA):

Yarime, M. (2003). From end-of-pipe technology to clean technology : effects of environmental regulation on technological change in the chlor-alkali Industry in Japan and Western Europe. [Doctoral Thesis, Maastricht University]. Datawyse. https://doi.org/10.26481/dis.20030508my

Document status and date:

Published: 01/01/2003

DOI:

10.26481/dis.20030508my

Document Version:

Publisher's PDF, also known as Version of record

\section{Please check the document version of this publication:}

- A submitted manuscript is the version of the article upon submission and before peer-review. There can be important differences between the submitted version and the official published version of record. People interested in the research are advised to contact the author for the final version of the publication, or visit the DOI to the publisher's website.

- The final author version and the galley proof are versions of the publication after peer review.

- The final published version features the final layout of the paper including the volume, issue and page numbers.

Link to publication

\footnotetext{
General rights rights.

- You may freely distribute the URL identifying the publication in the public portal. please follow below link for the End User Agreement:

www.umlib.nl/taverne-license

Take down policy

If you believe that this document breaches copyright please contact us at:

repository@maastrichtuniversity.nl

providing details and we will investigate your claim.
}

Copyright and moral rights for the publications made accessible in the public portal are retained by the authors and/or other copyright owners and it is a condition of accessing publications that users recognise and abide by the legal requirements associated with these

- Users may download and print one copy of any publication from the public portal for the purpose of private study or research.

- You may not further distribute the material or use it for any profit-making activity or commercial gain

If the publication is distributed under the terms of Article $25 \mathrm{fa}$ of the Dutch Copyright Act, indicated by the "Taverne" license above,

Download date: 26 Apr. 2023 


\section{From End-of-Pipe Technology to Clean Technology:}

Effects of Environmental Regulation on Technological Change in the Chlor-Alkali Industry in Japan and Western Europe

\section{PROEFSCHRIFT}

ter verkrijging van de graad van doctor aan de Universiteit Maastricht,

op gezag van de Rector Magnificus, Prof. dr. A.C. Nieuwenhuijzen Kruseman volgens het besluit van het College van Decanen, in het openbaar te verdedigen

op donderdag 8 mei 2003 om 14.00 uur

\section{Masaru Yarime}


Promotor:

Prof. Dr. L.K. Mytelka

Beoordelingscommissie:

Prof. Dr. R. Cowan (voorzitter)

Dr. R. Kemp

Professor W.E. Steinmueller (SPRU, University of Sussex)

The following institution sponsored this $\mathrm{PhD}$ thesis research:

United Nations University Institute for New Technologies,

Maastricht, The Netherlands 


\section{Acknowledgement}

Writing this Ph.D. dissertation was a long process, and its completion owes a great deal to many people. I would like to express my gratitude to all the people working at the United Nations University Institute for New Technologies (UNU/TNTECH) and Maastricht Economic Research Institute on Innovation and Technology (MERIT) in Maastricht. I'm particularly grateful to Professor Lynn Mytelka, who provided me with valuable guidance and warm encouragement without which I could not have completed this dissertation. I appreciate very much comments and suggestions of Dr. Anthony Bartzokas, which improved this dissertation greatly. I would also like to thank Ms. Corien Gijsbers for her help kindly given to me in various occasions since I first came to Maastricht in 1995. Professor Yasunori Baba of the University of Tokyo introduced me to the economics of technological change when I was a senior student of chemical engineering. I'm grateful to him for having orientated me to this exciting field. In the process of writing this dissertation, different institutions provided me with financial support. I gratefully acknowledge the Graduate Scholarship of Matsuo Foundation, Ph.D. Fellowship of the United Nations University Institute of Advanced Studies (UNU/IAS), and the Huygens Scholarship of the Netherlands Organization for International Cooperation in Higher Education (NUFFIC). Finally, I would like to thank my family for having encouraged and supported me during the long course of my learning in Japan, the United States, and Europe. 
3.3 THCHNOLOGICAL CHANGE PRIOR TO THE EFFECTS OF ENVIRONMENTAL

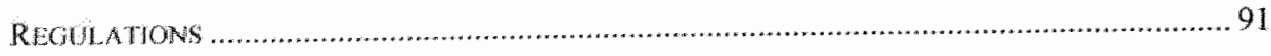

3.3.1 Development of the Mercury Process........................................................... 91

3.3 .2 Development of the Diaphrogm Process ......................................................... 99

3.3.3 Diffusion of the Mercury Process in Western Europe and Japan..................... 106

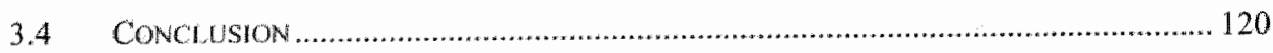

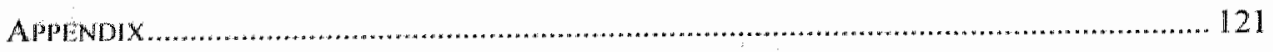

\section{ENVIRONMENTAL REGULATION AND TECHNOLOGICAL CHANGE IN} THE JAPANESE CHLOR-ALKALI INDUSTRY

4.1 Regul atory Decision on The PHAse OUT OF THE MERCuRY Process .............. 123

4.2 Conversion of THE Mercury Process to THE DIA.PHRAGM PROCESS............... 127

4.3 INTERRUPTION OF THE PROCESS CONVERSION SCHEDULE AND EVAlUATION OF THE

ION EXCHANGE MEMBRANE PROCESS ...................................................................... 135

4.4 TECHNOLOGICAL DeVElopmENT OF THE ION EXCHANGE MEMBRANE PROCESS ... 138

4.4.1 Characteristics of the Ion Exchange Membrane Process................................ 138

4.4.2 Patents on Technologies for Chlor-Alkali Producrion.................................. 145

4.4.3 Technological Developments of the Ion Exchange Membrane Process by

Innovative Companies in Japan ..................................................................... 151

4.5 MODIFICATION OF REGULATORY SCHEDULE AND ADOPTION OF THE ION EXCHANGE MEMBRANE PROCESS

4.6 Costly Transtinon from the Mercury Process to THE DIAPHragm Process AND THEN TO THE ION EXChange Membrane Process

4.7 Conclusion

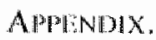

5. ENVIRONMENTAL REGULATION AND TECHNOLOGICAL CHANGE IN THE WESTERN EUROPEAN CHLOR-ALKALI INDUSTRY

5.1 IMPOSTTION OF EMISSION STANDARDS ON MERCURY

5.1.1 Paris Commission

5.1.2 Ewropean Community.

5.2 REDUCTION OF MERCURY EMISSIONS WITH END-OF-PIPE TECHNOLOGIS

5.2.1 Patents on Chlor-Alkali Production Technologies. 
5.2.2 Development of End-of-Pipe Technologies for the Reduethon of Mercm

Emissions

5.2.3 Contimed Use of the Mercury Process with End-of-Pipe Technologies

5.3 DELAYED DEVELOPMENT OF TECHNOLOGIES FOR THE ION EXCHANGE MEMHRANE

PROCESS.

5.4 SLOW DIFFUSION OF THE ION EXChANGE MEMBRANI PROClSS ........................... 269

5.4 .1 Avallability of Information on the Ion Exchange Membrane Process............. 269

5.4 .2 Profitabitity of the Adoption of the Lon Exchange Membrane Process ............ 272

5.4.3 Long Lifetime of Chlor-Alkali Plants Based on the Mercury Process............. 281

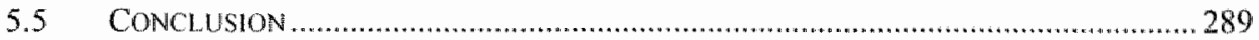

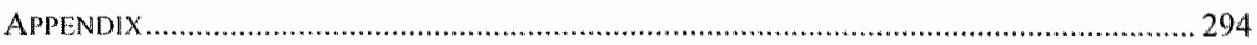

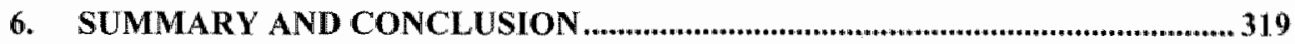

APPENDIX. EFFECTS OF ENVTRONMENTAL REGULATION ON

TECHNOLOGICAL CHANGE OF THE CHEMICAL PROCESSES FOR CHLOR-

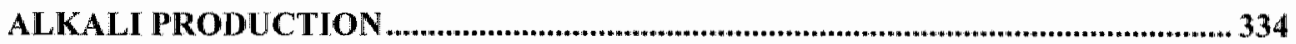

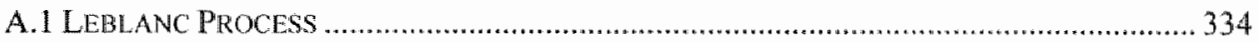

A.1.1 Hydrogen Chloride Emissions ................................................................ 337

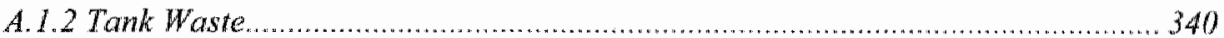

A.1.3 Nitrogen Oxides Emissions.................................................................... 342

A. 1.4 Improvement of the Leblanc Process through End-of-Pipe Technologies.......... 343

A.2 AMMONIA SODA PROCESS .................................................................................... 344

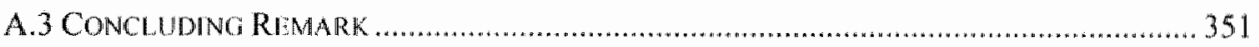

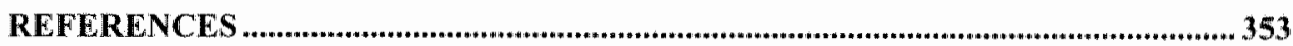

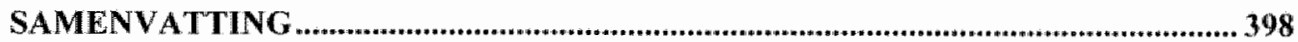

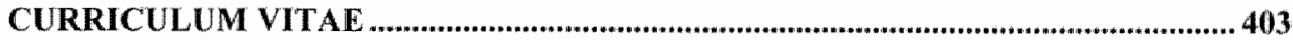




\section{List of Figures}

FIGURE 2-1 ALLOCATION OF R\&D BETWEEN POLLUTION ABATEMENT TECHNDL OGY AND

OUTPUT PRODUCTION TECHNOLOGY

FIGURE 2-2 INCENTIVES TO INNOVATE WITHOUT DIFFUSION, FOLLOWED BY POLICY

ADNUSTMENT.

Figure 2-3 Incentives to InNovate WITH Diffusion AND POLICY AdUUSTMENT

Figure 2-4 INCENTIVIS TO INNONATION WITH THE POSSIBILITY OF IMITATION AND NO POLICY

ADUUSTMENT

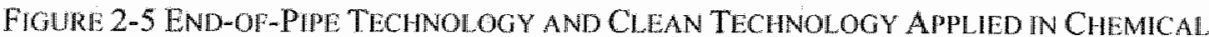

PROCESS INDUSTRIES

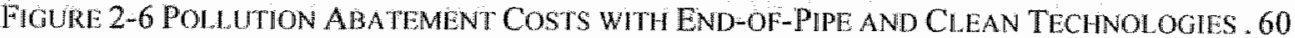

FIGURE 2-7 POLLUTION ABATEMENT COSTS WITH IMPROVEMENTS IN THE ENID-OF-PIPE

TECHNOLOGY AND THE CLEAN TECHNOLOGY

FIGURE 2-8 OPERATING COSTS WITH THE END-OF-PIPE TECHNOLOGY AND THE CLEAN

TECHNOLOGY

Figure 2-9 Production Costs WITH The END-OF-PIPE TECHNOLOGY AND THE CleAN

TECHNOLOGY

FIGURE 2-10 COST SAVING WITH THE PROCESS CONVERSION FROM THE ORIGINAL.

TECHNOLOGY EQUIPPED WITH THE END-OF-PIPE TECHNOLOGY TO THE EFFICIENT CLEAN

TRCHNOLOGY

Figure 2-11 Diverging EFHects of Environmental. REgulations on Technological

ChANGE.

FIGURI: 3-1 Evolution or Production TECHNOLOGIES IN THE CHLOR-ALKAL INDUSTRY .. 88

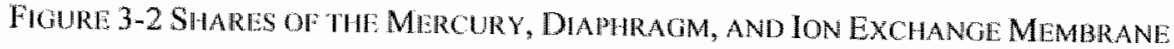

PROCESSES IN WESTRRN EUROPE, THE UNITED STATES, AND JAPAN IN 1998 90

Figure 3-3 Flow Diagram of the Mercury Process

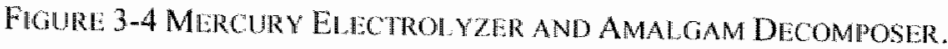
94

Figure 3-5 Flow Diagram of the Diaphiragm Process

Figure $3-6$ DIAPHRAGM El GCTROL rzer.

Figure 3-7 Shares of The Mercury and the Diaphragm Processes in Western Europe, THE: UNTED STATES, AND JAPAN IN 1972 


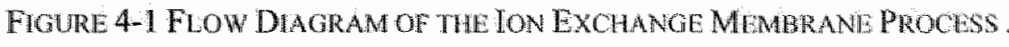
140

FIGURE 4-2 ION EXCHANGE MEMBRANE EleCTrOL YZER

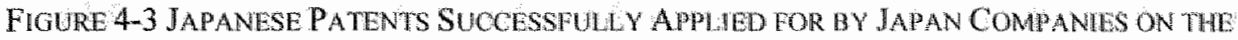

MERCURY, DIAPHRAGM, AND ION EXChANGH MEMBRANE PROCESSES

FIGURE 4-4 R\&D EXPENDITURES AND PERSONNEL FOIR THE ION EXCHANOE MEMBRANL

PROCESS AT ASAHI CHEMTCAL INDUSTRY

FIGURE 4-5 R\&D PERSONNEL for THE ION EXCHANGE MEMBRANE PROCEss at ASAH GLASS

Figure 4-6 TeChNological Developments of Chlor-Alkal Piroduction PROCesses By JAPANESE COMPANIES

Figure 4-7 Supply of the Diaphragm and The Ion ExChange Mimbrane Processes by JAPANESE FIRMS.

Figure 4-8 EnERgy CONSUMptIon of THE MERCURY, DLAPHRAgM, AND ION EXCHANGE

MEMBRANE PROCESSES

Figure 4-9 Production Capactites of the Mercury, Diaphragm, and Ion Exchangl:

MEMBRANE PROCESSES IN THE IAPANESE ChLOR-ALKALI INDUSTRY

Figure 4-10 Operating Period of the Dialyhagm Process at Chllor-Alkali Plants IN

JAPAN.

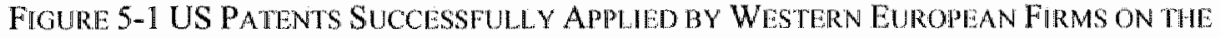

MERCURY and ION EXCHANGE MEMBRane Processes.

FIGURE 5-2 US PATENTS SUCCESSFULLY APPLIED FOR BY JAPANESE COMPANIES ON

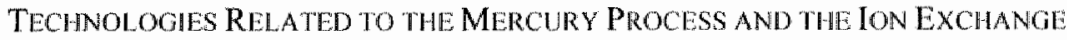

MEMBRANE PROCESS

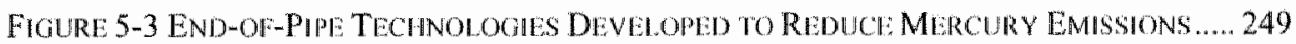

Figure 5-4 MERcury EMISSIONS TO WATER, PRODUCTS, AND AIR From CHLOR-ALKAL,

PLantS IN WESTERN EuROPE:

FIGURE 5-5 Production CAPACITES BASED ON THI MERCURY, DIAPHRAGM, AND ION

EXChANGE MEMBRANE PROCESSES IN THE WISSTERN EUROPEAN Chlor-ALKAl!

INDUSTRY

FIGURE 5-6 TECHNOLOGICAL DEVIGHOPMENTS BY COMPANIES IN WESTERN EUROPE 263

FIGURE 5-7 SUPPLY OF THE MERCURY AND THE ION EXCHANGE MEMBRANE PLOCESS1SS BY WESTERN EUROPEAN FIRMS 
FIGURE 5-8 SUPPL Y OF THE ION EXCHANGE MEMBRANE PROCESS WY JAPANESE AND WESTERN

EUROPEAN FTMS. 268

FIGURE 5 9 COST SAVING FROM THE CONVERSION FrOM THE MERCUR Y PROCESS TO THE ION

EXCHANGE MEMBRANE PROCESS AND ANNUALIZED INVESTMENT COST 280

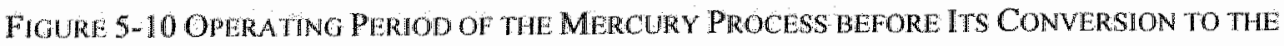
ION EXCHANGE MEMBRANE PROCESS IN THE WESTERN EUROPEAN CHLOR-ALKALI INDUSTRY 282

Figure 5-1 11 OpERATING PERIOD OF THE EXISTING CHLOR-AlkAlI PLANTS BASED ON THE MERCURY PROCESS IN WESTERN EUROPE 284

Figure 5-12 INSTALLATION OF THE MERCURy, DIAPHRAGM, AND ION EXCHANGE MEMBRANE

PROCESSES IN THE WORLD 287

Fugure 5-13 ShAres OF THE MERCURY, DIAPHRAGM, AND ION EXChANGE MEMBrane. PROCESSES IN THE WORLD 288

Figure 6-I Diverging impacts of Envirommental Regulations on Technological CHANGE IN THE CHLOR-ALKALI INDUSTRY IN JAPAN AND WESTERN EUROPE .323 


\section{List of Tables}

TABLE 3-1 APPLICATIONS OF CHLORWE IN JAPAN .......................................................... 81

TABLE 3-2 APPLICATIONS OF CHLORINE IN WESTERN EUROPE.......................................... 82

TABLE $3-3$ APPLICATIONS OF CAUSTIC SODA IN JAPAN .................................................... 83

TABLE 3-4 APPLICATIONS OF CAUSTIC SODA IN WESTERN EUROPE ...................................... 84

TABLE 3-5 ChLOR-ALKal. PRODUCTION CAPACITIES IN THE WORLD................................... 85

TABLE 3-6 ChLOR-ALKALI PRODUCTION CAPACITIES IN WGSTERN EUROPH:.......................... 85

TABLE 3-7 CHLOR-AIKALI PI.ANTS IN WESTERN EUROPE AND JAPAN .................................. 86

TABLE 3-8 MANOR TECHNOLOGIES OF THE MERCURY PROCESS IN THE EARL Y 1970 S .............. 98

TABLE 3-9 Major TECHNOLOGIES OF THE DLAPHRAGM PROCESS IN THE EARLY 1970s......... 105

TAble 3-10 Chlor-Alkali Production Processes In Western Europe in 1957 ........... 107

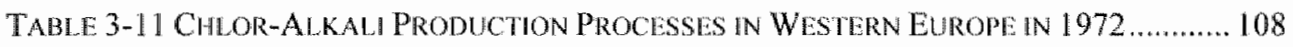

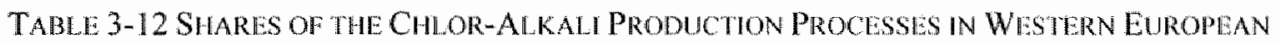

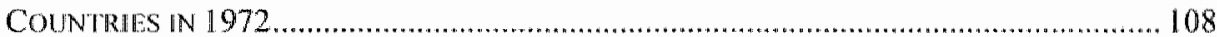

TABLE 3-13 ChLOR-ALKALI PRODUCTION PROCESSES IN THE UNITED STATES IN $1946 \ldots . . . . .109$

TABLE 3-14 TRENDS IN THE SHARES OF THE CHLOR-Alkal. PRODUCTON PROCRSSES IN THE

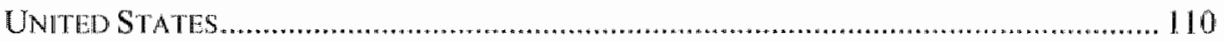

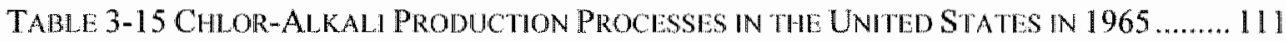

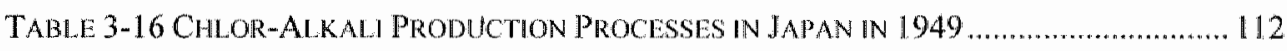

Table 3-17 Shares of the Chlor-Al.kali Production Processes in Japan.................. 112

TABLE 3-18 CHLOR-ALKALI PRODUCTON TECHNOLOGHES IN IAPAN IN $1972 \ldots \ldots \ldots \ldots \ldots \ldots . . . .113$

TABLE 3-19 WORLD PRODUCTION OF MERCURY IN THE: MIDDLE OF THE $1960 \mathrm{~s}$.................... 115

TABLE 3-20 WORLD PRODUCTION OF ASBESTOS IN THE LATE 1930\$ ................................ 115

TABLE 3-21 IMPORTS, EXPORTS, PRODUCTION, AND CONSUMPTION OF AsRISTOS IN THE:

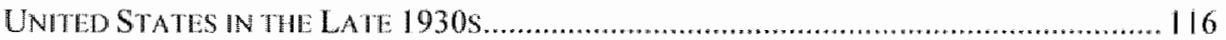

TABLE 3-22 PRODUCTION OF SALT IN WEST GERMANY AND THE UNTTED STATTSS IN TIHE EARLY

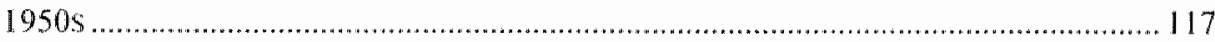

TABLE 3-23 WORLD PRODUCTUON OF RAYON ................................................................. 118

Table 3-24 Shares of Chlor-Alkal. Production Capacities Based on the Mercury,

Diaphragm, and ION EXChange MEMBrane Process Im Western Europe, THE

UNITED STATES, AND JAPAN IN 1998 
TABLE 3-25 SFARES OF CHLOR-ALKALI PRODUCTION CAPACITES BASED ON THE MERCURY AND THE DUAPHRAGM PROCESSES IN WESTERN EUROPE, THE UNTED STATES, AND JAPAN IN 1972

TABLE 4-1 CHRONOLOGY OF ENVIRONMENTAL REGULATIONS ON MERCURY EMISSIONS FROM

CHLOR-ALKALI PLANTS IN JAPAN. 125

TAIILE 4-2 MeMBERS OF THE COMMTTEE ROR THE PROMOTION OF PROCESS CONWERSIONS IN THE SODA INDUSTRY

TABLE 4-3 TAX REDUCTIONS FOR THE PROCESS CONVERSION IN THE CHLOR-ALKALI INDUSTRY

TABLE 4-4 TECHNOLOGIES FOR THE DIAPHRAGM PROCESS ADOPTED DURING THE FIRST PHASE OF THE PROCESS CONVERSION PROGRAM

TABLE 4-5 QUALTY OF CAUSTIC SODA PRODUCED WITH TME MERCURY PROCESS AND THE

DIAPHRAGM PROCESS

TABLE 4-6 ELECTRICITY PRICES IN JAPAN

TABle 4-7 ExCHANGE OF CAUSTIC SODA BETWEEN THE MERCURY PROCESS AND DIAPHRAgM

PROCESS OPERATORS

TABLE 4-8 MEMBERS OF THE EXPER T COMMUTTEE FOR TECHNICAL EVALUATHON OF THE ION

EXChange MEMBRANE PROCESS

TABLE 4-9 JAPANESE PATENTS SUCCESSFU L L APPLIED BY JAPANESE COMPANIES ON THE

Diaphragm Process and the Ion Exchange Membrane Process (I).

TABLE 4-10 JAPANESE PATENTS SUCCESSFULLY APPLIED BY JAPANESE COMPANIES ON THE

DIAPHRAgM Process and THE ION EXchange Membrane Process (II)

TADLE 4-11 CHRONOLOGY OF TECHNOLOGICAL DEVELOPMENTS RELATED TO THE ION

Exchange Membrane Process at Asah Chemical Industry

TABLE 4-12 ChRONOLOGY OF TECHNOLOGICAL DEVELOPMENTS REL ATED TO THE ION

Exchange MEmbrane Process at ASAh GLASS

TABLE 4-13 CHRONOLOOY OF TECHNOLOGICAL DEVELOPMENTS RELATED TO THE ION

EXCHANGE MEMGRANE PROCESS AT TOKUYAMA SODA.

TABLL 4-14 CHRONOLOGY OF TECHNOLOGICAL DEVELOPMENTS RELATED TO THE ION

EXChange MEMHRANe PROCESS AT CEC

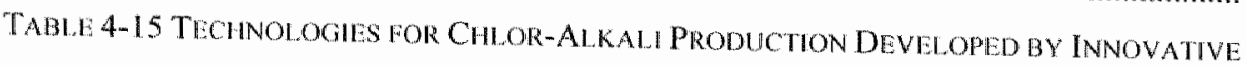

COMPANIES IN JAPAN.

TABIE 4-16 USE OF ION EXCHANGE MEMBRANES FOR SALT PRODUCTION IN JAPAN 
TABLE 4-17 SUPPLY OF THE DLAPHIRAM AND JON EXCHANOU MEMBRANE PROCESSES BY

INAOVATVWE COMPANIES IN JAPAN

TABle 4-18 El ectric Power Consumption of The ION ExChANGe MbMbrane Process

TECHNOLOGIES DEVELOPED BY JAPANESE COMPANES

TABLE 4-19 ADOPTION OF THE ION EXChANGE MEMBRANE PROCESS BY CHLOR-ALKaLI

PRODUCERS IN JAPAN

TABLE 4-20 INVESTMENT COSTS FOR THE PROCESS CONVERSION IN THE JAPANESE CHLOR-

ALKALI INDUSTRY

TABLE 4-2I SOURCES OF INVESTMENT CAPTTAL For THE FIRST PHASE OF THE PROCesS

CONVERSION

TABLE 4-22 LIST OF CHIOR-ALKALI PLANTS IN JAPAN

TABle 4-23 JAPANESE PATENTS ON THE MERCuRY, Diaphragm, and ION EXChANGe

MEMBRANE PROCESSES GRANTED TO JAPANESE FIRMS

TABle 4-24 Energy Consumption of The Mercury, DLAPHragm, and ION ExChange

Membrane Processes

Table 4-25 Production Capacties of the Mercury Process, Diaphragm Process, and

Ion Exchange Membrane Process in the Japanese Chlor-Al.kal.l Industrit...... 201

TABLE 4-26 SUPPLy OF THE DIAPHRAGM AND ION EXCHANGE MEMBRANE PROCESSES BY

JAPANESE FIRMS

TABle 4-27 Supply List of the ION Exchange MEMBrane: Process by ASAH Chemical.

INDUSTRY. 203

TABLE 4-28 SUPPly LIST OF THE ION EXCHANGE MEMBRANE PROCESS by ASAH Gi.ass .... 205 TABLE 4-29 SUPPLY LIST OF THE ION EXCHANGE MEMBRANE PROCESS BY TOKUYAMA SODA

TABLE 4-30 SUPPLY LIST OF THE DIAPHRAGM PROCESS BY CEC. .208

TABLE 4-31 SUPPLY LIST OF THE CME ION EXCHANGE MEMBRANE: PROCESS BY CEC ......... 209

TABLE 4-32 Sluply LIST OF THE MBC ION EXChangl: MEMBRANE PROCESS By CEC........ 211

TABLE 4-33 SUPPLY LIST OF THE BITAC ION EXCHANGE MEMBRANE PROCESS BY CEC ...... 212

Table 4-34 Operating Period of The Diaphragm Process at Chlor-Alkal Plants an

JAPAN 213

TAgle 5-1 EMISSIONS OF MERCuRy in Europlan Conntries IN THE 1970 . 218 
TABLE 5-2 PARCOM DECISHON 80/2 ON LMTT VALUES FOR MERCURY EMIISSIONS IN WATER FROM EXISTING AND NEW BRTE RECIRCULATION CHLORALKALI PLANTS (EXIT OF THE PURIFACATION PLANT).

TABLE 5-3 PARCOM DECISION 81/1 ON LIMIT VALUES FOR EXISTING WASTE BRINE CHLORALKALI PLANTS

TABLE 5-4 PARCOM DECISION 81/2 ON LIMTT VALUES FOR EXISTING BRINE RECIRCULATION CHLOR-ALKAL PLANTS (EXIT OF THE FACTORY STTE)

TABLE 5-5 PARCOM RECOMMENDATION 85/1 ON LIMIT VALUES FOR MERCURY EMISSIONS IN

Water from Extsting Brine Recirculation Chlor-Alkall Plants (EXIT of FACTORY SITE)

TABle 5-6 PARCOM DECision 82/1 ON NEW Chloralkal Plants using Mercury Cells

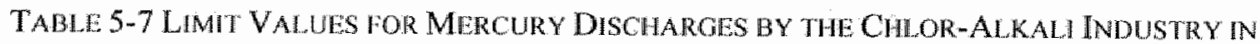
THE COUNCIL DIRECTIVE $82 / 176 / \mathrm{EEC}$

TABLE 5-8 QUALTY OBJECTVES FOR MERCURY DISCHARgES BY THE CHLOR-ALKALI INDUSTRY IN THE COUNCIL DIRECTIVE 82/176/EEC

TABLE 5-9 ENVIROMMENTAL REgulations ON MERCURY EMISSIONS From THE CHLOR-

Alkal Plants IN Western Europe.

TABLE 5-10 US PATENTS SUCCESSFULLY APPLIED BY WESTERN EUROPEAN COMPANIES ON

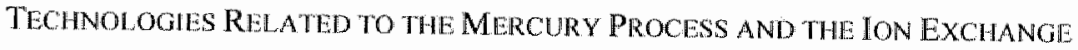
Membrane Process

TABLE 5-11 US PATENTS SUCCESSFULLY APPLIED BY COMPAMIES IN THE WESTERN EUROPEAN CI WOR-ALKALI INDUSTRY ON TICHNOLOGIES RELATED TO THE MERCURY PROCESS ... 241 TABLE 5-12 TECHNOLOGICAL DEVELOPMENT OF THE ION EXCHANGE MEMBRANE PROCESS AT $\mathrm{ICl}$ 255

TABRE 5-13 TECHNOLOGICAL. DEVRloPMENT OF THE ION EXCHANGE MEMBRANE PROCESS AT UHDE:

TABLE 5-14 TECHNOLOGICAL DEVGoPMENT OF THE ION EXCHANGE MEMBRANE PROCESS AT

DE NORA 259

TABEE 5-15 TECHNOL OGIES DEVELOPEO BY COMPANIES IN WESTERN EUROPE 261

TABLE 5-16 Supply of THE MERCURY aND THE ION EXChange MEMBrane Processes BY INNOVATIVE COMPANIES IN WESTERN EUROPE 
TABLE 5-17 PRESENTATIONS ON CHLOR-ALRALI PRODHCTON PROCESSES AT THE LONDON

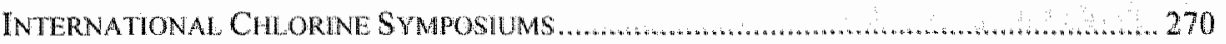

TABLE 5-18 PARTICIPANTS IN THE LONDON INTERNATIONAL CHLORINE SYMPOSIUMS......... 270

TABLE 5-19 LIST OF ChLOR-ALKALI PLANTS IN WESTERN EUROPE ....................................... 296

TABLE 5-20 ChLOR-ALKALI PLANTS IN WIESTERN EUROPE WITHIN AND OUTSIDL THE

CATCHMENT AREA OF THE PARIS CONWENTION.

TABLE 5-21 US PATENTS SUCCESSFULLY APPLIED BY WESTERN EUROPEAN COMPANIES ON

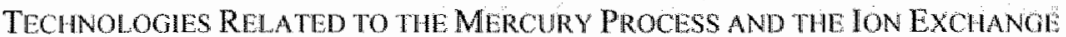

Membrane Process 299

TABLE 5-22 US PATENTS SUCCESSFULLY APPLIED FOR BY JAPANESE COMPANIES ON

TECHNOLOGIES RELATED TO THE MERCURY PROCESS AND THE ION EXCHANGE

MEMBrane PrOCESS 300

TABle 5-23 Mercury Emissions to WATER, Products, and Air From Chlor-Al.kAll

PLANTS IN WESTERN EUROPE. 301

TABLE 5-24 MERcury EMISSIONS from IndividuAl. ChILR-Al KML PLANIS IN WESTERN

EUROPE IN 1999

TABLE 5-25 CHLOR-AIKKALI PRODUCTON CAPACITIES BASED ON THE MERCUR Y PROCESS AND

THE NON-MERCuRY PROCESSES IN WESTERN EUROPE 304

TABLE 5-26 INSTALLA TIONS OF THE MERCURY AND THE ION EXCHANGE MEMBRANE

Processes by Western European firms 304

TABLE 5-27 SUPply OF THE ION EXChANGE MEMBRANE PROCESS BY JAPANESE AND WESTERN

EUROPEAN FURMS. 305

TABLE 5-28 SUPPL Y LIST OF THE ION EXCHANGE MEMBRANE PROCESS BY ICL ..................... 306

TABLE 5-29 SUPPl. LIST OF The ION EXChANGF MEMBRANE PROCESS By UHDE............... 308

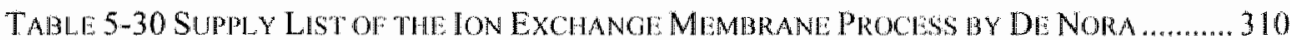

TABle 5-31 NumbEr OF Cell Elaments of Elaftrol yzers

TABLE 5-32 COST SAVING FROM THE CONVERSION OF THE MERCURY PROCESS TO THE ION

EXChange MEMBRANE Process In WESTERN Europe:

TABLE 5-33 START-UP YEAR OF THE MERCURY PROCESS AND THE ION EXCHANGE MEMBRANI:

PROCESS IN WESTERN EUROPE 313

TABLE 5-34 OpERATING YEARS OF THE EXISTING CHLOR-AIKALI PLANTS BASED ON THE

MERCURY PROCESS IN WESTERN EUROPE 
TABLE 5-35 MSTAL ATON OF THE MERCURY, DIAPHAGM, AMD ION EXCHANGE MEMBRANE

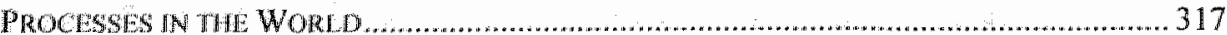

TARLE: 5-36 SHARES OF THE MERCURY, DIAPHRAGM, AND ION EXCHANGE MEMBRANE

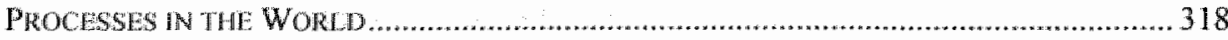




\section{Introduction}

\subsection{Problem and Research Methods}

Our standard of living has improved significantly through the development of a wide range of industries in the past years. Along with numerous products useful in our life, the intensive industrial development has at the same time produced undesirable emissions, which have begun to impose serious burdens on the natural environment. Metals, for instance, have been used so pervasively that currently there are few industrial operations which do not discharge metal-containing emissions into the air, water, or soil. According to one estimate, world-wide industrial emissions of nickel $(\mathrm{Ni})$, cadmium $(\mathrm{Cd})$, copper $(\mathrm{Cu})$, zinc $(\mathrm{Zn})$, and lead $(\mathrm{Pb})$ into the atmosphere averaged approximately $240,380,1,800,17,000$, and 22,000 tonnes per year, respectively, between 1850 and 1900 (Nriagu, 1979). From the beginning of this century to the 1980s, emissions of such toxic metals increased almost exponentially, roughly in parallel to the rate of industrial growth. In the period between 1900 and 1980 the atmospheric emission rates for $\mathrm{Cu}, \mathrm{Zn}, \mathrm{Cd}, \mathrm{Pb}$, and $\mathrm{Ni}$ rose by 6-, 8-, 8-, 9-, and 51-fold, respectively (Nriagu, 1994).

As the natural environment does not possess an infinite carrying capacity, the current industrial input rates are increasingly interfering with the limited capabilities of ecosystems to cope with pollution. Responding to the serious concern on the ongoing contamination of air, water, and soil with pollutants such as non-degradable toxic metals, regulations and policies have been introduced by governments around the world for the aim of reducing emissions from industrial activities. We could observe some sign of decline in emissions rates in recent years, reflecting the efforts devoted for pollution abatement, particularly in countries located in the industrialized world.

There is a growing concern, however, about negative impacts of increasingly tightened environmental regulations on industry (Jaffe, Peterson, Portney, and Stavins, 1995). It is argued that stringent environmental regulations will force firms to invest a considerable amount of financial resources for compliance and that as a result their competitiveness will be lost against those in countries where lax regulations are implemented. In other words, environmental restrictions impose significant costs, slow productivity, and thereby hinder the ability of companies to compete in international markets (Palmer, Oates, and Portney, 1995). Theoretical analysis is often employed to show that environmental regulations should reduce 
procluctivity by requiring firms to spend additional resounces for pollution abatement and control without increasing production output.

On the opposite side, an increasing number of people claim that stringent environmental regulations will enhance the competitive position of firms. For example, they argue that the ever-increasing stringency of environmental regulations will encourage firms to conduct more research and development ( $R \& D$ ) activities and, consequently, produce more innovation in the long run (Porter and van der Linde, 1995a). That is, the necessity to comply with environmental policy will prompt compantes to re-examine their products and production processes carefully and in the end will lead to technological improvements. Spurred by stringent environmental regulations, companies will go beyond mere compliance with regulations and may succeed in creating radically new technologies. That means that regulation-induced R\&D activities could lead to an innovation which has not discovered previously. Successful cases, many of which are those in the U.S., are cited to claim that stringent environmental regulations actually encourage innovation in industry (Porter and van der Linde, 1995b). Their views are conflicting, and the debate still continues. A careful analysis is required to fully evaluate technological impacts of environmental regulation. What would be particularly important is to examine the nature and characteristics of technological change and to incorporate it into the analysis.

Recently, the World Commission on Environment and Development has publicly addressed the concept of "sustainable development." The Commission's report, Our Common Futwre, defined the concept as "development that meets the needs of the present without compromising the ability of future generations to meet their own needs" (World Commission on Envirommental and Development, 1987). The idea of sustainability has become one of the most important principles in guiding our thinking about our long-term relationship with the enviromment. We are now urged to take a balanced and integrated approach to the achievement of both environmental protection and economic development in the future. As stressed by the Organisation for Economic Co-operation and Development (1997), full development and extensive utilization of appropriate technologies in industry will be the key to achieving sustainable development. What we need to consider now is to formulate envirommental regulations in such a way as to encourage innovations on technologies that have the potential to reduce excessive environmental burdens while securing sound economic development. 
Our empirical study is conducted to examine how enviromental regulations affect the course and character of technological cliange through innovative activities of industry. As we can see in empirical studies conducted previously, it is very difficult to measure the stringency of environmental regulations and its effects on subsequent innovations at aggregate levels. To overcome the problems of previous empirical studies due to their aggregate nature and to understand well the nature of the relationship between environmental regulation and innovation, a detailed case study is conducted at a micro-level in this research. It is expected to shed complementary light on the question of how environmental regulations influence firms' activities with regard to the development and adoption of new technologies. It does so by conducting interviews with companies and policy makers as well as analyzing detailed. data on patents and technological processes.

While previous empirical studies mainly deal with the effects of environmental regulation either on the invention or the diffusion of new technologies, this research examines the whole process of innovation, which covers the technological situation prior to the introduction of environmental regulations, the development of new technologies by innovators, and their adoption by themselves and other firms. Closely examining environmental regulations relevant to the case, our study aims at assessing their dynamic impacts on companies' R\&D and adoption of technologies in the entire process of innovation. A historical approach is thus taken in the empirical study. It covers the technological situation before the introduction of environmental regulations, the contents and schedules of the regulations and their modifications, companies' $R \& D$ activities, and adoptions of new technologies, which carnot be analyzed separately when we aim at understanding fully the linkages with one another.

According to the Industrial Pollution Projection System developed by the World Bank (Hettige, Martin, Singh, and Wheeler, 1994), the most pollution-intensive seetors in terms of toxic waste per dollar of output are "chemical process industries" in a brovid sense, which mclude, among others, the chlor-alkali, fertilizers, pesticides, plastics, paper, and metals industries. In contrast to "physical process industries" sucl1 as the machinery and automobile: industries, in which the assembling process plays a crucial role, the chemical process industries depend critically on chemical reactions to produce main products, and that means that by-products are created almost inevitably in the production processes. Thus, practically speaking, the chemical process industries should be given a prime emphasis in our efforts to reduce pollutants emitted into the enviromment. And research on these industries is expected 
to reveal casses in which the effects of environmental regulations on technological change can be observed more clearly, compared with lass pollution-intensive industries. Accordingly, we pay close attention to the chemical process industries in this analysis. As a sector that belongs to the chemical process industries, the chlor-alkali industry is the focus of our case study. This sector is chosen because it is known to emit a large amount of mercury as an effluent while mercury has been the focus of serious public concerns and intensive environmental policies for a long time.

When we analyze process technologies for pollution abatement in chemical process industries, we make extensive use of chemical reaction equations. By doing this, we can clearly classify green innovation into two categories. The first one is end-of-pipe technologies which deal with emissions at the end of the production facilities without any change in the chemical reactions producing the main products. The second category is clean technologies which eliminate undesirable by-products from within the production processes by replacing the current chemical reactions with different routes.

To make an assessment of the impacts of newly introduced environmental regulations on innovation, it is necessary to know the initial conditions of the technological situation. For this purpose, we examine what kinds of technologies had been developed by which companies prior to the introduction of environmental regulations. The trajectory of technological changes is traced by identifying which parts of technologies have been actually modified, in a similar vein to the morphological analysis used by Foray and Grubler (1990). Examination of chemical reactions equations involved in production processes helps us follow the direction and timing of technological change in detail. We also look at data on the types of technologies that had been developed and adopted in order to identify which companies had gained innovative experience and capabillities before environmental regulations started to infuence technological outcones.

As we will see later, in the case of the chlor-alkali industry, basically there are three types of production processes, namely, the mercury process, the diaphragm process, and the ion exchange membrane process. The mercury process had been predominantly developed and adopted in Western Europe and Japan by the time of the early 1970s, just before environmental regulations on mercury emissions were imposed on the chlor-alkali industry. In other words, similar technological conditions existed initially in Western Europe and Japan. Since then, while many of the chlor-alkali manufacturers in Western Europe have continued to use the mercury process, whose mercury emissions have been mainly treated with end-of- 
pipe technologies, the ion exchange membrane proeess has become the dominant production method in the Japanese chlor-alkali industry. Thus, we make a comparison between Japan and Western Europe as a case study appropriate for examining the effects of environmental regulation on technological change, in the sense that we can observe how cnvironmental regulations have contributed to the divergence of initially simillar technological situations to different outcomes'.

Our empirical study examines how environmental regulations on mercury emissions have influenced innovative activities of firms and consequent technological change in the chlor-alkali industry in Japan and Western Europe. We first look at the environmental regulations on mercury emissions from clalor-alkali plants. Considering the difficulties in making quantitative assessment of the stringency of different regulations, we cllosely look at the cletails of the regulations related to mercury emissions. We trace the chronology of different regulatory approaches to the same issue in the two regions, while taking into account institutional aspects of the formation and implementation of environmental regulations and. other related public policies. Official documents of regulatory bodies are surveyed, and interviews are conducted with public authorities and industry associations in each region to obtain detailed information.

Then we make an in-depth investigation into companies' technological responses to environmental regulations. We examine how and when companies conducted innovative activities for what kinds of technology, end-of-pipe technologies or clean technologies, in particular. Interviews are conducted with innovatiwe companies in the chlor-alkali industry in each region to obtain information on the timing and extent of their R\&D activities. It is not easy, however, to secure detailed data on R\&D activities specifically linked to particular technologies. Particularly in our case, we are interested in differentiating R\&D between endof-pipe technologies for the mercury process and clean technologies, including the diaphragm process and the ion exchange membrane process for chlor-alkali production. Furthermore, the use of R\&D measures is not always satisfactory as a proxy for a wide range of technical activities (Freeman, 1994; Griliches, 1990). Thus we also examine the outputs of technological activities conducted by companies.

\footnotetext{
'As the diaphragm process has been the doninant production process in the US chilor-alkali indlustry, its initiat technological conditions were different from those of the Western European or Japanese chlor-alkali industry, and thus we do not examinge in detail the US case in this research.
} 
As an indicator of innovative outputs, patenting activity is analyzed in our study. Using the data on patents a a measurement of inmovation generally poses several difficulties. Firstly, it has been reported that the propensity to apply for patents waries widely across industries (Levin, Klevorick, Nelson, and Winter, 1987). Patenting is relatively umimportant in the automobile industry, for instance, whereas many innovations tend to be patented in the chemical industry. In our study, the focus is placed on innovations in one sector, namely, the chlor-akkali industry, and hence the inter-industry variations of the propensity to patent do not matter. Moreover, since the chlor-alkali industry is a branch of the chemical industry, to which the importance of patents is generally considered to be high, we reasonably expect that patent data would capture many of the relevant innovations made in the industry. Secondly, the propensity to patent might change across time. For example, it is said that recently the ratio of patents to R\&D expenditures has fallen in many industrialized countries. Here we are interested in comparing the relative importance in $R \& D$ between end-of-pipe technologies for the mercury process and clean technologies, which include the diaphragm process and the ion exchange membrane process, but not necessarily the absolute number of patent applications on each process. As we expect that a change in the tendency to patent across time affects different types of chlor-alkali technologies in the same way, the temporal variations of the propensity to patent will not pose a serious problem. We use data on successful patent applications, instead of that on all patent applications, because the quantity of patent applications would be influenced by the strategies of companies and we are interested in equalizing the quality of patents used as an indicator of technological outputs.

While we assume that patent data captures the extent of R\&D activities made in the chlor-alkali industry reasonably well, patents do not necessarily reflect the degree of technological progress exactly. Hence other data on the trends in the performance of various technologies are also collected from other sources. We make an extensive use of reports published in scientific, technical, and trade journals as well as papers presented at seminars and conferences. That contributes to increasing our understanding of technological aspects of each process in detail.

Then the diffusion of new technologies is discussed by examining factors that would affect their adoption by companies. Basically, we consider two prime factors relevant to technological diffusion, namely, the availability of information on new technologies and the profitability of their adoption (Stoneman and David, 1986). The information availability is examined by analyzing reports presented at conferences organized by industry associations 
and technical organizations and papers published in trade journals. The profitability of new technologies is evaluated by using data on the construction cost and the operating cost of the new technologies, compared with the old technology. We then examine the age of the plants based on the old technology as it cructally affects the timing of making investments for replacing the existing technology with new technologies. Detailed data on the existing and new processes are obtained from engineering firms which supply production technologies as well as chlor-allkali manufacturers in the two regions.

\subsection{Outline of the Thesis}

In Chapter 2, we first review theoretical and empirical research previously conducted on effects of environmental regulation on technological change. Our criticism focuses on the way in which technological change for pollution abatement is dealt with in previous studics. In particular, they did not pay sufficient attention to the distinction between end-of-pipe technologies and clean technologies, an aspect which would be crucial in analyzing technological impacts of environmental regulation. Theoretical models mostly assume pollution abatement technologies that reduce emissions incrementally while the marginal pollution abatement cost is increasing. Effectively, that means that the technologies assumed in the models are basically of the end-of-pipe type. On the other hand, the possibility of eliminating emissions from within the production process by using clean technologies has been mostly ignored. Since clean technologies do not produce emissions in the lirst place, the marginal analysis of the pollution abatement cost curve, which is extensively used in theoretical models, becomes inappropriate when we take into account the existence ofl" clean technologies.

Empirical studies mostly did not pay attention the distinction between different types of technology either when examining impacts of environmental regulation on technological change. As many of the previous empirical work examined patents at aggregate levels as the indicator of innovations, they either focused on equipment of the end-of-pipe type such as scrubbers and filters, or included all the innovations observed. That is because it is very difficult to identify clearly the range of clean technologies which could be relevant for their analyses without detailed information on specific production processes. Without taking clean technologies into account, the group of end-of-pupe technologies will limit too narrowly the range of technological change for pollution abatement. On the other hand, if we include all 
types of innovation, the group will contain technologies which have little connection with envirommental aspects and be too broad to be appropriately defined as a range of green innovations. We argue that it is important to examine the nature and character of technologies in detail for an accurate analysis of green iniovation.

Then we move on to show that there are basically two types of technology, namely, end-of-pipe technologies and clean technologies, to deal with emissions formed by industrial activities. End-of-pipe technologies are aimed at reducing emissions at the end of the production facilities, without changing the reactions which produce the main product. Clean technologies, on the other hand, are defined as those which replace the main reactions with different ones, effectively eliminating undesirable by-products from within the production processes. It is end-of-pipe teclinologies that have been mostly developed in the past to reduce emissions from industrial processes. Since end-of-pipe technologies treat pollutants at the end of the pipe for emissions without affecting the main production process, it is relatively easy to adopt and operate them, and various types of the end-of-pipe equipment have been widely adopted in industry. While end-of-pipe technologies only increase the production costs because additional costs are required to install them at the end of the manufacturing facillities, clean technologies, which are aimed at avoiding the formation of pollutants from the beginning by altering the whole facilities, could improve the main production process and potentially reduce the manufacturing cost in the long run.

Incorporating this technological distinction between the end-of-pipe technology and the clean technology, our analytical framework is developed for the effects of environmental regulations on technological change. We argue that different environmental regulations could lead to diverging types of teclanological change. Relatively weak environmental regulations will encourage the adoption of end-of-pipe technologies, which are likely to be much less expensive than clean technologies, at least initially. That in turn will induce more investment in the existing production technology, whose emissions can be expected to be reduced by adopting end-of-pipe technologies. That will make the transition to clean technologies a slow process even when the clean technologies later become more efficient in production, because more plants will have already been built with the old technology by that time, and there will be strong incentives to maintain these existing plants until the end of their lifetimes unless the clean technologies are extremely efficient.

On the other hand, regulations which are stringent enough cannot be complied with just by installing end-of-pipe technologies. That effectively will demand abandoning the existing 
production teclanologies, and, as a consequence, $R \& D D$ activities for inmovation on clean technologies will be encouraged. As there are normally multiple options for cllean technologies, however, a rigidly fixed regulatory schedule will induce companies to make premature decisilons on alternative technologies, which may not be the most appropriate choice from a long-term perspective. Replacenent of these technologies with the one which has turned out to be the best in the end will be costly.

With this analytical framework, we conduct our empirical study of the chlor-alkali industry. In Chapter 3, we look at the history of technological evolution in the chlor-alkali industry, which has a history of more than one hundred years. Since the beginning of the loth century, the production technologies used in the chlor-alkali industry have experienced several major innovations, including chemical and electrolytic processes. Among the electrolytic production processes, we see that the mercury process had become the dominant production process in Western Europe and Japan by the early 1970s, before environmental regulations on mercury emissions started to be imposed in the two regions. We observe that several firms in Western Europe and Japan had developed advanced technologies for the mercury process, and these technologies accounted for the majority of those used by the operators of mercury-based chlor-alkali plants in the two regions. That suggests that there were equally innovative companies in both regions on chlor-alkali production technologies prior to the introduction of environmental regulations, which means that the initial technological conditions in this industry were similar in Western Europe and Japan.

Since environmental regulations were imposed for reducing mercury emissions from chlor-alkali plants in the early 1970s, however, diverging paths of technological change have energed in Japan and Western Europe. The remaining chapters intend to investigate how different environmental policies have contributed to the different technological outcomes between the two regions. We examine the Japanese case in Chapter 4 . In Japan the government imposed a strict regulatory mandate on the chlor-alkali industry to phase out the existing plants based on the mercury process in a very short period of time. That stringent policy gave a spur to innovative companies to develop alternative clean technologies. The regulatory approach, which was initially fixed in a rigid schedule, resulted in inducing many of the chlor-alkali producers to adopt the diaphragm process, as its performance was relatively well established at that time, compared with that of the still-infant ion exchange membrane process. The diaphragm process, however, later turned out to be an inefficient technology, while the ion exchange membrane process was in the process of rapid 
improvement Based on incoming information on the situation of technological developments from the industry, the government interrupted the implementation of the original regulation for a while to assess the extent of progress in developing the ion exchange membrane process. Following an evaluation by experts of the industrial feasibility of the ion exchange membrane process, the regulatory schedule was subsequently modified to allow more time for process conversion. That change in the schedule allowed the remaining mercury process plants to be converted directly to the ion exchange membrane process, which has since progressed to become the best technology among the alternatives, economically as well as environmentally. On the other hand, those mercury-based plants which had adopted the diaphragm process earlier had to be converted again to the ion exchange membrane process. That has made a substantial amount of investment in plants abandoned well before the end of their physical lifetime.

The case of technological change in the chlor-alkali industry in Western Europe is examined in Chapter 5. Less stringent regulations were adopted in Western Europe, where emission standards were imposed on chlor-alkali plants to reduce their mercury emissions. Most of the companies in the industry have chosen end-of-pipe technologies, an option which was much cheaper and more certain than making investment to develop new clean technologies with unclear performance. Various types of end-of-pipe equipment were developed and adopted to reduce mercury emissions to such an extent that regulatory requirements were complied with by most of the mercury process operators. During the following period, many chlor-alkali plants were constructed, relying on the well-established mercury process equipped with end-of-pipe technologies for pollution abatement. Since these plants have not yet reached the end of their physical lifetime, which normally is forty years or longer, chlor-alkali producers in Western Europe have strong incentives to continue to use mercury-based plants, although the ion exchange membrane process has become the most efficient production technology and has been adopted in other countries, including many industrializing countries. In short, relatively weak regulations adopted in Western Europe promoted considerable progress in end-of-pipe technologies to reduce mercury emissions, but resulted in discouraging the development of the ion exchange membrane process, a prime example of the clean technology, even though there were several companies that were imnovative on chlor-alkali production technologies. As the mercury process, equipped with end-of-pipe teclanologies to reduce mercury emissions, has continued to be used in many 
chlor-alkali plants, the diffusion of the efficient ion exchange membrane process has been slow and limited.

Finally, Chapter 6 gives the summary and conclusion of our research. Relatively weak regulations, whose introduction is intended to improve the environmental performance of industrial activities, would encourage innovations on end-of-pipe technologies, and that in effect could work to prolong the life of existing production processes which are in fact getting obsolescent. Stringent regulations, while promoting innovative activities on dean technologies, could induce premature decisions to choose inappropriate technologies. Only when the schedule of implementing stringent regulations maintains a certain degree of flexibility, allowing enough time and experiment for technological progress, will the possibility be secured that efficient clean technologies are fully developed and widely adopted in industry. With our finding of the diverging effects of environmental regulations on technological change, we discuss implications for corporate strategies, policy making, and institutional setups in our attempt to make a transition from end-of-pipe technology to clean technology. 


\section{Analytical Framework for the Effects of Environmental Regulation on Technological Change}

\subsection{Previous Studies of the Effects of Environmental Regulation on}

\section{Technological Change}

\subsubsection{Theoretical Models}

Traditionally, the theoretical foundations for correcting environmental problems have been based on the theory of externalities (e.g. Baumol and Oates, 1988) ${ }^{2}$. With no prices to provide the proper incentives for reducing polluting activities, the inevitable result is that excessive burdens will be imposed on the absorptive capacity of the environment. The obvious solution to this problem is to place an appropriate price, the so-called Pigouvian tax, on polluting activities so that the social costs are fully internalized. A set of Pigouvian taxes equal to marginal social damage then can produce an optimal outcome. This approach essentially focuses on the static efficiency of the problem without paying due attention to the dynamic nature of environmental issues, particularly the effects of technological change. It is assumed that necessary technologies already exist and are readily available to anybody who wants to adopt them and that he or she can smoothly adjust the emission level, depending on economic incentives provided by tax or tradable emission permits.

Environmental degradation, however, is usually a long-term process, in which leclnological change could potentially produce effects of several orders of magnitude larger than the gains and losses calculated in a static framework. Technologies necessary for reducing emissions may not exist, and, even when they exist, their characteristics and performance may not be stable or well established. As Orr (1976) put it, "(w)hat is missing was the view that environmental policy is fundamentally the need to establish a framework that provides continuous and detailed technological adaptation to the impacts on the environment of growth, change in product mix, and change in process technology" (p. 442). This crucial aspect has begun to be addressed in recent studies which examine the effects of environmental regulation on technological change. The new approaches take into account the decisions made by firms on their investment for the development and adoption of

\footnotetext{
3hare are also ther approaches to solving envirommental problems, Coase (1960) proposed to assign liability for damages and let parties bargain to matual benefit to eliminate excessive pollution. This approach, significant
} 
technologies to deal with pollution. These actiwities essentially take place in a dynamic context, making the traditional arguments exclusively focused on the static efficiency seriously inadequate. We examine in the following section these previous theoretical models on the effects of envirommental policy on the development and adoption of new technology for pollution abatement.

Magat (1978) extended the static comparison of effuent taxes and effluent standards to a dynamic world in which firms invest resources in improving their abatement technology as well as their production technology. He employed a simple model of production in which a firm employs one variable input, labor, (at rate $L$ ) to produce its output (at rate $y$ ) and a pollutant (at discharge rate $x$ ). This joint production relation is represented by the production function

$$
L=g(A y, B x)
$$

Technical change occurs through product augmentation, where $A y$ and $B x$ represent the effective output rate and the effective effluent rate, respectively, with the augmentation parameters $A$ and $B$ respectively measuring the levels of the output production and effluent abatement components of the technology. It is assumed that employing more of the input $L$ either raises the output rate $y$, lowers the pollution rate $x$, or some combination of these two effects. Technological advance occurs through expenditures $M$ by a firm which produces a combination of output technology innovation and effluent abatement technology innovation. The parameter $B$ measures the allocation of effective R\&D effort between the two types of technological advance, that is, the bias or direction of technological change. For a given expenditure $M$ on $\mathrm{R} \& \mathrm{D}$, the tradeoff between output technology innovation $\dot{A} / A$ and abatement technology innovation $\dot{B} / B$ occurs along a smooth innovation-possibilities frontict, and increases in R\&D spending $M$ shift out the frontier. A graphic illustration is given in Figure 2-1.

as a theoretical possibility, requires a strong assumption of low transaction costs to achieve an efficient outcome, however, See Fartell (1987) for more detailed discussions on this approach. 


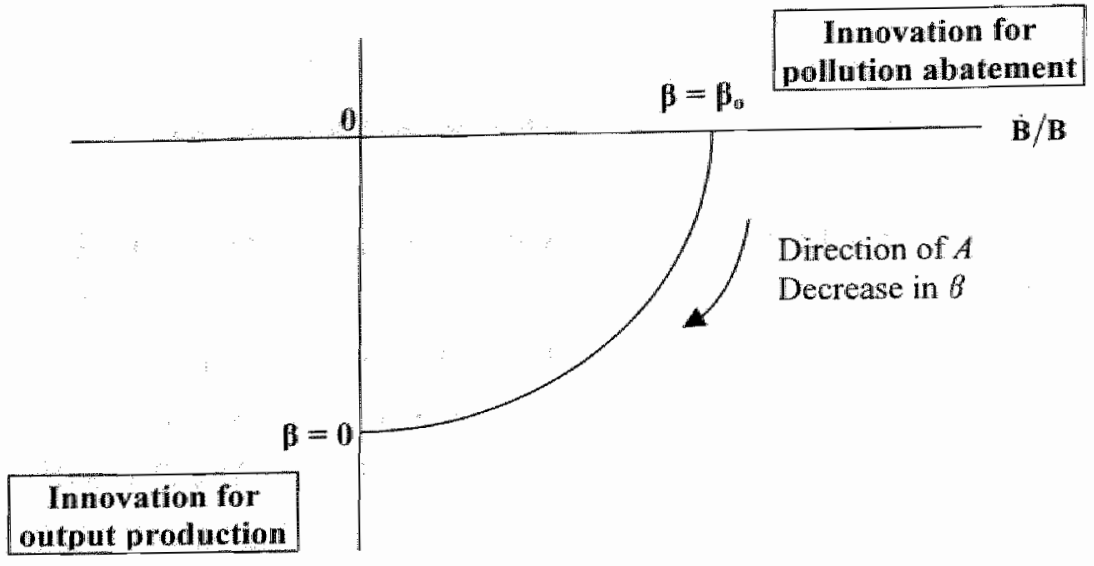

$$
\dot{\mathbf{A}} / \mathbf{A}
$$

Figure 2-1 Allocation of R\&D between Pollution Abatement Technology and Output Production Technology

(Magat, 1978)

With this model, the found that both the constant tax and the constant standard policies will induce a typical firm to increase R\&D effort. (Here the typical firm means that labor substitution between output production and pollution abatement is not particularly difficult.) His analysis showed, however, that the two policy control policies lead to a different allocation of $R \& D$ effort between improvement in abatement technology and improvement in production technology. On the condition that labor substitution is easy, the constant tax induces a pattern of ever-increasing allocations to effluent abatement technology improvement. The constant standard, on the other hand, leads to a direction of technical advance which diverges toward relatively more output techology improvement or diverges toward relatively more effluent abatement technology improvement, depending on the initial value of the direction.

In this model one of the chief assumptions is the tradeoff in the allocation of R\&D between pollution abatement technology and output production technology, analogous to the innovation possibilities frontier model. As we will discuss later, however, in the case of clean technologies, the creation of pollutants is avoided in the first place, and therefore there is no trade-off between pollution abatement and output production. In this case, pollution 
abatement technology is not necessary, and all the $R \& D$ resources will be allocated to improve the efficiency in output production technology, implying that Magat"s model is not appropriate for the analysis of clean technologies.

There are other theoretical studies which focused on the marginal analysis of pollution abatement. Downing and White (1986) constructed a simple model of pollution control innovation by a profit-maximizing polluter who is subject to pollution control policies, including direct regulation as well as economic instruments ${ }^{3}$. A graphic illustration of the model is given in Figure 2-2. The marginal cost curve of abatement and the marginal damage curve of pollution are represented by $M C$ and $M D$, respectively. Their analysis assumes that the control authority has perfect information on the costs of reducing emissions as well as on the benefits of improving environmental quality. Furthermore, it is assumed that the authority reacts immediately to the new innovation, which in turn is fully expected by companies.

\footnotetext{
"Here we consider effuent fees or taxes as representing instruments based on economic incentives. Other economic instruments, notably tradable emission permits, are not examined, as the implementation of emission permits trading is rather difficult because of high transaction costs, particularly when there are many small emitters. Potential sources of transaction costs, would be searching and information, bargaining and decision, and monitoring and enforcement (Stavins, 1995). In this context, see also Marin (1991) for a criticism and Milliman and Prince (1992) for their reply.
} 


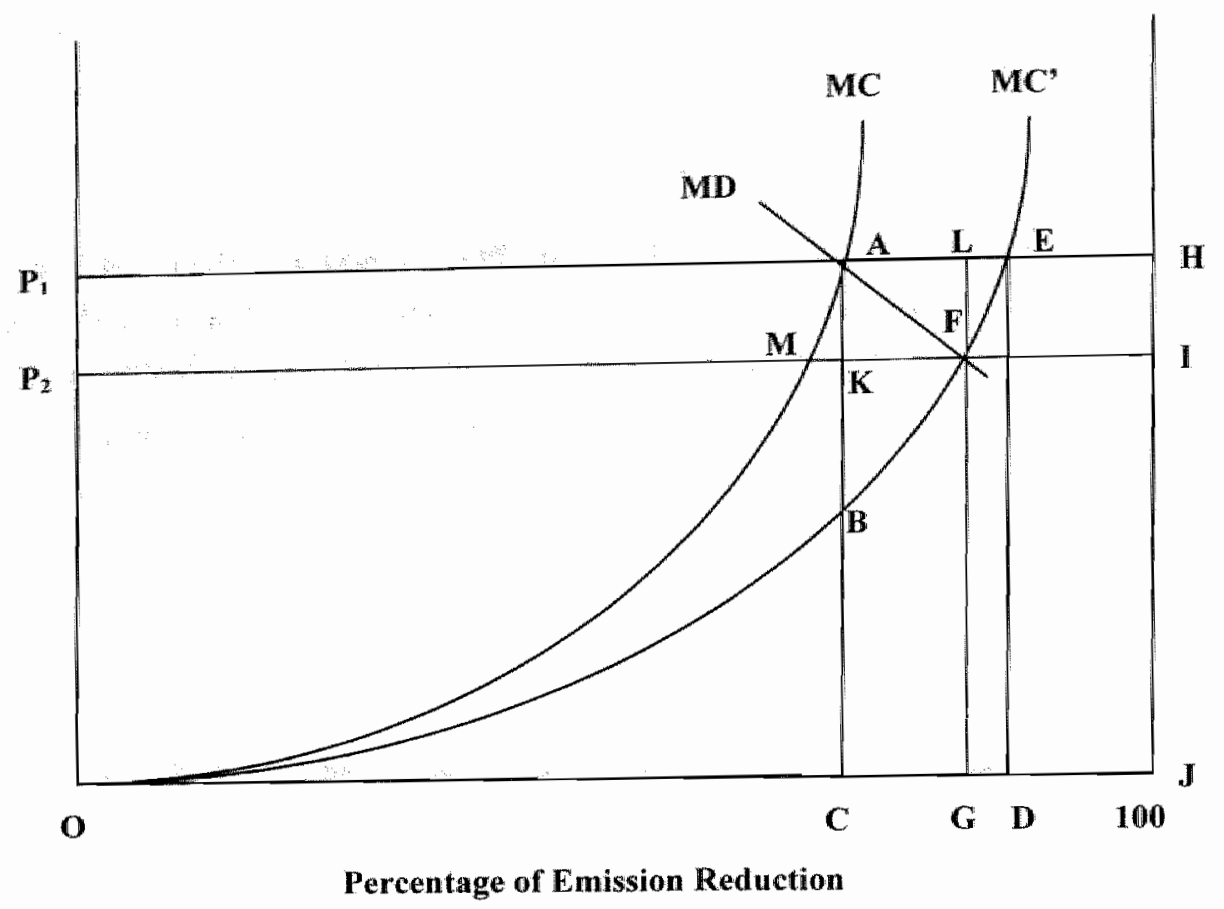

\section{Figure 2-2 Incentives to Innovate without Diffusion, followed by Policy Adjustment} (Downing and White, 1986)

We first consider the case in which the polluter (and the innovation) is a small enough part of the overall pollution problem so that none of the important marginal conditions are changed by the innovation. The benefit to the polluter from the innovation $(M C \rightarrow M C)$ under the effluent fee at $P$, is area $O A E$, the same as the social benefits from the innovation, and the polluter will adopt the innovation when the initial cost of investment for abatenent $X$ is less than $O A E$. On the other hand, under the direct regulation at $C$, the benefit to the polluter from the innovation is area $O A B$, which is smaller than $O A E$ :

$$
O A B<O A E \text {. }
$$

Thus the methods relying on effluent fees are better than direct controls in encouraging innovation".

\footnotetext{
${ }^{4}$ Jung. Krutilla, and Boyd (1996) evaluated the incentive effects of policy instruments for innovation at the industry level, taking into account firm heterogeneity. Their results suggest, consistent with the firm-level amalysis, that incentive-based instruments provide more incentives than performance standards.
} 
When marginal conditions are changed by the innowation, the results remain the same as long as the policy maker does not make any adjustments. In the case where the pollution control authority makes the socially appropriate adjustments (ratcheting), the cfludent fee is reduced from $P_{y}$ to $P_{2}$ or the emission standard is raised from $G$ to $G$. The benefit from the innovation under the effluent fee system is area $(O A H J$ - OFL), that is, OAHIF, wherets whe imnovation benefit under direct regulation is area $(O A C-O F G)$, which is equivalent to (OAB $-B F G C$ ). Since $O A H F$ is larger than $O A B$ and hence ts larger than $(O A B-B F G C)$

$$
O A H I F>(O A B-B F G C) \text {, }
$$

the benefit from the innovation is larger under the effluent system than under direct regulation. Indeed, the innovation benefit under direct regulation could conceivably be negative. This model basically suggests, in line with other studies adopting similar approaches (Wenders, 1975; Zerbe, 1970), that the effluent fee system will provide more incentives to innovate than direct regulation.

While Downing and White (1986) assumed that the innowation is specific to the innovating polluter and cannot be transferred to any other polluter, Milliman and Prince (1989) extended their model by considering the possibility of the adoption of the innovation by other companies. Now there are three steps involwed in the entire process of technological change: invention of a new technology; diffusion of the new technology across fimm; and optimal agency reaction to adjust pollution controls in response to the innovation. They examined firm incentives for technological change under various policy instruments, including direct controls and economic instruments such as emission subsidies, emission taxes, free marketable permits, and auctioned marketable permits. The model is illustrated in Figure 2-3. 
(a) Innovator

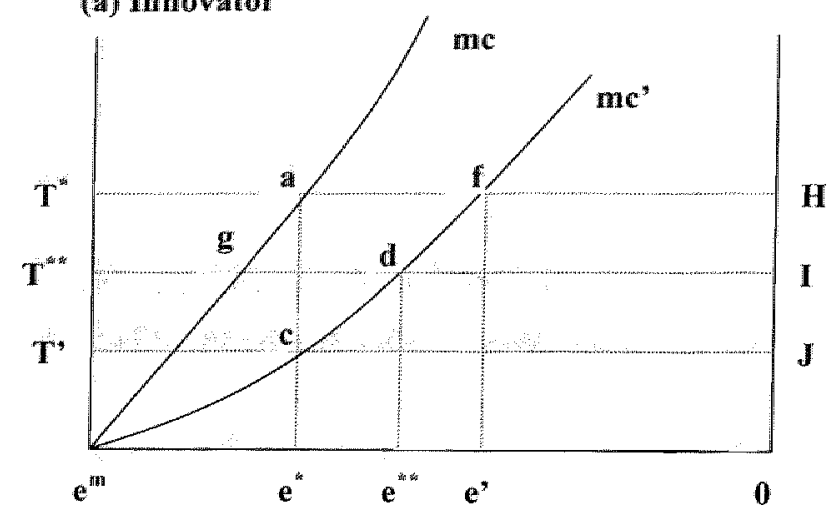

(b) Non-innovator
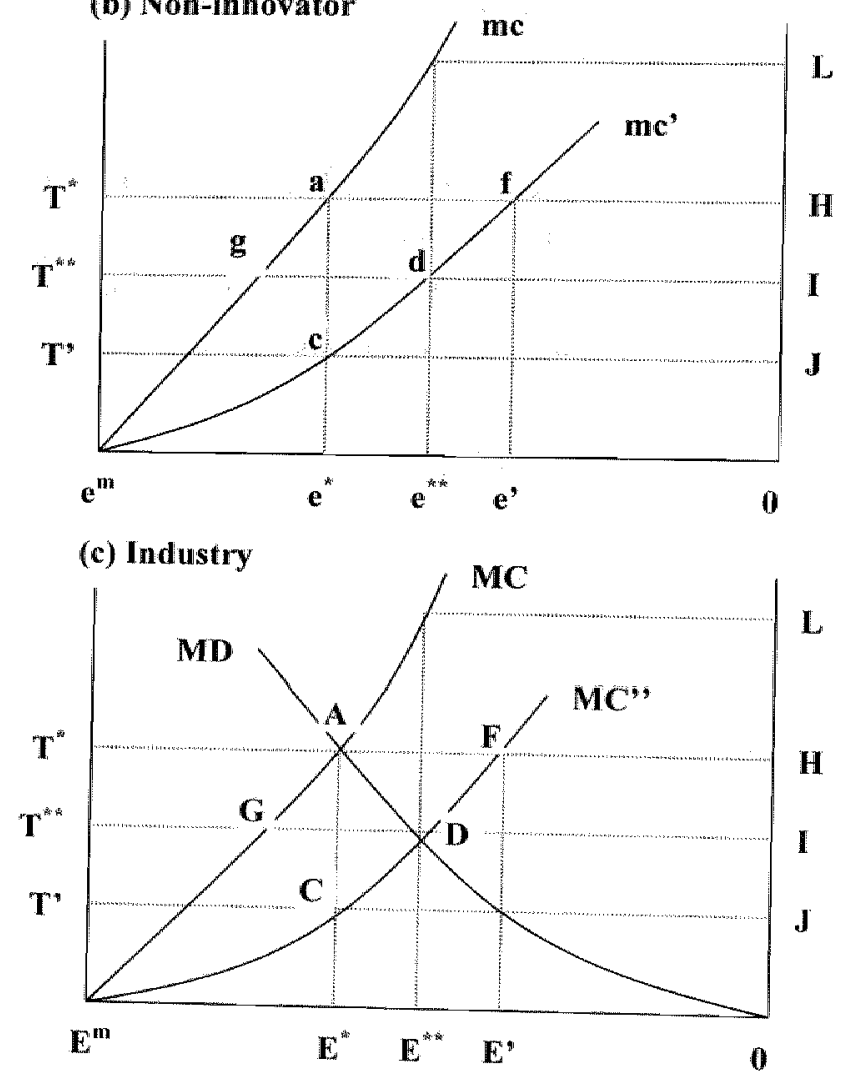

Figure 2-3 Incentives to Innovate with Diffusion and Policy Adjustment (Milliman and Prince, 1989) 
A large number $N$ of identical firms in a competitive industry are each disclarging a homogeneous emission into the enwiromment. The public regulator intends to reduce these emissions to the optimal tate of $E^{*}$ per time period at the industry level (Figure 2-30) either by imposing direct emission control of $e^{\prime \prime}$ per time period on each firm (Figure 2-3a and Figure 2-3b), where $N e^{*}=E^{*}$ (Figure 2-3c), or by establishing a per unit tax equating $T^{*}$ on firm emissions. A single firm develops an innovation which shifts its marginal cost curve from $m c$ to $m c^{\prime \prime}$ (Figure 2-3a). Initially, the aggregate curve $M C$ remains unchanged due to the small size of the firm relative to the entire industry. This is different from the case of Downing and White (1986) in Figure 2-2, where the marginal cost curve $M C$ shifts to $M C$ ' after innovation. Widespread diffusion, however, shifts $n c$ to $m c$ ' for many non-innovating firms (Figure 2-3b), thus eventually shifting $M C$ to $M C^{*}$ " (Figure 2-3c). This necessitates control adjustment to restore efficiency, that is, optimal agency response, either by reducing allowed emission levels to $e^{* * *}$ per firm under direct controls ( $E^{* * *}$ in industry) or by lowering the tax rate from $T^{*}$ to $T^{* * *}$ under emission taxes. It is assumed that the regulator possesses perfect information on current abatement technology, but lags in perceiving a discovery, and that political pressures prevent the regulator from imposing optimal agency response prior to the completion of diffusion.

Firm incentives to promote a particular step, namely, innovation, diffusion, or optimal agency response, are determined by the induced changes in firm abatement costs. Now firm abatement costs are in three forms: the direct cost of abatement (equipment expenses, operating costs); the associated tran'ffer losses (payments made by the firm, such as emission taxes); and the associated transfer gains (payments made to the firm, such as patent royalties). Without any patent on the innovation, diffusion generates no additional innovator gains under direct controls and emission taxes because the innovator lacks a method for capturing rents enjoyed by the copying firms. Hence the imnovator gains from the entire process of technological change for non-patented discoveries are the same as in the case of Downing and White (1986); that is, the innovation changes marginal conditions and the control authority adjusts properly, namely, $e^{m}$ aflld under emission taxes and $e^{m} a c-e^{*} c d e^{* *}$ under direct controls. We can see that emission taxes clearly generate abatement cost reductions for nonpatented technologies.

A patent, however, could allow the innovator to capture some of the gains enjoyed by copying firms. Milliman and Prince (1989) incorporated this aspect into their model by assuming that the innovator captures a set percentage $z(0<z \leq I)$ of all cost reductions 
accruing to non-innovators from patent use, including any beneficial changes in transfer gains or losses. Non-innovator gains from the adoption of the innovation per firm, which are to be divided between the innovating firm and non-innowating firms, are $e^{m}$ ac under direct controls. and $e^{m}$ af under emission taxes. Hence innovator royalties under the two policy instruments are the percentage $z$ times industry-wide non-imnovator gains, or $z(N-1) e^{m} a c$ and $z(N-$ 1) $e^{\prime \prime}$ af, respectively. After control adjustments by the regulator, innovator royalties become $z(N-1) e^{m} k d$ under direct control and $z(N-1) e^{m} g d$ under emission taxes. Royalties increase under direct controls because, with control adjustment, costs without patent access rise $e^{m} a e^{*}$ to $e^{m} k e^{*}$ (Figure 2-3b). Under emission taxes, on the other hand, royalties decrease because abatement costs without patent access decline with control adjustment. Initially, area $e^{n n}$ af (Figure 2-3b) is subject to capture by the innovator with tax rate $T^{*}$; after the lower tax rate $T^{4 *}$ is implemented, the smaller area $e^{m} g d$ becomes subject to capture.

In sum, innovator gains from the entire process of technological change for patented discoveriess are gains for non-patented technology plas royalties, that is, $e^{m} a c-e^{*} c d e^{\text {bix }}+z N$ $-1) e^{m} k d$ under direct controls and $e^{m} a H I d+z(N-l) e^{m} g d$ under emission taxes. We can see that the more firms there are in the industry, that is, a larger $N$, the more royalties the innovator receives and hence the more innovator gains. While the abatement cost reductions under direct controls are smaller than those under emission taxes, that is,

$$
e^{\prime \prime \prime} a c-e^{*} c d e^{*{ }^{*}}<e^{n s} a H I d,
$$

royalties are larger in the former case than in the latter case, that is,

$$
z(N-l) e^{m} k d>z(N-1) e^{m n} g d
$$

Therefore, we cannot unambiguously tell whether direct controls or emission taxes create more innovation benefits for patented technologies. When the innovator can capture all of the benefits accruing to the adoption of the innovation by non-innovating firms, that is, $z=1$, the innovator gains from the total process of technological change under direct controls are

$$
\begin{aligned}
& e^{m \prime} a c-e^{*} c d e^{* * *}+(N-1) e^{m k} k d \\
& =N e^{n \prime} k d-\left(e^{*} c d e^{* *}+c a k d\right) \\
& =N e^{n+\prime} k d-e^{*} a k e^{* *} .
\end{aligned}
$$

That means that the innovator gains from the total process under direct controls consist of the benefits to all $N$ firms of adopting the innovation minus the cost of reducing emissions from $e^{*}$ to $e^{* *}$ by the innovator, which would not have been required if it were not for the regulatory adjustment following the diffusion of the innovation. Similarly, with $z=l$, the total innovator gains under emission taxes are 


$$
\begin{aligned}
& e^{m} a H I d+\left(N-D e^{m} g d\right. \\
& =N e^{m} g d+e^{m} a H D-e^{m} g d \\
& =N e^{m} g d+g a H I
\end{aligned}
$$

This means that under emission taxes the total innovator gains consist of the benefits to all $\mathbb{N}$ firms of adopting the innovation plus the reduction in the abatement cost by the innovator following the reduction in the tax rate from $T^{*}$ to $T^{* *}$. To see the difference in the total benefits under the two policy instruments, we have

$$
\begin{aligned}
& \left(N e^{m} k d-e^{*} a k e^{* *}\right)-\left(N e^{n z} g d+g a H I\right) \\
& =N g k d-e^{*} a k e^{* *}-g a H I .
\end{aligned}
$$

We can see that when there are many firms in the industry, that is $N$ is large, the value could conceivably be positive. In other words, total innovator gains could be larger under direct controls than under emission taxes, a result which is in contrast to the case where the innovation cannot be patented.

They also considered the case in which the innovator is an outside suppliet firm. Since the supplier is not discharging emissions, no private gains are forthcoming from innovation itself; only diffusion and optimal agency response are relevant. Here too it is assumed that the supplier firm can patent an innovation and captures a set percentage $z(0<z \leq l)$ of all private gains accruing to industry firms from patent use. The total patent royalties with diffusion are ${ }_{z} E^{m} A C$ under direct controls and $z E^{n} A F$ under emission taxes. With control adjustment, royalties decline under emission taxes to $z E^{n h} G D$, but increase under direct controls to $z E^{\prime \prime h} K D$. Overall, outside innovator gains from the entire process of technological change are unambiguously positive under all regimes, as they can earn patent royalties without paying any direct costs or taxes. Direct controls, in particular, will encourage innowation by increasing the stringency of the standard, thus increasing the innovation gains.

While Milliman and Prince (1989) assumed that the innovator can appropriate a lixed fraction of the private gains to all the non-innovating firms in the industry from the new technology, Fischer, Parry, and Pizer (1998) considered a case in which the royalty level for the new technology is endogenously determined by the desire of the innovator to atract payment from the marginal, non-innovating firms. Their model consists of a three-stage process of innovation, diffusion, and emission abatement with a fixed number of $n$ identical., competitive firms, one of which is an innovator. First, the innovating firm decides how much to invest in R\&D to develop an emissions abaternent technology. Then the other $n-I$ firms decide whether to adopt this technology in return for a royalty fee or to use an imitation 
technology which is not completely equivalent to the original innovation. Finally, all firms choose emissions abatement to minimize costs, given an emission tax. In this model it is assumed that the rate of effluent taxes is fixed at the pre-innovation leve; that is, there is no policy adjustment following the innovation and its subsequent diffusion to other frms in the industry.

Since firms reduce emissions until the tax rate equals marginal abatement costs, abatement per frrm increases as marginal costs shift down, depicted in by $\mathrm{a}^{\circ}, \mathrm{a}^{\circ}$, and $\mathrm{a}^{\prime}$ with the original technology, the imitation, and the patented technology, respectively. The innovator gains the full abatement cost effect for itself, the area $0 h j$ in the top panel (a). Noninnovators, however, although they realize the same cost savings, are only willing to pay less to adopt the patented technology. This area olj equals the benefit from using the patented technology over the original technology, the area $0 h j$, less the benefit from using the imitation over the old technology, the area $0 h l^{\prime}$, that is,

$$
0 h j-O h l=0 l j \text {. }
$$

Overall, the innovator gets $n$ times the abatement cost effect, $0 h j$, less $(n-1)$ times the imitation effect, Ohl; that is,

$$
\begin{aligned}
& n O h j-(n-l) O h l \\
& =n(O h j-O h l)+0 h l \\
& =n O l j+0 h l .
\end{aligned}
$$

When the imitation technology performs as well as the new, patented technology, that is, $l$ moves to $j$, the innovator gains become $0 h j$. That means that no firm would pay any royalties, because the equivalent imitation technology is freely available, and the innovator gains are limited to the reduction in its abatement costs only. On the other hand, when it is not possible to adopt any imitation technology, that is, $l$ reaches $h$, then the innovator gains become $n 0 h$. In this case the innovator can gain all the benelits through the reduction in abatement costs in the industry. We obtain similar results in the case of emission standards, although the innovator gains from diffusion are smaller than in the case of effuent taxes. In either case, innovation gains which can be captured by the innovator through licenses are constrained by the availability and performance of imitation technologies. 
(a) Innovator

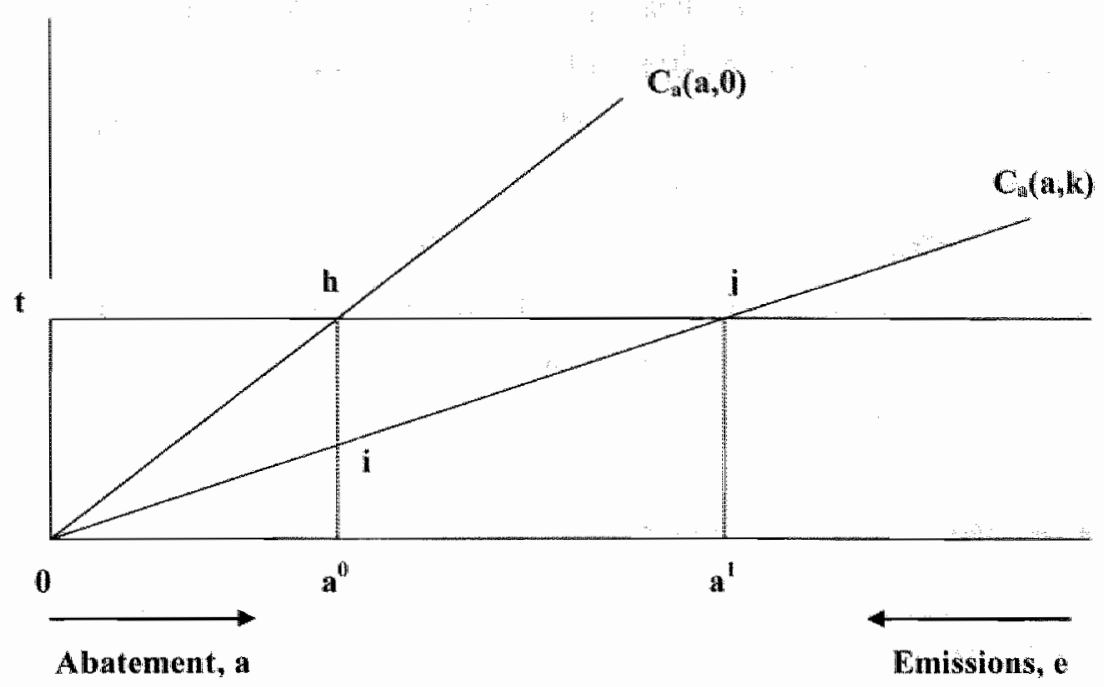

(b) Non-Innovator

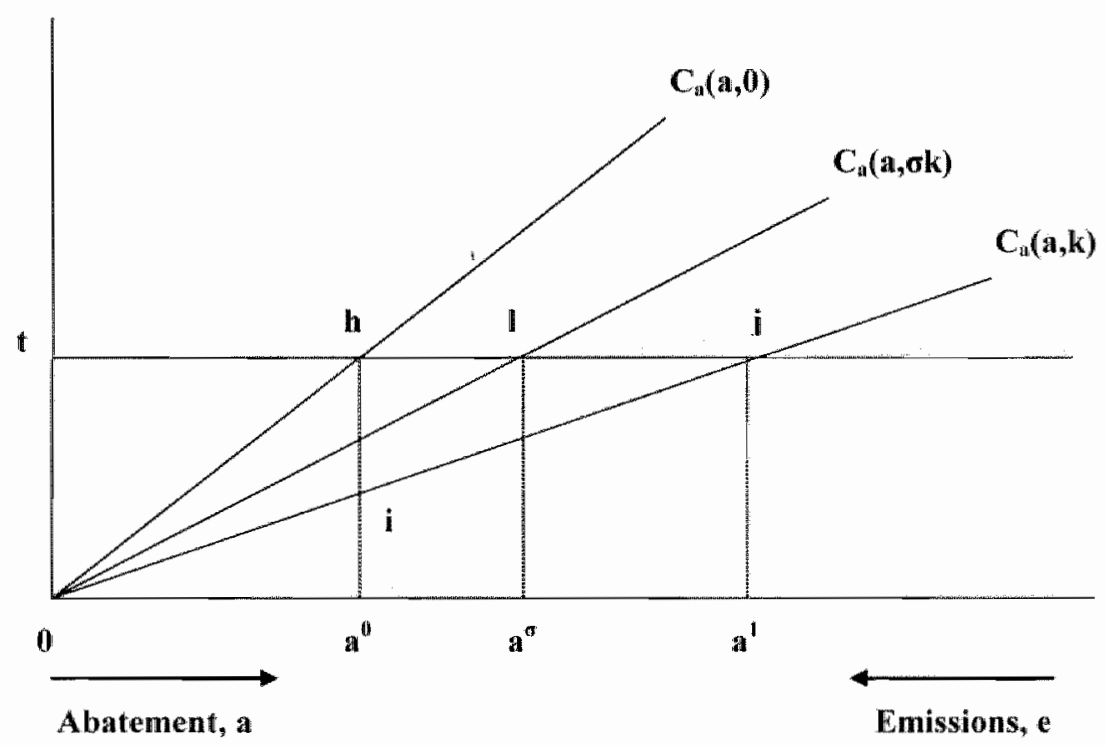

Figure 2-4 Incentives to Innovation with the Possibility of Imitation and No Policy Adjustment

(Fischer, Pary, and Pizer, 1998) 
We can draw some implications from these models. First, when each firm develops its specific technology and there is no diffusion of new technologies to other firms as long as the reduction in pollution emissions is so small that policy is not adjusted to a new, socially appropriate level, innovation benefits under emission taxes are larger than those under command-and-control approaches. In other words, emission taxes will encourage more innovation than command-and-control approaches. When the effects of new technologies are large enough as to prompt policy makers to adjust the control regulation, effluent taxes are again better in inducing innovation than direct control approaches. That is because, while the post-innovation policy adjustment is to raise the effluent standard level under direct control approaches, it is to lower the tax level under emission taxes, which will increase benefits accruing to innovation.

In cases where diffusion of imnovation takes place, as long as innovation is patentable, royalties through adoption of innovation by other firms will increase innovation benefits to the innovator. When there is no adjustment of regulation, innovation benefits will be higher under emission taxes than under command-and-control instruments. If the innovation is diffused thoroughly in the industry, followed by an appropriate policy change, innovation benefits under command-and-control could be higher than under emission taxes. The reason is that the policy adjustment required under command-and-control is to raise the emission standard level, and that will increase the benefits of adopting the innovation by other firms, which in turn will increase the royalty payments to the innovator, on the assumption that the royallies are proportional to the benefits through the adoption of the imnovation. On the other hand, emission taxes will be lowered after the diffusion of the innovation, and that will reduce the benefits to the adopters of the innovation, hence reducing the royalties to the innovator. When imitation technologies are available, they will work to constrain the level of the royalties to the innovator. As the performance of imitation technologies is better, the adopters of the original innovation are willing to pay less to the innovator.

There are many criticisms to various aspects and assumptions contained in these models ". Here our criticism focuses on the assumptions about technological change, particularly the exclusive focus on the end-of-pipe technology for pollution abatement. As we have discussed, Magat (1978) analyzed a case in which there is a tradeoff in R\&D between improvement in output production technology and improvement in pollution abatement

\footnotetext{
For a comprehensive eritique of previous theoretical approaches, see Kemp (1995).
} 
technology. Here the technology considered for pollution abatement is basically that of the end-of-pipe type, and the possibility of developing clean technologies is not taken into account. In our research, the focus is placed on a choice between the end-of-pipe technology and the clean technology. As clean technologies, which do not require any pollution abatement, could achieve improvement in output production as well at the same time, they do not involve any tradeoff between implowement in output production and that in pollution abatement. That is, when a clean technology is chosen, it is not necessary to conduct R\&D on end-of-pipe technology. Hence what will be of critical importance to firms is not to consider the optimal combination of $\mathbb{R} \& D$ efforts between pollution abatement and output production, but rather to choose the end-of-pipe technology or the clean technology for the target of R\&D.

Also, the marginal cost curve of pollution abatement, which has been commonly used in theoretical models, basically means the use of end-of-pipe technologies. The previous models we have discussed (Downing and White, 1986; Fischer, Parry, and Pizer, 1998; Milliman and Prince, 1989) assume that the marginal cost of pollution abatement increases as emissions are reduced. And it is also assumed that the scope for innovation is limited to those in which marginal abatement costs are lowered. In other words, marginal abatement costs are continuous and strictly increasing over a relevant region, and technology adoption is modeled simply as a decline in marginal abatement costs. Effectively, these assumptions mean that pollution abatement is implemented with end-of-pipe technologies. There is, however, another type of technologies for dealing with emissions from the production process, namely, clean technologies. In contrast to end-of-pipe technologies, clean technologies will eliminate the creation of pollutants from within the production process by altering the chemical reactions producing the main product. Since there is no pollution emission in the first place, the marginal abatement cost curve becomes irrelevant for the analysis of clean technologies. Later we will discuss the distinction between end-of-pipe and clean technologies in detail and incorporate into our analytical framework the difference in the dynamic character of technological improwement between the two types of green innovation. This point will have crucial implications in considering the effects of environmental regulation on technological change theoretically as well as empirically. 


\subsubsection{Empirical studies}

There are not so many empirical studies which examined the effects of envirommental regulation on innovation. And most of the previous studies were conducted at aggregate lewels. As one of the influential studies in this area, Lanjouw and Mody (1996) used patent data to investigate the extent of innovation which occurred in the 1970 s and 1980 s. They found that the ratio of water pollution patents to total US patents was flat in the early $1970 \mathrm{~s}$ and rose in the late 1970s to a new plateau, paralleling pollution control expenditures with a two- to three-year lag. And similarly the dramatic fall in water pollution control expenditure during the early 1980 s was followed by a dip in patenting. The same pattern was also observed in industrial air pollution. Based on these findings, they suggest that certain plausible connections exist between environmental regulation and innovation.

In similar vein, Bhanagar and Cohen (1999) studied how environmental patent applications by U.S. manufacturing industries responded to envirommental regulation during the period of 1983 through 1992 . They found that environmental innovation, as measured by the number of successful environmental patent applications, responded to increases in pollution abatement expenditures. They also used government monitoring activities as a proxy for the stringency of environmental regulation and found that increased monitoring and enforcement activities related to existing regulations did not provide incentives to innovate.

Ratnayake (1999) took a broader view of innovation, looking at R\&D in addition to patents. He examined whether environmental regulations enhance or hinder R\&D expenditures, using the data for eight major U.S. industries for the period from 1982 to 1992. His findings suggest no strong evidence to support the view that environmental regulations, measured by pollution abatement costs, have any significant impact on R\&D expenditures on pollution abatement technologies.

Jaffe and Palmer (1997) looked at aggregate innovative activities rather than just eirvironmental technologies. Using panel data on U.S. industries from the middle of the $1970 \mathrm{~s}$ to the early 1990 s, they found that lagged environmental compliance expenditures, which is used as an indicator of the regulatory stringency, have a significant positive effect on total private expenditures on R\&D. However, they could not find any evidence that industries" inventive outputs, measured by successful total patent applications, were related to the

\footnotetext{
"Rethatively speaking, more research has been done on the diffusion of environmentally beneficial technologies. particularly those of the end-of-pipe type. For example, Kemp (1998) made a careful study of the diftusion of
} 
compliance costs. They suggest that their finding might imply that incremental R\&D activity induced by envirommental regulations is not productive or produces results that accomplish only regulatory compliance but that do not come out as patentable innovations.

Overall, these studies produced mixed results on the impact of environmental regulations on innovation. These results require a careful examination, and here we focus our attention to the ways in which the stringency of envirommental regulation and the extent of innovation are measured. In these studies, the stringency of environmental regulations is mostly measured by pollution abatement costs and expenditures (PACE) ${ }^{7}$. While this is not unreasonable, as there is no direct way to measure and compare the stringency of environmental regulations between different industries and countries, we can point out several problems in adopting PACE for that purpose. First, the use of them assumes that high PACE is the result of large efforts made by industries to reduce pollution, therefore reflecting strict environmental regulations. That is, the measurement of PACE is a type of input-oriented indicator of environmental regulation, which are based on input afforts devoted to environmental protection (van Beers and van den Bergh, 1997). Regulatory compliance expenditures as a measure of environmental regulatory burden on industry, however, fall short of providing an exogenous measure of regulatory burden, because the level of these costs also depends on the ability of an industry in reacting to regulations. For example, an inmovative, competitive industry may respond to environmental regulations in a more efficient, cheaper way than a less innovative industry, and hence the former may spend less for compliance, independent of the stringency of environmental regulations.

Furthermore, there are no precise definition of PACE and no simple way to measure it accurately. For example, an investment in energy-saving equipment, which is itself environmentally friendly technology, may have been carried out as a part of normal, profitmaximizing business behavior. Especially in the case of clean technologies, it is difficult to establish what portion of the total investment expenditures should be allocated to pollution

biological waste-water treament technologies in the food and beverage industry in the Netherlards. Here the focus of our discussion is placed on previous stud ies of the development side of lechnological change.

Gray and Shadbegian (1993; 1995) also use the PACE data to examine the impact of environmental regulation on manufactuing productivity at the plat level. There are other approdehes to the ineasurentent. Ir Tobey (1990) the degree of the stringency of environmental policy is measured on a scale from one (tolerant) to seven (stric). Gray and shadbegian (1998) created indices, incorporating the membership rate in major conservation organizations and the percent voting Democratic in Congressional elections to capture diffenences in political support for regulatory stringency. Qualitative indices of regulatory stringency are also used, such as the Conservation Foundation Index, the Fund for Renewable Energy and the Enironment (FREE) Index, and the 
abatement and control. Methodologies of their measurement are diverse across countries, which will make international comparisons difficult ${ }^{3}$.

Instead of input-oriented indicators like the $\mathrm{PACE}$, output-oriented indicators are also used to measure the stringency of environmental regulations. Output-oriented indicators are generally based on the concrete data of environmental situations, such as pollutant emissions

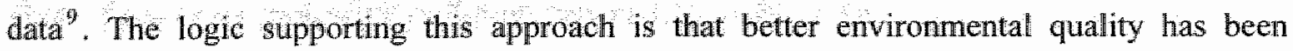
achieved as a result of stricter environmental regulations. Although these output-oriented indicators, unlike the input-oriented indicators, take into account the results of compensating financial support from the government, they also have some limitations. One of the problems is that high quality of the environment is not necessarily due to the imposition of strict environmettal regulations. Natural environmental conditions or other social factors might have produced the current situation without any effect of such regulations. Although the aggregate nature of these studies makes it almost inevitable to use the PACE incurred by firms to measure the stringency of environmental regulations, it is an indicator which is indirect at most and could be even misleading. We need other ways to deal with environmental regulations more directly.

The analysis of innovation for environmental protection also needs to be treated with caution. Lanjouw and Mody (1996) used patents on pollution control technology to examine the connections between environmental regulation and innovation. Their patent data cover nine environmental fields, namely, industrial and vehicular air pollution, waste pollution, hazardous and solid waste disposal, incineration and recycling of waste, oill spill clean-up, and alternative energy. Relevant patents were identified by determining the International Patent Catssification (IPC) classes corresponding to various types of environmentally responsive innovation. For example, the IPC classes which are considered to include patents on technologies dealing with industrial air pollution are as follows: chemical purification of waste gases (B01D-53/34), chemical purification of waste gases by catalytic conversion (B01D-53/36), purifying/modifying gases containing carbon monoxide (C10K-1/3), adding materials to fuels or fires to reduce smoke (C10L-3), burning uncombusted material... (F23B-

Green Index, which was complied by simply adding up the number of statutes from environmental laws (Levinson, 1996).

"A number of issues related to the concept of PACE and the treatment of its statistical estimation are discussed in Schmalensee (1904).

"Xing and Kolstad (1995), for example, adopted sulfur dioxide ( $\left.\mathrm{SO}_{2}\right)$ as a varable to reflect the overall level of environmental regulations when they examined the impact of environmental regulations on foreign direct investment. 
5), removing solid residues, i.e, soot blowers ( $F 231-3$ ), and ... dewices for trating smoke on fumes (F231-15). These IPC clisses were identified by using three keywords, namely" "Treat," "scrub," and "remove" Simillarly, Bhanagar and Cohen (1999) used successful emwironmental patent applications as a proxy for environmental innovation. Those patents counted as environmental patents involve hazardous or toxic waste destruction or containment, recycling or reusing waste, acid rain prevention, solid waste disposal, altemative energy sources, air pollution prevention, and water pollution prevention. As we can see from these lists, most of the technologies identified as environmental techmologies are equipment installed at the end of the main process to remove or reduce emissions. That is, these studies basically looked at end-of-pipe technologies when they examined the technological effects of environmental regulations. The possibility of technologies for eliminating pollution from within the production process by changing the main chemical reaction, that is, clean technologies, is mostly missing from their consideration of innovations related to environmental protection.

Jaffe and Palmer (1997), on the other hand, used data on the whole R\&D expenditures and patent applications in industries to examine the full extent of innowation. That is, their research covers not only technologies for environmental protection, which would include clean technologies as well as end-of-pipe technologies, but also technologies related to products and production processes in general. While this approach does not fail to capture imnovations potentially influenced by environmental regulation in any way, many innovations which are not related to considerations for envirommental protection are also included in the data set. Thus this method of technological measurement would not be entirely appropriate for the analysis of the effects of environmental regulation on technological change.

In sum, their results seem to suggest that increased stringency in environmental regulation encourages patent applications for environmental technologies, mainly those of the end-of-pipe type, but does not influence applications for patents on technologies in general. On the other hand, more stringent regulation seems to raise R\&D expenditures in general, but not those on technologies designed for pollution abatement and control, which are basically end-of-pipe technologies. As these findings are mixed at aggregate levels, an in-depth analysis is necessary to thoroughly investigate the relationship between environmental regulation and technological change. In particular, attention needs to be paid to the crucial aspect of technological characteristics, that is, the distinction between end-of-pipe technologies and clean technologies. While technologies of the former type are relativelly easy to find, those of the latter are particularly difficult to identify at aggregate levels, as they do 
not produce pollutant emissions in the first place and require detailed knowledge and observation. In the following sections, we will examine the difference between end-of-pipe technologies and clean teehnologies and, based on that, discuss our framework for the analysis of effects of environmental regulation on techrological change.

\subsection{Technologies for Dealing with Emissions from Chemical Industries}

Here we analyze technologies for dealing with emissions from the chemical process industries, which are considered to be among the most pollution-intensive sectors, by explicitly considering chemical reaction equations ${ }^{0 .}$. In the chemical process industries, production processes basically consist of four components, namely, the reaction system, separation system, recycling system, and waste treatment system (Mizsey, 1994) ${ }^{11}$. A production process used in the chemical process industries normally start with input materials $I_{a}$ and $I_{b}$ and produce main product $M$ and by-product $B$

$$
I_{a}+I_{b}>M+B
$$

It can be schematically drawn as in Figure 2-5.

\footnotetext{
10 Teblinological trends in pollution-imtensive industries, including, other than those mentioned above, the iron and stes, petrolem relining, and textile industries, are discussed in more detail in Bartzokas and Yarime (1997). In addition, the reaction system norinally involves the heat exchange system for the provision of energy. Finergy consumption wastes, including the gas and ask from fuel combustion, are emitted from the heat exchange system. For making out discussion simple, we do not consider this type of waste here.
} 
Clean Technology
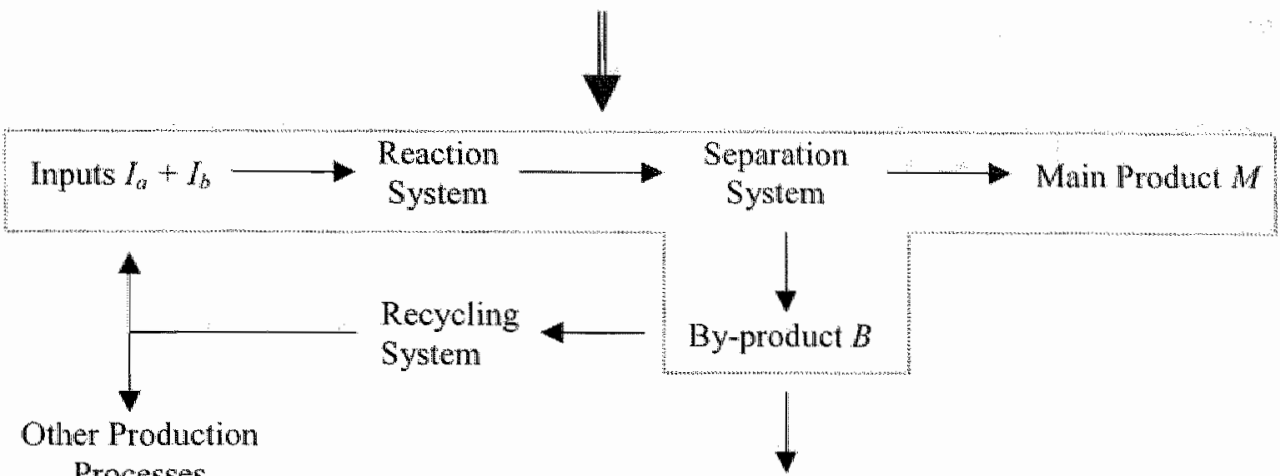

Processes

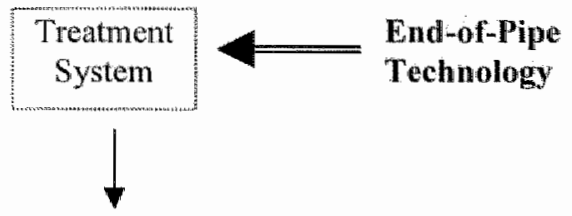

Residues

Figure 2-5 End-of-Pipe Technology and Clean Technology Applied in Chemical Process Industries

The types of technological change designed for environmental protection can be different, depending on the source of pollution, that is, the main product $M^{*}$ or by-product $B^{* 12}$. When the main product $M^{*}$ causes 'disruptions on the environment, the product itself needs to be changed. Among the examples are the chlorofluorocarbons (CFCs), which have been replaced by substitute chemical substances, following the intenational agreement on the phase-out of their production and use ${ }^{13}$. When the by-product $B^{\prime \prime}$ of a manufacturing process is the source of pollution, there are, broadly speaking, two types of technological change to deal with them, that is, the end-of-pipe technology and the clean technology ${ }^{14}$. Since traditionally the source of environmental disruption in the chemical process industries has

\footnotetext{
12 The asterisk denotes that the substance is a pollutant or a hazardous material.

"Technological change for the main product is discussed in more detail in Appendix.

1. Depending on the focus of analysis, other ways of classification would be possible. Green and $\| r w i n$ (1996), for example, suggesi that envirommental technologies can be divided into four categories; (1) end-of pipe treatment; (2) end-ot-pipe recovery for use in the same process or for use elsewhere; (3) officiency improwements in the production process (waste minimization) and substitution of process materials; and (4) radical redesign of the production process.
} 
been the by-product in many cases, we concentrate our discussions on the case of technological change for dealing with the by-product.

\subsubsection{Rnd-of-Pipe Technology}

End-of-pipe technologies aim at removing or transforming wastes emitted from the production process. Basically, it is just added to the end of the production process and deals with by-product $B_{l}$ " without altering the main chemical reactions in the manufacturing process. Therefore, the chemical composition of the main product $M_{1}$ will not be affected; that is,

$$
\begin{aligned}
& I_{a l}+I_{H I}>M_{i}+B_{i}^{*} \\
& \quad \Rightarrow I_{a I}+I_{b I} \rightarrow M_{l}+B_{i}^{\prime \prime} .
\end{aligned}
$$

In addition to raw materials, auxiliary materials might also be inwolved in the production process. These materials are not consumed in the chemical reactions, and among notable examples are catalysts. Since auxiliary materials could be hazardous substances, for instance, heavy metals, it is critical to ensure that they are not emitted to the environment. When the chemical reactions involved in the process are not modified, that is,

$$
\begin{aligned}
& I_{a l}+I_{b l}+A^{*} \rightarrow M_{l}+B_{l}+A^{*} \\
& \quad \Rightarrow I_{a l}+I_{b i}+A^{*} \rightarrow M_{l}+B_{l}+A^{*},
\end{aligned}
$$

end-of-pipe technologies will be emplloyed to deal with the auxiliary material $A$. Useful materials, including the by-product as well as the auxiliary material, could be recovered and fed back into the original production process ${ }^{15}$. In principle, the application of end-of-pipe technologies does not require any change in the production process per se, and its consequent influence will be very limited and predictable.

End-ol-pipe technologies have been used extensively in industry for the treatment of air emissions and waste water. A variety of techniques have been used to remove gaseous. pollutants from effluent streams. Among the techniques used extensively are absorption,

\footnotetext{
${ }_{15}$ In some cases, it could be possible to sell that by-product as an input to other manufacturing processes. The concept of "industrial clusiering" has been proposed as a key methodiology to achieve Zero IEmissions (Pauli, 1995). A potential problem of this approach is that, since the adoption of a new technology in one process will influenee other processes through the interconnedted web of production processes, once an industrial cluster has been fixed, separate individuall introductions of process changes could become very difficult, and coordination among them will be costly, In effect, all the industries involved may get technologically locked-in together (Yarime, 1999\%.
} 
adsorption, condensation, incineration, and selective diffusion through membrane ${ }^{\text {th }}$. for removal of particles from gaseous effuents, there are several classes of control equipment: They are chambers, cyclones, electrostatic precipitators, Gilters, and sonbbers" Industrial waste waters may contain toxic constituents such as heavy metals, or hazardous dissolved or immiscible solvents. There are also a number of end-of-pipe technologies have been adopted. to deal with them ${ }^{18}$.

An example of the use of end-of-pipe technologies can be seen in the production of nitric acid $\left(\mathrm{HNO}_{3}\right)$. The chief environmental problem of nitric acid plant operation is the discharge of nitrogen oxides $\left(\mathrm{NO}_{\mathrm{x}}\right)$, which consists of nitric oxide $(\mathrm{NO})$ and nitrogen dioxide $\left(\mathrm{NO}_{2}\right.$ ), from the vent stack (European Fertilizers Manufacturers' Association, 1995). In the oxidation section of nitric acid plants, ammonia is reacted with air on catalysts, forming nitric oxide and water $\left(\mathrm{H}_{2} \mathrm{O}\right)$ according to the main equation:

$$
4 \mathrm{NH}_{3}+5 \mathrm{O}_{2}>4 \mathrm{NO}+6 \mathrm{H}_{2} \mathrm{O} \text {. }
$$

Nitric oxide is oxidized further to nitrogen dioxide as the combustion gases are cooled, according to the equation:

$$
2 \mathrm{NO}+\mathrm{O}_{2} \leftrightarrow 2 \mathrm{NO}_{2}^{*} \text {. }
$$

\footnotetext{
${ }^{16}$ Absorption is commonly used for devices such as columns containing paching or regularly spaced plates, open spray chambers and towers, and combinations of sprayed and packed chambers. Industrial applications of adsorption include odor control and the removal of volatile solvents such as betzene, ethanol, and trichloroethylene from effluent strearns. Condensation is carried out in a device which appropriately cools the gas stream to remove condensed liquid. Incineration involves the combustion of unwanted chemicals at high temperature to convert them to harmless products such as earbon dioxide and water and is an important process for the treatment of toxic chemicals, where virtually complete removal. is necessary. Selective difiusion processes through membrane have been applied for removing gases such as carbon dioxide, hydrogen sullide, and hydrogen from natural gas (Flagan and Seinfeld, 1988).

${ }^{13}$ Mechanical collectors such as setiling chambers and cyclones are typically suitable for relatively lango particles and are often used as precleaners for the more efficient final control devices. Electrostatio precipitators are one of the most widely adopted particulate control devices, routinely used for fly ash removal from power plant fue gases as well as for the colfection of particles and acid mists in the chemical and metallurgical process industries. The filtration of particles from gas streams is a major class of particulate air pollution control devices, and fabric filters are frequently used to remove solid particles from industrial gases, whereby the dusty gas flows through fabric bags and the particles accumulate on the cloth, and, in particular, to treat combustion gases from coal-fired boilers. Scrubbers are wet collection devices in which small particles can be removed from the gas flow by coltision with water droplets, with the possibility of simultaneously removing soluble gaseous pollutants (filagan and Seinfeld, 1988). The handling and disposal of large volumes of scrubbing liquids must be uncleriaken, however.

${ }^{13}$ Liquid waste streanns with a high suspended solids content have been cleaned up by solids removal in clarifiers, thickeners, and liquid cyclones and by accelerated settling by inclined settlers. Dissolved air flotation techniques have been used to deal with waste streams with very finely divided solids in suspension. Final dewatering of the sludges obtained can be carried out on a continuous fitter or a centrifuge, and the separated solids can be burned or discarded to landfill. Liquid waste streams containing an insoluble liquid, such as those which arise from extraction processes, from steam ejectors operating on solvent distillation systems, or from the loss of heat excharge fluid from a heat exchanger, are phase-separated with a simple settler prior to final
} 
The absorption of the nitrogen oxide to water and its reaction to nitric acid take place according to the equation ${ }^{19}$ :

$$
3 \mathrm{NO}_{2}+\mathrm{H}_{2} \mathrm{O}<-2 \mathrm{HNO}_{2}+\mathrm{NO}^{\circ}
$$

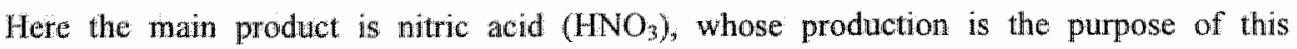
industrial process, and the by-product are nitric acid ( $\mathrm{NO}$ ) and nitrogen dioxide $\left(\mathrm{NO}_{2}\right)$, which together comprise harmful nitrogen oxides $\left(\mathrm{NO}_{4}\right)$.

There are two types of end-of-pipe technologies for $\mathrm{NO}_{\mathrm{x}}$ control. One type of technology is non-selective catalytic reduction (NSCR), and the other is selective catalytic reduction (SCR). In the NSCR process, $\mathrm{NO}_{\mathrm{x}}$ and free oxygen in the waste gas reacts with hydrogen, natural gas; or naphtha over a platinum, rhodium, or palladium catalyst, reducing $\mathrm{NO}_{\mathrm{x}}$ to nitrogen and water. In the SCR process, $\mathrm{NO}_{x}$ in the tail gas reacts with ammonia and only to a lesser extent with oxygen over a catalyst; which can be vanadium pentoxide, platinum, iron/chromium oxides, or zeolites. In either case, the tail gas is preheated and mixed with the reactant gas, and the mixture is passed into a reactor containing the catalyst bed. Thus the main reactions producing nitric acid are not changed, and only these end-of-pipe technologies are added to the main process.

These technologies of the end-of-pipe type are basically designed for installation at the end of the production process, without altering the chemical reactions manufacturing the main product. Technical principles and properties of this type of equipment have been well understood in academic disciplines, particularly in chemical engineering, which deals with how to clesign chemical reactors and equipment based on transport phenomena (Bird, Stewart, and Lightfoot, 1960), thermodynamics (Smith and Van Ness, 1959), and chemical reaction engineering (Levenspiel, 1962). And their feasibilities have been demonstrated through traditional uses for pollution control in many industrial sectors. Thus the scope of R\&D activities for end-of-pipe technologies will be relatively limited, and the uncertainty accompanied by this exploration for new equipment will not be so large. Compared with modifying the whole production process, the installation of an end-pipe technology to the existing production facilities will be relatively easy and cost much less, at least from a shortterm perspective.

disposal. The concentration of residual organics can be further reduced with an, entrained or dissolved air llotation unil coupled with the initial separator (Hocking 1998).

To make it easy to make a distinction between the main product and the by-product in chemical reactions, the main product is underlined with a straght line like $M$, and the by-produci by a dotted line like $B$. 
Just as end-of-pipe technologies do not affeet the mam process, being urstalled at the end of the existing production facilities, however, their operating costs are simply added to the output production costs, which will result in an inerease in the total manufacturing costs. While the operating costs of end-of-pipe technologies could decline, the output production costs will not be changed, as R\&D activity and learning experience on end-of-pipe technologies will not improve the principal process producing the main product. Furthermore, although there are some types of end-of-pipe technologies which are very effective in reducing emissions, it will be extremely difficult, technically speaking, to completely eliminate pollutant discharges with end-of-pipe technologies, and some of the materials will be inevitably emitted to the environment. When the environmental regulation is so stringent as to require total elimination, the adoption of end-of-pipe technologies is not sufficient, and clean technologies will need to be developed and employed.

\subsubsection{Clean Technology}

The function of the clean technology is to eliminate the creation of pollutants from within the production process ${ }^{20}$. In chemical process industries, this means that the chemical reactions involved in producing the main product are modified. New routes of chemical reactions in which the formation of pollutants is prevented in the first place had to be found, and technologies which are feasible to implement them at the industrial level need to be developed $^{21}$. By changing the input materials from $I_{a l}$ and $I_{b y}$ to $I_{a 2}$ and $I_{b z}$ (including the possibility of using the same $I_{b}$ instead), the environmentally undesirable by-product $B_{l}{ }^{*}$ can be changed to another material $B_{2 ;}$ that is,

$$
\begin{aligned}
I_{a j} & +I_{b j}>M_{1}+B_{1}{ }^{*} \\
& \Rightarrow I_{a_{2}}+I_{b_{2}} \rightarrow M_{1}+B_{2} .
\end{aligned}
$$

Various types of clean technologies have begun to be developed and utilized in industrial production.

\footnotetext{
20 There are many ways of defining clean technology. Hanmer (1997) takes the tem in a broad sense, incorporating technologies for pollutant and waste minimization, as well as energy and natural resource efficiency, applicable to various stages in the production. use, and disposable/reuse of products and to the provision of service. Jackson (1994) adlopts a view that it is an operational approach to the development of the system of production and consumption, which incorporates a preventive approach to environmental protection. To address the qualitative difference from the end-of-pipe teclanology, we define the clean teclinology rather narrowly in this research. For a detailed discussion on various ways of defining the clean technology, see McMeekiri and Green (1995).
} 
For example; methyl methacrylate $\left(\mathrm{MMA}, \mathrm{CH}=\mathrm{C}\left(\mathrm{CH}_{3}\right) \mathrm{COOCH}_{3}\right)$, which is an important monomer in the plastic industry, is usually synthesized from propylene $\left(\mathrm{CH}_{3} \mathrm{CH}=\mathrm{CH}_{2}\right)$ and benzene $\left(\mathrm{C}_{6} \mathrm{H}_{6}\right)$ via acetone $\left(\mathrm{CH}_{3} \mathrm{COCH}_{3}\right)$. This route, which is called the acetone-cyanohydrin $(\mathrm{ACH})$ route, allso contains hazardous reagents such as hydrogen cyanide ( $\mathrm{HCN}$ ) and sulfuric acid $\left(\mathrm{H}_{2} \mathrm{SO}_{4}\right)$. The chemical reactions involved in this process are given below (Tkeda, Tokutom, and Nakajima, 1998):

$$
\begin{aligned}
& \mathrm{C}_{6} \mathrm{H}_{6}+\mathrm{CH}_{3} \mathrm{CH}=\mathrm{CH}_{2}+>\mathrm{C}_{6} \mathrm{H}_{5}-\mathrm{CH}(\mathrm{CH})_{2} \\
& \mathrm{C}_{6} \mathrm{H}_{3}-\mathrm{CH}\left(\mathrm{CH}_{3}\right)_{2}+\mathrm{O}_{2}>\mathrm{C}_{3} \mathrm{H}_{5} \mathrm{OH}+\mathrm{CH}_{3} \mathrm{COCH}_{3} \\
& \mathrm{CH}_{3} \mathrm{COCH}+\mathrm{HCN}>\left(\mathrm{CH}_{3}\right)_{2} \mathrm{C}(\mathrm{OH}) \mathrm{CN} \\
& \left(\mathrm{CH}_{3}\right)_{2} \mathrm{C}(\mathrm{OH}) \mathrm{CN}+\mathrm{H}_{2} \mathrm{SO}_{4}>\mathrm{CH}_{2}=\mathrm{C}\left(\mathrm{CH}_{3}\right) \mathrm{CONH}_{2}+\mathrm{H}_{2} \mathrm{SO}_{4} \\
& \mathrm{CH}_{2}=\mathrm{C}\left(\mathrm{CH}_{3}\right) \mathrm{CONH}_{2} \mathrm{H}_{2} \mathrm{SO}_{4}+\mathrm{CH}_{3} \mathrm{OH}>\mathrm{CH}_{2}=\mathrm{C}\left(\mathrm{CH}_{3}\right) \mathrm{COOCH}_{3}+\mathrm{NH}_{4} \mathrm{HSO}_{4} .
\end{aligned}
$$

The overall stoichiometry is as follows:

$$
\begin{gathered}
\mathrm{CH}_{3} \mathrm{CH}=\mathrm{CH}_{2}+\mathrm{C}_{6} \mathrm{H}_{6}+\mathrm{O}_{2}+\mathrm{HCN}+\mathrm{H}_{2} \mathrm{SO}_{4}+\mathrm{CH}_{3} \mathrm{OH} \\
\rightarrow \mathrm{CH}_{2}=\mathrm{C}\left(\mathrm{CH}_{3}\right) \mathrm{COOCH}+\mathrm{C}_{6} \mathrm{H}_{5} \mathrm{OH}+\mathrm{NH}_{4} \mathrm{HSO}_{4}
\end{gathered}
$$

While phenol $\left(\mathrm{C}_{6} \mathrm{H}_{5} \mathrm{OH}\right)$ can be used for other purposes in different industrial sectors, ammonium hydrosulfate $\left(\mathrm{NH}_{4} \mathrm{HSO}_{4}\right)$ is formed as process waste, which has often been simply dumped at sea.

In contrast, a new production path to $\mathrm{MMA}$, the so-called ethylene route, is an example of the clean technology. The route uses as inputs ethylene $\left(\mathrm{CH}_{2}=\mathrm{CH}_{2}\right)$ and the synthesis gas, which consists of carbon monoxide $(\mathrm{CO})$ and hydrogen $\left(\mathrm{H}_{2}\right)$. The chemical reactions involved in the ethylene process are as follows (Suckling, 1994):

$$
\begin{aligned}
& \mathrm{CH}_{2}=\mathrm{CH}_{2}+\mathrm{CO}+\mathrm{H}_{2} \rightarrow \mathrm{CH}_{3} \mathrm{CH}_{2} \mathrm{CHO} \\
& \mathrm{CO}+2 \mathrm{H}_{2} \rightarrow \mathrm{CH}_{3} \mathrm{OH} \\
& \mathrm{CH} \mathrm{OH}+1 / 2 \mathrm{O}_{2} \rightarrow \mathrm{HCHO}+\mathrm{H}_{2} \mathrm{O} \\
& \mathrm{CH}_{3} \mathrm{CH}_{2} \mathrm{CHO}+\mathrm{HCHO} \rightarrow \mathrm{CH}_{2}=\mathrm{C}\left(\mathrm{CH}_{3}\right) \mathrm{CHO}+\mathrm{H}_{2} \mathrm{O} \\
& \mathrm{CH}_{2}=\mathrm{C}\left(\mathrm{CH}_{3}\right) \mathrm{CHO}+1 / 2 \mathrm{O}_{2} \rightarrow \mathrm{CH}_{2}=\mathrm{C}\left(\mathrm{CH}_{3}\right) \mathrm{COOH} \\
& \mathrm{CH}_{2}=\mathrm{C}\left(\mathrm{CH}_{3}\right) \mathrm{COOH}+\mathrm{CH}_{3} \mathrm{OH} \rightarrow \mathrm{CH}_{2}=\mathrm{C}\left(\mathrm{CH}_{3}\right) \mathrm{COOCH}_{3}+\mathrm{H}_{2} \mathrm{O} .
\end{aligned}
$$

The overall stoichiometry thus becomes:

$$
\mathrm{CH}_{2}=\mathrm{CH}_{2}+3 \mathrm{CO}+5 \mathrm{H}_{2}+\mathrm{O}_{2} \rightarrow \mathrm{CH}_{2}=\mathrm{CCH}_{3} \mathrm{COOCH}_{3}+3 \mathrm{H}_{2} \mathrm{O}
$$

The by-product is only water $\left(\mathrm{H}_{2} \mathrm{O}\right)$, a harmless substance.

\footnotetext{
"As in methodology for achieving this, Anastas and Warner (1998) propose "green chemistry." which is defined as the utilization of a set of principles that reduces or eliminates the use or generation of hazardous substances in the design, manufacture and application of chemical products.
} 
Another clean technology, the so-called $C_{4}$ oxidation route, stants with isobutane $\left(\mathrm{CH}_{2}=\mathrm{CCH}_{3} \mathrm{CH}_{3}\right)$ as raw material. Isobutane is oxidized to form methacrylio acid and then to MMA as is shown in the following chenical reactions (Kkeda, Tokutoni, and Nakajima, 1998):

$$
\begin{aligned}
& \mathrm{CH}_{2}=\mathrm{C}\left(\mathrm{CH}_{3}\right)_{2}+\mathrm{H}_{2} \mathrm{O} \rightarrow\left(\mathrm{CH}_{3}\right)_{3} \mathrm{COH} \\
& \left(\mathrm{CH}_{3}\right)_{3} \mathrm{COH}+\mathrm{O}_{2}>\mathrm{CH}_{2}=\mathrm{C}\left(\mathrm{CH}_{3}\right) \mathrm{CHO}+2 \mathrm{H}_{2} \mathrm{O} \\
& \mathrm{CH}_{2}=\mathrm{C}\left(\mathrm{CH}_{3}\right) \mathrm{CHO}+1 / 2 \mathrm{O}_{2} \rightarrow \mathrm{CH}_{2}=\mathrm{C}\left(\mathrm{CH}_{3}\right) \mathrm{COOH} \\
& \mathrm{CH}_{2}=\mathrm{C}\left(\mathrm{CH}_{3}\right) \mathrm{COOH}+\mathrm{CH}_{3} \mathrm{OH} \rightarrow \mathrm{CH}=\mathrm{C}\left(\mathrm{CH}_{3}\right) \mathrm{COOCH}_{3}+\mathrm{H}_{2} \mathrm{O} .
\end{aligned}
$$

Therefore, the overall stoichiometry can be expressed as follows:

$$
\mathrm{CH}_{2}=\mathrm{C}\left(\mathrm{CH}_{3}\right)_{2}+3 / 2 \mathrm{O}_{2}+\mathrm{CH}_{3} \mathrm{OH} \rightarrow \mathrm{CH}_{2}=\mathrm{C}\left(\mathrm{CH}_{2}\right) \mathrm{COOCH}_{3}+2 \mathrm{H}_{2} \mathrm{O}_{n}
$$

Again, water is the only by-product. The formation of the umwanted by-product ammonium. hydrosulfate is avoided by changing the chemical reactions producing the main product MMA.

In many industrial processes, auxiliary materialls are also used to produce the main product. An auxiliary material $A_{/}$can enhance the rate of the principal reaction while it is not changed itself during the reaction:

$$
I_{b l}+I_{b l}+A_{l}>M_{l}+B_{l}+A_{l} \text {. }
$$

One notable example is the use of catalysts. When a hazardous auxiliary substance $A_{l}$ " is used, it is desirable to avoid its discharge to the environment. That could be achieved by replacing it with another material $A_{2}$; that is,

$$
\begin{aligned}
I_{a l} & +I_{b l}+A_{l}{ }^{*}>M_{l}+B_{l}+A_{l}^{*} \\
& \Rightarrow I_{a l}+I_{b l}+A_{2}>M_{l}+B_{l}+A_{2} .
\end{aligned}
$$

In some cases, it might be necessary to change the input materials from $I_{a i}$ and $l_{h, j}$ to different substances $I_{a 2}$ and $I_{b 2}$, together with change in the auxiliary material. That would also affect the by-product, changing $B_{1}$ to $B_{2}$ :

$$
\begin{aligned}
I_{b j}+ & +I_{b 1}+A_{i}{ }^{*} \rightarrow M_{1}+B_{3}+A_{i}{ }^{*} \\
& \Rightarrow I_{b 2}+I_{b 2}+A_{2}>M_{i}+B_{2}+A_{2} .
\end{aligned}
$$

A tragic example of this case concerns emissions of mercury from the production process of acetaldehyde $\left(\mathrm{CH}_{3} \mathrm{CHO}\right.$ ), which has been used as a starting material for making many organic compounds. Initially, the industrial process for producing acetaldetyde, the socalled acetylene process, started with acetylene $(\mathrm{CH}=\mathrm{CH})$, whose production utilized calcium carbide and coke produced from coal. The reactions involved were as follows (Heaton, 1996): 


$$
\begin{aligned}
& \mathrm{CaCO}_{3}=\mathrm{CaO}+\mathrm{CO}_{2} \\
& \mathrm{CaO}+3 \mathrm{C}-\mathrm{CaC}_{2}+\mathrm{CO} \\
& \mathrm{CaC}_{2}+2 \mathrm{H}_{2} \mathrm{O}-\mathrm{CH} \equiv \mathrm{CH}+\mathrm{Ca}(\mathrm{OH})_{2}
\end{aligned}
$$

The acetylene was then reacted with water, using mercury $(\mathrm{Hg})$ as a catalyst:

$$
\mathrm{CH} \equiv \mathrm{CH}+\mathrm{H}_{2} \mathrm{O}+\mathrm{Hg}^{*} \rightarrow \mathrm{CH}_{2} \mathrm{CHO}+\mathrm{Hg}^{*}
$$

At the same time, a type of organic mereury, namely, dimethyll mercury, was also produced as a by-product in the production process (Nishimura and Okamura, 2001). The waste waters discharged by an acetaldehyde plant at the Minamata Bay in the southem part of Japan contained traces of dimethyl mercury. This harmful substance was then ingested in the fish diet of the inhabitants and eventually caused incidences of brain damage and death among those who had fish in the region. Although the acetylene process had once accounted for two thirds of the total national production of acetaldehyde, it was in the end abandoned completely in Japan following this tragedy (Iijima, 1990a).

The acetylene process has been replaced by the Wacker process. In this process, ethylene $\left(\mathrm{CH}_{2}=\mathrm{CH}_{2}\right)$ is oxidized in aqueous solutions of palladium chloride $(\mathrm{PdCl})$ and copper chloride $\left(\mathrm{CuCl}_{2}\right.$ ) as is shown in the following chemical reactions (Gates, 1992):

$$
\begin{aligned}
& \mathrm{CH}_{2}=\mathrm{CH}_{2}+\mathrm{H}_{2} \mathrm{O}+\mathrm{PdCl}_{2}>\mathrm{CH}_{3} \mathrm{CHO}+\mathrm{Pd}+2 \mathrm{HCl} \\
& \mathrm{Pd}+2 \mathrm{CuCl}_{2} \rightarrow \mathrm{PdCl}_{2}+2 \mathrm{CuCl} \\
& 2 \mathrm{CuCl}+1 / 2 \mathrm{O}_{2}+2 \mathrm{HCl} \rightarrow 2 \mathrm{CuCl}_{2}+\mathrm{H}_{2} \mathrm{O}
\end{aligned}
$$

Summing these chemical reaction equations gives the simple stoichiometry of the ethylene axidation:

$$
\mathrm{CH}_{2}=\mathrm{CH}_{2}+1 / 2 \mathrm{O}_{2} \rightarrow \mathrm{CH}_{3} \mathrm{CHO} \text {. }
$$

Here palladium chloride and copper chloride perform the function of catalysis, and the acetaldehyde production does not rely on the toxic mercury, thus completely eliminating its emissions to the environment. The ethylene process soon become an very efficient technology economically and has completely replaced the acetylene process in the end (Nishino, 1998).

As we have seen, in contrast to end-of-pipe technologies, which are designed for just being installed at the end of to the existing production facilities, clean technologies concern the whole production process. Clean technologies involve fundamental changes in the main chemical reactions for total elimination of pollutant emissions, a result which is very difficult to achieve simply by treating emissions at the end of the production process. The development of clean technologies demands careful and intensive research activities on novel. 
reactions, input materials, or catalysts. The performance of new clean techologies would be lower initially, with higher costs of producing the main product by using them. The technical performance could make a significant progress subsequently, depending on the extent of R\&D efforts and learning experiences, and the output production cost could be reduced in the long run. That is not likely to happen in the case of end-of-pipe technologies, because they do not make any change in the main production process, and their operation costs are simply added to the output production cost.

On the other hand, as we have seen, there are usually multiple choices of clean technologies which can replace the existing, pollution-laden technology. With a large degree of uncertainty about technological and economic consequences of allemative technologies, it is no easy task to choose one which will be the most appropriate from a long-term parspective. Furthermore, as the chemical reactions are changed, so are the reaction conditions, including temperature and pressure. That will require revisions and modifications of the size and shape of plant and equipment and the materials used for their constructions. An important implication of that is that the investment costs required for clean technologies will be much larger than those for end-of-pipe technologies. Once a particular clean technology has been established, it will be very costly to make a switch to another one later.

In sum, by using chemical reaction equations, we have classified pollution abatement technologies used in the chemical process industries into two categories, namely, the end-ofpipe technology and the clean technology. Whille end-of-pipe technologies have been traditionally adopted and their technical properties have been relatively well established, clean technologies are radically new innovations, affecting the entire production process, and thus involve a large uncertainty in R\&D as well as in future progress. And, as clean technologies replace the whole production process, there exists multiplicity in technological options, and the large investment required for installation gives the character of rigidity to clean technologies. With this qualitative distinction between the end-of-pipe technology and the clean technology, we will construct our analytical framework for the effects of environmental regulation on technological change in the following sections. Then our empirical study will examine the case of technological change observed in the chlor-alkali industry in Japan and Western Europe in the subsequent chapters. 


\subsection{Diverging Effects of Environmental Regulations on Technological Change}

\subsubsection{Environmental Policy Making under Uncertainty}

As we saw in many of the earlier theoretical models, the advantages of policy instruments based on economic incentives have been often claimed by economists. These models are mostly constructed on the condition of the certainty and completeness of information possessed by the agents. The regulator is assumed to have complete information on the marginal damage curve of pollution. In other words, public authorities have sufficient capabilities to identify the mechanism of the behavior and reactions of the pollutants and then to calculate accurately the damage caused by the pollution on the environment. According to this information, the government is assumed to be able to set the proper level of the Pigouvian tax upon the activities of the generator of an externality, which should be equal to the marginal damage produced by that activity.

The amount of information necessary for the implementation of optimal policies, however, will be prohibitively large. There is a significant amount of uncertainty involved in identifying the sources of pollution and in understanding the scientific mechanisms of the behavior of the polluting substances in the environment. And, as research activities continue to generate new findings, scientific information itself will be subject to change ${ }^{22}$. It is unlikely that we can expect, in a reasonable period of time, to have certain, full information concerning the social cost of the damages. Thus it will be extremely difficult, if not impossible, to estimate accurately the costs of the environmental damages imposed by emissions, including increased illness, reduced recreational opportunities, impairment of materials, and ecological impacts ${ }^{23}$. In the presence of such a large extent of uncertainty about sources, mechanisms, and damages of environmental pollution, we cannot expect to be completely sure whether the level of the emission tax is optimal or not ${ }^{24}$. There seems to be

\footnotetext{
${ }^{22}$ This point is particularly true in the case of the potential impacts of the greenhouse gasses on climate chamge. More details on the progress in scientific knowledge can be seen in the reports made by the Working Group l of the Intergovernmental Panel on Climate Change (Houghton, Ding. Griggs, Noguer, van der Linden, Dai, Maskell, and Johnson, 2001; Houghton, Meira Filho, Callander. Harris, Kattenberg, and Maskell, 1996.

${ }_{23}$ The contingent valuation method has been proposed by economists to estimate the damage done by spills of oill. chemicals, or other substances. It involves the use of sample surveys or questionnaires to elicit the willingness of respondents to pay for hypothetical projects or programs. See Portney (1994) for an overview of the technique and the debate surrounding it and Hanemann (1994) and Diamond and Hausman (1994) for cases for and against, respectively.

${ }^{24}$ The hoice between price and quantitative instruments in the presence of uncertainty about marginal danage furretion or marginal control cost has been discussed in terms of static efficiency in the absence of technical change. When the marginal damage fumction is uncertain, all instruments yield the same expected social surplus because firms respond to the policy choice along the cost curve, independent of the shape of the damage function. In the case of uncertainty about the marginal control cast, on the other thand, the choice of the optimal
} 
no general way in which we can obtain the accurate and detalled information required to implement the Pigouvian tax approach.

Instead; Baumol and Oates (1988) propose the environmental charges and standards approach, that is, the use of pollution charges to achieve a predetermined set of standards for environmental quality. They argue that; under appropriate conditions, the use of unit taxes is the least-cost method for the achievement of specified targets. If the initial taxes do not reduce the pollution in the emvironment sufficiently to satisfy the present acceptability standards, public authorities will raise the tax rates, and some of the polluting firm will have to modify their operations as tax rates are changed. This procedure will be repeated until the level of emissions will be adjusted to meet the specified targets. A crucial problem of this approach, as they acknowledge, is that such an iterative process will not be costless. Policy makers need to keep monitoring the accurate level of pollutants in the environment and to make necessary adjustments in the tax rates frequently. That approach will make the administrative costs rather high ${ }^{25}$.

In practice, economic instruments have been used only to an minor degree, compared with conventional, command-and-control instruments. Regarded as more practical and easier to implement than the economic approaches, command-and-control instruments have been adopted far more frequently in the past to combat various types of pollution ${ }^{26}$. For air and water pollution control, all of the OECD countries have policies based on ambient environmental standards, and all use specific source discharge standards to accomplish them

\footnotetext{
instrument depends on the relative slopes of the marginal damage and marginal cost functions. When the marginal damage curve is steeper than the marginal cost curve, quantitative instruments will be the better policy atpproach, and vice versa (Adar and Griffin, 1976; Fishelson, 1976; Weitzman, 1974). Mixtures of pollicy instruments are discussed by Roberts and Spence (1976). Mendelsohn (1984) show that when innowation is possible, additional welfare loss is induced with price instruments, becaltse firms overreact to the price instrument, producing too much or too littice entission.

${ }^{25}$ Cole and Grossman (1999) argue that where abatenent costs are relatively low and monitoring costs are relatively high, command-and-control is likely to be at least as effieient (and effective) as sflutent taxes.

${ }^{36}$ Other factors could be considered for the predominance of command-und-controll over market-based instruments: the training and experience of legislators may make them more confortable with a direct standards approach than with market-based approaches; the time needed to leam about market-based instruments may represent signiticant opportunity costs; standards tend to hide the costs of pollution control while emphasizing the benefits; standards may offer greater opportunities for symbolic politics: and finally, at the level of the legislatture, command-and-control standards offer legislators a greater degree of control over the distributional effects of environmental regulation (Keohane, Revesz, and Stavins, 1998). On the other hand, firms would be likely to prefer direct controls over emission taxes because entission standards serve as a barrier to entry for new firms, thus raising profits of existing firms (Dean and Brown, 1995). Taxes also require hirms to pay not only abatement costs the reduce pollution to a specified level, but also costs of polluting up to that level (Buchanan and Tullock, 1975). For a unified framework for the political economy of environmental regulation, which views the outputs of environmental policy as emerging from a struggle between key interest groups. see Hahm (1990).
} 
(Kopp, Portney, and DeWitt, 1990). Aecording to a comprehensive survey of the use of economic instruments in OECD member countries, the number of economic instruments, defined narrowly to exclude subsidies, liability and administrative charges, was about 100 , which was equivalent to an average of seven per country (Organisation for Economic Cooperation and Development; 1994). Many of these instruments were of little significance, and only a small proportion could be categorized as ccoriomic instruments in the stricter sense of measures which use financial incentives to encourage more appropriate environmental behavior. Economic efficiency was seldom a stated goal of the economic instruments ${ }^{27}$, and the principal objective of the charging systems appeared to raise revenues. Based on these findings, the study concluded that the way in which environmental policies in OECD countries achieved changes in polluting behavior and consequent improvements in the environment was through measures of the command-and-control type. It is thus very difficult for an empirical study to compare the effects of different economic instruments on technological change in the same environmental issue.

Accordingly, in the subsequent discussions, we will focus on the analysis of the effects of command-and-control approaches on technological change. Given the presence of uncertainty concerning the estimation of damages on the environment due to pollutants, the decisions on emission standards will be inevitably influenced by subjective evaluations of what must be met for an acceptable environment ${ }^{28}$. It could be possible that different standards are adopted for the reduction in emissions of an identical pollutant, depending on historical, political, or social circumstances. For example, in one country, based on a very high estimation of the social costs of the pollution, the polluting industry might be required to completely eliminate emissions of the pollutant from the production process. In another country, on the other hand, the estumation of the damage of the pollutant on the environment might be lower, leading to the imposition of relatively weak standards on the same pollutant.

\footnotetext{
${ }^{2}$ A notable exception is the emission trading systems, which have been adopted for pollution control over the pust decade. The use of this type of instrument, however, has been largely confined to the United States (Stavins, 2000; Inited States Environmental Protection Agency, 2001), and other countries have little experience of implenenting it.

An increasing number of science and technology shdies suggest that, when there is a debate on the estimation of the damage caused by pollution, we cannot not always axpect that the debate will be closed purely in an objective way. For case studies on how disputes in various issues concerning science and technology have been resolved or closed, see, for example, Brickman. Jasanoft, and Igen (1985), Engelhard, Tristam, and Caplan (1987), and Nelkin (1992).
} 


\subsubsection{Choice between the End-of-Pipe Technology and the Clean Technology}

With the distinction between the end-of-pipe technology and the clean technology, we discuss the effects of command-and-control instruments on immovation ${ }^{29}$. We first consider firms" decisions on the adoption of the two types of technologies. For the existing original technology, we assume the following conditions about the abatenent costs:

$$
\begin{aligned}
& A C_{O}(O)=0 \text { (cost of no pollution abatement is zero) } \\
& \frac{\partial A C_{a}(a)}{\partial a}>0 \text { (marginal cost of pollution abatement is positive) } \\
& \frac{\partial^{2} A C_{n}(a)}{\partial a^{2}}>0 \text { (marginal cost is increasing) } \\
& A C_{o}(I)=\infty \text { (cost of total abatement is infinite), }
\end{aligned}
$$

where a represents the degree of pollution abatement and $0 \leq a<1$. The marginal cost curve is shown by $M C_{0}$ in Figure 2-6. New equipment of the end-of-pipe type can be installed to the existing production facilities with the (anmualized) investment cost $I C_{p}$. The new technology satisfies the following conditions ${ }^{30}$ :

$$
\begin{aligned}
& A C_{w}(0)=0 \\
& 0<\frac{\partial A C_{0}(a)}{\partial a}<\frac{\partial A C_{o}(a)}{\partial a} \\
& \frac{\partial^{2} A C_{u}(a)}{\partial a^{2}}>0 \\
& A C_{i}(1)=\infty .
\end{aligned}
$$

That is, pollution abatement can be achieved at lower cost with the new end-of-pipe technology, as is illustrated by the marginal cost curve $M C_{0}$ in Figure 2-6. Since the end-ofpipe technology does not affect the main reactions of the manufacturing process, as we can see in Figure 2-5, the costs of its installation and operation are simply added on to the ariginal production cost $P C_{s,}$, which will not be affected by the technological change from $M C_{B}$ to $M C_{c}$

\footnotetext{
294 The impacts of environmental policy on market structure or competitive conditions are not considered here. See, for example, Ulph (1997) for more discussions on these issues.

${ }^{3}$ The scrubber technology used for the gas desulfurization, an equipment of the end-of-pipe, is assumed to satisfy these conditions in Bellas (1998).
} 


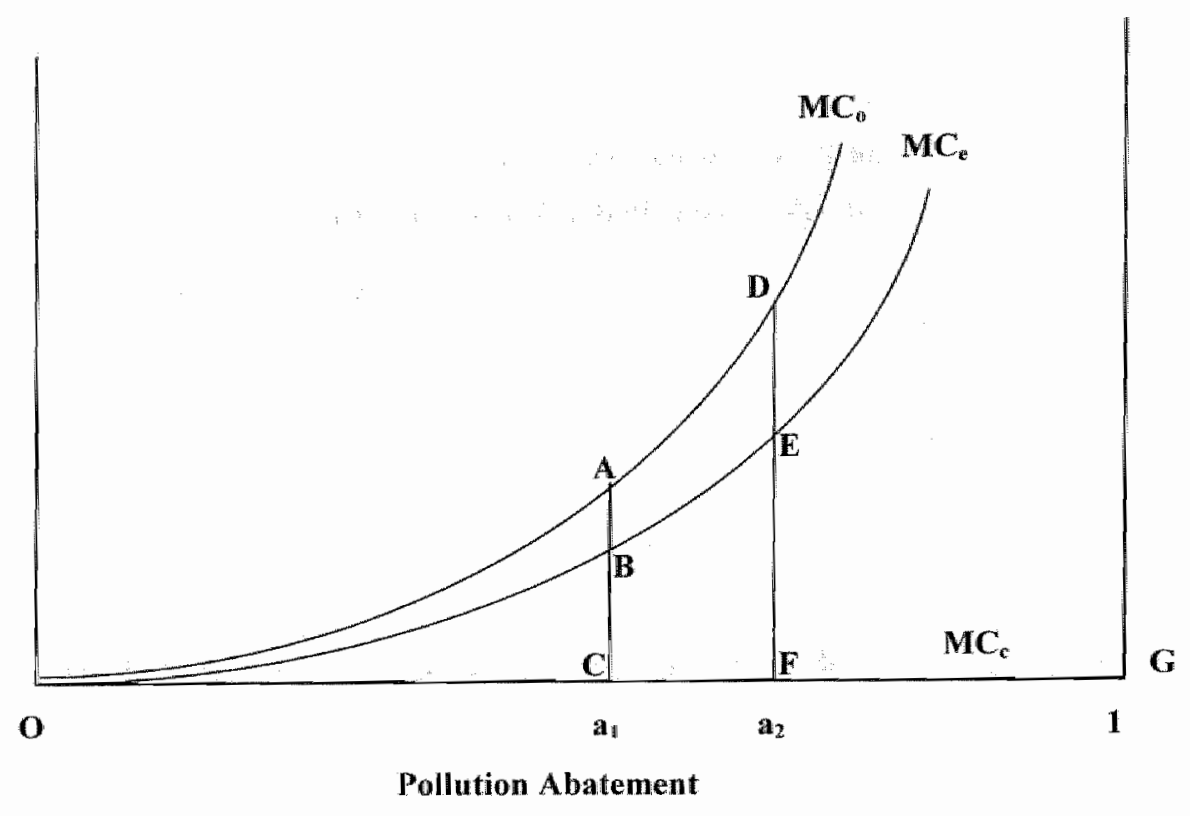

Figure 2-6 Pollution Abatement Costs with End-of-Pipe and Clean Technologies

The clean technology, on the other hand, is a type of technology with which pollution is eliminated from within the production process, meaning that pollutants do not form in the first place. Hence the convex, strictly increasing marginal cost curve assumed for the end-of-pipe technology becomes inappropriate for the analysis of the clean technology. Instead, the marginal cost is zero over the whole region of pollution abatement:

$$
\begin{aligned}
& A C_{C}(0)=0 \\
& \frac{\partial A C \cdot(a)}{\partial a}=0 .
\end{aligned}
$$

That is, we can simply write

$$
A C_{i}=0 \text {. }
$$

Hence, the marginal cost curve for the clean technology $M C_{C}$ does not depend on the level of pollution abatement $a$, and is represented by the straight line $O G$. On the other hand, since the clean technology involves radical modifications of the main production process, as Figure 2-5 
shows, the output production cost $P C$, will be signficantly affected, and the (annulized) investment cost of its adoption $I \mathrm{C}_{\mathrm{c}}$ will be very large.

With the distinction between the end-of-pipe technology and the clean technology, we frst consider which technology firms will choose. Broadly speaking there are two bypes of theoretical approaches to the adoption of technologies, depending on what is considered as the key factor in determining technological adoption, namely, information-based and profitbased approaches (Karshenas and Stoneman, 1995). The first type of theoretical approach, analogous to the epidemic or contagious models for the analysis of the spread of diseases, emphasizes that technological diffusion results from the spread of information (Griliches, 1957). In the simplest models, the use of new technology is constrained by the number of people who know the existence of that technology. As time proceeds, the experience of users leads to the spreading of knowledge on the existence of that technology to non-users, who in turn become users, leading to a further spread of information. In the case of process technologies, however, it is very unlikely that manufacturers are unaware of their existence for a long time, at least in industrialized countries, because nomally information on technologies are quickly available through trade journals, meetings, conferences and other opportunities. Specialized engineering firms, in particular, are eager to provide detailed information on their technological information to potential customers. While this is basically an empirical question, we assume that manufacturers will adopt a technology when the benefits from adoption is larger than the cost of adoption, that is, the profit-based approach (David, 1975).

Thus we consider that firms will choose a technology which is less costly to adopt, given the different nature and characteristics of the end-of-pipe technology and the clean technology. As we have discussed, the end-of-pipe technology does not fundamentally influence the main production process, and hence its output production cost will not be affected, remaining the same as the original one $P C_{o}$. The clean technology, on the other hand, means that the main manufacturing process is significantly changed, and accordingly the output production cost $P C_{c}$ will diverge from $P C_{o}$. Since the clean technology is a newly developed technology, it is likely that its output production cost is larger than that of the old technology, at least initially, because otherwise it would have been already adopted. Hence we assume that

$$
P C_{c}>P C_{0}
$$


As for initial investment, the end-of-pipe technology is generally less complicated, designed to be installed at the end of the manufacturing process, whereas the clean technology changes the main process and requires the alteration of the whole production facilities. Hence we can reasonably assume that the investment cost, which would not vary depending on the degree of pollution abatement, is much larger for the clean technology than for the end-ofpipe technology ${ }^{3}$. Thus we have

$$
1 C_{e}>1 C_{e} \text {. }
$$

Regarding the pollution abatement costs with the end-of-pipe technology, when an emission standard $a$ is introduced at $a=a_{l}$ (Figure 2-6), we can see that the operating cost of the equipment aimed exclusively at reducing emissions is area $O B C$. When a more stringent emission standard $a_{2}$ is imposed, then the cost necessary for operating the end-of-pipe equipment for reducing emissions will be increased to $O E F$; that is, we have

$$
A C_{e}\left(a_{2}\right)=O E F>O B C=A C_{i}\left(a_{1}\right)\left(a_{2}>a_{1}\right) \text {. }
$$

The clean technology, on the other hand, does not produce any emissions, and thus there is no cost specifically for reducing emissions. As the emission standard is raised, while the clean technology will not be affected, the pollution abatement cost with the end-of-pipe technology will be increased. Regarding the scale of the abatement cost, however, Robinson (1985) reports that the operating cost of abatement equipment normally represents less than 2 percent of the production costs in chemical process industries. Thus, as long as the emission standard $a$ is not extremely stringent, we expect that the operation cost of the end-of-pipe equipment $A C_{k}(a)$ would be much smaller than the level of the output production cost:

$$
P C_{o}>A C_{d}(a) \text {. }
$$

With the output production costs $P C_{n}$ and $P C_{i,}$ investment costs $/ C_{0}$ and $I C_{C}$, and pollution abatement cost $A C_{e}(a)$, we can see which technological choice can provide a less costly measure for emission reduction. Given that the investment cost and the output production are higher with the clean technology than with the end-of-pipe technology, unless the emission standard is imposed at such a high level that the pollution abatement cost becomes significantly large, we can reasonably expect that it is more costly to deal with emissions with the clean technology than with the end-of-pipe technology; that is,

$$
P C_{c^{*}}+I C_{i}-\left(P C_{0}+I C_{i}+A C_{i}(a)\right)>0 \text {. }
$$

\footnotetext{
3 Yanagioka (1993) reports that the cost of installing end-of pipe equipment for dealing with emissions from
clectric powert plants, whose sector is consideredt as of clectric power plants, whose sector is considered as ore of the most polluting in industry, accounts for 20 per
cent of the investment cost for the whole plant.
} 
This implies that; facing a relatively weak regulation imposed on pollutant emissions; companies will choose to adopt the end-of-pipe technology, rather than to newly introduce the clean technology, at least while the development of the clean technology is still in its infancy. Only when the emission standard is too stringent to be complied with by the end-of-pipe techmology, effectively demanding that the phase-out of the existing production technology is necessary, companies will adopt the clean technology to eliminate emissions. Otherwise, it is likely that the imposition of a moderate emission standard will create incentives for companies to adopt the end-of-pipe technology, rather than the clean technology ${ }^{3}$.

Innovating firms, on the other hand, make a choice for their R\&D investment between the two types of technological measures for pollution abatement. In making that decision, innovating firms consider the demands for the technologies they develop, because, as discussed in the models of Milliman and Prince (1989) and Fischer, Parry, and Pizer (1998), innovation gains to the innovating fims will be significantly influenced by how much of their technologies will be adopted by other producers in the industry ${ }^{3,3}$. When the innovating firms are those outside the industry, notably, specialized engineering firms ${ }^{3 \text {, }}$, the adoption of their technologies by other firms is particularly inportant, because, as they are not involved in production, there are no benefits from the reduction in production cost, and thus technology licensing is the only source of revenues. As long as it is regarded that the clean technology is more costly for pollution abatement than the end-of-pipe technology, polluting manufacturers will choose the latter, not allowing the developers of the clean technology to recoup $R \& D$ expenditures on it through its adoption by other firms. Expecting that, the innovating firms will have little incentive to invest a large amount of resources in the clean technology, whose development will take a long period of time with a large uncertainty in ultimate outcones.

To sum up, pollution-emitting producers, under pressure to comply with emission standards within a regulatory framework, will adopt end-of-pipe technologies as long as the cost of pollution abatement with them is smaller than that with clean technologies. The expectation that few innovation benefits can be gained from the development of clean

\footnotetext{
${ }^{32}$ Here there is another choice to companies that that they simply do not comply with the regulation. This possibility, however, is increasingly difficult to take, at least in the industrialized countries, considering that, when it is disclosed to the public, potential negative effects on corpotate image and reputation will be prohibitively high.

${ }^{33}$ It is reported by Arora (1997) that in chemical process industries technology licensing is actually used by many innovating companies as an important means of generating revenue from process innowations.

34 The importance of innovation activities of process plant contractors is discussed in Hutcheson, Pearson, and Ball (1996).
} 
techrollogies will in turn encourage innovating firms to concentrate their $R \& D$ efforts on endof-pipe technologies, rather than on clean technologies. Thus the development of clean technologies will not be promoted, even when there is a possibility that these radically new technologies will becone

On the other hand, if the regulation imposed on pollutant emissions is so stringent that it is extremelly costly or technically impossible to achieve that target with the end-of-pipe technology, then pollution-laden mamafacturers will be prompted to adopt the clean technology. In this case, innovating firms can be sure that there will be sufficient demands for the clean technology to be adopted by manufactures in the industry and thus will be encoutraged to make investments for $R \& D$ on their new innovations. As the investment cost of installing the clean technology and the production cost with it will be higher than with the end-of-pipe technology, however, manufacturers have to incur larger expenditures for pollution abatement, at least initially.

\subsubsection{Technological Progress through R\&D and Learning}

In the previous section we have assumed that the performance of the two types of pollution abatement technologies and hence the production costs with them are fixed. It is well known, however, that technologies generally do not remain the same and will progress. In particular, we can conceptually identify two mechanisms, namely, R\&D activities and actual experimentation of technologies, that is, technological learning, which will work to improve the performance of technologies. The importance of R\&D for technological progress has been well illustrated in the history of industrial innovations; including those in the chemical industry (for example, Freeman, 1982). Technological learning basically takes place in two forms. The first is learning-by-doing (Arrow; 1962). It has been generally considered as a form of leaning that takes place at the manufacturing stage after the product has been designed, that is, after the R\&D stage has been completed. Leaning at this stage consists of reducing real labor costs per unit of output ${ }^{7,5}$. Learning-by-using (Rosenberg, 1982), on the other hand depends, not on the experience involved in producing the product, but on its utilization by the finall user, particularly in the case of capital goods. The performance characteristics of a durable capital good often cannot be understood until after prolonged experience with it, and many significant characteristics are revealed only after prolonged use,

\footnotetext{
${ }^{36}$ For a historical neview of various ypes of the leaming curve, see Yelle (1979).
} 
notably, the useful life of a durable capital good. Thus extensive uses of capital goods generate valuable information for innovating firms to make important modifications which will be incorporated in subsequent models.

While we can conceptually differentiate the R\&D activities and technological learning, in practice there are intricate interactions between R\&D and technological learning. In contrast to the traditional "linear model," in which innovation proceeds linearly from scientific research to development, the newly proposed "chain model" places importance on feedback from downstream phases in the linear model to upstream phases as well as interactions between science and innovative process at every phase of the innovation process (Kline and Rosenberg, 1986) ${ }^{36}$. As Watanabe (1995) discusses the "virtual spin cycle" between R\&D, adoption, and learning in the case of photovoltaic development in Japan, phases of technological change are closely interlinked, and it is very difficulty to treat them separately as sources of technological dynamics. Hence here we simplify our argument by formulating a model in which technologies will improve as time passes 37 .

By incorporating the crucial point that the performance of the two types of pollution abatement technologies will improve, we now modify the previous argument on the effects of environmental regulation on technological change. An improvement in the performance of the end-of-pipe technology will reduce the cost of operating the equipment for pollution abatement $A C_{e}(a)$. In Figure 2-7, the marginal cost curve improves from $M C_{e}$ to $M C_{k^{\prime}}{ }^{\prime}$ after time $t^{\prime}$ has passed.

\footnotetext{
16. The linear model has also been criticized by other models which emphasize much mote complex, cwolutionary interactions between innovation phases (McKelvey, 1996; Ruttan, 2001; Stokes, 1997).

3.7 On this point. Grubler (1998) constructed a model in which production costs (i. a measure of technological improvement decrease in response to totall expenditures including both R\&D investments and production capacity investments (i.e. a measure of technological learning). As R\&D investments and capacity investments are quallatively different, a question remans whether it is appropriate to just combine the hwo types of irvestments into one figure.
} 


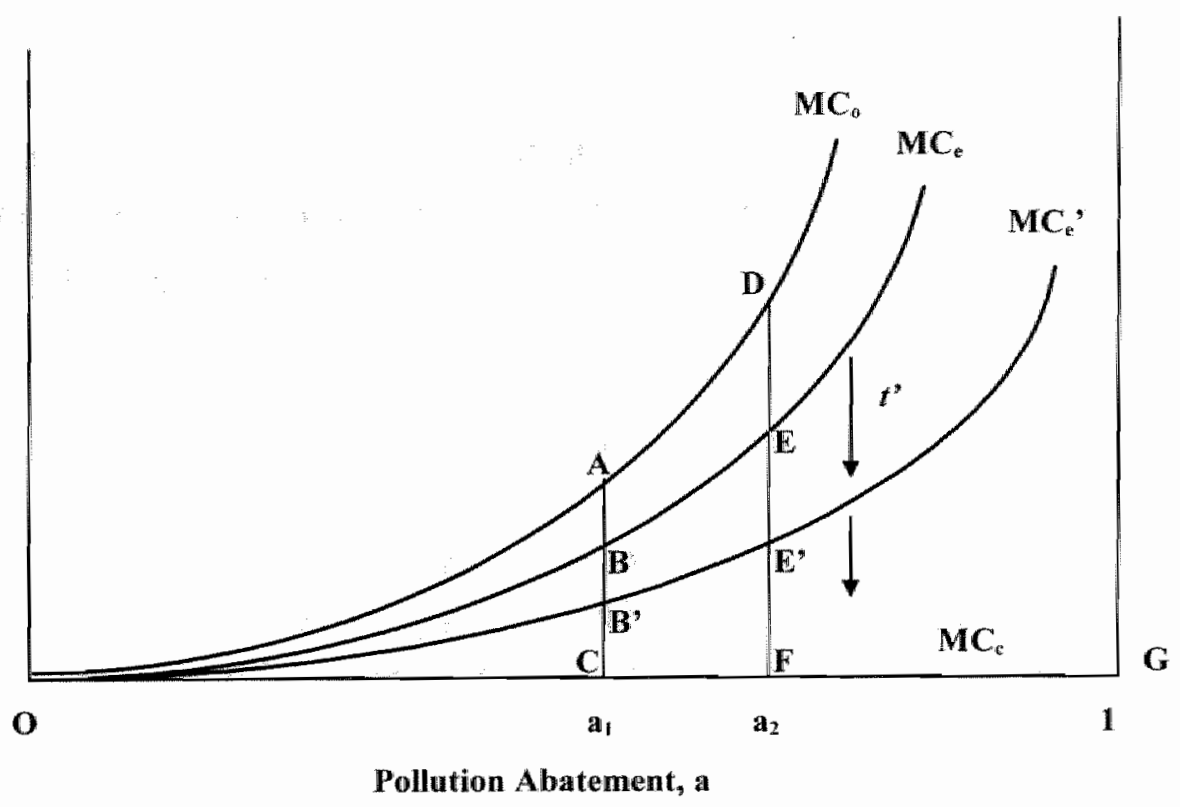

Figure 2-7 Pollution Abatement Costs with Improvements in the End-of-Pipe Technology and the Clean Technology

As the end-of-pipe technology is basically separate from the output production technology, however, R\&D on the end-of-pipe technology will have no impact on the main production process. Hence the production cost $P C_{o}$ will not be affected. And, as we discussed above, the abatement cost $A C_{C}(a)$ is larger when the level of pollution abatement is higher. A schematic illustration is given in Figure $2-8(a)$. The following conditions are satisfied:

$$
\begin{aligned}
& \frac{\partial A C_{(a, t)}}{\partial r}<0 \\
& \frac{\partial^{2} A C_{i}(a, t)}{\partial^{2} t}>0 \\
& A C_{t}\left(a_{t}, t\right)<A C_{e}\left(a_{2}, t\right)\left(a_{t}<a_{2}\right) \\
& \frac{\partial P C_{t}(t)}{\partial t}=0\left(P C_{0} \text { is constant }\right),
\end{aligned}
$$


where $t$ represents the time passed since the time when the technology was developed for the first time. While improvements can be expected in the performance of the end-of-pipe technology, which will reduce the pollution abatement cost $A C_{e}\left(a_{n}\right)$ with it, basically they will not affect the main production process, and the production cost $P C_{6}$ will remain the same. The abatement cost is simply added to the production cost of the original process. Hence the total production cost with the original production process equipped with the end-of-pipe technology will be $P C_{0}+A C_{e}(a, t)$.

On the other hand, the clean technology will not show any improvement specifically in pollution abatement costs because it makes no pollutant emissions in the first place. That means that the marginal abatement cost curve $M C_{c}$ remains unchanged in Figure 2-7. Technological progress through R\&D and leanning, however, will be directed to reduce the output production cost $P C_{c}$. As we discussed above, the clean technology involves a wholly new process, and the extent of technological progress is subject to uncertainty. Moreover, there are usually multiple choices of the clean technology, whose ultimate outcomes cannot be predicted accurately in advance. For the sake of simplicity, here we consider only two kinds of the clean technology. The first clean technology $c$, looks promising at the beginning, but will faill to achieve significant progress in the long run. The second clean teclinology $c_{2}$ initially seems to be far inferior to the existing production technology, but will succeed in improving rapidly, reducing the output production cost to less than that with the original technology. Figure 2-8(b) gives a schematic illustration. That is, we have

$$
\begin{aligned}
& P C_{o}<P C_{c t}(0)<P C_{c 2}(0) \\
& \frac{\partial P C_{c} 2(t)}{\partial t}<\frac{\partial P C_{c t}(t)}{\partial t}<0 \\
& P C_{c 2}\left(t^{4}\right)=P C_{0} \\
& \frac{\partial^{2} P C_{c t}(t)}{\partial t^{2}}>0 \\
& \frac{\partial^{2} P C_{2}(t)}{\partial t^{2}}>0 .
\end{aligned}
$$

We have asstumed that the decline in the production cost will be subject to diminishing returns. After the time $t$ " has passed since the technological development, the production cost with the clean technology $c_{2}$ will become lower than that with the original technology. 
(a) End-of-Pipe Technollogy

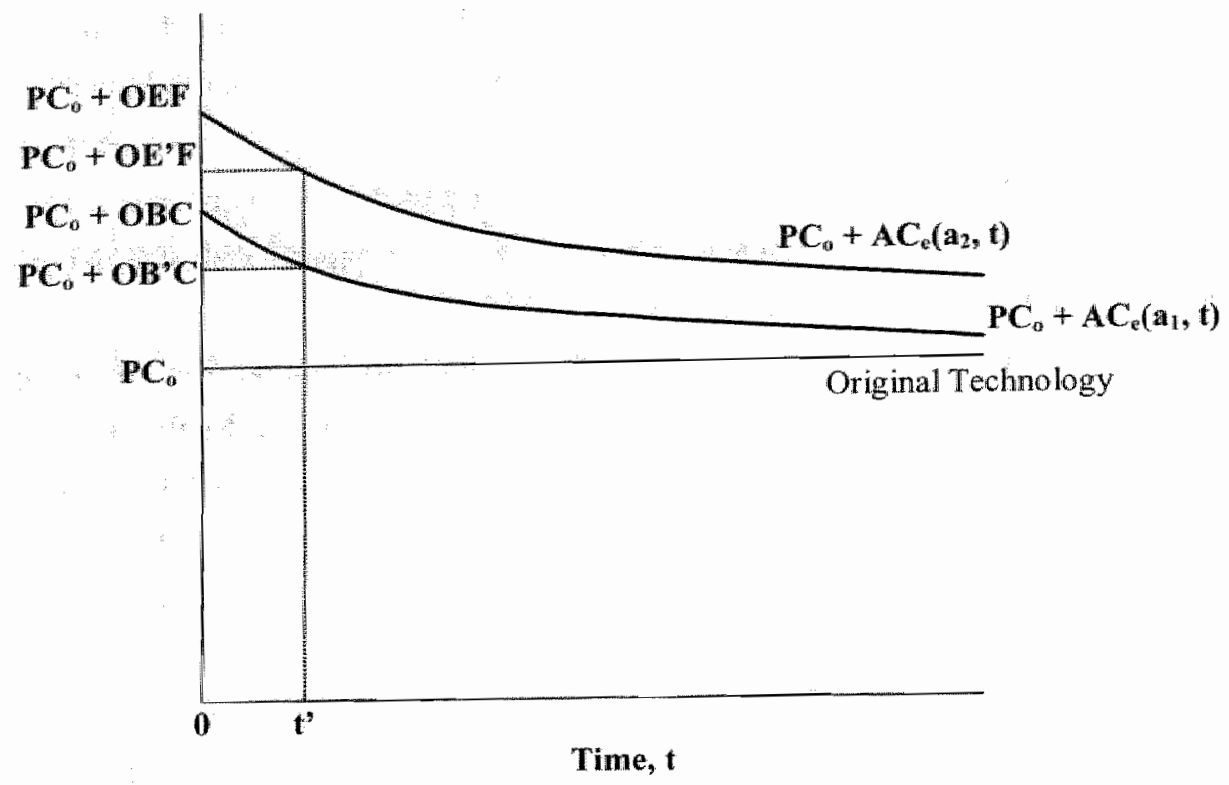

(b) Clean Technology

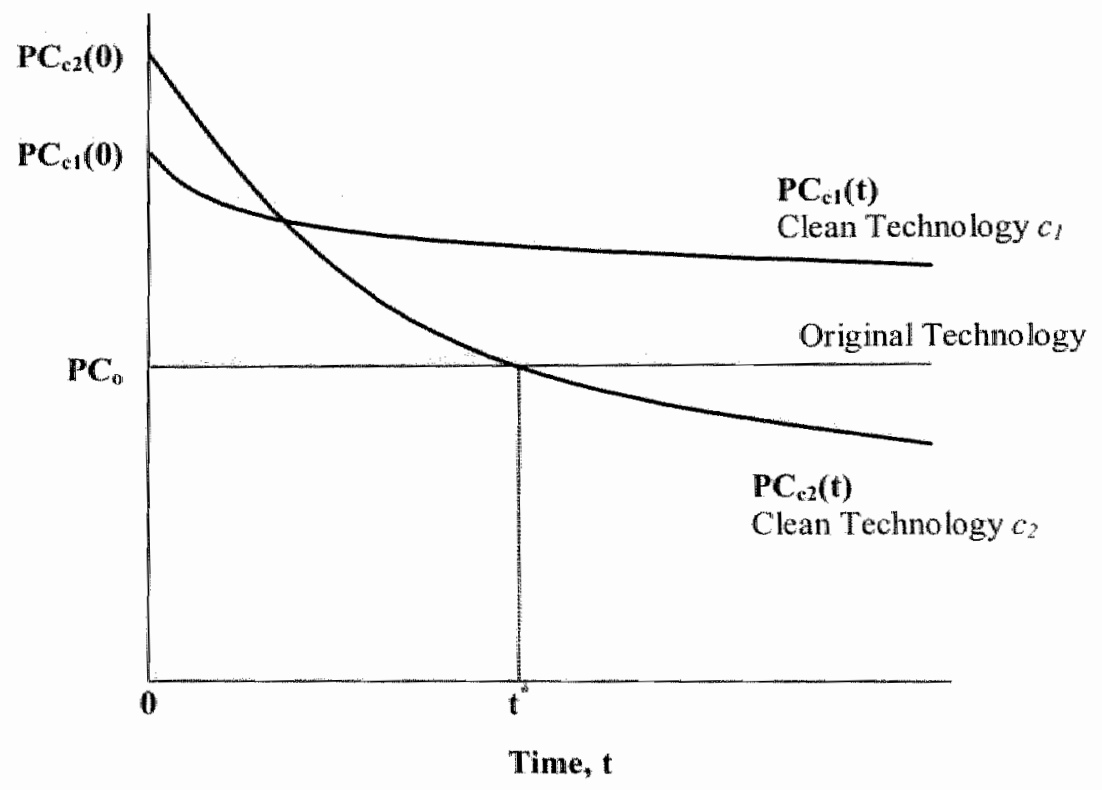

Figure 2-8 Operating Costs with the End-of-Pipe Technology and the Clean Technology 
As we discussed in the static case, when the effuent standard introduced is not extremely stringent, meaning that the pollution abatement cost $A C_{\mathrm{e}}$ is relatively small, it is likely that even the clean technology $c_{j}$, which is intially more efficient the clean techology $c_{2}$ is costly to adopt, compared with the end-of-pipe technology; that is, we have the same result as in the case of no technological progress:

$$
P C_{C l}(0)+I C_{c l}-\left(P C_{0}+I C_{e}+A C_{e}(a, 0)\right)>0
$$

That is, prompted by the regulation to reduce pollution to a certain emission standard, normally by a specified deadline, companies will adopt the end-of-pipe technology, rather than the more expensive clean technology. Users" decisions on the adoption of the end-ofpipe technology will create more demands for it, and that will encourage further research and development and learning on the end-of-pipe technology, reducing the pollution abatement cost further. While there is a possibility for the development of the clean technology $c_{2}$, which will become better than the original technology in the long run economically as well as environmentally, it is unlikely that this technological option will be pursued, as the regulation normally requires compliance with emission standards in a relatively short period of time, which will not give sufficient time for technological progress. As long as the end-of-pipe technollogy works to reduce emissions to a certain extent, pollution-emitting producers have a strong incentive to continue to use the existing production technology.

In contrast, when the envitonmental regulation is such a stringent one that effectively the phase out of the existing production technology is the only option, manufactures need to switch to a new clean technology. As there are normally multiple options of the clean technology, which one will turn out to be the most efficient could not be known ex ante without intensive R\&D efforts and technological learning through the use of it. If the regulatory schedule demands an immediate abolishment of the existing production technology, however, companies will have no choilce other than to adopt a clean technology whose production cost is the smallest at that time, that is, the clean technology $c_{\%}$. Adoptions of that technology will promote progress in performance through R\&D and learning, but how much the technological progress will be cannot be exactly predicted under the existence of a high degree of uncertainty concerning subsequent technological change. Eliminating diversity in technological options at an earlier stage, the stringent regulation will result in forcing firms to choose a particular type of the clean technology which may not be the best option from a long-term perspective. A schematic illustration of this situation is given in Figure 2-9. 


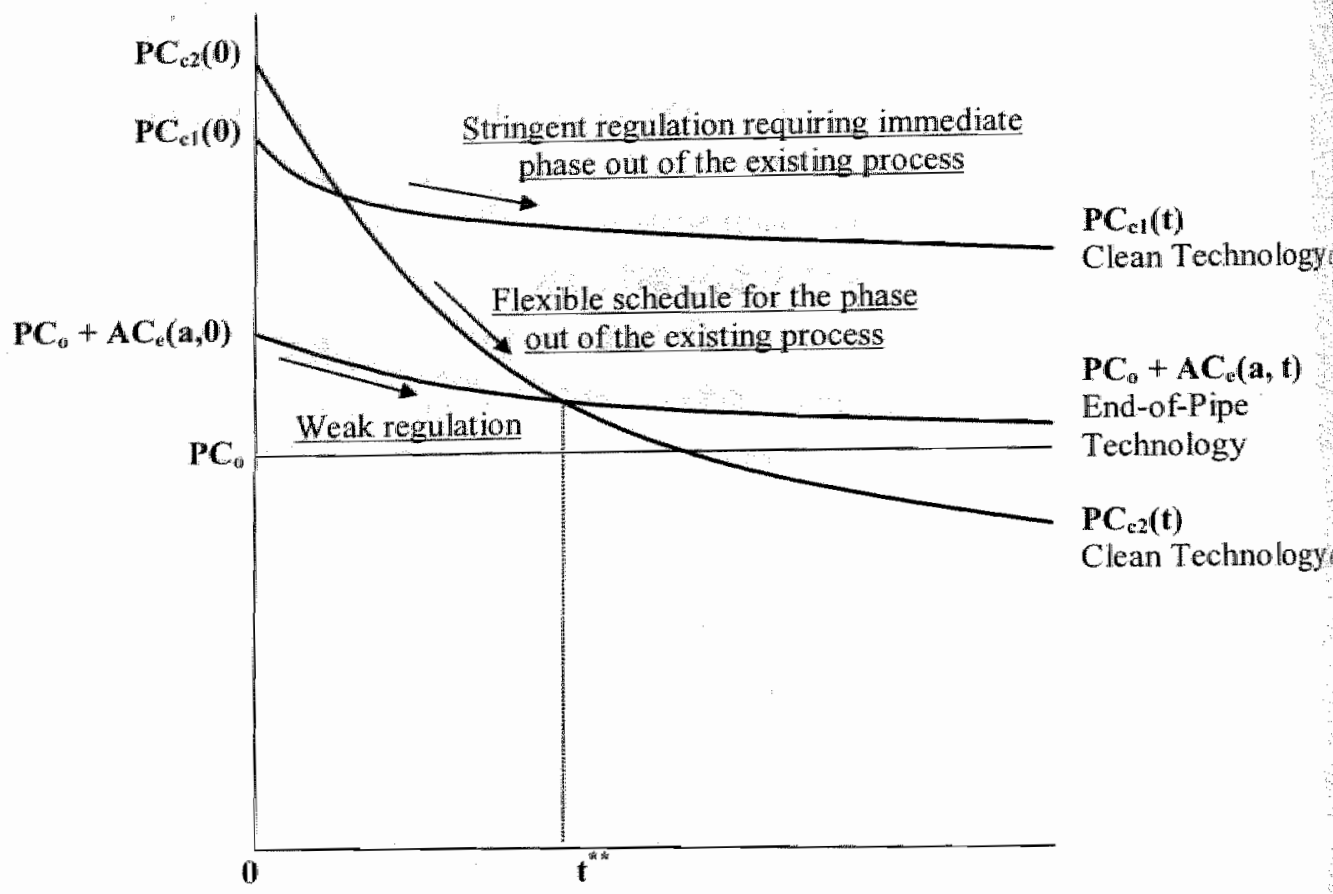

Time, $t$

Figure 2-9 Production Costs with the End-of-Pipe Technology and the Clean Technology

As investment expenditures entail sunk costs and cannot be fully recouped later, investment has a characteristic of some degree of irreversibility. Especially in the case of the chemical process industries, plant investment takes a long period of time and costs a significant amount of money, and the degree of irreversibility is significantly large. Once a large investment has been made on a particular type of the clean technology, it will be considerably costly to switch at a later stage to a better technology, which will be known ex post. In other words, the intial choice of the clean technology c/ carries the character of technologicall lock-in ${ }^{36}$.

\footnotetext{
积 The possibility of technological lock-in has been addressed theoretically by Arthur (1989) and empirically by David (1985). Foray and Gribler (1990) examined the case of technologicall lock-in in the ferrous casting industry, which has had observed the diffusion of different technologies between France and Germany. Theit analysis emphasizes the crucial tature of the initial stage of diffusion, where the accumulation of knowledge and learning occurs, bringing about the difierent teclmological trajectories. Frankel (1955) and Bahmann, Odening. Weikard and Brandes (1996) showed that technological conplementarity and the existence of sunk costs can
} 
With a flexible schedule, however, government regulation can provide an opportunity to experiment other technological alternatives, mcluding the clean technology $t$, which seems to be a promising technology but is still in its infancy at an intial stage. Through R\&D investment and learning experience, further technological progress will be promoted subsequently, which otherwise would not happen under a rigidly fixed regulatory selhedule. Therefore, there are two possibilities concerning the consequence of the imposition of the stringent regulation for the phase out of the existing technology; that is, we will observe the dominance of the ultimately inefficient technology $c$, or the emergence of the best technology $c_{7}$. By allowing more time and flexibility for actual experimentation of various types of the clean technology, the stringent regulation can help to make the right techological choice, that is, the clean technology $c_{2}$.

Even in a region where such a strong regulation has not been introduced, there is a possibility that the efficient clean technology $c_{2}$, whose development has been encouraged by a stringent regulation, will become available later to pollution emitters. In that case, those producers who has been subject to relativelly weak regullations, observing that the clean technology has become more efficient than the original technology, that is,

$$
P C_{c 2}(t)<P C_{i}+A C_{e}(a, t)\left(t>t^{i k \text { tat }}\right)
$$

in Figure 2-9, will choose the clean technology when they construct new plants, on the assumption that the initial investment cost is equal between the original technology and the clean technology $c_{2}$ :

$$
I C_{0}=I C_{12} \text {. }
$$

For plants which have already been well established with the original pollution-burden technology, equipped with the end-of-pipe technology for pollution reduction, however, the replacement of the old technology with the new clean technology $c_{2}$ will not happen immediately after time $r$. That is because the saving in the production cost from the conversion of the existing technology to the clean technology will not yet be sufficient at this moment to offset the large amount of the initial investment cost $/ C_{c 2}$ required for the introduction of the new clean technology; that is,

$$
I C_{c 2}>P C_{o}+A C_{e}(a, t)-P C_{c 2}(t)\left(t \approx t^{* * i}\right)
$$

\footnotetext{
lead to a state of lock-in. Cowan and Gunby (1996). Cowan and Hullén (1996), and froremarn-Peck (1996) alsan discussed other cases of technological lock-in. In the case of technologies for environmental protection, Kenp (1995) emphnasizes the importance of creating "market niche" to secure the diversity of technological options. For a eritical apposisal of the arguments on technological lock-in, particularly from the perspective which emphasizes the efficiency of the market mechanism, see Liebowit2 and Margolis (1990; 1995).
} 
in Figure 2-10. If the clean technology $c_{2}$ progress substantially to the extent that, after time $t^{* * *}$ has passed, the saving in the production cost can cover the investment cost, that is,

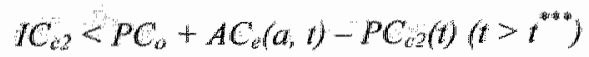

in Figure $2-10(a)$, then the operators of the plants based on the old production technology will switch to the new clean technology:

On the other hand, if the efficuency of the clean technology $c_{2}$ does not improve sufficiently, then the cost saving from the technological conversion will never offset the investment cost; that is, for any $t$,

$$
A C_{c_{2}}>P C_{0}+A C_{e}(a, 1)-P C_{c 2}(t)
$$

as shown in Figure 2-10(b). In this case, it will not be economical to convert the existing plants based on the original production technology to those based on the new clean technology. After time $t^{*}$, there will be no new introduction of the old production technology, and the clean technology will be adopted whenever plants are newly constructed. By that time, however, more plants will have been constructed with the old technology, equipped with the end-of-pipe technology, whose development was encouraged by the relatively weak environmental regulations. Once investment has been made on plants with the old production technology, there will be strong incentives to continue to utilize them until they cannot be used physically. As the lifetime of chemical plants is normally over 40 years ${ }^{39}$, it will take a long period of time before the clean technology replaces the old technology, even though it has become clear that the latter is inferior to the former, economically as well as environmentally.

\footnotetext{
${ }^{30}$ Jafle. Newell, and Stwins (1999) argue that a primary driver of replacement purchases for durable goods is the goods useful lifetime. In the case of industrial facilities, the typical service life would be in the range of 40 to 80 years.
} 


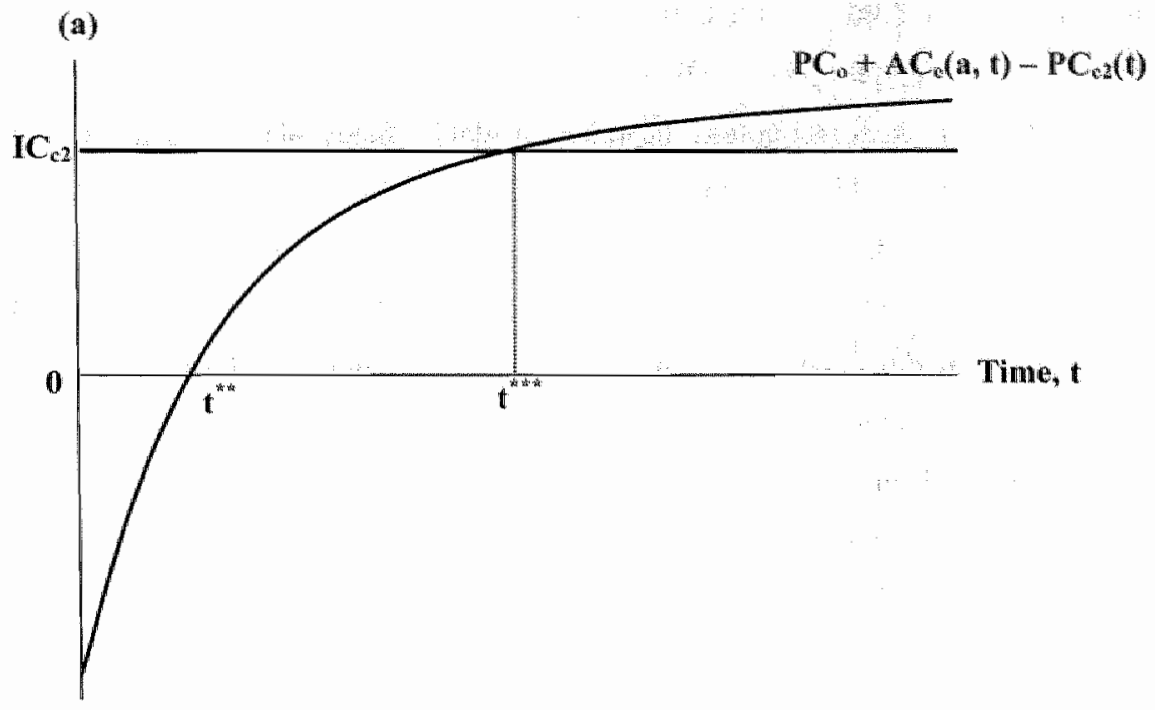

(b)

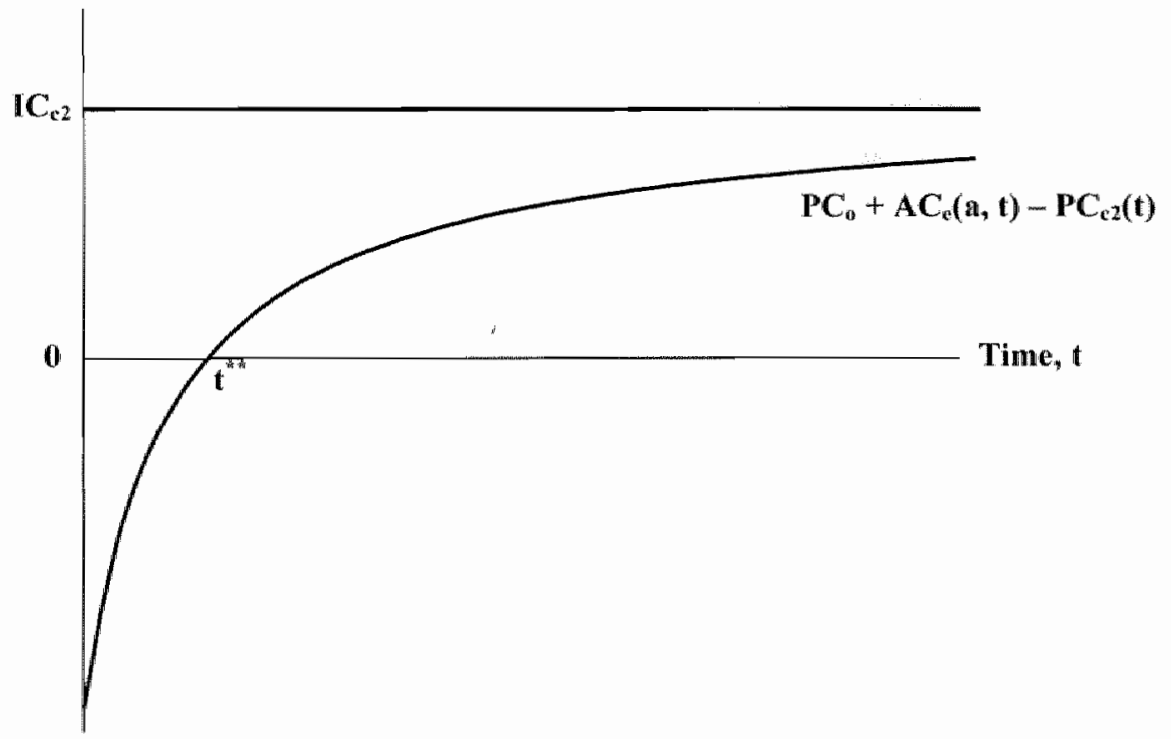

Figure 2-10 Cost Saving with the Process Conversion from the Original Techuology Equipped with the End-of-Pipe Technology to the Efficient Clean Technology

Under a weak regulatory framework, the end-of-pipe technology will be favored for reducing emissions, because it is initially much cheaper than the clean technology. With the 
end-of-pipe technology installed, the original production technology will continue to be adopted, and more investments will be made on plants with this technology. By the time that ${ }^{t}$ a more efficient clean tedhnology becomes available, many plants will have alleady been constructed with the old production technology. Adoptions of the end-of-pipe technology, by" succeeding in reducing pollutant emissions, effectively function to prolong the lifetime of the original, pollution-intensive technology, which may be in a process of technological obsolescence. In other words, the imposition of weak regulation, by pushing the course of technological trajectory towards an extension of the existing technology, will block the development of clean, potentially more efficient, technologies.

Figure 2-11 summarizes our analytical framework for the effects of environmental regulation on technological change. 


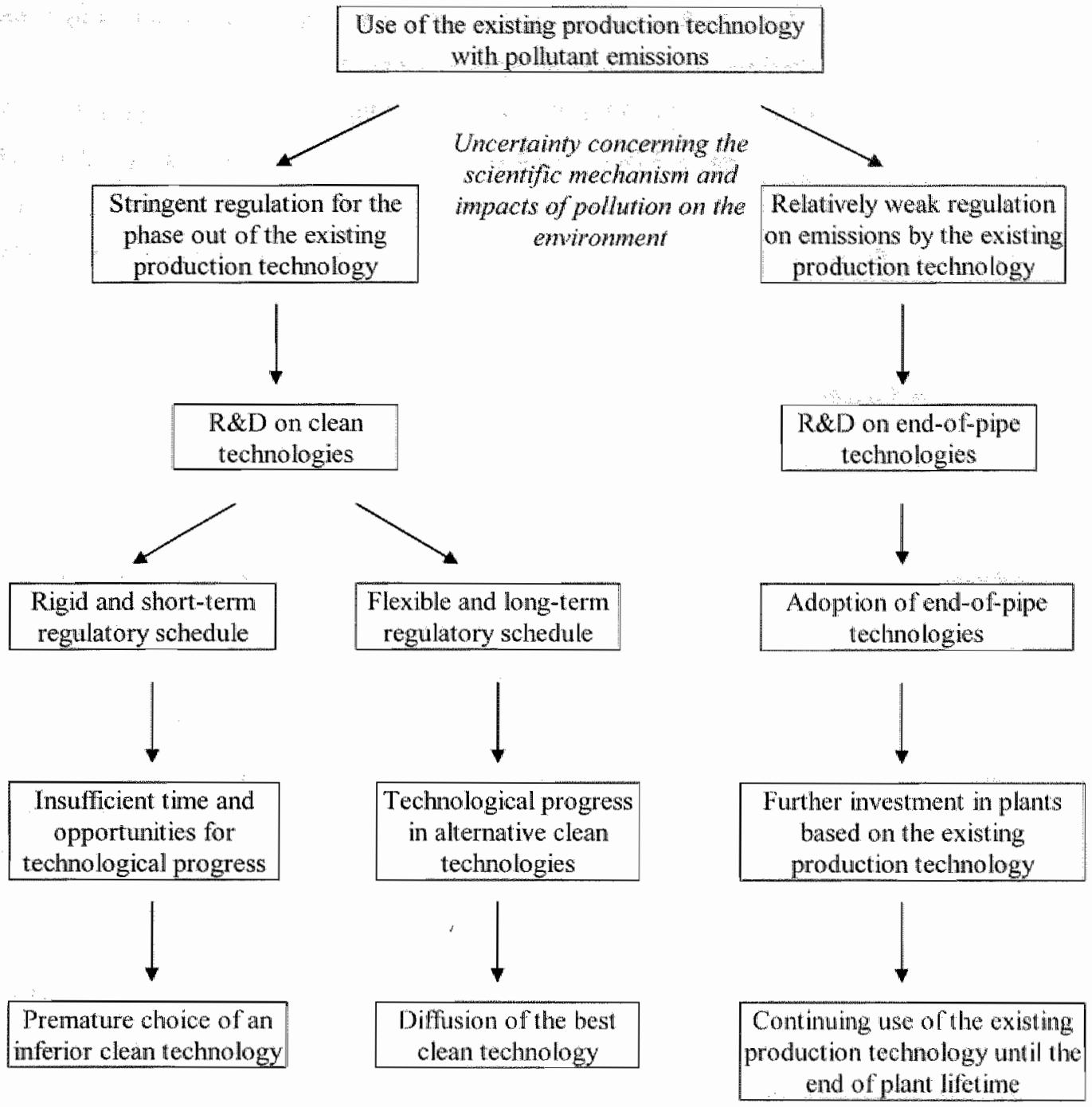

\section{Figure 2-11 Diverging Effects of Environmental Regulations on Technological Change}

\subsection{Conclusion}

Previous studies on the effects of environmental regulation on technological change mostly considered only the end-of-pipe technology for pollution abatement. In theoretical models, the increasing marginal abatement cost curve has been normally used to represent the character of technologies which reduce emissions. In empirical investigations, the focus has been mainly 
on technologies exelusively used for reducing emissions, including, for example, filters and scrubbers. These technologies are basically equipment of the end-of-pipe type.

In our discussion, we explicitly took into account the possibility of clean technology and emphasized the qualitative difference between the end-of-pipe technology and the clean techology by using chemical reaction equations. Basically, the end-of-pipe technology is just installed at the end of manufacturing plants and will not affect the main production process. While the cost of pollution abatement is relatively small with the use of the end-of-pipe technology, it will rise as emission standards become more stringent. The clean technology, in contrast, eliminates the formation of pollution from within the production plant by altering the whole process. The use of the marginal pollution abatement cost curve, traditionally used in previous studies, is thus inappropriate for the analysis of the clean technology, which produces no emission in the first place. Although the initial investment necessary for the installation of the clean technology will be large, there is a possibility that its performance will improve significantly through R\&D and learning, as the clean technology involwes radical innovations in the whole production facilities. This difference between the two types of technologies for pollution abatement is crucial in our analytical framework for the diverging impacts of environmental regulations on technological change.

When an envirommental issue accurs, normally there is a large degree of uncertainty about where the sources of pollution are located, what the mechanisms of physical, chemical, or biological transformation of the substances are, and how much damage has been or is expected to be made on the human health or other living organisms. Given the existence of this uncertainty, scientific arguments cannot exclusively determine environmental policies, and other factors, including historical, political, and social contexts, will influence the outcome of policy discussions. Reflecting that, it would be quite possible that diverse regulations are imposed on the same environmental issue in different regions.

When a relatively weak regulation is imposed, firms will be induced to choose end-ofpipe technologies, rather than clean technologies. That is because it is cheaper, at least intially, to reduce emissions by using end-of-pipe technologies, which are just installed at the end of the manufacturing facilities, than clean technologies involving radical changes in the whole production process. As there are more demands for end-of-pipe technologies, R\&D efforts will be directed toward improving the performance of end-of-pipe equipment, and learming experience will be accumulated on this type of technology. With end-of-pipe technologies installed for successfully reducing emissions, companies will invest in and 
continue to use the existing production technology, instead of trying to develop radlically new clean technologies, which may be the most efficient from a long-term perspective.

On the other hand, when the imposed regulation is so stingent as to effectively require the abolishment of the existing production techmology, firms will be prompted to find new clean technologies. Normally, there are multiple options of clean technologies, and a large degree of uncertainty exists concerning which technology will progress to become the best in the long run. Thus, as long as the regulation is rigidly fixed, demanding the phase out of the existing technology immediately, there is a possibility that a wrong technological choice could be made by companies, without sufficient time or opportunities allowed for R\&D and learning. It will be known ex ante that the chosen technology may not be appropriate, after it has been used extensively for a certain period of time. Only when the regulatory schedule maintains some flexibility in schedule and timing, various types of clean technology will be tested and experimented, and there is a chance that the most efficient clean technology will be developed and adopted in the end.

Then the best clean technology developed in a region with a stringent regulation could later become available to polluting manufacturers in other regions where the imposed regulations were not so strong. Induced by the relatively weak regulations, however, those manufacturers have adopted end-of-pipe technologies to reduce emissions, and by the time when the best clean technology is available, new plants have been already established, based on the existing pollution-laden production technology. Unless the new clean technology is significantly more efficient than the old production technology equipped with end-of-pipe technologies, the operators of these new plants will have strong incentives to continue to use them until the end of their physical life time, which normally goes beyond forty years. Effectively, the weak regulations work to help the surwival of the existing production technology, which may be actually in a process of technological obsolescence.

In short, when the regulation is relatively weak, firms will be induced to adopt end-ofpipe technologies, instead of clean technologies. On the other hand, when a very stringent regulation is imposed, firms will be encouraged to make innovative efforts to develop new clean technologies, but an inappropriate technology might be chosen by companies if the regulation is implemented in a rigid and inflexible way. Stringent environmental regulations coupled with flexibility which allows sufficient time for R\&D and learning will work to promote the emergence of the best clean technology. With this analytical framework for the diverging effects of environmental regulations on technological change based on the 
distinction between the end-of-pipe technology and the clean technology, we will examine in the next two chapters the technological impacts of envirommental regulation on mercury emissions in the chlor-alkali industry in Japan and Western Europe.

\section{Appendix}

\section{Product Change}

The main product $M$ could be the source of environmental problems. Usually that means the existing main product has to be replaced with a different one, as, particularly in the chemical industry, it would be difficult to recycle completely used products, which are mainly in gas or liquid phase ${ }^{40}$. A new product should be designed so that its detrimental effects on the environment will be eliminated or reduced ", although the impact of products on the environment may not be always predictable or even understood for decades. In the chemical industry, a product change normally requires a change in the chemical composition of the final product.

When the chemical composition of the main product $M_{i}^{*}$ is changed to obtain $M_{2}$, at least one of the input materials $I_{a}$ and $I_{b l}$, needs to be replaced with different substance(s) $I_{a z}$ and $I_{b 2}$ (including the possibility of the same $I_{b i}$ ). Therefore, the whole chemical reaction will be altered as follows:

$$
\begin{aligned}
& I_{a l}+I_{b l}>M_{l}^{*}+B_{i} \\
& \Rightarrow I_{a z}+I_{b 2}>M_{2}+B_{l} .
\end{aligned}
$$

It should be noted that in many cases the composition of the by-product $B$, would also be transformed to $B_{2}$ as a result; that is,

$$
I_{i a f}+I_{b i}>M_{l}^{*}+B_{i}
$$

\footnotetext{
"In the "mechanical" industries, including automobile and electric and electronic industries, practices of closed-toop recycling. now called "inverse manufucturing," has been emerging. What would be potentially crucial in achieving inverse manufacturing is dynamic aspects of technology, in particular, the gap between the pace of innovation and the product life-span, that is, the length of time that each product is likely to be used by consumers. When consumers finish using products, say, five years later, while the parts of old products might be reusable physically, probably they could be obsolescent lechnologically, and it would be very difficult to incorporate them to thew commercial products. This gap would be particularly large in the case of laigh-tech products like computers (Baba, Yarime, and Hatashima, 1997).

"As a useful tool for integrated designing, Life Cycle Assessment (LCA) has been proposed recently and begun to be adopted among firms. That approach is aimed at evaluating the environnental impacts of a product throughout its life cycle from the phase of raw material acquisition wia production to consumption. For more intomation on LCA, see, for example. Society of Environmental Toxicology and Chemistry (1991).
} 


$$
\Rightarrow I_{a 1}+I_{b 2} \rightarrow M_{z}+B_{2}
$$

That means the whole chemical reaction would be changed. Therefore allhough this case could be considered basically as product innovation, process innovation would also be required at the same time.

The use of tetraethyl lead $\left(\mathrm{Pb}\left(\mathrm{C}_{2} \mathrm{H}_{5}\right)_{4}\right)^{\prime \prime}$ in gasoline provided a high-octane gasoline for many years. However, this substance has now been phased out in many parts of the world, inclluding Europe, Japan, and the US, in favor of methyl $x$-butyl ether $\left(\mathrm{CH}_{3} \mathrm{OC}\left(\mathrm{CH}_{3}\right)_{3}, \mathrm{MTBE}\right)$. Commercial production of MTBE began in 1979, shortly after the discovery of its octaneimproving capability for motor fuels. Although a higher proportion of this additive was required for equivalent octane enhancement, it was less costly and eliminated the hazardous lead particulate discharges associated with the tetraethyl lead previously used for this purpose. Hence the convenient industrial method of producing tetraethyl lead, that is, the reaction of a sodium-lead alloy $(\mathrm{Na}-\mathrm{Pb})$ with chloroethane $\left(\mathrm{C}_{2} \mathrm{H}_{5} \mathrm{Cl}\right)$

$$
\mathrm{Na}-\mathrm{Pb}+4 \mathrm{C}_{2} \mathrm{H}_{5} \mathrm{Cl}>\mathrm{Pb}\left(\mathrm{C}_{2} \mathrm{H}_{5}\right)_{4}{ }^{*}+\mathrm{Na}^{+}+4 \mathrm{Cl}^{-}
$$

was replaced with the liquid phase reaction of methanol $\left(\mathrm{CH}_{3} \mathrm{OH}\right)$ with isobutylene $\left(\mathrm{CH}_{2}=\mathrm{C}\left(\mathrm{CH}_{3}\right)_{2}\right)$, which gives this novel, oxygenated gasoline additive (Hocking, 1998):

$$
\mathrm{CH}_{3} \mathrm{OH}+\mathrm{CH}_{2}=\mathrm{C}\left(\mathrm{CH}_{3}\right)_{2} \rightarrow \mathrm{CH}_{3} \mathrm{OCC}\left(\mathrm{CH}_{3}\right)_{2}
$$

Another recent example involves the replacement of chlorofluorocarbons (CFCs). CFCs were once hailed as wonder products, following the discovery of the first substance, $\mathrm{CFC}-12$, in 1930 . Their chemical inertness, non-flammability, and non-toxic nature rapidly led to their large-scalle use as safe refrigerants, aerosol propellants and form blowing agents in the production of polyurethane foams. In 1974, however, it was first suggested that because of their great stability they could rise, unchanged, into the stratosphere, where they would be broken down by the short wavelength UV-B radiation to form chlorine radicals. These would then attack and destroy ozone molecules through chain reactions. The consequence of the thinning of the ozone layer would be that it could no longer prevent the harmfinl short wavelength UV-B radiation reaching the surface of the earth. Following the Montreal Protocol signed in $1987, \mathrm{CFCs}$, including $\mathrm{CFC}-11\left(\mathrm{CCl}_{3} \mathrm{~F}\right), \mathrm{CFC}-12\left(\mathrm{CCH}_{2} \mathrm{~F}_{2}\right)$, and $\mathrm{CFC}-113$ $\left(\mathrm{CClF}_{2} \mathrm{CCl} \mathrm{F}_{2} \mathrm{~F}\right)$, were phased out by 1996. To produce $\mathrm{CFC}-12$, tetrachloromethane (CCl $)$ could be reacted with hydrogen fluoride $(\mathrm{HF})$ :

$$
\mathrm{CCl}_{4}+2 \mathrm{HF} \rightarrow \mathrm{CCl}_{2} \mathrm{~F}_{2}+2 \mathrm{HCl}
$$


CFC alternatives include hydrochlorofluorocarbons (HCFCs) and hydrofluorocarbons (HFCs) such as $\mathrm{HFC}-134 \mathrm{a}\left(\mathrm{CF}_{3} \mathrm{CH}_{2} \mathrm{~F}\right)$ and $\mathrm{HFC}-32\left(\mathrm{CH}_{2} \mathrm{~F}_{2}\right)$, whose associated ozone depletion potential (ODP) is zero because they don't contain any chlorine and, therefore, will not be able to attack ozone molecules. New products are much more complex than the CFCs they are replacing, and the required change in the route of chemical reactions would also be large. A well-studied multi-step synthesis of HFC-134a involves the hydrogenolysis of CFC$114 \mathrm{a}\left(\mathrm{CF}_{3} \mathrm{CCl}_{2} \mathrm{~F}\right)$ derived from tetrachloroethylene $\left(\mathrm{CCl}_{2}=\mathrm{CCl}_{2}\right)$ through a series of transformation (Manzer and Rao, 1993):

$$
\begin{aligned}
& \mathrm{CCl}_{2}=\mathrm{CCl}_{2}+\mathrm{Cl}_{2}>\mathrm{CCl}_{3} \mathrm{CCl}_{3} \\
& \mathrm{CCl}_{3} \mathrm{CCl}_{3}+3 \mathrm{HF}>\mathrm{CF}_{2} \mathrm{ClCCl}_{2} \mathrm{~F}+3 \mathrm{HCl} \\
& \mathrm{CF}_{2} \mathrm{ClCCl}_{2} \mathrm{~F}+\mathrm{HF}>\mathrm{CF}_{2} \mathrm{ClCF}_{2} \mathrm{Cl}+\mathrm{HCl} \\
& \mathrm{CF}_{2} \mathrm{ClCF}_{2} \mathrm{Cl}>\mathrm{CF}_{3} \mathrm{CCl}_{2} \mathrm{~F} \\
& \mathrm{CF}_{3} \mathrm{CCl}_{2} \mathrm{~F}+2 \mathrm{H}_{2}>\mathrm{CF}_{3} \mathrm{CH}_{2} \mathrm{~F}+2 \mathrm{HCl} .
\end{aligned}
$$

The overall stoichiometry is thus as follows:

$$
\mathrm{CCl}_{2}=\mathrm{CCl}_{2}+\mathrm{Cl}_{3}+4 \mathrm{HF}+2 \mathrm{H}_{2}->\mathrm{CF}_{3} \mathrm{CH}_{2} \mathrm{E}+6 \mathrm{HCl} \text {. }
$$

While most CFCs are produced in a single catalytic step, alternatives such as $\mathrm{HFC}-134 \mathrm{a}$ would normally require 2 to 5 complex catalytic steps (Koch, Krause, Manzer, Mehdizadeh, Odom, and Sengupta, 1996).

The long-term viability of HFCs is not secured, however. Although the volumes of HFCs emitted to the atmosphere are very low, compared with carbon dioxide $\left(\mathrm{CO}_{2}\right)$, they have a large global warming potential (GWP). As HFCs have been listed as one of greenhouse gases in the Kyoto Protocols, development activities will continue to find more environmentally desirable replacements for $\mathrm{CFCs}$. 


\section{Technological Background of the Chlor-Alkali Industry}

\subsection{Production of Chlor-Alkali Products}

\subsubsection{Chlorine and Caustic Soda}

The chlor-alkali industry produces a group of commodity chemicals, including chlorine $\left(\mathrm{Cl}_{2}\right)$. sodium hydroxide (caustic soda, $\mathrm{NaOH}$ ), sodium carbonate (soda ash, $\mathrm{Na}_{2} \mathrm{CO}_{3}$ ), potassium hydroxide (caustic potash, $\mathrm{KOH}$ ), and hydrochloric acid (muriatic acid or anhydrous, HCl). The analysis of this research is focused on chlorine and caustic soda, the most important products in the chlor-alkali industry.

\section{Chlorine}

Initially, chlorine was used as a disinfectant for water treatment and the exploitation of natural resources such as pulp and paper. Inorganic chemistry applications followed, and then organic chemicals began to take large quantities. Since chlorine is a highly reactive element, it is used widely in industry as a strong oxidizing agent and as a specific chlorinating agent. Table 3-1 and Table 3-2 give the current distributions of applications of chlorine in Japan and Western Europe.

Table 3-1 Applications of Chlorine in Japan

\begin{tabular}{|l|c|}
\hline \multicolumn{1}{|c|}{ Application } & Amount of Demand $\left(\mathrm{Cl}_{2} 10^{3}\right.$ tonnes/year) \\
\hline Vinylchloride & $1,862(37.5 \%)$ \\
\hline Inorganic Chemicals & $402(8.1 \%)$ \\
\hline Chloromethanes & $298(6.0 \%)$ \\
\hline TDI $^{*}$ MDl & $293(5.9 \%)$ \\
\hline Propylene Oxide & $235(4.7 \%)$ \\
\hline Dyes and Intermediates & $206(4.2 \%)$ \\
\hline Pulp and Paper & $177(3.6 \%)$ \\
\hline Chlorinated Solvents & $171(3.4 \%)$ \\
\hline Food & $55(1.1 \%)$ \\
\hline Others & $1,267(25.5 \%)$ \\
\hline & $4,966(100 \%)$ \\
\hline
\end{tabular}

a: tolylene disocyanate.

b: diphenylmethane dissocyanate

Source: Japan Soda Industry Association (1999a). 
Table 3-2 Applications of Chlorine in Western Europe

\begin{tabular}{|l|c|}
\hline \multicolumn{1}{|c|}{ Application } & Amount of Demand $\left(\mathrm{Cl}_{2} 10^{3}\right.$ tonnes/year $)$ \\
\hline Polywinyl Chloride & $3,200(35 \%)$ \\
\hline Chlorinated $\mathrm{C}_{\text {and }} \mathrm{C}_{2} \mathrm{~s}$ & $1,200(13 \%)$ \\
\hline Phosgene & $1,000(11 \%)$ \\
\hline Propylene Oxide & $1,000(11 \%)$ \\
\hline Hydrochloric Acid & $500(5 \%)$ \\
\hline Sodium Hypochlorite & $400(4 \%)$ \\
\hline Others & $1,900(21 \%)$ \\
\hline
\end{tabular}

Source: Euro Chlor (1999a).

Although the applications of chlorine are classified in different ways between Japan and Western Europe, they show similar compositions. Polyvinyl chloride (PVC), which is produced by polymerizing vinyl chloride, is the largest single application of chlorine in Japan and Western Europe, accounting for $37.5 \%$ and $35 \%$ of production, respectively. Ethylene is chlorinated to produce ethylene dichloride (EDC), and then hydrogen chloride is removed to produce vinyl chloride monomer (VCM). With an anmual production of more than 20 million, PVC is the second largest of all plastics after polyethylene. Since the start of its industrial production in the 1930s, PVC has been used extensively in the building industry and for the production of consumer goods and packages.

Inorganic compounds produced from chlorine include hydrochloric acid (hydrogen chloride, $\mathrm{HCl}$ ), metal chlorides and non-metal chlorides. Hydrochloric acid is used for faod processing. Metal chlorides have many applications, including the use of aluminium and iron chlorides as catalysts in synthesis and as flocculants in water treatment. Zine chloride is used in galvanization. Non-metal chlorides such as the phosphorus and sulfur chlorides are widely used as intermediates for agrochemicals, notably for pesticides and herbicides. They are also used in the production of plasticizers, stabilizers and coloring materials for plastics. Hypochlorites, including sodium hypochlorite, have been used for a long time as bleaching agents for the paper and pulp industry and as disinfectants for water treatment. Chlorine dioxide has replaced elemental chlorine in new processes for bleaching paper-making pulps.

Chlorine is also widely used for producing chlorinated $C_{1}$ and $C_{2}$ molecules ${ }^{42}$, including chloromethanes and chlorinated solvents. Chloromethane, together with silicon, is used for synthesizing silicones. Silicones are polymeric compounds, and a variety of sillicone materials

\footnotetext{
$\mathrm{C}_{1}$ and $\mathrm{C}_{2}$ smolecules denote those which contain one and two carbon alom(s), respectively.
} 
include oils, waxes, and rubbers. Chlorinated solvents have been used widely since the 1920 s because they possess properties which are unusual in other organic solvents, such as good solvency, high volatility, and consequently high speed of drying, and non-flammability. Four chlorinated solvents are mainly used, namely, trichloroethylene, perchloroethylene, methylene chloride and 1,1,1-trichloroethane. In recent years, however, because of the concerns about health and environmental impacts, their consumption has been sharply reduced and currently represents only a small percent of the total usage of chlorine ${ }^{43}$.

Many chlorinated derivatives are used in organic synthesis, whether or not chlorine is contained in final products. They are frequently used in various chemical reactions which give rise to various chemical products, including food additives, cosmetics, detergents, photographic products, paints and adhesives. Phosgene and propylene oxide, both of which do not contain chlorine, are used for the synthesis of polyurethanes. Phosgene is reacted with amines to produce isocyanates such as tolylene diisocyanate (TDI) and diphenylmethane divisocyanate (MDI), which are intermediates for the synthesis of polyurethanes. Propylene oxide is made by the chlorohydrin process, which requires the use of chlorine. Polyurethanes have many different applications, mainly in the form of foams, including furniture, beds and buildings.

\section{Caustic Soda}

Caustic soda has been used for a wide range of industrial applications as well as for the production of consumer products. The current applications of caustic soda in Japan and Europe are shown in Table 3-3 and Table 3-4.

Table 3-3 Applications of Caustic Soda in Japan

\begin{tabular}{|l|c|}
\hline \multicolumn{1}{|c|}{ Application } & Amount of Demand (NaOH $10^{3}$ tonnes/year) \\
\hline Inorganic Chemicals & $498(13.4 \%)$ \\
\hline Organic and Petro Chemicals & $144(3.9 \%)$ \\
\hline Other Chemicals & $1,165(31.5 \%)$ \\
\hline Pulp and Paper & $392(10.6 \%)$ \\
\hline Food & $132(3.6 \%)$ \\
\hline Dyeing Preparation & $104(2.8 \%)$ \\
\hline Dyes and Intermediates & $103(2.8 \%)$ \\
\hline
\end{tabular}

\footnotetext{
43 Recently, the environmental effects of chlorinated organic substances have been hotly debated. This is an example of the main product as the source of pollution and is not discussed in detail in this rescarch (see Appendix). For diverse perspectives on this debate, see, for example, Aikawa (1998), Martin and Martens (1996). Thornton (2000), and Kleijn, Tukker, and van der Voet (1997).
} 


\begin{tabular}{|l|c|}
\hline Chemical Fiber & $91(2.5 \%)$ \\
\hline Alumina & $76(2.1 \%)$ \\
\hline Electrolysis & $72(1.9 \%)$ \\
\hline Soaps and Detergents & $48(1.3 \%)$ \\
\hline Oil Refining & $34(0.9 \%)$ \\
\hline Cellophane & $16(0.4 \%)$ \\
\hline Others & $827(22.3 \%)$ \\
\hline \multicolumn{1}{|c|}{ Total } & $3.702(100 \%)$ \\
\hline
\end{tabular}

Source: Japan Soda Industry Association (1999a):

Table 3-4 Applications of Caustic Soda in Western Europe

\begin{tabular}{|c|c|}
\hline Application & Amount of Demand ( $\mathrm{NaOH} 10^{3}$ tonnes/year) \\
\hline Chemicals & $4,900(53 \%)$ \\
\hline Paper & $1,000(11 \%)$ \\
\hline Consumer Products & $700(7 \%)$ \\
\hline Aluminium Processing & $400(4 \%)$ \\
\hline Others & $2,300(25 \%)$ \\
\hline Total & $9,300(100 \%)$ \\
\hline
\end{tabular}

Source: Euro Chlor (1999a).

As in the case of chlorine, the applications of caustic soda in both regions show similar outlets. About half of caustic soda produced is consumed for manufacturing various industrial chemicals. Large amounts of caustic soda are used in the organic and inorganic chemicals industries. Since caustic soda is a highly alkaline material, it is widely used for neutralizing acids and dissolving materials which are difficult to dissolve. A variety of reactions can occur with organic as well as inorganic materials.

Approximately one tenth goes to the pulp and paper industry, in which caustic soda has been widely used for a long time. The Kraft process, which was originally developed in 1879 , is currently the preeminent chemical pulping procedure. In this process, wood chips are cooked in pulping liquor consisting of a solution of sodium hydroxide, that is, caustic soda, and sodium sulfide in water, the so-called white water, and much of the lignin originally present in the wood is dissolved. Caustic soda is also used in the bleaching steps for pulp brightening.

In the textile industry, rayon is made from wood pulp by using caustic soda. In the viscose process, the pulp is dissolved in carbon disulfide and caustic soda to give a thick brown liquid, which is then forced through fine nozzles into acid, producing a cellulose filament. Caustic soda has also been important for aluminium processing since around 1900 . 
Alumina is recovered from bauxite by extraction with caustio soda, which is now frequently referred to as the Bayer process. Caustic soda also plays an important role in manufacturing consumer products. Soaps, for example, are made by boiling animal fats with caustic soda ${ }^{4}$.

\subsubsection{Production}

The world chlor-alkali production capacity was 43.5 million tonnes of chlorine in 1996 . Table 3-5 provides a breakdown of the production capacity by geographical region. The world largest producing country is the United States. With its annual production capacity of more than 13 million tonnes of chlorine, it accounts for about $30 \%$ of the world production capacity. Following the United States, Western Europe is globally the second largest chloralkali producing region, representing $23 \%$ of the world capacity. Japan's production capacity accounts for approximately one tenth of the world production.

Table 3-5 Chlor-Alkali Production Capacities in the World

\begin{tabular}{|c|c|}
\hline Region & Production Capacity $\left(\mathrm{Cl}_{2} 10^{3}\right.$ tomnes/year) \\
\hline North America & $13,500(3 \| \%)$ \\
\hline Western Europe & $10,000(23 \%)$ \\
\hline Eastem Europe & $6,100(14 \%)$ \\
\hline Asia (excluding Japan) & $6,100(14 \%)$ \\
\hline Japan & $4,300(10 \%)$ \\
\hline Central \& South America & $1,300(3 \%)$ \\
\hline Middle East & $1,300(3 \%)$ \\
\hline Other & $900(2 \%)$ \\
\hline Total & $43,500(100 \%)$ \\
\hline
\end{tabular}

Source: SRI (1996).

Within Western Europe, Germany is by far the largest producing country, as is shown in Table 3-6. Germany represents $38 \%$ of the total installed capacity in the region, followed by France, Unitted Kingdom, Italy, Belgium and Spain. The largest two countries account for more than half of the total production capacity in Western Europe.

Table 3-6 Chlor-Alkali Production Capacities in Western Europe

\begin{tabular}{|l|c|}
\hline Country & Production Capacity $\left(\mathrm{Cl}_{2} \llbracket 0^{3}\right.$ tonnes/year $)$ \\
\hline Germany & $4,379(38.3 \%)$ \\
\hline
\end{tabular}

\footnotetext{
Where is the third product of the electrolysis of brine, namely, hydrogen $\left(\mathrm{H}_{2}\right)$. It is very pure and hats a wide varicy of uses. It is used is as at chemical feedstock for organic hydrogenation, catalytic reductions, and ammonia symthes is and to provide hot flames or protective atmospheres in welding technology, melallurgy, or: glass manufacture. It is also used in the manufacture of high-purty hydrogen chloride by combustion with chloride and as a fuel for heating and drying.
} 


\begin{tabular}{|l|c|}
\hline France & $1,686(14.8 \%)$ \\
\hline UK & $1,216(10.6 \%)$ \\
\hline Italy & $982(8.6 \%)$ \\
\hline Belgium & $832(7.3 \%)$ \\
\hline Spain & $802(7.0 \%)$ \\
\hline Netherlands & $647(5.7 \%)$ \\
\hline Sweden & $292(2.6 \%)$ \\
\hline Norway & $180(1.6 \%)$ \\
\hline Finland & $115(1.0 \%)$ \\
\hline Switzerland & $104(0.9 \%)$ \\
\hline Portugal & $89(0.8 \%)$ \\
\hline Austria & $60(0.5 \%)$ \\
\hline Greece & $37(0.3 \%)$ \\
\hline Ireland & $6(0.1 \%)$ \\
\hline \multicolumn{1}{|c|}{ Total } & $11,427(100 \%)$ \\
\hline
\end{tabular}

Sources: Euro Chlor (1998a), European IPPC Bureau (1999).

The number and scale of chlor-alkali plants in Western Europe and Japan are given in Table 3-7. In 1998 the production capacity of Western Europe was 11.4 million tonnes of chlorine. Across the 15 countries, there were 44 chlor-alkali producers operating 80 plants, with an average production capacity of 142,800 tomnes of chlorine per year. In the same year, the annual production capacity of the Japanese chlor-alkali industry was 4.4 million tonnes of caustic soda, equivalent to 4 million tonnes of chlorine. In total, 29 companies were operating 40 chlor-alkali plants, and the average production capacity was 111,000 tonnes of caustic soda per year, equal to 99,000 tonne of chlorine per year. Thus the average plant capacity in Western Europe is approximately 1.5 times larger than that in Japan.

Table 3-7 Chlor-Alkali Plants in Western Europe and Japan

\begin{tabular}{|l|c|c|c|c|}
\hline & $\begin{array}{c}\text { Capacity } \\
\left(\mathrm{Cl}_{2} 10^{3} \text { tyear }\right)\end{array}$ & Producers & Plants & $\begin{array}{c}\text { Average Plant Capacity } \\
\left(\mathrm{Cl}_{2} 10^{3} \text { tyear }\right)\end{array}$ \\
\hline Western Europe & 11,400 & 44 & 80 & 142,800 \\
\hline Japan & 4,000 & 29 & 40 & 99,000 \\
\hline
\end{tabular}

Sources: Euro Chlor (1998a), European IPPC Bureau (1999), and Japan Soda Industry Association (1998b).

The production of chlorine and caustic soda is significantly integrated with the downstream businesses, such as the PVC production, and in many cases forms part of an integrated petrochemicals and plastic complex. For example, among 15 petrochemical industrial complexes operating in Japan in 1997, chlor-alkali plants supplied chlorine and 
caustic soda in 10 of them (Japan Soda Industry Association, 1998b). Being classified as a toxic and corrosive gas, chlorine is difficult to store and handle, and thus the transportation of chlorine is normally kept to a minimum. More than $85 \%$ of the chlorine produced in Western Europe is used on the same or adjacent sites for other chemical processes and converted to chlorinated organic products and intermediates (Lindley, 1997). While very little chlorine trade occurs in its elemental form, chlorine derivatives, including $\mathrm{EDC}$, VCM, and PVC, ara traded widely in the international market. Caustic soda is usually shipped as solution of about $50 \%$ concentration and is bought and sold freely in the world market.

As chlorine and caustic soda, which are co-produced by a fixed ratio through the electrolysis of brine, are consumed separately for different purposes, demands for the two products are not normally balanced. Generally speaking, caustic demand in a developing country exceeds chlorine demand because caustic-consuming basic industries such as mineral processing, paper, glass, and textile manufacture normally precede the development of the chlorine-consuming petrochemical and plastics industries. Hence, industrialized countries, including Western Europe and Japan, tend to have excess amounts of caustic soda, which can be exported to industrializing countries such as those in Asia.

\subsection{Three Dominant Technologies for Chlor-Alkali Production: Mercury} Process, Diaphragm Process, and Ion Exchange Membrane Process

Traditionally, two types of production technologies were used in the chlor-alkali industry:

- Chemical processes

- Electrolytic processes.

Figure 3-1 gives a schematic illustration of the evolution of various technologies used for chlor-alkali production since the birth of the chlor-alkali industry. 

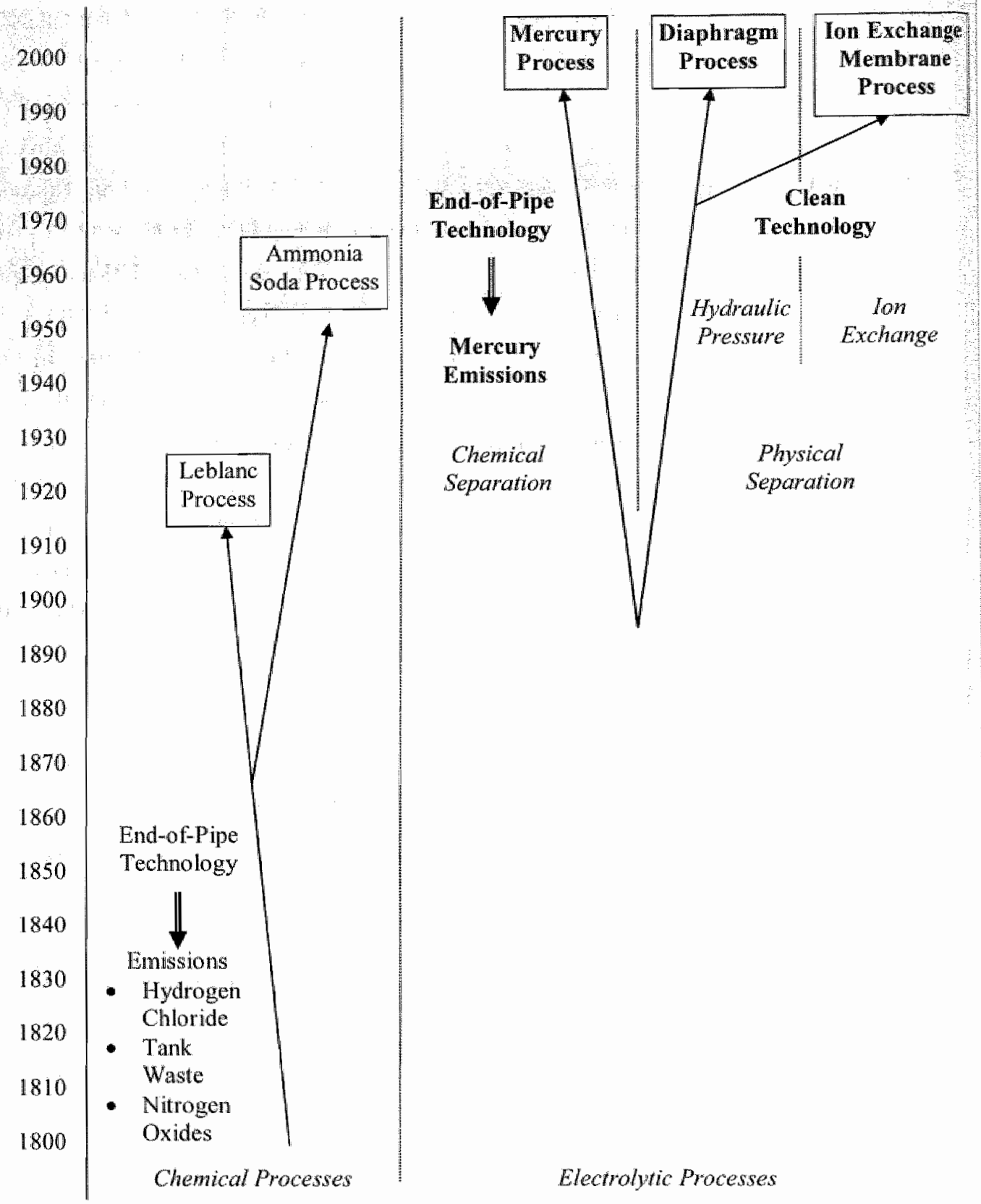

Figure 3-1 Evolution of Production Technologies in the Chlor-Alkali Industry 
From the beginning of the industrial production of alkali products at the end of the 18 th century through the 19th century, the production processes were based on chemicall reactions: There are two types of chemical processes ${ }^{45}$ :

- Leblanc process

- Ammonia soda process (Solvay process).

At around the turn of the 19 th century, a radically new way of producing alkali was invented based on the principle of electrolysis. In electrolytic processes, an aqueous solution of sodium chloride $(\mathrm{NaCl}$ ), that is, salt, commonly called brine, is decomposed by electrolysis with direct current, producing chlorine, hydrogen, and sodium hydroxide. For each tonne of chlorine produced, 1.12 tonnes of caustic soda and 0.028 tonnes of hydrogen are produced at the same time ${ }^{46}$. The electrolytic production of chlorine and caustic soda depends on a large current of amount of electricity. Thus the chlor-alkali industry is a major user of electric power, and actually its unit consumption of electricity is the one of the largest, following the aluminium, carbide, and ferroalloy industries. The Japanese chlor-alkali inclustry, for instance, consumed approximately 10.7 billion $\mathrm{kWh}$ of electricity in 1996 , accounting for $3 \%$ of the total industry consumption and $18 \%$ of the total chemical industry consumption (Japan Soda Industry Association, 1998aj. As energy cost accounts for a significant part of the total manufacturing cost, one of the major targets of innovative activities in the chlor-alkali industry has been to develop technologies to reduce energy consumption.

Three types of electrolytic processes are currently in use for commercial manufacturing of chlorine and caustic soda in the world:

- Mercury process

- Diaphragm process

- Ion Exchange Membrane process

Each process represents a different method of keeping chlonine produced at the anode separate from the caustic soda and hydrogen produced, directly or indirectly, at the cathode ${ }^{47}$.

Figure 3-2 shows the shares of the three processes in the chlor-alkali industry in Western Europe, the United States and Japan. (Data are given in Table 3-24 in Appendix at

\footnotetext{
45 Although the Leblanc process and the ammonia soda process are riot the foeus of our research, the diverging impacts of environmental regulations on technological change are similar to those observed in the case of the electrolytic processes. More detailed discussions are given in Appendix.

"tho As both chilorine and caustic soda are used as the unit of measurement in the indusiry, both of them appeatr in this research. The conversion factor is $35.5: 40 ;$ that is, $11 \mathrm{Cl}_{2}=1.12 \mathrm{t} \mathrm{NaOH}$.
} 
the end of this chapter). As you can see clearly, different production processes are dominant in the three regions. In Western Europe, approximately $60 \%$ of the chlor-alkali plants are based on the mercury process. In the United States, more than $70 \%$ of the chlor-alkali plants are using the diaphragm process. In Japan, while there is no chlor-alkali plants based on the mercury process, the ion exchange membrane process has been adopted by more than $90 \%$ of the chlor-alkali plants. In the other wo regions, the diffusion of the ion exchange membrane process is limited to approximately $10 \%$

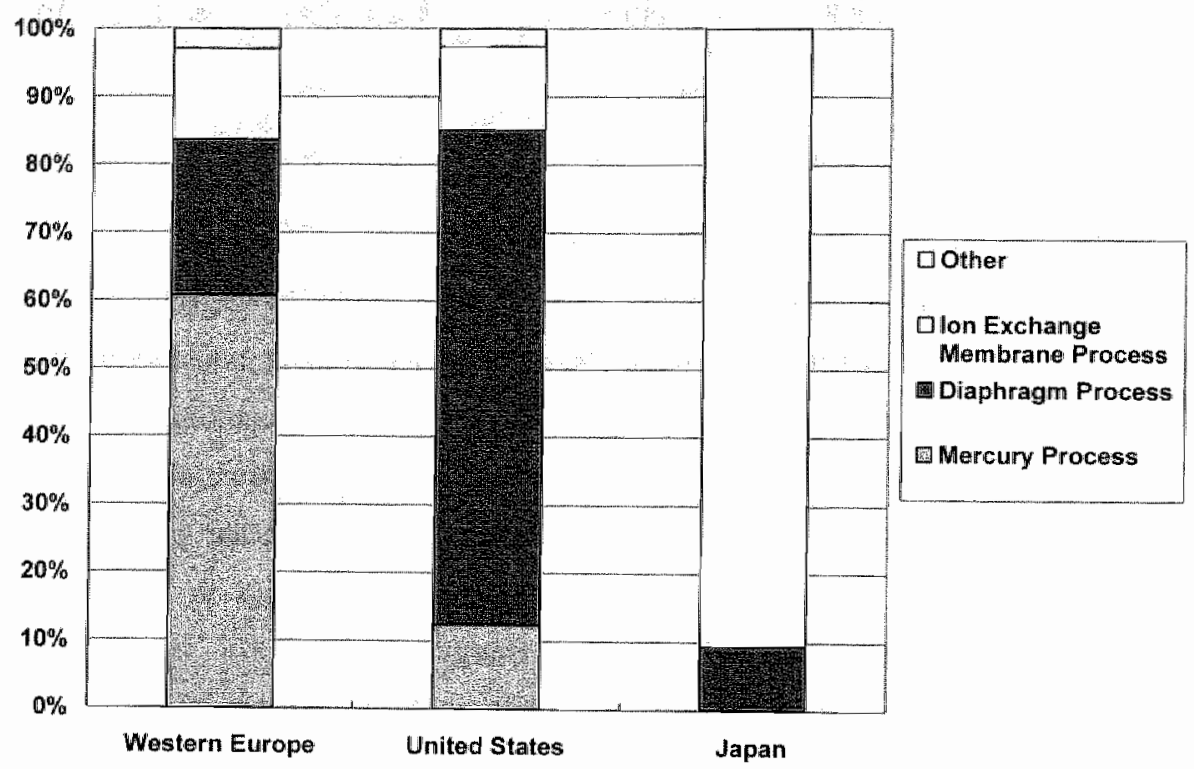

Figure 3-2 Shares of the Mereury, Diaphragm, and Ion Exchange Membrane Processes in Western Europe, the United States, and Japan in 1998

To investigate why the divergent courses of technological change have occurred between Westem Europe and Japan, we first trace the historical evolution of the electrolytic processes up to the early $1970 \mathrm{~s}$, when environmental regulations began to be introduced on mercury emissions from chlor-alkali plants. Then, in the next two chapters, we examine how environmental regulations have influenced the course of technological change in Western Europe and Japan since then.

\footnotetext{
Anode is a posilve electrode, to which negative ions (anions) migrate, and cathode is a negative electrode, to
which positive ions (cations) migrate.
} 


\subsection{Technological Change Prior to the Effects of Environmental Regulations}

It had been well known for a long time that electrolysis of brine resulted in the formation of chlorine at the anode, and of caustic soda and hydrogen at the cathode (Haber, 1971). The decomposition of salt water by means of an electric current was demonstrated as early as 1800. During the period 1832-1834, the laws governing the electrolysis of aqueous salt solutions were formulated by Faraday. While a patent was granted in Britain in 1852 for the electrolytic production of chlorine from brine, laboratory success was slowly converted into commercial viability. Since electrolysis is a power-intensive process, the supply of cheap electricity was indispensable for the industrial feasibility of electrolysis. As the accumulator was not useful for industrial purposes, progress was delayed until the development of an efficient dynamo in the late 1860s. The first experiments on an industrial scale were not until the 1880 s because of technical as well as commercial difficulties to overcome. One of the most demanding technical difficulties facing the infant electrolytic technology was how to devise a means of continuous separation of chlorine and sodium hydroxide. Eventually, two different processes were developed in the late 1880 s and the early 1890 s to accomplish this separation by using mercury and diaphragm, that is, the mercury process and the diaphragm process.

\subsubsection{Development of the Mercury Process}

A simplified flow diagram of the mercury process is given in Figure 3-3. Several steps are common to all of the chlor-alkali production processes, whether mercury, diaphragm, or ion exchange membrane (Curlin, Bommaraju, and Hansson, 1991; Hocking, 1998; Kelham, 1996; Schmittinger, Curlin, Asawa, Kotowski, Beer, Greenberg, Zelfel, and Breitstadt, 1986). 


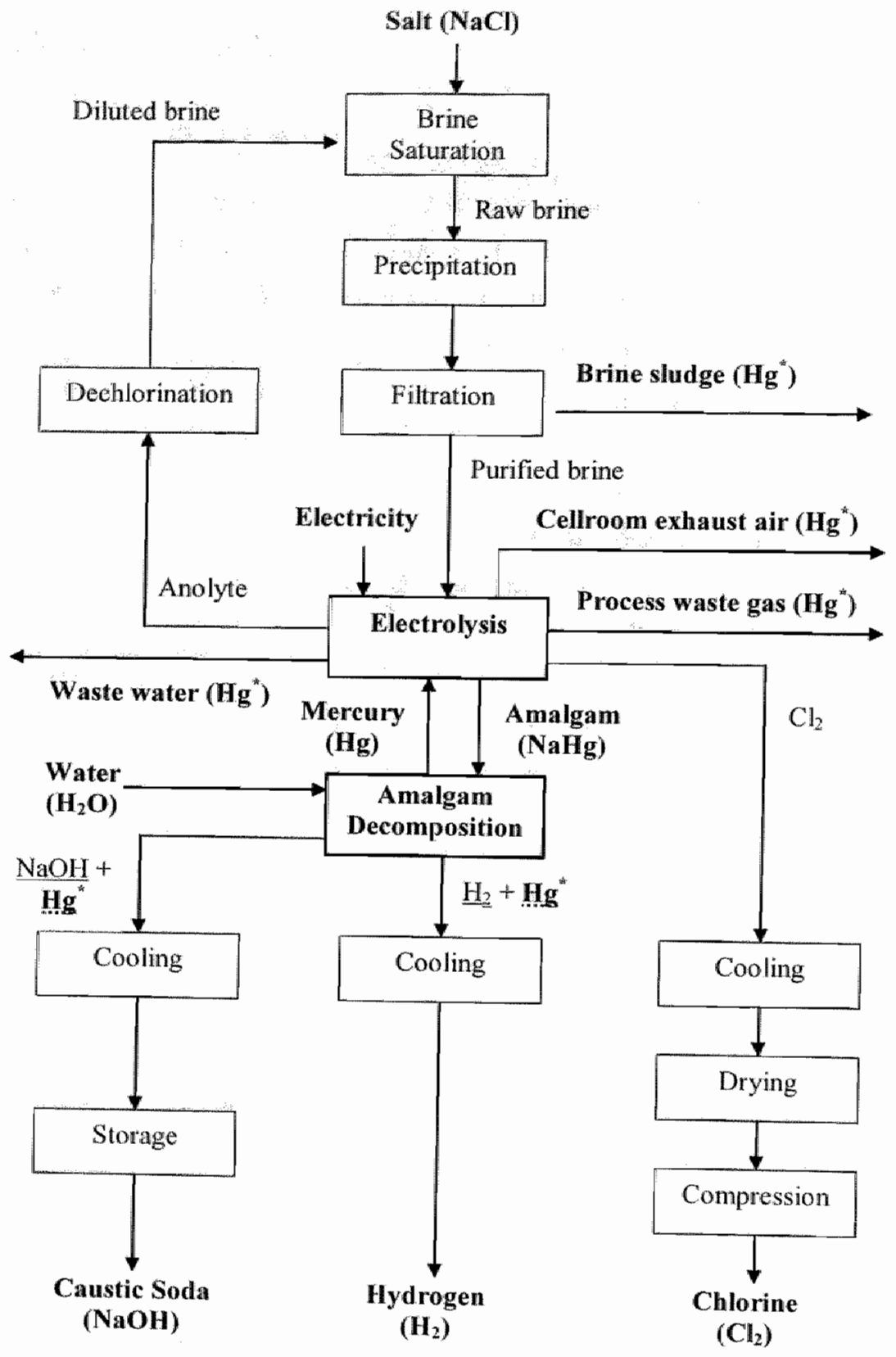

Figure 3-3 Flow Diagram of the Mercury Process

Based on Schmirtinger et al. (1986). 
The basic raw material for the mercury process is nomally solid salt. Saturated brine first goes through the precipitation-filtration step because sodium chloride, whether solutionmined or obtained as either mined or solar-evaporated solid salt, contains various impurities. Since these traces of heavy metals in the brine give rise to dangerous operating conditions in the electrolyzer, brine for the mercury process must meet stringent purity standards. For undertaking electrolysis, electricity must be provided in the form of direct ourrent, and rectifiers are used to transform alternate current to direct current.

The mercury process involved two electrochemical units, namely, an electrolytic cell and an amalgam decomposer (Schmittinger, 2000). Amalgam decomposition is a unique step for the mercury process, which thus requires mercury removal from the products. Figure $3-4$ gives a schematic illustration of the two electrochemical units. In the electrolytic cell, the purified brine flows through an elongated, slightly inclined trough. Mercury, which functions as the cathode, flows concurrently with the brine over the base plate. Anodes are suspended in the brine from above. The evolution of chlorine takes place at the anode in all of the three processes. At the anode, chlorine ions $\left(\mathrm{Cl}^{-}\right)$lose electrons $(\mathrm{e})$ to form chlorine atoms $\left(\mathrm{Cl}^{*}\right)$ :

$$
\mathrm{Cl}^{-} \rightarrow \mathrm{Cl}^{*}+\mathrm{e}^{*} \text {. }
$$

Then chlorine atoms combine to escape as chlorine molecules $\left(\mathrm{Cl}_{2}\right)$ :

$$
2 \mathrm{Cl}^{\circ} \rightarrow \underline{\mathrm{Cl}}
$$

As the chlorine produced by any of the electrolyzer processes is saturated with water vapor at high temperature, it is first cooled, with water removed, and then dried.

Unlike the diaphragm or ion exchange membrane process, in which hydrogen and sodium hydroxide are produced at the cathode, the cathodic reaction in mercury cells is the discharge of sodium ions (Na ${ }^{*}$ to form dilute sodium amalgam with a thin film of mercury. As mercury itself acts as a separator for the anode and cathode products, the mercury process contains no mechanical barriers. First, sodium ions gain electrons to form sodium atoms (Na):

$$
\mathrm{Na}^{+}+\mathrm{e}^{-} \rightarrow \mathrm{Na} \text {. }
$$

Then, the sodium atom immediately dissolves in the mercury ( $\left.\mathrm{Hg}^{*}\right)$ film electrode to form sodium amalgam ( $\mathrm{NaHg})$ :

$$
\mathrm{Na}+\mathrm{Hg}^{*} \rightarrow \mathrm{NaHg}
$$

The liquid amalgam then passes into the decomposer, where it reacts with water $\left(\mathrm{H}_{2} \mathrm{O}\right)$ to form sodium hydroxide $(\mathrm{NaOH})$ solution and hydrogen $\left(\mathrm{H}_{2}\right)$ :

$$
2 \mathrm{NaHg}+2 \mathrm{H}_{2} \mathrm{O}>\underline{2 \mathrm{NaOH}}+\underline{\mathrm{H}}_{2}+2 \mathrm{Hg}^{\prime \prime} \text {. }
$$




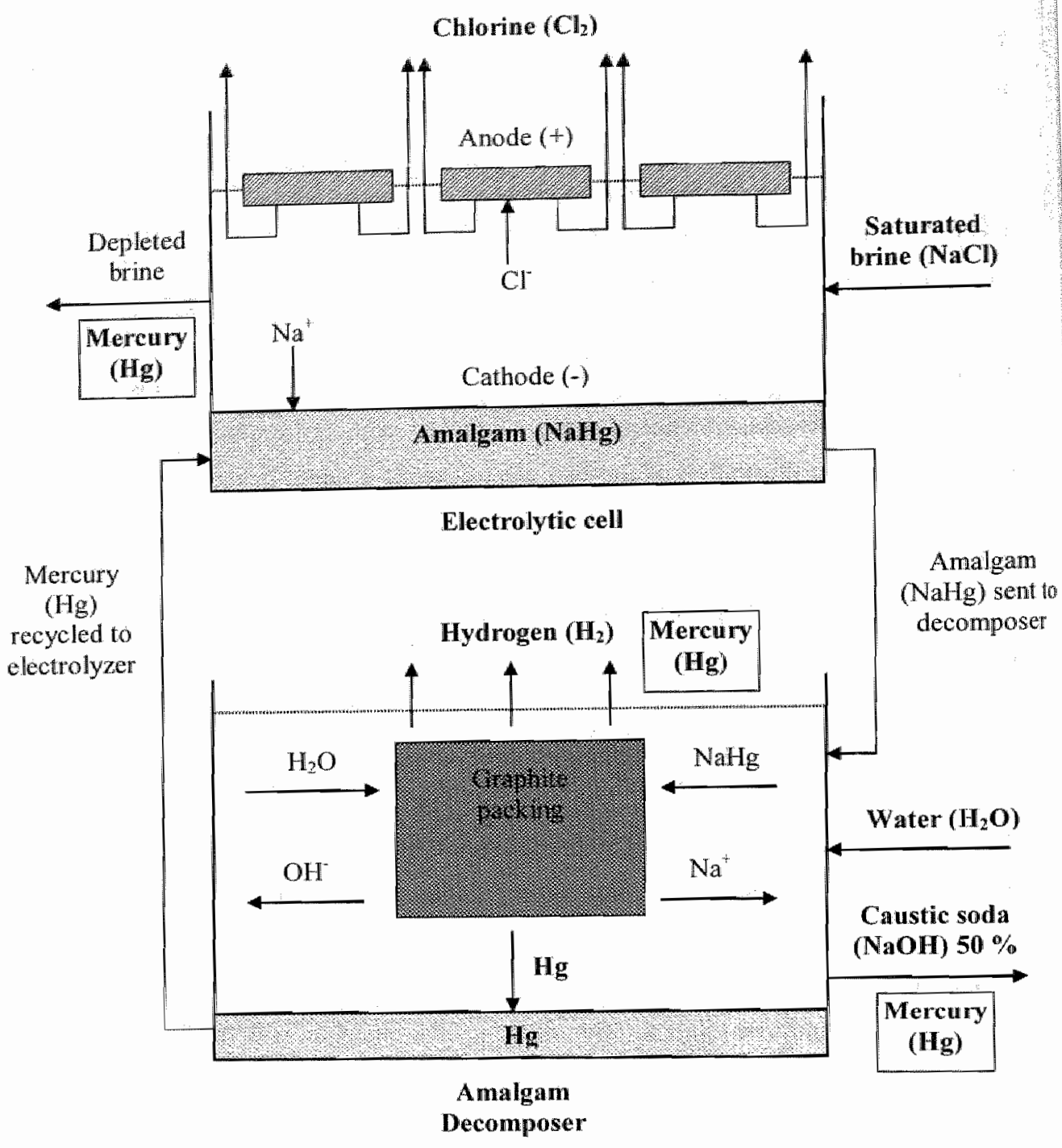

Figure 3-4 Mercury Electrolyzer and Amalgam Decomposer

Basad on Schmintinger et al (1986).

The process has been made continuous by periodically replenishing the brine and removing the caustic soda. The depleted brine leaving the electrolyzers is dechlorinated to recover the dissolved chlorine and to prevent corrosion during further processing. Dechlorinated brine is then resaturated with solid salt and returned to the cell for further use. 
The hydrogen produced in the mercury process is relatively pure and thus requires only cooling to remove water along with entramed salt and caustic.

While physical barriers, such as diaphragms and ion exchange membranes, are used in the case of the diaphragm process and the ion exchange membrane process, mercury is a crucial substance to separate caustic soda from chlorine in the mercury process. As can be seen in Figure 3-3 and Figure 3-4, the facilities are designed to recover most of the mercury used in the production process within the plant, by allowing mercury to flow from the decomposer back into the electrolysis cell once the sodium hydroxide thas been removed. it is inevitable, however, that some amount of mercury is released to the environment through products, air, water, and solid wastes. That necessitates the adoption of technological measures to prevent the emissions of mercury from the mercury-based plants. Basically, there are two ways to meet this purpose. One is to install equipment at the end of the production process, that is, the end-of-pipe technology. The other is to replace the mercury process with another production process which does not use mercury, that is, the clean technology. As we will see later, this difference in the adoption of technological measures for pollution abatement will have significant consequences.

To solve the difficulty of separating chlorine and caustic soda, an electrolytic cell in which the cathode consisted of a layer of mercury was invented by an American chemist, Hamilton Young Castner (Warren, 1980). By 1892 he had patented the electrolytic cell, and subsequently an electrolytic alkali plant was constructed in Britain ${ }^{48}$. Almost in the same period, a similar mercury-cathode system was developed by an Austrian engineer, Carl Kellner. He set up a company to work his process in Austria and sold the other European rights to Solvay in Belgium. Ultimately the two inventors licensed their patents and conducted industrial operations jointly. A new company, the Castner-Kellner Alkali Company, was established in 1895 at Runcorn in Britain, and their process was successfully put into operation two years later. Of 35 electrolytic alkali works in production or near ready to begin outside Britain by the beginning of 1900 , seven were using the Castner-Kellner process.

The Castner-Kellner process was subsequently established in Germany, Belgium, and Russia by Solvay (Haber, 1971). The design of the Castner-Kellner cell, which was rocked periodically from side to side so that mercury flowed from one compartment to the other, received modifications by the engineers of Solvay. Experiments started in 1898, resulting in 
the development of a sloping cell, the somalled long cell, in which the mercury flowed continuousty by gravity along the bottom of an elongated trough. The long cell became the basis of all subsequent mercury cell designs. Solvay later started to offer two models of the mercury process to the market.

The long cell was also introduced to Britain in 1902 by Castner-Kellner, replacing the rocking cell (Collins and Entwisle, 1980). A majority share of the Castner-Kellner, together with the Runcom plant, was acquired by Brunner-Mond in 1920. Subsequently, they became part of the newly formed Imperial Chemical Industries (ICD) in 1926. Technological development continued at $\mathrm{ICI}$, with emphasis on steel baseplates to alleviate the current loading limitation associated with cathode mushrooms, and the steel baseplate cell became widely adopted throughout the $\mathrm{ICl}$ group. The area of the brine cell was increased from 12.5 $\mathrm{m}^{2}$ in the 1940 s to $25 \mathrm{~m}^{2}$ in the 1960 s.

In the United States, Mathieson Alkali acquired the license on the mercury cell from Castner-Kellner in 1894, and the first U.S. plant of this type was subsequently opened at Saltville, Virginia (Haber, 1971). Initially, the cells were fitted with carbon anodes, which had only a very limited lifetime. Castner invented a method of graphitizing his carbon, which, together with some other improvements, made it possible to build a much larger commercial plant in 1897 at Niagara Falls, New York. Cheap and abundant supply of electricity as well as good local supply of salt was essential for successful working of the electrolytic process. Thus, it was after large amounts of direct current electricity could be supplied economically with the invention of dynamos in such a place as Niagara Falls, that the electrolytic process became commercially feasible. Since then, Mathieson had been the only major licensor of the mercury process in the United States.

In the 1930s and the 1940s, rapid progress was made on the mercury process technology in the German I. G. Farbenindustrie plants through exchange of information and sharing of the results of research and development. By the end of the Second World War, Germany had reached a position of technical leadership in the mercury process for chloralkali production (MacMullin, 1947) $)^{49}$. After the end of the war, IGi Farben was broken up

\footnotetext{
16. A number of patents dealing with mencury cells actually issucd prior to 1982 , the first being that of Nolf, Britisty pattent 4349 (1882) (MacMullin, 1962).

4ks Jufter the end of the Second World War, many American technical investigattors, including a dozen people selected from the chlor-alkali industry were sent to Germany to study the technical developments and progress there. Mary reports were written on German chlor-alkali progless and developments, and a tremerdous amount of information was uncovered in the files of the German chemical plants. Much of this was brought back to the United States later. Through the Chlorine Institue, the chlot-alkal industry association in the U.S., about 1,900
} 
into three companies, namely, Badische Anilin \& Soda-Fabrik (BASF) in Ludwigshafen. Bayer in Leverkusen, and Hoechst in Frankfurt (Aftalion, 1991). Subsequently many prototypes were developed in the plants of Bayer and Hoechst. In 1952 Hoechst, through its subsidiary Knapsack-Griesheim, acquired a share in Uhde, an engineering company, and the cooperation between the two companies started in 1954 (Krupp Uhde, 2001). Hoechsi-Uhde cells later came to be regarded to represent the achevement of the horizontal Geman mercury cell. BASF, on the other hand, had cooperated with the Krebs engineering group since 1951 for the development and installation of mercury cells (MacMullin, 1962). Various prototypes were installed at the Ludwigshafen works of BASF. Many installations of KrebsZurich cells and Krebs-BASF cells were in operation principally in Europe.

Mercury cells of the horizontal type were also developed by De Nora based in Milan, Itally. The De Nora cells had evolved through a series of changes since they were introduced. in 1950, although the basic principle remained unchanged; all the cells had a protected electrolyzer trough and a vertical decomposer. They were widely adopted, as there were at least 60 De Nora plants located in 25 countries in the 1960s (MacMullin, 1962). The company also offered a commercial version of the vertical cathode mercury cell, which was known as the fluent amalgam cell. The principal advantage of the fluent amalgam cell was the economy of building space as compared to that of horizontal mercury cells.

In Japan, on the other hand, the production of electrolytic alkali began during the First World War. The development of the mercury process started by Osaka Soda in 1911, and its Daiso cell was industrialized in 1915. By 1918, about 10,000 tons of caustic soda had come to be produced annually in this way (Japan Soda Industry Association, 1952). The Krebs mercury cell was imported to Japan for the lirst time in 1935. By the Second World War, the Daiso and Krebs cells, which shared similar structures, had come to become the major technologies used in Japar. In 1937 the production of caustic soda reached 369,000 tonnes, the maximum level before the war. After the end of the war, information on advanced. mercury process technologies developed by the German chlor-alkali industry became available to those in the Japanese chlor-alkali industry through a research report. The socalled $\mathrm{PB}$ report soon began to work as the textbook for chlor-alkali engineers in the post-war

pages of scientifie reports on the German chlor-alkali industry, called the "Chlor Fako Reporls," were translated and distributed. All these reports constituted significantly the subsequent development of the chlof salks il technology (Murtay. 1949). 
Japan $^{50}$. In particular, the Kureha cell was subsequently developed in Japan by Kureha Chenical. It later came to be regarded as one of the best mercury cells in the world and was exported to other countries.

By the middle of the 1960 s, a number of technologies for the mercury process had been developed and become available in the market.. They were mainly provided by Western European and Japanese companies, except for one technology supplier based in the United States. In particular, Solvay, De Nora, Hoechst-Uhde, Krebs, and ICI in Western Europe, and Osaka Soda, Kureha Chemical, Asahi Glass, Toyo Soda, Tokuyama Soda, and Mitsui Engineering and Shipbuilding, which later established Chlorine Engineers Corp. (CEC), in Japan were the companies which made major innovations on the mercury process, as suggested by technical papers and books written by industry experts at that time (Chlorine Institute, 1972; Japan Soda Industry Association, 1975; Kuhn, 1971; MacMullin, 1962; Smith, 1968, 1975; Sommers, 1965; Sommers, 1967). Table 3-8 gives some of the characteristics of each of the technologies supplied by these companies. This implies that both in Western Europe and in Japan there were several companies which were equally innovative on the mercury process for chlor-alkali production.

Table 3-8 Major Technologies of the Mercury Process in the Early 1970s

\begin{tabular}{|c|c|c|c|}
\hline Technology & $\begin{array}{l}\text { Cell current } \\
(\mathrm{kA})\end{array}$ & $\begin{array}{l}\text { Current density } \\
\therefore\left(\mathrm{kA} / \mathrm{m}^{2}\right)\end{array}$ & $\begin{array}{l}\text { Power consumption } \\
\left(\mathrm{DC}, \mathrm{kWh} / \mathrm{ton} \mathrm{Cl}_{2}\right)\end{array}$ \\
\hline $\begin{array}{r}\text { Solvay (WE) } \\
\mathrm{V}-100 \mathrm{~F} \\
\mathrm{~V}-200 \mathrm{~F} \\
\end{array}$ & $\begin{array}{c}96 \\
160 \\
\end{array}$ & $\begin{array}{l}5.33 \\
5.33 \\
\end{array}$ & $\begin{array}{l}3,125 \\
3,125 \\
\end{array}$ \\
\hline $\begin{array}{c}\text { De Nora (WE) } \\
14 \times 3 \mathrm{~F} \\
18 \times 4 \\
24 \times 5 \\
\end{array}$ & $\begin{array}{c}60 \\
100 \\
200 \\
\end{array}$ & $\begin{array}{c}5.05 \\
4.878 \\
5.85 \\
\end{array}$ & $\begin{array}{l}3,240 \\
3,240 \\
3,312 \\
\end{array}$ \\
\hline $\begin{array}{l}\text { Hoechst-Uhde (WE) } \\
\qquad \begin{array}{l}10 \mathrm{~m}^{2} \\
20 \mathrm{~m}^{2} \\
31.5 \mathrm{~m}^{2}\end{array} \\
\end{array}$ & $\begin{array}{r}60 \\
120 \\
189 \\
\end{array}$ & $\begin{array}{l}6.0 \\
6.0 \\
6.0 \\
\end{array}$ & $\begin{array}{l}3,240 \\
3,240 \\
3,240 \\
\end{array}$ \\
\hline Krebs-BASI" (WE) & $\begin{array}{r}50 \\
150 \\
\end{array}$ & $\begin{array}{l}4.25 \\
4.13 \\
\end{array}$ & $\begin{array}{l}3,175 \\
3,240 \\
\end{array}$ \\
\hline $\begin{array}{c}\text { Krebs-Zurich (WE) } \\
\text { ZT } 80-10-8 \\
Z T 120-15-8 \\
\end{array}$ & $\begin{array}{r}80 \\
120 \\
\end{array}$ & $\begin{array}{l}8.0 \\
8.0 \\
\end{array}$ & $\begin{array}{l}3,310 \\
3,310 \\
\end{array}$ \\
\hline
\end{tabular}

\footnotetext{
50cording to an engineer who studied and worked on the PB report, even 90 per cent of the technologies subsequenty developed in Japan could be satid to hawe originated from this report (Sugino, 1991).
} 


\begin{tabular}{|c|c|c|c|}
\hline $\begin{array}{c}\text { ICI (WE) } \\
\text { Steel Base }\end{array}$ & 90 & 7.2 & 3,380 \\
\hline $\begin{array}{c}\text { Olin Mathieson (US) } \\
\text { E-8 }\end{array}$ & 35 & 5.58 & 3,164 \\
$\mathbb{E}-11$ & 125 & 8.33 & 3,444 \\
\hline $\begin{array}{c}\text { Osaka Soda (JP) } \\
\text { Daiso }\end{array}$ & $\mathrm{n} / \mathrm{a}$ & $\mathrm{n} / \mathrm{a}$ & $\mathrm{n} / \mathrm{a}$ \\
\hline $\begin{array}{c}\text { Kureha Chemical (JP) } \\
\text { HD-3 }\end{array}$ & 80 & 8.13 & 3,175 \\
HD-4 & 150 & 7.57 & 3,096 \\
\hline $\begin{array}{c}\text { Toyo Soda (JP) } \\
\text { ToSO III-A }\end{array}$ & 140 & 5.49 & 3,024 \\
TOSO IV & 180 & 6.62 & 3,130 \\
\hline Asahi Glass (JP) & & 3,240 \\
Rotation Type 60kA & 60 & 7.27 & 3,190 \\
\hline Mitsui-Toa Gosei (JP) & 200 & 9.3 & $1 \mathrm{a}$ \\
TOA 270-G & 120 & 4.01 & \\
\hline Tokuyama Soda (JP) & & & \\
Tokuso 59 & & & \\
\hline
\end{tabular}

WE: Western Europe; US: United States; JP: Japan

Sources: Sommers (1965), Sommers: (1967), Japan Soda Industry Association (1975), Colliws and Entwisle (1980), Japan Soda Industry Association (1982).

\subsubsection{Development of the Diaphragm Process}

Another electrolytic route to produce chlor-alkali products is the diaphragm process. There are several differences in the flow diagram between the mercury and diaphragm processes (Curlin, Florkiewicz, Luke, Minz, and Schmittinger, 2000; Hocking, 1998; Kelham, 1996; Schmittinger, Curlin, Asawa, Kotowski, Beer, Greenberg, Zelfel, and Breitstadt, 1986). Figure 3-5 gives a basic flow diagram of the diaphragm process. As in the case of the mercury process, electricity is transformed by rectifiers and provided in the form of direct current. On the other hand, for the diaphragm process solution-mined brine could be used in place of solid. salt. Salt recovery is also undertaken in the diaphragm process. 


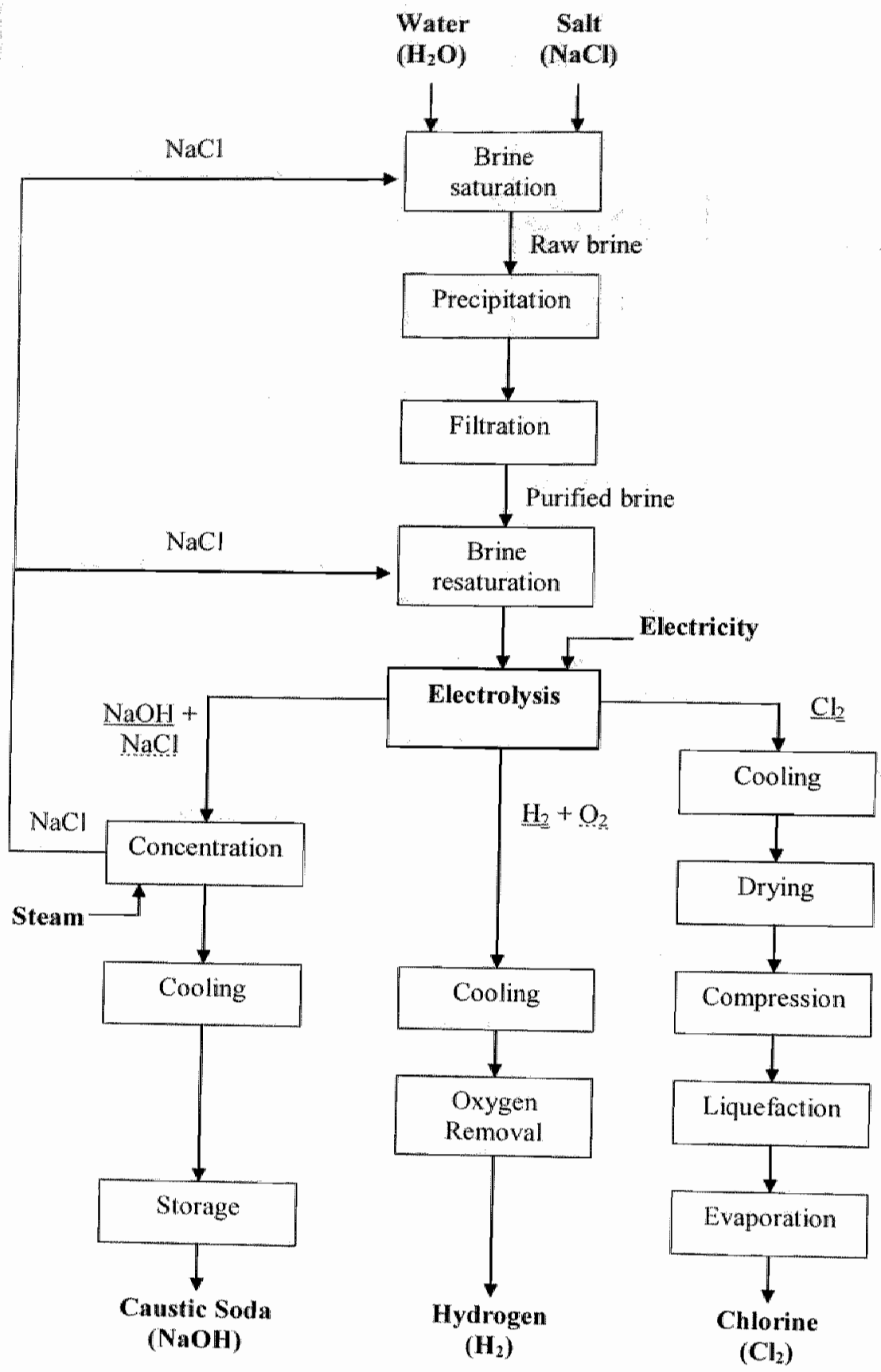

Figure 3-5 Flow Diagram of the Diaphragm Process Based on Schmintinger et al (1986). 
In the diaphragm electrolyzer, the anode area is separated from the cathode aren by a porous diaphragm based on asbestos (Curlin, Bommaraju, and Hansson, 1991). As shown in Figure $3-6$, saturated brine is introduced into the anode compartment. The principal reactions at the anode are the same as those in the mercury process. First, chloride rons lose electrons to form chlorine atoms:

$$
\mathrm{Cl}^{-}-\mathrm{e}^{-} \rightarrow \mathrm{Cl}^{*} \text {. }
$$

Subsequently, chlorine atoms combine to escape as chlorine molecules:

$$
2 \mathrm{Cl}^{\circ} \rightarrow \mathrm{Cl}_{2}
$$

The liquid solution in the anode compartment (anolyte) flows through the diaphragm into the cathode compartment due to the hydraulic pressure originating from the difference in liguid level between the two compartments.

At the cathode, water is decomposed to form hydrogen and hydroxyl ions $\left(\mathrm{OH}^{-}\right)$:

$$
2 \mathrm{H}_{2} \mathrm{O}+2 \mathrm{e}^{-\prime} \rightarrow \mathrm{H}_{2}+2 \mathrm{OH}^{-}
$$

Then hydroxyl ions combine with sodium ions to form sodium hydroxide, that is, caustic soda in the catholyte:

$$
\mathrm{OH}^{-}+\mathrm{Na}^{+} \rightarrow \mathrm{NaOH}
$$

Unlike the mercury process, which can produce highly concentrated caustic soda, the concentration of caustic soda produced in the diaphragm process is lower than that required for commercial purposes. Thus the unit for caustic concentration is necessary in the diaphragm process. This step, however, requires additional energy, and this is basically responsible for the fact that the total energy consumption for chlor-alkali production by the diaphragm process is larger than that by the mercury process. 


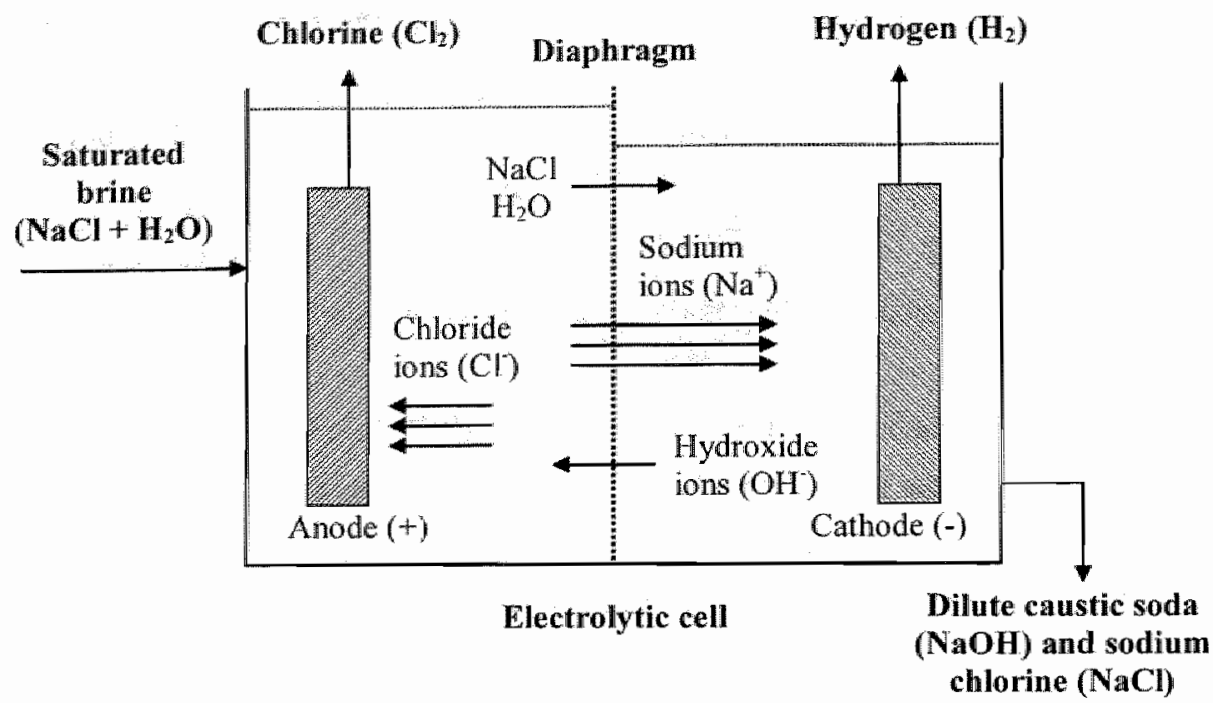

Figure 3-6 Diaphragm Electrolyzer

Based on Curlin, Bommaraju, and Hansson (1991).

As you can see, the diaphragm process does not rely on the use of mercury in producing chlorine and caustic soda, which are separated by the porous diaphragm. Thus there is no emission of mercury from the production process. On the other hand, asbestos used in the diaphragm has long been known as a hazardous substance, and regulations have been introduced, including exposure levels at workplace, in many countries ${ }^{51}$. The chlor-alkali industry, however, has been mostly exempted from these regulations, mainly because of the claim that asbestos is an indispensable material for the diaphragm used in chlor-alkali production. According to the industry, asbestos exhibits a highly favorable combination of essential characteristics, including sufficient mechanical strength, high chemical resistance to both acids and bases, low electrical resistance, uniform and consistent deposits on the cathode, appropriate physical structure to permit flow of depleted brine with minimum back migration

\footnotetext{
In the Untied States, for instance, the Occupational Safety and Health Administration of the Department of Labor and the Environmental Protection Agency have introduced various types of regulation on asbestos (see, for example, Occupational Salfey and Health Administration, 1993; United States Enwironmental Protection Agency, 2000).
} 
of hydroxyl ion, and an acceptable service life, and controlled use of asbestos should be allowed (Chlorine Institute; 1995; Trettin, 1997) ${ }^{32}$.

As an alternative technique to separate chlorine and caustic soda, porous cennent diaphragms were originally invented by Brewer in 1886 (Haber, 1958). The first electrolytic pllant based on the diaphragm process started to operate in 1890 by the Griesheim Company near Frankfurt, Germany. In this plant, potassium chloride ( $\mathrm{KCl}$ ), instead of sodium chloride, was treated because caustic potash (potassium hydroxide, $\mathrm{KOH}$ ) was more valuable at that time. While the cell was operated batch-wise and the current efficiency was poor, ar around 70 to 80 per cent, the cell was simple, inexpensive and relatively large in capacity (Kircher, 1962). The Griesheim cell was the first commercially successful diaphragm cell, and the simplicity of the design of the process led other firms to apply for a license. By 1900 , four out of eight German electrolytic plants and two out of four French plants had come to use the Griesheim diaphragm cell (Haber, 1971).

The Griesheim cell was followed by about twenty other designs. In Britain, another type of diaphragm cell was developed in the 1890 s by Hargreaves and Bird. They formed a company at Cheshire in 1899, and their plant with the Hargreaves-Bird cell was opened two years later (Kircher, 1962). This cell was based on a non-percolating diaphragm and reduced the back migration of hydroxide ions by adding carbon dioxide and steam to the cathode compartment, converting the caustic to sodium carbonate. This was the first commercialization of the vertical diaphragm cell.

In the United States, a type of the diaphragm process was developed by Le Sueur, who had also designed a mercury cell, and a small plant based on it was built in 1893 (Haber, 1958). It was the first commercial production of electrolytic caustic soda in the world. The Le Sueur cell made use of a percolating diaphragm for the first time and had become the basis of all modern diaphragn chlor-alkali cells. Brine was permitted to flow into the anolyte and through the diaphragm by the device of maintaining the electrolyte level higher on the anode than on the cathode side. The slow percolation of electrolyte through the diaphragm countered the migration of hydroxyl ions toward the anode compartment. Consequently, continuous operation became possible, and much higher current efficiency was obtained than with a nonpercolating diaphragm such as in the Griesheim cell. The Le Sueur cell was licensed to

\footnotetext{
5 As attempts have been made recently to avoid the use of asbestos in, for example, fireproofing materials, one of the principal applications of asbestos (Block, Dolhert, Petrakis, and Webster, 2000), several compatuies hawe started to develop diaphragms which do not consist of asbestos (Florkiewicz, 1998; Stadig, 1993).
} 
several companies in the U.S., notably paper-naking firms, which were dependent on a cheap supply of chlorine.

These early diaphragm cells have been mostly replaced by designs invented in the 1900s (Haber; 1971). In the United States, Townsend and Sperry made electrolytic cell inventions and sold their desigin to the development company founded by a civil engineer, Hooker. The Townsend cell, later known as Hooker cell, was first used in 1906 at the plant of Hooker Electrochemical Company at Niagara Falls. In Germany, the Billiter cell was developed in 1907 and was widely used in the world during the 1920s. Another widely employed diaphragm cell, the Gibbs cell, was developed in the United States in 1908.

The next major development took place in 1913, when a celll with finger cathodes and side-entering anodes was designed by Marsh (Kircher, 1962). This increased the electrode area per unit of cell volume or cell floor space, reducing capital investment per unit of production. Diaphragms were made of asbestos paper wrapped around the cathodes and sealed with cement and putty. The putty joints, however, provided a poor seal, and the Marsh. cell was plagued with leaks and its current efficiency never equaled that of cells with more simple construction. In an attempt to overcome the disadvantage of the Marsh cell, Stuart, a technologist of Hooker Electrochenical Company, invented in 1928 a method of depositing asbestos fiber onto the cathode by immersing it in slurry and applying a vacuum. With the flexibility of cell design permitted by the deposited asbestos diaphragm, the Hooker Type S cell was developed and has been further improved through various stages.

Filter press cells, which had been used extensively for hydrogen-oxygen electrodialysis, started to be designed also for chlor-alkali production by several early workers. Although the filter press design was attractive in terms of requiring a minimum of conductor material between cells, a minimum of floor space and low investment cost; the only commercial use of the filler press for chlor-alkali had been limited to the Dow Chemical Company in the U.S. (Murray, 1949). Dow had developed filter press cells through several stages characterized by simple, rugged, inexpensive construction. Detailed data on the performance of this technology, however, had not been disclosed to outside companies for a long time.

In the late 1960s PPG Industries in the U.S. made development efforts and succeeded in commercializing its Glanor electrolyzer in the early 1970s (PPG Industries, 1981). It consisted of ten bipolar elements securely clamped together with tie rods between two end electrode elements, forming a sealed electrolyzer module of eleven cells. They were called bipolar because one side of each element acted as a cathode and the other as an anode, and 
they were clamped together with the anode side of one element toward the cathode side of the next element so that the space between formed a cell. The advantage of the bipolar design was that it permitted current to flow internally within an electrolyzer from one cell to another. Accordingly, the current path could be shorter and of lower resistance than in comventional cells, in which the current flowed through external bus bars.

In Japan, the diaphragm process was industrialized for the first time by Hodogaya in 1915 (Yamaguchi, 1999b). Subsequently, the Nakano cell and the Yoshimura cell, named after the inventors, respectively, were deweloped and began to be installed in 1920. Nippon Soda also developed a bipolar diaphragm cell, and Tsurumi Soda developed and installed a monopolar diaphragm cell in its own plants. At the same time, various types of the diaphragm cell, including the Townsend cell, Allen-Moore cell, Nelson cell, Billiter-Siemens cell, and Billiter-Leykam cell, were all introduced from foreign countries. After the Second World War, however, as the mercury process increased its share steadily, many types of the diaphragm electrolytic cell, such as the Nakano cell and Allen-Moore cell, disappeared from chlor-alkali plants in Japan. Overall, compared with the remarkable technological advance made on the mercury process, the extent of technological progress of the diaphragm process in Japan was rather limited, and the main focus was placed on incremental improvements on the existing technologies, which were mainly introduced from technology suppliers based in foreign countries, particularly the United States.

Although mote than thirty types of diaphragm cells had been developed in the past, all new diaphragm cells available in the early 1970s were basically of two types: the Stuart (Hooker) type and the filter press type (Chlorine Institute, 1972; Jackson, Cooke, and Woodhall, 1971; Kircher, 1962; Kuhn, 1971; Smith, 1968; Sommers, 1957a, 1957b, 1965). The Stuart type cells included the Hooker Type S cells and Diamond cells whereas the filter press type cells included the Dow cells and Glanom cells. Table 3-9 gives some characteristics of the technologies for the diaphragm process which were available at the time of the early 1970s. As you can see, technological development of the diaphragm process was basically led by the US companies, namely, Hooker, Diamond Shamrock, Dow, and PPG, which were followed by some Japanese companies.

Table 3-9 Major Technologies of the Diaphragm Process in the Early 1970s

\begin{tabular}{|c|c|c|c|}
\hline Technology & $\begin{array}{c}\text { Cell Current } \\
(\mathrm{kA})\end{array}$ & $\begin{array}{c}\text { Current Density } \\
\left(\mathrm{kA} / \mathrm{m}^{2}\right)\end{array}$ & $\begin{array}{c}\text { Power Consumption } \\
\left(\mathrm{DC}, \mathrm{kWh} / \text { short ton } \mathrm{Cl}_{2}\right)\end{array}$ \\
\hline Hooker (US) & & & \\
\hline
\end{tabular}




\begin{tabular}{|c|c|c|c|}
\hline $\begin{array}{l}S-3 \mathrm{D} \\
\mathrm{S}-4 \\
\mathrm{H}-4 \\
\end{array}$ & $\begin{array}{l}40 \\
55 \\
150 \\
\end{array}$ & $\begin{array}{r}1.435 \\
1.287 \\
- \\
\end{array}$ & $\begin{array}{l}2,810 \\
2,830 \\
2,671^{*} \\
\end{array}$ \\
\hline $\begin{array}{l}\text { Diamond shamrock (US) } \\
\text { D-3 } \\
\text { DS-85 }\end{array}$ & $\begin{array}{c}30 \\
100-150 \\
\end{array}$ & $\begin{array}{c}1.294 \\
1.82-2.74 \\
\end{array}$ & $\begin{array}{c}2,750 \\
2,459-2,882^{\circ} \\
\end{array}$ \\
\hline $\begin{array}{l}\text { Dow (US) } \\
\text { Dow }\end{array}$ & $\mathrm{N} / \mathrm{a}$ & $\mathrm{N} / \mathrm{a}$ & $\mathrm{n} / \mathrm{a}$ \\
\hline $\begin{array}{l}\text { PPG (US) } \\
\quad \text { Glanor V } 1144 \\
\end{array}$ & 792 & 1.975 & $2,487-2,513^{*}$ \\
\hline $\begin{array}{l}\text { Nippon Soda (JP) } \\
B-5 \\
B M-50\end{array}$ & $\begin{array}{c}25 \\
250-300\end{array}$ & $\begin{array}{c}0.975 \\
1.80-1.90\end{array}$ & $\begin{array}{c}2,540^{\circ} \\
2,540 \cdots, 2,681\end{array}$ \\
\hline $\begin{array}{l}\text { Tsurumi Soda (JP) } \\
\text { TSB-4 } \\
\text { TSBM } 7\end{array}$ & $\begin{array}{l}24 \\
50\end{array}$ & $\begin{array}{r}0.81 \\
2.0 \\
\end{array}$ & $\begin{array}{l}2,328^{*} \\
2.513^{\prime \prime}\end{array}$ \\
\hline $\begin{array}{l}\text { Showa Denko (JP) } \\
\text { SD-7 }\end{array}$ & 75 & 1.73 & $2,521^{*}$ \\
\hline
\end{tabular}

* The unit is $\mathrm{kWh} / \mathrm{t} \mathrm{NaOH}$.

Sowrces: Sommers (1965), Japan Soda Industry Association (1975).

\subsubsection{Diffusion of the Mercury Process in Western Europe and Japan}

As we have seen in the previous section, the industrial production of chlor-alkali products started with the mercury and the diaphragm processes almost simultaneously at the end of the 19 th century. Technological development of the two production processes was initially pursued both in the Western Europe and in the United States. Subsequently, however, technological progress in the mercury process was mainly made by companies in Western Europe, whereas the diaphragm process was mainly improved by companies in the United States. Although the two production processes had remained basic to the chlor-alkali industry, different types of production technologies had come to be adopted in Western Europe, the United States, and Japan.

In Western Europe, the mercury process has been dominant since the beginning of the electrolytic production of chlor-alkali products. Table 3-10 gives the distribution of the chloralkali production processes in Western Europe in the late 1950s. As you can see, more than 80 per cent of the chlor-alkali production capacities were based on the mercury process while the diaphragm process accounted for only 15 of the total capacities. For the mercury process, 
almost all of the technologies were supplied by Western European companies, notably, Solway, De Nora, ICI, Krebs, and Uhde ${ }^{33}$.

Table 3-10 Chlor-Alkali Production Processes in Western Europe in 1957

\begin{tabular}{|c|c|c|}
\hline Type of Technology & Installed Units & Production Capacity $\left(\mathrm{Cl}_{2}\right.$ Vday) \\
\hline Mercury process & $83(71 \%)$ & $6,010(83.1 \%)$ \\
\hline Solvay (WE) & 10 & 875 \\
\hline De Nora (WE) & 14 & 867 \\
\hline BASF (WE) & 6 & 805 \\
\hline $1 \mathrm{CI}(\mathrm{WE})$ & 5 & 660 \\
\hline Krebs (WE) & 23 & 634 \\
\hline Uhde (WE) & 3 & 593 \\
\hline I.G. (WE) & 7 & 463 \\
\hline Hoechst (WE) & 3 & 407 \\
\hline Other Unknown & 12 & 706 \\
\hline Diaphragm process & $25(21 \%)$ & $1,106(15.3 \%)$ \\
\hline Gibbs (US) & 4 & 520 \\
\hline Billiter (WE) & 4 & 174 \\
\hline Hooker (US) & 3 & 165 \\
\hline $\operatorname{Krebs}(\mathrm{WE})$ & 4 & 33 \\
\hline Other/Unknown & 10 & 214 \\
\hline Sodium & $3(3 \%)$ & $61(0.8 \%)$ \\
\hline Other/Unknown & $6(5 \%)$ & $52(0.7 \%)$ \\
\hline Total & $117(100 \%)$ & $7,229(100 \%)$ \\
\hline
\end{tabular}

* Data as of June 1, 1957. No data was available either on process or on capacity for 23 plants, which are hence excluded from the table.

a: When both the mercury and the diaphragm processes were used, the production capacity was divided equally between them.

Calculation based on Sommers (1957a).

Although official data on the trends in production technologies in the Western European chlor-alkali industry are scarcely published, we can infer that the mercury process continued to be used in the subsequent period ${ }^{54}$. As you can see in Table 3-11, which strows the compositions of technologies used in Western Europe in 1972, the mercury process accounted

\footnotetext{
53 BASF cooperated closely with Krebs for technological development whereas Hoechst and Uhde jointly developed its techuologies of the mercury process.

${ }^{34}$ Before the World War 1 the alkali industry of the whole world was characterized by concented action, with the exchange of information and adherence to apportioned markets. The center of this unofficial combine was Solvay \& Cie. of Belgium, which, with its associates in other countries, exercised a dominant influence on the alkali industry (Ahlquist, 1936). Because of the peculiar tradition of the alkali industry, no official figures were published in Europe either by the industry or by the government agencies, and hence most of the information was derived from individual investigations.
} 
for almost 80 per cent of the total installations at chlor-alkali plants. The major suppliers of technologies for the mercury process were De Nora, Hoechst-Uhde, Krebs, Solvay, and ICI. Compared with Table 3-10, we can see that the composition of the technology suppliers for the mercury process in Western Europe had basically remained unchanged since the end of the Second World War.

Table 3 11 Chlor-Alkali Production Processes in Western Europe in 1972

\begin{tabular}{|l|r|}
\hline Type of Technology & Installed Units \\
\hline Mercury Process & $146(78 \%)$ \\
\hline De Nora.WE) & 29 \\
\hline Hoechst-Uhde (WE) & 24 \\
\hline Krebs (WE) & 24 \\
\hline Solvay (WE) & 14 \\
\hline Krebskosmo (WE) & 12 \\
\hline LG. (WE) & 8 \\
\hline ICI (WE) & \\
\hline BASF (WE) & \\
\hline Other/Unknown & \\
\hline Diaphragm Process & $34(18 \%)$ \\
\hline Hooker (US) & \\
\hline Pestalozza (WE) & \\
\hline Billiter (WE) & \\
\hline Other/Unknown & \\
\hline Sodium & $5(3 \%)$ \\
\hline Other & $1(1 \%)$ \\
\hline Total & $186(100 \%)$ \\
\hline
\end{tabular}

No data was availlable for 36 plants, which are hence excluded from the table. Calculation based on Chlorine Institute (1972).

As regards the production capacity in the same year, there is no detailed data available to outside the industry. Table 3-12 only gives rough estimations about the shares of the mercury and the diaphragm processes used in some Western European countries. Nevertheless, we could see from this table that the mercury process remained the dominant technology in the early 1970 s for the chlor-alkali production.

Table 3-12 Shares of the Chlor-Alkali Production Processes in Western European Countries in 1972

\begin{tabular}{|l|c|c|}
\hline \multicolumn{1}{|c|}{ Country } & Mercury Process & Diaphragm Process \\
\hline Belgium & 90 & 10 \\
\hline France $^{\mathrm{a}}$ & 70 & 28 \\
\hline West Germany & 89 & 11 \\
\hline
\end{tabular}




\begin{tabular}{|l|c|c|}
\hline Italy & 99 & 1 \\
\hline Netherlands & 75 & 25 \\
\hline Sweden & 100 & 0 \\
\hline United Kingdom & 90 & 10 \\
\hline Total $^{b}$ & 86 & 13 \\
\hline
\end{tabular}

a: Electrolysis of molten salt of metallic sodium accounts for $2 \%$.

b: All others account for $1 \%$.

Source: Koyama (1972).

In the United States, in contrast, there was a proliferation of the diaphragm process to chlor-alkali plants. By the Second World War, the diaphragm process had come to dominate the U.S. chlor-alkali industry. Table 3-13 shows the distribution of various types of the mercury process used in the chlorine plants in the United States immediately after the war. In 1946, the diaphragm process accounted for almost 90 per cent of the total production in the U.S. Most of the technologies for the diaphragm process were provided by American companies; Hooker cells were used most extensively, in 43 per cent of the capacity, followed by Dow's bipolar cells representing 17.5 per cent. Mercury cells, on the other hand, accounted for only 4 per cent of the U.S. chlor-alkali production.

Table 3-13 Chlor-Alkali Production Processes in the United States in 1946

\begin{tabular}{|c|c|c|}
\hline Type of Technology & Installed Units & $\begin{array}{l}\text { Production Capacity* } \\
\left(\mathrm{Cl}_{2} \text { short tons/year) }\right.\end{array}$ \\
\hline Mercury Process & $3(5 \%)$ & $68,400(4.3 \%)$ \\
\hline Castner (US) & 1 & 40,200 \\
\hline $\mathbb{I C I}(\mathrm{WE})$ & 1 & 23,800 \\
\hline Sorensen (WE) & 1 & 4,400 \\
\hline Diaphragm Process & $54(90 \%)$ & $1,411,790(88.6 \%)$ \\
\hline Hooker-S (US) & 24 & 491,000 \\
\hline Hooker-Columbia (US) & 3 & 193,500 \\
\hline Dow-Buppolar (US) & 3 & 278,000 \\
\hline Vorce (US) & 4 & 151,700 \\
\hline Gibbs (US) & 3 & 93,000 \\
\hline Diamond (US) & 2 & 90,500 \\
\hline Allen-Moore KML (US) & 5 & 64,700 \\
\hline Wheeler (US) & 3 & 23,400 \\
\hline Hargreaves Bird (WE) & 3 & 11,000 \\
\hline Nelson (US) & 1 & 7,300 \\
\hline Larcher (US) & 1 & 4,400 \\
\hline Townsend (US) & 1 & 2,560 \\
\hline MacDonald (US) & 1 & 730 \\
\hline Fused Salt Process (Downs) & $2(3 \%)$ & $92,000(5.8 \%)$ \\
\hline
\end{tabular}




\begin{tabular}{|c|c|c|}
\hline Nitrosyl process & $1(2 \%)$ & $20,000(1.3 \%)$ \\
\hline Total & $60(100 \%)$ & $1,592,190(100 \%)$ \\
\hline
\end{tabular}

* Built or under construction at the time of 1946.

Source: MacMullin (1947).

Shares of the chlor-alkalli production processes used in the United States in the following years are given in Table 3-14. The share of the mercury process increased gradually alter the end of the war, reaching the peak of just less than 30 per cent in the late 1960 s. Nevertheless, the diaphragm process remained the dominant process in the United States throughout the post-war period. The share of the diaphragm process started to rise again at the end of the $1960 \mathrm{~s}$, and by the early 1970s, the diaphragm process had come to account for more than 70 per cent of the total capacity in the U.S. chlor-alkali industry.

Table 3-14 Trends in the Shares of the Chlor-Alkali Production Processes in the United States

\begin{tabular}{|c|c|c|c|}
\hline Year & Mercury Process & Diaphragm Process & Other Processes \\
\hline 1952 & 12 & 80 & 8 \\
\hline 1957 & 14.4 & 79.0 & 6.6 \\
\hline 1962 & 18.5 & 76.2 & 5.3 \\
\hline 1963 & 20.8 & 74.1 & 5.1 \\
\hline 1964 & 23.0 & 72.2 & 4.8 \\
\hline 1965 & 24.2 & 71.2 & 4.6 \\
\hline 1966 & 26.5 & 69.7 & 3.8 \\
\hline 1967 & 26.7 & 69.8 & 3.5 \\
\hline 1968 & 28.6 & 68.1 & 3.3 \\
\hline 1969 & 27.9 & 69.2 & 2.9 \\
\hline 1970 & 27.2 & 69.6 & 3.2 \\
\hline 1971 & 27.2 & 69.8 & 3.0 \\
\hline 1972 & 24.2 & 72.4 & 3.4 \\
\hline
\end{tabular}

Figures are expressed as percentages of the total production capacity.

Sources: Gardiner (1978) for 1952; Sommers (1957b) for 1957; Chlorine Institute (1999b) for 1962 onward as of July 1 of each year.

The composition of chlor-alkali production processes used in the U.S. in the middle of the $1960 \mathrm{~s}$ is given in Table $3-15^{55}$. The diaphragm process had remained the main teclmology for the U.S. chlor-alkali production for the 20 years following the end of the Second World War. Hooker continued to be a dominant supplier of technologies, accounting for more than one third of the total production capacities in the U.S., followed by Dow Chemical. On the 
other hand, production units based on the mercury process were also introduced during the same period. They were mostly prowided by Mathieson in the United States, and De Nota, Solvay, and Uhde in Western Europe.

Table 3-15 Chlor-Alkali Production Processes in the United States in 1965

\begin{tabular}{|c|c|c|}
\hline Type of Technology & Installed Units & $\begin{array}{l}\text { Production Capacify } \\
\left(\mathrm{Cl}_{2} \text { short tons/day }\right)\end{array}$ \\
\hline Mercury Process & $31(37 \%)$ & $4,811(26.6 \%)$ \\
\hline Mathieson (US) & & 1,365 \\
\hline De Nora (WE) & 1 & 1,285 \\
\hline Solvay (WE) & & 1,091 \\
\hline Uhde (WE) & & 480 \\
\hline $\mathrm{ICI}(\mathrm{WE})$ & & 230 \\
\hline Krebs-BASF (WE) & & 185 \\
\hline Dow (US) & & 125 \\
\hline $\mathrm{BASF}(\mathrm{WE})$ & & 50 \\
\hline Diaphragm Process & $45(54 \%)$ & $11,984(66.4 \%)$ \\
\hline Hooker (US) & 2 & 6,548 \\
\hline Dow (US) & & 3,010 \\
\hline Diamond (US) & & 1,333 \\
\hline Columbia Southern (US) & & 600 \\
\hline Gibbs (US) & & 274 \\
\hline Allen-Moore (US) & & 78 \\
\hline Vorce (US) & & 70 \\
\hline Tucker Windecker (US) & & 35 \\
\hline Wheeler (US) & & 26 \\
\hline Townsend (US) & & 10 \\
\hline Fused Salt Process (Downs) & $5(6 \%)$ & $780(4.3 \%)$ \\
\hline $\mathrm{KNO}_{3}-\mathrm{HNO}_{3}$ Reaction & $1(1 \%)$ & $60(0.3 \%)$ \\
\hline Unknown & $2(2 \%)$ & $425(2.4 \%)$ \\
\hline Total & $84(100 \%)$ & $18,060(100 \%)$ \\
\hline
\end{tabular}

Data include projected constructions and expansions.

Sounce: Sommers (1965).

In Japan, both the mercury process and the diaphragm process were used at the initial stage of industrial development. Table 3-16 gives the shares of the chlor-alkali production processes in Iapan shortly after the Second World War. In 1949, the mercury process accounted for 43 per cent of the total production capacity whereas the diaphragm process accounted for 57 per cent. While most of the diaphragm process technologies were introduced

\footnotetext{
53. The data for 1965 in Table $3-15$ is slighty diferent from that in Table 3-14. That is probably becanse of the difference in the date of counting.
} 
from foreign providers, notably Billiter-Siemens, almost two thirds of the production capacities based on the mercury process were provided by one Japanese company, Osaka Soda (currently Daiso), with the rest of the mercury process provided by two companies based in Western Europe, namely, Krebs and Solvay.

Table 3-16 Chlor-Alkali Production Processes in Japan in 1949

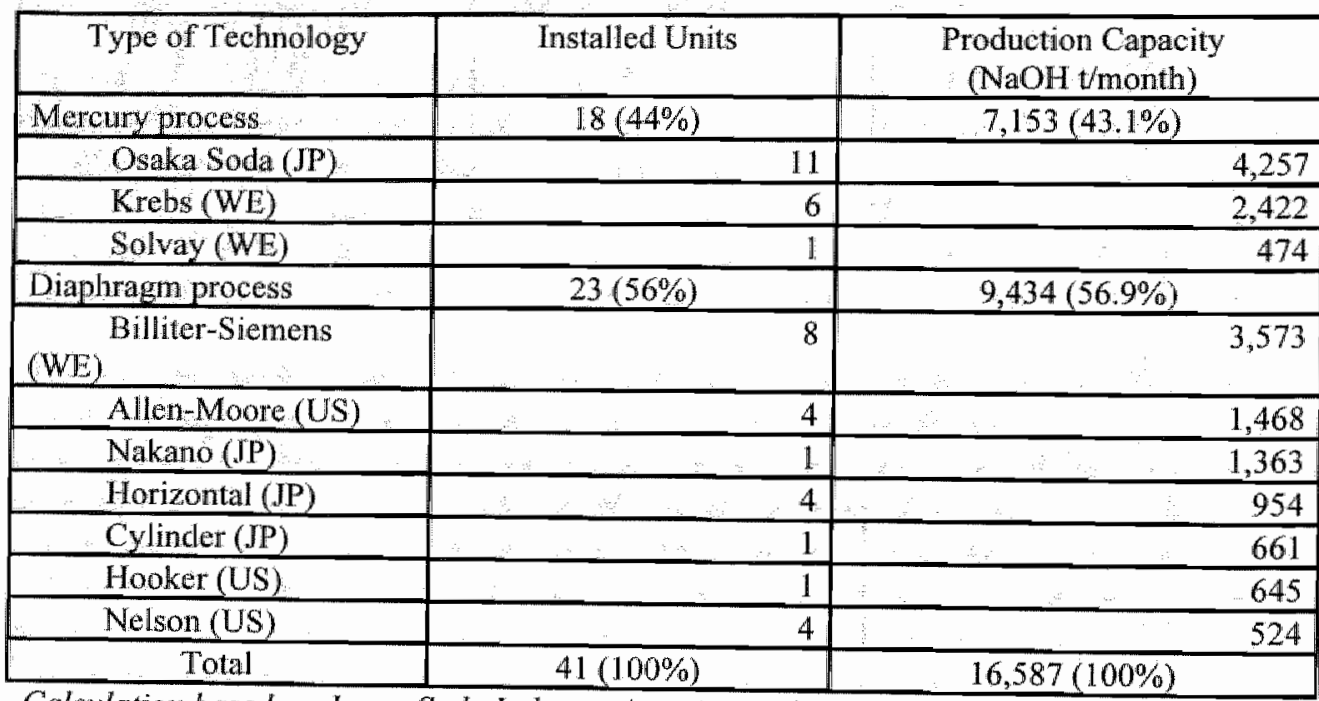

Calculation based on Japan Soda Industry Association (1952).

After the end of the Second World War, detailed information on advanced technologies for the mercury process developed in Western Europe became available to Japan. As many Japanese companies started to direct innovative efforts toward the mercury process, various types of technologies were developed in the post-war period. Table $3-17$ gives the trends in the shares of the chlor-alkali production processes used in the Japanese industry. As you can see, the mercury process had come to become the dominant technology in Japan by the early 1970 s, representing more than 95 per cent of the total production capacity at that time. In the meantime, technological development for the diaphragm process had stagnated since the end of the war, and its share continued to decline steadily.

Table 3-17 Shares of the Chlor-Alkali Production Processes in Japan

\begin{tabular}{|c|c|c|}
\hline Year & Mercury Process & Diaphragm Process \\
\hline 1950 & 43.6 & 56.4 \\
\hline 1951 & 41.8 & 58.2 \\
\hline 1952 & 46.1 & 53.9 \\
\hline 1953 & 47.9 & 52.1 \\
\hline
\end{tabular}




\begin{tabular}{|c|c|c|}
\hline 1954 & 51.5 & 48.5 \\
\hline 1955 & 55.6 & 44.4 \\
\hline 1956 & 55.2 & 44.8 \\
\hline 1957 & 62.9 & 37.1 \\
\hline 1958 & 66.6 & 33.4 \\
\hline 1959 & 66.8 & 33.2 \\
\hline 1960 & 71.6 & 28.4 \\
\hline 1961 & 78.8 & 21.2 \\
\hline 1962 & 80.3 & 19.7 \\
\hline 1963 & 80.9 & 19.1 \\
\hline 1964 & 82.2 & 17.8 \\
\hline 1965 & 85.6 & 14.4 \\
\hline 1966 & 86.3 & 13.7 \\
\hline 1967 & 87.3 & 12.7 \\
\hline 1968 & 89.9 & 10.1 \\
\hline 1969 & 91.1 & 8.9 \\
\hline 1970 & 92.2 & 7.8 \\
\hline 1971 & 95.2 & 4.8 \\
\hline 1972 & 95.6 & 4.4 \\
\hline
\end{tabular}

Figures are expresses as percentages of the total production capacity.

Source: Calculation based on the production capacity data in Japan Soda Indwisty Association (1982) as of March in each year, except for August in 1959 and May in 1952.

The types of technologies used for chlor-alkali production at the time of 1972 are shown in Table 3-18. We can observe that technologies for the mercury process were mainly provided by De Nora, Uhde, and Krebs based in Westem Europe, and Mitsui Engineering and Shipbuilding (MES), Osaka Soda, Asahi Glass, and Kureha Chemical based in Japan. Although there are cases in which the technology suppliers are not kmown, considering other information sources on the development of technologies in technical and trade joumals, we could safely infer that the remaining chlor-alkali producers in Japan have adopted technologies provided by these suppliers mentioned above.

Table 3-18 Chlor-Alkali Production Technologies in Japan in 1972

\begin{tabular}{|l|r|}
\hline Type of Technology & Installed Units \\
\hline Mercury Process & $66(76 \%)$ \\
\hline De Nora (WE) & 9 \\
\hline Mitsui Engineering and Shipbuilding (JP) & 8 \\
\hline Osaka Soda (JP) & 6 \\
\hline Uhde (WE) & 4 \\
\hline Kureha Chemical Industry (JP) & 4 \\
\hline Asahi Glass (JP) & 4 \\
\hline
\end{tabular}




\begin{tabular}{|c|c|}
\hline Krebs (WE) & 3 \\
\hline Krebskosmo (WE) & 3 \\
\hline Toyo Soda (JP) & 1 \\
\hline Tokuyama Sodd (JP) & 1 \\
\hline Asahi Chemical Industry (JP) & 1 \\
\hline Olin (US) & 1 \\
\hline Other/Unknown & 21 \\
\hline Diaphragm Process & $16(18 \%)$ \\
\hline Billiter (WE) & 4 \\
\hline Hooker (US) & 3 \\
\hline Allen-Moore (US) & 1 \\
\hline Nelson (US) & 1 \\
\hline Nippon Soda (JP) & 1 \\
\hline Tsurumi Soda (JP) & 1 \\
\hline Other/Unknown & 5 \\
\hline Sodium & $4(5 \%)$ \\
\hline Unknown & $1(1 \%)$ \\
\hline Total & $87(100 \%)$ \\
\hline
\end{tabular}

Calculation based on Japan Soda Industry Association (1952), Chlorine Institute (1972).

There are several factors which are considered to have contributed to the different courses of technological change prior to the 1970s between the mercury process in Westem Europe and Japan and the diaphragm process in the United States. We first consider the availability of materials necessary for chlor-alkali production. They include mercury for the mercury process and asbestos for diaphragm used in the diaphragm process, and different types of salt surtable for use in each of the two production processes. Then we also consider demand-side factors, including the different qualities of caustic soda between the mercury proeess and the diaphragm process, which would influence the technological preference.

Regarding the choice of the mercury process in Western Europe, a large amount of mercury was readily available for use in the chlor-alkali industry in Western Europe, particularly in Spain and Italy. In 1928, a cartel known as Mercurio Europeo was organized by Spanish and Italian producers to control production, distribution, and sale at a time when world stocks of mercury were in excess of demand (Goldwater, 1972). Although detailed data has not been available, it is estimated that more than 80 per cent of world production was controlled by the interests who formed the combine. By agreement, 55 per cent of sales were allocated to Spain and 45 per cent to Italy. While the Mercurio Europeo cartel was dissolved in 1950, the two countries renained the two major mercury-producing countries. As Table 
3-19 shows, the production of mercury in Spain and Italy in the niddle of the 1960 s accounted for more than half of the world production.

Table 3-19 World Production of Mercury in the Middle of the $1960 \mathrm{~s}$

\begin{tabular}{|c|c|}
\hline Country & Annual Production (tlasks) \\
\hline Spain & $78,322(30.7 \%)$ \\
\hline Italy & $57,001(22,4 \%)$ \\
\hline U.S.S.R. & $35,000(13.7 \%)$ \\
\hline China & $26,000(10.2 \%)$ \\
\hline Yugoslavia & $17,318(6.8 \%)$ \\
\hline United States & $14,142(5.5 \%)$ \\
\hline Mexico & $12,561(4.9 \%)$ \\
\hline Other & $14,629(5.7 \%)$ \\
\hline Total & $254,973(100 \%)$ \\
\hline
\end{tabular}

a: Data are of the year 1964.

b: The standard commercial unit of mercury is the flask containing 76 pounds avoirdupois. The flask has not always been exactly 76 pounds, but the Spanish flask was $34.5 \mathrm{~kg}$, the Californian, Russian, and Italian flasks $34.7 \mathrm{~kg}$, and the Mexican flask $34.15 \mathrm{~kg}$ (Goldwater, 1972).

Source: United States Department of the Interior (1968).

In the United States, on the other hand, most of the chlor-alkali plants in had been based on the diaphragm process. The main material of diaphragms used for chlor-alkall production was asbestos. As Table 3-20 shows, the principal asbestos-producing countries in the late 1930 s were Canada, the Soviet Union ${ }^{56}$, Southern Rhodesia, the Union of South Africa, the United States, and Swaziland. In particular, Canada was the dominant producer of asbestos, accounting for 60 per cent of the world production.

Table 3-20 World Production of Asbestos in the Late 1930s

\begin{tabular}{|l|c|}
\hline \multicolumn{1}{|c|}{ Country } & Annual Production (short tons) \\
\hline Canada & $364,472(60.2 \%)$ \\
\hline Southern Rhodesia & $58,313(9.6 \%)$ \\
\hline Union of South Africa & $22,050(3.6 \%)$ \\
\hline United States & $15,459(2.6 \%)$ \\
\hline Swaziland & $7,973(1.3 \%)$ \\
\hline \multicolumn{1}{|c|}{ World Total } & $605,000(100 \%)$ \\
\hline
\end{tabular}

a: Data are of the year 1939, except for the world total, with the data of the average of 1937 . 1939.

Source: United States Tariff Commission (1951).

\footnotetext{
56 Although the statistics on the Soviet Union was not avalable, it was estimated that its asbestos production accounted for most ol the remander, making the country the second largest producer after Canada (United States Tariff Commission. 1951 ).
} 
As the production of asbestos in the United States was minor in relation to the world production, the country depended upon imports for most of its asbestos requirements. Table $3-21$ gives the figures for imports, exports, and consumption of asbestos in the United States in the late 1930s. Imports totaled 243,000 tons, accounting for 96 per cent of the consumption of asbestos in the United States. And more than 90 per cent of the imports came from the neighboring Canada, the largest producing country in the world. Asbestos was basically free of duty, under the Tariff Act of 1922 and later under the Tariff Act of 1930, and its duty-free status was bound in the trade agreement with Canada, effective January 1936 and January 1939 (United States Tariff Commission, 1951). Also, the Canadian asbestos deposits, which were primarily located in the Eastern Townships of Quebec, the Cochrane district of Ontario, and the Cassiar district of north-western British Columbia, were close to the main United States consuming centers (Avery, Conant, and Wiessenborn, 1959). As several of the Linited States asbestos manufacturess owned and operated asbestos mines in Canada, there was a close relationship between Canadian producers of asbestos and United States consumers of it. Thus we can see that asbestos was readily available for use as the key material of the diaphragm to chlor-allkali producers located in the United States.

Table 3-21 Imports, Exports, Production, and Consumption of Asbestos in the United States in the Late 1930s

\begin{tabular}{|l|r|}
\hline & \multicolumn{2}{|c|}{ Quantity (short tons) } \\
\hline Imports & \multicolumn{2}{|c|}{243,079} \\
\hline Canada & \\
\hline Southern Rhodlesia & \\
\hline Union of South Africa & 4,893 \\
\hline All other countries & 4,761 \\
\hline Exports & \\
\hline Production & 2,653 \\
\hline Consumption & 11,452 \\
\hline
\end{tabular}

Data are of the average of 1937-39.

Source: United States Tariff Commission (1951).

The sources of salt, the principal input material for chlor-alkali production, could have also influenced the technological choice between the mercury process and the diaphragm process. Solid salt can be obtained from three sources: rock salt, salt from solution-mined brine, and solar salt. While the diaphragm process can take full advantage of cheap brine where it is available from brine wells, the mercury process requires solid salt to achieve 
efficient utilization of salt, although it can also operate with brine as a nw material where that is sufficiently cheap to offset the high unit consumption (MacMullin, 1947). As you can see in Table 3-22, the sources of salt were different between countries in Western Europe and the United States. While the salt produced in West Germany was mostly rock salt, 60 per cent of the salt production in the United States came from brine wells. Hence, the cliaphragm process was favorable in the United States whereas the mercury process was favorable in West Germany, and probably in neighboring countries as well.

Table 3-22 Production of Salt in West Germany and the United States in the Early 1950s

\begin{tabular}{|c|c|c|c|c|}
\hline Country & Rock & Brine & Evaporated & Total \\
\hline West Germany & $3,523(91.5 \%)$ & $328(8.5 \%)$ & 0 & $3,851(100 \%)$ \\
\hline United States & $4,479(21.5 \%)$ & $12,608(60.6 \%)$ & $3,702(17.8 \%)$ & $20,789(100 \%)$ \\
\hline
\end{tabular}

Data are of 1953 . Figures are expressed in $10^{3}$ short tons.

Source: Harris (1960).

These factors can be considered to have influenced the choice of technological options at the initial stage of the technological development in the chlor-alkali industry. Technological development of the mercury process was mainly pursed by companies in Western Europe, notably Solvay, Krebs, De Nora, Uhde, and ICI, whereas companies in the United States mostly concentrated their innovative efforts on the diaphragm process, particularly companies such as Hooker, Diamond, PPG, and Dow. Without extensive technological interactions between the two regions, each process had been improved in its unique way and chlor-alkali producers subsequently adopted the process which was readily provided by technology suppliers in that region. In this way, learning experiences had been accumulated on the production process specific to the region, which in turn had contributed to further technological progress on that process.

In the post-war period, the mercury process was increasingly adlopted all over the world. As you can see in Table 3-14, the share of the mercury process increased rapidly in Japan. Even in the United States, where the majority of the chlor-alkali plants had been originally based on the diaphragm process, the mercury process increased its share gradually following the end of the war. One of the reasons for the increased use of the mercury process can be considered to concern a demand-side factor, particularly, the quality of caustic soda. Highquality caustic soda with little impurity is required for the production of rayon, a textile made from cellulose. As Table 3-23 gives the world-wide trends in the production of rayon since 1930 , the rayon industry experienced a significant expansion and became one of the major 
sectors which consume caustic soda in the post-war period. Since the quality of the caustic soda produced by the mercury process is much purer than that produced by the diaphragm process, the increased demand for caustic soda from the rayon industry induced chlor-allkali producers to choose the mercury process for their production. In Japan, where the chlor-alkali industry had used the mercury process and the diaphragm process equally, mostly relying on technologies introduced from Europe and the United States, several innovative companies, including Osaka Soda, Kureha Chemical, Mitsui Engineering and Shipbuilding, and Asahi Glass, started to focus their efforts to develop technologies for the mercury process. By the middle of the 1960s, however, the rayon production had leveled off in most parts of the world. In the United States, as the production of rayon had declined by 1970 , the mercury process also started to decrease its share in the chlor-alkali industry.

Table 3-23 World Production of Rayon

\begin{tabular}{|c|c|c|c|c|c|c|}
\hline Year & $\begin{array}{c}\text { Western } \\
\text { Europe }\end{array}$ & $\begin{array}{c}\text { United } \\
\text { States }\end{array}$ & Japan & $\begin{array}{c}\text { Socialist } \\
\text { countries }\end{array}$ & Others & Total \\
\hline 1930 & 130 & 58 & 17 & - & 2 & 207 \\
\hline 1940 & 665 & 214 & 225 & - & 23 & 1,127 \\
\hline 1950 & 791 & 375 & 121 & -9 & 54 & 1,341 \\
\hline 1955 & 967 & 495 & 425 & 425 & 47 & 2,359 \\
\hline 1965 & 1,101 & 506 & 446 & 684 & 238 & 2,975 \\
\hline 1970 & 1,021 & 391 & 451 & 901 & 240 & 3,004 \\
\hline
\end{tabular}

Figures are expressed in $10^{3}$ tomnes/year.

a: Figures of socialist countries from 1930 to 1950 are included in those of Western Europe. Source: Sakota (1977).

In this way, by the beginning of the $1970 \mathrm{~s}$, most of the chlor-alkali plants in Western Europe and Japan had come to be based on the mercury process. Figure 3-7 shows the shares of the metcury and the diaphragm processes in Western Europe, the United States, and Japan in 1972. (Data are given in Table 3-25 in Appendix at the end of this chapter). 


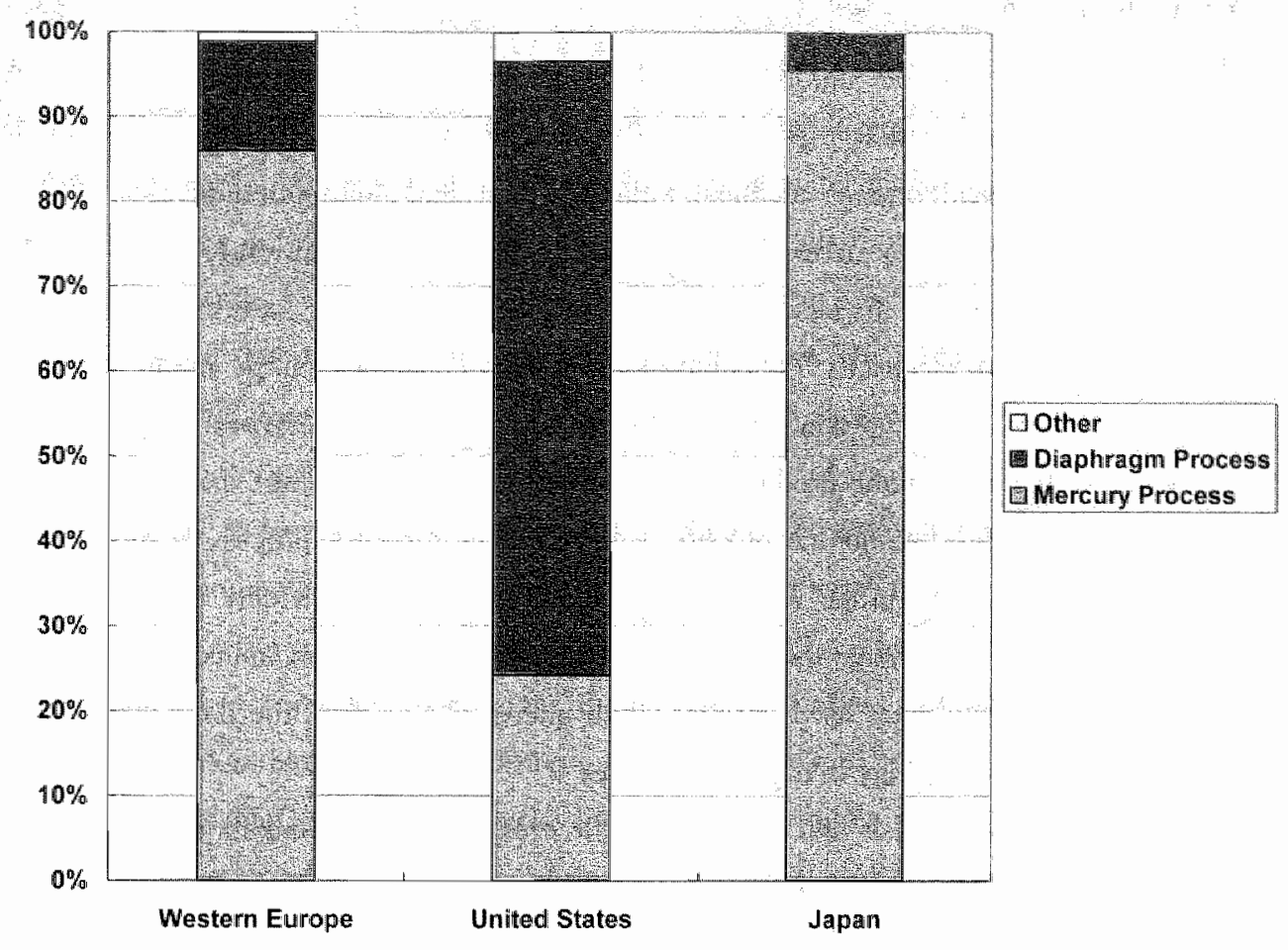

Figure 3-7 Shares of the Mercury and the Diaphragm Processes in Western Europe, the United States, and Japan in 1972

While the diaphragm process had continued to be the major technology in the Untied States, the mercury process had become dominant in Western Europe and Japan. Several companies in each of Western Europe and Japan succeeded in making innovations on the mercury process, and their technologies had been widely adopted by chlor-alkali producers in these regions. Therefore, we can say that the initial conditions in terms of technological development and adoption in Western Europe and Japan were similar at the time of the early 1970s, just before environmental regulations started to be imposed on mercury emissions from chlor-alkali plants in the two regions. That will make it easier to ste clearly the effects of the introduction of environmental regulations at a later stage on the course of technological change, without influences of other complicating factors. 


\subsection{Conclusion}

The main products of the chlor-alkali industry are chlorine and caustic soda. The two substances have been widely used as intermediate materials in various industries, including the inorganic chemical, organic chemical, pulp and paper, and aluminum industries. Although chemical processes had been traditionally used in the industry, currently the chlor-alkali products are produced by the electrolysis of brine, that is, salt water. As brine is electrolyzed with intensive use of electricity, the chlor-alkali industry consumes a large amount of electric power. There are three types of electrolytic processes used in the world for commercial production of the chlor-alkali products, namely, the mercury process, the diaphragm process, and the ion exchange membrane process. Currently, the mercury process is the dominant technology in Western Europe whereas the diaphragm process is widely used in the U.S. chlor-alkali industry. In Japan, the ion exchange membrane process accounts for almost all of the production technologies used in chlor-alkali plants. In this way, the three processes are used as the major technology in different regions.

The mercury process and the diaphragm process for chlor-alkali production were invented almost in the same period, at the end of the 19 th century. Since then, technologies for the mercury process had been mainly developed in Western Europe whereas U.S. companies had been involved in improving technologies for the diaphragm process. Both processes were initially introduced from Western Europe and the United States to the Japanese chlor-alkali industry at the beginning of the 20 th century. After the end of the Second World War, in the United States, where the diaphragm process had been initially preferred, technological progress was pursued subsequently by innovating companies on the diaphragm process. Aithough the share of the mercury process increased slightly in the postwar period, the diaphragm process had remained the dominant technology in the United States. On the other hand, innovative companies in Western Europe and Japan devoted research and development efforts to the mercury process. Through learning and knowledge accumulation based on the increased use in the industry, technologies for the mercury process were improved further, and more chlor-alkali producers adopted the mercury process in these two regions.

By the late $1960 \mathrm{~s}$, the mercury process had come to dominate the chlor-alkali industry in Japan as well as in Western Europe. In each region, there were several innovative companies which made successful technological developments for the mercury process. In 
Western Europe the major mnowating companies included De Nora, Uhde, Krebs, Solvay, and $\mathbb{C l}$, whereas in Japan Osaka Soda, Kureha Chemical Industry, Asahi Glass, Tokuyama Soda, Asahi Chemical Industry, and Mitsui Engineering and Shipbuilding, which later established Chlorine Engineers Corp., succeded in developing their own technologies. "That suggests that several companies in Western Europe and in Japan were equally innovative on the mercury process technologies, before environmental regulations started to be introduced in the early 1970 s to reduce mercury emissions to the environment: In other words, the imitial technological conditions in the clalor-alkali industry were similar in Western Europe and Japan prior to any influence of envirommental regulations.

Since then, Western Europe and Japan have taken divergent courses of technological change in the same industry. The mercury process has been phased out in Japan, and currently almost all of the chlor-alkali production capacities are based on the lon exchange membrane process, which has been developed since the $1970 \mathrm{~s}$. In contrast, the mercury process has continued to be dominant in Westem Europe, while the penetration of the membrane process to chlor-alkali plants has been relatively limited. In the following two chapters, we will investigate how environmental regulations on mercury emissions have influenced the patteitns of technological change in Japan and Western Europe. We will closely look at the ways in which different technological trajectories have emerged between the two regions; that is, we will examine why and how the option of developing end-of-pipe technologies have been chosen to reduce mercury emissions in Western Europe whereas the ion exchange membrane process, a clean technology which eliminates mercury pollution from within the production process, has been invented and widely diffused in Japan.

\section{Appendix}

Table 3-24 Shares of Chlor-Alkali Production Capacities Based on the Mercury, Diaphragm, and Ion Exchange Membrane Process in Western Europe, the United States, and Japan in 1998

\begin{tabular}{|l|c|c|c|c|}
\hline & $\begin{array}{c}\text { Mercury } \\
\text { Process }\end{array}$ & $\begin{array}{c}\text { Diaphragm } \\
\text { Process }\end{array}$ & $\begin{array}{c}\text { Ion Exchange } \\
\text { Membrane Process }\end{array}$ & Other \\
\hline Western Europe & 60.7 & 23.0 & 13.4 & 2.9 \\
\hline United States & 12.4 & 72.8 & 12.2 & 2.6 \\
\hline Japan & 0 & 9.5 & 90.5 & 0 \\
\hline
\end{tabular}


Sowres: Western Europe: Euro Chlor (1998a) and Evropean IPPC Bureau (1999): United States: Chlorine Instirute (1999b), and Japam: Japan Soda Industry Association (1998b).

Table 3-25 Shares of Chlor-Alkali Production Capacities Based on the Mercury and the Diaphragm Processes in Western Europe, the United States, and Japan in 1972

\begin{tabular}{|l|c|c|c|}
\hline & Mercury Process & Diaphragm Process & Other \\
\hline Western Europe & 86 & 13 & 1 \\
\hline United States & 24.2 & 72.4 & 3.4 \\
\hline Japan & 95.6 & 4.4 & 0 \\
\hline
\end{tabular}

Sources: Western Europe: Koyama (1972); United States: Chlorine Institute (1999b); and Japan: Japan Soda Industry Association (1982). 


\section{Environmental Regulation and Technological Change in the Japanese Chlor-Alkali Industry}

\subsection{Regulatory Decision on the Phase out of the Mercury Process}

In May 1956, four cases of an unknown disease with nervous symptoms were reported in Minamata in the southern part of Japan. Further investigations revealed that more patients were suffering from the same symptoms among inhabitants in the Minamata Bay area. Initially, heavy metals such as selenium, manganese, and thallium were suspected as the agent causing the disease, but later the disease was proved to be methyl mercury poisoning caused by ingestion of seafood caught in the Minamata Bay and the neighboring seas; hence it has become called the Minamata disease. Although cases of poisoning from methyl mercury had been known for one hundred years, it was the first case in which mereury poisoning was caused by inlalation or absorption of fish and shellfish contaminated by methyl mercury (Tsubaki and Irukayama, 1977).

Near the Minamata Bay an acetaldehyde plant had been operated by Chisso, the largest manufacturer of this chemical substance in Japan at that time, while also producing chemical fertilizers, industrial chemicals, and synthetic plastics and fibers. Mercury had been used as a catalyst for producing acetaldehyde and vinyl chloride. As mercury began to be regarded as the suspect of causing the Minamata disease, the wastewater from both the acetaldehyde and vinyl chloride plants was first stored in a pool, and later it was processed in a cyclator. While dissolved inorganic mercury compounds were precipitated, methyl mercury in the wastewater was not removed in the cyclator, however, and the effluent containing methyl mercury continued to be discharged into the Minamata Bay. As subsequent examinations revealed that seafood from the Minamata Bay still contained abnormal levels of mercury, the wastewater flow from the acetaldehyde plant was finally altered to form a complete recirculating system in May 1966. In the meantime, another case of patients suffering from the same symptoms was reported in the Agano River basin, Niggata, in July 1965, which subsequently came to be called the second Minamata disease. In May 1968, 12 years after the first discovery of the Minamata disease, the acetaldehyde plant finally ceased its operation. Four months later, the Ministry of Public Health and Welfare made an official statement that the causative agent of the Minamata discase was the methyl mercury compound emitted from the acetaldehyde plant 
of Chisso. In March 1971, the winyl chloride manufacturing process was converted to the ethylene process, in which no mercury was involved.

Mercury had been widely used as catalyst for symthesizing acetaldehyde by the hydration of acetylene. During the period from 1932 to $1968,456,300$ tonnes of acetaldehyde were produced in the Minamata plant (Jijma, 1990b) of $1,181.1$ tonnes of mercury inpunted in total, 204.9 tonnes were consumed, and the loss of mercury discharged in the wastewater was estimated to be 81.3 tonnes. The synthesis of vinyl chloride was made by a process in which acetylene was reacted with hydrogen chloride in the gaseous state, and mercuric chloride adsorbed onto activated carbon, so-called mercury dregs, was used as a catalyst. The total amount of 510,000 tomnes of vinyl chloride was produced in the period from 1941 to 1971. With 178 tonnes of mercury consumed in total, the estimated loss of mercury was 0.2 tonnes, a figure which was much smaller than that for the acetaldehyde manufacture. While it had become clear that the material which caused the Minamata disease was the methyl mercury emitted from the acetaldehyde plant, at that time there was no scientific explanation which explained in a satisfactory manner, qualitatively as well as quantitatively, why methy] mercury, a form of organic mercury, was formed in the plant, where acetaldehyde was synthesized from acetylene with the use of inorganic mercury as a catalyst ${ }^{57}$.

Having seen the misery of the Minamata disease, which caused at least 700 patients who had been recognized by the government by the end of 1972, the general public started to have a grave concern about pollution in the environment. The Basic Law for Environmental Pollution Control was enacted in August 1967, establishing environmental quality standards based on the designation of pollutants' target ranges, the liability of polluters, and the responsibilities of the national as well as local governments. It was then followed by other regulations to control mercury emitted to the environment. The chlor-alkali industry, in particular, was using a large amount of mercury for the mereury process in the 1960 s and thus invited public attention, although the emissions from the industry did not inclucle any trace of methyl mercury, the organic mercury which caused the Minamata disease. Without any organic substances involved in the relevant chemical reactions, there was no possibility of the formation of organic mercury within chlor-alkali plants. Nevertheless, in June 1968 the

\footnotetext{
5: A book which has been published recently tries to elacidate the scientific mechanism of the formation of methyl meroury in the process of synthesizing acetaldehyde from acetylene with inorganic mercury (Nishimura and Okamura, 2001). According to the athors, methyl mercury was formed at the Minamata plant because the high concentration of chlorine ions in the reactor, caused by the inappropriate management of the process water,
} 
Ministry of International Trade and Industry (MTTI) ${ }^{58}$ started to investigate mercury uses in chlor-alkali plants, in the presence of a sigmificant degree of uncertainty in the selentifie mechanism of the transformation of mercury in the emvironment ${ }^{59}$. This was the first involvement of the government in issues related to mercury emissions of the chlor-alkali industry. In February 1969, all the waters linked to chlor-alkali plants based on the mercury process became subject to the Law for the Conservation of Water Quality in Public Areas (Japan Soda Industry Association, 1982). At this moment, the emphasis of these measures was basically place on how to reduce, but not necessarily eliminate, mercury emissions into the environment.

Table 4-1 lists chronologically major regulations and measures on mercury emissions, particularly those related to the chlor-alkali industry.

Table 4-1 Chronology of Environmental Regulations on Mercury Emissions from ChlorAlkali Plants in Japan

\begin{tabular}{|c|c|}
\hline Year & Environmental Regulation \\
\hline June 1968 & First government investigation on mencury uses in chlor-alkali plants \\
\hline February 1969 & $\begin{array}{l}\text { All mercury chlor-alkali plants subject to the Law for the Conservation } \\
\text { of Water Quality in Public Areas }\end{array}$ \\
\hline May - June 1973 & $\begin{array}{l}\text { Newspaper reports on the third and fourth Minamata disease due to } \\
\text { mercury pollution from chlor-alkali production processes (proved later to } \\
\text { be false) }\end{array}$ \\
\hline June 1973 & $\begin{array}{l}\text { Establishment of the Council for the Promotion of Countermeasures } \\
\text { against Mercury Pollution. }\end{array}$ \\
\hline November 1973 & $\begin{array}{l}\text { Government mandate for completion of the closed system of mercury by } \\
\text { December } 1973 \text { and conversion of } 2 / 3 \text { of the mercury process to the } \\
\text { diaphagm process by } 9 / 1975 \text { (phase I) and the rest by } 3 / 1978 \text { (plnase II) }\end{array}$ \\
\hline April 1976 & $\begin{array}{l}\text { Completion of the first phase of process conversion to the diaphragm } \\
\text { process }\end{array}$ \\
\hline May 1977 & Postponement of the second phase of process conversion \\
\hline June 1979 & Evaluation report on the ion exchange membrane process \\
\hline September 1979 & $\begin{array}{l}\text { Government mandate for completion of the second phase of process } \\
\text { conversion to the ion exchange membrane process by December } 1984\end{array}$ \\
\hline June 1986 & $\begin{array}{l}\text { Completion of the second phase of process conversion to the ion } \\
\text { exchange membrane process and phase-out of the mercury process }\end{array}$ \\
\hline
\end{tabular}

helped to create methyl chloride mercury, which was easy to evaporate, thus easy to leak to the ortside of the system.

${ }_{58}$ MITI has been recently reorganized into the Ministry of Economy, Trade, and Industry (METT).

sy At that time there were some research results which suggested that aquatic micro-organisms could convert inorganic mercury into the melyyl mercuric ion and, under certain conditions, also into the water-immiscible, wolatile dimethyl mercury (Bouveng, 1972). 
Then, in May 1973, a newspaper published an article which suggested that a case of the third Minamata disease was discovered in the Ariake Sea area in Kyushu (Asahi Shinbum, 1973a). Just one month later the same newspaper reported a similar incident which happened near Tokuyama Bay in the western part of Japan (Asahi Shinbun, 1973b). As both cases were linked to industrial complexes which involved chlor-alkali plants, the public pressure was growing to demand some measures to stop mercury emissions from these plants, although there was no scientific evidence to support these allegations, which proved to be false later. Many fishermen went on demonstrations against mercury-based chlor-alkali plants in coastal areas throughout Japan, and some of the plants were actually forced to halt their operations. The Environmental Agency, which had been established just two years earlier, organized the Heallh Examination Committee, and conducted medical examinations of inhabitants of nine marine areas, including the Ariake Sea and Tokuyama Bay areas. No case of the Minamata disease or methyl mercury poisoning was found in any area other than Minamata Bay and its neighboring seas (Irukayama, 1977). Neverthelless, the public pressure for immediate actions was so fierce that the Japanese government was prompted to take measures to cut mercury emissions.

On June 12, 1973, in the wake of the controversies triggered by the newspaper reports, the government established the Council for the Promotion of Countermeasures against Mercury Pollution (Countermeasures Council) in the Environmental Agency. It was chaired by the Minister of State for Environment, assisted by the Admimistrative Vice-Minister and the State Secretary for Environment, and consisted of members from twelve ministries and agencies in the government (Japanese Ministry of International Trade and Industry, 1979). As all relevant ministries and agencies were represented, with only the Ministry of Justice and the Ministry of Posts and Telecommunications absent, the Countermeasures Council could coordinate policies of different government bodies and thus was decisive in making the government's position on the issue of mercury emissions.

At the first meeting held on Jume 14, 1973, the Countermeasures Council decided that, after the completion of installing the so-called closed system for effluents containing mercury by the end of September 1974, as many mercury plants as possible should be converted to the diaphragm process by the end of September 1975. The chlor-alkali industry association argued that there were many technical as well as economic difficulties in the conversion of the existing mercury plants to the diaphragm process and that its implementation would take a long period ol time (Japan Soda Industry Association, 1973a). The statement of the industry 
was also handed over to the Minister of the Environmental Agency when the representitives of the industry visited the Agency to discuss the issue (Japan Soda Industry Association, 1973b). The industry's request was not accepted by the Minister, however, and the thind meeting of the Countermeasures Council, which was subsequently held on November 1973 , agreed on the following concrete schedule for the process conversion program (Comincil for the Promotion of Countermeasures against Mercury Pollution, 1973):

Two thirds of the existing mercury plants are to be converted to the diaphragn process by September 1975, and the remaining one third by March 1978.

That means that there were only less than two years left for many of the existing mercury plants to conduct the technological conversion from the mercury process to the non-mercury, diaphragm process.

\subsection{Conversion of the Mercury Process to the Diaphragm Process}

Following the government's decision to convert the existing mercury plants to the diaphragm process, MITI organized the Committee for the Promotion of Process Conversion in the Soda Industry (Conversion Committee) on September 14, 1973, as a private consulting body to the Director-General of MITI's Basic Industries Bureau. As shown in Table 4-2, the members of the Conversion Committee were selected from banks, academics, journalism, and industry, reflecting the relevant issues to be discussed. Along with a subcommittee, three expert groups were established on finance and tax, technology and regulation, and supply and demand coordination to have more detailed and informed discussions on the schedule and criteria for the process conversion program and financial and tax incentives to support it.

Table 4-2 Members of the Committee for the Promotion of Process Conversions in the Soda Industry

\begin{tabular}{|l|l|}
\hline $\begin{array}{l}\text { President, Japan Development Bank; Member, Central } \\
\text { Council for Countermeasures against Public Nuisance }\end{array}$ & $\begin{array}{l}\text { ISHIHARA Amao } \\
\text { (Chairman) }\end{array}$ \\
\hline Governor, Chiba Prefecture & TOMONO Takeo \\
\hline President, Industrial Bank of Japan & MASAMUNE Isao \\
\hline President, Long-Term Credit Bank of Japan & SUGIURA Shunsuke \\
\hline Professor, University of Tokyo & MUKAIBO Takashi \\
\hline Professor, Yokohama National University & MATSUNO Takeo \\
\hline $\begin{array}{l}\text { Member, Central Council for Countermeasures against Public } \\
\text { Nuisance; Member, Science and Technology Council }\end{array}$ & KUROKAWA Matake \\
\hline $\begin{array}{l}\text { Editorial Board Member, Asahi Newspaper; Member, Central } \\
\text { Council for Countermeasures against Public Nuisance }\end{array}$ & KISHIDA Junnosuke \\
\hline
\end{tabular}




\begin{tabular}{|l|l|}
\hline Editorial Board Member, Nhon Keizai Newspaper & KAMADA Isao \\
\hline Chamman, Japan Paper Manufacturers' Association & KANEKO Saichiro \\
\hline Chaiman, Japan Chemical Fibers Association & YASUI Yoshizo \\
\hline Chaiman, Vinyl Chloride Industry Association & SHIMAMURA Michiyasu \\
\hline Counselor, Japan Soda Industry Association & NMNOMIYA Yoshimoto \\
\hline $\begin{array}{l}\text { Vice Chaiman, Japan Soda Industry Association; Chairman, } \\
\text { Committee for Countermeasures against Mercury }\end{array}$ & IMAI Hiroshi \\
\hline Director-General, Basic Industries Bureau & IIZUKA Shiro \\
\hline
\end{tabular}

Source: Japan Soda Industry Association (1974a).

The Conversion Committee decidled on the criteria for the conversion of mercury plants specified: as follows (Japanese Ministry of International. Trade and Industry, 1973):

1. Plants whose mercury consumption per unit caustic soda is higher than the average of the soda industry are to be completely converted by September 1975.

2. Plants whose mercury consumption per unit caustic soda is lower than the average of the soda industry are to be converted in the following way.

a. Facilities which will end their lifetime by September 1975 are to be converted partially by September 1975 and completely by March 1978, depending on the conditions of depreciation and mercury management.

b. Facilities which will not end their lifetime by September 1975 are, in principle, to be converted completely by March 1978 .

In this way, the process conversion program was decided to be implemented in two steps: the first phase for two thirds of mercury plants to be converted by September 1975 and the second phase for the remaining one third to be converted by March 1978 .

For the implementation of the process conversion program, tax reductions were introduced to stupport newly converted or expanded production facilities. Table 4-3 shows the new scheme for tax reductions. The special depreciation rate applicable for the first year was one third at the beginning and then was reduced gradually. While the new tax reduction scheme was initially targeted to the diaphragm process, after the fiscall year 1978 this preferential tax treatment became applicable to the ion exchange membrane process, which had been just developed by several innovative companies in the Japanese chlor-alkali industry.

Table 4-3 Tax Reductions for the Process Conversion in the Chlor-Alkali Industry

\begin{tabular}{|c|c|c|c|}
\hline Fiscal Year & Targeted process & $\begin{array}{c}\text { Special depreciation } \\
\text { rate }^{b}\end{array}$ & $\begin{array}{c}\text { Special tax rate on fixed } \\
\text { assets }^{c}\end{array}$ \\
\hline
\end{tabular}




\begin{tabular}{|c|c|c|c|}
\hline 1973 & $\mathrm{D}$ & $\mathrm{U} / 3$ & $1 / 2$ \\
\hline 1974 & $\mathrm{D}$ & $1 / 3$ & $1 / 2$ \\
\hline 1975 & $\mathrm{D}$ & $1 / 3$ & $1 / 2$ \\
\hline 1976 & $\mathrm{D}$ & $25 / 100$ & $3 / 5$ \\
\hline 1977 & $\mathrm{D}$ & $25 / 100$ & $3 / 5$ \\
\hline 1978 & $\mathrm{IM}$ & $25 / 100$ & $3 / 5$ \\
\hline 1979 & $\mathrm{IM}$ & $25 / 100$ & $3 / 5$ \\
\hline 1980 & $\mathrm{IM}$ & $20 / 100$ & $3 / 5$ \\
\hline 1981 & $\mathrm{IM}$ & $20 / 100$ & $3 / 5$ \\
\hline 1982 & $\mathrm{IM}$ & $18 / 100$ & $3 / 5$ \\
\hline 1983 & $\mathrm{IM}$ & $18 / 100$ & $3 / 5$ \\
\hline 1984 & $\mathrm{IM}$ & $18 / 100$ & $3 / 5$ \\
\hline 1985 & $\mathrm{IM}$ & $16 / 100$ & $2 / 3$ \\
\hline 1986 & $\mathrm{IM}$ & $16 / 100$ & $2 / 3$ \\
\hline
\end{tabular}

D: Diaphragm process; IM: Ion exchange membrane process

a: A fiscal year starts in April and ends in March next year. Exceptions in the table are April December in 1984, January - December in 1985, and January - June in 1986.

$b$ : The special depreciation rate was applied for the first year, in addition to the normal depreciation rate.

c: The special tax rate was applied for three years after purchase.

Source: Japan Soda Industry Association (1985).

When the official decision was made on the phase out of the mercury process, it was by far the dominant technology adopted for the chlor-alkali production in Japan, accounting for $95 \%$ of the total capacity as you can see in Table $3-17$. In replacing the mercury process, the only alternative technology available at that time was the diaphragm process, a type of process technology which was used for only $5 \%$ of the total production. As the regulatory schedule for process conversions specified that two thirds of the mercury process plants must be converted to the diaphragm process just in two years, there was not sufficient time for companies in the chlor-alkali industry to newly develop by themselves diaphragm-based technologies which could be feasible at the industrial level. Consequently, technologies necessary for the diaphragm process had to be introduced mostly from foreign companies.

The types of technologies for the diaphragm process adopted during the first phase of the process conversion program are shown in Table 4-4. Under the policy schemes, the first diaphragm plant converted from the mercury process started to operate in March 1974, and other conversions followed in the subsequent period up to 1976. Reflecting the most advanced development of the diaphragm process in the U.S. at that time (see Table 3-9), many of the technologies adopted for the diaphragm process were provided by American 
suppliers. Dramond Shamrock based in the U.S. accounted for $32 \%$ of the total capacity, Hooker based in the U.S. for $27 \%$, and PPG based in the U.S. for $26 \%$. Only $15 \%$ of the total production capacity relied on technologies provided by Japanese companies. While Nippon Soda, Tsurumi Soda, and Showa Denko had previous technical experiences on the diaphragn proeess, the technology developed by Kureha Chemical Industry was the first to be introduced for commerelal purposes in the chlor-alkali industry.

Table 44 Technologies for the Diaphragm Process Adopted during the First Phase of the Process Conversion Program

\begin{tabular}{|c|c|c|c|}
\hline $\begin{array}{l}\text { Technology } \\
\text { (Company) }\end{array}$ & $\begin{array}{c}\text { Start-up } \\
\text { Year }\end{array}$ & Plant & $\begin{array}{c}\text { Capacity } \\
\text { (NaOH } t / y)\end{array}$ \\
\hline \multirow{14}{*}{$\begin{array}{l}\text { DS } \\
\text { (Diamond Shamrock, } \\
\text { US) }\end{array}$} & 1974 & Asahi Glass, Kita-Kyushu & 16,300 \\
\hline & 1974 & Sumitomo Chemical, Ohita & 15,400 \\
\hline & 1974 & Mitsui Toatsu, Nagoya & 59,100 \\
\hline & 1975 & Ajinomoto, Kawasaki & 35,700 \\
\hline & 1975 & Tokuyama Soda, Tokuyama. & 190,400 \\
\hline & 1975 & Mitsui Toatsi, Ohmuta & 80,200 \\
\hline & 1975 & Nihon Vinyl Chloride, Chiba & 86,600 \\
\hline & 1975 & Osaka Soda, Matsuyama & 44,400 \\
\hline & 1976 & Toagosei Chemical, Tokushima & 148,500 \\
\hline & 1976 & Hodogaya Chemical, Kohriyama & 24,500 \\
\hline & 1976 & Nikkei Kako, Kanbara & 36,600 \\
\hline & 1976 & Toyo Soda, Yokkaichi & 70,800 \\
\hline & 1977 & Nankai Chemical, Tosa & 15,700 \\
\hline & Total & 13 plants & $\begin{array}{r}31,216,793 \\
(31.9 \%) \\
\end{array}$ \\
\hline \multirow{13}{*}{$\begin{array}{l}\text { Hooker } \\
\text { (Hooker, US) }\end{array}$} & 1974 & Mitsubishi Gas Chemical, Naniwa & 12,200 \\
\hline & 1974 & Kanegafuchi Chemical, Takasago & 99,300 \\
\hline & 1974 & Central Chemical, Kawasaki & 61,000 \\
\hline & 1974 & Sanyo Kokusaku Pulp, Iwakuni & 28,000 \\
\hline & 1975 & Hokkaido Soda, Tomakomai & 119,500 \\
\hline & 1975 & Shin-etsu Chemical, Naoetsu & 40,200 \\
\hline & 1975 & Osaka Soda, Amagasaki & 51,100 \\
\hline & 1975 & Denki Kagaku Kogyo, Ohme & 61,000 \\
\hline & 1975 & Mitsubishi Monsanto, Yokkaichi & 56,400 \\
\hline & 1975 & Tekkosha, Sakata & 36,500 \\
\hline & 1975 & Mitsubishi Chemical, Kurosaki & 40,000 \\
\hline & 1975 & Ryonichi, Mizushima & 97,600 \\
\hline & Total & 12 plants & $702.800(27.2 \%)$ \\
\hline \multirow{3}{*}{$\begin{array}{l}\text { Glanor } \\
\text { (PPG, US) }\end{array}$} & 1975 & Asahi Glass, Kashima & 160,000 \\
\hline & 1975 & Toyo Soda, Nanyo & 156,200 \\
\hline & 1975 & Asahi Glass, Chiba & 180,000 \\
\hline
\end{tabular}




\begin{tabular}{|c|c|c|c|}
\hline \multirow[t]{2}{*}{ 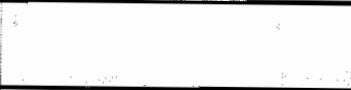 } & 1976 & Sumitomo Chemical Kikumoto & 174,200 \\
\hline & Total & 4 plants & $670,400(26,0 \%)$ \\
\hline \multirow{3}{*}{$\begin{array}{l}\text { BM } \\
\text { (Nippon Soda, Japan) }\end{array}$} & 1974 & Nippon Soda, Nihongi & 25,800 \\
\hline & 1975 & Chiba Chlorine Chemical, Chiba & 114,400 \\
\hline & Total & 2 plants & $137,200(5,3 \%)$ \\
\hline \multirow{3}{*}{$\begin{array}{l}\text { TSBM } \\
\text { (Tsurumi Soda, Japan) }\end{array}$} & 1974 & Tsurumi Soda, Tsurumi & 10,500 \\
\hline & 1974 & Showa Enso, Gushikawa & 3,100 \\
\hline & Total & 2 plants & $13,600(0.5 \%)$ \\
\hline \multirow{3}{*}{$\begin{array}{l}\mathrm{SD} \\
\text { (Showa Denko, Japan) }\end{array}$} & 1975 & Showa Denko, Kawasaki & 103,100 \\
\hline & 1975 & Kanto Denka Kogyo, Mizushima & 38,200 \\
\hline & Total & 2 plants & $141,300(5.5 \%)$ \\
\hline \multirow[t]{2}{*}{$\begin{array}{l}\text { SK } \\
\text { (Kureha Chem., Japan) }\end{array}$} & 1976 & $\begin{array}{lll}\text { Kureha } & \text { Chemical } & \text { Industry, } \\
\text { Nishiki } & & \\
\end{array}$ & 93,500 \\
\hline & Total & & $93,500(3.6 \%)$ \\
\hline \multicolumn{2}{|l|}{ Total } & 36 plants & $2,583,000$ \\
\hline
\end{tabular}

Sources:

DS and Glanor: Chlorine Engineers Corp. (1999b).

Hooker: European Chemical News (1974) (comerted from daily capacities).

BM: Calculation based on Japan Soda Industry Association (1982) (comverted from monthly capacities).

TSBM: Tsurumi Soda (2001), Nikkei Sangyo Shimbun (1975b), Showa Chemical (2001).

SD: Takeshita (1990), Nikkei Sangyo Shinbun (1975a), Kanto Denka Kogyo (1998).

SK: Shibata, Kokubu, and Okazaki (1977).

As many mercury-based plants were converted to the diaphragm process, however, the serious concern which had been raised previously, that is, the high production cost of the diaphragm process with the output of low-quality caustic soda, materialized in the industry. Many users who had previously purchased caustic soda produced by the mercury process demanded the same level of high quality for caustic soda. For about $25 \%$ of all the applications, caustic soda produced by the diaphragm process was considered not to be suitable, especially for the manufacture of chemical fibers such as rayon (Japan Soda Industry Association, 1982). Since rayon is a thin fiber whose diameter is in the order of micro, i.e. 10 "meters, it can be easily cut when impurities exist in caustic soda (Sakota, 1977). Hence the manufacturing of chemical fibers requires caustic soda which contains as fewer impurities as possible.

Table 4-5 shows the results of an analysis of the quality of caustic soda produced by the mercury and diaphragm processes. While the caustic soda produced by the mercury process was relatively pure, the diaphragm process produced caustic soda which contained more 
impurities, notably sodium chloride. Its concentration was $1 \%$ a level which was much higher than that acceptable for use in the manufacture of chemical fibers.

Table 4-5 Quality of Caustic Soda Produced with the Mercury Process and the Diaphragm Process

\begin{tabular}{|c|c|c|c|c|}
\hline \multirow{2}{*}{ 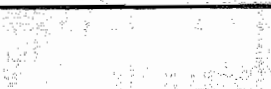 } & \multirow{2}{*}{$\begin{array}{l}\text { Mercury } \\
\text { process }\end{array}$} & \multirow{2}{*}{$\begin{array}{l}\text { Diaphragm } \\
\text { process }\end{array}$} & \multicolumn{2}{|c|}{ Chemical fiber grade } \\
\hline & & & No. 1 & $N_{0.2}$ \\
\hline $\begin{array}{c}\text { Soditum chloride } \\
\text { (NaCl) }\end{array}$ & 0.003 & 1.0 & $>0.07$ & $>0.40$ \\
\hline $\begin{array}{l}\text { Sodium carbonate } \\
\qquad\left(\mathrm{Na}_{2} \mathrm{CO}_{3}\right)\end{array}$ & 0.037 & 0.07 & $>0.3$ & $>0.4$ \\
\hline $\begin{array}{l}\text { Silicon dioxide } \\
\left(\mathrm{SiO}_{2}\right)\end{array}$ & 0.0035 & 0.02 & $>0.03$ & $>0.15$ \\
\hline $\begin{array}{l}\text { Aluminium oxide } \\
\left(\mathrm{A}_{2} \mathrm{O}_{3}\right)\end{array}$ & 0.00044 & 0.0005 & $>0.02$ & $>0.04$ \\
\hline $\begin{array}{c}\text { Calcium oxide } \\
\text { (CaO) }\end{array}$ & 0.0004 & 0.003 & $>0.005$ & $>0.008$ \\
\hline $\begin{array}{c}\text { Iron(III) oxide } \\
\left(\mathrm{Fe}_{2} \mathrm{O}_{3}\right)\end{array}$ & 0.00015 & 0.0009 & $>0.003$ & $>0.005$ \\
\hline $\begin{array}{l}\text { Sodium sulfate } \\
\left(\mathrm{Na}_{2} \mathrm{SO}_{4}\right)\end{array}$ & 0.0026 & 0.02 & - & $\overline{-}$ \\
\hline
\end{tabular}

Figures are expressed in percentage.

a: 1975

b: 1974

c: Japan Industrial Standard (JIS) K 1204-1955, K 1205-1955

Sources: Sakota (1977), Industrial Structure Council (1972).

As the demand for the poor-quality caustic soda was low, manufacturers who had already converted their plants to the diaphragm process had difficulties in selling their products to customers. They argued for a level playing-field; that is, they demanded that diaphragm and mercury plant operators deal with, that is, consume and sell., caustic soda produced by the diaphragm and mercury processes in the same proportion by making barter trades with each other. MITI, intending to promote the conversion program smoothly, responded to this claim by issuing an administrative guidance in June 1975. With its instruction, caustic soda producers had to submit their production plans every three months to MITI. MITI, in turn, based on its demand projection for the quarter, revised the production plans and mediated barter trades among the producers between caustic soda produced by the diaphragm process and that produced by the mercury process (Japanese Ministry of International "Trade and Industry, 1975b), 
Furthermore, the diaphragm process was also at a disadvantage in terms of the energy consumption, which occupies a major part of the chlor-alkali production process. At that time, the energy consumption of the diaphragm process was approximately $3,400 \mathrm{k}$ Wh per tonne of caustic soda, which was larger than that of the mercury process, $3,200 \mathrm{kWh}$ per tome of caustic soda (Japan Soda Industry Association, 1975). This difficulty worsened by the oil crisis which happened during the 1970 s. Table 4-6 shows the trends in the electricity prices for average consumers, large consumers, and chlor-alkali producers in Japan since the beginning of the $1970 \mathrm{~s}$. The price of electricity used for chlor-alkali production almost tripled after the first phase of the energy crisis, from 3.10 yen/kWh in 1970 to $9.10 \mathrm{yen} / \mathrm{k}$ Wh in 1977 . By the early 1980s, the electricity price for chlor-alkali producers had reached 14.80, a lovel which is more than four times larger than the price at the beginning of the 1970 s.

Table 4-6 Electricity Prices in Japan

\begin{tabular}{|c|c|c|c|}
\hline Year & Normal Consumer & Large Consumer & Chlor-Alkali Producer \\
\hline 1970 & 6.35 & 3.92 & 3.10 \\
\hline 1971 & 6.52 & 3.98 & 3.40 \\
\hline 1972 & 6.57 & 3.99 & 3.30 \\
\hline 1973 & 6.76 & 4.17 & 4.16 \\
\hline 1974 & 10.62 & 7.72 & 7.14 \\
\hline 1975 & 11.61 & 8.49 & 7.69 \\
\hline 1976 & 13.20 & 9.75 & 8.42 \\
\hline 1977 & 14.51 & 10.62 & 9.10 \\
\hline 1978 & 14.02 & 9.95 & 8.42 \\
\hline 1979 & 14.69 & 10.52 & 9.12 \\
\hline 1980 & 22.47 & 17.07 & 14.31 \\
\hline 1981 & 23.14 & 17.30 & 14.80 \\
\hline 1982 & 23.44 & 17.40 & 14.45 \\
\hline 1983 & 23.53 & 17.35 & 14.35 \\
\hline 1984 & 23.53 & 17.23 & 13.34 \\
\hline 1985 & 23.71 & 17.38 & 13.36 \\
\hline 1986 & 21.93 & 15.66 & 11.73 \\
\hline
\end{tabular}

Source: Japan Soda Industry Association (1988).

Heavily dependent on electricity, chlor-alkali producers were particularly hit by the soaring energy cost. As the cost of caustic soda produced at newly constructed diaphragm plants became significantly larger than that at the existing mercury plants, the barter trading system was modified in October 1976 to include financial compensations reflecting the cost difference. In exchanging caustic soda, mercury process operators had to pay their 
counterparts using the diaphragn process for the cost difference, which was initially determined to be 5,000 yen per tonne of caustic soda and was changed one year later to 5,500 yen per tonne (Japan Soda Industry Association, 1980a). Table 4-7 gives the figures which show the extent to which caustic soda was exchanged between the operators of the two types of production processes. Until the barter trading system was finally abandoned in September 1980, approximately $6 \%$ of the total caustic soda production was exchanged in average, and more than 3 billion yen was transferred from operators of the mereury process to those of the diaphragm process.

Table 4-7 Exchange of Caustic Soda between the Mercury Process and Diaphragm Process Operators

\begin{tabular}{|c|c|c|c|}
\hline Period & $\begin{array}{c}\text { Quantity } \\
\text { exchanged (tonnes) }\end{array}$ & $\begin{array}{c}\text { Exchange/Production } \\
(\%)\end{array}$ & $\begin{array}{l}\text { Financial transfer } \\
\text { (thousand yen) }\end{array}$ \\
\hline $\begin{array}{l}1975 \\
\text { July - September } \\
\text { October - December }\end{array}$ & $\begin{array}{l}32,674 \\
57,167\end{array}$ & $\begin{array}{l}4.4 \\
7.3\end{array}$ & - \\
\hline $\begin{array}{l}1976 \\
\text { January - March } \\
\text { April - June } \\
\text { July - September } \\
\text { October - December }\end{array}$ & $\begin{array}{l}58,165 \\
60,718 \\
49,517 \\
50,240\end{array}$ & $\begin{array}{l}7.6 \\
8.5 \\
6.8 \\
7.3\end{array}$ & $\begin{array}{c}- \\
- \\
251,200\end{array}$ \\
\hline $\begin{array}{l}1977 \\
\text { January - March } \\
\text { April - June } \\
\text { July - September } \\
\text { October - December }\end{array}$ & $\begin{array}{l}48,275 \\
51,791 \\
49,805 \\
46,993\end{array}$ & $\begin{array}{l}6.8 \\
7.2 \\
6.8 \\
6.6\end{array}$ & $\begin{array}{l}241,375 \\
258,955 \\
273,927 \\
258,462\end{array}$ \\
\hline $\begin{array}{l}1978 \\
\text { January - March } \\
\text { April - June } \\
\text { July - September } \\
\text { October - December }\end{array}$ & $\begin{array}{l}44,037 \\
45,240 \\
45,335 \\
43,598\end{array}$ & $\begin{array}{l}6.1 \\
6.6 \\
6.5 \\
6.6\end{array}$ & $\begin{array}{l}242,203 \\
248,820 \\
249,343 \\
239,789\end{array}$ \\
\hline $\begin{array}{l}1979 \\
\text { January - March } \\
\text { April - Iune } \\
\text { July - September } \\
\text { October - December }\end{array}$ & $\begin{array}{l}38,731 \\
39,758 \\
41,623 \\
46,005\end{array}$ & $\begin{array}{l}5.8 \\
5.6 \\
5.1 \\
5.5\end{array}$ & $\begin{array}{l}213,020 \\
218,669 \\
228,927 \\
253,027\end{array}$ \\
\hline $\begin{array}{l}1980 \\
\text { January - March } \\
\text { Aprill - June } \\
\text { July - September }\end{array}$ & $\begin{array}{l}42,402 \\
41,576 \\
41,647\end{array}$ & $\begin{array}{l}5.0 \\
5.2 \\
5.5\end{array}$ & $\begin{array}{l}233,211 \\
228,668 \\
229,059\end{array}$ \\
\hline Total & 975,297 & 6.3 & $3,868,655$ \\
\hline
\end{tabular}

Sounce: Japan Soda Industry Association (1982). 
The first phase of the conversion program was completed in April 1976. By that time, the proportion of the production capacity of the mercury process had dropped to approximately $40 \%$ whereas the share of the diaphragm process had increased significantly from the level of less than $5 \%$ prior to the conversion program. That was achieved half a year behind the schedule, due to the technical as well as economic problems caused by the oil crisis at that time (Japanese Ministry of International Trade and Industry, 1975a). Heavily impacted by the rising energy cost following the oil crisis, the chlor-alkali industry; particularly its members which was still operating mercury-based plants, claimed that they did not have sufficient financial resources to conduct more process conversions and made a request to the Liberal Democratic Party, the party in power at that time, as well as to MITI that the implementation of the second phase of the process conversion program should be postponed (Japan Soda Industry Association, 1979a).

\subsection{Interruption of the Process Conversion Schedule and Evaluation of the Ion Exchange Membrane Process}

In these circumstances, the fourth meeting of the Countermeasures Council took place in May 1977. MITI explained to the other members that the caustic soda produced by the diaphragm process had a low quality and thus was very difficult to use. And at the same time, it was also mentioned that a newly developed process, the ion exchange membrane process, was in a process of rapid progress and that it was expected to be able to produce high-quality caustic soda. Taking into account the situation of the technological progress of the emerging ion exchange membrane process, the Countermeasures Council made a decision that the implementation of the second phase of the conversion program should be suspended until an appropriate judgment could be made on the feasibility of the ion exchange membrane process at the industrial scale (Council for the Promotion of Countermeasures against Mercury Pollution, 1977)

\footnotetext{
6i) It was also decided at the meeting that the safety of the closed system, which had been already installed in the existing mercury plants, would be examined thoroughly by an expert group. Accordingly, the Expert Committee for Examination of the Closed System (Examination Connnittee) was established in June 1977 as a subcommittee in the Conversion Comnittee. It was chaired by an academic rescarcher, MATSUNO Takeo, Professor of Yokohama National University, for independent investigations. The first result of its investigations was published in October 1977, coneluding that the closed systen instatled at mercury plants was functioning properly and that there was no mercury pollution which would pose threat to the health of the local people
} 
Then, an expert group was established to make a technical ewaluation of the ion exchange menbrane process, with a specified deadline of October 1977. The newly created subeommittee, the Expert Committee for Technical Evaluation of the Ion Exchange Membrane Process, the so-called Evaluation Committee, set out to do its assigned task in June 1977. As Table 4-8 shows, the four members who constituted the Evaluation Committee were all academic researchers of public research institutes. This selection of the experts was a reflection of the government's intention that the committee's technological evaluation should be conducted in a neutral arena, avoiding any intervention of particular industrial or corporate interests.

Table 4-8 Members of the Expert Committee for Technical Evaluation of the Ion Exchange Membrane Process

\begin{tabular}{|l|l|l|}
\hline \multicolumn{1}{|c|}{ Position } & \multicolumn{1}{c|}{ Name } & \multicolumn{1}{c|}{ Expertise } \\
\hline Professor, Kyoto University & YOSHIZAWA Shiro & Electrochemistry \\
\hline $\begin{array}{l}\text { Professor, Yokohama National } \\
\text { University }\end{array}$ & MATSUNO Takeo & $\begin{array}{l}\text { Electrochemistry, } \\
\text { Environmental Chemistry }\end{array}$ \\
\hline Professor, University of Tokyo & TSURUTA Teiji & Polymer Chemistry \\
\hline Director, Tokyo Industrial Laboratory & ISHISAKA Seiichi & System Engineering \\
\hline
\end{tabular}

Source: Expert Committee for Technical Evaluation of the Ion Exchange Membrane (1977).

The Evaluation Committee made a thorough examination of technologies which were being developed at that time by chlor-alkali companies, domestic as well as foreign, through documents, interviews, and, in some cases, visits to plant sites. In evaluating the technologies, the committee paid particular attention to the following aspects: performance, including power and steam consumption, caustic soda concentration, electricity density, and product quality; operation and maintenance management; durability and stability of ion exchange membranes; environmental and safety measures; and construction and operational costs. The findings of the Evaluation Committee were published in October 1977 (Expert Committee for Technical Evaluation of the Ion Exchange Membrane Process, 1977). The Committee"s technical evaluation of the ion exchange membrane process at that time was as follows:

While we could consider overall that, as far as the current situation in Japan is concerned, the ion exchange membrane process technology has reached a level appropriate for industrialization, we should be cautious about its evaluation,

(Expert Commitee for Examination of the Closed System. 1977). The conclusion of the first repont was recontirmed by the Examination Committe in June 1979 (Expert Committee for Examination of the Closed System. 1979) 
taking into full account the importance of caustic soda and chlorine as basic chemical materials and its impacts on other industries. In order to conclude that this technology is industrially viable, it is indispensable that the durability of various materials, including, among others, ion exchange membranes and electrolytic cells, and the operational performance of plants are well demonstrated. At this moment, however, we have not yet obtained sufficient dat on these aspects, and thus it is necessary to continue our observation to obtain mote data on the operation of commercial plants for at least two years. If it is confirmed that the current operational performance is maintained throughout the period, we can regard this technology as industrially established.

As regards the development of the ion exchange membranes, they are only produced in a small scale, just meeting the demand. Hence it is also necessary, by the time when the ion exchange membrane process technology reaches the level of industrial viability, that a system for stable supply of ion exchange membranes is established.

While recognizing that several companies had already possessed technologies for the membrane process ready for industrial applications, the Evaluation Committee asked for more data to reach a conclusion with sufficient confidence. Based on the recommendation, the government made a decision to postpone the process conversion program for about two years. In September 1978, almost one year after the publication of the first report, the members of the Evaluation Committee resumed their activities to see the technological progress made during the past year ${ }^{61}$. Basically, they followed the same procedure, evaluating again different types of the membrane process by reviewing reports and documents, undertaking interviews with firms in Japan as well as in foreign countries, and doing fieldwork. It was found that, as several companies actively conducted R\&D activities, a considerable progress had been made on the ion exchange membrane process in one year.

In particular, three companies, namely, Asahi Chemical Industry, Asahi Glass, and Tokuyama Soda, were found to be well ahead of other companies in developing their technologies for the ion exchange membrane process. Asahi Chemical Industry"s first

\footnotetext{
Whe of the members, ISHISAKA Seiichi, was replaced by SHIROZUKA Tadastri, Professor of Waseda University (applied chemistry), before the publication of the second report (Expent Committee for Technical Evaluation of the Ion Exchange Membrane Process, 1979).
} 
commercial plant and Asahi Glass"s demonstration plant had already had experiences of stable operation for several years. Another commercial plamt constructed by Asahi Chemical Industry and the first commercial plant of Asahi Glass had been operated reliably since the beginning of their operations, though for shorter periods. Tokuyama Soda had also started to operate commercial plants, and both of them had been ruming without any serious problems since the replacement of the original ion exchange membranes with those currently in use. These exampiles of stable and reliable plant operation convinced the members of the Evaluation Committee that the ion exchange membrane process not only eliminated mercury emissions into the environment, but also had surpassed the mercury process in the efficiency of energy consumption while producing caustic soda with the same quality as the mercury process.

With these findings in hand, the Evaluation Committee published its second report in June 1979, making the following judgment (Expert Committee for Technical Evaluation of the Ion Exchange Membrane Process, 1979):

Taking into account the operating experiences of various plants overall, our Committee considers that the ion exchange membrane process technology in Japan has reached a level which could be regarded as an established industrial technology.

In the following section, we examine in detail how the ion exchange membrane process. has been developed by innovative companies in the Japanese chlor-alkali industry.

\subsection{Technological Development of the Ion Exchange Membrane Process}

\subsubsection{Characteristics of the Ion Exchange Membrane Process}

We first closely examine the technological characteristics of the ion exchange membrane process by analyzing the chemical reactions involved, as we have done previously for the mercury process and the diaphragm process. The ion exchange membrane process operates in a similar way to the diaphragm process, with basically the same chemical reactions which does not involve any use of mercury throughout the whole production process. (Curlin, Bommaraju, and Hansson, 1991; Schmittinger, 2000). Figure 4-1 gives a simplified flow diagram of the ion exchange membrane process. 
In the ion exchange membrane process, a higher degree of brine quality is required than the mercury process because ion exchange membranes are extremely sensitive to brine impurities such as calcium and magnesium ions (Japan Soda Industry Association, 1998b). When impurities precipitate, ion exchange membranes are physically disrupted, which will lead to a substantial reduction in the current efficiency ${ }^{62}$. The circulating brine must be rigorously purified to avoid any buildup of these substances to undesirable levels. While the primary purification step, which consists of precipitation and filtration, produces brine satisfactory for both the mercury process and the diaphragm process, it is not sufficient to meet the extremely high level of brine purity required for the ion exchange membrane process makes. Thus, following the primary purification by the precipitation-filtration step, the brine goes through an additional step for fine purification, as the life expectancy of the expensive ion exchange membrane also depends on the purity of the brine.

6he current efficiency of an electrolytic process is the tatio of the arnount of material produced to the theoretically expected quantities. Inefficiencies arise from secondary reactions occurring at the anode and cathode and in the bulk. 


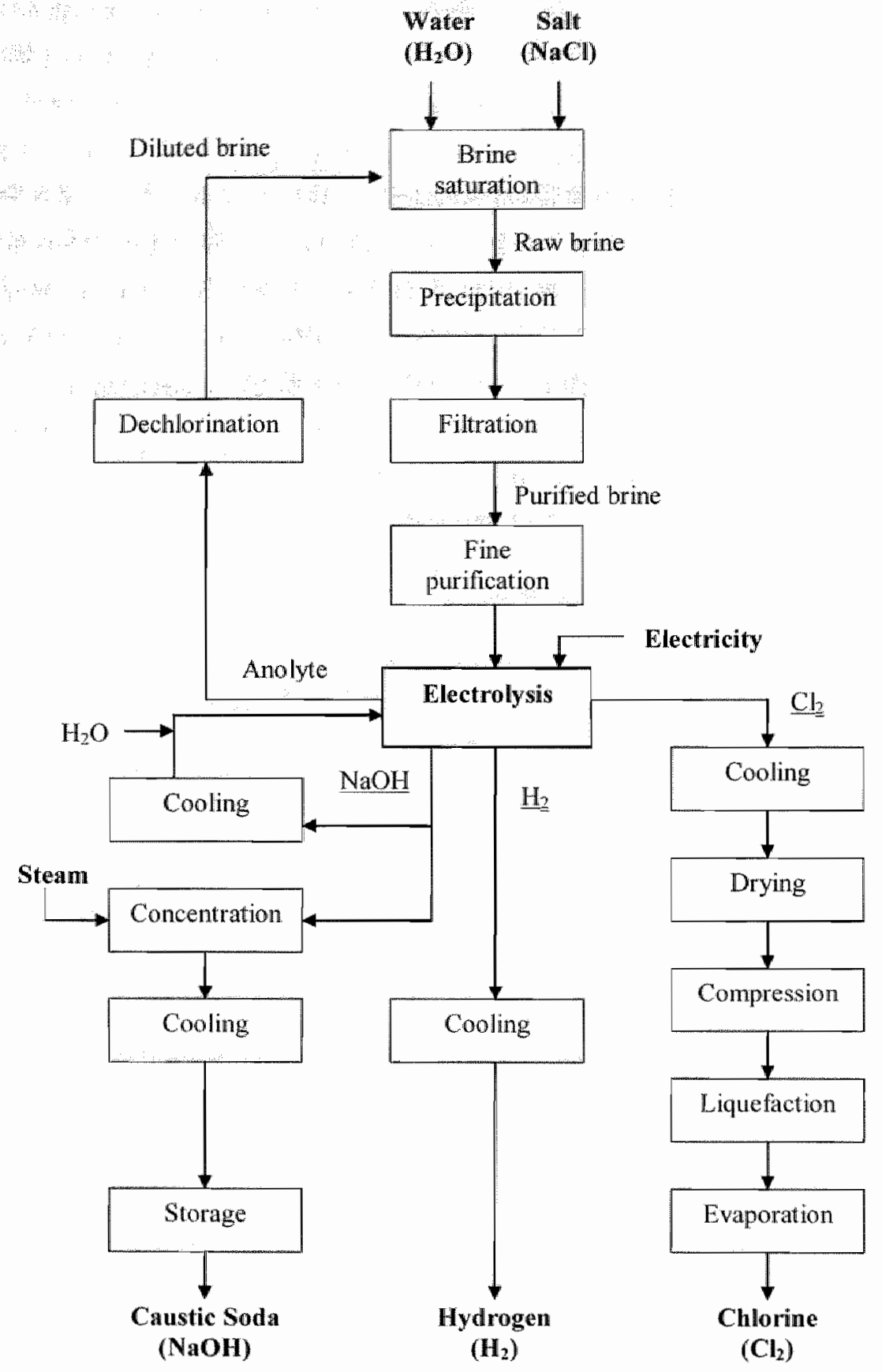

Figure 4-1 Flow Diagram of the Ion Exchange Membrane Process

Based on Curlin, Bommaraju, and Hansson (1991). 
The purified brine is then fed into the electrolyzer, which consists of cell, electrodes, that is, anode and cathode, and ion exchange membrane. The anode and cathode are separated by a cation-permeable ion exchange membrane, as is shown in Figure 4-2. Saturated brine $(\mathrm{NaCl})$ is first fed into the anode compartment. Chlorine ions $(\mathrm{Cl})$ are attracted to the anode to form chlorine $\left(\mathrm{Cl}_{2}\right)$ :

$$
2 \mathrm{Cl}^{-}>\mathrm{Cl}_{2}+2 \mathrm{e}^{-}
$$

whereas sodium ions $\left(\mathrm{Na}^{2}\right)$ migrate through the ion exchange membrane into the cathode compartment. Depleted brine is discharged from the cell and, as in the mercury process, is dechlorinated and recirculated. While hydraulic pressure prevents the reverse flow of hydroxide ions $\left(\mathrm{OH}^{\circ}\right)$ physically through the porous diaphragm in the case of the diaphragm process, the ion exchange membrane allows only sodium ions to pass through in the direction from the anode to the cathode and thus inhibits the reverse flow of hyclroxide ions electrochemically.

Water $\left(\mathrm{H}_{2} \mathrm{O}\right)$ is electrolyzed in the cathode compartment. Hydrogen $\left(\mathrm{H}_{2}\right)$ is evolved at the cathode by combining hydrogen ions $\left(\mathrm{H}^{*}\right)$ :

$$
2 \mathrm{H}^{+*}+2 \mathrm{e}^{-}>\underline{H}_{2}
$$

Hydroxide ions, together with the permeating sodium ions, form sodium hydroxide $(\mathrm{NaOH})$, that is, caustic soda:

$$
\mathrm{Na}^{*}+\mathrm{OH}^{-} \rightarrow \text { NaOH}
$$

Strong caustic of about $33 \%$ is produced either by controlling the water addition rate directly to the catholyte or by recirculating caustic to which water has been added. To produce $50 \%$ caustic soda, the caustic solution coming out of the cell needs to be concentrated by evaporation. Caustic soda solution obtained by the ion exchange membrane process contains few impurities, owing to the selective permeability of the ion exchange membrame, and the chloride content in it is as low as that from the mercury process. Since the catholyte is a strong caustic, however, there is some inevitable back-migration of hydroxide ions into the anolyte, which results in a loss of current efficiency. 


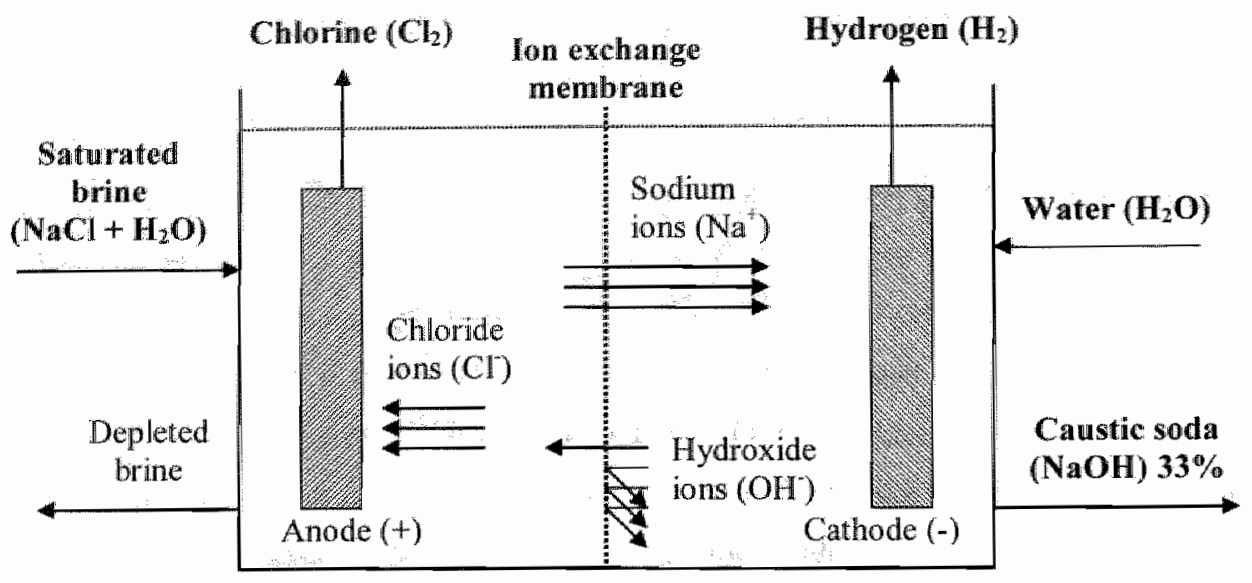

Electrolytic cell

\section{Figure 4-2 Ion Exchange Membrane Electrolyzer}

Based on Curlin, Bommaraju, and Hanssan (1991).

As you can see in examining the chemical reactions involved in the ion exchange membrane process, the process's most important advantages is that it poses no serious environmental problems. In contrast to the mercury process, there are no chemical reactions involving mercury $(\mathrm{Hg})$ within the production process (see Figure 3-3 and Figure 3-4). Hence the ion exchange membrane process avoids the serious environmental concern regarding the mercury process while achieving the same level of high purity of caustic produced by the mercury process. Without any pollutant included in the manufacturing process from the very outset, the ion exchange membrane process is a prime example of the clean technology as defined in Chapter 2. This is in sharp contrast to the end-of-pipe technology, which is aimed at reducing emissions of pollutant, mercury for example, at the end of the production process facilities.

As you would expect, the component which is critical to the well functioning of the ion exchange membrane process is the ion exchange membrane. While the ion exchange membrane determines the electrolytic cell performance, including the current efficiency and cell voltage, and hence energy consumption, it also needs to have a sufficient strength to withstand exposition to chlorine on one side and strong caustic on the other in the electrolytic cell. Although the idea of the ion exchange membrane process for the production of chlorine 
and caustic soda had been known for many years, earlier work falled as a resull of non. availabillity of suitable ion exchange membranes which could resist the very demanding conditions within the chlor-alkah cell. A significant amount of research and development efforts had been devoted to invent the ion exchange membranes sutuble for the production of chlorine and caustic soda.

Basically, ion exchange means the exchange of ions of the same charge between a solution, which is normally aqueous, and a solid in contact with it (Dorfiner, 1990). The process occurs widely in nature, particularly in the absorption and retention of water-soluble fertilizers by soils. For example, when a potassium salt is dissolved in water and applied to soil, potassium ions $\left(\mathrm{K}^{4}\right)$ are absorbed by the soil and sodium ions $\left(\mathrm{Na}^{+}\right)$and calcium ions $\left(\mathrm{Ca}^{2+}\right)$ are released from it. In this case, the soil is acting as an ion exchanger. Synthetic ion exchange resins consist of various copolymers with a cross-linked three dimensional structure to which ionic groups have been attached. An anionic resin has negative ions built into its structure and hence exchanges positive ions whereas a cationic resin has positive ions built in and exchanges negative ions. The ion exchange membrane is an ion exchange body in membrane form and thus provides special functional characteristics which cannot be obtained with ion exchange resins.

A report on ion exchange resins was published for the first time in 1935 by researchers in the United Kingdom, and the first industrial production of ion exclaange resins stared in 1938 at the Wolten plant of IG Farben in Germany (Shimizu, 1992). In the United States, Resinous Products and Chemical started its industrial production of ion exchange resins in 1940. Some experimental work on ion exchange membranes was done in the 1930s and 1940s, but it was not yet possible to obtain ion exchange membranes to be applicable for industrial purposes. In 1950, Juda and McRae reported the first successful development of ion exchange membranes which had electrical resistance combined with adequate mechanicall strength for use on the industrial scale (Juda and McRae, 1950). With this report of the fabrication of membranes from ion exchange bodies of synthetic resin, a period of technological progress of ion exchange membranes started in the United States, Western Europe, and Japan. Research efforts were devoted for the development and utilization of ion exchange membranes composed of hydrocarbon polymers and their use for electrodiallysis, a method of separating water containing a salt into pure water and more concentrated solution.

In the United States and Western Europe, research activities were directed toward water desalination. The companies and organizations which sought for the production and 
utilization of ion exchange membranes for that purpose included Ionics in the U.S., Permutit in the U.K, and T.N.O., the Dutch Organization for Applied Scientific Research (Kawate, Tsuzura, and Shimizu, 1990). The Kennedy administration of the U.S. lent its support to water conversion projects in its space programs, and research and development activities were pursued vigorously with financial assistance from the Office of Saline Water. Since electrodiallysis inherently involves concentration, the problem of scale formation also impeded progress at early stages in water desalination applications. This problem was solved later by a technology developed by lonics, leading to the widespread use of ion exchange membranes for water desalination. American Machine and Foundry and General Electric also manufactured ion exchange membranes in the early 1960 s, when they were cooperating with the National Aeronautic and Space Agency (NASA) for developing fuel cells with ion exchange membranes as barriers (McRae, 1974).

The possibility of using the ion exchange membrane for chlor-alkali production had been considered since a relatively early stage in the history of its development. A number of companies, such as Hooker cooperating with Rohm and Haas, and Ionics with Diamond Alkali, worked for developing the ion exchange membrane process for the chlor-alkali production in the 1950s and 1960s (Currey and Ahern. 1974). Technologies developed in these periods, however, were never put into commercial use, primarily because the available ion exchange membranes, which were mostly based on hydrocarbons, did not have either sufficient chemical stability or economic viability. Since the chemical structure of the plastic materials was not inert to chlorine, hypochlorite, and caustic, the ion exchange membrane was eroded or corroded after a relatively short period of use (see Figure 4-2). Its degradation proceeded to the extent that it had to be replaced with a new one. The second problem was the performance of the ion exchange membrane. While the ion exchange membrane was the key to the cell's performance with regard to voltage and current efficiency, good voltages could be achieved only at the expense of low current efticiencies and visa versa. The marginal cell power performance coupled with the membrane replacement problem was never fully resolved initially, discouraging chlor-alkali producers to make further development efforts on the ion exchange membrane process until the 1970s.

These long-standing problems started to be solved by the advent of the perfluorinated ion exchange membrane, Nafion. Prior to the development of Nafion by Du Pont, the Plastic Development Group of the company had already discovered Teflon, a form of tetrafluoroethylene (TFE) polymer (Edwards, 1979). Looking for uses of this material, the 
group started to do research on a new type of monomer with which to co-polymerize TFE and succeeded in establishing a general method for synthesizing perfluorovinylether. The com polymerization of TFE and perfluorovinylether produced $X R$ resins, a precursor to other useful types of polymer invented later. Then, the Nafion membrane was invented at the company's experimental station in 1962 (Grot, 1986). This membrane possessed the heat and chemical resistance necessary for use in such a harsh environment as in chlor-alkali electrolyzers and, with functional groups of sulfonic acid, also provided low electric resistance, although it exhibited low current efficiency. It was actually demonstrated in 1964 that these perfluorinated polymers in a film form could be used as a separator in chlor-alkali cells (Brooks, 1988). Together with early applications of them for fuel cells, that led to a broader recognition of the potential for these materials within the chlor-alkali industry.

Nevertheless, substantial technological progress had to be made in the following years in order to achieve commercial applications of the membrane. While the perfluorinated films had the desirable electrical and chemical properties, it was necessary to supplement the physical properties with appropriate mechanical strength and handling characteristics to be used in commercial chlor-alkali electrolytic cells. And, as the ion rejection properties of the membranes had resulted in current efficiencies less than $90 \%$, one of the most difficult problems to be solved was how to prevent the diffusion of hydroxyl ions $(\mathrm{OH})$ at a high concentration of caustic soda (see Figure 4-2). On this aspect, several Japanese companies later succeeded in making innovations and removed the obstacles along the way toward the industrial application of the ion exchange membrane for use in chlor-alkali production. In the subsequent sections, we will examine in detail how the Japanese companies conducted their innovative activities for the development of the ion exchange membrane process in the chloralkali industry.

\subsubsection{Patents on Technologies for Chlor-Alkali Production}

To investigate the extent of innovative activities conducted by the Japanese firms, we analyzed data on patent applications on the ion exchange membrane process, along with those on the mercury process and the diaphragm process. Figure 4-3 shows the trends in successful applications for Japanese patents by Japanese firms from the late 1960 s to the late 1980s. (Detailed data are given in Table 4-23 in Appendix at the end of this chapter). Patent data on technologies related to the mercury process were obtained from the data assembled by the industry association (Japan Soda Industry Association, 1982). The data covers patents granted 
up to the end of the $1970 \mathrm{~s}$. Patents on technologies related to the diaphragm process and the ion exchange membrane proeess were selected by using the data set constructed by the industry association and shared by its member companies (Japan Soda Industry Association, $1976,1977,1978 \mathrm{a}, 1978 \mathrm{~b}, 1979 \mathrm{~b}, 1991 \mathrm{a}, 1991 \mathrm{~b}, 1992 \mathrm{a}, 1992 \mathrm{~b})$. The data set contains both granted patents and unexamined patent applications which were published in the period until 1988.

We picked up only patent applications which were successfully granted, and those selected patents are classified into three processes, that is, the mercury process, the diaphragm process, and the ion exchange membrane process. They are arranged by the year of application, rather than by the year of publication. As it normally takes 18 months before patent applications are published, that is expected to make it possible for us to examine when innovations were actually made. In the case of patents on the mercury process, information on the date of patent application is not included in the data. As it took at least two years for patents to be granted after their application, we here assumed a two-year lag between patent application and granting. 


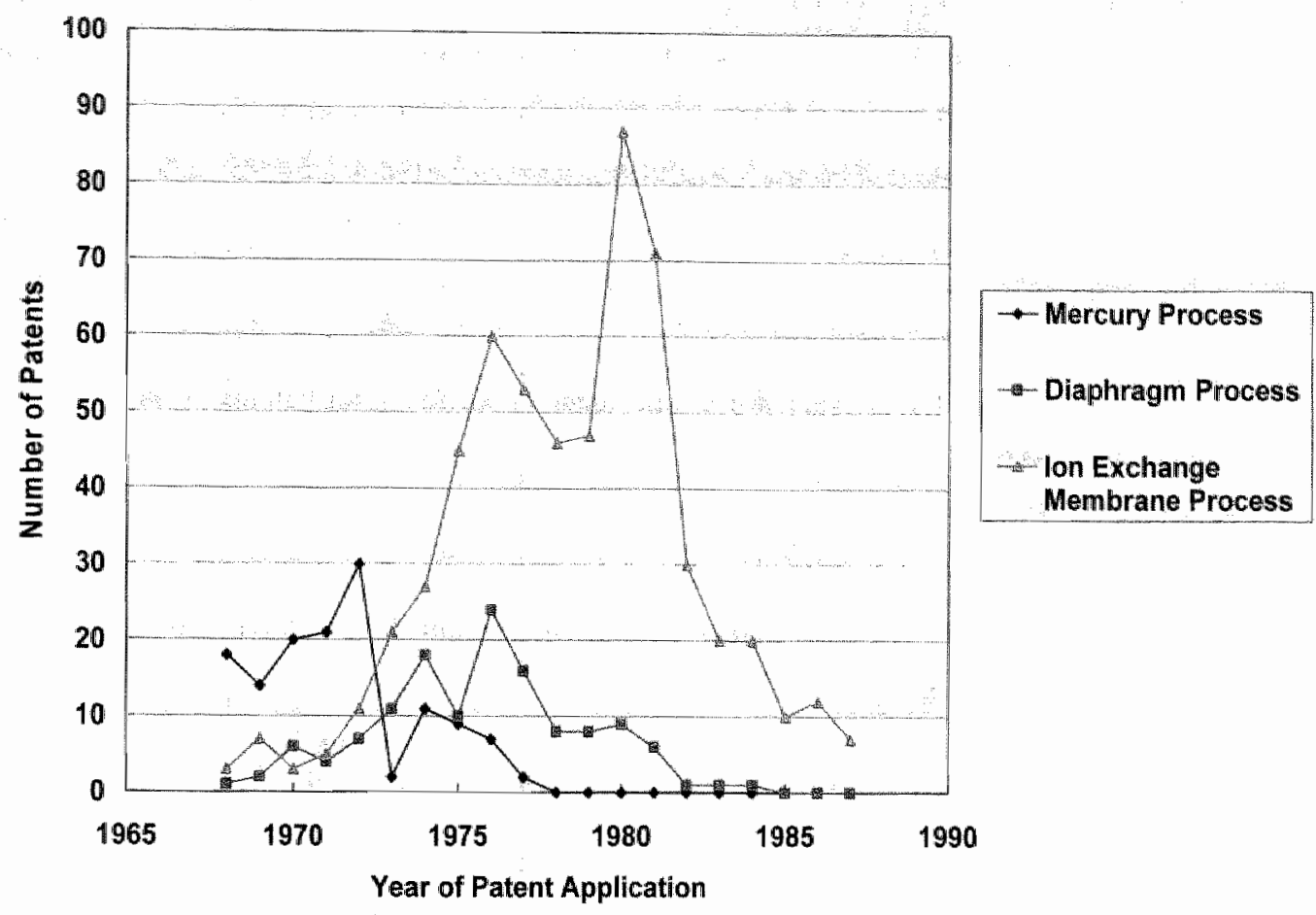

Figure 4-3 Japanese Patents Sncessfully Applied for by Japan Companies on the Mercury, Diaphragm, and Ion Exchange Membrane Processes

As you can see in Figure 4-3, most of the patents granted in the late 1960s were related to the mercury process. The number of successful patents on the mercury process rose at the begimning of the 1970 s, as the general public's concern on mercury pollution increased. It then decreased subsequently, coinciding with the government decision that the mercury-based plants in the Japanese chlor-alkali industry were to be phased out rather immediately. On the other hand, patents successfully applied on technologies related to the diaphragm process were few in the later 1960 s and the early 1970s. They increased to some extent in the middle of the 1970s, as patent applications on the mercury process declined. Then, successful patent applications on the diaphragm process started to drop in the late 1970s, and it had almost stopped by the middle of the $1980 \mathrm{~s}$.

Regarding the ion exchange membrane process, although several patent applications were already seen in the late 1960s, most of the patents granted were on ion exchange 
membranes based on hydrocarbon polymers (e.g. Japanese Patent Publication No. 47-40860, $\mathrm{No}_{*} 49-28351$ ). As salt had been traditionally produced at salt fields by using the solar power, this type of ion exchange membranes was developed for the purpose of replacing solar evaporation as the method of producing salt from sea water. Hydrocarbon-based ion exchange membranes, however, could not maintain its chemical stability in a strong alkalline enwironment, and the application of jon exchange membranes for use in chlor-alkali electrolytic cells had been very limited. In the early 1970s, at the time of the government's decision to phase out the mercury process in Japan, applications for patents on ion exchange membranes started to rise rapidly. After a patent application was filed on a new type of ion exchange membranes based on fluorocarbon polymers (Japanese Patent Publication No. 5213228), on which there had been only one patent application before (Japanese Patent Publication No. 36-20742), other patent applications continued for this type of ion exchange membrames (Japanese Patent Publication No. 57-3699, No. 54-20960). Then successful patent applications on the ion exchange membrane process increased rapidly in the middle of the 1970 s and remained large in the 1980 s, while there were few patent applications of the mercury process and the diaphragm process in the 1980s.

In Section 3.3, we identified the Japanese firms which were innovative on the mercury process, namely, Mitsui Engineering and Shipbuilding (MES) ${ }^{63}$, Osaka Soda, Kureha Chemical Industry, Asahi Glass, Toyo Soda, Toktuyama Soda, and Asahi Chemical Industry, and those companies which were innovative on the diaphragm process, namely, Nippon Soda, Tsurumi Soda, and Showa Denko (see Table 3-8, Table 3-9, and Table 3-18). We examine how these companies, which had strong expertise on the technologies for chlor-alkali production in the past, pursued their innovative activities on the production processes without the use of mercury, when they faced the government"s decision to abolish the mercury process in the early $1970 \mathrm{~s}$.

We first look at the patenting activities of these companies for clean technologies for chlor-alkali production, that is, the diaphragm process and the ion exchange membrane process. Table 4-9 and Table 4-10 show the trends on Japanese patents successfully applied by these innovative companies, that is, Asahi Chemical Industry, Asahi Glass, Tokuyama

\footnotetext{
B.3 Misui Engine ering and Shiphilding established an engineering company. Chlorine Engineers Corp. (CEC). with Mitsui in 1973 (Chlone Engineers Corp., 1998). Since then, the new company has provided technologies and rebated services for the replacement of chlor-aikali plants based on the mercury process.
} 
Soda, and CEC, on techologies related to the diaphragn process and those related to the lon exchange membrane process, respectively.

Table 4-9 Japanese Patents Successfully Applied by Japanese Companies on the Diaphragm Process and the Ion Exchange Membrane Process (I)

\begin{tabular}{|c|c|c|c|c|c|c|c|c|}
\hline \multirow{2}{*}{ Year $^{\text {㳯 }}$} & \multicolumn{2}{|c|}{ Asahi Chemical } & \multicolumn{2}{|c|}{ Asahi Glass } & \multicolumn{2}{|c|}{ Tokuyama Soda } & \multicolumn{2}{|c|}{$\mathrm{CEC}^{\circ}$} \\
\hline & $D$ & $\mathrm{IM}$ & $\mathrm{D}$ & IM & $\mathrm{D}$ & $\mathrm{IM}$ & $\mathrm{D}$ & $\mathrm{IM}$ \\
\hline 1968 & 0 & 0 & 0 & 1 & 0 & 0 & 0 & 0 \\
\hline 1969 & 0 & 3 & 0 & 1 & 0 & 3 & 0 & 0 \\
\hline 1970 & 1 & 2 & 0 & 1 & 1 & 0 & 0 & 0 \\
\hline 1971 & 0 & 0 & 0 & 0 & 0 & 2 & 0 & 0 \\
\hline 1972 & 4 & 0 & 0 & 0 & 1 & 8 & 0 & 0 \\
\hline 1973 & 0 & 2 & 0 & 0 & 3 & 13 & 0 & 0 \\
\hline 1974 & 1 & 8 & 0 & 1 & 2 & 4 & 0 & 0 \\
\hline 1975 & 1 & 5 & 2 & 13 & 1 & 14 & 1 & 0 \\
\hline 1976 & 1 & 6 & 3 & 12 & 8 & 20 & 0 & 9 \\
\hline 1977 & 2 & 6 & 2 & 10 & 2 & 23 & 2 & 6 \\
\hline 1978 & 0 & 6 & 2 & 6 & 1 & 20 & 2 & 6 \\
\hline 1979 & 0 & 10 & 0 & 15 & 0 & 7 & 3 & 9 \\
\hline 1980 & 0 & 15 & 3 & 51 & 1 & 2 & 0 & 11 \\
\hline 1981 & 1 & 2 & 0 & 30 & 0 & 17 & 1 & 13 \\
\hline 1982 & 0 & 1 & 0 & 4 & 0 & 5 & 0 & 9 \\
\hline 1983 & 0 & 1 & 0 & 2 & 0 & 1 & 0 & 18 \\
\hline 1984 & 0 & 0 & 0 & 7 & 0 & 3 & 1 & 4 \\
\hline 1985 & 0 & 1 & 0 & 4 & 0 & 1 & 0 & 1 \\
\hline 1986 & 0 & 0 & 0 & 6 & 0 & 5 & 0 & 1 \\
\hline 1987 & 0 & 2 & 0 & 5 & 0 & 0 & 0 & 0 \\
\hline Total & 88 & 560 & 96 & 1352 & 160 & 1184 & 0 & 0 \\
\hline
\end{tabular}

a: Year of patent applications.

b: Data of CEC includes that of Toyo Soda.

Table 4-10 Japanese Patents Successfully Applied by Japanese Companies on the Diaphragm Process and the Ion Exchange Membrane Process (II)

\begin{tabular}{|c|c|c|c|c|c|c|c|c|c|c|}
\hline Year $^{\text {Th }}$ & \multicolumn{2}{|c|}{$\begin{array}{c}\text { Kureha } \\
\text { Chemical }\end{array}$} & \multicolumn{2}{c|}{ Osaka Soda } & \multicolumn{2}{c|}{$\begin{array}{c}\text { Nippon } \\
\text { Soda }\end{array}$} & \multicolumn{2}{c|}{$\begin{array}{c}\text { Tsurumi } \\
\text { Soda }\end{array}$} & \multicolumn{2}{|c|}{$\begin{array}{c}\text { Showa } \\
\text { Denko }\end{array}$} \\
\cline { 2 - 11 } & $\mathrm{D}$ & $\mathrm{IM}$ & $\mathrm{D}$ & $\mathrm{IM}$ & $\mathrm{D}$ & $\mathrm{IM}$ & $\mathrm{D}$ & $\mathrm{IM}$ & $\mathrm{D}$ & IM \\
\hline 1968 & 0 & 0 & 0 & 0 & 0 & 0 & 0 & 0 & 1 & 0 \\
\hline 1969 & 0 & 0 & 0 & 0 & 0 & 0 & 0 & 0 & 0 & 0 \\
\hline 1970 & 0 & 0 & 0 & 0 & 2 & 0 & 0 & 0 & 1 & 0 \\
\hline 1971 & 0 & 0 & 0 & 0 & 1 & 0 & 0 & 0 & 1 & 0 \\
\hline 1972 & 1 & 0 & 0 & 0 & 1 & 0 & 0 & 0 & 0 & 0 \\
\hline 1973 & 2 & 0 & 2 & 0 & 2 & 0 & 0 & 0 & 0 & 0 \\
\hline 1974 & 8 & 7 & 2 & 0 & 0 & 0 & 1 & 0 & 0 & 0 \\
\hline
\end{tabular}




\begin{tabular}{|c|c|c|c|c|c|c|c|c|c|c|}
\hline 1975 & 3 & 9 & 1 & 2 & 1 & 0 & 0 & 0 & 0 & 0 \\
\hline 1976 & 1 & 0 & 0 & 0 & 1 & 0 & 0 & 0 & 0 & 1 \\
\hline 1977 & 1 & 1 & 2 & 2 & 1 & 0 & 0 & 0 & 1 & 0 \\
\hline 1978 & 0 & 3 & 0 & 0 & 0 & 0 & 0 & 0 & 2 & 0 \\
\hline 1979 & 0 & 0 & 1 & 0 & 1 & 0 & 0 & 0 & 1 & 0 \\
\hline 1980 & 0 & 0 & 2 & 0 & 0 & 0 & 0 & 0 & 0 & 4 \\
\hline 1981 & 0 & 0 & 1 & 0 & 0 & 0 & 0 & 0 & 1 & 2 \\
\hline 1982 & 0 & 0 & 1 & 0 & 0 & 0 & 0 & 0 & 0 & 0 \\
\hline 1983 & 0 & 0 & 0 & 1 & 0 & 0 & 0 & 0 & 0 & 0 \\
\hline 1984 & 0 & 0 & 0 & 0 & 0 & 0 & 0 & 0 & 0 & 3 \\
\hline 1985 & 0 & 0 & 0 & 1 & 0 & 0 & 0 & 0 & 0 & 1 \\
\hline 1986 & 0 & 0 & 0 & 0 & 0 & 0 & 0 & 0 & 0 & 0 \\
\hline 1987 & 0 & 0 & 0 & 0 & 0 & 0 & 0 & 0 & 0 & 0 \\
\hline Total & 0 & 0 & 0 & 0 & 0 & 0 & 2 & 0 & 12 & 12 \\
\hline
\end{tabular}

a: Year of patent applications.

These tables suggest that Asahi Chemical Industry, Asahi Glass, and Tokuyama Soda had been doing research on technologies related to ion exchange membranes since the late 1960 s, althongh the level of successful patent applications was low. Detailed analysis of the patent data shows that these ion exchange membranes mostly belonged to the hydrocarbon type, which was basically intended for use in the salt production process. Then, in the early 1970s, the three companies started to be actively engaged in applying much more for patents on the ion exchange membrane process for chlor-alkali production. A little later, Chemical Engineers Corp. (CEC), cooperating with Toyo Soda, followed them in the middle of the 1970s. These intensive R\&D activities later led to their success in developing their own technologies for the ion exchange membrane process and subsequently provided these technologies to other chlor-alkali producers.

On the other hand, Kureha Chemical Industry and Osaka Soda, which had also been innovative companies on the mercury process in the past, did not have any successful patent applications on the ion exchange membrane process until the beginning of the 1970s. While they were granted patents for their technologies related to the diaphragm process in the $1970 \mathrm{~s}$, their successful patent applications for the ion exchange membrane process technologies remained relatively few in the 1970s and the 1980s, compared with Asahi Chemical Industry, Asahi Glass, and Tokuyama Soda. Similarly, the three companies which had previously developed their own technologies for the diaphragm process, namely, Nippon Soda, Showa Denko, and Tsurumi Soda, successfully applied for patents on the diaplaragm process in the 
1970s. Their patent applications on the ion exchange membrane process, however, were few, and were not comparable to those made by Asahi Chemical Industry, Asali Glass, or Tokuyama Soda:

\subsubsection{Technological Developments of the Ion Exchange Membrane Process by Innovative Companies in Japan}

As we have seen in the preceding section, Asahi Chemical Industry, Asahi Glass, Tokuyama Soda, and CEC were actively engaged in R\&D activities on the ion exchange membrane process. In the present section, we examine in detail how these companies conducted R\&D activities for chlor-alkali production and subsequently succeeded in developing their own technologies for the ion exchange membrane process.

\section{Asahi Chemical Industry}

Among the Japanese firms which were innovative on chlor-alkali production technologies, Asahi Chemical Industry ${ }^{64}$ was the first to reach the industrial stage of the ion exchange membrane process. Since 1950 , the company had already working on an R\&D progran on ion exchange membranes based on hydrocarbon to be used for various types of separating operation in chemical processes. In 1961, after ten years of R\&D activities on ion exchange membranes, the first plant started to operate at Kawasaki for the manufacture of its ion exchange membranes, Aciplex. At the same time, the company began the commercial production of salt by ellectrodialysis with these membranes at Onahama. The plant, with a capacity of 50,000 tonnes per year, which was expanded later to 190,000 tonnes per year, represented the first commercial application of ion exchange membranes in the world. This eventually led to increasing the range of applications of ion exchange membranes in other industrial areas, including the desalination of brine by electrodialysis and the electroreduction of uranium. In 1971 Asahi Chemical succeeded in commercializing the synthesis of adiponitrile, an intermediate to nylon 6/6, at the Nobeoka plant $(25,000$ tonnes/year) through the electrolytic dimerization of acrylonitrile by using ion exchange membranes. The electrolytic cells adopted in this process turned out later to be the prototype of electrolyzers

\footnotetext{
at This section is based on the information obtained through the author"s interview with Mr. Hiloshi Oh-hama, Mr. Masao Hamada, and Mr. Mitsuo Yoshida of Asahi Chemical Indusiry (Ohmanana, Mamada, and Yoshida, 1998).
} 
for the chlor-alkali production: This development helped the company to recognize the ion exchange membrane as a promising technology in the future.

These previous experiences of working on ion exchange membranes have functioned as the basis for the subseguent technological development of the ion exchange membrane process for chlor-alkali production. In 1967 Asahi Chemical started R\&D activities on the ion exchange membrane process of brine electrolysis for chlor-alkali production, with bencliscale facilities constructed at the Nobeoka site. Engineers found that the knowledge and expertige gained through developing other electrochemical processes in the past, including the manufacture of salt, adiponitrile, and other materials, were often useful in dealing with practical problems in this development work. Although initial research efforts were directed toward the development of a three-compartment method using hydrocarbon-based ion exchange membranes, they were later concentrated on the development of a two-compartment method using ion exchange membranes of the perfluorosulfonic acid type.

In May 1973 a pilot plant started to operate at an annual capacity of 4,000 tonnes, utilizing Nafion membranes, the only type of ion exchange membranes based on perfluorosulfonic acid which were available for large-scale applications at that time. The operation of the plant generated some data, which suggested that, as a production process for high-quality caustic soda, chlorine and hydrogen, the ion exchange membrane process would surpass the diaphragm process and become comparable to the mercury process. Intensive discussions within the company were followed by the formation of a large organization, together with a basic strategy for the ion exchange membrane technology. It was almost at the same time that the newspapers reported the case of the third Minanata disease, leading to the government's decision to phase out all the mercury processes used for the chlor-alkali production.

The company's chlor-alkali plant in Nobeoka was originally built in 1933 to supply caustic soda and chlorine for the manufacturing of other products, notably, rayon at the production site. The plant was based on the mercury process, and its production capacity had grown to approximately 100,000 tons of caustic sodla per year by the time that the official process conversion program was mandated. Initially, it was planned that the mercury plant would be converted to the diaphragm process with separators made of asbestos. However, since the diaphragm process was found to produce caustic soda which contained various impurities, including, among others, $1 \%$ of salt, it was not an appropriate process for providing caustic soda to be used in the production of rayon, which was one of the company's 
main products at that time. The necessity of high-quality caustic soda required a change in the original conversion plan, and in 1974 the company made a decision to adopt the ion exchange membrane process for the plant, although that technology was still in its infancy and was not yet established for industrial applications. With this decision, Asahi Chemical was exenpted from the mandate for immediate conversion of the mercury process to the diaphragm process and was allowed some time for technological development of the ion exchange membrane process.

At that time, the perfluorosulfonic acid membrane Nafion, which was developed in the 19605 , was the only type of ion exchange membranes applicable to the chlor-alkali cell because it did not contain any $\mathrm{C}-\mathrm{H}$ bond. However, ion exchange membranes having sulfonic acid exchange groups did not have high current efficiency in strong concentrations of caustic soda due to the counter migration of $\mathrm{OH}^{*}$ ions from catholyte to anolyte. By the time when the decision was made to convert the mencury plant, the company, with the idea that a higher current efficiency could be achieved if the ion exchange membrane contains perfluorocarboxylic acid functional groups, had initiated R\&D on this type of ion exchange membranes.

In 1975, with an anmual production capacity of 40,000 tonnes, a new plant with the use of ion exchange membranes came on stream at the Nobeoka site. It was the first commercial.. scale plant relying on the ion exchange membrane process in the world. Since the performance of the company's own ion exchange nembranes was not yet sufficient for industrial applications, the Nafion membranes were adopted for the plant at the beginning. The electric power consumption of the new process was $3,520 \mathrm{kWh} / \mathrm{t} \mathrm{NaOH}$, whereas that of the mercury process was approximately $3,200 \mathrm{kWh} / \mathrm{t} \mathrm{NaOH}$. In addition, since the concentration of the caustic soda was low, steam was necessary to increase it to the commercial level of $50 \%$, raising the total energy consumption to $3,925 \mathrm{kWh} / \mathrm{NaOH}$. This relatively low performance, coupled with the low current efficiency of $80 \%$, prompted the company to focus its research efforts to improve the quality of ion exchange membranes.

A result of the intensive $R \& D$ was the invention of ion exchange membranes based on perfluorocarboxylic acid. The production of this type of ion exchange membranes was raade possible by chemically modifying one side of sulfonic acid membranes to obtain a region of carboxylic acid groups. Contributing to achieving a higher current efficiency of more than $95 \%$ without increasing the electrical resistance, this development proved to be one of the technological breakthroughs in establishing the ion exchange membrane process as an 
industrially viable technology for chlor-alkali production. The Nafion membranes based on perfluorosulfonic acid which were adopted at the beginning of the plant operation were all replaced by the newly developed membranes in 1976. As a result, the electric power consumption was reduced to $2,700 \mathrm{kWh} / \mathrm{NaOH}$. The initial production capacity of the Nobeoka plant was doubled to 80,000 tons in August 1977 and was further increased to 120,000 tons in March 1982 , when the last of the mercury electrolyzers was shut down at the Nobeoka site.

Table 4-11 gives the chronology of technological developments related to the ion exchange membrane process at Asahi Chemical Industry.

Table 4-11 Chronology of Technological Developments Related to the Ion Exchange Membrane Process at Asahi Chemical Industry

\begin{tabular}{|c|l|}
\hline Year & \multicolumn{1}{|c|}{ Technologicall Development } \\
\hline 1967 & $\begin{array}{l}\text { Start of R\&D on the ion exchange membrane process of brine electrolysis for chlor- } \\
\text { alkali production with bench-Scale facilities }\end{array}$ \\
\hline 1973 & $\begin{array}{l}\text { Pilot plant for brine electrolysis with Nafion membranes based on fuorosulfonic } \\
\text { acid }\end{array}$ \\
\hline 1975 & $\begin{array}{l}\text { Decision to convert the mercury process at the Nobeoka site to the ion exchange } \\
\text { membrane process } \\
\text { Start of R\&D on ion exchange membranes based on fluorocarbonic acid }\end{array}$ \\
\hline 1976 & $\begin{array}{l}\text { Bench-scale facilities for the production of ion exchange membranes based on } \\
\text { fluorocarbonic acid }\end{array}$ \\
\hline 1977 & $\begin{array}{l}\text { First license of Asani Chemical's ion exchange membrane process to an outside firm } \\
\text { Expansion of the ion exchange membrane process at the Nobeoka site }\end{array}$ \\
\hline 1982 & $\begin{array}{l}\text { Expansion of the ion exchange membrane process at the Nobeoka site, eliminating } \\
\text { the mercury process }\end{array}$ \\
\hline
\end{tabular}

Innovative efforts were conducted intensively for the development of the ion exchange membrane process. Figure $4-4$ gives the trends in the R\&D expenditures and personnel which Asthi Chemical Industry devoted for innovation on the ion exchange membrane process. The absolute figures of the expenditures as well as personnel in 1975 are normalized to 100 . 


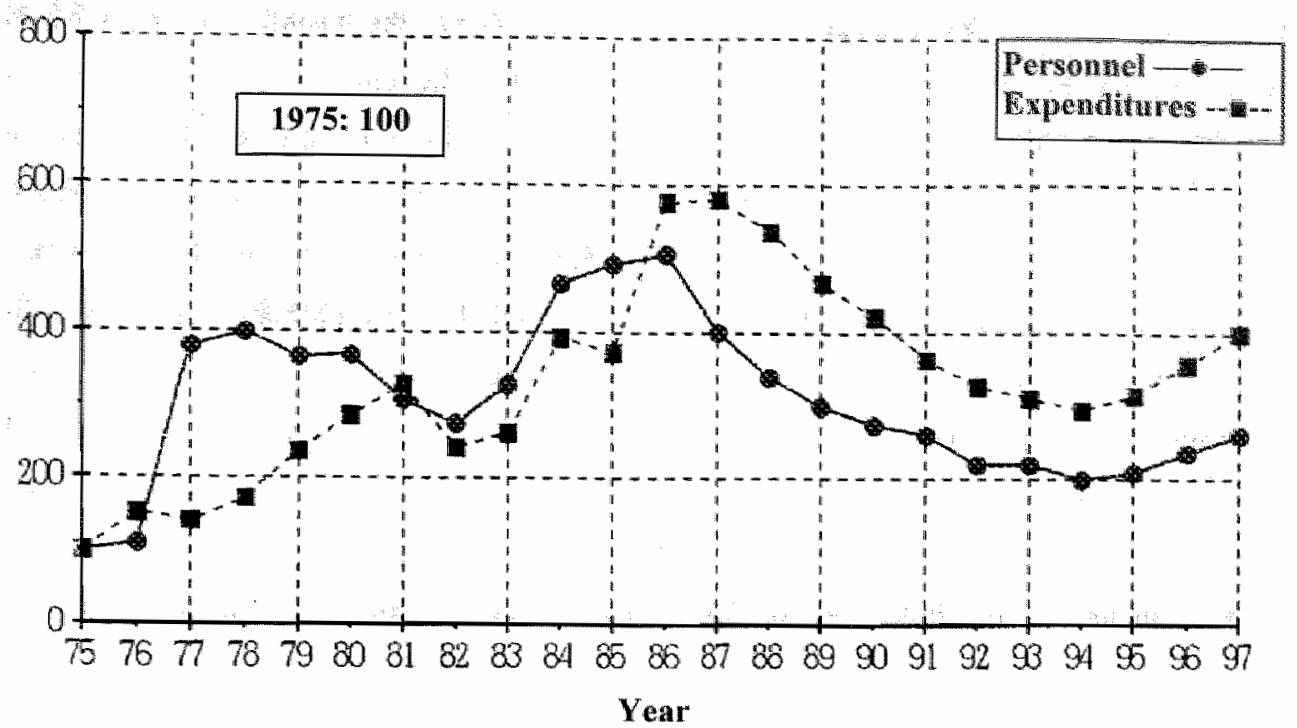

Figure 4-4 R\&D Expenditures and Personnel for the Ion Exchange Membrane Process at Asahi Chemical Industry

Source: Asahi Chemical Industry.

In the period from 1973 to 1997 , R\&D expenditures amounted to 13 billion yen at the ion exchange membrane process division and to three billion yen at the headquarters, with roughly one half spent on personnel and the other half on actual research activities. During this period the anmual R\&D expenditures fluctuated between 400 million yen and one billion yen. In the first five years three billion yen was spent on R\&D by the corporate headquarters. As the headquarters is normally responsible for conducting R\&D projects whose outcomes are perceived to be highly uncertain, that suggests that the development of the ion exchange membrane process for chlor-alkali production was regarded by the company as a risky project. Following the initial period in which R\&D activities were conducted at the corporate as well as the division levels in parallel, the main responsibility for the project was shifted to the ion exchange membrane process division. The number of the personnel involved in this lechnological development varied from the minimum of 50 to the maximum of 250 . The R\&D expenditures and personnel, with small declines at the beginning of the 1980 s, continued to increase until the middle of the 1980s, when the government's process conversion program was completed, and then decreased steadily. Recently they have started to rise again, as the company, having finished providing its ion exchange membrane process technology to other 
chlor-alkal producers based in lapan, is now trying to increase the business of supplying its technology to chlor-alkali producers in other parts of the world.

The effects of the rapid increase in R\&D activities in the middle of the 1970 s can be seen in some measures of innovation outputs. Table $4-9$ shows the trends in successful patent applications by Asahi Chemical Industry on technologies related to the ion exchange membrane process. A small number of patents were applied on ion exchange membranes in the late $1960 \mathrm{~s}$, as the company was engaged in producing as well as using ion exchange membranes for salt production. These membranes were based on hydrocarbons, however, and were not suitable for use in chlor-alkali production. In the early 1970s, immediately after the government's decision on the phase out of the mercury process, patent applications on the ion exchange membrane process began to pick up quickly. They had a peak at the beginning of the $1980 \mathrm{~s}$ and were then followed by a rather rapid decrease. In this period, there were several patents granted on technologies which were crucial for the successful application of the ion exchange membrane process for chlor-alkali production. Among notable examples were the invention of a bumpy surface on the ion exchange membrane and the invention of carbonate membranes with three layers.

Having developed its technology for the ion exchange membrane process and used it at its own chlor-alkali production plant, Asahi Chemical Industry started to supply it to outside companies. Chlor-alkali plants to which Asahi Chemical Industry provided its technology for the ion exchange membrane process are listed in Table 4-27 in the appendix to the present chapter. Encouraged by the government's decision on the phase-out of the mercury process in Japan in 1973, the company's ion exchange membrane process was adopted by other chloralkali producers in Japan. The first process which was installed in plants outside the company was for Denki Kagaku Kogyo at Ohme, Tokyo, for a 60,000 tonne/year plant which started operation in 1976. At that time the potential performance of the ion exchange membrane process was not yet fully realized. While the Nafion ion exchange membranes were initially adopted for the plant, they were subsequently replaced with the ion exchange membranes developed by Asahi Chemical Industry in 1978. The completion and startup of a chlor-alkali plant in 1982 at Akzo Zout Chemie (currently Akzo Nobel) in the Netherlands was based on the technology provided by Asahi Chemical and was the first large-scale ion exchange membrane process adopted in Western Europe. The total capacity of the chlor-alkali plants based on the ion exchange membrane technology of Asah Chemical Industry is currently about 4.8 million tomnes out of about 16.7 million tonnes all over the world. The company is 
also supplying its ion exchange membranes to other companies and has so far provided about 6 million tonnes of them in the world:

\section{Asahi Glass}

Asahi Glass ${ }^{65}$ was established in 1907 as the first company to begin the production of sheet glass in Japan. The chemical division started operations in 1917 with the production of soda ash, which was used for its own manufacturing of sheet glass. Subsequently, the company expanded its business activities to include various alkalis and chlorine derivatives. In 1963 the company moved into the field of fluorine chemistry with the production of chlorofluoromethane refrigerants, solvents, and urethane-forming agents. This was followed by the introduction of a series of new products, including an ethylene-TFE copolymer and a fluorinated rubber.

In the meantime, the company started R\&D activities in 1952 on ion exchange membranes for desalination and concentration of sea water as well as on electrodialytic cell technology. In 1960 Asahi Glass began to produce its ion exchange membrane, Selemion, at the industrial level for the first time in Japan, and subsequently the company's plant for salt production utilizing ion exchange membrames started to operate. In 1964 the company started to produce chlorine and caustic soda by brine electrolysis, changed from the traditional chemical processes. Hence the company had technical experiences on fluorine chemistry and sea water dialysis with ion exchange membranes and chlor-alkali production, prior to developing its own technology for the ion exchange membrane process of brine electrolysis.

In May 1973, amid the widespread public concern over mencury pollution triggered by the newspaper articles, the company started to conduct R\&D activities aimed at developing a new process using ion exchange membranes for the chlor-alkali production. A project team was established at the central research center, along with the chemical division and its R\&D department. The deadline of September 1975 , which was initially set by the government for the conversion of the mercury process, however, allowed too short a time for sufficient technological development of the ion exchange membrane process for industrial applications, and consequently Asahi Glass introduced the diaphragm process from Diamond Shamrock to its Kitakyushu plant in 1974 and from PPG to its Kashima plant in 1975 (see Table 4-4).

\footnotetext{
* This section is based on the information obtained through the author's interview with Mr. Kimihiko Sato of Asahi Glass (Sato, 1998). The company has no organzational or financial relationship with Asahi Chemical Industry. Asahi llterally means the rising sun and is used for many corporate names in Japan.
} 
Then, 1975, the company succeeded in developing the perfluorocarboxylate membrane, flemion, which made it possible to produce strong caustic solution with lhigh current efficiency. A pilot plant with a production capacity of 155 tonnes of caustic soda per month started to operate at its Kansai plant in Osaka with the newly developed ion exchange membranes. During the following two years, intensive R\&D efforts were continued to improve the themion membranes. The introduction of a carboxylic acid grouping to the sidechains gave a high current efficiency, but with a relatively poor voltage, and was attacked by the anolyte-side conditions. A technologieal compromise was that a laminated membrane was produced with a thick layer of a sulfonic acid strueture on the anolyte side to give low voltage and physical integrity and a thin layer containing carboxylic structures on the catholyte side to provide a good current efficiency. A demonstration plant with a production capacity of 269 tonnes of caustic soda per month was constructed in 1976. The first commercial chlor-alkali plant based on ion exchange membranes started to operate at the Osaka site in 1978 with an anmual production capacity of 795 tonnes of caustic soda.

A further enhancement of the performance of ion exchange membranes was made by adding surface coatings to promote the release of bubbles, which reduced thickness, and by incorporating reinforcing meshes. In 1.981 an improwed type of the Flemion membrane was developed, with a hydrophilic surface on non-conductive porous materials. This technological invention made it possible for the first time to operate the so-called zero-gap electrolyzer, a type of electrolyzer which has little space between the electrodes and the lon exchange membrane, leading to a reduction in the electric current resistance. While the limit to the minimum distance between the electrodes was previously $7 \mathrm{~mm}$, because of the necessity to remove gases, the zero-gap electrolyzer reduced the inter-electrode distance to virtually zero and brought about a significant voltage reduction, resulting in a decrease in energy consumption. Subsequently, a new electrolyzer system, AZEC, was commercialized in 1982 and began to be provided to other companies.

Table 4-12 summarizes the chronology of teclnological development related to the ion exchange membrane process at Asahi Glass.

Table 4-12 Chronology of Technological Developments Related to the Ion Exchange Membrane Process at Asahi Glass

\begin{tabular}{|c|l|}
\hline Year & \multicolumn{1}{|c|}{ Technological Development } \\
\hline 1973 & $\begin{array}{l}\text { Start of R\&D on the ion exchange membranes process for chlor-alkali } \\
\text { production }\end{array}$ \\
\hline
\end{tabular}




\begin{tabular}{|c|c|}
\hline 1975 & $\begin{array}{l}\text { Development of a perfluorocarboxylate ion exchange membrane; Flemion } \\
\text { Start-up of a pilot plant based on the ion exchange membrane process }\end{array}$ \\
\hline 1976 & Start-up of a demonstration plant based on the ion exchange membrane process \\
\hline 1978 & $\begin{array}{l}\text { Start-up of a commercial plant based on the ion exchange nembrane process at } \\
\text { Osaka } \\
\text { Start of the commercial production of the Flemion ion exchange membranes } \\
\text { Development of a large filter press type cell with finite gap }\end{array}$ \\
\hline 1980 & $\begin{array}{l}\text { First supply of Asahi Glass's ion exchange membrane process to an outside } \\
\text { firm }\end{array}$ \\
\hline 1981 & Development of the Flemion membranes with hydrophilic inorganic coating \\
\hline 1982 & Development of the AZEC electrolyzer with zero gap and activated cathodes \\
\hline
\end{tabular}

The trends in the R\&D personnel involved for the development of the ion exchange membrane process at Asahi Glass are shown in Figure $4-5^{66}$. The R\&D project which was initiated in 1973 conducted in such a large scale that about one third of the company's engineers who have expertise on chemicall technology were engaged in this project at that time. The central research center led the initial stage of the project, which was followed by the chemical division's attempts to industrialize the ion exchange membrane process. More than 100 scientists and engineers continued to be engaged until the new technology for the ion exchange membrane process was fully established.

\footnotetext{
Since the scale of the vertical axis has not been disclosed for this figure, it is not possible to discuss the trends in detail. Nevertheless, we can see at least that R\&D activities increased from 1973 to 1976, initially at the centrall research center and subsequently at the division.
} 


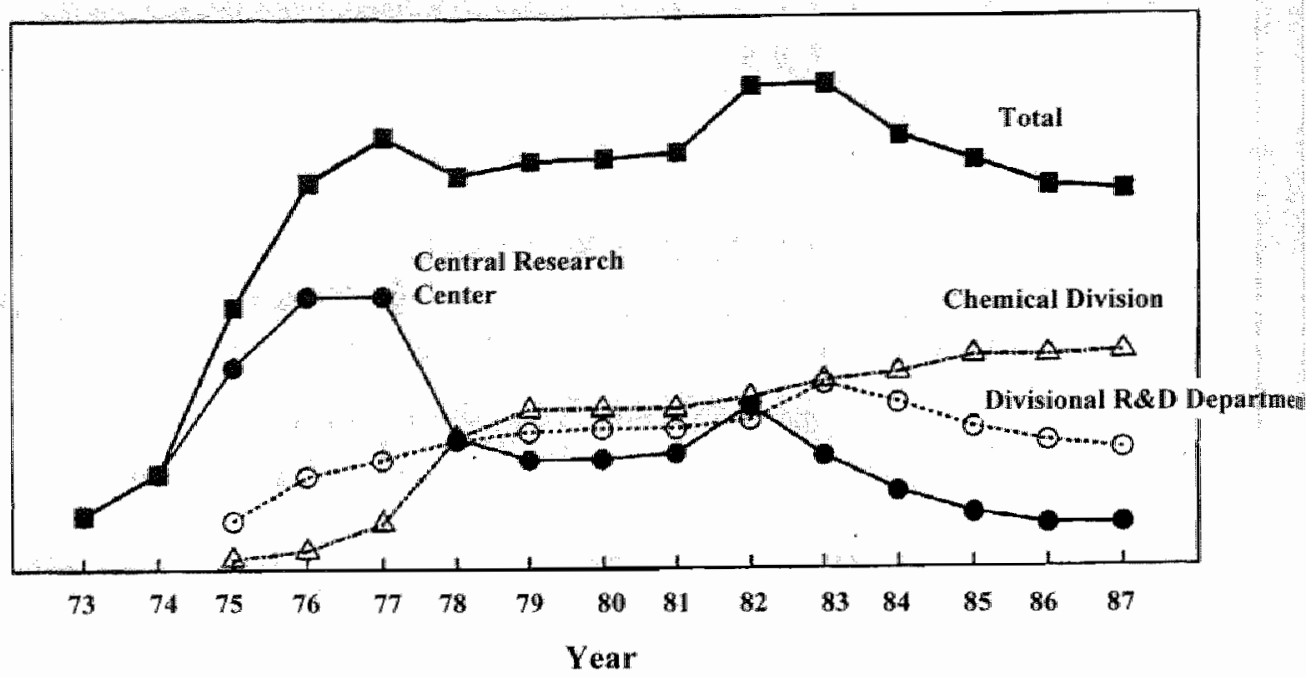

Figure 4-5 R\&D Personnel for the Ion Exchange Membrane Process at Asahi Glass

Source: Asahi Glass.

The increased R\&D activities at the central research center and later at the divisional department were followed by many patent applications made on technologies related to the ion exchange membrane process, as you can see in Table 4-9. In the late $1960 \mathrm{~s}$, most of the patents granted were on ion exchange membranes of the hydrocarbon type, which were basically used for salt production. Then, after a few years in the early 1970 s when there was no patent applications related to the ion exchange membrane process, successful patent applications started to increase rapidly in the middle of the $1970 \mathrm{~s}$, particularly on ion exchange menbranes based on perfluorocarbon, followed by those on electrolytic cells related to the ion exchange membranes for use in chlor-alkali production.

The technologies developed by Asahi Glass were provided to other chlor-alkali producers. The chlor-alkali plants to which the company's ion exchange membrane process was supplied are given in Table 4-28 at the end of this chapter. The first plant outside the company began to operate at Nippon Carbide in Toyama in November 1980 . Asahi Glass's technology was also adopted by Kashima Chlorine \& Alkali in July 1983 for its large-scale plant with an annual production capacity of 400,000 tonne of caustic soda in Kashima. Since then, Asahi Glass's technology for the ion exchange membrane process had been mainly adopted by other chlor-alkali producers based in Japan up to the middle of the $1980 \mathrm{~s}$. Then 
recently it has been increasingly adopted for chlor-alkali plants overseas, particularly in other Asian countries, and in total the company has suppled approximately 50 plants with its ion exchange membrane process technology. The cumulative annual production capacities of these plants have reached more than 3.7 million tonnes of caustic soda. As witl any new technology, the company faced many technical problems in the early stages of the commetrial operation of the ion exchange membrane process. Nonetheless, these probllems were finally solved, as the company could have a wide wariety of learning expenience and know-how in cell operations and their conditions. In developing the ion exchange membrane process, it has been crucial to gain practical experiences of operating commercial plants by closely cooperating with the users of the company's teclunology.

\section{Toknyama Soda}

Tokuyama Soda ${ }^{67}$ started its corporate history in 1918, when the first ammonia-soda plant in Japan was constructed by the company. The company had obtained experience and knowledge about the mercury process since the first mercury-based plant was constructed in 1952. Tokuyama Soda was one of the largest producers and suppliers of caustic soda, chlorine and other rellated products in Japan in the 1970s. As regards ion exchange membranes, the company started $\mathbb{R} \& D$ activities in 1950, mainly on electrodialysis for brine desalination and salt production. The production of Tokuyama Soda' ion exchange membrane, Neosepta, started in 1963, and the company' trial salt plant based on the ion exchange membrane began to operate in 1965. The company subsequently had become one of the major suppliers in the world of ion exchange membranes and related system technologies for electrodialysis. These previous experience of working on the mercury process and technologies related to ion exchange membranes used for salt production gave Tokuyama Soda useful expertise in later developing the ion exchange membrane process for chlor-alkali production.

Tokuyama Soda began to undertake R\&D on the ion exchange membrane process for chlor-alkali production in 1972 by using ion exchange membranes of a hydrocarbon type. As the ion exchange membrane containing perfluorinated sulfonic acid groups, Nafion, was introduced to the market, a bench-scale plant with this type of ion exchange membranes was set up in 1973. Subsequently, a semi-commercial plant was constructed in 1975 with a production capacity of 1,500 tonnes of caustic soda per year. The technologies for the ion 
exchange membrane process, however, had not been sufficiently developed by September 1975, the deadine set by the Japanese government for the conversion of the mercury process, and the diaphragm process was introduced from Diamond Shamrock based in the United States to its chlor-alkali plant in 1975 (see Table 4-4).

In the meantine, as the performance of the Nafion membranes originally used was not: satisfactory in the electrolysis of sodium chloride solution for chllor-alkali production, the company later developed a type of ion exchange membranes which had a thin layer of carboxylic acid groups on one of the surfaces of the membrane of perfluorinated sulfonic acid groups. Following several years of intensive R\&D activities on laboratory cells, pilot cells and intermediate-size practical cells, a commercial plant based on the ion exchange membrane process with a production capacity of 10,000 tonnes per year came into operation in June 1977. This commercial plant was equipped with three electrolyzers, each containing 40 bipolar cells and ion exchange membranes based on a fluorocarbon resin which were developed by the company, Neosepta.

Table 4-13 gives the chronology of technological developments related to the ion exchange membrane process for chlor-alkali production at Tokuyama Soda.

Table 4-13 Chronology of Technological Developments Related to the Ion Exchange Membrane Process at Tokuyama Soda

\begin{tabular}{|c|l|}
\hline Year & \multicolumn{1}{|c|}{ Technological Development } \\
\hline 1972 & $\begin{array}{l}\text { Start of R\&D on the ion exchange membrane process with the hydrocarbon-type } \\
\text { ion exchange membranes }\end{array}$ \\
\hline 1973 & Start-up of a bench-scale plant with the Nafion membranes \\
\hline 1974 & Construction of a pilot plant with the Nafion membranes \\
\hline 1975 & Construction of a semi-commercial plant with the Nafion membranes \\
\hline 1976 & $\begin{array}{l}\text { Long-run durability test of ion exchange membranes based on fluorocarbon resins } \\
\text { in small-sized laboratory cells }\end{array}$ \\
\hline 1977 & $\begin{array}{l}\text { Test run of a pretical electrolyzer of the TSE-270 type } \\
\text { Construction of a commercial plant with the Nafion membranes } \\
\text { Test run of Neosepta-F C-1000 membranes at the seni-commercial plant }\end{array}$ \\
\hline 1979 & $\begin{array}{l}\text { Start of commercial operation with the Neosepta-F C-1000 membranes } \\
\text { Development of the Neosepta-F C-2000 membranes }\end{array}$ \\
\hline 1981 & $\begin{array}{l}\text { Start of commercial operation with the Neosepta-F C-2000 membranes } \\
\text { Construction of a manufacturing plamt for the Neosepta-F membranes }\end{array}$ \\
\hline
\end{tabular}

\footnotetext{
(7) This section is based on the unformation obtained through the author's interviews with Dr. Sata and Mr. Matsuetri of Tokuyama Sode (Matsuura, 2002; Sata, 2002).
} 
The trends in successfin patent applications made by Tokuyama Soda are shown in Table 4-9. At the end of the 1960s there were several patent applications made on ion exchange membranes. They were basically based on hydrocarbonis and hence were primarily intended for use in the salt production process. Then, in the early 1970 , as R\&D on the ion exchange membrane process for chlor-alkali production was initiated, relevant patent applications increased rapidly. The number of patents successfully applied on technologies related to the ion exchange membrane process remained large until the late 1970 s, and then started to decline in the $1980 \mathrm{~s}$. By the late 1980 s, there had been no new patent grated on the ion exchange membrane process.

Tokuyama Soda's technology for the ion exchange membrane process became available for adoption by other chlor-alkali producers at the beginning of the 1980 s as a package of ion exchange membranes, electrolyzers, and associated facilities. Table 4-29 in the appendix to this chapter shows the chlor-alkali plants to which Tokuyama Soda"s ion exchange membrane process was installed. As you can see, the company's ion exchange membrane process has been adopted mainly by companies in other Asian countries. The first adoption of Tokuyama Soda's technology occurted in 1981 at a small plant of Kokuto Chemical based in South Korea. It was followed by the adoption of the technology by a Taiwanese chlor-alkali producer in 1982. After an interval of a few years, a chlor-alkali producer in Kuwait adopted in Tokuyama Soda"s process technology in 1986, and the last adoption was made by a Chinese chlor-alkali producer in 1987. Since then, however, the company has basically stopped providing its ion exchange membrane process to other chlor-alkali producers ${ }^{68}$.

\section{Chlorine Engineers Corp.}

Chlorine Engineers Corp. $(\mathrm{CEC})^{69}$ is an engineering company which was established in 1973 as a joint venture between Mitsui Corporation and Mitsui Engineering and Shipbuilding (MES). MES had previously been one of the major suppliers of the mercury process to chloralkali plants in Japan (see Table 3-18). The creation of CEC was to provide engineering and related services for the conversion of mercury-based chlor-alkali plants, as was mandated by the government decision on their phase out at that time. While Asahi Chemical, Asahi Glass,

\footnotetext{
13. Recently, the company has changed its corporate name to Tokuyama, removing Soda from the original name. That suggests that the company"s focus has shifted from the chlor walkalli business to other areas, while continuing the operation of its chlor-alkali production plant.

${ }^{6}$ "This section is based on the information obtained through the author"s interview with Dr. Kenzo Yamaguch: of Chlorine Engineers Corp. (Yamaguchi, 1999a).
} 
and Tokuyama soda has been producing chlor-alkali products, $C E C$ has not been engaged in chlor-alkali manufacture, but is a specialized engineering company supplying production technologies to chlor-alkali producers.

The initial target of $\mathrm{CEC}^{*}$ s technological development was on the diaphragm process. When the government made the decision on the phase out of the mercury process in the early 1970 s, the ion exchange membrane process for chlor-alkali production was still in its infancy, and its teehnological performance was far inferior to that of the diaphragm process, which had been well established at the industrial level. CEC hence expected that most of the chlor-alkali producers would adopt the diaphragm process when converting mercury-based plants. Rather than trying to develop its own technologies for the diaphragm process within the short period of time limited by the regulatory schedule, the company chose to introduce necessary technologies from outside. These technologies were supplied by foreign companies, namely, the DS cell by Diamond Shamrack and the Glanor cell by PPG, both of which were based in the United States. The chlor-alkali producers to which the diaphragm process was installed by CEC are listed in Table 4-30. The first case of the adoption of CEC's diaphragm process technology was implemented by Asahi Glass in Kitakyushu in February 1974. By May 1977. when the government decided to review the initial schedule of the conversion program, 18 chlor-alkali plants in Japan had adopted the diaphragm process supplied by CEC. The production capacities of chlor-alkali plants based on the company's diaphragm process had reached almost 1.5 million tonnes of caustic soda per year, which accounted for more than $50 \%$ of the total domestic capacity in the Japanese chlor-alkali industry at that time.

It was getting clear, however, that the ion exchange membrane process was emerging as औnew promising technology for chlor-alkali production, with its technical performance in a process of rapid improvement. Thus the company also started to develop its own technologies for the ion exchange membrane process. As major technological innovations had been already made on ion exchange membranes by the first movers, including Asahi Chemical Industry, Asali Glass, and Toknyama Soda, the focus of the company"s R\&D activities was placed on electrolytio cells, another majot component of the ton exchange membrane process (see Figure 4-2). The first progtan intended for commercial applications was the development of the Chiorine Engineers' Membrane Electrolyzer (CME). In the process of developing $\mathrm{CME}$, CEC maintained cooperation with Toa Gosei, the partner company for the development of technologies for the mercury process in the past (see Table 3-8). A test cell of CME was installed in 1975 , during the first phase of the conversion program of mercury-based plants. 
Two pilot cells were subsequently established in 1977. In 1980 the CEC $s$ first commercial plant, with a production capacity of eight tonnes of caustic soda per day, was construeted-in Okinawa, Japan. It was a plant converted from the diapliragm process; In the same year; another electrolytic cell was added to the pilot facilities, which was based on the carboxylictype Nafion membrane. Table 4-31 in the appendix to this chapter shows the chronology of installations of the CME ion exchange membrame process to chlor-alkali plants.

In the meantime, chlor-alkall producers in Japan were severely hit by the rapid rise in the energy price following the oil crisis in the late 1970s. In particular, those chlor-alkali producers who had converted their plants from the mercury process to the diaphragm process suffered most from the price hike. As the diaphragm process consumed more energy, hence raising its production cost, there was a strong denand for replacing the diaphragm process. An installation of the ion exchange membrane process, a new technology which consumed less energy with a lower production cost, however, required a large amount of initial investment, and it was difficult for the plant operators, who had already hit by the rise in the energy cost, to implement process conversions again. Thus CEC tried to develop a new type of electrolytic cells for the ion exchange membrane process which could be readily retrofitted to the existing plants based on the diaphragm process. In 1980 CEC started to cooperate closely with Mitsui Toatsu Chemical ${ }^{70}$ in conducting R\&D activities on the Membrane Bag Cell (MBC). While the CME technology was intended for use to replace mercury- or diaphragm-based plants, the MBC technology was designed to be retrofit to the existing plants using the diaphragm process. In the MBC process, ion exchange membranes formed like a bag were mounted on the anode in place of the deposited asbestos diaphragm. The anode assembly and the cathode can used in the existing diaphragm cells could be utilized with only minor adjustments, thus making the cost of process conversion significantly smaller than that necessary for complete replacement.

The development of $\mathrm{MBC}$ was completed in 1981, and the first MBC-type electrolyzer, with the Nafion membranes installed, began to operate at Mitsui Toatsu Chemical's Nagoya plant in 1982 . Table $4-32$ in the appendix to the present chapter gives the supply record of the MBC process to chlor-alkali producers by CEC. Most of the retrofittings of the ion exchange membrane process to the existing plants based on the diaphragm process were carried out in the period from 1982 to 1984 , just before the completion of the second phase of the 
conversion program mandated by the govemment: While the electric power consumption of the retrofit ion exchange membrane process was higher than that of a newly installed process, the initial investment required for retrofiting was set by the company to be less expensive: Almost $90 \%$ of the DS diaphragm electrolytic cells which had been installed by CEC during the first phase of the process conversion program turned out to be converted again to the retrofit ion exchange membrane process. In 1988, just after mercury-based plants finished process conversion completely, the retrofit-type technology accounted for $29 \%$ of all of the ion exchange membrane process installed in the Japanese chlor-alkali industry.

As the technical performance of the ion exchange membrane process continued to improve further, however, these retrofit cells were to be eventually replaced with ion exchange membrane cells which were designed for new installations. Then, in 1991, CEC started to develop a new type of membrane electrolyzer, jointly working with Tosoh, formerly known as Toyo Soda', one of the largest chlor-alkali producers in Japan. Following the stage of establishing pilot plants, the development of the BiTAC (an abbreviation of Bipole of Tosoh and CEC) process reached at the industrial level in 1993. As Table 4-33 in the appendix to this chapter shows the supply list of the BiTAC process since then, CEC has provided the BiTAC technology to chlor-alkali plants in other countries as well as to Tosoh's plants. The chronology of technological developments related to the ion exchange membrane process at CEC is given in Table 4-14.

Tablle 4-14 Chronology of Technological Developments Related to the Ion Exchange Membrane Process at CEC

\begin{tabular}{|c|l|}
\hline Year & \multicolumn{1}{|c|}{ Technological Development } \\
\hline 1975 & $\begin{array}{l}\text { Start of R\&D on the ion exchange membrane process with installation of a test } \\
\text { electrolytic cell }\end{array}$ \\
\hline 1977 & Construction of a pilot plant based on the ion exchange membrane process CME \\
\hline 1980 & $\begin{array}{l}\text { Construction of the first commercial plant based on the ion exchange membrane } \\
\text { process CME } \\
\text { Test of large-size cells with the Nafion membrane }\end{array}$ \\
\hline 1981 & Development of the retrofit ion exchange membrane process MBC \\
\hline 1982 & First installation of the retrofit ion exchange membrane process MBC \\
\hline 1984 & $\begin{array}{l}\text { Application of the ion exchange membrane technology CME for commercial } \\
\text { conversion projects }\end{array}$ \\
\hline 1993 & \begin{tabular}{l} 
Development of the ion exchange membrane process BiTAC \\
\hline
\end{tabular} \\
\hline
\end{tabular}

\footnotetext{
${ }^{7 *}$ Mitsui Tontsu Chemical merged with Mitsui Petrochemical in 1997 to create Mitsui Chemical (Mitsubishi
Chemical. 2001).
} 
In developing technologies for the ion exchange membrane process, CEC cooperated with several chlor-alkali producers, including Toa Gosei for CME, Mitsui Toatsu Chemical for MBC, and Tosoh for BiTAC. That was particularly important, because CEC, as an engineering company specializing in providing technologies and related services to chloralkali manufacturers without engaging itself in manufacturing, needed detailed information on the actual use of its membrane process technologies for further improvement. This is in contrast with the cases of technological development by Asahi Chemical Industry, Asahi Glass, and Tokuyama Soda, all of which have been chlor-alkali producers with their own technologies and thus could utilize their own experiences of using them.

\section{Kureha Chemical Industry}

Following the Japanese government's decision made in 1973 to abolish all the chlor-alkali plants employing the mercury process, Kureha Chemical Industry instigated a program to develop an electrolytic cell for the diaphragm process to take the place of the mercury cells used by the company at that time (Shibata, Kokubu, and Okazaki, 1977). In April 1976, the company's electrolytic cells based on the mercury process were abolished. At the same time the company developed a new type of electrolytic cells designed for use in the diaphragm process, the SK diaphragm cells, and the commercial production using them was initiated. One of the primary aims in the development of this type of diaphragm cells was to utilize the existing facilities, including buildings and rectifiers, busbars, and cranes, as much as possible, so as to restrict the investment required for the process conversion.

On the other hand, Kureha Chemical Industry did not develop any technology which could be utilized at the industrial level for the ion exchange membrane process. As we can see in Table 4-10, in the early 1970s, the company's patent applications were targeted on technologies related to the diaphragm process, and then patent applications started to be made on technologies for the ion exchange membrane process in the middle of the 1970s. The number of successful patent applications on the ion exchange membrane process was almost the same as those on the diaphragm process in the end. However, whille the research activities on the diaphragm process led to the industrialization of the SK diaphragm cell, the company introduced technologies for the ion exchange membrane process from an outside company, namely, Asahi Chemical Industry, in 1985.

\footnotetext{
Toyo Soda was renamed to Tosoh in 1987 (Tosoh, 2001).
} 


\section{Oraka Soda}

As we have seen in 3.3.1, Osaka Soda was one of the pioneering companies in Japan in the development of the mercury process. Just after the end of the Second World War, the technology provided by the company accounted for more than half of the production capacities based on the mercury process in Japan (see Table 3-16). By the beginning of the 1970 s, the company had come to rank third, following De Nora and MES, in supplying the mercury process to Japanese chllor-alkali plant operators.

Following the government decision on the phase out of the mercury process in the $1970 \mathrm{~s}$, however, the company had to use clean technologies without relying mercury for chlor-alkali production. As Table 4-10 suggests, while the number of successful patent applications on the diaphragm process was at the equal levell as that of other innovative companies in Japan, there were only much fewer patent applications which were granted on the ion exchange membrane process, suggesting the company's R\&D efforts had been mainly directed to the diaphragm process. Eventually, this company did not develop technologies by itself either for the diaphragm process or the ion exchange membrane process. Instead, the diaphragm process was introduced from two U.S. companies, namely, Diamond Shamrock and Hooker, and the ion exchange membrane process was supplied by $\mathrm{CEC}$.

\section{Nippon Soda}

Nippon Soda was established in 1920, and its chlor-alkali production was started with the Nakano-type electrolytic cell of the diaphragm process, which was originally developed by the corporate founder, NAKANO Yurei, at the Nihongi site (Nippon Soda, 2001). Although the Nakano cells ceased to operate after the Second World War, the company made further improvements in the electrolytic cell. Subsequently, the company developed the B cells and the BM cells equipped with metal anodes and expanded their production capacities. Table 4-10 suggests that Nippon soda continued to make R\&D activities on the diaphragm process throughout the 1970s. The company"s enlarged electrolytic cell was later adopted by Chiba Chlorine Chemical in 1975 (Japan Soda Industry Association, 1982). On the other hand, the company did not make any significant innovations on the ion exchange membrane process, as suggested by no successful patent applications seen in Table 4-10. 


\section{Showa Denko}

Showa Denko started its electrolytic production of caustic soda in 1935 with the diaphragin process using horizontal diaphragm cells (Takeshita, 1990). Later, the mereury process was added to the company's production facilities. With the advent of a dimensionally stable electrode in the 1960 s, the company started to develop a type of vertical diaphragm cells, the SD cell. Its commercial operation was initiated in 1969, and the production capacity of the diaphragm plant with it was expanded subsequently. Following the government"s decision the phase out of the mercury process in the early $1970 \mathrm{~s}$, the operation of the mercury plant was discontinued in 1975. And at the same time the company made an agreement with Hitachi Engineering and Shipbuilding to promote the development of the company's diaphragm process technology and its sales to other chlor-alkali producers (Nikket Sangyo Shinbun, 1976). The result, however, was that Showa Denko's technology was adopted by only one company, Kanto Denka Kogyo, which introduced it to the Mizushima plant in 1975 (Kanto Denka Kogyo, 1998). Table 4-10 suggests that, after having been engaged in developing technologies for the diaphragm process in the late 1960 s and the 1970 s, the company started to make R\&D activities on the ion exchange membrane process in the 1980s. These efforts to innovate on the ion exchange membrane process did not result in a successful development of technologies for industrial uses.

\section{Tsurumi Soda}

Tsurumi Soda started to produce chlor-alkali products in 1934 with the diaphragm process (Tsurumi Soda, 2001). The company was the only Japanese company which had never adopted the mercury process for chlor-alkali production since its establishment. Thus the company's technological expertise was accumulated solely on the diaphragm process, and that led to the development of the TSB cell and the TSBM cell, both of which have becn designed for use in the diaphragm process. Relying solely on the diaphragm process, Tsurumi Soda did not face technological as well as financial difficulties when other chlor-alkali producers had to cope with the issue of converting the existing plants based on the mercury process in the 1970s. The company's technology for the diaphragm process was also adopted by Showa Enso in 1974 (Showa Chemical, 2001). On the other hand, the company did not make innovations on the ion exchange membrane process, and the technology of Asahi Glass was introduced to its chlor-alkali plant in 1982 . 


\section{Comparison of the Innovative Companies in Japan}

As we have discussed above, various types of technologies for chlor-alkali production were developed by the innovative companies in Japan. Table 4-15 lists these technologies for the mercury process, the diaphragm process, and the ion exchange membrane process.

Table 4-15 Techmologies for Chlor-Alkali Production Developed by Innovative Companies in Japan

\begin{tabular}{|c|c|c|c|c|}
\hline \multirow[t]{2}{*}{ Company } & \multirow[t]{2}{*}{ Mercury Process } & \multirow{2}{*}{$\begin{array}{c}\text { Diaphragm } \\
\text { Process }\end{array}$} & \multicolumn{2}{|c|}{ Ion Exchange Membrame Process } \\
\hline & & & $\begin{array}{c}\text { Ion Exchange } \\
\text { Membrane }\end{array}$ & Electrolytic Cell \\
\hline Asahi Chemical & Asahi Chemical & - & Aciplex & Acilyzer \\
\hline Asahi Glass & Rotation & - & Flemion & Axec \\
\hline Tokuyama Soda & Tokuso & - & Neosepta & TSE \\
\hline CEC (MES) & Mitsui & (DS, Glanor) & $=$ & $\mathrm{CME}, \mathrm{MBC}, \mathrm{BITAC}$ \\
\hline Kureha Chemical & $\mathrm{HD}$ & $\mathrm{SK}$ & $=$ & - \\
\hline Osaka Soda & Daiso & - & $=$ & - \\
\hline Nippon Soda & - & $\mathrm{BM}$ & - & - \\
\hline Showa Denko. & $=$ & $\mathrm{SD}$ & - & - \\
\hline Tsurumi Soda & $=$ & TSBM & - & - \\
\hline
\end{tabular}

By the early 1970s, when the government decided to abolish all the mercury-based chlor-alkali plants, several technologies had been developed for the mercury process by innovative companies in Japan. They include the Mitsui-Toa Gosei cell of Mitsui Engineering and Shipbuilding (MES), which later established Chlorine Engineers Corp. (CEC), the HD cell of Kureha Chemical Industry, the Daiso cell of Osaka Sada, the Rotation cell of Asahi Glass, the Tokuso cell of Tokuyama Soda, and the Asahi Chemical cell of the Asahi Chemical Industry.

Among these companies which had previous experiences of developing technologies the mercury process, four companies, Asahi Chemical Industry, Asahi Glass, Tokuyama Soda, and $\mathrm{CEC}$, succeded in making innovations on the ion exchange membrane process. Technically speaking, the ion exchange membrane process basically consists of the jon exchange membrane and the electrolytic cell, as we can see in Figure 4-2. Asahi Chemical Industry, Asahi Glass, and Tokuyama Soda made innovations on both the ion exchange membrane, developing the Aciplex, Flemion, and Neosepta membranes, respectively, and the electrolytic cell for the ion exchange membrane process, that is, the Acilyzer, Azec, and TSE processes, respectively. CEC initially introduced technologies for the diaphragm process, namely, the DS cell and the Glanor cell, from foreign companies, whereas three types of the 
electrolytic cell were developed later by the company for the ion exchange membrane process, that is, the CME, MBC, and BiTAC processes.

There have not been major innovations on the ion exchange membrane process by the other companies with expertise on the mercury process, that is, Kureha Chemical Industry and Osaka Soda. While Kureha Chemical Industry industrialized its own electrolytic cell, the SK cell, for the diaphragm process, the company did not develop technologies for the ion exchange membrane process. Osaka Soda, once a leading innovator on the mercury process, did not make any significant innovations on either the diaphragm process or the ion exchange membrane process. Instead, the company introduced technologies from outside companies for the diaphragm process as well as for the ion exchange membrane process, without making its own imovations on either process.

On the other hand, Nippon Soda, Tsurumi Soda, and Showa Denko had already developed technologies for the diaphragm process, the BM, TSBM, and SD cells, respectively, by the early 1970 s. Following the government's decision to phase out the mercury process in Japan, the companies increased their production capacity based on the diaphragm process with their own technologies. Although there were several chlor-alkali producers who adopted the technologies developed by these companies, these cases were relatively rare, as the advanced technologies, that is, the DS and Glanor cells, were introduced from foreign companies, mostly those based in the United States. Regarding the ion exchange membrane process, these companies did not make any significant innovations which could be utilized for industrial applications.

Asahi Chemical Industry, Asahi Glass, and Tokuyama Soda had previously experiences of developing and utilizing ion exchange membranes for salt production. Unlike in Europe or the United States, rainfall has been generally abundant in Japan, and water desalination has not been given priority for the application of ion exchange membranes. On the other hand, natural rock salt has not been available in Japan, and salt had to be produced in solar fields. The traditional process of salt production was labor-intensive and constantly subject to adverse weather, with little prospect of significant improvement (Shimizu, 1993). Hence the three Japanese companies started to conduct R\&D activities on ion exchange membranes for the production of salt from sea water. In 1960 Asahi Glass began to produce its ion exchange membrane, Selemion, at the industrial level for the first time in Japan, and at the same time the company's first plant for salt production utilizing ion exchange membranes started to operate. The first trial of salt production with ion exchange membranes was immediately" 
followed by the other companies. In 1961 Asahi Chemical Industry initiated the manufacture of its ion exchange membrane, Aciplex, and the production of salt based on the membrane. The production of Tokuyana Soda" membrane, Neosepta, began in 1963, and the company" trial salt plant bused on the ion exchange membrane started to operate in 1965.

The new method of salt production by using lon exchange membranes was efficient in terms of space and cost, and the quality of the produced salt was sufficiently high as to be used for food (Hanafusa, 1998). Accordingly, the salt production process with the use of ion exchange membranes was diffused rather quickly in the salt industry in Japan. As Table 4-16 gives the start-up years of salt production based on the ion exchange membrane, all of the salt producers in Japan, namely, Shin-Nihon Chemical Industry ${ }^{72}$, Ako Sea Water Chemical Industry $^{73}$ "Kinkai Salt Manufacturing, Naikai Salt Industries, Naruto Salt Manufacturing, Sanuki Salt Industry, and Sakito Salt ${ }^{74}$, eventually introduced ion exchange membranes for salt production. The ion exchange membranes used by these salt producers were supplied by three companies, namely, Asahi Chemical, Asahi Glass, and Tokuyama Soda. By 1972, the traditional process had been completely replaced with the process with the ion exchange membrane for the production of salt applied for food in Japan (Japan Salt Industry Association, 2001).

As salt had been traditionally produced at salt fields by using the solar power, technological developments of the ion exchange membrane were conducted for the purpose of replacing solar evaporation as the method of producing salt from sea water. In this process, the three companies, that is, Asahi Chemical Industry, Asahi Glass, and Tokuyama Soda, gained earlier experiences of developing and improving ion exchange membranes. As these ion exchange membranes were based on hydrocarbons, however, they could not maintain their chemical stability in a strong alkaline environment and hence was not readily used for chlor-alkali production. The application of ion exchange membranes for use in chlor-alkali electrolytic cells did not occur until the 1970s.

Table 4-16 Use of Ion Exchange Membranes for Salt Production in Japan

\begin{tabular}{|l|c|l|}
\hline Supplier of Ion Exchange Membrane & Start-up Year & \multicolumn{1}{|c|}{ Salt Producer } \\
\hline Asahi Chemical Industry & 1962 & Shin-Nihon Chemical Industry \\
\cline { 2 - 3 } & 1967 & Ako Sea Water Chemical Industry \\
\cline { 2 - 3 } & 1967 & Naruto Salt Manufacturing \\
\hline
\end{tabular}

\footnotetext{
"Shin-Nihon Chemical Salt has been renamed to Shin-Nihon Salt (Shin-Nihon Salt, 2001).

Akro Sea Water Chemical Industry has been renamed to Ako Sea Water.

Sakito Salt Manufacturing has been renamed to Dia Salt (Dia Salt, 2001 ).
} 


\begin{tabular}{|l|c|l|}
\hline Asahi Glass & 1969 & Naikai Salt Industries \\
\cline { 2 - 3 } & 1972 & Sakito Salt Manufacturing \\
\hline Tokuyamai Soda & 1967 & Kinkai Salt Manufacturing \\
\cline { 2 - 3 } & 1971 & Sanuki Salt Industry \\
\hline
\end{tabular}

The chronology of the technological developments made by these companies are compared in Figure 4-6, which indicates the timing of R\&D activities, pilot plants, and commercial plants concerning the diaphragm process and the ion exchange membrane process for each company. Although the idea of using ion exchange membranes for electrolytic chloralkali production had existed since the 1950 s, the lack of suitable ion exchange membranes prevented the industrial realization of the ion exchange membrane process. In the meantime, several companies in Japan, including Asahi Chemical Industry, Asahi Glass, and Tokuyama Soda, had earlier experiences on developing ion exchange membranes primarily used for the manufacture of salt in the 1960s. Then, at the end of the $1960 \mathrm{~s}$, the Nafion membrane, which was invented by Du Pont, started to be available to companies in the Japanese chlor-alkali industry. That in effect worked to provide a fertile technological opportunity to these companies for the development of ion exchange membranes to be used in chlor-alkali production. 


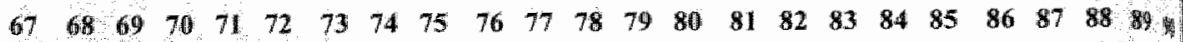

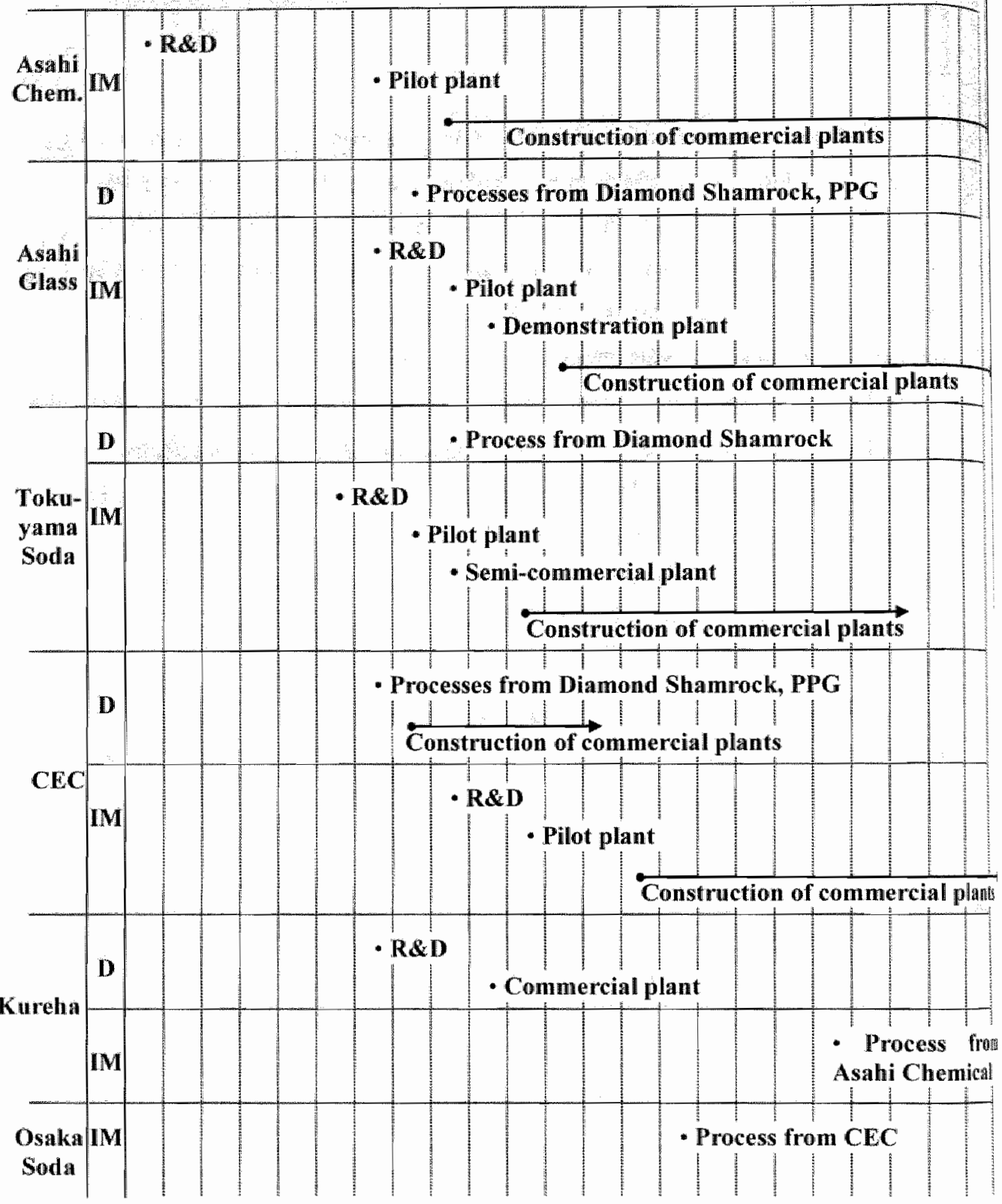

D: Diaphragm Process; IM: Ilon Exchange Membrane Process

Figure 4-6 Technological Developments of Chlor-Alkali Production Processes by Japanese Companies 
Comcided with the emergence of the Nafion membrane, the government's decision made in 1973 to phase out all the mercury-based plants in Japan created demands for clean technologies which would replace the mercury process. In particular, that provided a significant impetus for the innovative companies with previous expertise on ion exchange membranes to start intensive research efforts to develop the ion exchange membrane process for chlor-alkali production. While the government did not give any financial support to these companies when they conducted their R\&D activities on the ion exchange membrane process, the decision worked to assure them that there would be a large amount of secured demands for alternative processes and thus encouraged the innovative companies to invigorate R\&D efforts for developing the ion exchange membrane process. The guaranteed demand for clean technologies for chlor-alkali production helped the developers of the ion exchange membrane process to overcome the initial obstacle of its poor performance and uncertain technological progress in the future.

On the other hand, other companies which had been previously innovative on the mercury process, namely, Mitsui Engineering and Shipbuilding (MES), Kureha Chemical Industry, and Osaka Soda did not make significant innovations on the ion exchange membrane process. Unlike the three early innovators on the ion exchange membrane, that is, Asahi Chemical Industry, Asahi Glass, and Tokuyama Soda, these companies had not been involved in salt production previously and hence had little experience of developing the ion exchange membrane or utilizing it for other purposes. Thus, the initial focus of technological development was placed on the diaphragm process.

Immediately after the government decision on the phase out of the mercury process in the Japanese chlor-alkali industry, MES established CEC in 1973 to enter the business of converting the mercury process to clean processes which do not rely on any use of mercury in the production facilities. Without sufficient experience or expertise on the ion exchange membrane process, CEC picked up the diaphragm process for their technological target. The company decided to introduce technologies from foreign companies, namely, the DS cell from Diamond Shamrock in the United States and the Glanor cell from PPG also in the United States and provided these diaphragm process technologies to many chlor-alkali producers in Japan. The diaphragm process, however, turned out not to be appropriate for producing high-quality caustic soda, with various types of impurities contained In the meantime, the company saw a rapid progress in developing ion exchange membranes based 
on fluorocarbons by Asahi Chemical Industry, Asahi Glass, and Tokuyama Soda in the 1970 s. The company hence started to undertake R\&D activities on electrolytic cells designed for use in the ion exchange membrane process in the second half of the 1970 s. Following a successful operation of the pilot plant, the first commercial plant based on the ion exchange membrane process started to operate in 1980. Although CEC was the last company in developing technologies for the ion exchange membrane process, the company laas since then provided its process to many chlor-alkali producers in Japan. During the technological development, close cooperation with chlor-alkali manufacturers, including Toa Gosei Chemical and Toyo Soda, was of critical importance to $\mathrm{CEC}$. As an engineering company which has not been engaged in chlor-alkali production, the company could receive precious feedback from the practical experiences of these chlor-alkali manufacturers and utilize it for further technological improvement.

Another innovative company without previous experience on ion exchange membranes, Kureha Chemical Industry also chose the diaphragm process for the target of technological development. The company started R\&D activities on the diaphragm process in 1973, following the government decision on the phase out of the mercury process. The company subsequently succeeded in developing an electrolytic cell, the SK cell, and converted its own mercury-based plant to the diaphragm process in 1976 . The company, on the other hand, did not develop its own technologies for the ion exchange membrane process, although the patent data suggests that some R\&D activities were conducted later in the 1970s. Similarly, Osaka Soda, without technical background in the field of ion exchange membranes, made R\&D efforts on the diaphragm process, following the government's decision for the abolishment of the mercury process in 1973. As is indicated by the patent data, however, these innovative efforts did not result in successful technological development which could be utilized at the industrial level. In comparison to the diaphragm process, the ion exchange membrane process was not the focus of the company"s R\&D activities. In the end, its mercury-based chlor-alkali plants were converted to the ion exchange membrane process provided by an outside technology supplier, namely, CEC.

Figure 4-7 shows the trends in the supply of the diaphragm process and the ion exchange membrane process by the Japanese companies. (Detailed data are given in Table 4-26 in Appendix at the end of this chapter.) Following immediately the government clecision on the phase out of the mercury process, the supply of the diaphragm process increased rapidly and reached its peak in the middle of the 1970s. While the supplly of the diaphragm 
process then declined quickly and ceased in 1980, the ion exchange membrane process started to be supplied in the middle of the 1970 s and showed a large increase in the 1980s. After the supply of the ion exchange membrane process declined in the late 1980s, following the completion of the process conversion program in Japan, it picked up again in the $1990 \mathrm{~s}$, mainly because of an increase in its supply to chlor-alkali producers in other countries.

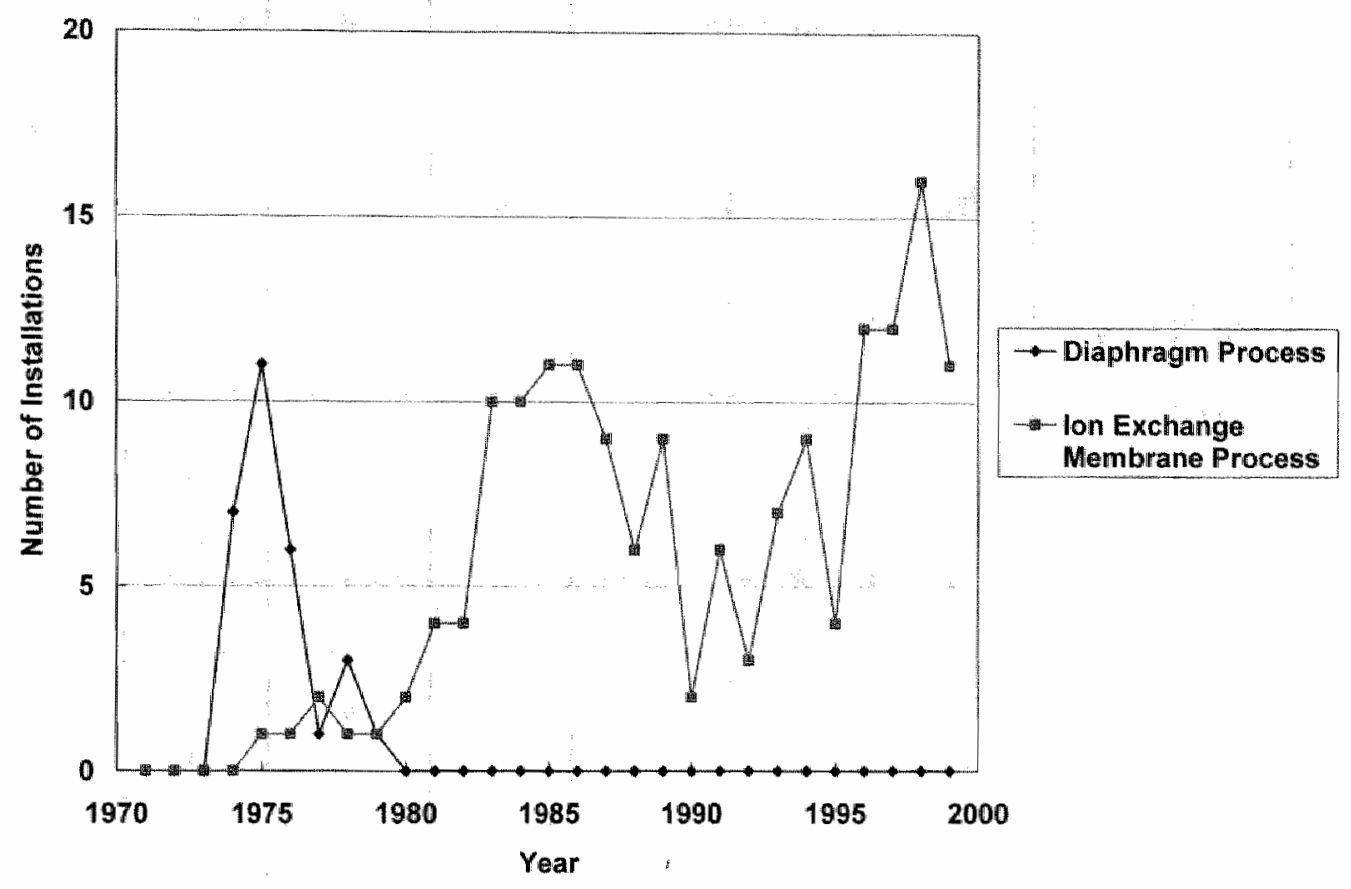

Figure 4-7 Supply of the Diaphragm and the Ion Exchange Membrane Processes by Japanese Firms

Table $4-17$ gives detailed data on the supply of the two processes by Asahi Chemical Industry, Asahi Glass, Tokuyama, and CEC. This table has been constructed by using the supply lists of the two production processes provided by these companies. (The supply lists of the companies are shown in Table 4-27, Table 4-28, Table 4-29, Table 4-30, Table 4-31, Table 4-32, and Table 4-33 in Appendix at the end of this chapter.) 
Table 4-17 Supply of the Diaphragm and Ion Exchange Membrane Processes by Innowative Companies in Iapan

\begin{tabular}{|c|c|c|c|c|c|c|c|c|}
\hline \multirow{2}{*}{ Year } & \multicolumn{2}{|c|}{ Assahi Chemical } & \multicolumn{2}{|c|}{ Asah Glass } & \multicolumn{2}{|c|}{ Tokuyama } & \multicolumn{2}{|c|}{$\mathrm{CEC}$} \\
\hline & $D$ & $\mathrm{IM}$ & $D$ & $\mathrm{IM}$ & $\mathrm{D}$ & $\mathrm{IM}$ & $\mathrm{D}$ & $1 \mathrm{M}$ \\
\hline 1971 & 0 & 0 & 0 & 0 & 0 & 0 & 0 & 0 \\
\hline 1972 & 0 & 0 & 0 & 0 & 0 & 0 & 0 & 0 \\
\hline 1973 & 0 & 0 & 0 & 0 & 0 & 0 & 0 & 0 \\
\hline 1974 & 0 & 0 & 0 & 0 & 0 & 0 & 4 & 0 \\
\hline 1975 & 0 & 1 & 0 & 0 & 0 & 0 & 8 & 0 \\
\hline 1976 & 0 & 1 & 0 & 0 & 0 & 0 & 5 & 0 \\
\hline 1977 & 0 & 1 & 0 & 0 & 0 & 1 & 1 & 0 \\
\hline 1978 & 0 & 0 & 0 & 1 & 0 & 0 & 3 & 0 \\
\hline 1979 & 0 & 1 & 0 & 0 & 0 & 0 & 1 & 0 \\
\hline 1980 & 0 & 0 & 0 & 1 & 0 & 0 & 0 & 1 \\
\hline 1981 & 0 & 1 & 0 & 1 & 0 & 1 & 0 & 1 \\
\hline 1982 & 0 & 1 & 0 & 1 & 0 & 1 & 0 & 1 \\
\hline 1983 & 0 & 2 & 0 & 2 & 0 & 0 & 0 & 6 \\
\hline 1984 & 0 & 0 & 0 & 1 & 0 & 0 & 0 & 9 \\
\hline 1985 & 0 & 1 & 0 & 6 & 0 & 0 & 0 & 4 \\
\hline 1986 & 0 & 5 & 0 & 4 & 0 & 1 & 0 & 2 \\
\hline 1987 & 0 & 4 & 0 & 2 & 0 & 1 & 0 & 3 \\
\hline 1988 & 0 & 2 & 0 & 1 & 0 & 0 & 0 & 3 \\
\hline 1989 & 0 & 0 & 0 & 6 & 0 & 0 & 0 & 3 \\
\hline 1990 & 0 & 0 & 0 & 1 & 0 & 0 & 0 & 1 \\
\hline 1991 & 0 & 2 & 0 & 3 & 0 & 0 & 0 & 1 \\
\hline 1992 & 0 & 0 & 0 & 1 & 0 & 0 & 0 & 2 \\
\hline 1993 & 0 & 2 & 0 & 1 & 0 & 0 & 0 & 4 \\
\hline 1994 & 0 & 3 & 0 & 2 & 0 & 0 & 0 & 4 \\
\hline 1995 & 0 & 0 & 0 & 1 & 0 & 0 & 0 & 3 \\
\hline 1996 & 0 & 4 & 0 & 2 & 0 & 0 & 0 & 6 \\
\hline 1997 & 0 & 3 & 0 & 8 & 0 & 0 & 0 & 1 \\
\hline 1998 & 0 & 10 & 0 & 3 & 0 & 0 & 0 & 3 \\
\hline 1999 & 0 & 3 & 0 & 3 & 0 & 0 & 0 & 5 \\
\hline Total & 0 & 376 & 0 & 408 & 0 & 40 & 176 & 504 \\
\hline
\end{tabular}

D: Diaphragm Process; M: Ion Exchange Membrane Process

As we can see in the table, in the second thalf of the 1970s, Asahi Chemical Industry, Asahi Glass, Tokuyama Soda succeeded in industrializing their technologies for the ion exchange membrane process and began to use them basically at their own chlor-alkali production plants. Then, in the 1980 s, these companies started to provide their technologies to other chlor-alkali producers in Japan. On the other hand, CEC introduced technologies for the diaphragm process from foreign companies and began to supply them to chlor-alkali 
producers in Japan in 1974, immediately after the government policy for the phase out of the mercury process. By 1977, when the imitial schedule of the govemment policy for the phase put of the mercury process reviewed, CEC's diaphragm process was adopted by many chloralkali producers in Japan. As the diaphragm process turned out to be an inappropriate technology, however, CEC, cooperating with several chlor-alkali producers, started to develop technologies for the ion exchange membrane process in the late 1970s. The company's ion exchange membrane process was supplied for the first time to a chlor-akkali producer in Japan in 1980. In the middle of the 1980s, as the deadline for the phase out of the mercury process approached, these four companies provided their technologies to many Japanese chlor-alkali producers who had to convert their mercury-based plants.

Having finished supplying domestic chlor-alkali producers with their ion exchange membrane process technologies, these companies started to seek actively their customers in other countries in the late 1980s. Particularly in other countries in Asia, including Tawan, South Korea, and Chira, the technologies developed by the Japanese companies were adopted by many chlor-alkali producers. Along with the remarkable economic development in these countries, their chlor-alkali productions have also been growing rapidly, and consequently many of the chlor-alkali producers avoided from adopting the mercury process, which has become technologically obsolescent, and instead could introduce the ion exchange membrane process to their new production facilities.

The intensified R\&D activities of the innovative companies in Japan, namely, Asahi Chemical Industry, Asahi Glass, Tokuyama Soda, and CEC, resulted in a rapid improvement in the technollogical performance of the ion exchange membrane process. One of the major indicators which represent the technological performance of technologies for chlor-alkali production is the energy consumption, as it accounts for a significant part of the total manufacturing cost. Table 4-18 shows the trends in the electric power consumption of the ion exchange membrane process technologies developed by Asahi Chemical Industry, Asahi Glass, Tokuyama Soda, and $\mathrm{CEC}^{75}$. Compared with the mercury process, whose energy consumption remained almost unchanged at the level of approximately $3,200 \mathrm{kWh} / \mathrm{NaOH}$, the ion exchange membrane process has shown a remarkable progress in its power consumption.

\footnotetext{
75. The electric power consumption is normally higher at a higher current density.
} 
Table 4-18 Electric Power Consunption of the Ion Exchange Membrane Process Technologies Developed by Japanese Companies

\begin{tabular}{|c|c|c|c|c|}
\hline Year & $\begin{array}{c}\text { Asahi Chemical } \\
\text { Industry }\end{array}$ & Asahi Glass & Tokuyama Soda & CEC \\
\hline 1975 & 3,500 & - & - & - \\
\hline 1976 & 2,700 & 3,200 & 3,200 & 3,200 \\
\hline 1977 & 2,620 & 2,740 & 3,000 & - \\
\hline 1978 & 2,570 & 2,610 & - & - \\
\hline 1979 & 2,500 & 2,470 & 2,495 & 2,600 \\
\hline 1980 & 2,420 & 2,340 & - & 2,400 \\
\hline 1981 & 2,200 & 2,080 & - & 2,200 \\
\hline 1982 & 2,200 & - & 2,160 & - \\
\hline 1983 & 2,200 & 2,080 & 2,080 & - \\
\hline 1984 & 2,100 & - & - & - \\
\hline 1985 & 2,100 & 2,100 & - & - \\
\hline
\end{tabular}

Figures are expressed in $\mathrm{kWh} / \mathrm{NaOH}$.

Sources:

Asahi Chemical Industry: 1975: Oh-hawa, Hamada, and Yoshida (1998) (at $\left.4 \mathrm{kAlm}^{2}\right)$. 1976 .

Seko (1976) (at 4 kA/m²). 1977, 1979, 1980, and 1981: Yomijama (1982). 1978: Seko (1980) (at $\left.3.56 \mathrm{kA}^{2} \mathrm{~m}^{2}\right)$. 1982: Seko, Yomijama, Ogawa, and Ono (1983) (at $\left.4 \mathrm{kA} / \mathrm{m}^{2}\right)$. 1983: Seko, Yomiyama, and Ogawa (1983) (at 4.0 kA/ $\left.\mathrm{m}^{2}\right)$. 1984: Seko, Ogawa, Ono, and Suzuki (1984) (at 4kA/m $\mathrm{m}^{2}$. 1985: Seko, Omura, and Yoshida (1986) (at $\left.4 \mathrm{kA}^{2} \mathrm{~m}^{2}\right)$.

Asahi Glass: 1976, 1977, 1978, 1980, and 1981: Nagamura, Ukihashi, and Shiragami (1983) (at $3 \mathrm{kA} / \mathrm{m}^{2}$ ). 1979: Nagamura, Ukihashi, and Shiragami (1980) (at $2 \mathrm{kA} / \mathrm{m}^{2}$ ). 1983:

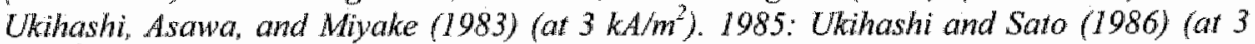
$k A / m^{2}, 35 \% \mathrm{NaOH}$.

Tokuyama Soda: 1979: Motami and Sata (1980) (at $\left.2 \mathrm{kA} / \mathrm{m}^{2}\right)$. 1982: Motani (1982). 1983:

Sata, Motani, and Ohashi (1983).

CEC: 1976, 1980, 1981, 1982: Yamaguchi and Kumagai (1990).

Among the innovatiwe companies, Asahi Chemical Industry initially took the lead in improving the energy consumption of the lon exchange membrane process. When the company started to operate the first commercial plant in 1975, the power consumption was $3,500 \mathrm{kWh} / \mathrm{NaOH}(3,925 \mathrm{kWh} / \mathrm{t} \mathrm{NaOH}$, including steam). Then it declined rapidly to about $2,200 \mathrm{kWh} / \mathrm{t} \mathrm{NaOH}$ in the early $1980 \mathrm{~s}$, achieving a reduction by $43 \%$, and has remained stable since then. The other companies have caught up with Asahi Chemical Industry quickly in a short period of time. When Asahi Glass developed the Flemion membrane in 1976, the power consumption for producing $40 \%$ caustic soda by its ion exchange membrane process was $3,200 \mathrm{kWh} / \mathrm{t} \mathrm{NaOH}$, a level which was almost equivalent to that of the mercury process at that time. By 1985, the power consumption with the company's AZEC electrolyzer with ion exchange membranes had been reduced to less than $2,200 \mathrm{kWh} / \mathrm{t} \mathrm{NaH}$. In the case of 
Tokuyama Soda, when the first commercial plant based on the ion exchange membrane process was installed in 1977 , its power consumption was more than $3,000 \mathrm{kWh} / \mathrm{t} \mathrm{NaOH}$. By the early 1980s, it had been reduced to less than $2 ; 100 \mathrm{kWh} / \mathrm{NaOH}$, the lowest among the three processes. The technological development by CEC for the ion exchange membrane process was delayed, compared with the other innovative companies in Japan. CEC's technology for the ion exchange membrane process, however, showed a rapid progress in reducing the energy consumption from the initial level of $3,200 \mathrm{kWh} / \mathrm{t} \mathrm{NaOH}$ to the level of $2,200 \mathrm{kWh} / \mathrm{t} \mathrm{NaOH}$ just in six years.

In this way, for the past twenty years, the energy consumption of the ion exchange membrane process has shown a remarkable improvement. To see the extent and speed of technological progress, we make a comparison between the mercury process, diaphragm process, and the ion exchange membrane process in terms of progress in the efficiency of energy consumption. Figure 4-8 shows the trends in the energy consumption of the three processes. (Detailed data are given in Table 4-24 in Appendix at the end of this chapter.) 


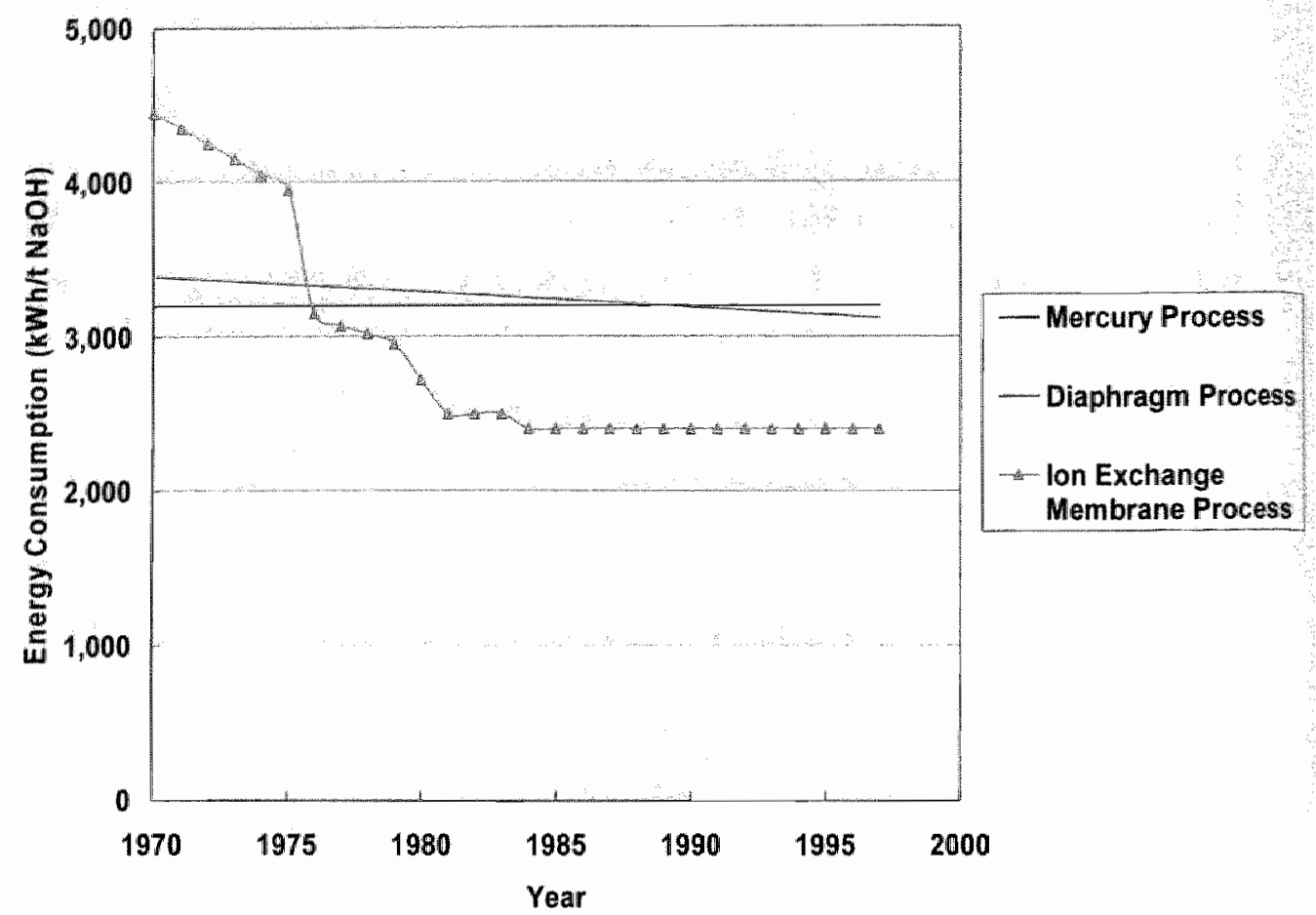

Figure 4-8 Energy Consumption of the Mercury, Diaphragm, and Ion Exchange Membrane Processes

The total energy consumption is the sum of the electric power consumption and, in the cases of the diaphragm process and the ion exchange membrane process, the steam consumption required to increase the concentration of caustic soda. Here the data on the energy consumption of the ion exchange membrane process is represented by that of the technology developed by Asahi Chemical Industry, except for 1970. With regard to the steam consumption required for concentrating caustic soda, it has been assumed to be $470 \mathrm{~kW} / \mathrm{h} / \mathrm{t}$ $\mathrm{NaOH}$ for the diaphragm process, and $450 \mathrm{kWh} / \mathrm{t} \mathrm{NaH}$ until 1979 and $300 \mathrm{kWh} / \mathrm{t} \mathrm{NaOH}$ thereafter for the ion exchange membrane process ${ }^{76}$. When data is not available, we have made an assumption of linear improvement in the energy efficiency. Figure 4-8 can be seen in

\footnotetext{
76 The development of the ion exchange membrane process can be traced in three phases. While the ion excltange membrane process produced 8 to $15 \%$ caustic soda in the first phase, which ended in 1979, caustic socta of $35 \%$ was produced in the second and the third phases (Chatterjee, 1984).
} 
relation to Figure 2-9, which we have developed in discussing our anallytical framework for the effects of environmental regulation on technological change.

Initially, the energy consumption of the ion exchange membrane process exceeded $4,800 \mathrm{kWh} / \mathrm{t} \mathrm{NaOH}$ (Morris, 1990). In 1970 the development of the ion exchange membrane process was still in its infancy, with a level of energy consumption at $4,500 \mathrm{kWh} / \mathrm{t} \mathrm{NaOH}$. At the middle of the 1970s, when the first commercial plant based on the ion exchange membrane process started to produce chlor-alkali products, the total energy consumption was more than 3,900 kWh/ NaOH, which included the consumption of steam for concentrating: caustic soda. In the decade from the middle of the 1970 s to the middle of the 1980 s, when R\&D activities were conducted intensively by the Japanese companies; the energy efficiency of the ion exchange menbrane process was improved significantly. Its total energy consumption soon surpassed the level of $3,200 \mathrm{kWh} / \mathrm{t} \mathrm{NaOH}$ of the mercury process, and by the middle of the $1980 \mathrm{~s}$, the electric power consumption had reached $2,100 \mathrm{kWh} / \mathrm{t} \mathrm{NaOH}$. Since then, the electric power consumption has remained almost unchanged at the same level. Although the theoretical power consumption for chlor-alkali production is calculated as 1,480 $\mathrm{kWh} / \mathrm{t} \mathrm{NaOH}$, the current level of $2,100 \mathrm{kWh} / \mathrm{t} \mathrm{NaOH}$ is considered by many industry experts to be fairly close to the practical limit with the current technological design (Seko, Ogawa, Ono, and Suzuki, 1984$)^{77}$.

On the other hand, the mercury process, which does not require any steam for the concentration of caustic soda, consumed electric power of $3,200 \mathrm{kWh} / \mathrm{NaOH}$ at the beginning of the 1970s. The smaller figure of energy consumption made the mercury process economically superior to the jon exchange membrane process at that time. The energy consumption of the mercury process has remained almost unchanged until now, at the same level of $3,200 \mathrm{kWh} / \mathrm{t} \mathrm{NaOH}$. In the case of the diaphragm process, its energy consumption had been larger than that of the mercury process. In the middle of the 1970s, when the government decision on the phase out of the mercury process, the energy consumption of the diaphragm process was much smaller than that of the ion exchange membrane process. Since then, however, the extent of progress in the technological performance of the diaphragm process has been small, and its total energy consumption, which is currently at the level of 3,120

\footnotetext{
Some people expect that it is possible to reduce the electrical energy consumption of the ion exchange membrane process by another 20 to $25 \%$ with the application of a fuel depolarized cathade, which has mot yel remched the level of industrialization. Some companies are also working on technologies which can produce dinectly $50 \%$ caustic soda (Nakao and Myake, 1995, Shimohira, Saito, Saito, and Miyake, 1993). If successful,
} 
KWh/t NaOH, has been surpassed by that of the ion exchange membrane process. In other words, while there has been basically no change in the energy consumption of the mercury process and very little improvement in the case of the diaphragm process since the $1970 \mathrm{~s}$, the ion exchange membrane process has reduced its energy consumption significantly, advancing it from the least to the most economically efficient technology ${ }^{78}$.

The quality of caustic soda produced also indicated the extent of technological progress of the ion exchange membrane process. To produce caustic soda of a high concentration, the ion exchange membrane needs to maintain its chemical stability in the strong alkali environment, and that requires technological sophistications in the chemical composition of the jon exchange membrane. In 1975, when the first commercial plant using the ion exchange membrane process started its operation, the concentration of caustic soda was $17 \%$. Since commercial applications of caustic soda normally require a concentration which is close to $50 \%$, a further step is necessary to increase the caustic concentration, consuming an extra amount of energy. As the additional energy is normally provided in the form of steam, it raises the production cost of the ion exchange membrane process. Since the middle of the 1970 s, the concentration of caustic soda has been increased, and its current level is approximately $35 \%$, implying that the steam cost for concentrating caustic soda has been reduced. Furthermore, the quality of caustic soda has been improved, as impurities contained in caustic soda have been reduced. The concentration of sodium chloride, a major substance among various impurities, in caustic soda has dropped from the level of hundreds parts per million (ppm) in the 1970 s to just a few ppm in the current period.

\subsection{Modification of Regulatory Schedule and Adoption of the Ion Exchange Membrane Process}

The rapid progress in the technological performance of the ion exchange membrane process was carefully monitored and assessed by the academic experts of the Evaluation Committee.

What will temove the necessity of using stean to further increase the concentration of caustic soda. This technological progress, however, might increase the consumption of electric power.

7\% While the electric power consumption of the ion exchange membrane process declined significantly, the current density las increased, from $2.5 \mathrm{kA} / \mathrm{m}^{2}$ to the present levell of $5 \mathrm{kA} / \mathrm{m}^{3}$. This has contributed to $\mathrm{keeping}$ the nominal capial cost for the process conversion almost unchanged over the 20 years. On the other hand, ion exchange membanes in the high carrent density operation usually do not show their good performance which would be obisined at lower cument density, and cell operation becomes more difficult because the increasing ourrent requires special cell design to achieve a homogeneous electrolyte distribution in the cell and the reliable 
Their final conclusion that the ion exchange membrane process had reached a stage at which it could be applied for industrial applications prompted the Countemeasures Council to review the regulatory schedule which had been rigidly fixed in a short-time framework.

In September 1979 the Countermeasures Council at its fifth neeting made a decision that the remaining mercury process plants were to be converted by the end of 1984 (Council for the Promotion of Countermeasures against Mercury Pollution, 1979). This extension of the deadline for process conversion enabled the operators of mercury-based plants to adopt the more efficient ion exchange membrane process in the second phase of the government program for process conversion, instead of the diaphragm process. Some manufacturers, particularly those whose chlor-alkali production had heavily depended on the mercury process, argued that they would need more time to see whether the newlly develloped. membrane process could be reliably used at the industrial level Japan Soda Industry Association, 1980b; Katsumura, 1979). Nevertheless, the Countermeasures Council maintained its original schedule for the completion of process conversions at subsequent meetings (Council for the Promotion of Countermeasures against Mercury Pollution, 1980, 1981, 1982).

Subsequently, the ion exchange membrane process technologies developed by the innovating companies came to be adopted by other chlor-alkali producers in Japan. By using Table 4-27, Table 4-28, Table 4-29, Table 4-31, Table 4-32, and Table 4-33, we obtain Table 4-19, which shows the adoption of the ion exchange membrane process at chlor-alkali plants in chronological order.

Table 4-19 Adoption of the lon Exchange Membrane Process by Chlor-Alkali Producers in Japan

\begin{tabular}{|l|l|l|}
\hline Year & \multicolumn{1}{|c|}{ Plant Site } & \multicolumn{1}{|c|}{ Technology Supplicr } \\
\hline 1975 & Asahi Chemical Industry, Nobeoka & Asahi Chemical Industry \\
\hline 1976 & Denki Kagaku Kogyo, Ohme & Asahi Chemical Industry \\
\hline 1977 & Tokuyama Soda, Tokuyama & Tokuyama Soda \\
\hline 1978 & Asahi Glass, Osaka & Asahi Glass \\
\hline 1980 & Nippon Carbide, Uozu & Asahi Glass \\
\cline { 2 - 3 } & Showa Enso, Gushikawa & CEC \\
\hline 1981 & Osaka Soda, Amagasaki & CEC \\
\hline 1982 & Tsurumi Soda, Tsurumi & Asahi Glass \\
\cline { 2 - 3 } & Mitsui Toatsu Chemical, Nagoya & CEC \\
\hline
\end{tabular}

discharging device. Currently, one of the targets of R\&D activities concening the ion exchange membrat process is to ovetcome these technical difficulties (e.g. Nakao, Shimohira, and Takechi. 1998 ). 


\begin{tabular}{|c|c|c|}
\hline \multirow[t]{8}{*}{1983} & Nikkei Kako, Kanbara & Asahi Chemical Industry \\
\hline & Kashima Chlorine \& Alkali, Kashima & Asahi Glass \\
\hline & Nankai Chemical Industry, Tosa & Asahi Glass \\
\hline & Mitsui Toatsu Chernical, Ohmuta & CEC \\
\hline & Osaka Soda, Matsuyama & $\mathrm{CEC}$ \\
\hline & Toyo Soda, Yokkaichi & $\mathrm{CEC}$ \\
\hline & Kanto Denka Kogyo, Mizushima & $\mathrm{CEC}$ \\
\hline & Tokuyama Soda, Tokuyama & $\mathrm{CEC}$ \\
\hline \multirow[t]{10}{*}{1984} & Sumitomo Chemical, Ohita. & $\mathrm{CEC}$ \\
\hline & Confidential & CEC \\
\hline & Confidential & $\mathrm{CEC}$ \\
\hline & Chiba Chlorine \& Alkali, Chiba & CEC \\
\hline & Ajinomoto, Kawasaki & $\mathrm{CEC}$ \\
\hline & Kansai Chlor-Alkali, Osaka & Asahi Glass \\
\hline & Hodogaya Chemical, Kolnriyama & $\mathrm{CEC}$ \\
\hline & Toa Gosei Chemical, Tokushima & CEC \\
\hline & Mitsui Toatsu Chemical, Nagoya & CEC \\
\hline & Mitsui Toatsu Chemical, Osaka & $\mathrm{CEC}$ \\
\hline \multirow[t]{8}{*}{1985} & Kureha Chemicall, Nishiki & Asahi Chemical Industry \\
\hline & Central Chemical, Kawasaki & Asahi Glass \\
\hline & Mitsubishi Chemical, Mizushima & Asahi Glass \\
\hline & Shin-etsu Chemical, Naoetsu & Asahi Glass \\
\hline & Confidential & Asahi Glass \\
\hline & Hokkaido Soda, Horobetsu & Asahi Glass \\
\hline & Toagosei Chemical, Nagoya & $\mathrm{CEC}$ \\
\hline & Osaka Soda, Kokura & CEC \\
\hline \multirow[t]{7}{*}{1986} & Okayama Chemical, Mizushima & Asahi Chemical Industry \\
\hline & Kanto Denka Kogyo, Shibukawa & Asahi Chemical Industry \\
\hline & Hokkaido Soda, Tomakomai & Asahi Glass \\
\hline & Nankai Chemical Industry, Wakayania & Asahi Glass \\
\hline & Asahi Glass, Chiba & Asahi Glass \\
\hline & Nippon Soda, Takaoka & CEC \\
\hline & Kanto Denka Kogyo, Mizushima & $\mathrm{CEC}$ \\
\hline \multirow[t]{2}{*}{1987} & Sumitomo Chemical, Kikumoto & Asahi Chemical Industry \\
\hline & Toagosei Chemical, Tokushima & CEC \\
\hline \multirow[t]{2}{*}{1988} & Hodogaya Chemical, Kohriyama & CEC \\
\hline & Confidential & CEC \\
\hline \multirow[t]{3}{*}{1989} & Mitsubishi Chemical, Kurosaki & Asahi Glass \\
\hline & Asahi Glass, Kashima & Asahi Glass \\
\hline & Kanegafuchi Chemical, Takasago & $\overline{\mathrm{CEC}}$ \\
\hline 1995 & Tosoh & $\mathrm{CEC}$ \\
\hline
\end{tabular}


As we cain see, in the second half of the 1970 s, the ion exchange membrute wrocess whs initially installed at chlor-alkali plants by the innovating compantes which had developed technologies by themselves, that is, Asahi Chenical Industry, Tokuyama Soda. and Asalt: Glass. Although at that time the technological performance of the ion exchange membratis process was not particularly favorable, compared with the diaphragm process, thesen companies could gain experiences of actually using their own technologies for industrial production and utilize these practical experiences for future developments of their technologies for the ion exchange membrane process. As further progress had been achieved in the technological performance, other chlor-alkali producers gradually started to introduce the ion exchange membrane process in the early 1980s. In the same period, CEC joined the three early movers in providing technologies for the ion exchange membrane process to chloralkali producers.

As chlor-alkali producers were hit by the second oil crisis at that time, severely deteriorating their financial situations, MITI contacted individual companies to see the progress on their conversion plans. It was then becoming clear that some of the companies would not be able to finish converting their mercury-based plants by the end of 1984 , the deadline which had been originally set by the Countermeasures Council. The Countermeasures Council convened again in December 1983 to discuss the issue and made a decision to extend the deadline to the middle of 1986, on the condition that the companies would start to convert their mercury-based plants by the end of 1984 (Council for the Promotion of Countermeasures against Mercury Pollution, 1983). As Table 4-19 indicates, most of the introductions of the ion exchange membrane process subsequently took place in a few years just before the extended deadline. The last chlor-alkali plant based on the mercury process was finally converted at the end of June in 1986. It was 13 years after the government's initial decision to phase out the mercury process in the Japanese chlor-alkali industry.

Figure 4-9 shows the overall trends in production capacities based on the mercury process, the diaphragm process, and the ion exchange membrane process from the early 1970 s. (Detailed data are given in Table 4-25 in Appendix at the end of this chapter.) 


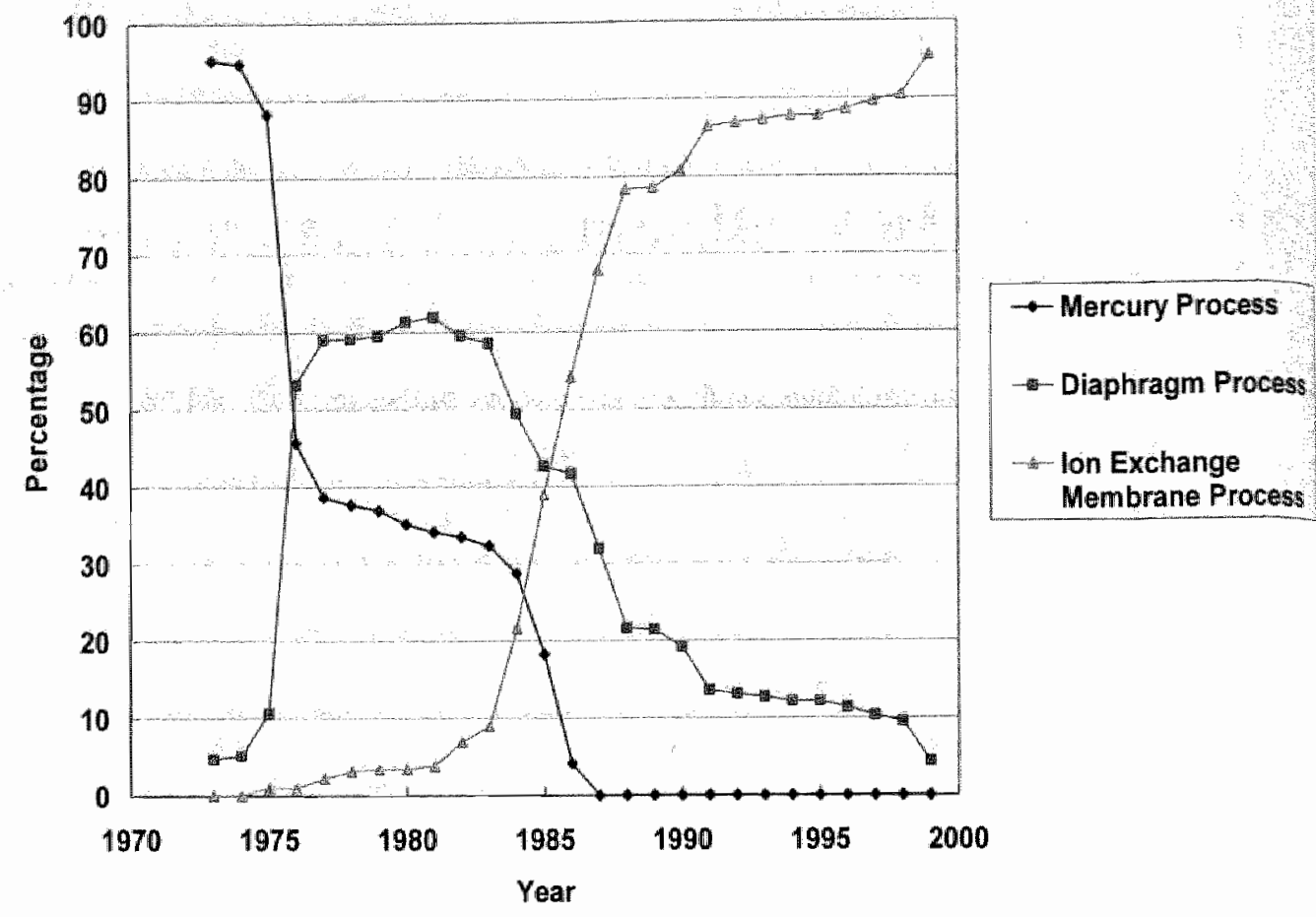

Figure 4-9 Production Capacities of the Mercury, Diaphragm, and Ion Exchange Membrane Processes in the Japanese Chlor-Alkali Industry

In 1973, just before the government's decision to phase out the mercury process, the mercury process accounted for more than $95 \%$ of the total production capacities whereas the diaphragm process was negligible. Following the government mandate for the phase out of the mercury process to be implemented with a rigid schedule, most of the mercury process plants were converted to the diaphragm process, with its energy consumption much lower than that of the ion exchange membrane process, making it the only clean technology which was feasible for industrial applications at that time. Its share was immediately raised to more than $60 \%$ in just seven years while the share of the mercury process declined rapidly.

In the meantime, the ion exchange membrane process began to emerge in the middle of the 1970s and was undergoing significant technological improvement. Due to the rapid rise of energy prices following the oil crisis which occurred in the 1970s, the disadvantage of the diaphragm process in terms of a higher production cost than the ion exchange membrane 
process became much worse. Furthermore, while the existing mercury-based plants were being converted to the diaphragm process rapidly in the late $1970 \mathrm{~s}$, a serious concern was growing among chlor-alkali producers who had already finished converting their plants to the diaphragm process. The production cost with the diaphragm process becane higher than that with the mercury process, and the quality of caustic soda produced with the diaphragm process was not sufficiently high, as Table 4-5 shows that the diaphragm process produced caustic soda which contained much more impurities, notably sodiun chloride, making it inappropriate for use in some industrial applications.

Accordingly, the newly developed ion exchange membrane process started to replace the mercury process and later the diaphragm process as well. When the mercury process was completely abolished in 1986 , the installed capacity of the ion exchange membrane process accounted for more than half of the total production capacity. Since then, the share of the ion exchange membrane process has increased steadily, reaching more than $95 \%$ in 1999 .

\subsection{Costly Transition from the Mercury Process to the Diaphragm Process and then to the lon Exchange Membrane Process}

Figure 4-9 shows that the diaphragm process has decreased its share steadily since the early $1980 \mathrm{~s}$, with the once dominant diaphragm process currently accounting for less than $5 \%$ of the total production capacities in Japan. This suggests that the mercury-based plants which had been converted to the diaphragm process were shortly converted again to the ion exchange membrame process. We thus examined how long the chlor-alkali plants which had introduced the diaphragm process were operated. Figure 4-10 shows the operating period of the diaphragm process adopted at chlor-alkali plants in Japan. (Detailed data are given in Tabile 4-34 in Appendix at the end of this chapter.) 


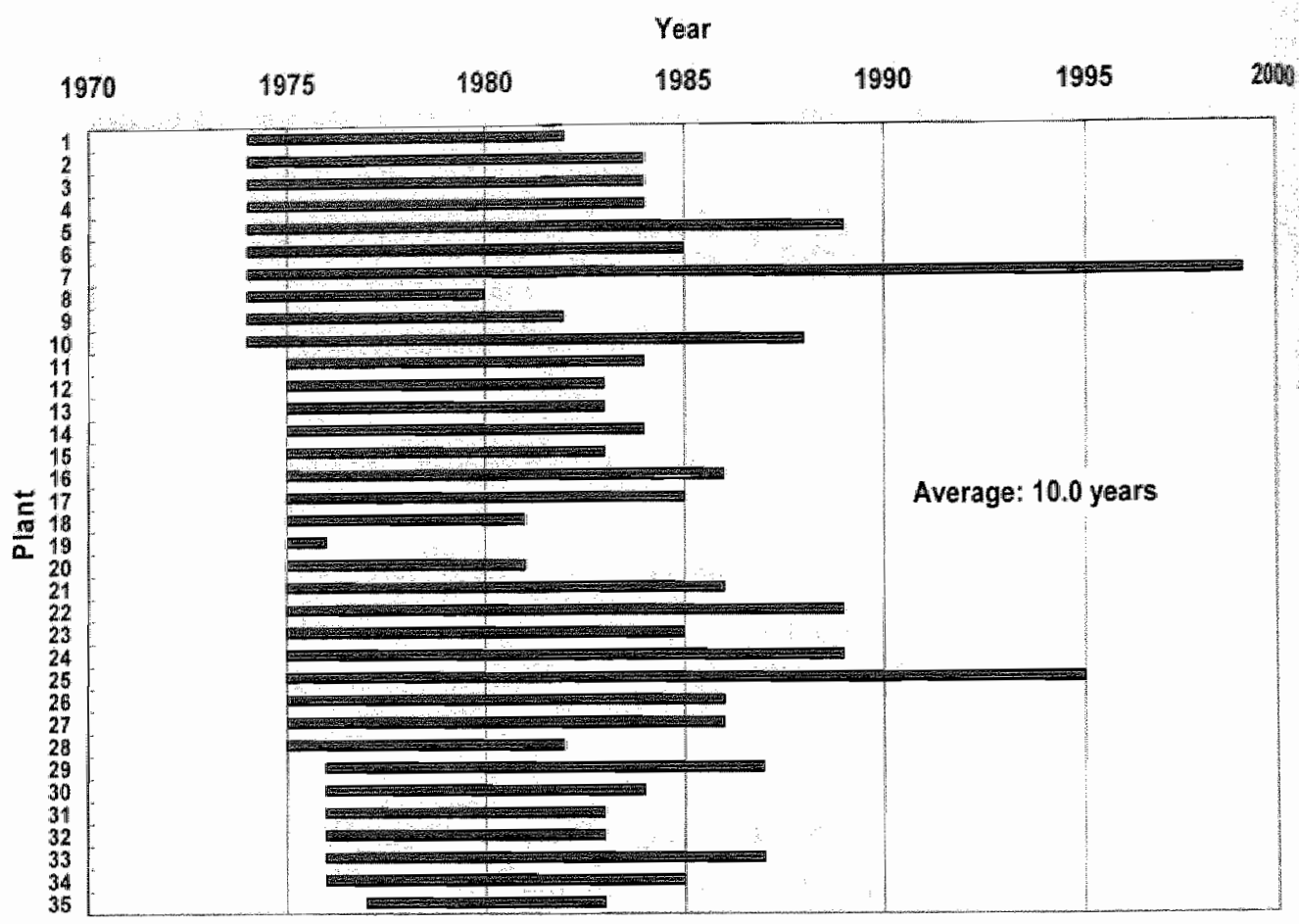

Figure 4-10 Operating Period of the Diaphragm Process at Chllor-Alkali Plants in Japan

As you can see, all of the chlor-alkali plants which had been converted to the diaphragm process following the government decision on the phase out of the mercury process were converted again to the ion exchange membrane process. As a result, the operating period of these diaphragm pllants was very short, an average of only 10 years. That is far shorter than the normal period of approximately 40 years for plant operation in the chemical process industry (Soctety of Chemical Engineers of Japan, 1998). In retrospect, we could argue that the investment needed to convert mercury-based plants to the diaphragm process was scrapped prematurely.

Process conversions at this scale normally require a signilicant amount of investment in the industry. Table 4-20 gives the composition of the investments used for the conversions of the mercury-based plants in Japan from the beginning of the process conversion program in the early 1970 s to its completion in the late 1980s. The investment costs include those for the comversion of the mercury process either to the diaphragm process or to the ion exchange 
membrane process and those for the conversion of the newly adopted diaplaragm process to the ion exchange membrane process. The investment costs are compared with the annual turnovers of the Japanese chlor-alkali industry as a whole.

Table 4-20 Investment Costs for the Process Conversion in the Japanese Chllor-Alkali Industry

\begin{tabular}{|c|c|c|c|c|}
\hline $\begin{array}{l}\text { Fiscal } \\
\text { Year }\end{array}$ & $\begin{array}{c}\text { Mercury Process }> \\
\text { Diaphragm or lon Exchange } \\
\text { Membrane Process }\end{array}$ & $\begin{array}{c}\text { Diaphragm Process - } \\
\text { Ion Exchange } \\
\text { Membrane Process }\end{array}$ & $\begin{array}{c}\text { Total } \\
\text { Investment }\end{array}$ & $\begin{array}{l}\text { Industry } \\
\text { Tumover }\end{array}$ \\
\hline 1973 & \multirow[t]{5}{*}{231.8} & \multirow[t]{5}{*}{0} & \multirow[t]{5}{*}{231.8} & \multirow[t]{5}{*}{$630.9^{\mathrm{a}}$} \\
\hline 1974 & & & & \\
\hline 1975 & & & & \\
\hline 1976 & & & & \\
\hline 1977 & & & & \\
\hline 1978 & \multirow[t]{4}{*}{1.9} & \multirow[t]{4}{*}{2.7} & \multirow[t]{4}{*}{4.6} & \multirow[t]{4}{*}{594.7} \\
\hline 1979 & & & & \\
\hline 1980 & & & & \\
\hline 1981 & & & & \\
\hline 1982 & 3.7 & 1.3 & 5.0 & 172.1 \\
\hline 1983 & 5.6 & 10.0 & 15.6 & 184.5 \\
\hline 1984 & 11.2 & 5.0 & 16.2 & 190.2 \\
\hline 1985 & 18.6 & 5.7 & 24.3 & 180.4 \\
\hline 1986 & 14.5 & 6.0 & 20.5 & 167.3 \\
\hline 1987 & 0 & 14.4 & 14.4 & 169.0 \\
\hline 1988 & 0 & 1.6 & 1.6 & 185.0 \\
\hline Total & 287.3 & 46.7 & 334.0 & - \\
\hline
\end{tabular}

Figures are expressed in Japanese billion yen.

a: The annual turnovers for 1973 and 1974 are assumed to be the same as that for 1975 . Sotwces: Investment: Japanese Ministry of International Trade and Industry (1989). Industry Turnover: Japanese Ministry of lnternational Trade and Indwstry (1985; 1990)

The process conversions which were undertaken from 1973 to 1988 cost the Japanese chlor-alkali industry 334 billion yen as a whole. Of the total cost of 287.3 billion yen invested in converting the existing mercury-based plants to the diaphragm or ion exchange membrane process, 231.8 billion yen was spent during the first phase of the process conversion program which was implemented from 1973 to 1977 . That means that approximately $80 \%$ of the total investment for converting mercury-based plants was made at the initial stage of the process conversion program.

At this stage of the conversion program, as indicated in Table 4-4, 41 plants introduced the diaphragm process, the only clean technology which it had been well-established could be 
reliably used for industrial applications. Only 3 plants, as Table 4-19 shows, adopted the ion exchange membrane process; whose technological development was still in its infancy. Assuming that the investment cost for the construction of a plant is equal between the diaphragm process and the ion exchange membrane process. more than $90 \%$ of the investment of 231.8 billion yen spent in the first phase of the conversion program was used to introduce the diaphragn process, rather than the ion exchange membrane process, during the first phase of the conversion program. And almost all of these plants were later switched to the newly developed ion exchange membrane process.

This amount of financial resources constituted a considerable burden on the chlor-alkali industry, which had already been severely hit by the rise in energy prices following the oil crisis in the $1970 \mathrm{~s}$. The sum of the industry's annual turnovers in the first phase of the conversion program, that is, from 1973 to 1977 , was 630.9 billion yen. The amount of financial resources devoted to convert mercury-based plants to the diaphragm process, which would be converted again to the ion exchange membrane process in a very short period of time, reached more than one third of the industry's turnover in the same period. This clearly indicates that the investment necessary for process conversions had a significant impact on the financial condition of the Japanese chlor-alkali industry as a whole.

As the investment required such a large amount of financial resources in such a short period of time, chlor-alkali producers asked the government for financial support (Japan Soda Industry Association, 1974c). The Conversion Committee made a similar recommendation to provide the industry with financial resources and tax reductions for the process conversion (Committee for the Promotion of Process Conversions in the Soda Industry, 1973) ${ }^{79}$. The Ministry of Finance, however, insisting on the Polluters Pay Principle (PPP), initially claimed that all of the necessary investment should be financed by the industry (Taiima, 1997). Negotiations between MITI and the Ministry of Finance finally resulted in the agreement that Japan Development Bank and Hokkaido-Tohoku Development Finance Public Corporation ${ }^{80}$

\footnotetext{
79 The Conversion Committe also made a recomnendation to provide loans for the investments related to scrapping muteny process tacilities, most of which had not yet been depreciated completely. This recommendation, although strongly supported by chlor-alkali producers, was rejected by the Ministry of Finance (Tajum, 1997). As some of the mercury process facilities to be abolished were relatively new and lechologically sophisticated, plant operators were hoping to sell them in other countries in order to finance the necessiny investments. MITI, however, fearing to be eriticized for exporting pollution, decided that the scrapped metcury process facilitics were in principle prohibited from being exported to foreign countries (Japanese Minisury of hntarnational Tracte and lndustry, 1974).

Japan Dewelopment Bank and Hokkado olloku Developmant Finance Pubtic Corponation were merged on Octaber 1, 1999, creating the Development Bank of Japan.
} 
were to provide loans for the conversion of the mercury process to the diaphragm process in the chlor-alkali industry (Japan Soda Industry Association, 1974b). The interest rate was set to be the most preferential rate, $7.7 \%$ for the fiscal year 1974, al figure which was less favorable than for loans for technological development but better than those for general countermeasures against public nuisance. Furthermore, $70 \%$ of the investment for the process conversion and $35 \%$ of the investment for the expansion of facilities were decided to be financed by the loans from the public financial institutions.

Table 4-21 shows the sources from which plant operators financed the investment capital necessary for the first phase of the process conversion program. More than half of the total investment of 231.8 billion yen was financed through borrowings from the two public financial institutions. Together with borrowings from private financial institutions, about $90 \%$ of the total investment capital was financed through borrowings, making a heavy burden on the financial conditions of the companies.

Table 4-21 Sources of Investment Capital for the First Phase of the Process Conversion

\begin{tabular}{|l|c|r|r|}
\hline & Institution & $\begin{array}{r}\text { Interest rate } \\
\%\end{array}$ & \multicolumn{1}{c|}{$\begin{array}{c}\text { Amount } \\
\text { (billion yen) }\end{array}$} \\
\hline Borrowing & Public financial institutions & $7.9^{*}$ & $128.0(55.2 \%)$ \\
& - Japan Development Bank & 8.2 & 40.8 \\
& & 7.7 & 70.1 \\
& Hokkaido-Tohoku Development & 8.2 & 4.7 \\
& Finance Public Corporation & 7.7 & 12.4 \\
\cline { 2 - 4 } & Private Financial Institutions & $\mathrm{n} / \mathrm{a}$ & $81.6(35.2 \%)$ \\
\hline Self-financing & - & - & $22.2(9.6 \%)$ \\
\hline Total investment & - & - & 231.8 \\
\hline
\end{tabular}

* Average

Source: Japanese Ministry of Inrernational Trade and Industry (1979).

In retrospect, these financial resources could have been saved if the mercury-based plants that existed in the early 1970s had been converted directly to the ion exchange membrane process without going through the diaphragm process. To realize that route of technological change, however, a different schedule for the implementation of the government's pollicy to phase out the mercury process would have been required. If the requirement for the phase out of the mercury process had not been set to complete immediately, but implemented with some flexibility in timing, allowing more time to test and evaluate technological progress of alternative clean processes carefully, it would have been 
possible for the operators of the mercury process to switch directly to the ion exchange membrane process, avoiding this considerable waste in investment.

\subsection{Conclusion}

In this chapter, we examined the effects of environmental regulation on technological change in the Japanese chlor-alkali industry. We paid particullar attention to technological developments by those companies which had previous experiences of making innovations on chlor-alkali production technologies. At the beginning of the $1970 \mathrm{~s}$, the mercury process had become the dominant technology for chlor-alkali production, accounting for more than $95 \%$ of the production capacities of the Japanese chlor-alkali industry. The technologies used for the mercury process had been developed by several companies in Japan. Notably, Mitsui Engineering and Shipbuilding (MES), Osaka Soda, Kureha Chemical Industry, Asahi Glass, Tokuyama Soda, and Asahi Chemical Industry had been particularly innovative on the mercury process prior to the introduction of environmental regulations on mercury emissions. into the environment.

We next examined the environmental regulations introduced in Japan to deal with mercury emissions from chlor-alkali plants using the mercury process. In the 1960s Japan experienced the tragedy of the Minamata disease. Concerns were growing among the general public on the effects of mercury emitted to the environment, whether it was organic mercury, which caused the serious disease, or inorganic mercury. With public pressures increasing, the Japanese government had to take a very strong stance on the emissions of mercury from chlor-alkali plants, despite strong opposition from the chlor-alkali industry in Japan. The regulation set by the government demanded that chlor-alkali producers completely abolish the mercury process in less than five years. To facilitate the conversion of the existing mercurybased plants, the government provided financial support to chlor-alkali producers through preferential tax treatment and low-interest public loans. As the regulatory schedule for converting the mercury process to altemative clean technologies was rigidly fixed, however, most of the chlor-alkali manufacturers had no choice other than to adopt the diaphragm process. It was regarded by many as the only clean technology feasible for industrial chloralkali production at that time despite that, as the diaphragm process was less energy efficient, production costs with the diaphragm process were higher than with the mercury process. Althougl several innovative Japanese firms began to work on the diaphragm process, the 
regullatory schedule for process conversions intially lacked flexibility and did not allow sufficient time for new technological development. By 1976, wo thirds of the chlor-alkali production capacities in Japan had been converted to the diaphragm process, Overall, the technologies adopted for the diaphragm process in Japan following the government decision on the phase out of the mercury process were mostly those developed by foreign companies.

During this period, however, there were other companies who chose another type of clean technologies to replace the mercury process. Asahi Chemical Industry, Asahi Glass, and Tokuyama Soda focused their R\&D efforts on the ion exchange membrane process. These companies had earlier experiences of developing and utilizing ion exchange membranes primarily for the production of salt in the 1960 s. While the idea of using the ion exchange membrame for chlor-alkali production had existed since the 1950 s, its industrial realization was prevented by the unavailability of ion exchange membranes with chemical stability and mechanical strength that could reliably be used in the chlor-alkali electrolytic cell. Then, in the late 1960s, a new type of the ion exchange membrane developed in the United States became available to Japanese companies. That provided these companies with an opportunity to utilize their technological expertise for the improvement of ion exchange membranes for chlor-alkali production.

Shortly thereafter, the government decision to phase out the mercury process created a secure demand for mercury-free, clean technologies in the Japanese chlor-alkali industry. This provided a strong incentive for innovative companies to develop technologies for the ion exchange membrane process and to supply them to other chlor-alkali producers. In the absence of government financial support for their R\&D activities, and as the ion exchange membrane process for chlor-alkali production was still in its infancy in the early 1970 s, with its technological feasibility not yet firmly established, only those companies that had previous experience and expertise on the ion exchange membrane, that is, Asahi Chemicall Industry, Asahi Glass, and Tokuyama Soda, intensified their R\&D activities. These companies succeeded in developing their technologies for the ion exchange membrane process and started to uilize them for their own chlor-alkali plants. Through the practical experiences of using the newly developed technologies, these companies further improved the technical performance of the lion exchange membrane process.

While the ion exchange membrane process was undergoing rapid technological advancement, the disadvantage of the diaphragm process in terms of production costs was worsening, as energy prices soared following the oil crisis in the 1970s. Moreover, it had 
become clear among chlor-alkali producers that the quality of caustic soda produced by the diaphragm process was not high enough as to be used for several industrial applications. Under the circumstances, it was decided in 1977 that the implementation of the process conversion program would be interrupted for a while, and at the same time an expert committe was established to evaluate the extent of the technological progress of the newly emerging ion exchange inembrane process. The committee members, all of whom were from academic research institutes, interviewed and visited companies for detailed information on the on-going technological developments in the industry. In 1979 they finally agreed on the conclusion that the ion exchange membrane process had reached a stage ready for industrial applications.

With the expert evaluation of the technological progress, the government modified the original conversion program and postponed the deadline for the phase out of the mercury process to the middle of the 1980 s. This adjustment of the regulatory schedule allowed more time for innovative companies to undertake R\&D activities and to learn through actual experiences of operating chllor-alkali plants based on the ion exchange membrane process, promoting further progress of the promising, but not yet proved, new technology. In the end, the ion exchange membrane process had advanced to become the best technology among the three chlor-alkali processes economically as well as environmentally, and subsequently the remaining mercury-based plants were converted to the ion exchange membrane process. The phase out of the mercury process was completed in 1986, and currently almost all of the chlor-alkali plants in Japan are relying on the ion exchange membrane process. Furthermore, in addition to the environmental benefits and cost savings in the use of the ion exchange membrane process, innovative companies such as Asahi Chemical Industry, Asahi Glass, Tokuyama Sodta, and CEC are supplying their technologies to chlor-alkali producers in other countries, particullarly in Asia.

On the negative side, the mercurymbased plants which had been converted to the diaphragm process, immediately following the government decision on the phase out of the mercury process, had to be converted again to the ion exchange membrane process. The average operating period of the plants based on the diaploragm process was only ten years, a figure which is significantly shorter than the normal operating period of 40 years. This implies that a large amount of the capital investment made for the introduction of the diaphragm process, which was comparable to the industry's annual turnover at that time, was not utilized usefully untill the end of the technologies' lifetime and effectively ended up 
wasted. In retrospect, this could have been aroided if the initial policy for the phase out of the mercury process had maintained some degree of flexibility in its regulatory schedule, taking into account the state of technological development of alternative processes. As innovalions on the ion exchange membrane process were perceived to be on the horizon by several innovative companies at the time of the early 1970s, if the deadline for the phase out of the mercury process had been initially set for a later date, there could have been more time for necessary detailed experiments and evaluations of alternative technologies, and most of the mercury-based plants could have been converted directly to the ion exchange membrane process, without wasting investments on the diaphragm process.

To sum up, government policy for the phase out of the mercury process did encourage innovative companies to undertake R\&D activities on clean technologies. Applied on a 100 rigid schedule, however, the stringent regulation initially did not allow for sufficient time to see further technological progress of the newly emerging jon exchange membrane process while most of the chlor-alkali producers were induced to adopt the diaphragm process, which was to be abandoned soon. Only after the initial rigid regulatory schedule was relaxed, was the ion exchange membrane process widely adopted by the Japanese chlor-alkali industry. One of the policy implications we could draw from this case of technological change in the Japanese chlor-alkali industry is that, while stringent regulation is expected to encourage radical innovations on clean technologies, instead of incremental innovations on end-of-pipe technologies, the regulatory schedule should be sufficiently flexible incorporating accurate information on the state of technological development in industry. That will help to avoid choosing a technology which may not be the best one in the long run. This is particularly important in a case in which the speed of technological change is high and the degree of its uncertainty is large.

\section{Appendix}

\section{List of Interviewees in Japan}

Asahi Chemical Industries

- Mr. OH-HAMA Hiroshi, Corporate Auditor 
* Mr. MAMANA Masao, General Manager, Chemicals Strategic Planning Meprarinent, Chemicals Administration

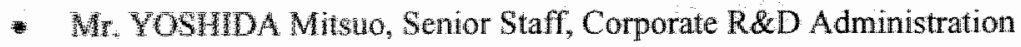

Anthens

- Mr. SATO Kimihiko, former General Manager, Technology Division

\section{Tokaymata Soda}

- Dr. SATA Toshikatsu, former Chief Researcher, Technology Research Center

- Dr. MATSUURA Shunji, Corporate Planning Division

Chlorine Engineers Corp.

- Dr. YAMAGUCHI Kenzo, Technical Advisor

Mitsubishi Chemical Corporation

- Mr. FUJII Toshiharu, General Manager, Global Enwironmental Department

\section{Stmitomo Chemical}

- Mr. FUKUNAGA Tadatsune, Manager, Environment and Safety Department

Japan Soda Industry Association

- Mr. AIKAWA Hiroaki, Director, Global Environment Department

- Mr. SAKAMOTO Akio, Manager, Public Relations Division

Japan Chentical Industry Association

- Mr. KAWAMATA Motoo, Deputy General Manager, Japan Responsible Care Council

Japow Salt Industry Association

- Mr. HANAFUSA Fumiyuki, Manager, Research Division 
- Mr. FUJII Kenya, Chemicals Division, Basic Industries Bureau

- Mr. TAJMA Keizo, former Manager, Petrochemical Group, Basic Chenicals Division, Basic Industries Bureau

Table 4-22 List of Chlor-Alkali Plants in Japan

\begin{tabular}{|c|c|c|c|c|c|}
\hline \multirow[t]{2}{*}{ Company } & \multirow[t]{2}{*}{ Site } & \multicolumn{4}{|c|}{ Capacity (NaOH $10^{3}$ tommes/year) } \\
\hline & & $\mathrm{Hg}$ & $\mathrm{D}$ & $\mathrm{MM}$ & Other \\
\hline Hokkaido Soda & Tomakomail & - & - & 132 & 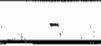 \\
\hline Tohoku Tosoh Chemical & Sakata & - & - & 54 & - \\
\hline Kureha Chemical Industry & Nishiki & - & 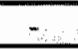 & 110 & - \\
\hline Showa Denko & Kawasaki & - & 59 & 57 & - \\
\hline Nippon Soda & Takasaki & - & - & 65 & - \\
\hline Kanto Denka Kogyo & Shibukawa & - & - & 45 & - \\
\hline Kanto Denka Kogyo & Mizushima & - & - & 58 & - \\
\hline Central Chemical & Kawasaki & - & - & 67 & - \\
\hline Tsurumi Soda & Tsurumi & - & - & 90 & - \\
\hline Nippon Light Metal & Kanbara & - & - & 50 & - \\
\hline Shin-etsu Chemical & Naoetsu & - & - & 46 & - \\
\hline Denki Kagaku Kogyo & Omi: & - & - & 52 & - \\
\hline Mitsui Chemical & Nagoya & - & - & 69 & - \\
\hline Mitsui Chemical & Osaka & - & - & 66 & - \\
\hline Mitsui Chemical & Ohmuta & - & - & 73 & - \\
\hline Toa Gosei & Nagoya & - & - & 73 & - \\
\hline Toa Gosei & Tokushima & - & - & 166 & - \\
\hline Nippon Carbide Industries & Uozu & - & - & 15 & - \\
\hline Asahi Glass & Kashima & - & 173 & 109 & - \\
\hline Asahi Glass & Chiba & - & - & 229 & - \\
\hline Asahi Glass & Kitakyushu. & - & - & 14 & 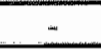 \\
\hline Kanegafuchi Chemicall Industry & Takasago & - & - & 297 & - \\
\hline Daiso & Amagasaki & - & - & 90 & - \\
\hline Daiso & Matsuyama & - & - & 43 & - \\
\hline Daiso & Kokura & 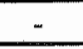 & - & 29 & - \\
\hline Nankai Chemical Industry & Wakayama & - & - & 32 & - \\
\hline Sumitomo Chemical & Ehime & - & - & 112 & - \\
\hline Sumitomo Chemical & Oita & - & - & 13 & - \\
\hline Nippon Paper Industries & Iwakuni & - & 27 & - & - \\
\hline Tosoh & Yokkaichi & - & - & 76 & - \\
\hline Tosoh & Nanyo & - & 163 & 423 & - \\
\hline Tokuyama & Tokuyama & - & - & 342 & - \\
\hline Mitsubishi Chemical & Mizushima & - & - & 116 & - \\
\hline Mitsubishi Chemical & Kurosaki & - & - & 35 & - \\
\hline Asahi Chemical Industry & Nobeoka & - & $=$ & 142 & - \\
\hline
\end{tabular}




\begin{tabular}{|c|c|c|c|c|c|}
\hline Showa Chemical & Gushikawa & - & - & 3 & - \\
\hline Kashima Chlorine \& Alkali & Kashima & - & - & 354 & - \\
\hline Chiba Chlorine \& Alkali & Chiba & - & - & 94 & - \\
\hline Kansai Chlor-Alkali & Osaka & - & - & 38 & - \\
\hline Okayama Chemical & Mizushima & - & - & 129 & - \\
\hline Total & & 0 & 3,376 & 32,064 & 0 \\
\hline
\end{tabular}

Data as of 1998.

Hg. Mercury process

D: Diaphragm process

IM: Ion exchange membrane process

Monthly production capacities have been transformed to annual production capacities: monthly capacity $\times 12 \times 0.86=$ annual capacity.

Source: Japar Soda Industry Association (1998b).

Table 4-23 Japanese Patents on the Mercury, Diaphragm, and Ion Exchange Membrane Processes Granted to Japanese Firms

\begin{tabular}{|c|c|c|c|}
\hline $\begin{array}{c}\text { Year of patent } \\
\text { applications }\end{array}$ & Mercury Process & Diaphragm Process & $\begin{array}{c}\text { Ion Exchange Membrane } \\
\text { Process }\end{array}$ \\
\hline 1968 & 18 & 1 & 3 \\
\hline 1969 & 14 & 2 & 7 \\
\hline 1970 & 20 & 6 & 3 \\
\hline 1971 & 21 & 4 & 5 \\
\hline 1972 & 30 & 7 & 11 \\
\hline 1973 & 2 & 11 & 21 \\
\hline 1974 & 11 & 18 & 27 \\
\hline 1975 & 9 & 10 & 45 \\
\hline 1976 & 7 & 24 & 60 \\
\hline 1977 & 2 & 16 & 53 \\
\hline 1978 & - & 8 & 46 \\
\hline 1979 & - & 8 & 47 \\
\hline 1980 & - & 9 & 87 \\
\hline 1981 & - & 6 & 71 \\
\hline 1982 & - & 1 & 30 \\
\hline 1983 & - & 1 & 20 \\
\hline 1984 & - & 1 & 20 \\
\hline 1985 & - & 0 & 10 \\
\hline 1986 & - & 0 & 12 \\
\hline 1987 & - & 0 & 7 \\
\hline Total & 1072 & & 4680 \\
\hline & & 1064 & 0 \\
\hline
\end{tabular}


Table 4-24 Energy Consumption of the Mercury, Diaphragm, and Ion Exehange Membrane Processes

\begin{tabular}{|c|c|c|c|}
\hline Year & $\begin{array}{l}\text { Mercury } \\
\text { Process } \\
\end{array}$ & $\begin{array}{c}\text { Diaphragm } \\
\text { Process } \\
\end{array}$ & $\begin{array}{c}\text { Ion Exchange Membrane } \\
\text { Process }\end{array}$ \\
\hline 1970 & 3,200 & - & 4,450 \\
\hline 1971 & $=$ & - & - \\
\hline 1972 & 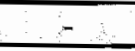 & $=$ & 2 \\
\hline 1973 & $=$ & - & - \\
\hline 1974 & 3,200 & 3,350 & $=$ \\
\hline 1975 & - & - & 3,950 \\
\hline 1976 & - & $=$ & 3,150 \\
\hline 1977 & $=$ & $\approx$ & 3,070 \\
\hline 1978 & - & $=$ & 3,020 \\
\hline 1979 & - & $=$ & 2,950 \\
\hline 1980 & - & $=$ & 2,720 \\
\hline 1981 & - & $=$ & 2,500 \\
\hline 1982 & $=$ & - & 2,500 \\
\hline 1983 & - & - & 2,500 \\
\hline 1984 & - & - & 2,400 \\
\hline 1985 & $=$ & - & - \\
\hline 1986 & - & - & - \\
\hline 1.987 & $=$ & - & - \\
\hline 1988 & $=$ & - & $=$ \\
\hline 1989 & $=$ & - & $=$ \\
\hline 1990 & - & - & $=$ \\
\hline 1991 & - & - & - \\
\hline 1992 & - & $-i$ & - \\
\hline 1993 & - & - & - \\
\hline 1994 & - & - & - \\
\hline 1995 & - & $=$ & $=$ \\
\hline 1996 & - & $=$ & $=$ \\
\hline 1997 & 3,200 & 3,120 & 2,400 \\
\hline
\end{tabular}

Sources:

Mercury Process: 1970: Kuhn (1971). 1974: Japan Soda Industry Association (1975). 1997: Japan Soda Industry Association (1998b).

Diaphragm Process: 1974: Japan Soda Industry Association (1975). 1997: Japan Soda Industry Association (1998b).

Ion Exchange Membrane Process: 1970: Chatterjec (1984). 1975-1984: Asahi Chemical Industry (see Table 4-18). 1997: Oh-hama, Hamada, and Yoshida (1998).

Table 4-25 Production Capacities of the Mercury Process, Diaphragm Process, and Ion Exchange Membrane Process in the Japanese Chlor-Alkali Industry

\begin{tabular}{|c|c|c|c|c|}
\hline Year & Mercury Process & Diaphragm Process & Ion Exchange & Total Production \\
\hline
\end{tabular}




\begin{tabular}{|c|c|c|c|c|}
\hline & & & Membrane Process & Capacity \\
\hline 1973 & $3,660(95.3 \%)$ & $180(4.7 \%)$ & 0 & 3,840 \\
\hline 1974 & $3,605(94.8 \%)$ & $196(5.2 \%)$ & 0 & 3,801 \\
\hline 1975 & $3,479(88.3 \%)$ & $421(10.7 \%)$ & $41(1.0 \%)$ & 3,941 \\
\hline 1976 & $2,064(45.8 \%)$ & $2,403(53.3 \%)$ & $41(0.9 \%)$ & 4,508 \\
\hline 1977 & $1,747(38.7 \%)$ & $2,667(59.1 \%)$ & $102(2.2 \%)$ & 4,516 \\
\hline 1978 & $1,697(37.7 \%)$ & $2,667(59.2 \%)$ & $142(3.1 \%)$ & 4,506 \\
\hline 1979 & $1,652(37.0 \%)$ & $2,655(59.6 \%)$ & $152(3.4 \%)$ & 4,459 \\
\hline 1980 & $1,591(35.2 \%)$ & $2,771(61.4 \%)$ & $152(3.4 \%)$ & 4,514 \\
\hline 1981 & $1,575(34.2 \%)$ & $2,852(62.0 \%)$ & $172(3.8 \%)$ & 4,599 \\
\hline 1982 & $1278(33.5 \%)$ & $2,273(59.6 \%)$ & $263(6.9 \%)$ & 3,814 \\
\hline 1983 & $1,234(32.4 \%)$ & $2,232(58.6 \%)$ & $343(9.0 \%)$ & 3,809 \\
\hline 1984 & $1,098(28.8 \%)$ & $1,885(49.5 \%)$ & $826(21.7 \%)$ & 3,809 \\
\hline 1985 & $681(18.3 \%)$ & $1,589(42.7 \%)$ & $1,448(39.0 \%)$ & 3,718 \\
\hline 1986 & $144(4.1 \%)$ & $1,445(41.7 \%)$ & $1,880(54.2 \%)$ & 3,469 \\
\hline 1987 & 0 & $1,174(32.0 \%)$ & $2,489(68.0 \%)$ & 3,663 \\
\hline 1988 & 0 & $770(21.6 \%)$ & $2,793(78.4 \%)$ & 3,563 \\
\hline 1989 & 0 & $788(21.5 \%)$ & $2,884(78.5 \%)$ & 3,672 \\
\hline 1990 & 0 & $751(19.2 \%)$ & $3,156(80.8 \%)$ & 3,907 \\
\hline 1991 & 0 & $531(13.6 \%)$ & $3,381(86.4 \%)$ & 3,912 \\
\hline 1992 & 0 & $522(13.1 \%)$ & $3,459(86.9 \%)$ & 3,981 \\
\hline 1993 & 0 & $511(12.7 \%)$ & $3,524(87.3 \%)$ & 4,035 \\
\hline 1994 & 0 & $493(12.2 \%)$ & $3,544(87.8 \%)$ & 4,037 \\
\hline 1995 & 0 & $493(12.2 \%)$ & $3,566(87.8 \%)$ & 4,059 \\
\hline 1996 & 0 & $473(11.4 \%)$ & $3,689(88.6 \%)$ & 4,162 \\
\hline 1997 & 0 & $449(10.3 \%)$ & $3,887(89.7 \%)$ & 4,336 \\
\hline 1998 & 0 & $190(4.4 \%)$ & $4,155(95.6 \%)$ & 4,345 \\
\hline 1999 & 0 & $4,008(90.5 \%)$ & 4,430 \\
\hline
\end{tabular}

Figures are expressed in $10^{3}$ tonnes of $100 \% \mathrm{NaOH}$ per year.

a: production capacity as of the end of March of each year

b. until 1981 annual production capacity = monthly production capacity $\times 12$ monihs; since 1982 production capacity = monthly production capacity $\times 12$ months $\times 0.846$ c: $15.4 \%=4.7 \%$ (maintenance and repair) $+10.7 \%$ (day-night fluctuation of power load) Sources: Japan Soda Industry Association (1995: 19996).

Table 4-26 Supply of the Diaphragm and Ion Exchange Membrane Processes by Japanese Firms

\begin{tabular}{|c|c|c|}
\hline Year & Diaphragm Process & Ion Exchange Membrane Process \\
\hline 1971 & 0 & 0 \\
\hline 1972 & 0 & 0 \\
\hline 1973 & 0 & 0 \\
\hline 1974 & 7 & 0 \\
\hline 1975 & 11 & 1 \\
\hline
\end{tabular}




\begin{tabular}{|c|c|c|}
\hline 1976 & 6 & 1 \\
\hline 1977 & 1 & 2 \\
\hline 1978 & 3 & 1 \\
\hline 1979 & 1 & 1 \\
\hline 1980 & 0 & 2 \\
\hline 1981 & 0 & 4 \\
\hline 1982 & 0 & 4 \\
\hline 1983 & 0 & 10 \\
\hline 1984 & 0 & 10 \\
\hline 1985 & 0 & 11 \\
\hline 1986 & 0 & 11 \\
\hline 1987 & 0 & 9 \\
\hline 1988 & 0 & 6 \\
\hline 1989 & 0 & 9 \\
\hline 1990 & 0 & 2 \\
\hline 1991 & 0 & 6 \\
\hline 1992 & 0 & 3 \\
\hline 1993 & 0 & 7 \\
\hline 1994 & 0 & 9 \\
\hline 1995 & 0 & 4 \\
\hline 1996 & 0 & 12 \\
\hline 1997 & 0 & 12 \\
\hline 1998 & 0 & 16 \\
\hline 1999 & 0 & 11 \\
\hline Total & 0 & 0 \\
\hline
\end{tabular}

Calculation based on Table 4-27, Table 4-28. Table 4-29, Table 4-30. Table 4-31, Table 4-32, and Table 4-33.

Table 4-27 Supply List of the Ion Exchange Membrane Process by Asahi Chemical Industry

\begin{tabular}{|l|c|c|}
\hline \multicolumn{1}{|c|}{ Plant Site } & Start-up & $\begin{array}{c}\text { Capacily } \\
\text { (t NaOH/year) }\end{array}$ \\
\hline $\begin{array}{l}\text { Asahi Chemical Industry } \\
\text { Nobeoka, Japan }\end{array}$ & $1975 / 77 / 82 / 86 / 91$ & 160,000 \\
\hline $\begin{array}{l}\text { Denki Kagaku Kogyo } \\
\text { Ohme, Japan }\end{array}$ & 1976 & 61,000 \\
\hline $\begin{array}{l}\text { Saskatoon Chemicals } \\
\text { Saskatoon, Canada }\end{array}$ & 1977 & 30,000 \\
\hline $\begin{array}{l}\text { St. Anne Chemicals } \\
\text { Nackawic, Canada }\end{array}$ & 1979 & 10,000 \\
\hline $\begin{array}{l}\text { Carter Holt Harvey Pulp and Paper } \\
\text { Kinleith, New Zealand }\end{array}$ & 1981 & 10,000 \\
\hline $\begin{array}{l}\text { Tasman Pulp and Paper } \\
\text { Kawerau, New Zealand }\end{array}$ & $1982 / 89$ & 12,000 \\
\hline
\end{tabular}




\begin{tabular}{|c|c|c|}
\hline $\begin{array}{l}\text { Akzo Nobel Chemicals } \\
\text { Rotterdam, The Netherlands }\end{array}$ & $1983 / 85$ & 300,000 \\
\hline $\begin{array}{l}\text { Nihon Keikinzoku } \\
\text { Kanbara, Japan }\end{array}$ & $1983 / 89$ & 52,000 \\
\hline $\begin{array}{l}\text { Kureha Chemical Ind. } \\
\text { Nishiki, Japan }\end{array}$ & $1985 / 90 / 97$ & 104,000 \\
\hline $\begin{array}{l}\text { Okayama Chemical } \\
\text { Mizushima, Japan }\end{array}$ & $1986 / 87 / 89 / 96$ & 126,000 \\
\hline $\begin{array}{l}\text { Yanguoxia Chemical Plant } \\
\text { Lanzhou, China }\end{array}$ & 1986 & 10,000 \\
\hline $\begin{array}{l}\text { Kanto Denka Kogyo } \\
\text { Shibukawa, Japan }\end{array}$ & 1986 & 54,000 \\
\hline $\begin{array}{l}\text { P.T. Sasa Inti } \\
\text { Probolinggo, Indonesia }\end{array}$ & $1986 / 88$ & 10,000 \\
\hline $\begin{array}{l}\text { Qiqihar General Chemical Factory } \\
\text { Qigihar, China }\end{array}$ & $1986 / 91$ & 30,000 \\
\hline $\begin{array}{l}\text { Sumitomo Chemical } \\
\text { Niihama, Japan }\end{array}$ & $1987 / 89 / 92 / 96$ & 113,000 \\
\hline $\begin{array}{l}\text { Daku Chemical Factory } \\
\text { Tianjin, China }\end{array}$ & $1987 / 90 / 96$ & 80,000 \\
\hline $\begin{array}{l}\text { Niachlor (Olin) } \\
\text { Niagara Falls, USA }\end{array}$ & $1987 / 98$ & 230,000 \\
\hline $\begin{array}{l}\text { Beijing No. } 2 \text { Chemical Factory } \\
\text { Beijing, China }\end{array}$ & 1987 & 20,000 \\
\hline $\begin{array}{l}\text { Sentrachem Ltd. (NCP Chlorkop) } \\
\text { Kempton Park, South Africa }\end{array}$ & $1988 / 90 / 96$ & 92,000 \\
\hline $\begin{array}{l}\text { Xuzhou Electrochemical Factory } \\
\text { Xuzhou, China }\end{array}$ & $1988 / 95$ & 50,000 \\
\hline $\begin{array}{l}\text { Oriental Chemical Industry } \\
\text { Kunsan, South Korea }\end{array}$ & $1991 / 95 / 96$ & 43,000 \\
\hline $\begin{array}{l}\text { Yunnan Chemical Works } \\
\text { Kunming, China }\end{array}$ & 1991 & 20,000 \\
\hline $\begin{array}{l}\text { Baling Petrochemical } \\
\text { Yueyang, China }\end{array}$ & $1993 / 95 / 98$ & 70,000 \\
\hline $\begin{array}{l}\text { Jidong Chemicals Plant } \\
\text { Tanshan, China }\end{array}$ & 1993 & 10,000 \\
\hline $\begin{array}{l}\text { Samsung Fine Chemicals } \\
\text { Ulsan, South Korea }\end{array}$ & $1994 / 95 / 99$ & 133,000 \\
\hline $\begin{array}{l}\text { Formosa Plastics } \\
\text { Kaohsiung, Taiwan }\end{array}$ & 1994 & 24,000 \\
\hline $\begin{array}{l}\text { Modi Alkalies \& Chemicals } \\
\text { Alwar, India }\end{array}$ & $1994 / 98$ & 30,000 \\
\hline $\begin{array}{l}\text { Qinghai Electrochemical Factory } \\
\text { Xining, China }\end{array}$ & 1998 & 10,000 \\
\hline $\begin{array}{l}\text { Hindustan Organic Chemicals } \\
\text { Rasayani, India }\end{array}$ & 1996 & 20,000 \\
\hline
\end{tabular}




\begin{tabular}{|c|c|c|}
\hline $\begin{array}{l}\text { DCM Shriram Consolidated } \\
\text { Thagadia, India }\end{array}$ & 1996 & 52,000 \\
\hline $\begin{array}{l}\text { LG Chemical } \\
\text { South Konea }\end{array}$ & $1996 / 98$ & 200,000 \\
\hline $\begin{array}{l}\text { Formosa Plastics Corporation } \\
\text { Taiwan }\end{array}$ & 1998 & 440,000 \\
\hline $\begin{array}{l}\text { Xian Chemical Plant } \\
\text { Xian, China }\end{array}$ & 1997 & 40,000 \\
\hline $\begin{array}{l}\text { CCM } \\
\text { Malaysia } \\
\end{array}$ & 1996 & 22,000 \\
\hline Confidential & 1999 & 92,000 \\
\hline $\begin{array}{l}\text { Namning Chemical } \\
\text { Nanning, China }\end{array}$ & 1998 & 20,000 \\
\hline $\begin{array}{l}\text { Tianjin Chemical } \\
\text { Tianjin, China }\end{array}$ & 1998 & 85,000 \\
\hline $\begin{array}{l}\text { Dow Chemical } \\
\text { Canada }\end{array}$ & 1997 & 70,000 \\
\hline $\begin{array}{l}\text { Dow Chemical } \\
\text { Gemmany }\end{array}$ & $1998 / 99$ & 330,000 \\
\hline $\begin{array}{l}\text { Fuzhou No. } 2 \text { Chemical Plant } \\
\text { China }\end{array}$ & 1998 & 40,000 \\
\hline $\begin{array}{l}\text { P.T. Sulfindo Adiusaha } \\
\text { Indonesia }\end{array}$ & $1997 / 98$ & 215,000 \\
\hline $\begin{array}{l}\text { Zhejiang Gala Chemical } \\
\text { China }\end{array}$ & 1998 & 20,000 \\
\hline Confidential & 1998 & 540,000 \\
\hline $\begin{array}{l}\text { P.T. Pabrik Kertas Tjiwi Kimia } \\
\text { Indonesia }\end{array}$ & 1998 & 22,000 \\
\hline $\begin{array}{l}\text { Dow Chemical } \\
\text { Stade, Germany }\end{array}$ & 1998 & 130,000 \\
\hline $\begin{array}{l}\text { Dow Chemical } \\
\text { Free Port, U,S.A. }\end{array}$ & 1999 & 550,000 \\
\hline Confidential & 1999 & 80,000 \\
\hline Total & & $38,896,000$ \\
\hline
\end{tabular}

* Acilyzer Process

Sowce: Asahi Chemical Indwsty (1998).

Table 4-28 Supply List of the Ion Exchange Membrane Process by Asahi Glass

\begin{tabular}{|l|c|c|}
\hline \multicolumn{1}{|c|}{ Plant Site } & Start-up Date & $\begin{array}{c}\text { Capacity } \\
(\mathrm{t} \mathrm{NaOH/year})\end{array}$ \\
\hline $\begin{array}{l}\text { Asahi Glass Kansai Factory } \\
\text { Osaka, Japan }\end{array}$ & August 1978 & 10,000 \\
\hline
\end{tabular}




\begin{tabular}{|c|c|c|}
\hline $\begin{array}{l}\text { Nippon Carbide } \\
\text { Toyama, Japan }\end{array}$ & November 1980 & 17,000 \\
\hline $\begin{array}{l}\text { THASCO Chemical } \\
\text { Bangkok, Thailand }\end{array}$ & July 1981 & 62,000 \\
\hline $\begin{array}{l}\text { Tsurumi Soda } \\
\text { Kanagawa, Japan }\end{array}$ & December 1982 & 34,000 \\
\hline $\begin{array}{l}\text { Kashima Chlorine \& Alkali } \\
\text { Ibaraki, Japan }\end{array}$ & July 1983 & 395,000 \\
\hline $\begin{array}{l}\text { Nankai Chemical Indiustry } \\
\text { Kochi, Japan }\end{array}$ & October 1983 & 15,000 \\
\hline $\begin{array}{l}\text { Kansai Chlor-Alkali } \\
\text { Osaka, Japan }\end{array}$ & April 1984 & 44,000 \\
\hline $\begin{array}{l}\text { Central Chemical } \\
\text { Kanagawa, Japan }\end{array}$ & April 1985 & 67,000 \\
\hline $\begin{array}{l}\text { Mitsubishi Chemical } \\
\text { Okayama, Japan }\end{array}$ & October 1985 & 127,000 \\
\hline $\begin{array}{l}\text { Shin-etsu Chiemical } \\
\text { Niigata, Japan } \\
\end{array}$ & Nowember 1985 & 44,000 \\
\hline $\begin{array}{l}\text { Confidential } \\
\text { Japan }\end{array}$ & November 1985 & Confidential \\
\hline $\begin{array}{l}\text { Hokkaido Soda } \\
\text { Hokkaido, Japan }\end{array}$ & November 1985 & 15,000 \\
\hline $\begin{array}{l}\text { Yee Fong Chemical \& Ind. } \\
\text { Taipei, Taiwan }\end{array}$ & November 1985 & 46,000 \\
\hline $\begin{array}{l}\text { Hokkaido Soda } \\
\text { Hokkaido, Japan }\end{array}$ & May 1986 & 152,000 \\
\hline $\begin{array}{l}\text { Nankai Chemical Industry } \\
\text { Wakayama, Japan }\end{array}$ & May 1986 & 35,000 \\
\hline $\begin{array}{l}\text { Shanghai Tian Yuan Chemical Works } \\
\text { Shanghai, China }\end{array}$ & July 1986 & 10,000 \\
\hline $\begin{array}{l}\text { Asahi Glass } \\
\text { Chiba, Japan }\end{array}$ & September 1986 & 216,000 \\
\hline $\begin{array}{l}\text { Hanwha Chemical Corporation } \\
\text { Yeosu, South Korea }\end{array}$ & April 1987 & 63,000 \\
\hline $\begin{array}{l}\text { Egyptian Petrochemical Company } \\
\text { Alexandria, Egypt }\end{array}$ & September 1987 & 85,000 \\
\hline $\begin{array}{l}\text { Taiwan Ch/orine Industry } \\
\text { Kaohsiung, Taiwan }\end{array}$ & April 1988 & 115,000 \\
\hline $\begin{array}{l}\text { ISK Singapore } \\
\text { Singapore }\end{array}$ & January 1989 & 9,000 \\
\hline $\begin{array}{l}\text { Asahimas Subentra Chemical } \\
\text { Anyer, Indonesia }\end{array}$ & June 1989 & 293,000 \\
\hline $\begin{array}{l}\text { Chung Hwa Pulp Corporation } \\
\text { Hualien, Taiwan }\end{array}$ & October 1989 & 20,000 \\
\hline $\begin{array}{l}\text { Mitsubishi Chemical } \\
\text { Fukuoka, Japan }\end{array}$ & October 1.989 & 40,000 \\
\hline
\end{tabular}




\begin{tabular}{|c|c|c|}
\hline $\begin{array}{l}\text { Thai Plastic \& Chemicals Public } \\
\text { Rayong, Thailand }\end{array}$ & November 1989 & 26,000 \\
\hline $\begin{array}{l}\text { Asahi Glass } \\
\text { Kashima, Japan }\end{array}$ & November 1989 & 124,000 \\
\hline $\begin{array}{l}\text { Shanghai Chlor-Alkali Complex } \\
\text { Shanghai, China }\end{array}$ & April 1990 & 155,000 \\
\hline $\begin{array}{l}\text { Hanwha Chemical Corporation } \\
\text { Ulsan, Korea }\end{array}$ & May 1991 & 134,000 \\
\hline $\begin{array}{l}\text { Jin-Hua Chemical Corporation } \\
\text { Liao-Ning, China }\end{array}$ & October 1991 & 120,000 \\
\hline $\begin{array}{l}\text { Solvay } \\
\text { France }\end{array}$ & December 1991 & Confidential \\
\hline $\begin{array}{l}\text { Solvay } \\
\text { Belgium } \\
\end{array}$ & April 1992 & Confidential \\
\hline $\begin{array}{l}\text { Zhejiang Gala Chemical } \\
\text { Zhejian, China }\end{array}$ & September 1.993 & 33,000 \\
\hline $\begin{array}{l}\text { Jiangmen Electrical Chemical } \\
\text { Guangdong, China }\end{array}$ & June 1994 & 20,000 \\
\hline $\begin{array}{l}\text { Tianjin Chemical Plant } \\
\text { Tianjin, China } \\
\end{array}$ & November 1994 & 25,000 \\
\hline $\begin{array}{l}\text { Baoding Electro-Chlorine Factory } \\
\text { Hebei, China }\end{array}$ & September 1995 & 20,000 \\
\hline $\begin{array}{l}\text { Taiyuan General Chem. Ind. Plant } \\
\text { Shanxi, China }\end{array}$ & January 1996 & 20,000 \\
\hline $\begin{array}{l}\text { Vinythai } \\
\text { Rayong, Thailand }\end{array}$ & March 1996 & 100,000 \\
\hline $\begin{array}{l}\text { Bangladesh Chemical Industries } \\
\text { Chittagong, Bangladesh }\end{array}$ & March 1997 & 7,000 \\
\hline $\begin{array}{l}\text { Travancore Cochin Chemicals } \\
\text { Kerala, India }\end{array}$ & May 1997 & 33,000 \\
\hline $\begin{array}{l}\text { Changzhou Chemical Plant } \\
\text { Jiangsu, China }\end{array}$ & May 1997 & 60,000 \\
\hline $\begin{array}{l}\text { Huhhot Chemical General Factory } \\
\text { Inner-Mongol, China }\end{array}$ & Jully 1997 & 20,000 \\
\hline $\begin{array}{l}\text { THASCO Chemical } \\
\text { Rayong, Thailand }\end{array}$ & October 1997 & 115,000 \\
\hline $\begin{array}{l}\text { Borregaard Industries } \\
\text { Sarpsborg, Norway }\end{array}$ & November 1997 & 42,000 \\
\hline $\begin{array}{l}\text { Jiujiang Chemical Plant } \\
\text { Jiangxi, China }\end{array}$ & December 1997 & 20,000 \\
\hline $\begin{array}{l}\text { Shanghai Chlor-Alkali Complex } \\
\text { Shanghai, China }\end{array}$ & December 1997 & 100,000 \\
\hline $\begin{array}{l}\text { Taixin Xinpu Chemicals } \\
\text { Jiangsu, China }\end{array}$ & May 1998 & 40,000 \\
\hline $\begin{array}{l}\text { Thai Organic Chemicals } \\
\text { Rayong, Thailand }\end{array}$ & June 1998 & 33,000 \\
\hline
\end{tabular}




\begin{tabular}{|l|c|c|}
\hline $\begin{array}{l}\text { Asahi Glass } \\
\text { Kashima, Japan }\end{array}$ & July 1998 & 166,000 \\
\hline $\begin{array}{l}\text { Resin Factory of Ping Ding Shan } \\
\text { Henan, China }\end{array}$ & January 1999 & 20,000 \\
\hline $\begin{array}{l}\text { Indupa S.A.I.C. } \\
\text { Bahia Blanca, Argentina }\end{array}$ & March 1999 & 76,000 \\
\hline $\begin{array}{l}\text { THASCO Chemical } \\
\text { Rayong, Thailand }\end{array}$ & July 1999 & 40,000 \\
\hline \multicolumn{1}{|c|}{ Total } & & $27,704,000$ \\
\hline
\end{tabular}

* AZEC Process

Source: Asahil Glass (1999).

Table 4-29 Supply List of the Ion Exchange Membrane Process by Tokuyama Soda

\begin{tabular}{|l|c|c|}
\hline \multicolumn{1}{|c|}{ Plant Site } & Start-up Date & Capacity (t NaOH/year) \\
\hline $\begin{array}{l}\text { Tokuyama Soda } \\
\text { Tokuyama }\end{array}$ & 1977 & 10,000 \\
\hline $\begin{array}{l}\text { Kokuto Chemical } \\
\text { South Korea }\end{array}$ & 1981 & 3,600 \\
\hline $\begin{array}{l}\text { Formosa Plastics } \\
\text { Kaohsiung, Taiwan }\end{array}$ & 1982 & $\mathrm{n} / \mathrm{a}$ \\
\hline $\begin{array}{l}\text { Petrochemical Industries } \\
\text { Shuaiba, Kuwait }\end{array}$ & 1986 & 36,000 \\
\hline $\begin{array}{l}\text { Dalian Chemical Industry } \\
\text { Dalian, China }\end{array}$ & 1987 & $\mathrm{n} / \mathrm{a}$ \\
\hline
\end{tabular}

* TSE Process

Source: Tokuyama (2002).

Table 4-30 Supply List of the Diaphragm Process by CEC

\begin{tabular}{|l|c|c|c|}
\hline \multicolumn{1}{|c|}{ Plant } & Start-up Date & $\begin{array}{c}\text { Capacity } \\
\text { (NaOH tonne/year) }\end{array}$ & Technology Type \\
\hline $\begin{array}{l}\text { Asahi Glass } \\
\text { Kita-Kyushu, Japan }\end{array}$ & February 1974 & 16,300 & DS \\
\hline $\begin{array}{l}\text { Ajinomoto } \\
\text { Thailand }\end{array}$ & February 1974 & 6,000 & DS \\
\hline $\begin{array}{l}\text { Sumitomo Chemical } \\
\text { Ohita, Japan }\end{array}$ & $\begin{array}{c}\text { September 1974- } \\
\text { March 1976 }\end{array}$ & 15,400 & DS \\
\hline $\begin{array}{l}\text { Mitsui Toatsu Chemical } \\
\text { Nagoya, Japan }\end{array}$ & December 1974 & 59,100 & DS \\
\hline $\begin{array}{l}\text { Asahi Glass } \\
\text { Kashima, Japan }\end{array}$ & March 1975 & 160,000 & Glanor \\
\hline $\begin{array}{l}\text { Ajinomoto } \\
\text { Kawasaki, Japan }\end{array}$ & April 1975 & 35,700 & DS \\
\hline $\begin{array}{l}\text { Tokuyama Soda } \\
\text { Tokuyama, Japan }\end{array}$ & April 1975 & 190,400 & DS \\
\hline
\end{tabular}




\begin{tabular}{|c|c|c|c|}
\hline $\begin{array}{l}\text { Missui Toatsu Chemical } \\
\text { Ohmuta, Japan }\end{array}$ & May 1975 & 80,200 & $\mathrm{DS}$ \\
\hline $\begin{array}{l}\text { Toyo Soda } \\
\text { Nanyo, Japan }\end{array}$ & Jume 1975 & 156,200 & Glanor \\
\hline $\begin{array}{l}\text { Asahi Glass } \\
\text { Chiba, Japan } \\
\end{array}$ & August 1975 & 180,000 & Glanor \\
\hline $\begin{array}{l}\text { Nihon Enka Vinyl } \\
\text { Chiba, Japan }\end{array}$ & November 1975 & 86,600 & $\mathrm{DS}$ \\
\hline $\begin{array}{l}\text { Osaka Soda } \\
\text { Matsuyama, Japan }\end{array}$ & November 1975 & 44,400 & $\overline{D S}$ \\
\hline $\begin{array}{l}\text { Toa Gosei Chemical } \\
\text { Tokushima, Japan }\end{array}$ & February 1976 & 148,500 & DS \\
\hline $\begin{array}{l}\text { Hodogaya Chemical } \\
\text { Kohriyama, Japan }\end{array}$ & February 1976 & 24,500 & $\mathrm{DS}$ \\
\hline $\begin{array}{l}\text { Nikkei Kako } \\
\text { Kanbara, Japan }\end{array}$ & February 1976 & 36,600 & DS \\
\hline $\begin{array}{l}\text { Sumitomo Chemical } \\
\text { Kikumoto, Japan } \\
\end{array}$ & March 1976 & 174,200 & Glanor \\
\hline $\begin{array}{l}\text { Toyo Soda } \\
\text { Yokkaichi, Japan }\end{array}$ & June 1976 & 70,800 & $\overline{\mathrm{DS}}$ \\
\hline $\begin{array}{l}\text { Nankai Chemical } \\
\text { Tosa, Japan }\end{array}$ & $\begin{array}{l}\text { April } 1977- \\
\text { August } 1978\end{array}$ & 15,700 & $\overline{D S}$ \\
\hline $\begin{array}{l}\text { Veb Chemi Combinat } \\
\text { East Germany }\end{array}$ & July 1978 & 120,300 & DS \\
\hline $\begin{array}{l}\text { BASF } \\
\text { West Germany }\end{array}$ & November 1978 & 184,100 & DS \\
\hline $\begin{array}{l}\text { AECI } \\
\text { South Africa }\end{array}$ & December 1978 & 18,000 & DS \\
\hline $\begin{array}{l}\text { Pechiney Ugine } \\
\text { Kuhlmann } \\
\text { France }\end{array}$ & May 1979 & 58,600 & DS \\
\hline $\begin{array}{l}\text { China National Technical } \\
\text { Import Corp., P. R. China }\end{array}$ & June 1988 & 200,000 & DS \\
\hline Total & - & $16,652,800$ & - \\
\hline
\end{tabular}

Soure: Chlorine Engineers Corp. (1999b).

Table 4-31 Supply List of the CME Ion Exchange Membrane Process by CEC

\begin{tabular}{|l|c|c|}
\hline \multicolumn{1}{|c|}{ Plant } & Start-up Date & $\begin{array}{c}\text { Capacity } \\
\text { (NaOH tonne/year) }\end{array}$ \\
\hline Showa Enso & November 1980 & 2,640 \\
Gushikawa, Japan & June 1985 & 240 \\
& Novenber 1989 & 240 \\
\hline Osaka Soda & June 1981 & 1,920 \\
Amagasaki, Japan & August 1982 & 960 \\
\hline Mitsul Toatsu Chemical & December $1983-$ February & 5,880 \\
\hline
\end{tabular}




\begin{tabular}{|c|c|c|}
\hline Ohmuta; Japan & $\begin{array}{c}1984 \\
\text { Aprill } 1988 \\
\text { October } 1989 \\
\text { December } 1989 \\
\end{array}$ & $\begin{array}{l}2,940 \\
3,420 \\
1,380\end{array}$ \\
\hline $\begin{array}{l}\text { Mitsui Toatsu Chemical } \\
\text { Nagoya, Japan }\end{array}$ & $\begin{array}{c}\text { November } 1984-\text { June } 1985 \\
\text { April } 1988 \\
\text { October } 1989 \\
\text { December } 1989 \\
\end{array}$ & $\begin{array}{l}5,880 \\
2,940 \\
1,380 \\
1,380 \\
\end{array}$ \\
\hline $\begin{array}{l}\text { Mitsui Toatsu Chenical } \\
\text { Osaka, Japan }\end{array}$ & $\begin{array}{c}\text { December } 1984 \\
\text { December } 1985 \\
\text { February } 1986 \\
\text { March } 1986 \\
\text { May } 1986 \\
\end{array}$ & $\begin{array}{c}22,320 \\
7,440 \\
14,880 \\
11,160 \\
3,720 \\
\end{array}$ \\
\hline $\begin{array}{l}\text { Chemfab Alkalis } \\
\text { India. }\end{array}$ & $\begin{array}{c}\text { June } 1985 \\
\text { September } 1988\end{array}$ & $\begin{array}{l}9,000 \\
4,500\end{array}$ \\
\hline $\begin{array}{l}\text { Toa Gosei Chemical } \\
\text { Japan }\end{array}$ & $\begin{array}{c}\text { October } 1985 \\
\text { December } 1985 \\
\text { April } 1988 \\
\end{array}$ & $\begin{array}{c}31,320 \\
31,320 \\
3,960 \\
\end{array}$ \\
\hline $\begin{array}{l}\text { Osaka Soda } \\
\text { Kokura, Japan }\end{array}$ & $\begin{array}{c}\text { December } 1985 \\
\text { February } 1986 \\
\text { December } 1987 \\
\end{array}$ & $\begin{array}{c}12,120 \\
13,080 \\
960 \\
\end{array}$ \\
\hline $\begin{array}{l}\text { Nippon Soda } \\
\text { Takaoka, Japan }\end{array}$ & $\begin{array}{c}\text { March } 1986 \\
\text { September } 1987\end{array}$ & $\begin{array}{c}54,000 \\
8,520\end{array}$ \\
\hline $\begin{array}{l}\text { Kanto Denka Kogyo } \\
\text { Mizushima, Japan }\end{array}$ & $\begin{array}{l}\text { April } 1986 \\
\text { June } 1986\end{array}$ & $\begin{array}{l}11,760 \\
3,960\end{array}$ \\
\hline $\begin{array}{l}\text { Plant A } \\
\text { Asia }\end{array}$ & $\begin{array}{c}\text { July } 1987 \\
\text { February } 1988\end{array}$ & $\begin{array}{l}8,760 \\
4,380\end{array}$ \\
\hline $\begin{array}{l}\text { Toa Gosei Chemical } \\
\text { Japan }\end{array}$ & $\begin{array}{c}\text { November } 1987 \\
\text { March } 1988 \\
\text { March } 1988 \\
\text { July } 1990\end{array}$ & $\begin{array}{c}82,800 \\
46,200 \\
1,560 \\
15,960\end{array}$ \\
\hline $\begin{array}{l}\text { Bayer } \\
\text { Germany }\end{array}$ & August 1.987 & 792 \\
\hline $\begin{array}{l}\text { Todlogaya Chemical } \\
\text { Kohriyama, Japan }\end{array}$ & $\begin{array}{c}\text { August } 1988 \\
\text { July } 1990\end{array}$ & $\begin{array}{l}13,680 \\
34,200\end{array}$ \\
\hline $\begin{array}{l}\text { Solvay } \\
\text { Spain }\end{array}$ & July 1988 & 1,764 \\
\hline $\begin{array}{l}\text { Plant B } \\
\text { Japan }\end{array}$ & October 1988 & 5,520 \\
\hline $\begin{array}{l}\text { Kanegafuchi Chemical } \\
\text { Takasago, Japan }\end{array}$ & $\begin{array}{c}\text { August } 1989-\text { March } 1990 \\
\text { April } 1990 \\
\text { May 1991 } \\
\end{array}$ & $\begin{array}{r}139,800 \\
18,840 \\
45,240 \\
\end{array}$ \\
\hline $\begin{array}{l}\text { Plant C } \\
\text { Asia }\end{array}$ & April 1989 & 10,320 \\
\hline $\begin{array}{l}\text { Plant D } \\
\text { U.S.A. }\end{array}$ & April 1989 & $1.0,800$ \\
\hline Plant E & February 1991 & 23,040 \\
\hline
\end{tabular}




\begin{tabular}{|l|c|c|}
\hline & September 1991 & 3,840 \\
\hline $\begin{array}{l}\text { Korea Otsuka } \\
\text { Korea }\end{array}$ & May 1990 & 21,600 \\
\hline $\begin{array}{l}\text { Morro Verde } \\
\text { Brazil }\end{array}$ & November 1992 & 19,560 \\
\hline $\begin{array}{l}\text { FPC U.S.A. } \\
\text { U.S.A. }\end{array}$ & May 1993 & 684,000 \\
\hline $\begin{array}{l}\text { Hukumchand Jute and Ind. } \\
\text { India }\end{array}$ & January 1993 & 15,660 \\
\hline $\begin{array}{l}\text { Ashok Organic Ind. } \\
\text { India }\end{array}$ & July 1993 & 19,980 \\
\hline $\begin{array}{l}\text { Union Ajinomoto } \\
\text { Philippine }\end{array}$ & September 1994 1994 & 4,320 \\
\hline $\begin{array}{l}\text { Vedan Enterprise } \\
\text { Vietnam }\end{array}$ & August 1995 & 19,800 \\
\hline $\begin{array}{l}\text { Vedan Enterprise } \\
\text { Vietnam }\end{array}$ & March 1996 & 19,800 \\
\hline $\begin{array}{l}\text { Ashok Organic Ind. } \\
\text { India }\end{array}$ & July 1996 & 19,800 \\
\hline $\begin{array}{l}\text { Southern } \\
\text { Ind. } \\
\text { India }\end{array}$ & Dectrochemical \\
\hline $\begin{array}{l}\text { Petkim Petrokimya Holding } \\
\text { Turkey }\end{array}$ & - & 50,000 \\
\hline
\end{tabular}

CME: Chlorine Engineers' Membrane Electrolyzer

Source: Chlorine Engineers Corp. (1999a).

Table 4-32 Supply List of the MBC Ion Exchange Membrane Process by CEC

\begin{tabular}{|c|c|c|}
\hline Plant & Start-up Date & $\begin{array}{c}\text { Capmcity } \\
\text { (NaOH tonne/year) }\end{array}$ \\
\hline $\begin{array}{l}\text { Mitsui Toatsu Chemical } \\
\text { Nagoya }_{3} \text { Japan }\end{array}$ & September 1982 - June 1983 & 61,680 \\
\hline $\begin{array}{l}\text { Tokuyama Soda } \\
\text { Tokuyama, Japan }\end{array}$ & $\begin{array}{c}\text { February } 1983 \text { - December } \\
1983 \\
\end{array}$ & 191,040 \\
\hline $\begin{array}{l}\text { Kanto Denka Kogyo } \\
\text { Mizushima, Japan }\end{array}$ & October 1983 - January 1984 & 52,920 \\
\hline $\begin{array}{l}\text { Mitsui Toatsu Chemical } \\
\text { Ohmuta, Japan }\end{array}$ & $\begin{array}{c}\text { December 1983-Marcl } \\
1984 \\
\end{array}$ & 61,680 \\
\hline $\begin{array}{l}\text { Toyo Soda } \\
\text { Yokkaichi, Japan }\end{array}$ & April 1983 - September 1983 & 58,800 \\
\hline $\begin{array}{l}\text { Osaka Soda } \\
\text { Matsuyama, Japan }\end{array}$ & April 1983 -July 1984 & 36,720 \\
\hline $\begin{array}{l}\text { Hodogaya Chemical } \\
\text { Kohriyama, Japan }\end{array}$ & February 1984 - August 1984 & 35,280 \\
\hline
\end{tabular}




\begin{tabular}{|l|c|c|}
\hline $\begin{array}{l}\text { Sumitomo Chemical } \\
\text { Ohita, Japan }\end{array}$ & November 1984 & 14,760 \\
\hline $\begin{array}{l}\text { Toa Gosei Chemical } \\
\text { Tokushima, Japan }\end{array}$ & May 1984-October 1984 & 31,560 \\
\hline $\begin{array}{l}\text { Name withheld by request } \\
\text { Japan }\end{array}$ & April 1984-December 1984 & 6,600 \\
\hline $\begin{array}{l}\text { Chiba Chlorine \& Alkali } \\
\text { Chiba, Japan }\end{array}$ & October 1984-March 1985 & 111,480 \\
\hline $\begin{array}{l}\text { Ajinomoto } \\
\text { Kawasaki, Japan }\end{array}$ & December 1984-July 1985 & 38,160 \\
\hline $\begin{array}{l}\text { Name withheld by request } \\
\text { Japan }\end{array}$ & July 1984 & 5,880 \\
\hline $\begin{array}{l}\text { Name withheld by request } \\
\text { Overseas }\end{array}$ & May 1985 & 1,560 \\
\hline \multicolumn{1}{|c|}{ Total } & - & $5,664,960$ \\
\hline
\end{tabular}

MBC: Membrane Bag Cell

Source: Chlorine Engineers Corp. (1999c).

Table 4-33 Supply List of the BiTAC Ion Exchange Membrane Process by CEC

\begin{tabular}{|c|c|c|}
\hline Plant & Start-up Date & $\begin{array}{c}\text { Capacity } \\
\text { (NaOH tonne/year) }\end{array}$ \\
\hline $\begin{array}{l}\text { Tosoh } \\
\text { Japan }\end{array}$ & April 1992 & 972 \\
\hline $\begin{array}{l}\text { Tosoh } \\
\text { Japan } \\
\end{array}$ & September 1993 & 1,204 \\
\hline $\begin{array}{l}\text { Confidential } \\
\text { Japan }\end{array}$ & February 1994 & 14,820 \\
\hline $\begin{array}{l}\text { Confidential } \\
\text { Korea }\end{array}$ & October 1994 & 27,000 \\
\hline $\begin{array}{l}\text { Tosoh } \\
\text { Japan }\end{array}$ & July 1995 & 20,000 \\
\hline $\begin{array}{l}\text { Confidential } \\
\text { Korea } \\
\end{array}$ & December 1995 & 35,470 \\
\hline $\begin{array}{l}\text { Polifin } \\
\text { South Africa }\end{array}$ & April 1996 & 22,410 \\
\hline $\begin{array}{l}\text { Confidential } \\
\text { Japan }\end{array}$ & August 1996 & 87,900 \\
\hline $\begin{array}{l}\text { Tosoh } \\
\text { Japan }\end{array}$ & December 1996 & 118,900 \\
\hline $\begin{array}{l}\text { Wuxi } \\
\text { China }\end{array}$ & May 1997 & 30,000 \\
\hline $\begin{array}{l}\text { P\& G } \\
\text { Italy } \\
\end{array}$ & February 1998 & 8,382 \\
\hline $\begin{array}{l}\text { Tosoh } \\
\text { Japan }\end{array}$ & June 1998 & 40,000 \\
\hline
\end{tabular}




\begin{tabular}{|l|c|c|}
\hline $\begin{array}{l}\text { Wuhu } \\
\text { China }\end{array}$ & September 1998 & 20,000 \\
\hline $\begin{array}{l}\text { Bayer } \\
\text { U.S.A. }\end{array}$ & January 1999 & 320,000 \\
\hline $\begin{array}{l}\text { Honghe } \\
\text { China }\end{array}$ & March 1999 & 50,300 \\
\hline $\begin{array}{l}\text { Tosoh } \\
\text { Japan }\end{array}$ & June 1999 & 96,310 \\
\hline $\begin{array}{l}\text { Tosoh } \\
\text { Japan }\end{array}$ & June 1999 & 325,000 \\
\hline $\begin{array}{l}\text { Elite Chemicals Pty. } \\
\text { Australia }\end{array}$ & October 1999 & 2,880 \\
\hline \multicolumn{1}{|c|}{ Total } & - & $9,772,384$ \\
\hline
\end{tabular}

BiTAC: Bipole of Tosoh and CEC

Source: Chlorine Engineers Corp. (2000).

Table 4-34 Operating Period of the Diaphragm Process at Chlor-Alkali Plants in Japan

\begin{tabular}{|c|c|c|c|}
\hline Plant & $\begin{array}{l}\text { Start-up Year } \\
\text { of Diaphragm } \\
\text { Process } \\
\end{array}$ & $\begin{array}{c}\text { Conversion to Ion } \\
\text { Exchange Membirane } \\
\text { Process }\end{array}$ & $\begin{array}{c}\text { Operating Years } \\
\text { of Diaphragm } \\
\text { Process } \\
\end{array}$ \\
\hline Asahi Glass, Kita-Kyushu & 1974 & 1982 & 8 \\
\hline Sumitomo Chemical, Ohita & 1974 & 1984 & 10 \\
\hline Mitsui Toatsu, Nagoya & 1974 & 1984 & 10 \\
\hline $\begin{array}{l}\text { Mitsubishi Gas Chemical, } \\
\text { Naniwa }\end{array}$ & 1974 & 1984 & 10 \\
\hline Kanegafuchil Chemical, Takasago & 1974 & 1989 & 15 \\
\hline Central Chemical, Kawasaki & 1974 & 1985 & 11 \\
\hline Sanyo Kokusaku Pulp, Iwakuni & 1974 & 1999 & 25 \\
\hline Showa Enso, Gushikawa & 1974 & 1980 & 6 \\
\hline Tsurumi Soda, Tsurumi & 1974 & 1982 & 8 \\
\hline Nippon Soda, Nihongi & 1974 & $1988^{\circ}$ & 14 \\
\hline Ajinomoto, Kawasaki & 1975 & 1984 & 9 \\
\hline Tokuyama Soda, Tolkuyama & 1975 & 1983 & 8 \\
\hline Mitsui Toatsu, Ohmuta & 1975 & 1983 & 8 \\
\hline Nihon Vinyl Chloride, Chiba ${ }^{\mathrm{d}}$ & 1975 & 1984 & 9 \\
\hline Osaka Soda Matsuyama & 1975 & 1983 & 8 \\
\hline Hokkaido Soda, Tomakomai & 1975 & 1986 & 11 \\
\hline Shin-etsu Chemical, Naoetsu & 1975 & 1985 & 10 \\
\hline Osaka Soda, Amagasaki & 1975 & 1981 & 6 \\
\hline Denki Kagaku Kogyo, Ohme & 1975 & 1976 & 1 \\
\hline Mitsubishi Monsanto, Yokkaichi & 1975 & $1981^{6}$ & 6 \\
\hline Tekkosha, Sakata" & 1975 & 1986 & 11 \\
\hline Mitsubishi Chemical, Kurosaki & 1975 & 1989 & 14 \\
\hline Ryonichi, Mizushima & 1975 & 1985 & 10 \\
\hline
\end{tabular}




\begin{tabular}{|l|c|c|c|}
\hline Asahi Glass, Kashima & 1975 & 1989 & 14 \\
\hline Toyo Soda, Nanyo & 1975 & 1995 & 20 \\
\hline Asahi Glass, Chiba & 1975 & 1986 & 11 \\
\hline Kanto Denka Kogyo, Mizushima & 1975 & 1986 & 11 \\
\hline Chiba Chlorne Chemical, Chiba & 1975 & $1982^{\mathrm{h}}$ & 7 \\
\hline Toagosei Chemical, Tokushima & 1976 & 1987 & 11 \\
\hline Hodogaya Chemical, Kohriyama & 1976 & 1984 & 8 \\
\hline Nikkei Kako, Kanbara & 1976 & 1983 & 7 \\
\hline Toyo Soda, Yokkaichi & 1976 & 1983 & 7 \\
\hline Sumitomo Chemical, Kikumoto & 1976 & 1987 & 11 \\
\hline Kureha Chemical, Nishiki & 1976 & 1985 & 6 \\
\hline Nankai Chemical, Tosa & 1977 & 1983 & 10.0 \\
\hline Average & - & - & . \\
\hline
\end{tabular}

a: The Naniwa plant of Mitsubishi Gas Chemical was transferred to Kansai Chlor-Alkali in 1984 (Mitsubishi Gas Chemical, 2001).

b: Sanyo Kokusaku Pulp merged with Jujo Paper Industries in 1993, creating Nippon Paper Industries (Nippon Paper Industries, 2001).

c: The Nihongi plant of Nippon Soda was shut down in 1988 (Nikkei Kinyu Shinbun, 1987).

d: Nihon Vinyl Chloride was renamed to Chiba Chlorine \& Alkali in 1985 (Stumitomo Chemical, 1998).

e: The Yokkaichi plant of Mitsubishi Monsanto (currently Mitsubishi Chemical MKV) was closed in 1981 (Mitsubishi Chemical MKV, 2001).

f: Tekkosha was acquired by Toyo Soda in 1975 (Tosoh, 2001).

g." The Mizushima plant of Ryonichi was transferred to Mitsubishi Chemical in 1986 (Mitsubishi Chemical, 2001).

h. The Chiba plant of Chiba Chlorine Chemical ceased its operation in 1982 (Nihon Keizai Shivbun, 1982).

Sources: Table 4-4 and Table 4-19. 


\section{Environmental Regulation and Technological Change in the Western European Chlor-Alkali Industry}

\subsection{Imposition of Emission Standards on Mercury}

A serious concern was also growing in Western Europe during the 1960s about the impacts of mercury on the environment. However, the cause for the concern was the depletion of bird populations as a consequence of methyl mercury poisoning from seed grain, rather than the impacts on human health like those observed at the Minamata Bay in Japan. High mercury concentrations were also found in other wild fauna, particularly in predator species (Organisation for Economic Co-operation and Development, 1974). As scientific investigations were initiated, information about the use, disposal, fate and effects of mercury and mercury compounds grew gradually. Although some of the research results suggested that inorganic mercury could be transformed into methyl mercury by the action of microorganisms under aerobic conditions (e.g. Jensen and Jernelov, 1969), there was no report which confirmed that finding quantitatively. Nevertheless, that prompted fears that regulations should be imposed on emissions of mercury per se, in addition to methyl mercury, whose intake to human body caused the Minamata disease. Several policy measures were introduced in Sweden in the late 1960s to restrain the discharge of mercury from chlor-alkali plants, requiring these firms to install the "best available technology." These measures, however, did not include the setting of quantitative standards for liquid effluents containing mercury (Organisation for Economic Co-operation and Development, 1974). Similarly, there were no strict regulations introduced in the 1960 s on mercury emissions from chlor-alkali plants in other countries in Western Europe.

It was in the $1970 \mathrm{~s}$ that two institutions in Western Europe, namely, the Paris Commission and the European Community, that began to work almost in parallel to regulate mercury emissions from chlor-alkali plants based in Western Europe. In the following sections, we look at these regulations actually introduced by the two institutions.

\subsubsection{Paris Commission}

At the end of the 1960s and the beginning of the early 1970s, several regional agreements for the protection of the marine environment surrounding the Western Europe started to be 
established ${ }^{81}$. With the increasing concem on its impacts on the environment, mercury became onte of the substances which recetved a special attention in these agreenents. In February 1972, the Convention for the Prevention of Marine Pollution by Dumping from Ships and Aircraft, the so-called Oslo Convention, was adopted, and mercury was included in the list of the substances which were prohibited to be dumped into the sea. The prohibition of the dumping of mercury was extended to a global scale when the Convention on the Prevention of Marine Pollution by Dumping of Wastes and Other Matter (London Dumping Convention) was agreed in November 1972.

Negotiations on this issue resulted in the signing of the Convention for the Prevention of Marine Pollution from Land-Based Sources (Paris Convention) on 4 June 1974 (Convention for the Prevention of Marine Pollution from Land-Based Sources, 1974). The members of the convention included Denmark, Sweden, France, Norway, The Netherlands, United Kingdom, Portugal, Spain, Iceland, Germany, Belgium, and Ireland. With the European Economic Community also joining the convention by adding its signature in June 1975, the Paris Convention finally entered into force in May 1978 2 . As the sea area covered by the Paris Convention was basically the North-East Atlantic, defined as extending westwards to the east coast of Greenland, eastwards to the continental North Sea coast, south to the Straits of Gibraltar and northwards to the North Pole, the maritime area did not include the Baltic or Mediterranean seas; the Helsinki and Barcelona Conventions applied in these sea $\operatorname{areas}^{83}$.

The members of the Paris Convention agreed "to eliminate, if necessary by stages, the pollution of the maritime area from land-based sources by substances listed in Part I of Amex A to the present Convention" (Convention for the Prevention of Marine Pollution from LandBased Sources, 1974). "Pollution from land-based sources" meant the pollution of the maritime area through watercourses, from the coast, including introduction through underwater or other pipelines, from man-made structures placed within the limits of the

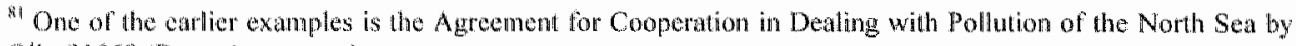
Oil of 1969 (Bonm Agreentuatst).

${ }^{2}$ The Compention for the Protection of the Marine Emwironment of the Nonth-East Atlantio, the OSPAR Conventiort, was adopted in September 1992 and entered into force in March 1998. The new Convention replaces the Oslo and Patis Comventions, bu Decisions, Recommendations and all other agreenents adopted under those Conventions will continte to be applicable, unaltered in the legal nature, unless they are teminated by new measures adopted under the 1992 OSPAR Convention (Convention for the Protection of the Matine Envirument of the North-Fast Athantic, 1992).
} 
maritime area, and by emissions into the atmosphere from land or from man-made structures. Mercury, along with other substances such as cadmium and organolialogen compounds, was placed in the "blacklist." They were sellected based on the three criteria, namely, persistence, toxicity or other noxious properties, and tendency to bio-accumulation. By the time of the establishment of the convention, it had come to be generally regarded that mercury compounds possessed all three characteristics.

In order to carry out the undertakings set out in the convention, the member countries, individually or jointly, had to implement "programmes and measures" (Convention for the Prevention of Marine Pollution from Land-Based Sources, 1974). They were to include specific regulations or standards governing the quality of the environment, discharges into the maritime area, including discharges into watercourses and emissions into the atmosphere which would affect the maritime area, and the composition and use of substances and products. The convention stipulated that these programmes and measures should take into account the latest technical developments and that the programmes should contain time limits for their completion.

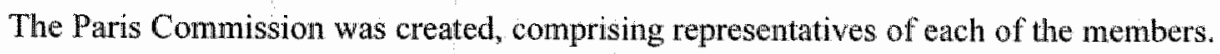
The commission then set up a standing scientific group, the Technical Working Group, to examine and discuss technical issues in detail. The standing scientific groups were usually assisted in its tasks by preparatory work undertaken by ad hoc or permanent working groups on specific subjects. The working groups reported on their work to the appropriate standing technical group, and each standing group in turn reported on its work to the Commission. The Commission had the power to take decisions and make recommendations, and decisions could be adopted by unanimity. In the ease of programmes and measures, when unanimity could not be obtained, they nevertheless might be adopted by a qualified majority, but in such cases they were applicable only to those countries which voted for them (Oslo and Paris Commissions, 1984).

The Commission conducted several studies on substances, particularly those listed in the blacklist, that is, the Part I of Annex. During each of these studies the technical groups tried to determine the origins of the sources of pollution. This was one of the most difficult tasks because these sources were often diffuse; they were not restricted to sources linked with

\footnotetext{
${ }^{83}$ The Comvention on the Protection of the Marine Environment of the Baltic Sea Area was estoblished in 1974 (Helsinki Convention), and the Convention for the Protection and Development of bla Marme Erivironment and Coastal Region of the Mediterranean Sea in 1976 (Barcelona Comvention).
} 
a certain type of production but also included losses associated with the use and consumption of other products. The origins of emissions had to be identified before any decision could be taken regarding programmes and measures; and mercury was no exception.

The sources of mercury eniission included chlor-alkali plants, agriculture, dentistry, electrical apparatus, control instruments, and paints. As Table 5-1 shows, the chlor-alkali industry was the onlly sector in which relatively abundant data was available on the discharges of mercury ${ }^{\text {ist }}$.

Table 5-1 Emissions of Mereury in European Countries in the 1970 s

\begin{tabular}{|l|c|c|c|c|c|c|}
\hline \multicolumn{1}{|c|}{ Country } & $\begin{array}{c}\text { Chlor-Alkali } \\
\text { Industry }\end{array}$ & Agriculture & Dentistry & $\begin{array}{c}\text { Electrical } \\
\text { Apparatus }\end{array}$ & $\begin{array}{c}\text { Control } \\
\text { Instruments }\end{array}$ & Paints \\
\hline Austria & $3,307^{\mathrm{a}}$ & $\mathrm{n} / \mathrm{a}$ & $\mathrm{n} / \mathrm{a}$ & $\mathrm{n} / \mathrm{a}$ & $\mathrm{n} / \mathrm{a}$ & $\mathrm{n} / \mathrm{a}$ \\
\hline Belgium & 18,621 & $\mathrm{n} / \mathrm{a}$ & $\mathrm{n} / \mathrm{a}$ & $\mathrm{n} / \mathrm{a}$ & $\mathrm{n} / \mathrm{a}$ & $\mathrm{n} / \mathrm{a}$ \\
\hline Denmark & 243 & $1 \mathrm{n} / 14$ & $\sim 3,000$ & $\sim 6,400$ & $\sim 2,000$ & $\mathrm{n} / \mathrm{a}$ \\
\hline Finland & $1,2 \| 0$ & 3,540 & $\mathrm{n} / \mathrm{a}$ & $\mathrm{n} / \mathrm{a}$ & $\mathrm{n} / \mathrm{a}$ & $\mathrm{n} / \mathrm{a}$ \\
\hline France & 54,281 & $\mathrm{n} / \mathrm{a}$ & $\mathrm{n} / \mathrm{a}$ & $\mathrm{n} / \mathrm{a}$ & $\mathrm{n} / \mathrm{a}$ & $\mathrm{n} / \mathrm{a}$ \\
\hline Germany & $101,000^{\mathrm{b}}$ & $\mathrm{n} / \mathrm{a}$ & $\mathrm{n} / \mathrm{a}$ & $\mathrm{n} / \mathrm{a}$ & $\mathrm{n} / \mathrm{a}$ & $\mathrm{n} / \mathrm{a}$ \\
\hline Greece & $1,500^{\mathrm{a}}$ & $\mathrm{n} / \mathrm{a}$ & $\mathrm{n} / \mathrm{a}$ & $\mathrm{n} / \mathrm{a}$ & $\mathrm{n} / \mathrm{a}$ & $\mathrm{n} / \mathrm{a}$ \\
\hline Iceland & $\mathrm{n} / \mathrm{a}$ & $\mathrm{n} / \mathrm{a}$ & $\mathrm{n} / \mathrm{a}$ & $\mathrm{n} / \mathrm{a}$ & $\mathrm{n} / \mathrm{a}$ & $\mathrm{n} / \mathrm{a}$ \\
\hline Ireland & $\mathrm{n} / \mathrm{a}$ & $\mathrm{n} / \mathrm{a}$ & $\mathrm{n} / \mathrm{a}$ & $\mathrm{n} / \mathrm{a}$ & $\mathrm{n} / \mathrm{a}$ & $\mathrm{n} / \mathrm{a}$ \\
\hline Italy & $155,000^{\circ}$ & $\mathrm{n} / \mathrm{a}$ & $\mathrm{n} / \mathrm{a}$ & $\mathrm{n} / \mathrm{a}$ & $\mathrm{n} / \mathrm{a}$ & $\mathrm{n} / \mathrm{a}$ \\
\hline Netherlands & $\sim 4,800$ & 700 & 4,500 & $\mathrm{n} / \mathrm{a}$ & $\mathrm{n} / \mathrm{a}$ & $\sim \mathrm{n} / 50$ \\
\hline Norway & 2,280 & 631 & $\mathrm{n} / \mathrm{a}$ & $\mathrm{n} / \mathrm{a}$ & $\mathrm{n} / \mathrm{a}$ & $\mathrm{n} / \mathrm{a}$ \\
\hline Portugal & $\mathrm{n} / \mathrm{a}$ & $\mathrm{n} / \mathrm{a}$ & $\mathrm{n} / \mathrm{a}$ & $\mathrm{n} / \mathrm{a}$ & $\mathrm{n} / \mathrm{a}$ & $\mathrm{n} / \mathrm{a}$ \\
\hline Spain & $\mathrm{n} / \mathrm{a}$ & $\mathrm{n} / \mathrm{a}$ & $\mathrm{n} / \mathrm{a}$ & $\mathrm{n} / \mathrm{a}$ & $\mathrm{n} / \mathrm{a}$ & $\mathrm{n} / \mathrm{a}$ \\
\hline Sweden & 2,900 & $\mathrm{n} / \mathrm{a}$ & $\mathrm{n} / \mathrm{a}$ & $\mathrm{n} / \mathrm{a}$ & $\mathrm{n} / \mathrm{a}$ & $\mathrm{n} / \mathrm{a}$ \\
\hline Switzerland & 2,650 & $\mathrm{n} / \mathrm{a}$ & $\mathrm{n} / \mathrm{a}$ & $\mathrm{n} / \mathrm{a}$ & $\mathrm{n} / \mathrm{a}$ & $\mathrm{n} / \mathrm{a}$ \\
\hline UK & 282,632 & $\mathrm{n} / \mathrm{a}$ & $\mathrm{n} / \mathrm{a}$ & $\mathrm{n} / \mathrm{a}$ & $\mathrm{n} / \mathrm{a}$ & $\mathrm{n} / \mathrm{a}$ \\
\hline
\end{tabular}

Data is of 1975 otherwise noted. Figures are in kilograms.

a: 1974 data

b: 1971 data

c: 1973 data

Soure: Organisation for Economic Co-operation and Development (1981).

Emitted mercury entered the sea through several pathways, namely via the atmosphere, rivers, pipelines linked to industry, sewage, and dumped waste. The Paris Commission, despite the scarcity of relevant data, estimated that the chlor-alkali industry accounted for

\footnotetext{
8. Nole that the data on mercury in the chlor-alkali industry was assembled in different ways. Some countries equated the figures for the consumption of mercury in the chlor-alkali industry with those for mercury supplied to the indastry whereas others equated the figares for the chlor-alkali mercury consumption with those for the industry"s mercury emissions. That would make direct comparisons between countries difficult.
} 
$40 \%$ of the mercury input to the marine enviromment in the middle of the 1970 s (Oslo and Paris Commissions, 1984). Accordingly, mercury discharges from the chlor-alkali industry became the primary subject for programmes and measures to be adopted.

As the convention itself did not give any quantitative definition of pollution or a level of pollution, the programmes and measures to be taken were open to wide interpretation and possibilities. The majority of the countries favored a policy for elimination of pollution by imposing strict limits on discharges, that is, by the uniform emission standards approach (Paris Commission, 1983a). Among the reasons cited for the advantages of applying emission standards were that emission standards could be based on the "best technical means available"; that they would enable standards to be imposed on an international basis; that emission standards would be easily controlled, enabling industry to take the necessary decisions; and that the emission standard approach would not exclude the use of more stringent standards if demanded by local conditions.

On the other hand, the United Kingdom and Portugal preferred the adoption of environmental quality objectives. Under this system, which was concerned with the use of the receiving waters, rather than the discharges into them, water quality standards were set to which all discharges would have to conform. The advantages of the environmental quality objective approach; its supporters argued, were that it would concentrate upon the protection of the quality of the aquatic environment, the aim and purpose of the convention, after all; that it would take account of all discharges as well as all natural or background levels of particular substances; and that it would also take account of the overall conditions of the water, including its assimilative capacity, and the differences between inland rivers and turbullent coastal waters.

Despite intensive discussions at several meetings of the Technical Working Group ${ }^{85}$, it was not possible to a make a conclusive comparison between the fwo policies on the basis of the monitoring data available. In November 1978, at its first meeting, the Paris Commission therefore decided to follow the dual approach of emission standards and environmental quality objectives for a period of five years (Paris Commission, 1978a). The agreed line of action included that there would be a uniform amission standard for mercury discharges from existing and new plants and that quality objectives for mercury should be formulated for

\footnotetext{
\$ For example, in the Fifth Meeting of the Technical Working Group, a number of questions and arguments were put to the United Kingdom, the main proponent of the EQO approach, which un turn made its respotise, which was shared by Portugal (Paris Commission, 1977).
} 
organisms, as soon as possible for water and, if appropriate, for sediments. The programmes and measures decided upon in implementing the emission standard approach were carried out only by the countries applying them, which represented the majority, whereas programmes and measures for environmental quality objectives were applicable only to the supporters of this type of policy. The neasures regarding new plants, however, were applied to all the countries, whether the emission standard or environmental quality objective approach was adopted:

The emission standard approach set maximum values to be applied for mercury discharges in effluent from existing and new chlor-alkali production plants. These maximun values differed, depending on the type of plants, namely, those which operate with brine used only once, generating more mercury emissions, or those with recycled brine. Furthermore, different maximum values were adopted according to whether they were to be applied at the outllet from the whole production site or at the outlet from the treatment plant. While many of the measures adopted were binding decisions, recommendations were used in cases where an agreement on binding decisions was difficult to reach.

The first decision on limit values was made at the second meeting in June 1980 as PARCOM Decision 80/2. Table 5-2 gives the limit walues for mercury emissions in water from existing and new brine-recirculation chlor-alkali plants. In particular, the limit value, as a monthly mean, was fixed at $0.5 \mathrm{~g}$ of: mercury per tonne of chllorine production capacity. These limit values were to apply from July 1, 1983, provided that limit values for waste brine plants have been agreed by that date. As it was acknowledged that discharges from the factory site as a whole could greatly exceed the emissuons at the exit of the treatment unit, the Commission asked the Working Group on Mercury Pollution to make proposals for limit values for chlor-alkali factory sites, which would cover all mercury-containing waste water streams.

Table 5-2 PARCOM Decision 80/2 on Limit Values for Mereury Emissions in Water from Existing and New Brine Recirculation Chloralkali Plants (exit of the purification plant)

\begin{tabular}{|l|l|l|l|}
\hline $\begin{array}{c}\text { Limits, expressed as } \\
\text { maximum concentration of } \\
\text { mercury }\end{array}$ & $\begin{array}{c}\text { Limit, expressed as } \\
\text { maximum amount of } \\
\text { mercury }\end{array}$ & $\begin{array}{c}\text { Deadline } \\
\text { for existing } \\
\text { enissions }\end{array}$ & Remarks \\
\hline $\begin{array}{l}\text { The limits, expressed as } \\
\text { maximum concentration of } \\
\begin{array}{l}\text { mercury, are calculated by } \\
\text { dividing the limits }\end{array}\end{array}$ & $\begin{array}{l}0.5 \text { g of mercury per } \\
\text { metric tomne of } \\
\text { chlorine production } \\
\text { capacity as a monthly }\end{array}$ & July 1983 & $\begin{array}{l}\text { The limits given in the } \\
\text { preceding columns are } \\
\text { applicable to the } \\
\text { mercury arising from }\end{array}$ \\
\hline
\end{tabular}




\begin{tabular}{|l|l|l|l|}
\hline $\begin{array}{l}\text { (expressed as maximum } \\
\text { amounts of mercury) by the } \\
\text { amount of water used per } \\
\text { metric tome of chlorine } \\
\text { production capacity. }\end{array}$ & $\begin{array}{l}\text { mean, and } 2.0 \mathrm{~g} \text { of } \\
\text { tonne of chlonine } \\
\text { production capacity as } \\
\text { adaily mean. }\end{array}$ & $\begin{array}{l}\text { the production process } \\
\text { and thus to be } \\
\text { observed ac the exit of } \\
\text { the purification plant } \\
\text { of the installation. }\end{array}$ \\
\hline
\end{tabular}

Sounce: Poris Commission (1980c).

At the third meeting held in 1981, the Commission examined a proposal prepared by the Technical Working Group concerning limit values for mercury emissions in water to be applied to existing waste brine chlor-alkali plants, that is, those without recurculation of brine. As previous reservations were lifted, the linit values for mercury enissions from the existing waste brine chlor-alkali plants were adopted in PARCOM Decision 81/1. Table 5-3 gives the limit values, which were fixed at $8 \mathrm{~g}$ of mercury per tonne of chlorine production capacity as a monthly mean to be achieved by July 1,1983 , and at $5 \mathrm{~g}$ of mercury per tonne of chlorine production capacity as a monthly mean to be achieved by July 1, 1986 .

Table 5-3 PARCOM Decision 81/1 on Limit Values for Existing Waste Brine Chloralkali Plants

\begin{tabular}{|c|c|c|c|}
\hline $\begin{array}{l}\text { Limits, expressed as } \\
\text { maximum concentrations } \\
\text { of mercury }\end{array}$ & $\begin{array}{l}\text { Limit, expressed as } \\
\text { maximum amount of } \\
\text { mercury }\end{array}$ & $\begin{array}{l}\text { Deadline for } \\
\text { existing } \\
\text { emissions }\end{array}$ & Remarks \\
\hline $\begin{array}{l}\text { The limits, expressed as } \\
\text { maximum concentration } \\
\text { of mercury, are } \\
\text { calculated by dividing } \\
\text { the limits (expressed as } \\
\text { maximum anounts of } \\
\text { mercury) by the amount } \\
\text { of water used per metric } \\
\text { tonne of chlorine } \\
\text { production capacity }\end{array}$ & $\begin{array}{l}\text { (i) } 8 \text { g mercury per } \\
\text { metric tonne of } \\
\text { chlorine production } \\
\text { capacity as a monthly } \\
\text { mean; } \\
\text { (ii) } 5 \mathrm{~g} \text { of mercury per } \\
\text { metric tonne of } \\
\text { chlorine production } \\
\text { capacity as a monthly } \\
\text { mean. }\end{array}$ & By 1 July 1986 & $\begin{array}{l}\text { The limits given in the } \\
\text { preceding columns are } \\
\text { applicable to the total } \\
\text { mercury arising in all } \\
\text { mercury-containing } \\
\text { wastewater streams } \\
\text { and thus to be } \\
\text { observed at the exit of } \\
\text { the chloralkali factory } \\
\text { site. }\end{array}$ \\
\hline
\end{tabular}

Source: Paris Commission (1981b).

After intense discussions at the same meeting, the Commission also decided on limit values for existing brine recirculation plants to be applied at the exit of the factory site (PARCOM Decision 81/2). They were $1.5 \mathrm{~g}$ of mercury per tonne of chlorine production capacity as a monthly mean and $6 \mathrm{~g}$ of mercury per tome as a daily mean to be applied from July 1,1983 , as given in Table $5-4$. These walues were legally binding. 
Table 5-4 PARCOM Decision 81/2 on Limit Vallues for Existing Brine Recirculation Chlor-Alkali Plants (exit of the factory site)

\begin{tabular}{|c|c|c|c|}
\hline $\begin{array}{l}\text { Limit values, expressed as } \\
\text { maximum concentration } \\
\text { of mencury }\end{array}$ & $\begin{array}{l}\text { Limit values, expressed } \\
\text { as maximum amount of } \\
\text { mercury }\end{array}$ & $\begin{array}{l}\text { Deadline } \\
\text { for existing } \\
\text { emissions }\end{array}$ & Remarks \\
\hline $\begin{array}{l}\text { The limit values, } \\
\text { expressed as maximum } \\
\text { concentration of mercury, } \\
\text { as calculated by diwding } \\
\text { the values in column } 2 \\
\text { (expressed as maximum } \\
\text { amounts of mercury) by } \\
\text { the amount of watter used } \\
\text { per metric tonne of } \\
\text { chlorine production } \\
\text { capacity }\end{array}$ & $\begin{array}{l}1.5 \mathrm{~g} \text { of mercury per } \\
\text { metric tonne of chlorine } \\
\text { production capacity as a } \\
\text { monthly mean, and } 6 \mathrm{~g} \\
\text { of mercury per metric } \\
\text { tomne of chlorine } \\
\text { production capacity as a } \\
\text { daily mean. }\end{array}$ & 1. July 1983 & $\begin{array}{l}\text { The limit values given } \\
\text { in the preceding } \\
\text { columns are } \\
\text { applicable to the total } \\
\text { mercury arising in all } \\
\text { mercury-containing } \\
\text { wastewater streams } \\
\text { and thus to be } \\
\text { observed at the exit of } \\
\text { the chloralkali factory } \\
\text { site. }\end{array}$ \\
\hline
\end{tabular}

Source: Paris Commission (1981a).

Regarding the existing brine-recirculation chlor-alkali plants, the Commission had actually proposed the adoption of more stringent limit values to be applied from July 1,1986 : $0.5 \mathrm{~g}$ of mercury per tonne of chlorine production capacity as a monthly mean and $2 \mathrm{~g}$ of mercury per tonne as a daily mean at the exit of the factory site. The Technical Working Group had considered these proposals and had recommended that the Commission should adopt the limit values as legally binding. While most of the countries were in favor of a legally binding decision on the limit values, the EEC reserved its position, because the proposed standards were more stringent than those in the relevant EEC Directive, and Spain also claimed that it was not able to accept the adoption of a more stringent limit value (Paris Commission, $1985 \mathrm{c}$ ). In 1985 , the Commission finally agreed to recommend the values referred above to the member countries, with the exception of Spain, which maintained a reservation (PARCOM Recommendation $85 / 1$ ).

Tablè 5-5 PARCOM Recommendation 85/1 on Limit Values for Mercury Emissions in Water from Existing Brine Recirculation Chlor-Alkali Plants (exit of factory site)

\begin{tabular}{|c|c|c|}
\hline $\begin{array}{l}\text { Limit values, expressed as } \\
\text { maximum amount of mercury }\end{array}$ & $\begin{array}{c}\text { Deadline for existing } \\
\text { emissions }\end{array}$ & Remark \\
\hline $\begin{array}{l}0.5 \mathrm{~g} \text { of mercury of chlorine } \\
\text { production capacity as a } \\
\text { monthly mean } \\
2 \mathrm{~g} \text { of mercury per tonne as a } \\
\text { daily mean }\end{array}$ & 1. July 1986 & $\begin{array}{l}\text { The limit values are applicable to the } \\
\text { total mercury arising in all mercury- } \\
\text { containing wastewater streams and } \\
\text { thus to be observed at the exit of the } \\
\text { chlor-alkall factory site. }\end{array}$ \\
\hline
\end{tabular}

Source: Paris Connmission (1985b). 
In the meantime, since the enwironmental quality objective approach was also approved in 1978 along with the uniform emission standards approsch, a task had been left to the Commission to set environmental standards for organisms, water and sediments with regard to quality objectives for mencury. In 1980, the Commission adopted its first environmental standards to be applied for organisms (PARCOM Decision 80/1). Based on the Technical Working Group"s recommendation, it was decided that a standard of $0.3 \mathrm{mg} / \mathrm{kg}$ of mercury in wet fish flesh should be the environmental standard for organisms.

PARCOM Decision 80/1 on Environmental Quality Standard for Mercury in Organisms

The Commission adopted TWG's recommendation that a standard of $0.3 \mathrm{~g} \mathrm{mg} / \mathrm{kg}$ of mercury in wet fish flesh should be the envirommental standard for organisms.

Source: Paris Commission (1980b).

Regarding the environmental quality objectives for water and sediments, the Technical Working Group had been unable to make progress on an environmental standard for water or on whether an environmental standard for sediments was appropriate. Then the Commission, after intensive discussions, confirmed its approval in principle of a "standstill" principle for water, that is, that the concentrations in water should not increase (Paris Commission, 1980a). Those countries having adopted the environmental quality objective approach were asked to submit data to the Commission every year on the emission standards fixed in order to respect the quality objectives. In the case of the United Kingdom, the emission standards were set in the range of $0-20 \mathrm{~g}$ of mercury per tonne of chlorine production capacity (Paris Commission, $1985 a)$.

Concerning new plants, the Commission made a recommendation as early as 1978 that new waste-brine plants should not be built in the future (PARCOM Recommendation 78/1).

\section{PARCOM Recommendation 78/1}

(b) The Commission recommends that no new waste-brine plans should be built.

Source: Paris Commission (19786).

By the third meeting held in 1981, the Technical Working Group tad not been able to decide whether the limit values for new plants should be $0.5 \mathrm{~g}$ or $1 \mathrm{~g}$ of mencury per tonne of chlorine production capacity (Paris Commission, 1983b). During the meeting, all countries 
except France were able to agree that in the construtetion of new plants account must be taken of the best technical means avalable to prevent pollution of the maritime area by mercury and were prepared to agree on the limit value of $0.5 \mathrm{~g}$ per tonne for new brine-recirculation plants. France argued that a global programme should be adopted, covering both the environmental quality objective and the emission standard approaches as well as prohibiting the construction of new waste-brine plants. With the reservation of Franee, the Commission was not able to reach a decision on this issue. Nevertheless, the previous recommendation that no new wastebrine plants should be built was maintained.

At the same meeting, the Commission asked the Working Group on Mercury Pollution to make an evaluation of mercury-free chlor-alkali production technologies. The Working Group expressed its opinion that the ion exchange membrane process was very interesting from the economic viewpoint as well as from the envirommental aspect. Accordingly the Technical. Working Group agreed to recommend to the Commission that, when the construction of new plants was considered, the use of the ion exchange membrane process should be encouraged whenever circumstances permit. Furthermore, it was also recommended that when major changes were to take place in the existing mercury-based plants, replacement with the ion exchange membrane process should be considered.

With the recommendations of the Mercury Working Group and the Technical Working Group on the feasibility of the ion exchange membrane process, the Commission discussed in its fourth meeting held in June 1982 whether it would be feasible to impose a prohibition on the mercury process in the construction of new chlor-alkali electrolysis plants (Paris Commission, 1984). Although some support was expressed for the eventual phasing out of the meicury process, a number of delegations expressed reservations on a total prohibition at the present time. It was pointed out that the new plants with the ion exchange membrane process being constructed in the Netherlands and Portugal at that time were, although promising, not yet operational and that consequently it would be wise to wait for actual experience with this new technology. In addition, it was expected that experience in countries outside Europe would also become available.

lin the end the Commission made a decision, which was to be effective from July 1 , 1982, that authorizations for new plants $\$$ might be granted only if such authorizations

\footnotetext{
"No "New plants" means existing industrial plants whose capacity for the electrolysis of alkali chlorides was to be substantially increased after July 1,1982 , as well as indusirial plants which would become operational after July 1. 1982 (Paris Commission, 1982).
} 
mcluded a reference to the standards corresponding to the "best teelincal means avallable" for preventing discharges of mercury (PARCOM Decision 82/1). According to the Commission, the application of the best technical means available would make it possible to limit discharges of mercury from the site of a new industrial plant using the recycled-brine process to less than $0.5 \mathrm{~g} /$ tonne of installed chlorine production capacity. These arrangements for the authorization of new plants had to be applied by all members, whether they followed the environmental quality objective or the emission standard approach.

Table 5-6 PARCOM Decision 82/1 on New Chloralkali Plants using Mercury Cells

\begin{tabular}{|l|l|c|}
\hline $\begin{array}{c}\text { Condition for authorization } \\
\text { of new plants }\end{array}$ & $\begin{array}{c}\text { Achievable level of discharges } \\
\text { of mercury }\end{array}$ & $\begin{array}{c}\text { Date for the decision to } \\
\text { be effective }\end{array}$ \\
\hline $\begin{array}{l}\text { Application of the best } \\
\text { technical means available }\end{array}$ & $\begin{array}{l}\text { Less than } 0.5 \mathrm{~g} / \text { tonne of } \\
\text { installed chlorine production } \\
\text { capacity }\end{array}$ & $1 \mathrm{Jully} 1982$ \\
\hline
\end{tabular}

Source: Paris Commission (1982).

Furthermore, the Commission agreed that when the construction of new plants was being considered, the use of mercury-free technologies, particularly the ion exchange membrane process, should be encouraged whenever circumstances permitted. It was also decided that the Commission would consider again later whether stricter rules, including the possibility of prohibiting the use of the mercury process, would be appropriate. The Technical Working Group examined the latest information available on the development of alternative technologies and confirmed its earlier opinion that from the technical point of view mereuryfree production processes should be encouraged whenever new plants were constructed. At the Commission's meeting held in 1985, however, three countries did not accept the strengthening of the measures on the use of mercury-free technologies, and the Commission's earlier recommendation was retained unchanged (Paris Commission, 1985c).

\subsubsection{European Community}

The work of the Paris Commission was carried out more or less in paraliel with a similar work conducted by the Commission of the European Communities. The differences between the work of the two organizations have been recognized, and it was particularly emphasized that that the Paris Commission considered pollution specifically from the point of view of protecting the marine environment. Nevertheless, a significant degree of duplication has been 
observed in the regulations of the two organizations, including those issued on mercury emissions from chlor-alkali plants.

In November 1973, the European Community adopted its First Action Programme on the Environment (Council of the European Communities, 1973). The Action Programme indicated that a detailed examination would be carried out of the different possible methods, such as establishing discharges or emission standards, in order to achieve and respect the quality objectives fixed with regard to water pollution. The programme stated that priority would be given to the regulation of discharges of toxic, persistent and bioaccumulative substances into fresh water.

In order to meet these objectives, the Council of the European Communities started to adopt a series of Directives ${ }^{87}$ proposed by the Commission. In May 1976, the Council approved a directive on pollution caused by certain dangerous substances discharged into the aquatic environment of the Community (Council of the European Communities, 1976). Directive $76 / 464 / \mathrm{EEC}$ identified the most dangerous substances, including mercury, in the "List I" or "blacklist" and established the basic principle according to which any discharge of a blacklist substance must be authorized beforehand by the relevant authority in the member countries. This authorization, which could only be granted for a limited period, was required to lay down an emission standard to be respected. As in the case of the Paris Commission, the Council agreed in this directive that, parallel to the emissions standards, quality objectives should also be established for substances on the blacklist. While this parallel approach was formally adopted, the directive indicated clearly that as a general rule the emission standards should be applied. This framework directive established the basic principles of regulations on aquatic pollution in the Community and was followed by a number of implementing directives.

In June 1979, the Commission, in accordance with the agreement reached in the parent Directive $76 / 464$, submitted to the Council two specific proposals for directives conceming emission standards and quality objectives respectively to be applied to mercury discharges by the chlor-alkali industry. In March 1982, after long and difficult negotiations, the Council finally adopted a single directive, Directive $82 / 176$, which contained limit values and quality objectives, together with methods of measurement and monitoring, concerning mercury

\footnotetext{
${ }^{87}$ Article 189 of the Treaty of Rome indicates that "[a] directive shall be binding, as to the result to be achieved, upon eacln Menther State to which it is addressed, but shall leave to the national authorities the choice of form and methods" (Craig and de Burca, 1995).
} 
emissions from chlor-alkali plants (Council of the European Commumites, 1982). This directive, concerned with only one substance discharged by only one manufacturing process, ${ }^{88}$. was the first of the daughter directives resulting from the framework Directive $76 / 464$ on water pollution caused by dangerous substances ${ }^{89}$.

The limit values and the time limits by which they were to be complied with are given in Table 5-7. The authorizations issued by the member countries had to contain provisions at least as stringent as these limit values and were to be reviewed at least every four years. Different limit values were laid down for plants using the lost brine and recycled brine processes. The limit values for mercury discharges were expressed in two ways, namely, in terms of concentration and quantity. The directive stated that the limit values expressed in terms of concentration should, in principle, not be exceeded. However, because the concentration of mercury in effluent depends on the volume of water involved, which varies with different processes and plants, the limit values expressed in terms of quantity in relation to installed chlorine capacity had to be observed in all cases. The limit values were expressed as monthly average, and daily average limit values were specified as four times the corresponding monthly average values.

Table 5-7 Limit Values for Mercury Discharges by the Chlor-Alkali Industry in the Council Directive 82/176/EEC

\begin{tabular}{|l|c|c|c|}
\hline \multirow{2}{*}{ Unit of measurement } & \multicolumn{2}{|c|}{ Limit values (monthly average) } & \multicolumn{1}{|c|}{ Remarks } \\
\cline { 2 - 4 } & I July 1983 & July 1986 & \\
\hline $\begin{array}{l}\text { Concentration for recycled } \\
\text { and lost brine plants } \\
\text { (micrograms of mercury } \\
\text { per litter) }\end{array}$ & $75 \mu \mathrm{g} / 1$ & $50 \mu \mathrm{g} / \mathrm{l}$ & $\begin{array}{l}\text { Applicable to the total } \\
\text { quantity of mercury present } \\
\text { in all mercury-containing } \\
\text { water discharged from the } \\
\text { site of the industrial plant }\end{array}$ \\
\hline $\begin{array}{l}\text { Quantity for recycled brine } \\
\text { plants } \\
\text { (grams of mercury per } \\
\text { tonne of installed chlorine } \\
\text { production capacity) }\end{array}$ & $0.5 \mathrm{~g} / \mathrm{t}$ & $0.5 \mathrm{~g} / \mathrm{t}$ & $\begin{array}{l}\text { Applicable to the mercury } \\
\text { present in effluent discharged } \\
\text { from the chlorine production } \\
\text { unit } \\
\text { Applicable to the total } \\
\text { quantity of mercury present } \\
\text { in all mercury-containing } \\
\text { water discharged from the }\end{array}$ \\
\hline
\end{tabular}

\footnotetext{
${ }^{83}$ A. separate directive was adopted in March 1984 (Directive 84/ $46 / \mathrm{EEC}$ ), which covered mercury discharges by sectors other than the chlor-alkali industry (Council of the European Communities, $1984 a$ ).

s. As regards ofluer dangerous substances, a directive on limit values and quality objectives for cadmium discharges (Directive 83/513/EEC) was adopted in September 1983 rouncil of the Curopean Communities. 1983). Another directive was adopted in October 1984 for discharges of hexachlorocyclohexane (Directive $84 / 491 / \mathrm{EEC}$ ) (Council of the Eutopean Communities, 1984b).
} 


\begin{tabular}{|c|c|c|c|}
\hline & & & ste of the industrial plant \\
\hline $\begin{array}{l}\text { Quantily for lost brine } \\
\text { plants } \\
\text { (grams of mercury per } \\
\text { tonne of installed chlorine } \\
\text { production capacity) }\end{array}$ & $8.0 \mathrm{~g} / \mathrm{t}$ & $5.0 \mathrm{~g} / \mathrm{t}$ & $\begin{array}{l}\text { Applicable to the total } \\
\text { quantity of mercury present } \\
\text { in all mercury-containing } \\
\text { water discharged from the } \\
\text { site of the industrial plant }\end{array}$ \\
\hline
\end{tabular}

Source: Councti of the European Communites (1982).

Four quality objectives for mercury concentrations were set in the directive, as laid down in Table 5-8. Those countries which adopted the environmental quality objective approach were required to fix emission standards so that the appropriate quality objectives would be complied with in the area affected by discharges of mercury from the chlor-alkali industry. The directive also stipulated that the concentration of mercury in sediments or in shellish should not increase significantly with time. Furthermore, the quality of the waters had to be sufficient to comply with the requirements of any other directive applicable to such waters as regards the presence of mercury.

Table 5-8 Quality Objectives for Mercury Discharges by the Chlor-Alkali Industry in the Council Directive 82/176/EEC

\begin{tabular}{|l|c|}
\hline \multicolumn{1}{|c|}{ Organism/water } & Quality objective \\
\hline Fish & $0.3 \mathrm{mg} / \mathrm{kg}$ wet flesh \\
\hline Inland surface waters & $1 \mu \mathrm{g} / \mathrm{l}$ \\
\hline Estuary waters & $0.5 \mu \mathrm{g} / 1$ \\
\hline Temritorial sea waters and internal coastal waters & $0.3 \mu \mathrm{g} /$ \\
\hline
\end{tabular}

Concentrations of mercury in waters are arithmetic means of the results obtained over a year. Source: Council of the European Communties (1982).

The directive made it clear that countries could grant authorizations for new plants only if such authorizations contain a reference to the standards corresponding to the best technical means available for preventing discharges of mercury. The directive included a statement of the Council and Commission, while not legally forming part of the directive, that "the application of the best technical means available makes it possible to limit discharges of mercury fiom the site of a new industrial plant using the recycled-brine process to less than $0.5 \mathrm{~g} /$ tonne of installed chlorine production capacity" (Council of the European Communities, 1982). A country, where for technical reasons the intended measures did not conform to the best technical means available, was required to provide the Commission with the justifications for these reasons. 
The treatment of new plants was an issue of particular importance in the process of formulating the directive (Haigh, 1987), Originally the Commission proposed limit values for new plants set at the level to be achieved by reeycled brine plants in July 1989 whereas the proposal for quality objectives made no such reference. France and Italy, on the one hand, argued that, if a country applying quality objectives did not have to apply the limit values that would otherwise apply in the case of a new plant, there would be distortion of competition. The United Kingdom, on the other hand, thought it was important to uphold the principle underlying the use of quality objectives; that $\ddot{\|}$, the emission standard to be applied to any plant, whether new or not, should be related to the quality to be met in the receiving waters. The resultant compromise was the directive which actually avoided requiring best technical means to be used, but in effect creating an atmosphere in which it would be very difficult not to use them. It was implicitly understood that it would be unrealistic to build a new plant which did not make use of processes based on the best technical means available.

These regulations, including the Decisions, Recommendations, and Directives, imposed since the 1970 s were aimed at reducing mercury emissions to water by basically using measures of the end-of-pipe type. It was in the late 1980 s that atmospheric emissions of mercury started to become the target of regulations. In 1988 the Paris Commission decided that its work on atmospheric emissions should concentrate on measures aimed at limiting the emissions of heavy metals and established the Atmospheric Inputs Working Group (Paris Commission, 1989). The Commission made discussions in the following year on a draft of a decision on reducing atmospheric emissions of mercury from the existing chlor-alkali plants. The draft specified a standard of $2 \mathrm{~g}$ of mercury per tonne of chlorine capacity for emissions to the atmosphere, including mercury in hydrogen relessed to the atmosphere or burn. This standard was to be complied with by the end of 1994 unless there was a firm commitment that the plant would be converted to a mercury-free process by the year 2000 . The draft also included a recommendation for a complete phasing out of the mercury process by 2010 (Paris Commission, 1990). As it was pointed out, however, that all countries were already obliged to use the best technical means and that the technology necessary to achieve the envisaged reductions was available, the Commission could not agree on the decision.

Meanwhile, environmental ministers from the North Sea coastal countries convened in The Hague, the Netherlands, in March 1990 for the Third International Conference on the 
Protection of the North Sea (INSC) ${ }^{90}$. The principal task of the conference was to review the implementation of commitments made at the first and second conferences, held in Bremen in 1984 and London in 1987, respectively 9 . A list of 36 hazardous substances was identified with the target of $50 \%$ or more reduction between 1985 and 1995 , and, in particular a $70 \%$ reduction target was established for the most dangerous substances to the environment, namely, dioxins, cadminm, lead, and mercury. The adopted Hague Declaration included what went beyond the regulations of the Paris Commission or the European Commission in regard to mercury emissions from chlor-alkali plants. That is, the environmental ministers agreed that existing mercury-based plants should be phased out as soon as practicable on a national basis with the objective that they should be phased out completely by 2010 . It was decided that mercury plants should be required to meet by 1996 a limit value of $2 \mathrm{~g}$ of mercury per tonne of chlorine capacity for emissions to the atmosphere, including those in hydrogen, unless there was a firm commitment that the plant would be converted to a mercury-free process by the year 2000 (Third International Conference on the Protection of the North Sea, 1990). While this declaration was not legally binding, it represented a political commitment by the environmental ministers ${ }^{22}$.

Several months later, following the measures agreed in the Hague Declaration, the Paris Commission adopted a decision, PARCOM Decision 90/3. A limit value of $2 \mathrm{~g}$ of mercury per tonne of chlorine capacity was specified for the atmospheric mercury emissions, including mercury in hydrogen. And, most significantly, the decision recommended that existing mercury plants should be completely phased out by 2010. It was formulated as a recommendation because a number of member countries, during negotiations at the Paris Commission, were not able to accept the proposed phase-out in the form of a PARCOM Decision.

\footnotetext{
The participating countries were Belgium, Denmark, France, Germany, Netherlands. Norway, Sweden and the United Kingdom, joined for the first time by Switzerlland.

"The history of iNSC started in 1983, when the German government proposed an international conference for the protection of the North Sea enviromment at ministerial level. The purpose was to make a political declaration which would stimutate and further ongoing work within the existing international conventions, including the Paris Convention, rather than to create another set of intemational agreements. For details, see Ehlers (1990).

"Skjarseth (1998) argues that by excluding the leasit ambitious countries and focusing political pressure at the ministerial level, it was possible to adopt stringernt international commitments that did not merely reflect the interests and preferences of the least ambitious members. Similarly. Haas (1993) argues that collective pollution control aflorts for the North Sea have developed through a "leader-laggard dynamic."
} 


\section{PARCOM Decision $90 / 3$ on Reducing Atmospheric Emissions from Existing}

Chlor-Alkali Plants

Contracting Parties to the Paris Commission for the Prevention of Marine Pollution from Land-Based Sources AGREE:

that existing mercury-based chlor-alkali plants shall be required to meet by $3 \mathbb{}$ December 1996 a standard of $2 \mathrm{~g} \mathrm{Hg} / \mathrm{t} \mathrm{Cl}$ capacity for emissions to the atmosphere, unless there is a firm commitment that the plant will be converted to mercury-free technology by the year 2000 ;

that mercury in hydrogen which is released to the atmosphere, or is burnt, is to be included in this standard;

AND RECOMMEND that existing mercury cell chlor-alkali plants be phased out as soon as practicable. The objective is that they should be phased out completely by 2010 .

Source: Paris Commission (1990).

In this way, the fwo institutions, the Paris Commission and the European Commission, made very similar regulations on mercury emissions almost in parallel. Table 5-9 gives the chronological development of envirommental regulations on mercury emissions from the chlor-alkali plants in Western Europe. Unlike the case of Japan, strong regulations such as those requiring the phase out of the mercury process were not adopted in Western Europe in the 1970s. Instead, emission standards were initialiy set as limit values on mercury released to water by both the Paris Commission and the European Community. These emission standards were subsequently tightened increasingly during the 1980s. Then in 1990, the recommendation was made for the phase out of the mercury process by the year 2010 .

Table 5-9 Environmental Regulations on Mercury Emissions from the Chlor-Alkali Plants in Western Europe

\begin{tabular}{|c|l|}
\hline Year & \multicolumn{1}{|c|}{ Regulation on mercury emissions } \\
\hline 1974 & $\begin{array}{l}\text { Paris Convention } \\
\text { Mercury listed in Annex A }\end{array}$ \\
\hline 1976 & $\begin{array}{l}\text { Council Directive 76/464/EEC } \\
\text { Mercury identified as List I substance }\end{array}$ \\
\hline 1978 & $\begin{array}{l}\text { PARCOM Recommendation } 78 / 1 \\
\text { No new waste-brine plants be built }\end{array}$ \\
\hline
\end{tabular}




\begin{tabular}{|c|c|}
\hline \multirow[t]{2}{*}{1980} & $\begin{array}{l}\text { PARCOM Decision } 80 / 1 \\
\text { Environmental quality standard for mercury in organisms } \\
\text { - } 0.3 \mathrm{mg} \mathrm{Hg} / \mathrm{kg} \text { in wet fish }\end{array}$ \\
\hline & $\begin{array}{l}\text { PARCOM Decision } 80 / 2 \\
\text { Limit values for mercury emissions in water from existing and new brine } \\
\text { recirculation plants (exit of the purification plant) } \\
0.5 \mathrm{~g} \mathrm{Hg} / \mathrm{Cl}_{2} \text { (monthly mean) after } 1 \text { July } 1983 \\
2.0 \mathrm{~g} \mathrm{Hg} / \mathrm{Cl}_{2} \text { (daily mean) after } 1 \mathrm{July} 1983\end{array}$ \\
\hline \multirow[t]{2}{*}{1981} & $\begin{array}{l}\text { PARCOM Decision 81/1 } \\
\text { Limit values for existing waste brine plants } \\
\text { - } 8 \mathrm{~g} \mathrm{Hg} / \mathrm{t} \mathrm{Cl} \text { (monthly mean) after } 1 \mathrm{July} 1983 \\
\text { - } 5 \mathrm{~g} \mathrm{Hg} / \mathrm{t} \mathrm{Cl} \text { (monthly mean) after } 1 \mathrm{July} 1986\end{array}$ \\
\hline & $\begin{array}{l}\text { PARCOM Decision } 81 / 2 \\
\text { Limit values for existing brine recirculation plants (exit of the factory site) } \\
\text { - } 1.5 \mathrm{~g} \mathrm{Hg} / \mathrm{t} \mathrm{Cl} \mathrm{Cl}_{2} \text { (monthly mean) after } 1 \mathrm{July} 1983 \\
\text { - } 6 \mathrm{~g} \mathrm{Hg} / \mathrm{t} \mathrm{Cl} \text { (daily mean) after } 1 \mathrm{July} 1983\end{array}$ \\
\hline 1982 & $\begin{array}{l}\text { Council Directive } 82 / 176 / \mathrm{EEC} \\
\text { Limit values for recycled brine plants } \\
\text { - } 0.5 \mathrm{~g} \mathrm{Hg} / \mathrm{t} \mathrm{Cl} \mathrm{l}_{2} \text { after } 1 \mathrm{July} 1983 \text { (exit of the purification plant) } \\
\text { - } 1.5 \mathrm{~g} \mathrm{Hg} / \mathrm{t} \mathrm{Cl} \text { after } 1 \mathrm{Jully} 1983 \text { (exit of the factory site) } \\
\text { - } 1.0 \mathrm{~g} \mathrm{Hg} / \mathrm{t} \mathrm{Cl} \text { after I July } 1986 \text { (exit of the factory site) } \\
\text { Limit values for lost brine plants } \\
\text { - } 8.0 \mathrm{~g} \mathrm{Hg} / \mathrm{t} \mathrm{Cl} \text { after I July } 1983 \\
\text { - } 5.0 \mathrm{~g} \mathrm{Hg} / \mathrm{t} \mathrm{Cl} 2 \text { after } 1 \mathrm{July} 1986 \\
\text { Quality objectives } \\
\text { - } 0.3 \mathrm{mg} \mathrm{Hg} / \mathrm{kg} \text { wet fish flesh } \\
\text { - } 1 \mu \mathrm{g} \mathrm{Hg} / \mathrm{l} \text { in inland surface waters } \\
\text { - } 0.5 \mu \mathrm{g} \mathrm{Hg} / \mathrm{in} \text { estuary waters } \\
\text { - } 0.3 \mu \mathrm{g} \mathrm{Hg} / \mathrm{l} \text { in territorial sea waters and internal coastal waters }\end{array}$ \\
\hline & $\begin{array}{l}\text { PARCOM Decision } 82 / 1 \\
\text { New chlor-alkali plants } \\
\text { - Application of the best technical means available (less than } 0.5 \mathrm{~g} \mathrm{Hg} / \mathrm{t} \mathrm{Cl} \text { ) after } 1 \\
\text { July } 1982 \\
\text { - Use of mercury-free technology, in particular membrane cells, encouraged }\end{array}$ \\
\hline 1985 & $\begin{array}{l}\text { PARCOM Recommendation } 85 / 1 \\
\text { Limnit values for mercury emissions in water from existing brine recirculation plants } \\
\text { (exit of factory site) } \\
\text { - } 0.5 \mathrm{~g} \mathrm{Hg} / \mathrm{C} \mathrm{Cl} \text { (monthly mean) after } 1 \mathrm{July} 1986 \\
\text { - } 2 \mathrm{~g} \mathrm{Hg} / \mathrm{t} \mathrm{Cl} \mathrm{Cl}_{2} \text { (daily mean) after } 1 \text { July } 1986\end{array}$ \\
\hline 1990 & $\begin{array}{l}\text { PARCOM Decision } 90 / 3 \\
\text { Reducing atmospheric emissions from existing plants } \\
\text { - } 2 \mathrm{~g} \mathrm{Hg} / \mathrm{t} \mathrm{Cl} \text { for mercury emissions to the atmosphere, including mercury in } \\
\text { hydrogen, after } 31 \text { December } 1996 \text {, unless the plant will be converted to mercury- } \\
\text { free technology by } 2000 \\
\text { - Recommendation for the phase-out of the existing mercury plants by } 2010\end{array}$ \\
\hline
\end{tabular}




\subsection{Reduction of Mercury Emissions with End-of-Pipe Technologies}

\subsubsection{Patents on Chlor-Alkali Production Technologies}

With the imposition of these regulations, which mainly anvolved emission standards, chloralkali producers operating the mercury process in Western Europe were required to reduce mercury emissions. In the 1970s, their emissions accounted for a major share of the total mercury emissions to the environment. As we have discussed above, there are bastcally two types of technologies to reduce emissions from the production process, that is, the end-of-pipe technology and the clean technology. Accordingly, two technological options were available to the operators of the mercury process for the abatement of mercury emissions. One option was to adopt end-of-pipe technologies to reduce mercury emissions and then to continue to rely on the mercury process for chlor-alkali production. The other option was to convert the mercury process to a clean technology. As we have seen in the case of technological change in the Japanese chlor-alkali industry, the diaphragm process and the ion exchange membrane process could be alternative production processes.

To see what kinds of technologies were developed in Western Europe, we examined successful patent applications by Western European companies. As there are major differences among countries in procedures and criteria for granting patents (Patel and Pavitt, 1995), international comparisons are most reliable when international patenting or patenting in one country is used. In Western Europe, with the entry into force of the European Patent Convention on 7 October 1977, the first European patent applications were received on 1 June 1978, and subsequently the European patents were granted for the furst time in 1980 (European Patent Office, 2000). Therefore, the European patents are not suitable for examining patents applied in the 1970 s, a period which is crucial for our examination of the development of chlor-alkal technologies in Western Europe.

We instead used the US patents for our research because the US patent database is a neutrall source of information, which covers patents applied since the beginning of the $1970 \mathrm{~s}$. Also, companies in Western Europe are reasonably expected to have strong incentives to obtain patent protection in the world's largest market for their technologies, which can be adopted all over the world. Data was obtained from the web-based patent database of the US Patent and Trademark Offree ${ }^{93}$. The patents included in this database were those issued in the

\footnotetext{
${ }^{2}$ The URL is hitp://www uspto,gov/patifindex himl.
} 
period from January 1, 1976, to December 31, 1998. For patents issued in the period from 1971 to 1975, we used the web-based database of the IBM Intellectual Property Network ${ }^{94}$.

Relevant patents were identified by using the International Patent Classification (IPC). The IPC, in its sixth edition, divides various types of technology into eight sectors with approximately 67,000 subdivisions, each of which has a symbol consisting of Arabic numerals and letters of the Latin alphabet. The appropriate IPC symbols are indicated on each patent document. In this study, we examined patents included in the following classes:

- C25B-1/16 Electrolytic production of alkali metal hydroxides

- C25B-1/26 Electrolytic production of chlorine or compounds thereof

- C25B-1/34 Simultaneous production of alkali metall hydroxides and chlorine, its oxyacids or salts

- C25B-1/36 - in mercury cathode cells

- $\mathrm{C} 25 \mathrm{~B}-1 / 38 \cdots$ with vertical mercury cathode

- C25B-1/40 - with horizontal mercury cathode

- C25B-1/42 - Decomposition of amalgams

- C25B-1/44 -.. with the aid of catalysts

- $\mathrm{C} 25 \mathrm{~B}-1 / 46$ - in diaphragm cells

In the first edition of IPC, which entered into force on September 1, 1968, the abovementioned classes did not exist. Instead, they were classified in the following way:

- C01B-7/06 Preparation of chlorine by electrolysis

- C01D-1/06 Preparation of hydroxides of sodium and/or potassium by electrolysis

- C01D-1/08 - with the aid of a liquid cathode

- ColD-1/10 * with a vertical cathode

- ColD-1/12 * with a horizontal cathode

- C01D-1/14 - Regulating the distance between the solid anode(s) and the liquid cathode

- C01D-1/16 - Working up the amalgam

- COID-1/18.*. with the aid of catalysts

Accordingly, we used the above patent classes for patents issued from 1971 to 1975.

\footnotetext{
"4 The database is currently called the Delphion Intellectual Property Network. The URL is luttp://www.delphion.condhome.
} 
These patent cllasses, however, include patents on other areas than the electrolytic production of sodium hydroxide, which is just one type of alkali metal hydroxides, and. chlorine. For example, the class of $\mathrm{C} 25 \mathrm{~B}-1 / 16$ includes patents related to the electrolytic production of potassium hydroxide, and the class of $\mathrm{C} 25 \mathrm{~B}-1 / 24$ includes patents on the electrolytic production of hypochlorite. Thus, by examining all the patent documents one by one, we excluded inappropriate patents from our analysis. Then we divided patents on the electrolytic production of sodium hydroxide and chlorine into the three categories of the mercury process, the diaphragm process, the ion exchange membrame process. The judgement was made by examining each patent document closely. For the category of the mercury process, we also picked up patents on technologies for dealing with mercury emissions. By using the following combinations of keywords, namely, mercury, and treat*, reduc*, remov* or recov*, we first collected 1,295 patents which could potentially be relevant. Then we selected those which are related to the chlor-alkali industry by examining each patent.

Figure 5-1 shows the trends in the US patents successfully applied by companies in Westem Europe since the end of the 1960 s for technologies related to the mercury process and the ion exchange membrane process for chlor-alkali production. (Detailed data are given in Table 5-21 in Appendix at the end of this chapter.) 


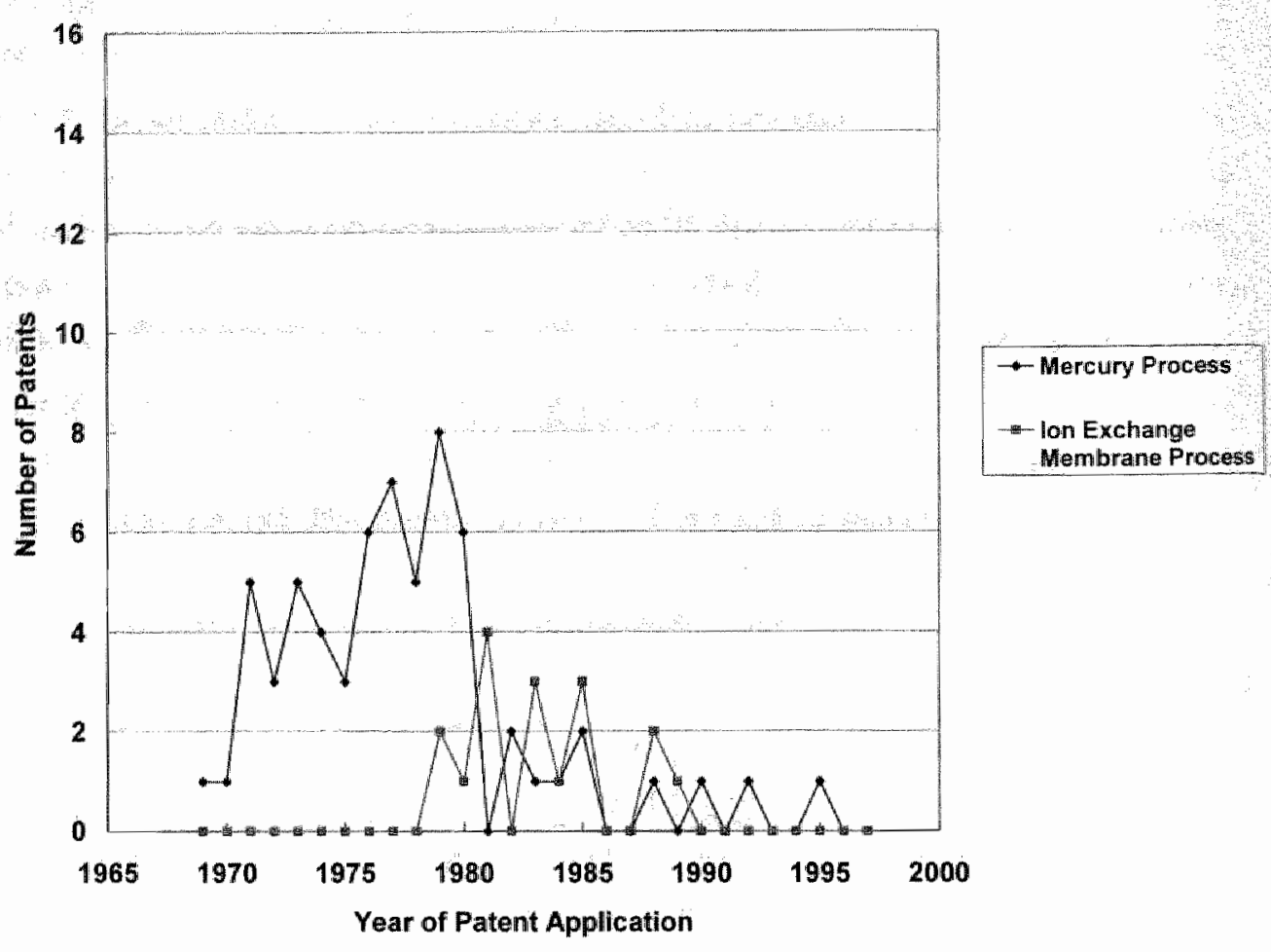

Figure 5-1. US Patents Successfully Applied by Western European Firms on the Mercury and lon Exchange Membrane Processes

As we can see, most of the patents successfully applied by Western European companies from the end of the 1960s to 1980, that is, 54 out of 60 patents, were targeted for technologies related to the mercury process. On the other hand, only 10 per cent of all the patents granted in the same period, namely, 6 patents, were related to the ion exchange membrane process. The number of patents on the mercury process increased from the level observed at the end of the 1960s and reached a peak in the late 1970s. Thereafter, relatively few patents were granted in the 1980s and 1990s. Although there were several patents on the ion exchange membrane process at the end of the $1970 \mathrm{~s}$ and in the 1980 s, overall more than three times as many patents were granted on the mereury process as on the ion exchange membrane process. That suggests that the focus of R\&D activities made by Western European companies were primarily aimed at developing technologies for reducing mercury emissions 
through end-of-pipe technologies, especially throughout the 1970s. On the other hand, that implies that these companies did not devote their innovative efforts to develloping technologies for the ion exchange membrane process until the end of the 1970s.

In order to make a comparison between Western Europe and Japan valid, it is necessary to maintain the same conditions. Thus we also examined the Japanese case by analyzing the US patent data with the same procedure. Figure 5-2 shows the trends in successful applications for US patents by Japanese companies in the same period on teclmologies related to the mercury process and the ion exchange membrane process. (Detailed data are given in Table 5-22 in Appendix at the end of this chapter.)

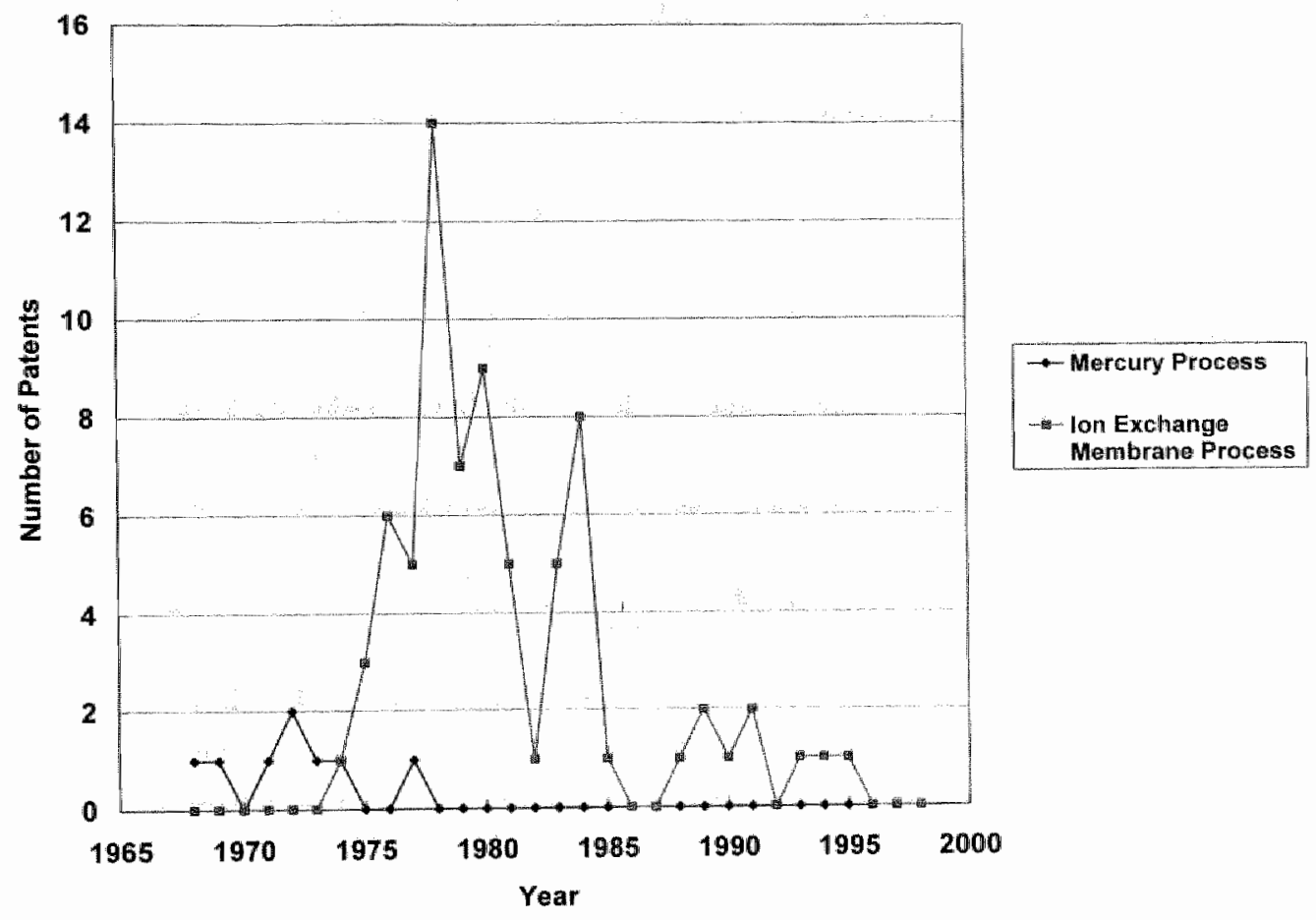

Figure 5-2 US Patents Successfully Applied for by Japanese Companies on Technologies Related to the Mercury Process and the Ion Exchange Membrane Process

Applications for patents on the ion exchange membrane process started to increase rapidly in the middle of the 1970s, following the government policy for the phase out of the mercury process in Japan. Subsequently, successful patent applications on technologies for 
the ion exchange membrane process reached a peak in 1978. The number of successful patent applications by lapanese firms on the ion exchange membrane process from the end of the 1960 s 101980 was 45 , which is far larger than that by companies in Western Europe, that is, 6 . Active patent applications on the ion exchange membrane process continued until the middle of the 1980s, and then the number of patents granted declined. On the other hand, the number of patents related to the mereury process remained rellatively small, with only several patents. applied from the end of the 1960s through the $1970 \mathrm{~s}$, compared with patents on the ion exchange membrane process.

Figure 5-1 and Figure 5-2 show a clear contrast in innovative efforts between companies in Western Europe and those in Japan. That is, during the 1970 s, the focus of patent applications made by the Western European companies was on the mercury process whereas the Japanese companies" patent applications were targeted at the ion exchange membrane process. As we have seen in Figure 3-3, while mercury can be mostly recovered for reuse during the operation of mercury-based plants, some of it inevitably escapes to the environment, through waste water, air, products, and solid wastes. And we have discussed in Chapter 3 that there are two types of technological options to deal with mercury emissions, namely, the end-of-pipe technology and the clean technology. Figure 5-1 suggests that endof-pipe technologies for the reduction in mercury emissions from the mercury chlor-alkali process were paid attention to in R\&D activities conducted by companies in Western Europe. This is in sharp contrast with the Japanese case. As indicated in Figure 5-2, most of the innovative activities of the Japanese companies were devoted to the development of technologies for the ion exchange membrane process, a prime example of the clean technology. This result supports our analysis based on the Japanese patent data in Chapter 4.

We have also seen in Chapter 3 that in Western Europe there were several companies which had been innovative on technologies related to the mercury process by the end of the 1960s. As Table 3-8 and Table 3-11 show, these companies were ICl, Hoechst-Uhde, De Nora, Bayer, Solvay, and Krebs, cooperating with BASF. We are interested in examining how these innovative companies made R\&D efforts on which production process since the 1970s, when regulations on mercury emissions from chlor-alkali plants started to be introduced in Western Europe. We first look at innovations on the mercury process made by these companies. Table 5-10 gives the trends in the US patents which were successfully applied by these imovative companies in Western Europe on technologies related to the mercury process and the ion exchange membrane process. 
Table 5-10 US Patents Successfully Applied by Western European Companies on Technologies Related to the Mercury Process and the lon Exchange Membrane Process

\begin{tabular}{|c|c|c|c|c|c|c|c|c|c|c|c|c|}
\hline \multirow[t]{2}{*}{ Year $^{9}$} & \multicolumn{2}{|c|}{$\mathrm{ICI}$} & \multicolumn{2}{|c|}{$\begin{array}{l}\text { Hoechst- } \\
\text { Uhde }\end{array}$} & \multicolumn{2}{|c|}{ De Nora } & \multicolumn{2}{|c|}{ Bayer } & \multicolumn{2}{|c|}{ Krebs $^{\text {B }}$} & \multicolumn{2}{|c|}{ Solvay } \\
\hline & $\mathrm{Hg}$ & IM & $\mathrm{Hg}$ & IM & $\mathrm{Hg}$ & $\mathrm{IM}$ & $\mathrm{Hg}$ & $\mathrm{IM}$ & $\mathrm{Hg}$ & IM & $\mathrm{Hg}$ & IM \\
\hline 1970 & 0 & 0 & 0 & 0 & 1 & 0 & 0 & 0 & 0 & 0 & 0 & 0 \\
\hline 1971 & 1 & 0 & 0 & 0 & 0 & 0 & 0 & 0 & 2 & 0 & 0 & 0 \\
\hline 1972 & 0 & 0 & 0 & 0 & 1 & 0 & 0 & 0 & 0 & 0 & 0 & 0 \\
\hline 1973 & 0 & 0 & 1 & 0 & 0 & 0 & 1 & 0 & 0 & 0 & 0 & 0 \\
\hline 1974 & 1 & 0 & 0 & 0 & 1 & 0 & 1 & 0 & 0 & 0 & 0 & 0 \\
\hline 1975 & 1 & 0 & 0 & 0 & 0 & 0 & 0 & 0 & 0 & 0 & 0 & 0 \\
\hline 1976 & 0 & 0 & 1 & 0 & 0 & 0 & 0 & 0 & 0 & 0 & 0 & 0 \\
\hline 1977 & 0 & 0 & 1 & 0 & 0 & 0 & 0 & 0 & 0 & 0 & 0 & 0 \\
\hline 1978 & 0 & 0 & 0 & 0 & 2 & 0 & 2 & 0 & 0 & 0 & 0 & 0 \\
\hline 1979 & 1 & 0 & 2 & 1 & 1 & 1 & 0 & 0 & 0 & 0 & 0 & 0 \\
\hline 1980 & 0 & 0 & 0 & 0 & 1 & 1 & 1 & 0 & 0 & 0 & 0 & 0 \\
\hline 1981 & 0 & 0 & 0 & 0 & 0 & 4 & 0 & 0 & 0 & 0 & 0 & 0 \\
\hline 1982 & 0 & 0 & 0 & 0 & 0 & 0 & 0 & 0 & 0 & 0 & 0 & 0 \\
\hline 1983 & 0 & 0 & 0 & 0 & 0 & 3 & 0 & 0 & 0 & 0 & 0 & 0 \\
\hline 1984 & 0 & $\Perp$ & 0 & 0 & 0 & 0 & 0 & 0 & 0 & 0 & 1 & 0 \\
\hline 1985 & 0 & 1 & 0 & 1 & 0 & 1 & 0 & 0 & 0 & 0 & 0 & 0 \\
\hline 1986 & 0 & 0 & 0 & 0 & 0 & 0 & 0 & 0 & 0 & 0 & 0 & 0 \\
\hline 1987 & 0 & 0 & 0 & 0 & 0 & 0 & 0 & 0 & 0 & 0 & 0 & 0 \\
\hline 1988 & 0 & 0 & 0 & 0 & 0 & 2 & 0 & 0 & 0 & 0 & 0 & 0 \\
\hline 1989 & 0 & 0 & 0 & 0 & 0 & 1 & 0 & 0 & 0 & 0 & 0 & 0 \\
\hline 1990 & 0 & 0 & 0 & 0 & 0 & 0 & 0 & 0 & 0 & 0 & 0 & 0 \\
\hline 1991 & 0 & 0 & 0 & 0 & 0 & 0 & 0 & 0 & 0 & 0 & 0 & 0 \\
\hline 1992 & 0 & 0 & 0 & 0 & 0 & 0 & 0 & 0 & 0 & 0 & 0 & 0 \\
\hline 1993 & 0 & 0 & 0 & 0 & 0 & 0 & 0 & 0 & 0 & 0 & 0 & 0 \\
\hline 1994 & 0 & 0 & 0 & 0 & 0 & 0 & 0 & 0 & 0 & 0 & 0 & 0 \\
\hline 1995 & 0 & 0 & 0 & 0 & 0 & 0 & 0 & 0 & 0 & 0 & 0 & 0 \\
\hline 1996 & 0 & 0 & 0 & 0 & 0 & 0 & 0 & 0 & 0 & 0 & 0 & 0 \\
\hline 1997 & 0 & 0 & a & 0 & 0 & 0 & 0 & 0 & 0 & 0 & 0 & 0 \\
\hline Total & 32 & 2 & 4 & 2 & 9 & 9 & 16 & 0 & 2 & 0 & 1 & 0 \\
\hline
\end{tabular}

Hg: Mercury Process; IM: Ion Exchange Membrane Process

a: Year of patent applications.

$b$ : The data of Krebs includes that of BASF.

Although the number of successful patent applications is small, we can see that, while these companies made patent applications basically on technologies related to the mercury process in the $1970 \mathrm{~s}$, successful patent applications started to appear on the ion exchange membrane process at the end of the 1970 s and the beginning of the 1980 s. That suggests that 
these companies initially focuses their R\&D activities on technologies telated to the mercury process in the 1970 s, when regulations on mercury emissions began to be introduced in Western Europe. Then they started to shift their innovative efforts to the ion exchange membrane process at the end of the 1970 s. To understand exactly what kinds of technologies were developed for the mercury process in the 1970 s, particularly whether these innovations were actually technological measures aimed at reducing mercury emissions, more detailed analysis of these technological developments is necessary. In the next section, we examine in detail what kinds of technologies have been actually developed and subsequently supplied by these companies in Western Europe.

\subsubsection{Development of End-of-Pipe Technologies for the Reduction of Mercury}

\section{Emissions}

As we can see in Figure 3-3 and Figure 3-4, mercury-based chlor-alkali plants discharge mercury to the environment. It is mainly emitted through waste water, process gases, and products (Schmittinger, Curlin, Asawa, Kotowski, Beer, Greenberg, Zelfel, and Breitstadt, 1986). Liquid effluent streams contain significant amounts of mercury. Mercury-containing wastewater has several sources in the production process. They include condensate and wash liquor from treatment of chlorine, hydrogen, and brine, stufling-box rinse water from pumps and blowers, and brine leakage. In addition, the cleaning operations of cells, floors, tanks, pipes, and dismantled apparatus normally produce waste waters containing mercury.

Mercury emissions to products include those to chlorine and caustic soda. Hot, moist chlorine leaving the cell contains small amounts of mercury chloride. This is almost complletely washed out in the subsequent cooling process and is fed back into the brine with the condensate. As there are only minute traces of mercury in the cooled and dried chlorine gas, normally mercury removal processes are not required for this product. On the other hand, the caustic soda produced with the mercury process inevitably contains mercury, and technical treatment is necessary to reduce the mercury content.

Mercury emissions to the atmosphere are accounted for by mercury in three sources, namely, process cxhaust, cellroom ventilation, and hydrogen ${ }^{95}$. Process exhaust refers to all gaseous streams by which mercury is emitted to the atmosphere, apart from in cellroom ventilation wir and in hydrogen as a product. Each plant has different streams, but typically 
purge air from cell end-boxes, vents from wash water collection tanks and exhaust from any vacuum system used to collect spilled mercury are the main sources of mercury emissions to the air. Mercury spillage occurs during essential operations involving ellectrolytic cells or decomposers, for example, opening electrolytic cells for anode changing or cleaning, assembling or dismantling equipment, and replacing defective pipes, and spillage leads to small losses in the air owing to the vapor pressure of mercury. Mercury is also emitted through unintended leakage from equipment including cells, pipes and vessels, via faulty seals. The hydrogen gas stream is nearly saturated with mercury when it leaves the decomposer.

To see whether innovations on the mercury process have been aimed at the reduction of mercury emissions through these various routes to the enviromment, we need to examine what kinds of technological developments have been made by companies in Western Europe concerning the mercury process. We look at the patent data in detail for that purpose. Table 5-11 shows the US patents granted to companies in the Western European chlor-alkali industry on technologies related to the mercury process.

Table 5-11 US Patents Successfully Applied by Companies in the Western European Chlor-Alkali Industry on Technologies Related to the Mercury Process

\begin{tabular}{|c|c|c|c|}
\hline Company & Patent No. & Year & Pattent Title \\
\hline \multirow[t]{4}{*}{ ICI } & US3718457 & 1.971 & $\begin{array}{l}\text { Process for the recovery of mercury from waste brine } \\
\text { from mercury cells }\end{array}$ \\
\hline & US3905880 & 1974 & Operation of mercury-cathode cells \\
\hline & US4060463 & 1975 & Operation of mercury-cathode cells \\
\hline & US4234405 & 1979 & Electrode for electrochemical processes \\
\hline \multirow[t]{5}{*}{$\begin{array}{l}\text { Hoechst- } \\
\text { Whde }\end{array}$} & US3922210 & 1973 & $\begin{array}{l}\text { Process of avoiding mercury emission from mercury- } \\
\text { using plants }\end{array}$ \\
\hline & US 4059438 & 1976 & $\begin{array}{l}\text { Process for the work-up of a contaminated inactive } \\
\text { mercury(II) chloride/active carbon-catalyst }\end{array}$ \\
\hline & US4108769 & 1977 & $\begin{array}{l}\text { Process for reducing the mercury content of industrial } \\
\text { waste waters }\end{array}$ \\
\hline & US4212715 & 1979 & $\begin{array}{l}\text { Process for reducing losses of mercury in alkali metal } \\
\text { chloride electrolysis }\end{array}$ \\
\hline & US4244801 & 1979 & $\begin{array}{l}\text { Apparatus to measure the distribution of the anode } \\
\text { currents in cells for alkali metal chloride }\end{array}$ \\
\hline De 1 & US3627652 & 1970 & $\begin{array}{l}\text { Method of operating mercury cathode electrolytic celll } \\
\text { plant }\end{array}$ \\
\hline
\end{tabular}

\footnotetext{
${ }^{35}$ Note that hydrogen released to the atmosphere or used or sold as a fuel is included in gaseous effluent, not classified as a product.
} 


\begin{tabular}{|c|c|c|c|}
\hline & US3833357 & 1972 & $\begin{array}{l}\text { A Process for decomposing alkali metal amalgams into } \\
\text { mercury, hydrogen and alkali metal bydroxide solutions }\end{array}$ \\
\hline & US4161433 & 1978 & Decomposition of alkali metal amalgams \\
\hline & US4166780 & 1978 & Novel electrollytic process \\
\hline & US4204937 & 1979 & Novel electrollytic amalgam denuder apparatus \\
\hline & US4263107 & 1980 & Electrolytic apparatus and process \\
\hline Solvay & US4565613 & 1984 & $\begin{array}{l}\text { Process for removing a layer of thick mercury from the } \\
\text { bottom of mercury-cathode electrolysis cells and a } \\
\text { process for the electrolysis of an aqueous solution of an } \\
\text { alkali metal halide in a mercury-cathode cell }\end{array}$ \\
\hline \multirow[t]{5}{*}{ Bayer } & US3890211 & 1973 & $\begin{array}{l}\text { Process for recovering energy from the decomposition of } \\
\text { amalgam in the electrolysis of alkali metal chlorides }\end{array}$ \\
\hline & US3895938 & 1974 & Purification of mercury \\
\hline & US4132759 & 1978 & $\begin{array}{l}\text { Method of purifying brine used in electrolysis by the } \\
\text { amalgam process }\end{array}$ \\
\hline & US4152226 & 1978 & \begin{tabular}{|l}
$\begin{array}{l}\text { Process and apparatus for monitoring amalgam } \\
\text { electrolysis cells }\end{array}$ \\
\end{tabular} \\
\hline & US 4323438 & 1980 & Anode for alkali metal chloride electrolysis \\
\hline \multirow[t]{3}{*}{ BASF } & US3755109 & 1971 & Electrolysis of alkali metal chlorides \\
\hline & US3755110 & 1971 & $\begin{array}{l}\text { Process for the recovery of mercury from the brine filter } \\
\text { sludge obtained in the electrolysis of alkali metal } \\
\text { chlorides by the amalgam process }\end{array}$ \\
\hline & US4077856 & 1976 & Removal of mercury from liquids \\
\hline \multirow{5}{*}{$\begin{array}{l}\text { Montedison } \\
\text { (EniChem) }\end{array}$} & US3849266 & 1973 & Process for the electrolysis of alkali chloride solution \\
\hline & US4087359 & 1976 & $\begin{array}{l}\text { Process for removing mercury and mercury salts from } \\
\text { liquid effluents }\end{array}$ \\
\hline & US430349I & 1980 & $\begin{array}{l}\text { Apparatus for cleaning the bottom of electrolytic mercury } \\
\text { cathode cells }\end{array}$ \\
\hline & US4465560 & 1983 & $\begin{array}{l}\text { Method and device for protecting the anodes of } \\
\text { electrolytic cells against overloads, short circuits and } \\
\text { unbalances }\end{array}$ \\
\hline & US5357002 & 1992 & \begin{tabular}{|l} 
Polymer containing chelating groups, process for \\
preparing it and its use in water purification
\end{tabular} \\
\hline \multirow{3}{*}{$\begin{array}{l}\text { Akzo Nobel } \\
\text { (Dynamit } \\
\text { Nobel) }\end{array}$} & US3763024 & 1971 & $\begin{array}{l}\text { Process and apparatus for controlling the spacing of the } \\
\text { electrodes of electrolytic cells }\end{array}$ \\
\hline & US3849267 & 1973 & $\begin{array}{l}\text { Process for recovering mercury from a gas containing } \\
\text { mercury vapor }\end{array}$ \\
\hline & US41 & 1978 & Process for removing mercury from a gas \\
\hline \multirow{4}{*}{$\begin{array}{l}\mathrm{BP} \\
\text { Chemicals }\end{array}$} & US3647359 & 1969 & Recovery of mercury \\
\hline & US3857704 & 1972 & Mercury recovery process \\
\hline & US3847598 & 1973 & Mercury recovery process \\
\hline & US4391681 & 1982 & $\begin{array}{l}\text { Method of inhibiting formation of and breaking of } \\
\text { mercury butter in chlor-alkali cells }\end{array}$ \\
\hline Hüls & US3981967 & 1971 & $\begin{array}{l}\text { Process for the recovery of bound mercury from mercury- } \\
\text { containing catalysts }\end{array}$ \\
\hline
\end{tabular}




\begin{tabular}{|l|l|l|l|}
\hline $\begin{array}{l}\text { Wacker } \\
\text { Chemie }\end{array}$ & US4234422 & 1979 & $\begin{array}{l}\text { Process for removal of mercury and nercury compounds } \\
\text { from aqueous solutions and industrial waste liquors }\end{array}$ \\
\hline
\end{tabular}

As we can see in the table, most of the technologies related to the mercury process developed by these innovative companies in Western Europe, including ICI, Hoechst-Uhde, De Nora, Solvay, Bayer, and BASF, are aimed at reducing mercury emissions through various routes to the environment. ICI developed in the early 1970 s a process for the recovery of mercury from waste brine from mercury cells (US Patent No. 3718457, 1971). Other innovations conceming the operation of the electrolytic cells of the mercury process are also useful to reduce mercury emissions (US Patent No. 3905880, 1974; No. 4060463, 1975). The system for removing mercury from the waste water at ICI's plant in Wilhelmshaven, Germany, consists of chemical precipitation of mercuric sulfide, followed by filtration (European IPPC Bureau, 1999). Bayer developed a method of purifying mercury (US Patent No. 3895938,1974 ) as well as a method of purifying brine used in electrolysis by the mercury process (US Patent No. 4132759, 1978).

Hoechst developed a process for the work-up of a contaminated inactive mercury(II) chloride/active carbon-catalyst (US Patent No. 4059438, 1976). The method of chemical demercurization at nomal pressure had already been used by the former $1 \mathrm{G}$ Farben Industrie and was further developed by Hoechst (European Chemical News, 1972). Pre-cooled hydrogen, which was saturated with mercury according to its temperature, was treated with chlorine-bearing brine, wet chlorine or chlorine water. The mercury was then converted to mercuric chloride and removed from the hydrogen. Using this method, the residual mercury content in the hydrogen could be reduced significantly. Other processes were also developed by the company for reducing the mercury content of industrial waste waters (US Patent No. 4108769,1977 ) and for reducing losses of mercury in alkali metal chloride electrolysis (US Patent No. 4212715, 1979). Uhde developed a process of avoiding mercury emission from mercury-using plants (US Patent No. 3922210, 1973). Use of the Bayer silver catalyst, developed for this application, instead of the activated carbon filter, could reduce the mercury content significantly.

De Nora also came to develop improwed mercury cells designed to reduce mercury emissions both in the ambient air and in the plant effluents (US4166780, US4204937, and US4263107). Among the main features connected to these improvements are the inlet/outlet boxes of the closed type, which significantly reduced the amount of wash water to be added to 
avoid carry over of chlorides into caustic soda while practically eliminating the need of sucking and treating mercury-contaninated air from the cell end boxes. Another technology is a cell bottom wiper. This device, which is normally located inside the inlet end box, can be operated from outside, making possible periodical mechanical cleaning of the cell bottom without opening the cell. That is, any impurity accumulated on the cell bottom, which could disturb mercury flow along the cell, can be elliminated by just pushing the wiper from the inlet towards the outlet end.

BASF developed a process for the recovery of mercury from the brine filter sludge obtained in the electrolysis of alkali metal chlorides by the mercury process (US Patent No. 3755110,1971 ). The company also developed a technology for the removal of mercury from liquids (US Patent No. 4077856, 1976). At BASF's plant located in Antwerp, hydroxylamine is used to reduce mercury concentration, followed by filtration and activated carbon filters (European IPPC Bureau, 1999). And all gases are treated in an absorption tower. The lower section of the tower is used to neutralize the chlorine in the gas, which is transformed into hypochlorite. Whille the mercury in the waste gas is partly absorbed by the hypochlorite in the llower section, absorption does not take place in the upper section of the tower, where no hypochlorite is contained, and the technology consists of adding hypochlorite in the upper section. For the treatment of hydrogen, the company uses a chemical reaction with copper oxide after the cooling step in order to absorb mercury.

Solvay developed a process for removing a layer of thick mercury from the bottom of mercury-cathode electrolysis cells and a process for the electrolysis of an aqueous solution of an alkali metal halide in a mercury-cathode cell (US Patent No. 4565613, 1984). At Solvay"s plant at Roermond, the process waste water is treated by means of sedimentation of solid mercury and subsequent precipilation of mercury with sodium bisulfide (Information Centre for Environmental Licensing, 1998). The mercury contained in waste gas has been reduced by adsorption on activated carbon impregnated with sulfur. By using filtration with activated carbon, the company achieved a reduction in mercury contained in hydrogen. Similarly, by adsorption on activated carbon, the company's plant at Antwerp removed mercury contained in hydrogen (Evropean IPPC Bureau, 1999). The company"s plant at Martorell, Spain, reduced mercury contained in waste gas by adsorption on activated carbon impregnated with sulfur (European IPPC Bureau 2000). 
In addition to the companies which had been previously innowative on the mercury process, other chlor-alkali producers, namely, BP Chemical, Akzo, Montedison (EniChem) Wacker Chemie, and Hüls, also made successful patent applications on teclnnologies for the reduction of mercury emissions. Montedison, Process for removing mercury and mercury salts from liquid effuents (US Patent No. 4087359, 1976). Montedison also developed an apparatus for cleaning the bottom of electrolytic mercury cells (US Patent No. 4303491 , 1980), which reduced the frequency of opening the cell, leading to a reduction in mercury emissions to cellroom ventilation air. Wacker Chemie developed a process for removal of mercury and mercury compounds from aqueous solutions and industrial waste liquors (US Patent No. 4234422, 1979). Hüls developed a process for the recovery of bound mercury from mercury-containing catalysts (US Patent No. 3981967, 1971). BP Chemicals developed a process for the recovery of mercury (US Patent No. 3647359, 1969; US Patent No. 3857704 . 1972; US Patent No. 3847598, 1973) as well as a method of inhibiting formation of and breaking of mercury butter in chlor-alkali cells (US Patent No. 4391681, 1982), which contributes to a reduction in mercury emissions to cell. room ventilation air.

Akzo succeeded in the early 1970 s in lowering the mercury concentration of the waste water by developing a one-stage process with the ion exchange resin ${ }^{97}$ (Rekers, 1973). Akzo"s plant in Hengelo treats the process water by sedimentation of solid mercury and subsequent removal of mercury in an ion exchange unit (Information Centre for Environmental Licensing, 1998). To remove mercury from hydrogen, the company utilizes a calomel reaction, followed by filtration with activated carbon. At Akzo Nobel in Bohus, the waste water treatment system consists of a mixing unit where hydrazine is added to the waste water, two sedimentation tanks, sand filters, activated carbon filters and ion exchange filters (Intormation Centre for Environmental Licensing, 1998). Akzo also developed a process for recovering mercury from a gas containing mercury vapor (US3849267, 1973; US4196173, 1978). The company"s calomel process has been used at its plant in Hengelo (Rekers, 1973). The mercury concentration in caustic soda at Akzo Nobel's plant at Bohus has been reduced by using filters with activated carbon. The hydrogen gas is scrubbed with chlorinated brine

\footnotetext{
Whe chlor-akali business of Montedison has been transferred to Enichem, which was founded in 1989 as a joint venture between the chemical operations of the Eni Group and the majority of the chemical operations of the Montedison Group (EniChem. 2001).

${ }^{9}$ Synthetic ion exchange resins normally consist of various copolymers having a cross-linked three-dimensional structure to which ionic groups hawe been attached. Note that this technology is differcht from the ion axchange membrane used for the chlor-alkali manufacture.
} 
before adsorption on activated carbon. Mercury emissions via process exhausts at the plant have been reduced by adsorption on activated carbon impregnated with sulfur.

As we have seen, these technologies developed for the abatement of mercury emissions from chlor-alkali plants in Western Europe are basically measures of the end-of-pipe type. Technologies for the reduction of mercury emissions to waste water normally include settling to remove large mercury droplets, followed by oxidation using lhypochlorite, chlonine or hydrogen peroxide to take remaining metallic mercury into solution. A process which has been firequently used for purifying depleted brine leaving the plant and any other mercurycontaining waste water is the precipitation of mercuric sulfide, followed by filtration. In the precipitation process, the mercuric sulfide is filtered from the waste water in sand or plate filters and then can be dissolved in hypochlorite and recycled to the cellroom brine system.

Several types of end-of-pipe technologies have been developed, notably filters, to remove mercury from caustic soda. They include plate filters with carbon pre-coat, candle filters with carbon pre-coat, and candle filters without pre-coat. Although all types of filters can achieve very low levels of mercury in the product, the predominant technique, which achieves low levels, has been the plate filter with carbon pre-coat. Mercury is absorbed on the carbon pre-coat and is discharged from the filter as a dry cake. On the other hand, the activated carbon filtration generates mercury-contaminated waste, and the discharged filter cake needs to be subjected to distillation to recover the mercury.

To achieve low levels of mercury in process exhaust, there are basically two principal single-stage processes, which are of the end-of-pipe type, namely, chemical process, including scrubbing with hypochlorite or chlorinated brine and use of a calomel reaction, and the use of sulfurized charcoal. By scrubbing with chlorine-containing brine, mercury(II) chloride $\left(\mathrm{HgCl}_{2}\right)$ is produced, forming a mercury-chlorine complex in the brine. After chlorine is removed, the brine is recirculated. By scrubbing with alkaline hypochlorite solution, the mercury contained in the process exhausts is also oxidized without any necessity of subsequent chlorine removal. The cleaned gas passes through a separator to remove entrained liquid droplets, and the mercury is recirculated via the brine. Another way of removing mercury from the process exhaust is to utilize a calomel reaction. By adding chlorine, mercury contained in the waste gas is converted to calomel $\left(\mathrm{Hg}_{2} \mathrm{Cl}_{2}\right)$. The calomel is then collected on rock salt or similar material in a packed column, allowing for direct recycling of mercury to the brine feed to the cellroom. Mercury contained in the process 
exhaust is allso removed by adsorption on activated carbon impregnated with sulfur or sulfuric acid, although that generates contaminated wastes at the same time.

The common approach to reducing the mercury content in hydrogen has been a wostage process. The first stage involves cooling, compression and cooling, or chemical process, for example, scrubbing with hypochlorite or use of a calomel reaction. The second stage is adsorption on iodized or sulfurized charcoal, while avoiding water condensation in the charcoal bed.

To keep the cellroom ventilation losses to a minimum, there are basically two ways, that is, purification of the ventilation air and prevention of mercury emissions at the sources. The purification of the ventilation air leaving the cellroom is basically done by using end-of-pipe technologies. Mercury cells are nomally set up in very large cellroom buildings, and a huge volume of ventilation air is necessary to remove the heat resulting from electrolysis in the cells. Because of the huge volume of the ventilation air, which is released from many points of the large cellroom, the removal of mercury by using end-of-pipe technologies has not been practical. Hence the only satisfactory way of controlling mercury losses to atmosphere has been to prevent mercury emissions at the sources. That requires a high standard of housekeeping and equipment maintenance in the cellroom ${ }^{9 \%}$. Since some mercury emissions inevitably occur when an electrolytic cell is opened for sampling the amalgam or cleaning the cells, mercury emissions can be reduced by minimizing the frequency and duration of the cell opening. The frequency of cell cleaning is directly related to the quantity of thick mercury, the so-called mercury butter, whose formation results from the existence of impurities in the brine. Thus technologies have been developed to monitor accurately the accumulation of the thick mercury in the cell and to reduce levels of impurities in the brine, such as heavy metals as well as calcium and magnesium. Also cell-bottom wipers have been invented to limit mercury emissions by making possible periodical mechanical cleaning of the cell bottom without opening the electrolytic cells.

\footnotetext{
The ease with which mercury cellrooms can be managed for the minimum emission of mercury would be influenced by several factors, including the climate and the age and nature of the plant design (Euro Chlor, 1993). The climate is considered important, as the mercury loss rate varies depending on the ambiont lemperature. With other conditions held constatnt, neretry losses are generally higher in summer than in winter and also during the day than at night. for the same reason, cellrooms in southem Europe would be expected to have higher losses than those in Nothern Europe due solely to the different climatio conditions. The plant desigr may also influence the extent to which mercury emissions can be reduced. In general, older plants were not designed for efficient contanment of mercury. Older designs of cells operated at lower curtent density requile larger buildings with larger floor areas, resulting in a greater potential for mercury emissions.
} 
As we have discussed above, various kinds of equipment of the end-of-pipe type have been adopted to curb mercury emissions from chlor-alkali plants to water, products, and air. Figure 543 gives athematic illustration of these technologies used to reduce mercury emisstons at a mercury-based chlor-alkali plant. Comparing with Figure 3-3, we can see that these technologies are primarily aimed at scrubbing, filtration, and adsorption and are installed at the end of the production process without making any changes in the chemical reactions involved; that is, they are end-of-pipe technologies. 


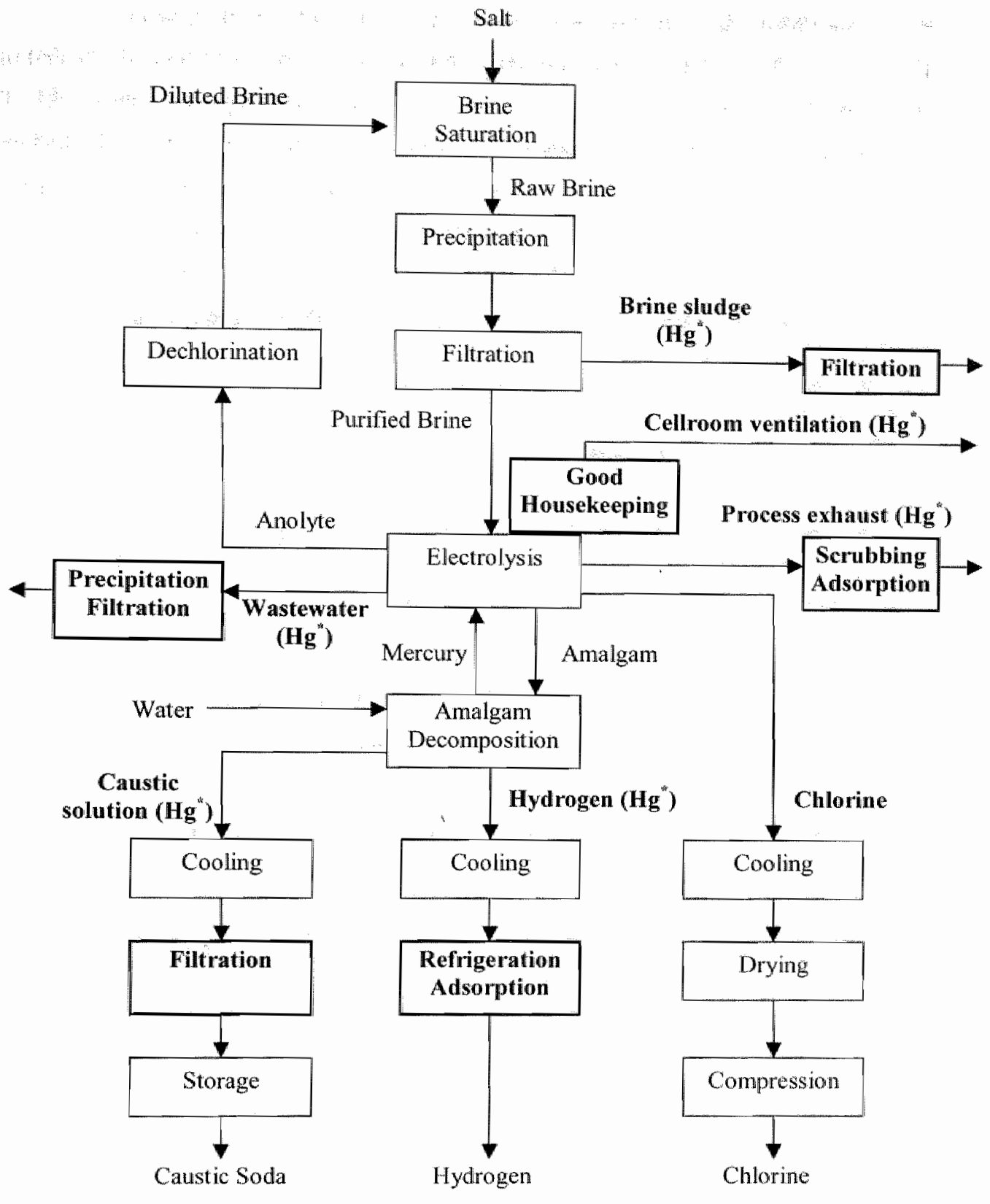

Figure 5-3 End-of-Pipe Technologies Developed to Reduce Mercury Emissions 


\subsubsection{Continued Use of the Mercury Process with End-of-Pipe Technologies}

The previous section shows that various types technologies, most of which are of the end-ofpipe type, have been developed by companies in Western Europe to reduce mencury emissions from chlor-alkali plants to water, products, and air. To see the effects of adoptions of these technologies at mercury-based chlor-alkali plants, we need to examine actual mercury emissions. Figure 5-4 shows the trends in mercury losses per unit production capacity of chlorine to water, products, and air from chlor-alkali plants in Western Europe since $1977^{99}$. (Detailed data are given in Table 5-23 in Appendix at the end of this chapter.)

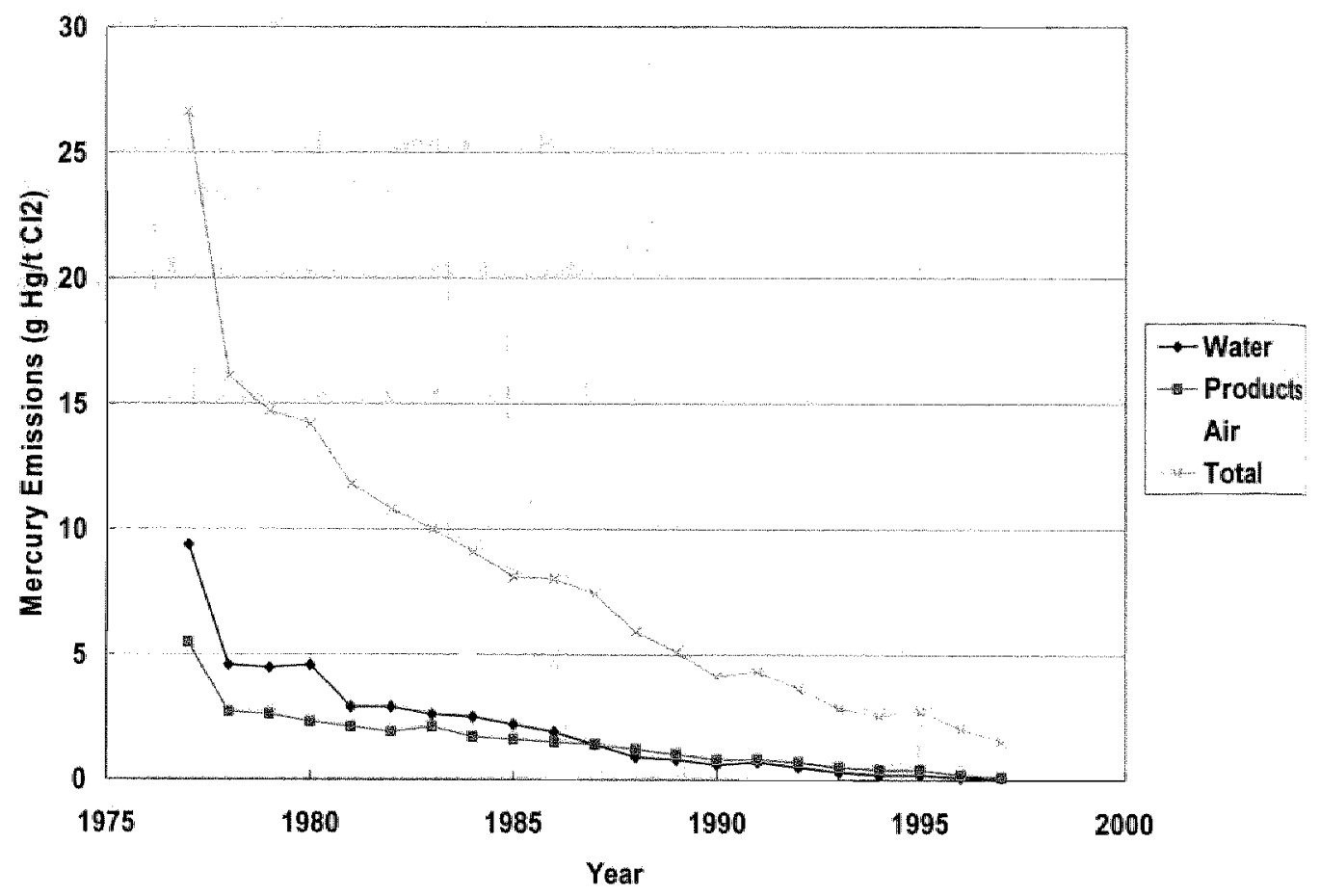

Figure 5-4 Mercury Emissions to Water, Products, and Air from Chlor-Alkali Plants in Western Europe

\footnotetext{
"The chlor-alkali industry association in Europe, Euro Chlon, represented all 38 Western European chlorine producers in 14 comntries at the time of 1997 (Euro Chlor, 1997). Note that the data collected by Euro Chllor includes those of Austria, Finland, Iraly, and Greece, which thave not been the nembers of the Paris Commission (subsequently the OSPAR Commission) For nore information on the data collected by the Paris Commission, see Appendix.
} 
According to the table, these end-of-pipe technological measures have made significant impacts on the amount of mercury emissions from chlor-alkali plants in Western Europe. Mercury losses per unit production capacity to water from ehlor-alkali plants located in Western Europe have decreased steadily since 1977 , from $9.4 \mathrm{~g} \mathrm{Hg}_{\mathrm{t} \mathrm{Cl}}$ to $0.11 \mathrm{~g} \mathrm{Hg/t} \mathrm{Cl}$, achieving a $99 \%$ reduction. A similar trend has been observed in the case of mercury losses through products. Over the last 20 years, a decrease of $98 \%$ was achieved, from $5.5 \mathrm{~g} \mathrm{Hg} / \mathrm{t}$ $\mathrm{Cl}_{2}$ in 1977 to $0.14 \mathrm{~g} \mathrm{Hg} / \mathrm{t} \mathrm{Cl} 2$ in 1997 . Mercury emissions to air, that is, those contained in process exhaust, ventilation air and hydrogen used as fuel, have also shown a large decrease since the late 1970s. Atmospheric emissions were reduced from $11.7 \mathrm{~g} \mathrm{Hg} / \mathrm{t} \mathrm{Cl}_{2}$ in 1977 to 1.2 $\mathrm{g} \mathrm{Hg} / \mathrm{t} \mathrm{Cl}$ in 1997 . The reduction rate of atmospheric enissions from 1982 to 1997 was $69 \%$, however, which was much smaller compared with that of emissions to products or water.

Concerning mercury discharges to water from existing waste brine chlor-alkali plants, the Paris Commission adopted in 1981 the limit values of $8 \mathrm{~g} \mathrm{Hg} / \mathrm{t} \mathrm{Cl} 2$ capacily to be complied with at the exit of a factory as a monthly mean from July 1983 , and $5 \mathrm{~g} \mathrm{Hg} / \mathrm{t} \mathrm{C.}$ capacity from July 1986. For brine recirculation plants, the European Communities made the decision in 1982 on the limit value of $1.5 \mathrm{~g} \mathrm{Hg} / \mathrm{t} \mathrm{Cl} 2$ to be effective after July 1983 , and the Paris Commission also adopted in 1985 the recommendation requiring the limit value of $0.5 \mathrm{~g}$ $\mathrm{Hg} / \mathrm{t} \mathrm{Cl}_{2}$ capacity from July 1986 . Figure $5-4$ suggests that, while we would expect vartations in the amount of mercury emissions among the individual plants, these emission targets have been met by mercury-based chlor-alkali plants in Western Europe. (For individual chlor-alkali plants located in Western Europe, chronological data since the 1970s is not publicly available. Only for the year 1999, detailed data on mercury emissions to water, products, and air has been published recently. The results are given Table 5-24 in the appendix at the end of this chapter.)

Also, there was the limit value for emissions to the atmosphere, as stipulated in paragraph 1 of PARCOM Decision $90 / 3$, that is, $2 \mathrm{~g} \mathrm{Hg} / \mathrm{t} \mathrm{Cl} 2$ capacity to be complied with by December 1996 (OSPAR Commission, 1999a). Figure 5-4 shows that, while air emissions currently account for the largest share of the total mercury emissions from chlor-alkali plants in Western Europe, all the existing mercury-based chlor-alkali plants have complied with the limit value for air emissions. These technological measures of the end-of-pipe type have functioned successfully to reduce mercury emissions to such an extent that all the environmental regulations introduced in Western Europe have been complied with. 
This remarkable success in reducing mercury emissions by using various types of endof-pipe technologies has made it possible for plant operators to continue to rely on the mercury process for chlor-alkali production. Figure 5-5 shows the trends in the shares of chlor-alkali production capacities based on the mercury process and the non-mercury processes, that is, the diaphragn and ion exchange membrane processes, in Western Europe. (Detailed data are given in Table 5-25 in Appendix at the end of this chapter.)

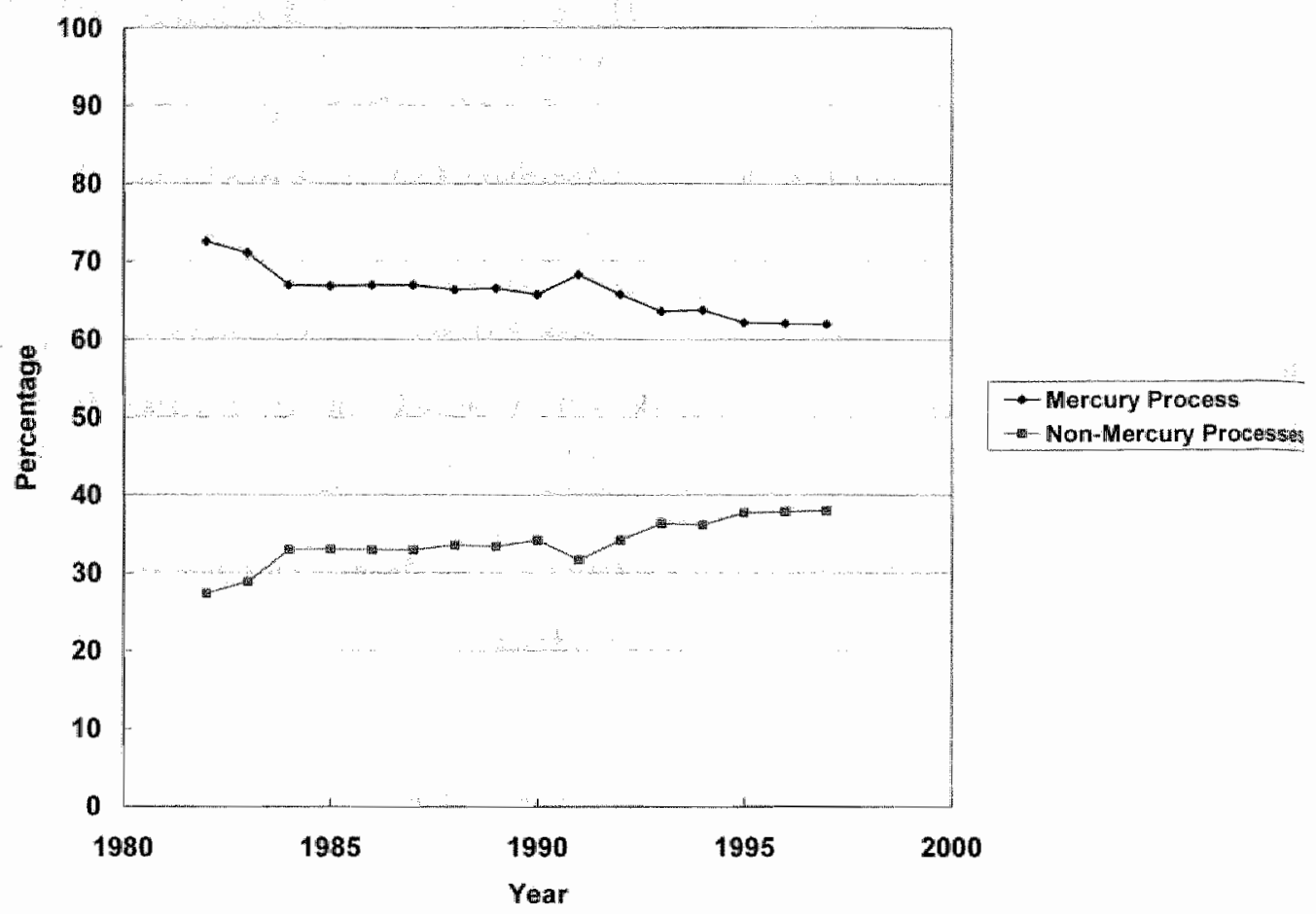

Figure 5-5 Production Capacities Based on the Mercury, Diaphragm, and Ion Exchange Membrane Processes in the Western European Chlor-Alkali Industry

Although the production capacities based on the mercury process have declined slightly since the early 1980s, the mercury process is still the dominant technology, currently accounting for more than $60 \%$ of the total production capacities in Western Europe. In other words, most of the European chlor-alkali producers have continued to use the mercury process by adopting various types of end-of-pipe technologies installed to reduce mercury emissions. This form of technological change is in sharp contrast to the Japanese case, where 
mercury emissions have been eliminated by phasing out the mercury process. Rather than installing end-of-pipe technologies for the abatement of mercury emissions, all the existing mercury-based chlor-alkali plants have been replaced with clean technologies, notably the ion exchange membrane process, which currently accounts almost all of the chlor-alkali production capacities in Japan.

\subsection{Delayed Development of Technologies for the Ion Exchange Membrane Process}

As we can see in while there were many successful patent applications on the mercury process by Western European companies during the 1970s, patents on the ion exchange membrane process started to appear at the end of the 1970s. In Chapter 3, we discussed that several companies in Western Europe, namely, ICl, Hoechst-Uhde, De Nora, Bayer, Solvay, and Krebs, cooperating with BASF, had been innovative on the mercury process in the past. Table 5-10 suggests that, in the 1970 s, when environmental regulations on mercury emissions were being introduced, these companies continued to focus on the mercury process, applying successfully for US patents on this process. On the other hand, patent applications made by these companies on the ion exchange membrane process have been relatively few. Only ICI, Hoechst-Uhde, and De Nora were granted patents on technologies related to the ion exchange membrane process. Their successful patent applications started at the end of the $1970 \mathrm{~s}$, later and fewer than those made by the innovative companies in Japan. Other companies, including Bayer, Solvay, and Krebs, did not have any US patents on the ion exchange membrane process. In the following sections, we examine in detail when and how innovative activities were conducted by these companies for technological development of the ion exchange membrane process.

\section{Imperial Chemical Industries}

The chlor-alkali production of Imperial Chemical Industries (ICI) ${ }^{100}$ started at the end of the 19th century, with the Castner-Kellner mercury cells introduced in 1897 at Runcorn in the northwest of England. This site is still the location of ICl's largest chlor-alkali plant with a production capacity of more than 700,000 tommes of chlorine per year. This figure is

\footnotetext{
10a This section is based on information obtained through the author's interview with Mr. Steve Ingleby, Mr. R. W. Curry and Mr. Cliff Broom of ICl (Ingleby, Curry, and Broom, 1999).
} 
significantly larger than that in the 19 h century; only 500 tons of caustic soda was produced in 1897, increasing to 3,500 tons in 1900. Mond Division, which was responsible for the alkali production, was located at Runcom because the country's main salt resources lied in that region. The electrolytic process was made possible by the increasing availability of electric generation capacity and essentially marked the beginning of the modem chlor-alkali industry. It replaced a variety of inefficient and expensive chlorine manufacturing processes based on oxidation of the by-product, hydrogen chloride, which prevailed before, and prowided a new source of high quality caustic soda, another chemical in increasing demand at that time ${ }^{101}$. New cellrooms based on the mercury process were constructed at Runcom in the 1930 s.

Since the beginning of the electrolytic production of chlor-alkali products, ICI's R\&D activities had been focused on the mercury process. Their main objective was to improve the reliability of the mercury process and to make it possible to operate the process continuously, as well as to develop technological measures for the reduction of mercury emissions (see Table 5-11). A major mercury cellroom, equipped with computer controlled anode adjustment and shorting resistant anode coatings, was commissioned in 1974, and mercury cells with steel baseplaces were introduced in 1976. The 1970s at the same time brought the realization of a need for reducing mercury emissions from its chlor-alkali plants, as mercury became one of the main targets of environmental regulations introduced in Western Europe. In addition to the development of end-of-pipe equipment, the optimization of process operation was effective in reducing mercury emissions, particularly those from cellrooms to the air.

On the other hand, the application of the ion exchange membrane for use in the chloralkali production had been recognized as a promising technology in the future for a long time. Some work on technologies related to the jon exchange membrane process was done by $\mathrm{ICl}$ as early as in the 1960s. The first ICI's patent on a zero-gap electrolytic cell, which could be utilized for the ion exchange membrane process, was indeed granted in 1962. As reliable ion exchange membranes with a sufficient lifetime for industrial uses were not available at that time, however, further R\&D efforts were not made on the ion exchange membrane process. Then, in the 1970s, there was the rapid technological progress on the ion exchange membrane process in Japan in response to the govermment regulation to phase out the mercury process in the chlor-alkali industry. Better ion exchange membranes suitable for use in chlor-alkali

\footnotetext{
10i The chemical processes used in the chlor-alkali industry prior to the invention of the electrolytic processes
} 
plants were developed by the Japanese companies and become avallable to Western Europe. That has provided ICI with strong incentives to invigorate its imnovative ellorts to develop technologies for the ion exchange membrane process. Subsequently, ICI made an agreement with Asahi Glass to introduce the ion exchange membrane, and an intensive R\&D program was initiated in the late 1970 s. A pilot plant utilizing the ion exchange membrane process with a production capacity of 6,000 tonnes of chlorine per year started to operate at its Lostock site in 1978 .

Table 5-12 gives the chronology of techrological development of the ion exchange membrane process at ICI.

Table 5-12 Technological Development of the lon Exchange Membrane Process at ICI

\begin{tabular}{|c|l|}
\hline Year & \multicolumn{1}{|c|}{ Technological Development } \\
\hline 1962 & First patent on electrolyzer for the ion exchange membrane process \\
\hline 1978 & Start of a pilot plant based on the ion exchange membrane process \\
\hline 1983 & $\begin{array}{l}\text { First commercial sale of the ion exchange membrane process technology to } \\
\text { outside firms }\end{array}$ \\
\hline 1989 & Introduction of the ion exchange membrane process to its own plant \\
\hline
\end{tabular}

As with the company's earlier technologies for the mercury process, the development of technologies for the ion exchange membrane process was originally intended to be used at plants within the company's group. Having experienced operating the pilot plant for a few years, however, the company recognized that opportunities would exist to sell its ion exchange membrane process technologies to chlor-alkali producers beyond the corporate group. Accordingly, the company decided to market the technology to outside companies, and the company's FM21 process technology was launched for commercialization in July 1981. Table 5-28 in the appendix to this chapter gives the list of the chlor-alkali plants to which ICI has supplied its ion exchange membrane process technologies.

As you can see, the first major contract was made with Nobel for its plant in Sweden in December $\$ 983$ to convert the mercury process. Since then, ICI's technology for the ion exchange membrane process has been adopted by chlor-alkali producers around the world, but not by those in Western Europe. ICI itself introduced the ion exchange membrane process to its Runcorn site in 1989 for the production of caustic potash (KOH) of 26,000 tonnes per year, replacing the mercury process. This represented the company's first installment of the jon exchange membrane process to its own production plants. At the Runcorn site, however,

and the effects of environmental regulations on technological change are discussed in more detain in Appendix. 
most of the chlor-alkali production is still based on the mercury process. The company also maintains a plant based on the mercury process at Wilhelmshaven, Germany, with the production capacity of 130,000 tonnes of chlorine per year. Hence a significant part of the company's chlor-alkali products is still produced by using the mercury process.

\section{Uhde}

Uhde ${ }^{102}$ is an engineering company, specializing in providing technologies for such product groupings as electrolysis, fertilizers, coke oven plants and machinery, polymers, organic chemicals, industrial plants, oil and gas technology, and off-sites. The electrolysis business accounts for more than one third of the totall turnover of the company. Uhde had been associated with Hoechst, one of the major chlor-alkali manufacturers in Germany, with its Griesheim plant going on stream in 1892 as one of the first chlor-allkali electrolyzers in the world ${ }^{103}$.

In the past, the focus of the company"s technological development had been placed on the mercury process. The Uhde mercury cells were develloped through decades of experience and research conducted cooperatively with Hoechst. Facillities necessary for R\&D activities were located in the sites of this company. By the 1960s, Hoechst-Uhde had developed four sizes of mercury cells rated according to cathode area, with each size available in two styles, i.e. with decomposer either alongside or undemeath the electrolyzer (Table 3-8). More than 100 chlor-alkali plants had been supplied with Uhde's mercury process technologies in the world.

The main emphasis of the R\&D activities during the 1970 s was placed on the mercury process, particularly on measures to reduce mercury emissions as well as to increase current density. Technological developments by the company have been focused on the removal of mercury from caustic soda, hydrogen, and waste water (see Table 5-11). In the middle of the 1970 s, while the mercury process was still the major target of technological development, Uhde started to conduct R\&D on the ion exchange membrane process. The availability of ion exchange membranes suitable for commercial-scalle application developed by the Japanese companies encouraged the company's technological development of the ion exchange membrane process. A very small cell consisting of 10 single elements was set up in 1975 ,

\footnotetext{
102 This section is based on the author"s interview with Dr. Benno Lüke and Mr. Roland Beckmann of Uhde (Luke and Beckmann, 1999).
} 
primarily intended for the testing of materials. The test runs revealed that the only sutable materials were stainless steel, nickel and titanium sheet for cells with long-term stability, and perfluorinated plastics for gaskets and hoses. Based on this experience, the frrst pilot plant with an annual capacity of 500 tonnes of caustic soda was commissioned in 1977.

The ion exchange membrane process developed in the late 1970 s and the early $1980 \mathrm{~s}$ was characterized by improved performance of ion exchange membranes. They were at the root of the breakthrough of the ion exchange membrane process technology, opening a broader spectrum of commercial applications. They made it possible to obtain caustic soda solution of a high concentration at reduced power consumption. The Flemion menibranes developed by Asahi Glass became available to Uhde through a technical agreement concluded in 1980. These ion exchange membranes were capablle of producing caustic soda solution at as high as $35 \%$. Then electrolytic cells based on the ion exchange membrane process with a large current were assembled and installed at the second pilot plant of Bayer in Leverkusen in 1981 .

Table 5-13 gives the chronological development of the membrane process by Uhde.

Table 5-13 Technological Development of the Ion Exchange Membrane Process at Ulnde

\begin{tabular}{|c|l|}
\hline Year & \multicolumn{1}{|c|}{ Technological Development } \\
\hline 1975 & Start of R\&D on the ion exchange membrane process with a small-scale plant \\
\hline 1977 & Start-up of the first pilot plant based on the ion exchange membrane process \\
\hline 1981 & $\begin{array}{l}\text { Start-up of the second pilot plant based on the ion exchange membrane } \\
\text { process }\end{array}$ \\
\hline 1984 & First supply of the ion exchange membrane process to outside firms \\
\hline 1987 & $\begin{array}{l}\text { Construction of the first full-scale pillot plant based on the ion exchange } \\
\text { membrane process at Hoechst }\end{array}$ \\
\hline
\end{tabular}

As the company shifted the emphasis of its R\&D activities from the mercury process to the ion exchange membrane process, the R\&D expenditures on the ion exchange membrane process increased significantly, from less than 1 million DM in 1980 to 4 million DM in 1995. This significant increase in $\mathbb{R} \& D$ expenditure was followed by a similar increase in the supply of the ion exchange membrane processes by the company to chlor-alkali producers around the world. Table 5-29 in the appendix to this chapter shows the chlor-alkali plants which adopted the ion exchange membrane process technologies developed by Uhde.

\footnotetext{
10 In 1996 Uhde was demerged from Hoechst and purchased by the Krupp Group, which formed Krupp-Uhde GmbH.
} 
The first industrial chlor-alkali facility using Uhde's ion exchange membrane process technology was commissioned in 1984 at Tofte in Norway. A full-scale pilot plant was buili at Hoechst in Frankfurt in 1987. Compared with the chlorine production capacity of several hundred thousand tonnes per annum at Hoechst, the capacity of the ion exchange membrane process of 10,000 tonnes per annum was relatively small. This pilot plant, however, was intended primarily for testing a modular unit for the use in electrolysis plants with large chlorine capacities, that is, for the construction of new grass-roots plants as well as for the conversion of existing mercury-based plants.

As we can see in the table, installations of Uhde's ion exchange membrane process mostly occurred in the 1990s. In the period from 1994 to 1999 , production capacities of $2,943,000 \times \mathrm{NaOH} / \mathrm{year}$ were commissioned, accounting for more than $80 \%$ of the total. capacities of $3,600,000$ t/year $\mathrm{NaOH}$ constructed by Uhde since 1984. During the same period, the ion exchange membrane process was introduced to 30 chlor-alkali plants, corresponding to $60 \%$ of the total number of chlor-alkali plants at which the ion exchange membrane process has been installed by the company.

\section{De Nora}

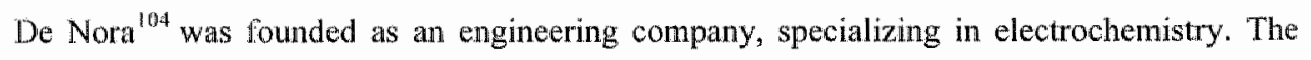
company's activities have been focused for a long time on the manufacture of chlorine, caustic soda (potash) and hydrogen by brine electrolysis with the mercury process. In particular, the company has maintained a share of more than half of the world market of coatings and support materials, with the dimensionally stable electrodes for chlor-alkali cells. Other areas of its activities are also related to chlor-alkali products, including on-site generation of active chlorine solution from seawater or brine for control of fouling in water circuits and disinfection, granular high concentration calcium hypochlorite, cathodic protection and fuel cells.

The company has conducted R\&D activities on technologies related to electrochemistry and its applications, particularly on cell designs and electrodes, anode as well as cathode, for use in electrolysis. De Nora"s mercury process technologies have evolved through a series of changes since they were first introduced in the 1950s. Subsequently, the company developed electrolytic celts for the mercury process of a horizontal type in various sizes (Table 3-8). By 
the early 1970 s, more than 130 chlor-alkali plants with a total capacity of over five million tomes per year had been based on the mercury process provided by De Nora. That corresponded to about one quarter of the world production capacities at that time, and the company was one of the leading providers of the mercury process technologies to chlor alkali producers not only in Western Europe but also in the United States and Japan (see Table 3-11, Table 3-15, and Table 3-18). Although the construetion of new, green-field plants based on the mercury process supplied by De Nora ended in 1985, expansions and relocations of mercury-based plants continued until 1994. Currently, modification of the existing mertury plants and provision of technical assistance for necessary adjustments at mercury-based plants are still undertaken by the company.

Table 5-14 gives the chronology of the technological development of the ion exchange membrane process by De Nora.

Table 5-14 Technological Development of the Ion Exchange Membrane Process at De Nora

\begin{tabular}{|c|l|}
\hline Year & \multicolumn{1}{|c|}{ Technological Development } \\
\hline Late 1970s & Start of R\&D on the ion exchange membrane process \\
\hline 1979 & Introduction of ion exchange membranes from Asahi Glass \\
\hline 1983 & $\begin{array}{l}\text { First supply of the ion exchange membrane process to outside chlor-alkali } \\
\text { producers }\end{array}$ \\
\hline
\end{tabular}

The company started to conduct its R\&D activities on the ion exchange membrane process in the late $1970 \mathrm{~s}$, following the development of ion exchange membranes suitable for use in chlor-alkali electrolytic cells by several Japanese companies. A research agreement was made between De Nora and Asahi Glass in 1979, and the ion exchange membranes developed by the Japanese company was introduced for De Nora's electrolytic cells. R\&D efforts on the ion exchange membrane process were reinforced in the early 1980 s, when a university professor with expertise on electrochemistry was invited to conduct innovative research on the ion exchange membrane process at the company. R\&D activities have been intensified since then, increasing expenditures as well as personnel significantly. A result can be observed in the increased patents successfully applied on technologies related to the ion exchange membrane process in the 1980 s (see Table 5-10).

\footnotetext{
in This section is based on the author's interview with Dr. Giuseppe Faita and Mr. Mareo Tenconi of De Nora (Faita and T"enconi, 1999).
} 
The trends in the supply of the ion exchange membrane process by De Nora are shown in Table 5-30 in appendix to this chapter. Die Nora's first chlor-alkali plant based on the ion exchange membrane process was constructed in 1983. Since then, approximately 40 chloralkali plants thave adopted the ion exchange membrane process prowided by De Nora, with the annual production capacities reaching nearly 13 million tonnes of chlorine in the world ${ }^{10}$. Many of these chlor-alkali plants are located in developing countries, notably Asian countries such as India and China, and the number of chlor-alkali plants which adopted De Nora's ion exchange membrane process is still limited in Westem Europe.

\section{Solway}

Solvay ${ }^{106}$ has been the largest chlor-alkali producer in Western Europe for a long time. In the past its innovative activities had been placed on the mercury process, and Solvay's mercury process had been adopted by many chlor-alkali producers in Western Europe (see Table 3-111). During the 1980s, when environmental regulations on mercury emissions were introduced, Solvay continued to rely on the mereury process for its chlor-alkali production. On the other hand, as Table 5-10 suggests, the company did not make any significant innovations on the ion exchange membrane process in the same period. Then, in the early $1990 \mathrm{~s}$, Solvay started to convert its mercury-based plants to the ion exchange membrane process by introducing technologies developed by Asahi Glass, although a significant part of the company"s chloralkali production is still based on the mercury process.

\section{Krebs}

Krebs had been one of the major engineering companies which had developed advanced technologies for the mencury process, cooperating with BASF, one of the major chlor-alkali producers in Germany. The company's technology had been adopted by many chlor-alkali producers not only in Westem Europe but also in Japan, as we can see in Table 3-11 and Table 3-18. Regarding the ion exchange membrane process, however, any remarkable immovations have not been made by the company, as is suggested in Table 5-10. Rather than developing its own technologies for the ion exchange membrane process, the company introduced Asahi Glass's technologies at the end of the 1980s (Krebs Swiss, 1997). Currently,

\footnotetext{
${ }^{1}$. Recently. Krupp Uhde and De Nora have made public a plan to nnerge their chlor-alkali R\&D, technology licensing, and plant construction activities into a 50-50 joint venture, named UhdeNora, in Milan (Alperowicz, D'Amico, and Westervelt, 2001; Chennical Week, 2001).
} 
Krebs is a European representative of Asahi Glass and has been working to provide the ion exchange membrane process technologies to chlor-alkall producers mainly located in Western Europe (Krebs Swiss, 2001).

\section{Technological Developments by Companies in Western Europe}

As we have discussed in the proceeding section, several Western European companies which had been previously innovative on the mercury process stucceded in developing their own technologies for the ion exchange membrane process. Table 5-15 lists the technologies developed by the innovative companies in Western Europe.

Table 5-15 Technologies Developed by Companies in Western Europe

\begin{tabular}{|l|c|c|c|}
\hline \multirow{2}{*}{ Company } & Mercury Process & \multicolumn{2}{|c|}{ Ion Exchange Membrane Process } \\
\cline { 2 - 4 } & & Ion Exchange Membrane & Electrolytic Cell \\
\hline ICI & Steel Base & - & FM, BiChlor \\
\hline Uhde & $10 \mathrm{~m}^{2}$ & - & Single Element \\
& $20 \mathrm{~m}^{2}$ & & \\
\hline De Nora & $31.5 \mathrm{~m}^{2}$ & & DD \\
& $14 \times 3 \mathrm{~F}$ & - & \\
& $18 \times 4$ & & \\
\hline Solvay & $24 \times 5$ & - & \\
& V-100F & & \\
\hline Krebs & V-200F & - & \\
& ZT $80-10-8$ & & \\
\hline
\end{tabular}

Among the inmovative companies based in Western Europe, three companies, namely, ICI, Uhde, and De Nora, have developed technologies for the ion exchange membrane process. Solvay and Krebs, on the other hand, did not make any signifrcant innovations on the ion exchange membrane process. As we have seen in Figure 4-2, the electrolyzer of the ion exchange membrame process basically consists of the ion exchange membrane and the electrolytic cell. While the three Japanese companies, that is, Asahi Chemical Industry, Asalhi Glass, and Tokuyama Soda, made innovations on both the ion exchange membrane and the electrolytic cell, the Westerm European innovators, that is, Uhde, De Nora, and ICI developed their technologies only for the electrolytic cefl but not for the ion exchange membrane. These European companics have introduced ion exchange membranes for their electrolytic cells from the three Japanese companies.

106 Interviews with Solway and Krebs were not possible to receive detaled information on their $\mathbb{R} \& \mathrm{D}$ ach 
The chronology of technological developments of chlor-alkali production processes by conpanies in Western Europe is shown in Figure $5-6$. 


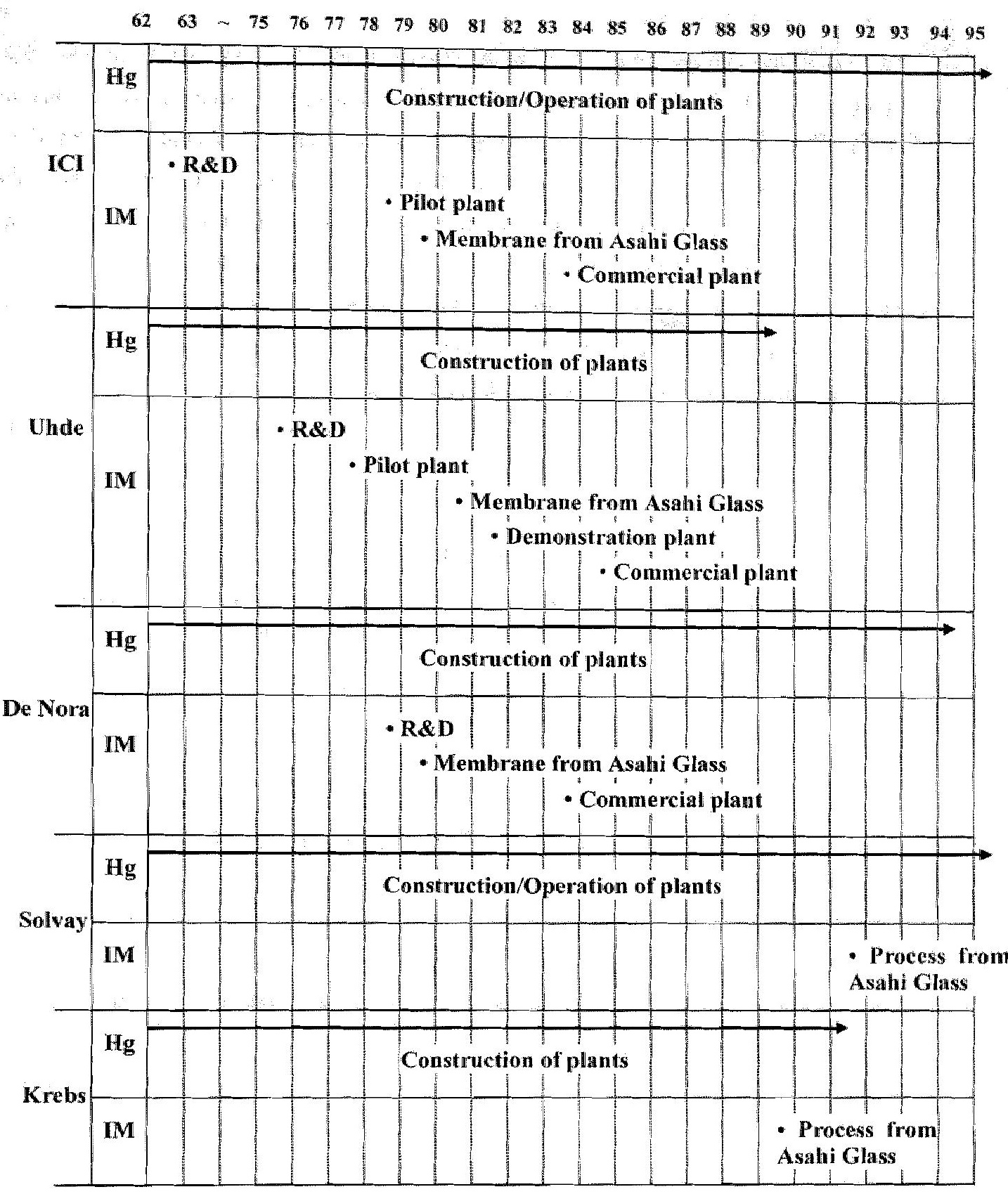

Hg: Mercury Process; IM: Ion Exchange Membrane Process

Figure 5-6 Technological Developments by Companies in Western Europe 
As we have seen in Figure 4-6, in the case of the Japanese chlor-alkali industry, R\&D activities on the ion exchange membrame process were first initiated by Asahi Chemical Industry in the late 1960 s and by other innowative companies, including Asahi Glass, Tokuyama Soda, in the early 1970 s, and the commercial operation of chlor-alkali plants based on the ion exchange membrane started in the middle of the 1970 s at these companies" own production sites. In Western Europe, ICI started to undertake R\&D activities on the ion exchange membrane process as early as the beginning of the 1960 s. With difficulties, however, in obtaining ion exchange membranes which had sufficient chemical and mechanical strength suitable for use in chlor-alkali electrolytic cells, the company had stopped its innovative efforts on the ion exchange membrane process subsequently. Other companies, including Uhde and De Nora, did not make any significant R\&D efforts on the ion exchange nembrane process until the late 1970s. In the meantime, the operation of the merctiry process continued to be dominant for the production of chlor-alkali products in Westem Europe. And R\&D efforts were directed towards developments of end-of-pipe technologies for the reduetion of mercury emissions, rather than alternative clean technologies for the replacement of the existing mercury process.

By the late $1970 \mathrm{~s}$, the Japanese companies had made major innovations on lion exchange membranes and had proved that the ion exchange membrane process was a wellestablished technology which could be reliable utilized for commercial production. The rapid progress in the technological performance of the jon exchange membrane process in Japan provided strong incentives and technological basis to European companies. Several innovative companies, namely, ICI, Uhde, and De Nora, then intensified R\&D efforts to develop their own technologies for the ion exchange membrame process in the late 1970s. By that time, however, novel types of the ion exchange membrane had been already invented by the Japanese companies, and there had been little room left to the later comers. That has induced the European companies to focus their development efforts on the other important components of the ion exchange membrane process, that is, the electrolytic cell. Ion exchange menbranes for use in their electrolytic cells were introduced from the Japanese companies. Their technologies started to be applied for commercial plants in the middle of the $1980 \mathrm{~s}$.

In short, compared with the Japanese case, technological developments of the jon exchange membrane process were delayed in Western Europe. These Western European firms, including $I C I$, Uhde, and De Nora, had made significant innovations on the mercury process 
by the beginning of the 1970s. With the introduction of emission standards on mercury emissions, the strong technological expertise on chlor-alkall production was not devoted to develop technologies for the ion exchange membrane process. That was in sharp contrast to the Japanese case, in which the mandate for the phase out of the mercury process prompted the equally innovative companies to develop and industrialize chlor-alkali production technologies based on the ion exchange membrane process.

The chlor-alkali production technologies developed by Western European companies have been subsequently adopted by other chlor-alkali producers. Figure 5-7 shows the trends in the number of installations of the mercury process as well as the ion exchange membrane process by companies in Western Europe. (Detailed data are given in Table 5-26 in Appendix at the end of this chapter.)

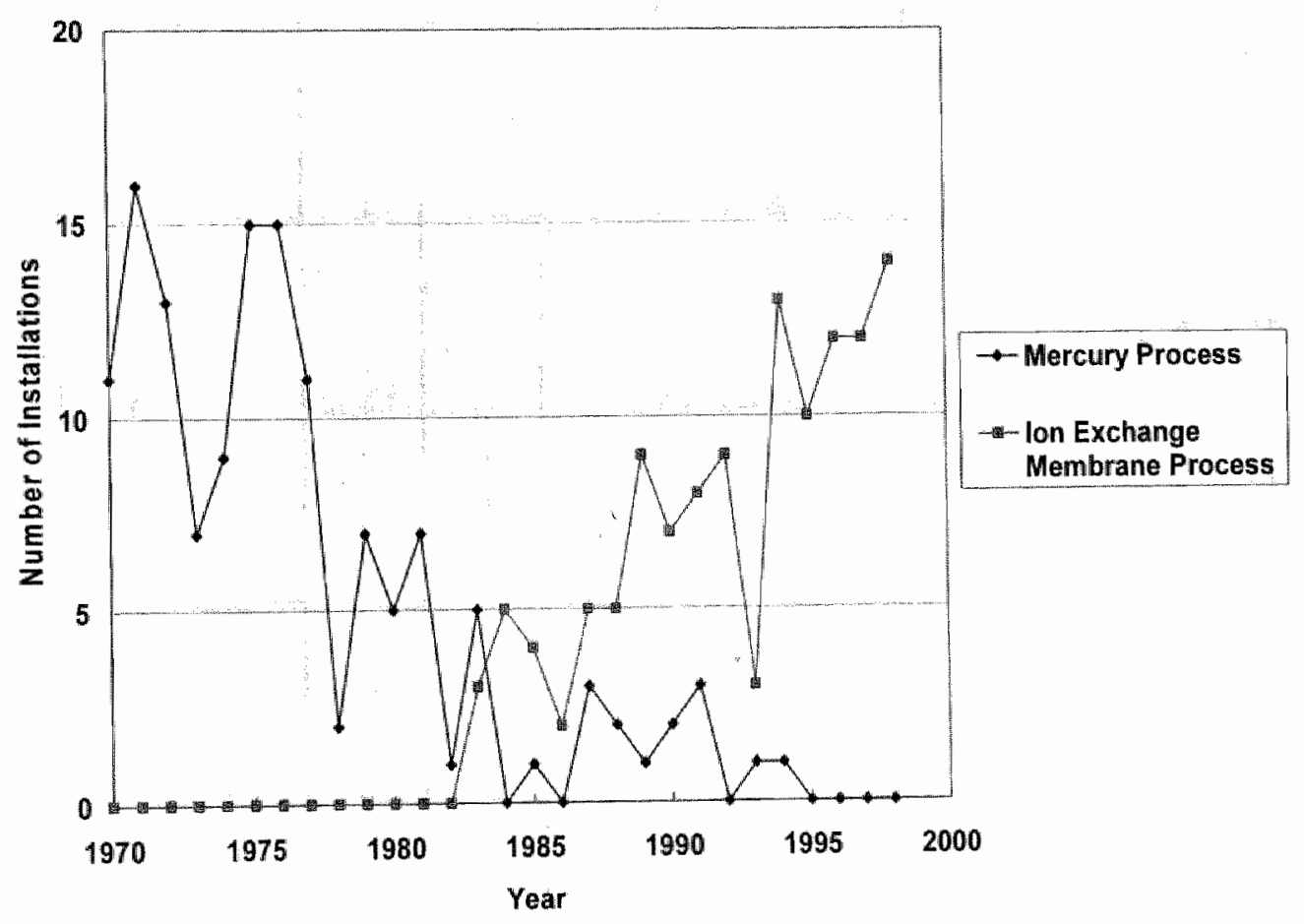

Figure 5-7 Supply of the Mercury and the Ion Exchange Membrane Processes by Western European Firms 
Figure 5-7 shows a contrast with the supply of the ion exchange membrane process by the Japanese companies (Figure 4-7). During the 1970s there was a large amount of supplies of the mercury process by Western European firms whereas the ion exchange membrane was not yet developed to such an extent that it could be provided to chlor-alkall producers. Then the supply of the ion exchange membrane started in the 1980 s and maintained an upward trend in the 1990s. Although the supply of the mereury process declined in the 1980s, it continued until the middle of the $1990 \mathrm{~s}$.

Detailed data on the supply of the mercury and the ion exchange membrane processes by $\mathrm{ICl}_{1}$ Uhde, De Nora, Solway, and Krebs are given in Table 5-16.

Table 5-16 Supply of the Mercury and the Ion Exchange Membrane Processes by Innovative Companies in Western Europe

\begin{tabular}{|c|c|c|c|c|c|c|c|c|c|c|}
\hline \multirow{2}{*}{ Year } & \multicolumn{2}{|c|}{ ICI } & \multicolumn{2}{c|}{ Uhde } & \multicolumn{2}{c|}{ De Nora } & \multicolumn{2}{c|}{ Solvay } & \multicolumn{2}{c|}{ Krebs } \\
\cline { 2 - 12 } & $\mathrm{Hg}$ & $\mathrm{IM}$ & $\mathrm{Hg}$ & $\mathrm{IM}$ & $\mathrm{Hg}$ & $\mathrm{IM}$ & $\mathrm{Hg}$ & $\mathrm{IM}$ & $\mathrm{Hg}$ & $\mathrm{IM}$ \\
\hline 1970 & 0 & 0 & 7 & 0 & 1 & 0 & 1 & 0 & 2 & 0 \\
\hline 1971 & 1 & 0 & 5 & 0 & 5 & 0 & 0 & 0 & 5 & 0 \\
\hline 1972 & 0 & 0 & 6 & 0 & 6 & 0 & 1 & 0 & 0 & 0 \\
\hline 1973 & 0 & 0 & 3 & 0 & 1 & 0 & 0 & 0 & 3 & 0 \\
\hline 1974 & 0 & 0 & 2 & 0 & 2 & 0 & 2 & 0 & 3 & 0 \\
\hline 1975 & 1 & 0 & 6 & 0 & 6 & 0 & 0 & 0 & 2 & 0 \\
\hline 1976 & 0 & 0 & 5 & 0 & 4 & 0 & 0 & 0 & 6 & 0 \\
\hline 1977 & 1 & 0 & 3 & 0 & 6 & 0 & 0 & 0 & 1 & 0 \\
\hline 1978 & 0 & 0 & 2 & 0 & 0 & 0 & 0 & 0 & 0 & 0 \\
\hline 1979 & 0 & 0 & 4 & 0 & 1 & 0 & 1 & 0 & 1 & 0 \\
\hline 1980 & 0 & 0 & 0 & 0 & 4 & 0 & 0 & 0 & 1 & 0 \\
\hline 1981 & 0 & 0 & 2 & 0 & 2 & 0 & 0 & 0 & 3 & 0 \\
\hline 1982 & 0 & 0 & 0 & 0 & 1 & 0 & 0 & 0 & 0 & 0 \\
\hline 1983 & 0 & 1 & 4 & 0 & 1 & 2 & 0 & 0 & 0 & 0 \\
\hline 1984 & 0 & 3 & 0 & 2 & 0 & 0 & 0 & 0 & 0 & 0 \\
\hline 1985 & 0 & 4 & 0 & 0 & 1 & 0 & 0 & 0 & 0 & 0 \\
\hline 1986 & 0 & 0 & 0 & 1 & 0 & 1 & 0 & 0 & 0 & 0 \\
\hline 1987 & 0 & 2 & 1 & 2 & 0 & 1 & 0 & 0 & 2 & 0 \\
\hline 1988 & 0 & 1 & 0 & 3 & 2 & 1 & 0 & 0 & 0 & 0 \\
\hline 1989 & 0 & 4 & 1 & 4 & 0 & 1 & 0 & 0 & 0 & 0 \\
\hline 1990 & 0 & 3 & 0 & 3 & 2 & 1 & 0 & 0 & 0 & 0 \\
\hline 1991 & 0 & 4 & 0 & 1 & 1 & 3 & 0 & 0 & 2 & 0 \\
\hline 1992 & 0 & 3 & 0 & 4 & 0 & 2 & 0 & 0 & 0 & 0 \\
\hline 1993 & 0 & 1 & 0 & 0 & 1 & 2 & 0 & 0 & 0 & 0 \\
\hline 1994 & 0 & 2 & 0 & 5 & 1 & 6 & 0 & 0 & 0 & 0 \\
\hline 1995 & 0 & 1 & 0 & 3 & 0 & 6 & 0 & 0 & 0 & 0 \\
\hline 1996 & 0 & 1 & 0 & 6 & 0 & 5 & 0 & 0 & 0 & 0 \\
\hline
\end{tabular}




\begin{tabular}{|c|c|c|c|c|c|c|c|c|c|c|}
\hline 1997 & 0 & 2 & 0 & 8 & 0 & 2 & 0 & 0 & 0 & 0 \\
\hline 1998 & 0 & 5 & 0 & 6 & 0 & 3 & 0 & 0 & 0 & 0 \\
\hline Total & 24 & 296 & 408 & 384 & 384 & 288 & 40 & 0 & 248 & 0 \\
\hline
\end{tabular}

Hg: Mercury Process; IM: Ion Exchange Membrane Process.

Figures refer to the number of installations.

Pillot plants are excluded.

Sources:

Mercury Process: Chlorine Institute (1998a; 1998b).

Ion Exchange Membrane Process. Imperial Chemical Industries (1999), Krupp-Uhde (1998), De Nora (1999).

Whille regulations on mercury emissions started to be imposed on the chlor-alkali industry in Western Europe in the 1970s, the suppliers continued to provide their mercury process technologies to chlor-alkali producers. Uhde, De Nora, and Krebs were particularly active in providing their mercury process technologies to chlor-alkali producers during the 1970 s. On the other hand, there was no commercial construction of the ion exchange membrane process by these companies in the same decade. Industrial applications of the ion exchange membrane process were started by ICI and De Nora in 1983 and by Uhde in 1984 , and since then installations by these companies at other chlor-alkali plants have followed steadily. The mercury process, however, continued to be provided by the Western European suppliers, although in a limited scale, during the 1980s. De Nora, in particular, continued to supply its ion exchange membrane process technology until the last one was completed in the middle of the 1990s. While new installations of the mercury process have been terminated, the operation of the mercury process has been still maintained by many chlor-alkali producers in Western Europe, including $\mathrm{ICl}$, which has almeady developed and started to provide its own technology for the ion exchange membrane process to other chlor-alkali producers.

The extent of the supply of the ion exchange membrane process by the Western European firms can be seen by comparing with that by the Japanese firms. Figure 5-8 shows the trend in the cumulative production capacities based on the ion exchange membrane process which have been supplied by the Western European fims, including $\mathbf{I C I}$, Uhde, and De Nora, and the Japanese firms, including Asahi Chemical Industry, Asahi Glass, Tokuyama Soda, and CEC. (Detailed data are given in Table 5-27). 


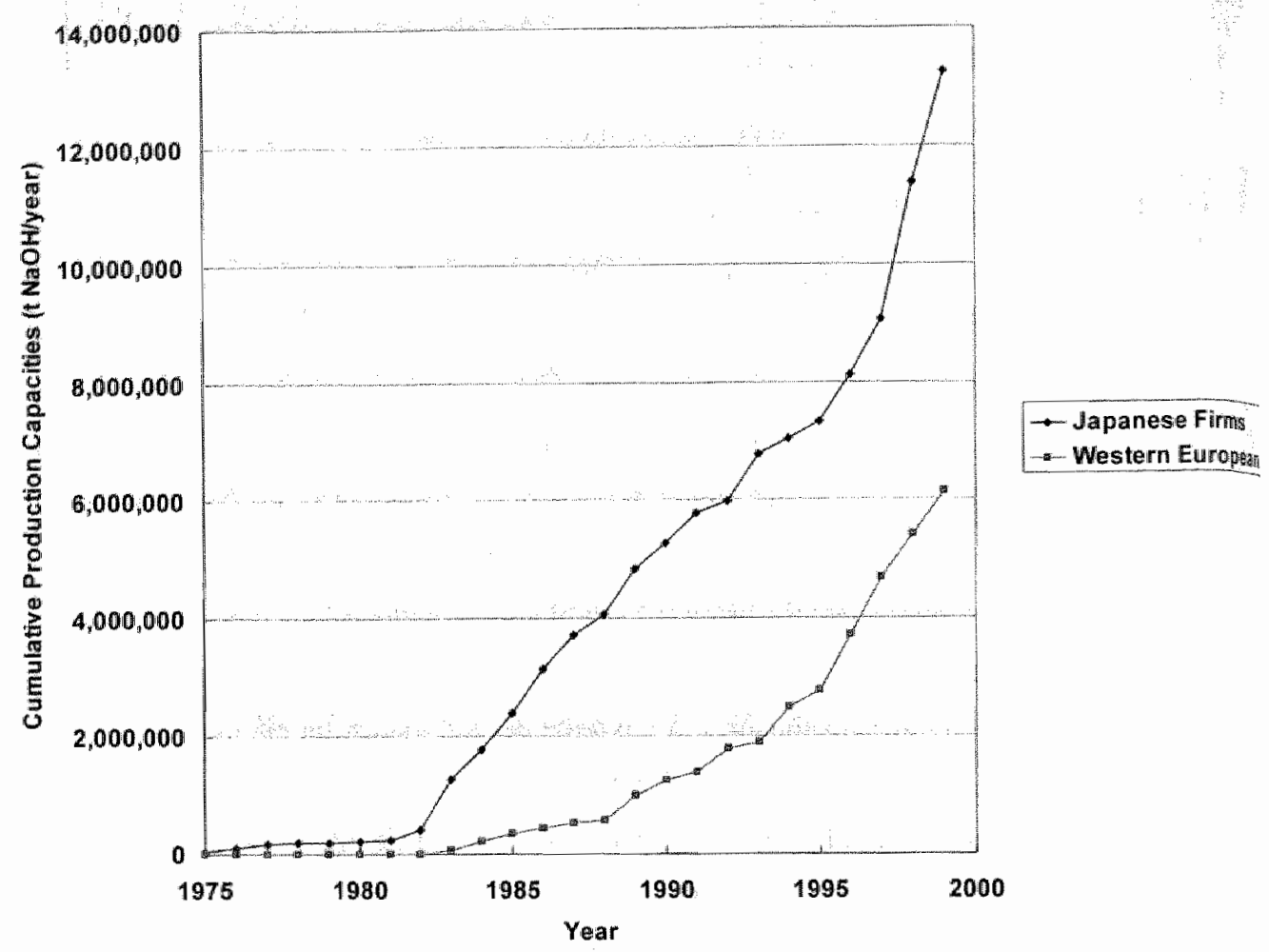

Figure 5-8 Supply of the llon Exchange Membrane Process by Japanese and Western European Firms

From the middle of the 1970 s to the early 1980s, while there was no supply of the ion exchange membrane process by the Western European firms, it was installed by the Japanese firms mainly at chlor-alkali plants operated by the innovative companies themselves. The experienced obtained in this period provided the Japanese companies with expertise valuable to improve their technologies, and that gave them advantages in supplying the ion exchange membrane process to chlor-alkali plants in other parts of the world. Although the Western European suppliers began to provide their technologies in the middle of the $1980 \mathrm{~s}$, their delayed start has resulted in the large gap with the Japanese early movers. 


\subsection{Slow Diffusion of the lon Exchange Membrane Process}

As Figure 5-5 shows, the mercury process has continued to be the dominant technology in Westem Europe, whereas the share of the ion exchange membrane process, which is now the most efficient technology without any emission of pollutants, is limited to less than $15 \%$. Although a sign of increase has been observed recently in the adoption of the ion exchange membrane process, its diffusion is still limited, particularly compared with the case of the Japanese chlor-alkali industry, in which almost all of the production capacities are currently based on the ion exchange membrane process.

In this section, we examine why the diffusion of the ion exchange membrane process has been slow among chlor-alkali producers in Western Europe. As we discussed in Chapter 2 , there are basically two factors which would inhibit the diffusion of a new technology. They concern the availability of information on the new technology and the profitability of its adoption. We consider them in turn for the analysis of the adoption of the ron exchange membrane process in Western Europe.

\subsubsection{Availability of Information on the Ion Exchange Membrane Process}

First, we examine whether the availability of information has been the limiting factor for the diffusion of the ion exchange membrane process in Western Europe. An academic paper on a successful commercial operation of chlor-alkali plant based on the ion exchange membrane process was published for the first time on the journal, Industrial and Engineering Chemistry, Product and Research Development, in 1976 by a researcher of Asahi Chemical Industry (Seko, 1976). In the middle of the 1970s, however, the European chlor-alkali industry was shon of "credible" information on the performance and the reliability of the ion exchange membrane process (Mellish, 1977). With fairly short experience of the new technology, chloralkali producers needed good solid data on any change in technology before spending money on new plants relying on it.. Since 1979, the Electrochemical Technology Group of the Society of Chemical Industry, a UK-based industry association of chemical companies, has organized a symposium on chlor-alkali technologies in London every three years. The organizing committees of these symposiums consisted of representatives of chlor-alkali producers in Westem Europe. The proceedings, edited by technological experts of chlor-alkali manufacturers in UK, were published one year after each symposium. Table 5-17 gives the trends in the number of presentations as well as participants of the symposiums. 
Table 5-17 Presentations on Chlor-Alkali Production Processes at the London International Chlorine Symposiums

\begin{tabular}{|c|c|c|c|c|}
\hline Year & Mercury process & Diaphragm process & $\begin{array}{c}\text { Ion Exchange } \\
\text { Membrane process }\end{array}$ & Total $^{\text {a }}$ \\
\hline 1979 & 4 & 5 & 9 & 23 \\
\hline 1982 & 0 & 4 & 9 & 24 \\
\hline 1985 & 0 & 0 & 12 & 30 \\
\hline 1988 & 0 & 1 & 15 & 29 \\
\hline 1991 & 1 & 1 & 11 & 26 \\
\hline 1994 & 0 & 5 & 9 & 28 \\
\hline 1997 & 1 & 4 & 8 & 26 \\
\hline 2000 & 1 & 2 & 7 & 25 \\
\hline
\end{tabular}

* Presentations which were not included in the proceedings are excluded. Only for 2000 all the presentations are included..

a: The total also includes presentations concerning general aspects such as economic, safety, and environmental issues.

Sources: 1976: Society of Chemical Industry (1977). 1979: Coulter (1980). 1982: Jackson (1983). 1985: Woll (1986). 1988: Prout and Moorhowse (1990). 1991: Prellington (1992). 1994: Curry (1995). 1997: Sealey (1998). 2000: Society of Chemical Industry (2000).

Entering in the 1980 s, paper presentations increasingly dealt with this new field of technology and more detailed technical information started to be disclosed. By the late $1980 \mathrm{~s}$, more than half of the presentations had come to focus on the ion exchange membrane process. In contrast, very few presentations have been made on the mercury process since $1980 \mathrm{~s}$. At each meeting, technical experts from process developers made presentations on their latest technologies to the audience from chlor-alkali producing companies. The compositions of participants in the meetings held in 1.991. and 1994 are given in Table 5-18. As we can see in the table, more than 200 people in each meeting, and the representatives of major chlor-akkali companies in Western Europe, including ICI, Whde, De Nora, Solvay, and Krebs, as well as those in Japan, such as Asahi Chemical Industry, Asahi Glass, and CEC, were all present at the meetings.

Table 5-18 Participants in the London International Chlorine Symposiums

\begin{tabular}{|l|l|c|c|}
\hline \multirow{2}{*}{ Country } & \multicolumn{1}{|c|}{ Company } & \multicolumn{2}{c|}{ Number of Participants } \\
\cline { 2 - 4 } & & 1991 & 1994 \\
\hline \multirow{4}{*}{ United Kingdom } & $\mathrm{ICI}$ & 17 & $\mathbb{1 9}$ \\
\cline { 2 - 4 } & Hays & 8 & 10 \\
\cline { 2 - 4 } & Roche & 3 & 5 \\
\cline { 2 - 4 } & Octel & 3 & 4 \\
\cline { 2 - 4 } & British Salt & 3 & 2 \\
\hline
\end{tabular}




\begin{tabular}{|c|c|c|c|}
\hline & Badger Cat. & 3 & 1 \\
\hline & Others & 14. & 18 \\
\hline & & 511 & 59 \\
\hline \multirow[t]{7}{*}{ Germany } & Uhde & 3 & 5 \\
\hline & Bayer & 4 & 4 \\
\hline & Lurgi & 3 & 0 \\
\hline & BASF & 3 & 2 \\
\hline & Dow (Stade) & 6 & 3 \\
\hline & Others & 8 & 6 \\
\hline & & 27 & 20 \\
\hline \multirow[t]{4}{*}{ Sweden } & Eka Nobel & 7 & 5 \\
\hline & Permescand & 5 & 3 \\
\hline & Others & 5 & 4 \\
\hline & & 17 & 12 \\
\hline \multirow[t]{3}{*}{ Italy } & De Nora & 7 & 6 \\
\hline & Others & 7 & 3 \\
\hline & & 14 & 9 \\
\hline \multirow[t]{4}{*}{ France } & Rhone Poulenc & 6 & 7 \\
\hline & Elf Atochem & 4 & 4 \\
\hline & Others & 2 & 3 \\
\hline & & 12 & 14 \\
\hline \multirow[t]{3}{*}{ Netherlands } & Akzo-Nobel & 5 & 7 \\
\hline & Others & 4 & 0 \\
\hline & & 9 & 7 \\
\hline \multirow[t]{3}{*}{ Betgium } & Solvay & 3 & 3 \\
\hline & Others & 6 & 3 \\
\hline & & 9 & 6 \\
\hline Finland & & 6 & 2 \\
\hline Norway & & 5 & 5 \\
\hline Switzerland & & 4 & 3 \\
\hline Ireland & & 2 & 2 \\
\hline Portugal & & 2 & 1 \\
\hline Spain & & 1 & 2 \\
\hline Austria & & 0 & 1 \\
\hline Denmark & & 0 & 1 \\
\hline Western Europe & & 164 & 154 \\
\hline \multirow[t]{7}{*}{ Japan } & $\mathrm{CEC}$ & 7 & 5 \\
\hline & Asahi Chemical & 6 & 3 \\
\hline & Asahi Glass & 4 & 2 \\
\hline & Mitsui Toatsu & 4 & 1 \\
\hline & Permelec Electrode & 2 & 1 \\
\hline & Du Pont & 2 & 0 \\
\hline & & 25 & 12 \\
\hline Other regions & & 58 & 65 \\
\hline
\end{tabular}


Source: Shiroki (1994).

In the meantime, following the publication of the seminal paper on the first commercial application of the ion exchange membrane process in 1976, papers and articles showing technical aspects of the ion exchange membrane process started to appear. They were mainly published in trade journals, such as the Journal of Applied Electrochemistry (e.g. Bergner, 1982), Chemistry and Industry (e.g. Jackson and Kelham, 1984), Chemical Engineering (e.g. Means and Beck, 1984), Chemical and Engineering News (e.g. Stinson, 1982), Chemical Week (e.g. Brooks, 1986), Chemische Industrie (e.g. Luke, 1989), and Chemiker-Zeitung (e.g. Bergner, 1977). At the same tine, there were an increasing number of reports on cases dealing with conversions of the mercury process to the tion exchange membrane process undergoing in the Japanese chlor-alkali industry. These various sources of information indicated that the newly developed technollogy of the ion exchange membrane process had reached a stage ready for industrial applications. Therefore, we could arguably conclude that it is highly unlikely that chlor-alkali producers in Western Europe were not aware of the feasibility or performance of the ion exchange membrane process. That would bring us to the second reason why the diffusion of a new technology could be delayed; that is, the profitability of the adoption of the ion exchange membrane process.

\subsubsection{Profitability of the Adoption of the Ion Exchange Membrane Process}

We discussed in Chapter 2 that a new clean technology is adopted when it is profitable to do so. That means, in the case of technological change for pollution abatement, the existing technology is replaced with a new clean technology when the total cost of operating the existing technology with the end-of-pipe technology is larger than that operating the clean technology:

$$
T C_{e}(a, t)>T C_{R}(t)
$$

that is,

$$
P C_{0}-P C_{C}(t)>I C_{0}-I C_{k}-A C_{e}(a, t)
$$

With this model, we examine the diffusion of the ion exchange membrane process in Western Furope. 


\section{Investment Cost of Introducing the Ion Exchange Membrane Process}

We first consider the investment cost of introducing the ion exchange membrane process. Capital costs required in the chemical process industries are often assumed to be subject to economies of scale, with a scaling-up factor. One of the most frequently used empirical rules is the so-called "sixth-tenth factor rule" (Bruni, 1964). This empirical rule bas been justified by noting that the cost of a piece of equipment or of an entire plant, at least in many industries having a continuous production process, depends mainly on the surface area of the plant equipment whereas production capacity depends on the volume. Assuming that plant equipment of different capacity have walls of equal thickness and that the cost of the equipment is proportional to their weight, the cost varies in proportion to their volume, i.e. their capacity, taken to the power of $2 / 3^{107}$.

In contrast to this general rule of $2 / 3$ scaling-up factor applied for a single large-scale production unit, a chlor-alkali electrolytic plant has multiple cell elements into a single unit, called electrolyzer. Each electrolyzer consists of a latge number of cell elements, following either of two basic designs; monopolar or bipolar. The elements are conmected in series with resultant low current and high voltage in a bipolar arrangement whereas in the monopolar type cell all anodes and cathodes are connected in parallel, forming an electrolyzer with high current and low voltage ${ }^{108}$. And then multiple electrolyzers are employed in a single direct cument circuit; usually bipolar electrolyzers are connected in parallel with low current and high voltage whereas monopolar electrolyzers are often connected in series, resulting in a high current circuit and low voltage. For example, one of the bipolar type electrolyzers produces 15,000 tomnes of caustic soda per year, meaning that a plant with an annual capacity of 120,000 tonnes of caustic soda would need eight electrolyzers (Schneiders and Luke, 1992). One recent case of the process conversion required 848 cell elements, and another case needed 1,536 cell elements (Kramer and Luke, 1990). In essence, electrolysis for chlor-alkali

\footnotetext{
Wh This rule can be demonstrated in eliementary geometry by considering spherical or cylindrical lanks whose hapght is constantly related to their dianeter. The surface area $A$ and the volume of a spherical tank are $A=4 \pi R^{2}$ $V=H / 3 \pi R^{3}$.

where $R$ is the dianter of the tank. The expital cost of the plant equipment $C$ is $C=a_{0} A=4 \pi c_{0}, R^{2}$.

where $c_{i}$, is the unit cost of the equipment material. From equation (5f-2) we can derive $R=(3 / 4 \pi)^{H / 3} V^{13}$.

Hence we abtain $C=3^{23}(4 \pi)^{1 / 4} c_{i 2} V^{23}=k V^{33}$

where $k=3^{y / 3}(4 \pi)^{l / 3} c_{k}$ which is constant.

dry Data on various lypes of the electrolytic cell are given in fible $5-31$ in Appendix at the end of this chapter.
} 
manufacture is a two-dimensional process, which consists of a large number of relatively small electrolytic cells connected with each other. We hence assume that the scaling-up factor can be approximated to unity.

In converting chlor-alkali plants from the mercury process to the lon exchange membrane process, while the rectifier, chllorine and hydrogen systems, and caustic storage could continue to be used, several new facilities will be required to utilize the ion exchange membrane process (Austin and Esayian, 1984). The use of high-performance ion exchange membranes requires a new secondary brine purification step to remove calcium and magnesium to a level of less than $50 \mathrm{ppb}$, but the cost of the brine system for the ion exchange membrane process is relatively small, $4-7 \%$ of the total capital investment (Schmittinger, Curlin, Asawa, Kotowski, Beer, Greenberg, Zelfel, and Breitstadt, 1986). In addition, many electrolyzer designs for the ion exchange membrane process include a caustic circulation loop to provide temperature control as well as mixing to achieve a uniform concentration profile in the cathode chamber. Deionized water is added to the catholyte loop to control the caustic concentration. When $50 \%$ caustic is required, evaporators will be needed to further concentrate the 32-35\% caustic produced by the ion exchange membrane electrolyzers, and additional steam generating facilities may also be required depending on the site situation. The installation of these facilities cost 3-4\% of the total investment(Schmittinger, Curlin, Asawa, Kotowski, Beer, Greenberg, Zelfel, and Breitstadt, 1986).

Taking these aspects into account, we assume here that the total investment cost of process conversion can be basically represented by the cost for the electrolytic cells and ion exchange membranes. Since the scaling-up factor can be approximated to be 1 , the wnit capital investment will be almost constant for plants of varying capacities, and thus the total capital investment will rise proportionately as the plant size increases. This treatment can be justified by the fact that the capital investment cost is normally discussed in this way by experts in the chlor-alkali industry, ahthough not so much information has been disclosed on the actual investment costs of converting the mercury process to the ion exchange membrane process $^{10 \%}$.

\footnotetext{
${ }^{106}$ Converting mercury cells to ion exchange membrane cells incrementally over a period of time within a merury cellrom is not generally considered to be practical or cost effective by those working in the industry (Lindlcy, 1997). First, because for ion exchange membrane ceils trace quantities of mercury can have a signiticant impact on the performanee of the ion exchange membrane, a separate recireulated brine system would be required. Second, since the cell layouts are totally different for ion exchange membrane and mercury: cells, with the power densities and heat loads different, a separate power supply system (rectifiers) would be needed. Furthermore, as the mercury cell room layout is designed to enable mercury to be contained, operating
} 
At the end of the 1970 s, when several plants based on the ion exchange membrane process started to operate in Japan, the three technology providers, namely, Asahi Chemical Industry, Asahi Glass, and Tokuyama Soda, reported that the investment cost of installing the ion exchange membrane process would be approximately 7 billion yen for a plant of an ammal capacity of 100,000 tomnes of caustic soda (Expent Committee for Technical Evaluation of the Ion Exchange Membrane Process, 1979). That corresponds to 320 US\$t $\mathrm{NaOH}$, which is equivalent to $360 \mathrm{US} \$ / \mathrm{Cl}_{2}{ }^{110}$. While this conversion cost was probably estimated to be lower, as this figure did not include a significant amount of investment costs required for dismantling the existing mercury process.

In the United Kingdom, Associated Octel Company converted its chlor-alkali plant at Ellesmere Port, Cheshire, with a capacity of $40,000 \mathrm{t} \mathrm{Cl}_{2}$ per year in 1992 from the mercury process to the ion exchange membrane process (Lot, 1995). In this case, new electrolytic cells could be installed in the existing cellroom, but the decontamination of mercury at the site required a significant treatment. A completely new caustic recirculating system and a holding tank had to be installed as a guard against iron and mercury contamination. Other equipment included a secondary brine treatment plant reducing calcium and magnesium ions in the brine down to ppb levels. As samples of the pure brine from the mercury cells system indicated high levels of silicate, a salt dissolving pit and a brine handling tank were taken ont of service and relined with plastic. The reused brine system was subsequently demercurized. The disposal of the mercury cell steelwork proved more time-consuming and costly. In total the company made an investment of $£ 11,583,000$ in this conversion project, including cellroom, new equipment, modifications to the existing plant, labor and administration, and the disposal of the contaminated steel. This figure corresponds to an investment of $510 \mathrm{US} \$ / \mathrm{t}$ $\mathrm{Cl}_{2}$ capacity.

A case of the conversion of the mercury process to the ion exchange membrane process at the Borregaard plant in Norway in 1997 has shown that the total cost was around 200 million NOK, equivalent to US\$ 28 million (Borregaard, 1998). A new electrolysis section was constructed, and a brine circuit for fittration, secondary pourification with ion exchange and dechlorination, a unit for concentrating caustic soda, and units for chlorine gas drying and

ion exchange membrane cells within the same celluoon would require some mercury containment activitios and some of the working practices. Tharefore, conversion from mercury celts to ion exchange membrane cells is nomally carried out for a complete celleoom at a single instance. 
absorption were newly installed. Among the reused equipment were the rectifiers, the units for hydrogen treatment and chlorine hydroxide production, and the sections for chlorine liquefaction and compression. Mercury filtration units for caustic, hydrogen and process exhaust were removed, and pumps, instruments and pipelines were replaced. A significant portion of the total conwersion cost was spent for cleaning the old plant and depositing, about half of which was invested on constructing a mercury disposal facility. With the annual production capacity of 40,000 tomes of chlorine, the unit cost of the conversion was 710 $\mathrm{USS} / \mathrm{t} \mathrm{Cl}_{2}$.

Technology suppliers, on the other hand, suggest smaller figures for the investment cost of installing the ion exchange membrane process. Asahi Chemical, one of the major technology suppliers, estimates the current investment cost of converting an existing mercury plant to the ion exchange membrane process is in the range of $300-350$ million Japanese yen for an annuall capacity of 10,000 tonnes of caustic soda (Hamada, 2000). That roughly corresponds to 280-320 US\$/t NaOH, which is equivalent to $310-360 \mathrm{US} \$ / \mathrm{t} \mathrm{Cl} 2$ capacity. In this estimation it is assumed that onlly the mercury cells are replaced by the ion exchange membrane cells, while reusing other equipment for salt solution, primary treatment of brine, chlorine and hydrogen treatment. For construction of a new plant in a green field, the cost will be 1.2-1.5 billion Japanese yen for a similar capacity. That means the unit cost of $990-1,200$ US\$/t NaOH, equivalent to $1,100-1,400 \mathrm{US} \$ / \mathrm{t} \mathrm{Cl}_{2}$. Uhde takes $600 \mathrm{DM} / \mathrm{t} \mathrm{NaOH}$, equivalent to $290 \mathrm{US \$} / \mathrm{t} \mathrm{NaOH}$, as a current investment figure for the conversion of a mercury-based plant to the ion exchange membrane process (Zimmermann, 2000). This figure, which corresponds to $320 \mathrm{US} \$ / \mathrm{t} \mathrm{Cl}$, is only for cellroom conversion, and various equipment are assumed to be used from the existing plant. Uhde also cites a very rough estimate of the total investment cost of $600-700$ US $\$ / \mathrm{t} \mathrm{NaOH}$ for a plant of $250,000-500,000$ t $\mathrm{NaOH}$ per year (Henson, 1997). This figure includes the total plant and equipment, piping, utilities and constructions, excluding only the land cost.

As we can see, the investment cost quoted varies depending on the technical requirements for any particular conversion as well as on what should be included in the calculation of the necessary costs. Technology suppliers quote figures at the lower end for the conversion costs, at around $350 \mathrm{US} \$ / \mathrm{t} \mathrm{Cl}$. They have not changed so much since the first

\footnotetext{
1/6 The indnstry prefers teminology for capacity and power consumption expressed in tonnes of caustic soda $(\mathrm{NaOH} 100 \%)$ because clatorine gas flows are expensive to measure. The conversion factor used is 1.128 tonnes of $\mathrm{NaOH} 100 \%$ for every tomne of chlorine produced.
} 
introduction of the ion exchange membrane process in the late 1970 s. Considering inflation, the real cost has indeed declined significantly, due partly to a decline in the price of ion exchange membranes and partly to an increase in the current density, which reduced the number of electrolytic cells (Bordoni, 2000, Luke and Beckmann, 1999). These frgures, however, represent the minimum costs necessary for the conversion of the existing mercurybased plants to the ion exchange membrane process. They do not include expenditures for cleamup and safe dismantling and disposal of equipment in contact with mercury, which is increasingly important as mercury-containing wastes above a threshold concentration, for example, $3 \%$ in the European Union as mandated by Directives $91 / 689 / \mathrm{EEC}$ and $94 / 904 / \mathrm{EC}$; are classified as "hazardous" (Euro Chlor, 1999b).

It would hence be reasonable to take cost figures based on the actual cases of process conversion including the costs of the cleaning and disposal of mercury. In that sense, the investment cost of $700 \mathrm{US} \$ / \mathrm{t} \mathrm{Cl}_{2}$ for the process conversion at Borregaard would be appropriate as the representative figure for the total investment cost of converting the existing mercury plants to the ion exchange membrane process, as it includes the costs necessary for cleanup and disposal of equipment contaminated with mercury This figure roughly corresponds to estimations made by those people working in the chlor-alkali industry in Western Europe. For example, Straasheijm (2000) cites $1,500 \mathrm{NLG} / \mathrm{t} \mathrm{Cl}$, equivalent to 630 $\mathrm{US} \$ / \mathrm{Cl}_{2}$ whereas Lindley (1997) estimates that a typical conversion cost would be in the range between 560 and $610 \mathrm{ECU} / \mathrm{t} \mathrm{Cl}$ for an average mercury plant capacity in Western Europe. Euro Chlor (1996) estimates the capital cost of conversion of an average size mercury plant (100,000 $\mathrm{t} \mathrm{Cl}_{2} / \mathrm{y}$ ear) to its equivalent ion exchange membrane plant to be approximately $700 \mathrm{ECU} / \mathrm{t} \mathrm{Cl} \mathrm{L}_{2}$ capacity. Therefore, considering that the nominal minimum investment cost has been virtually unchanged since the late 1970 s, we assume here that the nominal total investment cost per unit capacity has been constant at the level of 700 US\$/t $\mathrm{NaOH}$.

For this kind of production plants in the chemical process industries, the depreciation period is nomally taken to be 10 years, although the physical lifetime of these plants can be much longer. A major reason suggested by industry experts is that, given the unstable nature of developments in the chlor-alkali industry, predicting the economic wiability of this type of plant much beyond 10-15 years is considered difficult, and prudent accounting practices tend to be adopted (Lindley, 1997). Accordingly, we here assume a straight depreciation of 10 years. That means that, as the estimated cost for the conversion of the mercury process to the 


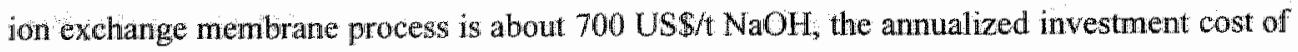
introducing the ion exchange membrane process $I C_{c}$ is 70 US $\$ / \mathrm{NaOH}$.

\section{Cost of Reducing Mercury Emissions with End-of-Pipe Technologïes}

It is very difficult to assess exactly the costs associated with pollution abatement with end-ofpipe technologies. We could see at least, however, that the scale of the cost of reducing mercury emissions with end-of-pipe technologies has been much smaller than that of converting the mercury process to the ion exchange membrane process. In the 1970 s, the investment cost of installing the calomel process for removing mercury from gases was. estimated to be $1.58 \mathrm{DM}$, equivalent to 0.79 US\$, per tonne of chlorine capacity (Richter, 2000). A similar estimation of the cost of scrubbing with chlorine-containing brine or with alkaline hypochlorite solution was in the range of 1.74-1.77 DM, corresponding to 0.87-0.88 US\$, per tonne of chlorine capacity. The operating cost of these processes, on the other hand, was reported to be in the range of 3-7\% of the investment (Rekers, 1973). The total cost of reducing mercury in liquids with pre-coated carbon filters was also reported to be approximately I US\$ per tonne of caustic soda. These figures indicate that the cost of reducing mercury emissions with end-of-pipe technologies in the 1970s was a little more than $0.1 \%$ of the cost of plant conversion from the mercury process to the ion exchange membrane process, which has been around 700 US $\$$ per tonne of production capacity.

Currently, the cost of installing a sulfurized active carbon system, including the heat exchanger necessary to increase the temperature after the cooling step, the equipped tower, and the filters, to remove mercury from liquids is reported to be in the range of $0.45-0.5$ million Euro for a plant with chlorine capacity of 166,000 tonne (European IPPC Bureau, 1999). That corresponds to 2.7-3.0 US $\$$ per tonne of chlorine capacity. The cost of installing the activated carbon filtration in pre-coated candle or plate filters is around 0.25 million Euro for a production capacity of 100,000 tonne of chlorine per year, which is equivalent to 2.5 US\$ per tonne of chlorine capacity. These figures still correspond to less than $1 \%$ of the investment cost of converting the mercury process to the ion exchange membrane process. We could therefore conclude that, compared with the investment cost of converting the mercury process to the ion exchange membrane process $I C_{k}$, the cost of installing and operating end-of-pipe technologies $I C_{e^{*}}+A C_{e^{*}}$ has been much smaller; that is,

$$
I C_{i},>>I C_{i,}+A C_{e} \text {. }
$$


Saving in Production Cast from the Conversion of the Mercury Process to the Ion Exchange Membrane Process

Next, we consider the saving in the production cost by the conversion of the mercury process to the ion exchange membrane process. The fixed costs for operators and other personnel, taxes, insurance, repairs, and maintenance have been approximately the same for the mercury process and the ion exchange membrane process (Euro Chlor, 1996; Schmittinger, Curlin, Asawa, Kotowski, Beer, Greenberg, Zelfel, and Breitstadt, 1986). Of the variable costs, the expense for salt, chemicals (e.g. precipitants), and anode reactivation are almost equal for both processes. The difference among the three processes shows up in the consumption of energy, in the form of electricity and steam, which normally accounts for about two thirds of the total operating cost. Therefore, we can focus on only one factor, that is, energy consumption, in considering cost saving by switching from the mercury process to the ion exchange membrane process.

As we have seen in Figure 4-8, the energy consumption of the ion exchange membrane process has shown a remarkable improvement since the early 1970s. Concomitant with the technological progress, the cost saving from the conversion of the mercury process to the ion exchange membrane process has increased. Figure 5-9 shows the trends in the cost saving from the conversion of the mercury process to the ion exchange membrane process in Western Europe, as compared with the annualized investment cost necessary for it. (Detailed data are given in Table 5-32 in Appendix at the end of this chapter.) It is constructed by using the data on the extent of technological progress and the electricity price. As mentioned above, we assumed that the energy consumption of the mercury process has been constant at the level of $3,200 \mathrm{kWh} / \mathrm{t} \mathrm{NaOH}$. The data on the average electricity price in Western Europe is obtained from International Energy Agency's Energy Information (International Energy Agency, 1992, 1993, 1999). Since the late 1970s, the electricity price in Western Europe has increased steadily; between 1978 and 1995 it rose by about $100 \%$, measured in US dollars. 


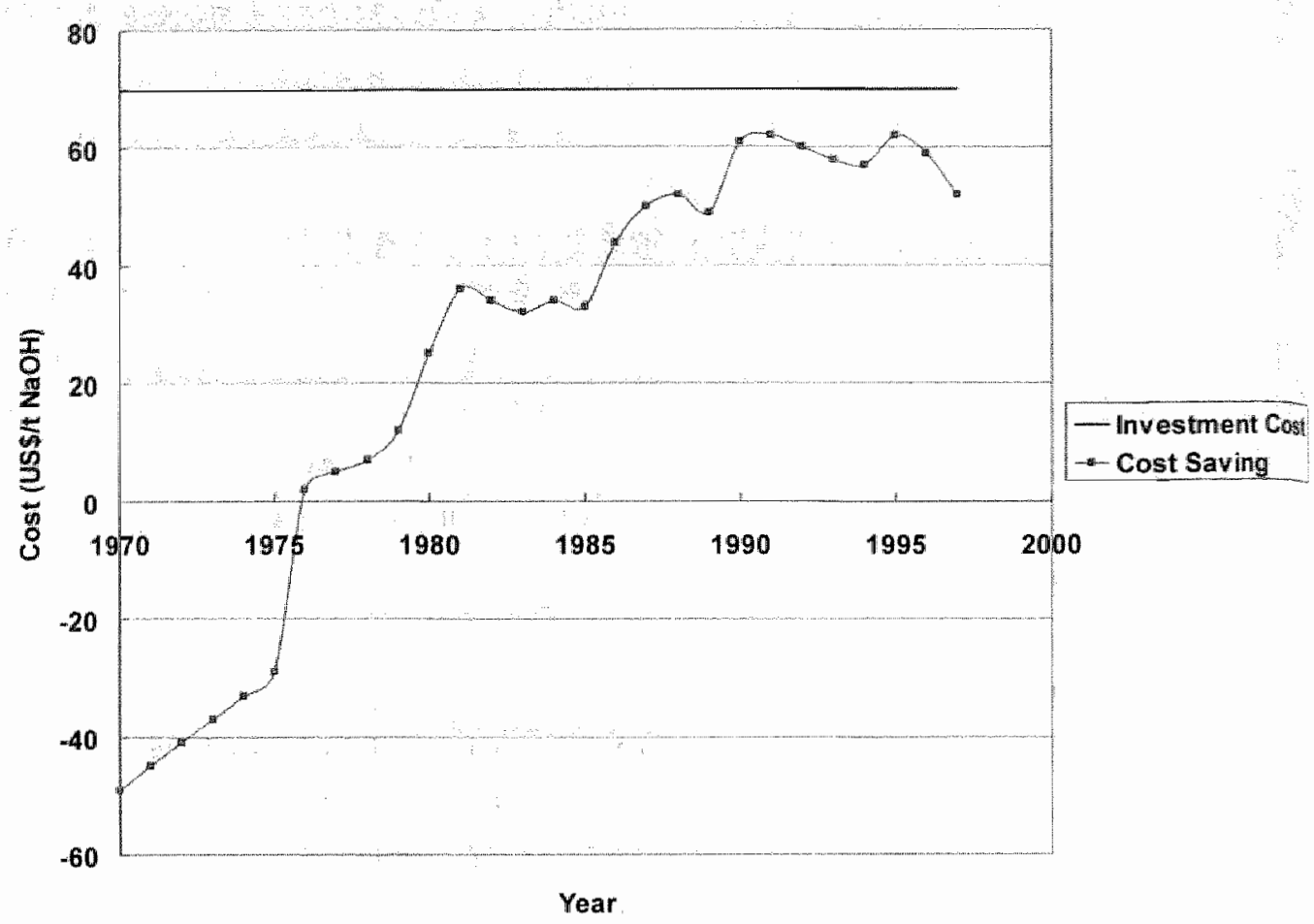

Figure 5-9 Cost Saving from the Conversion from the Mercury Process to the Ion Exchange Membrane Process and Annualized Investment Cost

Until the middle of the 1970s the ion exchange membrane process was less energyefficient than the mercury process, and thus the production of cost with the former was higher than that of the latter. Accordingly, there was no incentive, at least for commercial purposes, to adopt the ion exchange membrane process for chlor-alkali production in Western Europe. As the energy efficiency of the ion exchange membrane process was improved steadily, the operating cost of the ion exchange membrane process had become substantially lower than that of the mercury process by the early 1980s. Thus, for newly constructed chlor-alkali plants, the ion exchange membrane process has become the preferable technology since then. For the existing plants based on the mercury process, however, considering that these plants can still be used physically for chlor-alkali production, the expected cost saving needed to be large enough to justify the investment cost necessary to convert the mercury process to the ion exchange membrane process. 
We can see Figure 5-9 in relation to Figure 2-10(b), which has been discussed in the analytical framework. During the 1980 s, the cost saving by process conversion $P C_{0}-P C_{C}(t)$ was in the range of $30-50$ US\$ $\mathrm{NaOH}$ and thus remained short of completely offsetting the investment cost for the ion exchange membrane process $/ C$ of $70 \mathrm{US} \$ \mathrm{NAOH}$; that is,

$$
P C_{o}-P C_{e}(0)<I C_{c}
$$

Although the investment expenditure for process conversion could be lower for some plants, it has been still uneconomical for most of the mercury plant operators to convert their mercury-based plants to the ion exchange membrane process. Thus there exist large incentives to continue to use the mercury process at their existing plants as long as they can be utilized for chlor-alkali production, while inhibiting the diffusion of the ion exchange membrane process in Western Europe. That consideration leads us to examine the age of chlor-alkali plants based on the mercury process.

\subsubsection{Long Lifetime of Chlor-Alkali Plants Based on the Mercury Process}

The construction of a chlor-alkali plant, whether it is based on the mercury process or the ion exchange membrane process, is capital-intensive and requires dedicated buildings. The lifetime of a plant depends in part on the functional life of the building in which it is housed. While electrolytic cells and some other inventory are routinely maintained, refurbished, or renewed, plants can operate in the same layout and fulfill the commercial needs for a long period of time (Euro Chlor, 1998b). As we have discussed in the previous section, currently the cost saving from the conversion of the mercury process to the ion exchange membrane process is not sufficient to offset the necessary investment. Therefore, the introduction of the ion exchange membrane process, although currently the most efficient technology for chloralkali production, will be delayed until the existing mercury-based plants come to the end of their physical lifetimes.

In this section, we compare the operating period of chlor-alkali plants based on the mercury process and those based on the ion exchange membrane process in Western Europe. We would like to see how long the chlor-alkali plants which had been originally based on the mercury process were operated before conversion to the ion exchange membrane process. To do that, we investigate the timing of the construction of the new membrane-based plants as well as the original mercury-based plants. Then, by looking at the operating years of the existing mercury-based plants, we can examine whether these plants are close to the end of their lifetimes, that is, whether these plants are expected to be converted to the ion exchange 
membrane proeess soon. The data on the construction and conversion of these plants were basically obtained from the companies operating them.

Figure $5-10$ shows the operating period of the mercury process before it was converted to the ion exchange membrane process at 15 chlor-alkali plants in Western Europe. (Detailed data on the start-up year of the mercury and the ion exchange membrane processes of each plant are given in Table 5-33 in Appendix at the end of this chapter.)

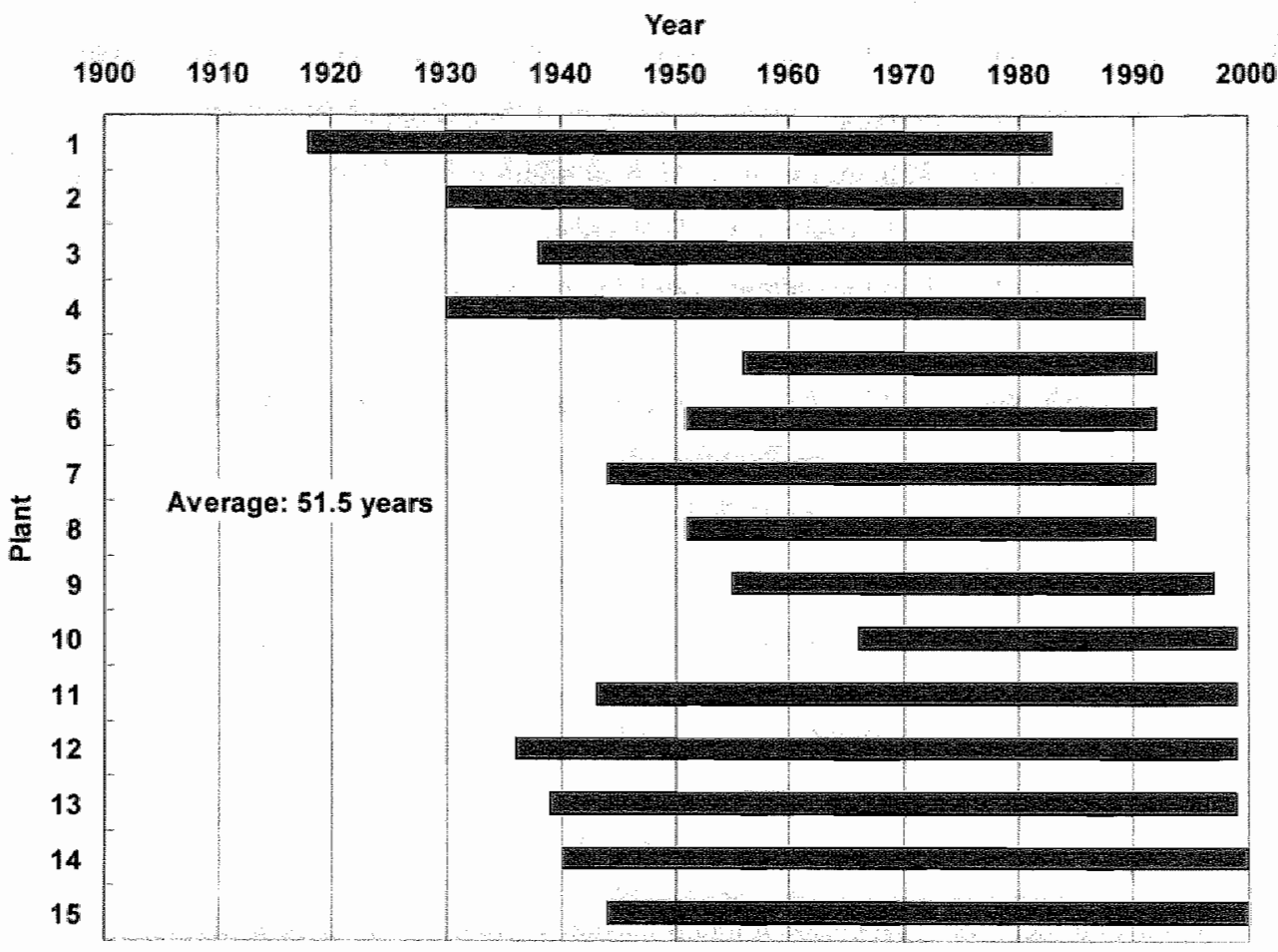

Figure 5-10 Operating Period of the Mercury Process before Its Conversion to the Ion Exchange Membrane Process in the Western European Chlor-Alkali Industry

Most of the installations of the ion exchange membrane process in the 1980 s were undertaken for newly constructed chlor-alkali plants, rather than for the conversion of the existing mercury process. As we have seen above, by the early 1980 s the energy consumption of the lon exchange membrane process had become much smaller than that of the mercury process. Accordingly, given that the construction cost was almost the same for the two production processes, it was reasonable for chlor-alkali producers to choose the ion exchange 
membrane process when they constructed new plants. In the case of Akzo Nobel's plant in Botlek, the company decided to establish a new plant with the ion axchange membrane process just next to a mercury-based plant. While the production capacity based on the ion exchange membrane process was increased significantly in order to meet growing denvands for chlorine, the existing mercury plant was abolished subsequently (Straasheijm, 1999). Although the storage and loading facilities which had been already established could be utilized for the ion exchange membrane process, most of the infrastructures, including those for cooling water supply, electrical provision, direct chlorination (for vinyl chloride monomer production) had to be newly constructed (Strasheijm, 2000).

While the ion exchange membrane process was introduced to new plants during the 1980 s, the conversion of the existing mercury-based plants was not economically attractive. In all of the cases except for two, the original mercury process was operated for at least 40 years, and in some plants the operating period reached 60 years. On average, the mercurybased plants which had been converted subsequently were utilized for more than 50 years. This figure corresponds to the general view held by experts in the industry that the lifetime of chlor-alkali plants based on the mercury process is normally in the range of $40-60$ years (Euro Chlor, 1998b). Once mercury-based plants had been constructed, the operators had strong incentives to continue to utilize them as long as possible, and the conversion of these plants did not take place untill they reached their physical lifetimes, the average of which was approximately 50 years.

Next we would like to know how long the existing chlor-alkali plants based on the mercury process have been operating. Figure 5-11 shows the operating period of 51 chloralkali plants currently operating with the mercury process in Western Europe. (Detailed data on each plant are given in Table 5-34 in Appendix at the end of this chapter.) 


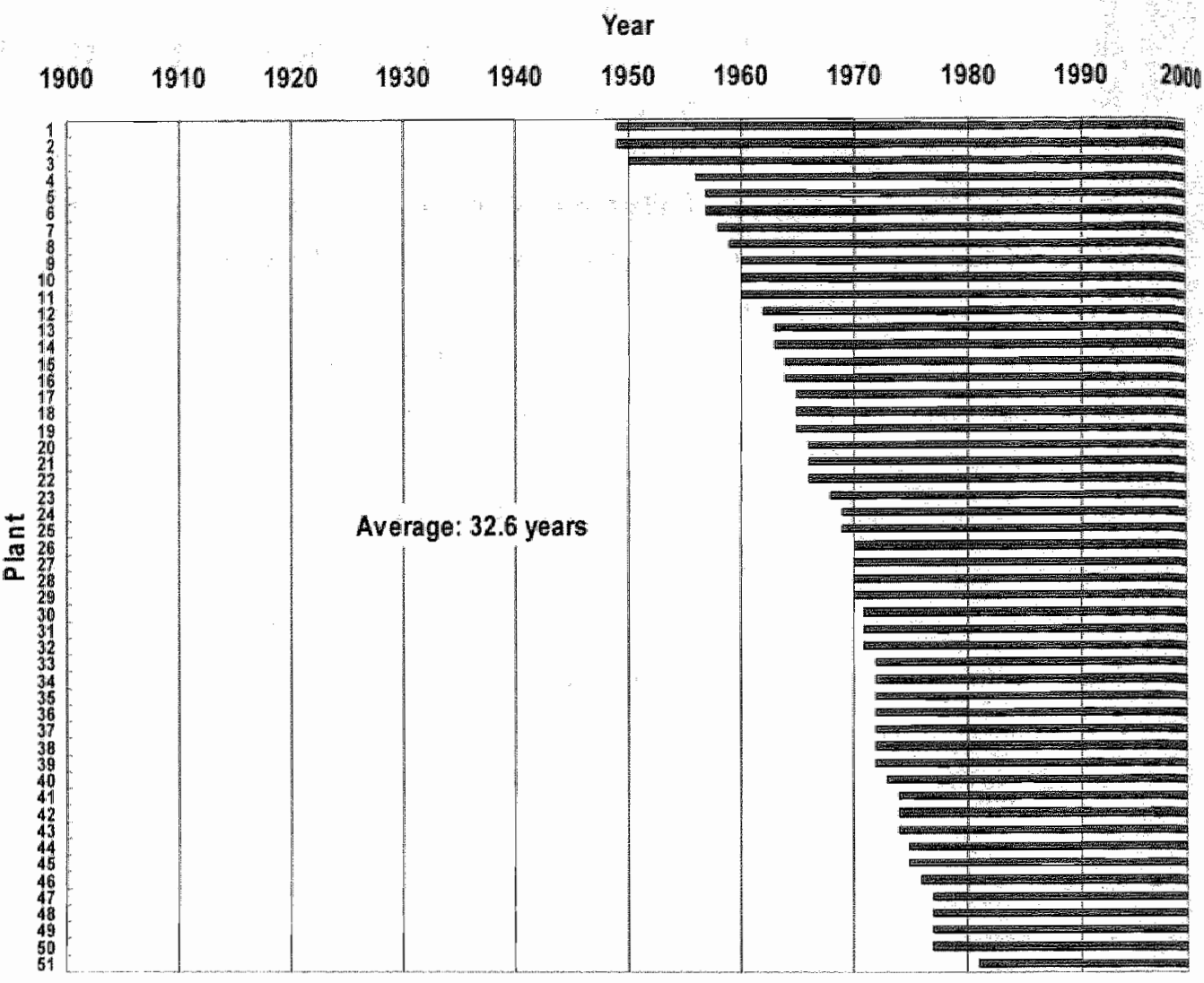

Figure 5-11 Operating Period of the Existing Chlor-Alkali Plants based on the Mercury Process in Western Europe

The figure indicates that many chlor-alkali plants were constructed in the 1960 s and the 1970 s by adopting the mercury process whereas at the beginning of the 1980 s the mercury process ceased to be adopted for newly constructed chlor-alkali plants in Western Europe. The average of the operating years of the existing mercury-based plants is a little longer than 30 years, which is 20 years shorter than the average lifetime of 50 years for the mercurybased plants which have been already converted to the ion exchange membrane process. While new construction of chlor-alkali plants based on the mercury process have been already terminated, most of the existing mercury-based plants have not yet reached the end of their physical lifetimes. 
In particular, we should note that there are many mercury plants which were buill in the 1970s. In the same period, as we have discussed earlier; envirommental regulations on mercury emissions started to be introduced in Western Europe. As these regulations were not so stringent as to require immediate phase out of the mercury process, chlor-alkali producers chose to rely on this process for the construction of new production facilities during the 1970 s, rather than to try to innovate on new clean technologies such as the ion exchange membrane process, which was still at its infant stage at that time. To comply with standards on mercury emissions from chlor-alkali plants, innovative companies directed R\&D efforts for end-ofpipe technologies designed to be installed at the linal stage of the mercury process. Reasonably good end-of-pipe technologies have been developed and adopted to reduce mercury emissions to the extent that the emission standards have been met by all of the mercury-based chlor-alkali plants in Western Europe.

On the other hand, innovations on end-of-pipe technologies to reduce mercury emissions helped chlor-alkali producers continue to build their new plants with the mescury process during the 1970 s. That has resulted in the current existence of many mercury-based plants which have not yet reached the end of their lifetimes. The operators of these relatively new plants have incentives to continue to use them as long as they can be utilized, avoiding plant conversions from the mercury process to the ion exchange membrane process. The success of end-of-pipe technologies in reducing mercury emissions has in effect prolonged the lifetime of the mercury process, which is actually in the process of technological obsolescence, while inhibiting the diffusion of advanced clean technologies such as the ion exchange menbrane process.

With this background, the European chlor-alkali industry is strongly opposed to the implementation of the mandated phase-out of all the mercury plants in Western Europe by 2010 (Hain, 1999). In an attempt to convince the OSPAR Commission to reverse this decision, the European industry association, Euro Chlor, organized a workshop in September 1999, inviting the members of the OSPAR Commission (OSPAR Commission, 1999b). At this workshop, where technical issues were mainly discussed without making any official deciston, Euro Chlor demanded that the recommendation for the phase-out of the mercury process by 2010 be dropped from the Decision 90/3. In place of it, the industry made a proposal for voluntary actions, with the commitment of all of the chlor-alkali producers currently using the mercury process. The voluntary actions specified that the European chlor-alkali industry will not increase production capacity based on the mercury process and that at the same time it 
will reduce mercury emissions further beyond the PARCOM Decision $90 / 3$ standard of $2 \mathrm{~g}$ $\mathrm{Hg} / \mathrm{t} \mathrm{Cl}_{2}$ capacity for emissions to the atmosphere (Euro Chlor, 1999c).

More concretely, the operators of mercury-based plants have pledged to achieve an annual weighted average level of mereury emissions to air, water and in products not exceeding $1.0 \mathrm{~g} \mathrm{Hg}^{\mathrm{t} \mathrm{Cl}_{2}}$ capacity by the end of 2007 and to work towards a level not exceeding $0.7 \mathrm{~g} \mathrm{Hg} / \mathrm{Cl}$ capacity by 2010 , "on condition that the plants concerned are allowed to operate beyond the year 2010." In addition, arguing that, depending on various factors such as design, age and geography, some plants may not be able to achieve the specified targets while others will be able to achieve even lower emission levels, the companies have made a further commitment that individual plants will not exceed a level of mercury emissions to air, water and in products of $1.5 \mathrm{~g} \mathrm{Hg} / \mathrm{t} \mathrm{Cl} 2$ capacity by the end of 2007 . It has also been agreed that shutdown mercury-based plants will not be sold or transferred to any third party for reuse ${ }^{1 / 1}$. Debates are still continued between the industry and the public authorities, and it remains to be seen whether the requirement for the phase out of the remaining mercury plants will be abandoned in Western Europe.

If we look at the situation in the world, the share of the lon exchange membrane process in chlor-alkali production has been increasing steadily. Figure 5-12 shows the trends in the installation of the mercury process, the diaphragm process, and the ion exchange membrane process at chlor-alkali plants in the world. (Detailed data are given in Table 5-35 in Appendix at the end of this chapter.)

\footnotetext{
117 Early in the 1990s a chlor-alkali producer in Pakistan, Ravi Alkalis Lid., considered importing a Damish mercuryabased chlor-alkali plant for rebuilding. The three-plant complex, owned by DS Industries APS in Copendhagen had been the focus of controversy in Denmark for over 20 years because in the 1960s and 1970s it had an history of violating water emissions limits. Its environmental performance dramatically improved in the 1980s and met all environmental regulations by 1990, when the company decided to shut down the plant. Under the Danish law, the unit would not be considered hezardous if it were reopened or rebuilt and used, as intended (Siddiqi. 1994). In the end, however, the Pakistani producer installed the ion exchange membrane process, instead of the used mercury process (Krupp-Uhde, 1998).
} 


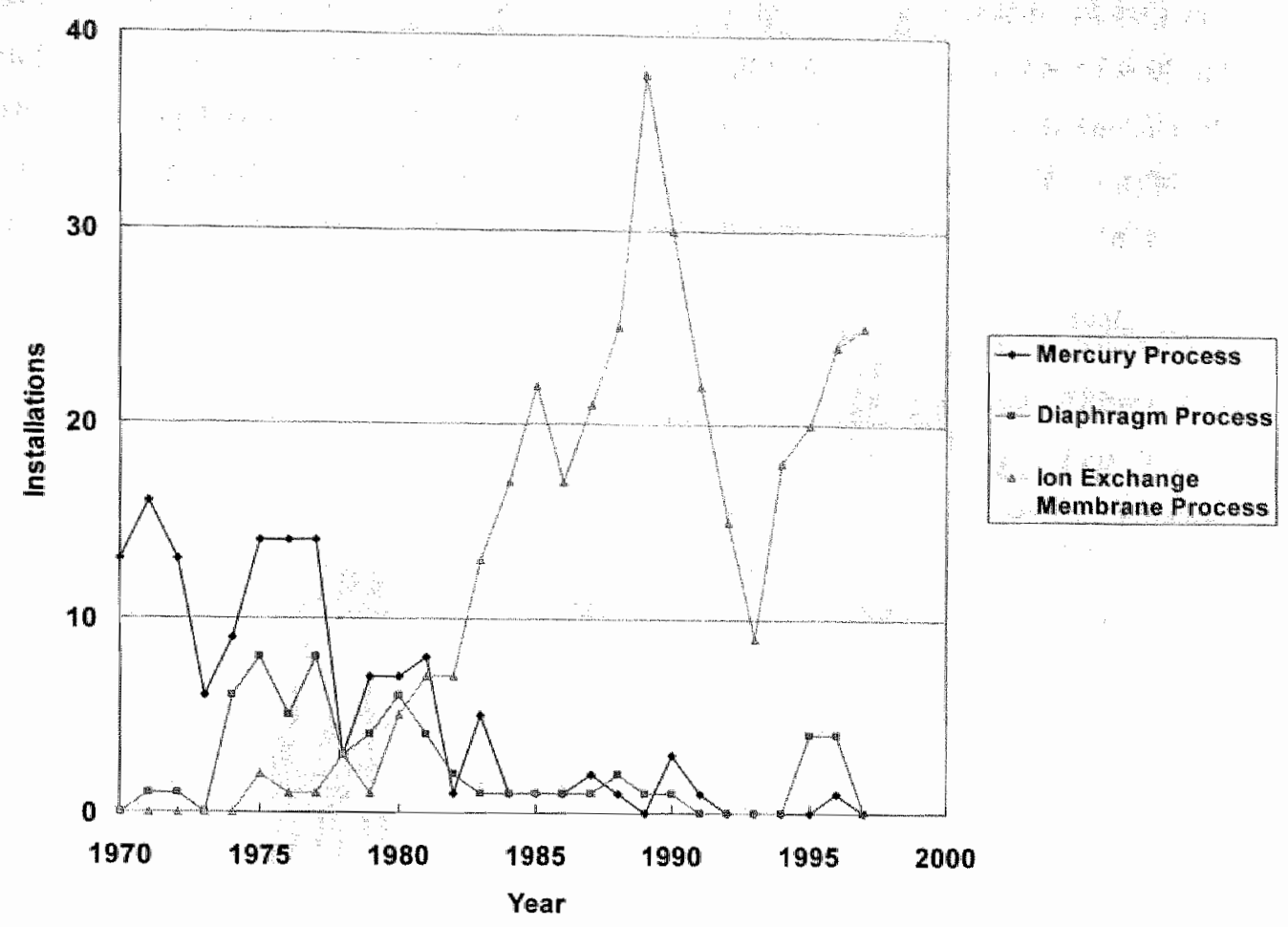

Figure 5-12 Installation of the Mercury, Diaphragm, and Ion Exchange Membrane Processes in the World

During the 1970s, the mercury process was the production technology which was adopted almost exclusively at chlor-alkali plants around the world. The only exception was Japan, where the newly established ion exchange membrane process started to be adopted by several innovative companies in the middle of the 1970 s. As the performance of the ion exchange membrane process had been improved by the early 1980 s, most of the chlor-alkali production processes installed in the 1980s were based on the ion exchange membrane process. On the other hand, the introduction of the mercury process has been virtually stopped, due to its less energy efficiency compared with that of the ion exchange membrane process, as well as due to the environmental and health concerns with mercury emissions.

These recent trends in the choice of chlor-alkali production technology are reflected in the relative composition of the world production capacities. Although there is no official data 
which covers detatled figures for the production capacities in different regions of the world; Figure 5-13 shows an estimation of the trends in the shares of production capacities based on the mereury process, the diaphragm process, and the ion exchange membrane process in the world chlor-alkali industry since 1980. (Data are given in Table 5-36 in Appendix at the end of this chapter.

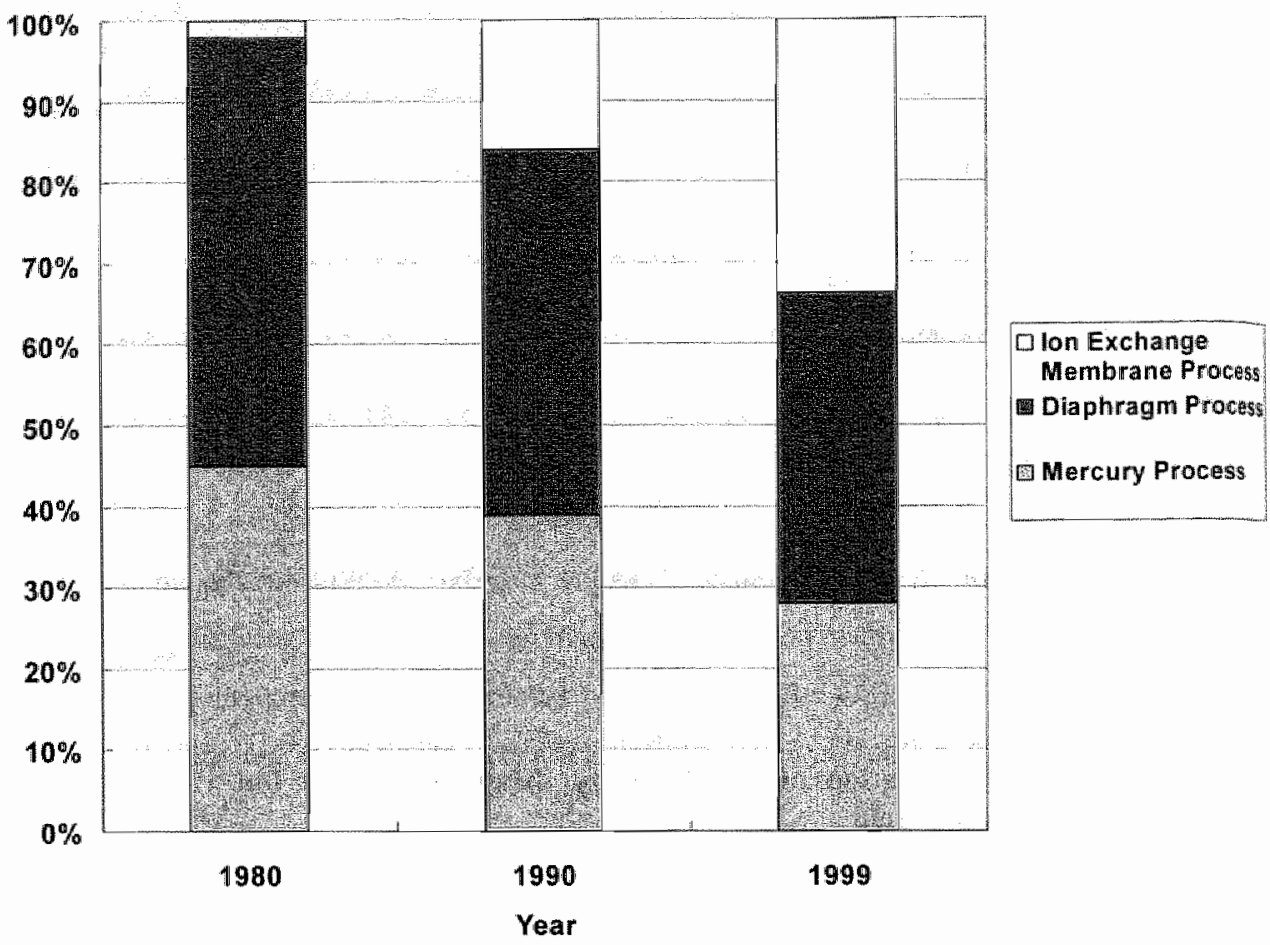

Figure 5-13 Shares of the Mercury, Diaphragm, and Ion Exchange Membrane Processes in the World

We can see that the share of the ion exchange membrane process in the world has been rising rapidly while the mercury process has been decreasing its share. In 1980, about a half of the world chlor-alkali production capacities were based on the mercury process and another half based on the diaphragm process, with the ion exchange membrane process almost negligible. Since then, however, the technological choice of the world chlor-alkali industry as a whole has been shifting steadily from the mercury and diaphragm processes towards the ion exchange membrane process. Over the period between the late 1970s and the end of the $1990 \mathrm{~s}$, 
the won membrane process increased its share in the world from almost zero to 30 per cent. That means that the newly established ion exchange membrane process bas surpassed the share of the century-old mercury process in just 20 years.

In developing countries, in particular, while the use of the pollution-laden mercury process has been increasingly avoided, the ion exchange membrane process has been in a process of rapid diffusion. In Taiwan, there are no chlor-alkali plants currently operating with the mercury process (Nakanishi, 1993). China and India have been increasingly constructing new chlor-alkali plants based on the ion exchange membrane process, and most of the chloralkali production capacities have been already based on the ron exchange membrane process in countries such as Indonesia, Thailand, South Africa, Egypt, and Saudi Arabia (Chlorine Institute, 1999a). This case of technological change in the chlor-alkali industry demonstrates an example of technological leapfrogging by choosing the clean technology over the end-ofpipe technology. At the same time, this case indicates that the "pollution haven," on which intensive research has been made by researchers since the 1970s (see, for example, Leonard, 1988; Low and Yeats, 1992), may not necessarily be an unavoidable fate for developing countries $^{12}$.

\subsection{Conclusion}

In this chapter, we examined the effects of environmental regulation on technological change in the Westem European chlor-alkali industry. Since the end of the 19th century, the mercury process had been the focus of technological development in Western Europe. By the early 1970s, advanced technologies had been developed for the mercury process by several innovative companies, notably, $I C l$, Hoechst-Uhde, De Nora, Solvay, and Krebs. Their technologies had been adopted not only by chlor-alkali producers in Western Europe but also by those in other parts of the world.

Then we look at the environmental polices introduced in Western Europe to regulate mercury emissions from chlor-alkali industry. Unlike Japan, there was no publicly reported case in which human bodies were seriously affected by the intake of mercury in Western. Europe. Nevertheless, as public concems on the potential impacts of mercury increased,

\footnotetext{
112 A recent empirical study shows that nnajor urban areas in China, Brazil, and Mexico, insteat of being the pollution haven, have all experienced significant improvement in air quality, contradicting the prediction of the pollution haven hypothesis (Wheefer, 2000).
} 
regulations started to be imposed on mercury released to the environment, particullarly to the aquatic ecosystems, in the 1970s. While the introduction of environmental policies on mercury occurred almost in the same period as that in Japan, Western Europe took a different approach to the regulation of mercury emissions from chlor-alkali industry. Rather than imposing a requirement for the phase out of the mercury process, the public authorities set emission standards and environmental quality objectives for mercury released from chloralkali plants. The levels of these standards were subsequently tightened during the 1980 s.

We next examined the effects of these regulations on R\&D activities undertaken by companies in the chlor-alkali industry in Western Europe. With the imposition of regulations limiting the amount of mercury released to the enviromment, chlor-alkali producers operating plants with the mercury process were required to reduce their emissions. And at the same time companies which had been innovative on chlor-alkali production technologies were encouraged to make R\&D efforts on technological measures for the abatement of mercury emissions. The patent data we analyzed indicate that those innovative companies, including ICI, Hoechst-Uhde, De Nora, Solvay, and Krebs, directed their R\&D activities to end-of-pipe technologies for the abatement of mercury emissions. Those technologies developed were mainly designed to work for filtration, adsorption, and scrubbing of mercury released from various points of the production facilities to air and waste water. The effects of these end-ofpipe technologies were significant in reducing mercury emissions from chlor-alkali plants; more than $90 \%$ of mercury released to air, waste water, and products in Western Europe has been eliminated since the late 1970 s. With the success in reducing mercury emission by adopting these end-of-pipe technologies, many chlor-alkali producers have continued to use the mercury process, whose current share is more than $60 \%$ of all the chlor-alkali production capacities in Western Europe.

On the other hand, the relatively weak regulatory approach to mercury emissions did not encourage innovative efforts to develop clean technologies which do not involve any use of mercury, such as the ion exchange membrane process. Among the innovative companies in the Western European chlor-alkali industry, ICI had been already involved in R\&D activities on the ion exchange membrane process since the early 1960s. The company, however, had stopped their efforts to develop technologies for the ion exchange membrane process subsequently, because of the unavailability of ion exchange membranes which had sufficient physical as well as chemical strength to be reliably utilized in the electrolytic cells. In the $1.970 \mathrm{~s}$, R\&D activities of the companies which had technological expertise on the mercury 
process, including De Nora, Hoechst-Uhde, Solvay, and Krebs, as well as ICI, were basically focused on the mercury process, rather than the ion exchange membrame process. And these companies continued to provide their technologies to other chlor-alkal producers in the 1980 s.

In the meantime, encouraged by the strong regulation for the phase out of the mercury process, the innovative companies in Japan invented new types of ion exchange membranes, and the technological performance of the ion exchange membrane process was improved rapidly. By the early 1980 s, this newly developed process had advanced to such an extent that it beeame effectively the only practical option when constructing new commercial plants. Obiserving the invention of ion exchange membranes with improved physical and chemicall strength, which led to the remarkable progress in the ion exchange membrane process, several innovative companies in Western Europe, particularly, ICl, Uhde, and De Nora, initiated R\&D activities on the ion exchange membrane process in the late 1970s. As advanced types of ion exchange membranes had been already developed by the Japanese companies, the focus of R\&D activities of these European firms was placed on electrolytie cells to be used in the ion exchange membrane process. Utilizing the ion exchange membranes introduced from Japan, ICI, Uhde, and De Nora started to provide their ion exchange membrane process teclnologies to other chlor-alkali producers in the middle of the 1980s:

We then considered why the diffusion of the ion exchange membrane process has been slow and limited. Basically, we examined two factors which can be mainly considered to affect the diffusion of a new technology, that is, the availability of information on the new technology and the profitability of the adoption of the new technology. To see whether a sufficient amount of information on the ion exchange membrane process has been available to chlor-alkali producers in Western Europe, we look at the trends in presentations made at industry conferences and papers published on technical and trade journals. We found that, although only a limited amount of information was available in the 1970 s regarding the newly developed ion exchange membrane process, there has been a plenty of opportunities since the 1980s to obtain detailed and reliable data on this technology with advanced performance. Therefore, we can reasonably conclude that the factor which has inhibited the acoption of the ion exchange membrane process in Western Europe was not the lack of information on the newly developed technology.

We next considered whether the adoption of the ion exchange membrane process has been economically beneficial to chlor-alkali producers in Western Europe. Estimations of the investment necessary for the installation of the ion exchange membrane process were 
obtained from ehlor-alkali producers who have introduced the new process and technology suppliers. The inwestment and operating costs of end-of-pipe technologies adopted for the reduction of mercury emissions were also estimated by using data on actual cases. We found that the irvestment cost of adopting the ion exchange membrane process is much larger than the cost necessary to install and operate end-of-pipe technologies to reduce mercury emissions. Then we then examined the cost saving from the conversion of the mercury process to the ion exclange membrane process. Although the energy consumption of the lion exchange membrane process for chlor-alkali production was larger than that of the mercury process in the early 1970 s, as the performance of the ion exchange membrane process has been improved rather quickly, by the middle of the 1980 s the ion exchange membrane process had come to consume much less energy than the mercury process. Accordingly, the operating cost of the latter is currently larger than the former. We found; however, that the scale of the cost saved by switching from the mercury process to the ion exchange membrane process has not yet been sufficient to justify the necessary investment for the replacement of the mercury process with the ion exchange membrane process. While it has been already economically beneficial to adopt the ion exchange membrane process for new green-field plants, there is a strong incentive to continue to use the existing mercury-based plants as long as they are can be utilized to produce chlor-alkali products. That has discouraged the adoption of the ion exchange membrane process by many operators of the mercury process in Western Europe. What is of critical importance for the diffusion of the ion exchange membrane process is the age of chlor-alkali plants based on the mercury process.

Hence we examined the operating years of the mercury-based plants which have already been converted to the ion exchange membrane process as well as that of the existing plants relying on the mercury process. Those mercury-based plamts which have already been switched to the ion exchange membrane process had been operated for a little longer than 50 years on average before the process conversion. That suggests that at least for this period of time mercury-based plants can be utilized for chlor-alkali production. On the other hand, the average of the operating years of the existing mercury-based plants is a little more than 30 years, a period which is about 20 years shorter than that in the case of the mercury-based plants which have already been converted to the ion exchange membrane process. That means that many of the existing plants relying on the mercury process have not yet reached the end of their physical lifetime. Thus, the operators of these plants have strong incentives to continue to use them for chlor-alkali production until they can no longer be utilized. 
In particular, the data on the start-up year of these existing mercury-based plants shows that there are many plants constructed with the mercury process in the $1970 \mathrm{~s}$. As we have discussed above, during the same decade the R\&D activities of the innovative companies in Western Europe were focused on technological measures for the reduction of mercury emissions. The patent data shows that there were actually many innovations on end-of-pipe technologies for pollution abatement. While various types of end-of-pipe technologies were successfully implemented in reducing mercury released to outside the production facilities, many plants based on the mercury process continued to be built during the $1970 \mathrm{~s}$. These relatively new plants can be utilized for commercial production for a long time before they reach the end of their lifetime.

Currently, despite a recent recommendation made by the regulators that the existing mercury-based plants be completely discarded by the year 2010 , the mercury process is still the dominant production technology in Western Europe, accounting for more than $60 \%$ of the total production capacities. The chlor-alkali industry has been consistently opposed to the mandate for the phase out of the mercury process and strongly demanding the policy makers to withdraw the deadline of 2010 . The pace of converting the existing mercury plants has been slow, and the diffusion of the ion exchange membrane process has been limited to a little more than $10 \%$ of the total production capacities in Western Europe. On the other hand, the ion exchange membrane process has been adopted by many chlor-alkali producers outside Western Europe, particularly in developing countries, leapfrogging the stage of employing the mercury process. Accordingly, the share of the ion exchange membrane process in the world production capacities has been increasing steadily.

In sum, the public authorities in Western Europe specified emission standards and environmental quality standards with regard to mercury emissions from chlor-alkali plants. This regulative approach, which was less stringent that that of the Japanese government, induced innovative companies in Western Europe to undertake R\&D activities on end-of-pipe technologies for the abatement of mercury released from chlor-alkali plants. Operators of mercury-based plants adopted these technologies, which worked successfully to reduce mercury emissions steadily. Thus, most of the chlor-alkali producers in Western Europe continued to use the mercury process supported with end-of-pipe technologies, a less expensive option than converting to clean technologies which would require comprehensive reorganization of the manufacturing process. During the $1970 \mathrm{~s}$, many more chlor-alkali plants were buit with the mercury process. 
On the other hand, these relatively less stringent regulations implemented in Western Europe did not clean did not create strong and sectured demands for new clean technologies and initially discouraged imnovative companies to make R\&D efforts on clean technologies such as the ion exchange membrane process. Although the ion exchange membrane process was ultimately to become better, economically as well as environmentally, than the mercury process in the end, its future progress in the technological performance could not be predicted with sufficient certainty, given the infant stage of technological development in the 1970 s. It was only after the ion exchange membrane process had been proved to be feasible for industrial applications with the invention of advanced ion exchange membranes in Japan that these R\&D efforts on the ion exchange membrane process were intensified by these innovative companies in Western Europe. By that time, however, many chlor-alkali plants had been constructed by using the mercury process, and that has resulted in the slow conversion of these relatively new plants to the ion exchange membrane process.

The environmental regulations which were aimed at the abatement of mercury emissions encouraged the development and adoption of end-of-pipe technologies, which indeed worked relatively well in reducing mercury emissions less expensively. This success, however, effectively helped to prolong the lifetime of the mercury process, which was actually in the process of technological obsolescence. This case of technological change in the Western European chlor-alkali industry implies that, under the existence of uncertainty, diversity, and rigidity of technological change, environmental regulations which are not very stringent could succeed in reducing pollutant emissions by inducing the development and adoption of end-of-pipe technologies. But at the same time innovations on clean technologies which would be the most appropriate techmology in terms of economic efficiency as well as environmental protection could be discouraged, by prolonging the life of the existing, pollution-laden technology.

\section{Appendix}

\section{List of Interviewees in Western Europe}

Imperial Chemical Industries ( $\mathrm{CCl}$ )

- Mr. Steve Ingleby, Chlor-chemicals Senior Technologist 
- Mr. R. W. Curry, Chlor-Akali Technical Section Manager

- Mr. Cliff Broom, Manufacturing Manager, JKL Cellrooms

\section{Whde}

- Dr--Ing. Benno Lüke, Manager Process Department, Electrolysïs Division

- Dipl.-Chem. Roland Beckmann, Head of Development Department, Electrolysis Division

De Nora

- Mr. Giuseppe Faita, Director, Research \& Technologies

- Mr. Marco Tenconi, Sales Manager (Plants)

Bayer

- Dr. Hermann Schubert, Corporate Staff, Quality, Environment and Safety Policy

Alkzo Nobel

- Ir. F. G. Straasheijm, Technology \& Manufacturing Manager, Chlor-Alkali

\section{EniChem}

- Mr. Antonio Pasquinucei, Research and Technology Manager, Polyurethanes and Chlor-Alkali Division

- Mr. Manlio Inverardi, Environmental Balance and Certification, Safety Health Environment Division

Euro Chlor

- Dr. Barrie S. Gilliatt, Executive Director

OSPAR Commission

- Dr. Stefan Hain, Depuly Secretary 
Table 5-19 List of Chlor-Alkali Plants in Western Europe

\begin{tabular}{|c|c|c|c|c|c|c|}
\hline \multirow{2}{*}{ Country } & \multirow[t]{2}{*}{ Company } & \multirow[t]{2}{*}{ Site (Basin) } & \multicolumn{4}{|c|}{ Capacity $\left(\mathrm{Cl}_{2} 10^{3}\right.$ vyear $)$} \\
\hline & & & Hg & $\mathrm{D}$ & $\mathrm{IM}$ & Other \\
\hline \multirow[t]{2}{*}{ Austria } & Donau Chemie & Briuckl (D) & 60 & - & - & - \\
\hline & Total & 60 & 60 & 0 & 0 & 0 \\
\hline \multirow[t]{6}{*}{ Belgium } & BASF & Antwerp $(A)$ & 100 & - & $=$ & - \\
\hline & Bayer & Antwerp (A) & - & $=$ & - & 50 \\
\hline & Solvay & Antwerp (A) & 230 & - & - & - \\
\hline & Solvay & Jemeppe $(A)$ & 82 & $=$ & 120 & - \\
\hline & $\begin{array}{l}\text { Tessenderlo } \\
\text { Chemie }\end{array}$ & Tessenderlo (A) & 250 & - & - & - \\
\hline & Total & 832 & 662 & 0 & 120 & 50 \\
\hline \multirow[t]{3}{*}{ Finland } & Akzo Nobel & Oulu (C) & 40 & - & - & - \\
\hline & Finnish Chemicals & Joutseno (C) & - & - & 75 & - \\
\hline & Total & 115 & 40 & 0 & 75 & 0 \\
\hline \multirow[t]{11}{*}{ France } & Albemarle & Thann $(A)$ & 72 & - & - & - \\
\hline & ChlorAlp & Pont de Claix (B) & - & 240 & - & - \\
\hline & Elf Atochem & Fos (B) & - & 160 & 110 & - \\
\hline & Elf Atochem & Jarrie (B) & 170 & - & - & - \\
\hline & Elf Atochem & Lavera (B) & 166 & 160 & $=$ & - \\
\hline & Elf Atochem & Saint Auban (B) & 184 & - & - & - \\
\hline & Métaux Spéciaux & Pomblières (B) & - & - & - & 20 \\
\hline & $\begin{array}{l}\text { Prod. Chimiques } \\
\text { d"Harbonnieres }\end{array}$ & Harbonnières (A) & 23 & - & - & - \\
\hline & Solvay & Tavaux $(\mathbb{B})$ & 241 & - & 122 & - \\
\hline & $\begin{array}{l}\text { Tessenderlo } \\
\text { Chemie }\end{array}$ & $\operatorname{Loos}(\mathrm{A})$ & 18 & - & - & 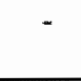 \\
\hline & Total & 1,686 & 874 & 560 & 232 & 20 \\
\hline \multirow[t]{16}{*}{ Germany } & BASF & Ludwigshafen (A) & 150 & 210 & - & - \\
\hline & Bayer & Brunsbuttel $(\mathrm{A})$ & - & - & - & 120 \\
\hline & Bayer & Dormagen $(A)$ & 300 & 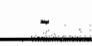 & - & 80 \\
\hline & Bayer & Leverkusen (A) & 300 & - & - & 30 \\
\hline & Bayer & Uerdingen $(A)$ & 130 & - & 90 & - \\
\hline & BSL & Schkopau (A) & 200 & - & $=$ & - \\
\hline & Calanese & Knapsack $(\mathrm{A})$ & 150 & - & - & - \\
\hline & Clariant & Gersthofen (D) & 60 & - & - & - \\
\hline & Dow & Stade (A) & - & 1,040 & 200 & - \\
\hline & $\mathrm{ECl}$ & Bitterfeld $(A)$ & 65 & 147 & $=$ & - \\
\hline & $\mathrm{ECl}$ & Tbbenbüren $(A)$ & 120 & - & - & - \\
\hline & Hüls & Luilsdorf $(A)$ & 98 & - & - & - \\
\hline & $1 \mathrm{CI}$ & Wilhelmshaven $(\mathrm{A})$ & 130 & - & - & $=$ \\
\hline & LII Europe & Frankfurt $(A)$ & 150 & - & - & - \\
\hline & Solvay & Rheinberg (A) & - & 200 & - & $=$ \\
\hline & Vestollit & Marl (A) & 180 & - & - & - \\
\hline
\end{tabular}




\begin{tabular}{|c|c|c|c|c|c|c|}
\hline \multirow{3}{*}{ 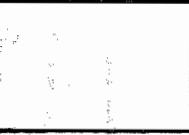 } & Vinnolit & Gendorf (D) & 72 & - & - & $=$ \\
\hline & Wacker & Burghausen (D) & 157 & - & - & - \\
\hline & Total & 4,379 & 2,262 & 1,597 & 290 & 230 \\
\hline \multirow[t]{2}{*}{ Greece } & Hellenic Petroleum & Thessaloniki (B) & 37 & 6 & - & - \\
\hline & Total & 37 & 37 & 0 & 0 & 0 \\
\hline \multirow[t]{2}{*}{ Ireland } & MicroBio & Fermoy (A) & - & $=$ & 6 & - \\
\hline & Total & 6 & 0 & 0 & 6 & 0 \\
\hline \multirow[t]{11}{*}{ Ttaly } & Altair Chimica & Volterra (B) & 27 & - & $\therefore$ & - \\
\hline & $\begin{array}{l}\text { Ausimont/ } \\
\text { Montedison }\end{array}$ & Bussi (B) & 70 & - & - & - \\
\hline & Caffarro & Toreviscosa (B) & 69 & - & - & - \\
\hline & EniChem & Assemini/Cagliari (B) & - & $\therefore$ & 170 & $=$ \\
\hline & EniChem & Porto Marghera (B) & 200 & - & - & $=$ \\
\hline & Enichem & Porto Torres (B) & 90 & - & - & - \\
\hline & EniChem & Priolo (B) & 190 & - & - & - \\
\hline & Eredi Zarelli & Picinisco (B) & 6 & $=$ & - & - \\
\hline & Solvay & Rosignano (B) & 120 & - & - & - \\
\hline & $\begin{array}{l}\text { Tessenderlo } \\
\text { Chemie }\end{array}$ & Pieve Vergonte $(\mathrm{B})$ & 40 & - & - & - \\
\hline & Total & 982 & 812 & 0 & 170 & 0 \\
\hline \multirow[t]{6}{*}{ Netherlands } & Akzo Nobel & Botlek (A) & - & - & 250 & - \\
\hline & Akzo Nobel & Delfzijl (A) & - & 125 & - & - \\
\hline & Akzo Nobel & Hengelo (A) & 70 & - & - & - \\
\hline & GEP & Bergen-op-Zoom (A) & - & - & 62 & - \\
\hline & Solvay & Linne Herten $(A)$ & 140 & - & - & - \\
\hline & Total & 647 & 210 & 125 & 312 & 0 \\
\hline \multirow[t]{4}{*}{ Norway } & Borregaard & Sarpsborg (A) & - & - & 40 & - \\
\hline & Elkem & Bremanger $(A)$ & - & $\sim$ & 10 & - \\
\hline & Norsk Hyåro & Rafnes (A) & - & 130 & - & - \\
\hline & Total & 180 & 0 & 130 & 50 & 0 \\
\hline \multirow[t]{3}{*}{ Portugal } & Solvay & Povoa $(\mathrm{A})$ & - & $=$ & 28 & - \\
\hline & Uniteca & Estarreja (A) & 48 & - & 13 & - \\
\hline & Total & 89 & 48 & 0 & 41 & 0 \\
\hline \multirow[t]{7}{*}{ Spain } & $\begin{array}{l}\text { Aragonesas } \\
\text { (EIASA) }\end{array}$ & Huelva (A) & 101 & 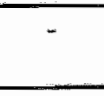 & - & $\overline{-}$ \\
\hline & $\begin{array}{l}\text { Aragonesas } \\
\text { (EIASA) }\end{array}$ & Sabinanigo (B) & 25 & - & - & - \\
\hline & $\begin{array}{l}\text { Aragonesas } \\
\text { (EIASA) }\end{array}$ & Villaseca (B) & 135 & $=$ & 40 & - \\
\hline & $\begin{array}{l}\text { Electroq. de } \\
\text { Hernani }\end{array}$ & Hernani $(A)$ & 15 & - & - & - \\
\hline & Elnosa & Lourizan (A) & 34 & - & - & - \\
\hline & Erkimia & Flix (B) & 150 & - & - & - \\
\hline & Quimica del Cinca & Monzon (B) & 30 & $=$ & - & - \\
\hline
\end{tabular}




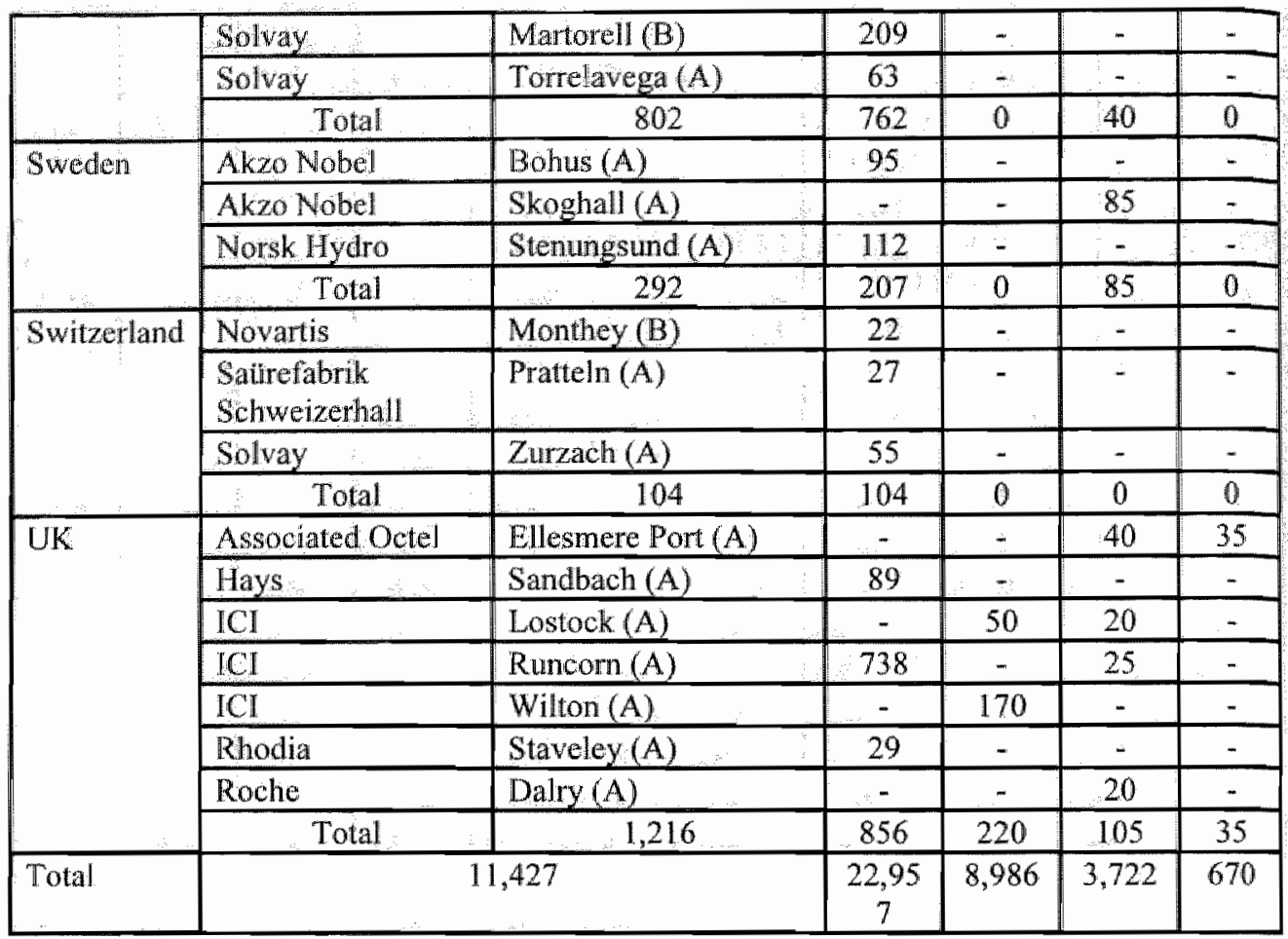

Data as of 1998 .

Basin

A: North-East Atlantic and North Sea (OSPAR Commission)

B: Mediterranean Sea (Barcelona Convention)

C: Baltic Sea (Helsinki Commission)

D: Black Sea (Black Sea Convention)

Process

Hg: Mercury process

D: Diaphragm process

IM: Ion Exchange Membrane process

Sources: Euro Chlor (1998a), European IPPC Bureau (1999).

Table 5-20 Chlor-Alkali Plants in Western Europe within and outside the Catchment Area of the Paris Convention

\begin{tabular}{|l|c|c|c|c|}
\hline \multirow{2}{*}{ Country } & \multicolumn{2}{|c|}{ Within catchment area } & \multicolumn{2}{c|}{ Outside catchment area } \\
\cline { 2 - 5 } & Mercury & Non-mercury & Mercury & Non-mercury \\
\hline Austria & - & - & 1 & - \\
\hline Belgium & 4 & - & - & - \\
\hline Denmark & - & - & - & - \\
\hline Finland & - & - & 1 & 1 \\
\hline France & 3 & - & 4 & 3 \\
\hline Germany & 12 & 5 & 3 & 1 \\
\hline
\end{tabular}




\begin{tabular}{|l|c|c|c|c|}
\hline Greece & - & - & 1 & - \\
\hline Iceland & - & - & - & \\
\hline Ireland & - & 1 & - & 1 \\
\hline Itally & - & - & - & \\
\hline Luxembourg & - & - & - & \\
\hline Netherlands & 2 & 3 & - & \\
\hline Norway & 1 & 2 & - & - \\
\hline Portugal & 2 & - & 5 & \\
\hline Spain & 4 & - & - & \\
\hline Sweden & 2 & 1 & 1 & - \\
\hline Switzerland & 2 & 1 & - & - \\
\hline United Kingdom & 3 & 5 & 200 & \\
\hline Total & 280 & 144 & & \\
\hline
\end{tabular}

Data as of 1997.

* Non-member countries of the Paris Commission

Sources: OSPAR Commission (1999c), Euro Chlor (1998a).

Under the Paris Convention, the member countries have been obliged to report annual data concerning mercury losses from chlor-alkali plants operating within the "catchment area" of the Paris Convention. (Data for Switzerland has been included since 1993.) That means those plants whose emissions were not considered to contribute to the pollution of the North-East Atlantic were excluded from the data submitted to the Paris Commission. (With regard to mercury losses to the air, however, data have been collected from all chlor-alkali plants operating in the member countries on a plant-by-plant basis). Table 5-20 gives the distribution of chlor-alkali plants within and outside the catchment area. While $63 \%$ of the chlor-alkali plants in Western Europe were located within the catchment area, $58 \%$ of the mercury plants were located within the catchment area.

Table 5-21 US Patents Successfully Applied by Western European Companies on Technologies Related to the Mercury Process and the Ion Exchange Membrane Process

\begin{tabular}{|c|c|c|}
\hline $\begin{array}{c}\text { Year of Patent } \\
\text { Application }\end{array}$ & Mercury Process & Ion Exchange Membrane Process \\
\hline 1969 & 1 & 0 \\
\hline 1970 & 1 & 0 \\
\hline 1971 & 5 & 0 \\
\hline 1972 & 3 & 0 \\
\hline 1973 & 5 & 0 \\
\hline 1974 & 4 & 0 \\
\hline 1975 & 3 & 0 \\
\hline 1976 & 6 & 0 \\
\hline 1977 & 7 & 0 \\
\hline 1978 & 5 & 0 \\
\hline 1979 & 8 & 2 \\
\hline 1980 & 6 & 1 \\
\hline
\end{tabular}




\begin{tabular}{|c|c|c|}
\hline 1981 & 0 & 4 \\
\hline 1982 & 2 & 0 \\
\hline 1983 & 1 & 3 \\
\hline 1984 & 1 & 1 \\
\hline 1985 & 2 & 3 \\
\hline 1986 & 0 & 0 \\
\hline 1987 & 0 & 0 \\
\hline 1988 & 1 & 2 \\
\hline 1989 & 0 & 1 \\
\hline 1990 & 1 & 0 \\
\hline 1991 & 0 & 0 \\
\hline 1992 & 1 & 0 \\
\hline 1993 & 0 & 0 \\
\hline 1994 & 0 & 0 \\
\hline 1995 & 1 & 0 \\
\hline 1996 & 0 & 0 \\
\hline 1997 & 0 & 0 \\
\hline Total & 512 & 136 \\
\hline
\end{tabular}

* US patents issued in the period from 1971 to 1999 .

Table 5-22 US Patents Successfully Applied for by Japanese Companies on Technologies Related to the Mercury Process and the Ion Exchange Membrane Process

\begin{tabular}{|c|c|c|}
\hline $\begin{array}{c}\text { Year of Patent } \\
\text { Application }\end{array}$ & Mercury Process & Ion Exchange Membrane Process \\
\hline 1968 & 1 & 0 \\
\hline 1969 & 1 & 0 \\
\hline 1970 & 0 & 0 \\
\hline 1971 & 1 & 0 \\
\hline 1972 & 2 & 0 \\
\hline 1973 & 1 & 0 \\
\hline 1974 & 1 & 1 \\
\hline 1975 & 0 & 3 \\
\hline 1976 & 0 & 6 \\
\hline 1977 & 1 & 5 \\
\hline 1978 & 0 & 14 \\
\hline 1979 & 0 & 7 \\
\hline 1980 & 0 & 9 \\
\hline 1981 & 0 & 5 \\
\hline 1982 & 0 & $\mathbb{1}$ \\
\hline 1983 & 0 & 5 \\
\hline 1984 & 0 & 8 \\
\hline 1985 & 0 & 1 \\
\hline 1986 & 0 & 0 \\
\hline
\end{tabular}




\begin{tabular}{|c|c|c|}
\hline 1987 & 0 & 0 \\
\hline 1988 & 0 & 1 \\
\hline 1989 & 0 & 2 \\
\hline 1990 & 0 & 1 \\
\hline 1991 & 0 & 2 \\
\hline 1992 & 0 & 0 \\
\hline 1993 & 0 & 1 \\
\hline 1994 & 0 & 1 \\
\hline 1995 & 0 & 1 \\
\hline 1996 & 0 & 0 \\
\hline 1997 & 0 & 0 \\
\hline 1998 & 0 & 0 \\
\hline Total & 64 & 0 \\
\hline
\end{tabular}

* US patents issued in 1971-1999.

Table 5-23 Mercury Emissions to Water, Products, and Air from Chlor-Alkali Plants in Western Europe

\begin{tabular}{|l|c|c|c|c|}
\hline Year & Water & Products & Air & Total \\
\hline 1977 & 9.4 & 5.5 & 11.7 & 26.6 \\
\hline 1978 & 4.6 & 2.7 & 8.8 & 16.1 \\
\hline 1979 & 4.5 & 2.6 & 7.6 & 14.7 \\
\hline 1980 & 4.6 & 2.3 & 7.3 & 14.2 \\
\hline 1981 & 2.9 & 2.1 & 6.8 & 11.8 \\
\hline 1982 & 2.9 & 1.9 & 6.0 & 10.8 \\
\hline 1983 & 2.6 & 2.1 & 5.3 & 10.0 \\
\hline 1984 & 2.5 & 1.7 & 4.9 & 9.1 \\
\hline 1985 & 2.2 & 1.6 & 4.3 & 8.1 \\
\hline 1986 & 1.9 & 1.5 & 4.6 & 8.0 \\
\hline 1987 & 1.4 & 1.4 & 4.6 & 7.4 \\
\hline 1988 & 0.9 & 1.2 & 3.8 & 5.9 \\
\hline 1989 & 0.8 & 1.0 & 3.3 & 5.1 \\
\hline 1990 & 0.6 & 0.8 & 2.7 & 4.1 \\
\hline 1991 & 0.7 & 0.8 & 2.8 & 4.3 \\
\hline 1992 & 0.5 & 0.7 & 2.4 & 3.6 \\
\hline 1993 & 0.3 & 0.5 & 2.0 & 2.8 \\
\hline 1994 & 0.2 & 0.4 & 1.9 & 2.5 \\
\hline 1995 & 0.2 & 0.4 & 2.1 & 2.7 \\
\hline 1996 & 0.1 & 0.2 & 1.7 & 2.0 \\
\hline 1997 & 0.1 & 0.1 & 1.2 & 1.5 \\
\hline
\end{tabular}

Figures are expressed in gram of mercury emitted per metric tonne of chlorine production capacity.

Source: Euro Chlor (1998c). 
Table 5-24 Mercury Emissions from Individual Chlor-Alkali Plants in Western Europe in 1999

\begin{tabular}{|c|c|c|c|c|}
\hline Plant & Products & Waste Water & Air & Total \\
\hline $\begin{array}{l}\text { Solvay } \\
\text { Lillo, Belgium }\end{array}$ & 0.050 & 0.020 & 0.680 & 0.750 \\
\hline $\begin{array}{l}\text { Tessenderlo } \\
\text { Tessenderlo, Belgium }\end{array}$ & 0.083 & 0.010 & 0.617 & 0.710 \\
\hline $\begin{array}{l}\text { BASF } \\
\text { Antwerpen, Belgium }\end{array}$ & 0.049 & 0.063 & 1.013 & 1.125 \\
\hline $\begin{array}{l}\text { Solvay } \\
\text { Jemeppe, Belgium }\end{array}$ & 0.050 & 0.280 & 1.780 & 2.110 \\
\hline $\begin{array}{l}\text { Eka Chenicals } \\
\text { Oulu, Finland }\end{array}$ & 0.127 & 0.125 & 1.322 & 1.574 \\
\hline $\begin{array}{l}\text { PC de Loos } \\
\text { Loos, France }\end{array}$ & 0.100 & 0.100 & 1.380 & 1.580 \\
\hline $\begin{array}{l}\text { Albemarle PPC } \\
\text { Thann, France }\end{array}$ & 0.102 & 0.090 & $\mathbb{1 . 6 0 0}$ & 1.792 \\
\hline $\begin{array}{l}\text { Solvay } \\
\text { Tavaux, France }\end{array}$ & 0.090 & 0.011 & 1.330 & 1.431 \\
\hline $\begin{array}{l}\text { Elf Atochem } \\
\text { Jarrie, France }\end{array}$ & 0.033 & 0.030 & 1.068 & 1.131 \\
\hline $\begin{array}{l}\text { SPC Harbonnières } \\
\text { Harbonnières, France }\end{array}$ & 0.320 & 0.001 & 1.123 & 1.444 \\
\hline $\begin{array}{l}\text { Elf Atochem } \\
\text { Lavera, France } \\
\end{array}$ & 0.043 & 0.130 & 0.971 & 1.144 \\
\hline $\begin{array}{l}\text { Elf Atochem } \\
\text { St Auban, France }\end{array}$ & 0.031 & 0.110 & 1.381 & 1.522 \\
\hline $\begin{array}{l}\text { ECI } \\
\text { Bitterfeld, Germany }\end{array}$ & 0.095 & 0.002 & 1.610 & 1.707 \\
\hline $\begin{array}{l}\text { Bayer } \\
\text { Uerdingen, Germany }\end{array}$ & 0.080 & 0.008 & 1.040 & 1.128 \\
\hline $\begin{array}{l}\text { ECI } \\
\text { Ibbenburen, Germany }\end{array}$ & 0.080 & 0.004 & 0.322 & 0.406 \\
\hline $\begin{array}{l}\text { Bayer } \\
\text { Leverkusen, Germany }\end{array}$ & 0.032 & 0.016 & 1.175 & 1.223 \\
\hline $\begin{array}{l}\text { BASF } \\
\text { Ludwigshafen, Gemany }\end{array}$ & 0.030 & 0.010 & 1.700 & 1.740 \\
\hline $\begin{array}{l}\text { ICI } \\
\text { Wilhelmshaven, Germany }\end{array}$ & 0.025 & 0.005 & 0.510 & 0.540 \\
\hline $\begin{array}{l}\text { Vestolit } \\
\text { Marl, Germany } \\
\end{array}$ & 0.060 & 0.010 & 1.670 & 1.740 \\
\hline $\begin{array}{l}\text { Hüls } \\
\text { Lillsdorf, Germany }\end{array}$ & 0.170 & 0.010 & 1.790 & 1.970 \\
\hline $\begin{array}{l}\text { Lill } \\
\text { Frankfurt, Germany }\end{array}$ & 0.063 & 0.012 & 0.995 & 1.070 \\
\hline Bayer & 0.036 & 0.000 & 1.540 & 1.576 \\
\hline
\end{tabular}




\begin{tabular}{|c|c|c|c|c|}
\hline Dormagen, Germany & & & & \\
\hline $\begin{array}{l}\text { Clariant } \\
\text { Gersthofen, Germany }\end{array}$ & 0.060 & 0.020 & 1.660 & 1.740 \\
\hline $\begin{array}{l}\text { Wacker Chemie } \\
\text { Burghausen, Germany }\end{array}$ & 0.080 & 0.003 & 0.760 & 0.843 \\
\hline $\begin{array}{l}\text { Celanese } \\
\text { Knapsack, Germany }\end{array}$ & 0.056 & 0.025 & 0.829 & 0.910 \\
\hline $\begin{array}{l}\text { Vinnolit } \\
\text { Gendorf, Germany }\end{array}$ & 0.040 & 0.020 & 1.330 & 1.390 \\
\hline $\begin{array}{l}\text { Akzo Nobel } \\
\text { Hengelo, Netherlands }\end{array}$ & 0.054 & 0.027 & 0.927 & 1.008 \\
\hline $\begin{array}{l}\text { Solvay } \\
\text { Linne-herten, Netherlands }\end{array}$ & 0.100 & 0.030 & 1.270 & 1.400 \\
\hline $\begin{array}{l}\text { Uniteca } \\
\text { Estarreja, Portugal }\end{array}$ & 0.500 & 0.300 & 1.900 & 2.700 \\
\hline $\begin{array}{l}\text { Quimica del Cinca } \\
\text { Monzon, Spain }\end{array}$ & 0.300 & 0.480 & 1.260 & 2.040 \\
\hline $\begin{array}{l}\text { Hernani } \\
\text { Hernani, Spain }\end{array}$ & 0.200 & 0.490 & 1.330 & 2.020 \\
\hline $\begin{array}{l}\text { Elnosa } \\
\text { Lourizan, Spain }\end{array}$ & 0.440 & 0.020 & 1.510 & 1.970 \\
\hline $\begin{array}{l}\text { Ercros } \\
\text { Flix, Spain }\end{array}$ & 0.330 & 0.130 & 1.450 & 1.910 \\
\hline $\begin{array}{l}\text { Solvay } \\
\text { Torrelavega, Spain }\end{array}$ & 0.762 & 0.055 & 1.442 & 2.259 \\
\hline $\begin{array}{l}\text { Solvay } \\
\text { Martorell, Spain }\end{array}$ & 0.070 & 0.050 & $0 . \overline{750}$ & 0.870 \\
\hline $\begin{array}{l}\text { Aragonesas } \\
\text { Sabinanigo, Spain }\end{array}$ & 0.400 & 0.300 & 1.400 & 2.100 \\
\hline $\begin{array}{l}\text { Aragonesas } \\
\text { Vilaseca, Spain }\end{array}$ & $0.110^{\prime}$ & 0.070 & 1.680 & 1.860 \\
\hline $\begin{array}{l}\text { Aragonesas } \\
\text { Huelva/Palos, Spain }\end{array}$ & 0.150 & 0.080 & 1.500 & 1.730 \\
\hline $\begin{array}{l}\text { Akzo Nobel } \\
\text { Bohus, Sweden }\end{array}$ & 0.012 & 0.006 & 0.250 & 0.268 \\
\hline $\begin{array}{l}\text { Hydro Polymers } \\
\text { Stenungsund, Sweden }\end{array}$ & 0.011 & 0.004 & 0.139 & 0.154 \\
\hline $\begin{array}{l}\text { Solvay } \\
\text { Zurzach, Switzerland }\end{array}$ & 0.040 & 0.080 & 1.370 & 1.490 \\
\hline $\begin{array}{l}\text { Novartis } \\
\text { Monthey, Switzerland }\end{array}$ & 0.022 & 0.007 & 0.848 & 0.877 \\
\hline $\begin{array}{l}\text { Säurefabrik } \\
\text { Pratteln, Switzerland }\end{array}$ & 0.140 & 0.050 & 0.370 & 0.560 \\
\hline $\begin{array}{l}\text { Rhodia } \\
\text { Staveley, UK }\end{array}$ & 0.050 & 0.005 & 0.470 & 0.525 \\
\hline Hays & 0.080 & 0.020 & 1.310 & 1.410 \\
\hline
\end{tabular}




\begin{tabular}{|l|c|c|c|c|}
\hline Sandbach, UK & & & \\
\hline $\begin{array}{l}\text { ICI } \\
\text { Runcorn, UK }\end{array}$ & 0.040 & 0.210 & 1.750 & 2.000 \\
\hline
\end{tabular}

* Figures are expressed in gram of mercury per tonne of chllorine production capacity.

* Denmark, Luxembourg, and Iceland have no chlor-alkali plants. Ireland and Norway have only mercury-free chlor-alkali plants. Austria, Greece, and Italy are not Contracting Parties to the OSPAR Convention and thus are not required to provide data on mercury emissions to the OSPAR Commission.

Sotrce: OSPAR Commission (2001).

Table 5-25 Chlor-Alkali Production Capacities based on the Mercury Process and the Non-Mercury Processes in Western Europe

\begin{tabular}{|c|c|c|c|}
\hline Year & Mercury Process & Non-Mercury Processes & Total \\
\hline 1982 & $5,137(72.6 \%)$ & $1,935(27.4 \%)$ & 7,072 \\
\hline 1983 & $5,060(71.1 \%)$ & $2,060(28.9 \%)$ & 7,120 \\
\hline 1984 & $5,079(67.0 \%)$ & $2,505(33.0 \%)$ & 7,584 \\
\hline 1985 & $5,076(66.9 \%)$ & $2,510(33.1 \%)$ & 7,586 \\
\hline 1986 & $5,094(67.0 \%)$ & $2,510(33.0 \%)$ & 7,603 \\
\hline 1987 & $5,097(67.0 \%)$ & $2,510(33.0 \%)$ & 7,607 \\
\hline 1988 & $5,012(66.4 \%)$ & $2,538(33.6 \%)$ & 7,550 \\
\hline 1989 & $4,883(66.6 \%)$ & $2,448(33.4 \%)$ & 7,331 \\
\hline 1990 & $4,810(65.8 \%)$ & $2,498(34.2 \%)$ & 7,308 \\
\hline 1991 & $5,036(68.3 \%)$ & $2,337(31.7 \%)$ & 7,372 \\
\hline 1992 & $4,788(65.8 \%)$ & $2,473(34.2 \%)$ & 7,281 \\
\hline 1993 & $4,468(63.6 \%)$ & $2,558(36.4 \%)$ & 7,026 \\
\hline 1994 & $4,438(63.8 \%)$ & $2,519(36.2 \%)$ & 6,957 \\
\hline 1995 & $4,480(62.2 \%)$ & $2,733(37.8 \%)$ & 7,214 \\
\hline 1996 & $4,481(62.1 \%)$ & $2,734(37.9 \%)$ & 7,215 \\
\hline 1997 & $4,486(62.0 \%)$ & $2,747(38.0 \%)$ & 7,233 \\
\hline
\end{tabular}

Figures are in thousand tonnes of chlorine per year.

a: Data for France and Spain are not included.

b: Data for Belgium, France, Spain and UK are not included.

c: For the Netherlands, the average of two figures for January and December 1983 is used.

Sowces:

1982-1995: Oslo and Paris Commissions (1997).

1996-97: OSPAR Commission (1999c).

Table 5-26 Installations of the Mercury and the Ion Exchange Membrane Processes by Western European Firms

\begin{tabular}{|c|c|c|}
\hline Year & Mercury Process & Ion Exchange Memabrane Process \\
\hline 1970 & 11 & 0 \\
\hline 1971 & 16 & 0 \\
\hline 1972 & 13 & 0 \\
\hline
\end{tabular}




\begin{tabular}{|c|c|c|}
\hline 1973 & 7 & 0 \\
\hline 1974 & 9 & 0 \\
\hline 1975 & 15 & 0 \\
\hline 1976 & 15 & 0 \\
\hline 1977 & 11 & 0 \\
\hline 1978 & 2 & 0 \\
\hline 1979 & 7 & 0 \\
\hline 1980 & 5 & 0 \\
\hline 1981 & 7 & 0 \\
\hline 1982 & 1 & 0 \\
\hline 1983 & 5 & 3 \\
\hline 1984 & 0 & 5 \\
\hline 1985 & 1 & 4 \\
\hline 1986 & 0 & 2 \\
\hline 1987 & 3 & 5 \\
\hline 1988 & 2 & 5 \\
\hline 1989 & 1 & 9 \\
\hline 1990 & 2 & 7 \\
\hline 1991 & 3 & 8 \\
\hline 1992 & 0 & 9 \\
\hline 1993 & 1 & 3 \\
\hline 1994 & 1 & 13 \\
\hline 1995 & 0 & 10 \\
\hline 1996 & 0 & 12 \\
\hline 1997 & 0 & 12 \\
\hline 1998 & 0 & 14 \\
\hline Total & 0 & 0 \\
\hline
\end{tabular}

Calculation based on Chlorine Institute (1998a; 1998b), Imperial Chemical Industries (1999), Krupp-Uhde (1998), and De Nora (1999).

Table 5-27 Supply of the Ion Exchange Membrane Process by Iapanese and Western European Firms

\begin{tabular}{|c|c|c|}
\hline Year & Japanese Firms & Western European Firms \\
\hline 1975 & 40,000 & 0 \\
\hline 1976 & 101,000 & 0 \\
\hline 1977 & 181,000 & 0 \\
\hline 1978 & 191,000 & 0 \\
\hline 1979 & 201,000 & 0 \\
\hline 1980 & 220,640 & 0 \\
\hline 1981 & 250,455 & 0 \\
\hline 1982 & 411,095 & 0 \\
\hline 1983 & $1,279,645$ & 61,016 \\
\hline 1984 & $1,790,948$ & 214,016 \\
\hline
\end{tabular}




\begin{tabular}{|l|l|l|}
\hline 1985 & $2,403,497$ & 342,366 \\
\hline 1986 & $3,146,171$ & 431,890 \\
\hline 1987 & $3,730,937$ & 517,954 \\
\hline 1988 & $4,074,327$ & 579,254 \\
\hline 1989 & $4,833,022$ & 995,606 \\
\hline 1990 & $5,283,361$ & $1,263,712$ \\
\hline 1991 & $5,796,600$ & $1,379,600$ \\
\hline 1992 & $5,989,735$ & $1,788,704$ \\
\hline 1993 & $6,774,759$ & $1,889,772$ \\
\hline 1994 & $7,035,383$ & $2,489,118$ \\
\hline 1995 & $7,334,650$ & $2,776,286$ \\
\hline 1996 & $8,111,690$ & $3,714,946$ \\
\hline 1997 & $9,066,993$ & $4,681,326$ \\
\hline 1998 & $11,379,070$ & $5,418,756$ \\
\hline 1999 & $13,241,560$ & $6,133,156$ \\
\hline
\end{tabular}

Figures are cumulative production capacities ( $\mathrm{t} \mathrm{NaOH} /$ year).

Calculation based on Table 4-27, Table 4-28. Table 4-29. Table 4-31. Table 4-32. Table 4-33, Table 5-28, Table 5-29, and Table 5-30.

Table 5-28 Supply List of the Ion Exchange Membrane Process by ICI

\begin{tabular}{|l|c|c|}
\hline \multicolumn{1}{|c|}{ Plant Site } & Start-up & $\begin{array}{c}\text { Capacily } \\
(\mathrm{t} \mathrm{NaOH} / \mathrm{y})\end{array}$ \\
\hline $\begin{array}{l}\text { Akzo Nobel } \\
\text { Sweden }\end{array}$ & $1983 / 85 / 89$ & 81,000 \\
\hline $\begin{array}{l}\text { Nippon Soda } \\
\text { Japan }\end{array}$ & 1984 & 920 \\
\hline $\begin{array}{l}\text { Elkem Bremanger } \\
\text { Norway }\end{array}$ & 1984 & 12,000 \\
\hline $\begin{array}{l}\text { CCM } \\
\text { Malaysia }\end{array}$ & $1984 / 92$ & 34,000 \\
\hline $\begin{array}{l}\text { Finnish Chemicals } \\
\text { Finland }\end{array}$ & 1984 & 89,000 \\
\hline $\begin{array}{l}\text { Tessenderlo } \\
\text { Belgium }\end{array}$ & 1985 & 300 \\
\hline $\begin{array}{l}\text { Fort James } \\
\text { USA }\end{array}$ & 1985 & 4,750 \\
\hline $\begin{array}{l}\text { Procter \& Gamble } \\
\text { Green Bay, USA }\end{array}$ & 1985 & $5,100)$ \\
\hline $\begin{array}{l}\text { Mondi } \\
\text { South Africa }\end{array}$ & 1985 & 22,500 \\
\hline $\begin{array}{l}\text { Elf Atochem Tacoma } \\
\text { USA }\end{array}$ & 1985 & 91,000 \\
\hline $\begin{array}{l}\text { ICI Lostock } \\
\text { Uk }\end{array}$ & 1986 & 18,000 \\
\hline Wesfarmers CSBP & & 6,000 \\
\hline
\end{tabular}




\begin{tabular}{|c|c|c|}
\hline Australia & & \\
\hline $\begin{array}{l}\text { Sabah Forest Industries } \\
\text { Malaysia }\end{array}$ & 1987 & 10,300 \\
\hline $\begin{array}{l}\text { Australian Paper } \\
\text { Australia }\end{array}$ & 1988 & 7,700 \\
\hline $\begin{array}{l}\text { Fort James } \\
\text { USA }\end{array}$ & 1989 & 5,100 \\
\hline $\begin{array}{l}\text { Prodesal } \\
\text { Colombia } \\
\end{array}$ & $1989 / 93$ & 22,000 \\
\hline $\begin{array}{l}\text { China General Plastics } \\
\text { Taiwan }\end{array}$ & 1989 & 35,000 \\
\hline $\begin{array}{l}\text { ICI Runcom } \\
\text { UK }\end{array}$ & 1989 & $\begin{array}{l}37,500 \\
(\mathrm{KOH}) \\
\end{array}$ \\
\hline $\begin{array}{l}\text { Orica } \\
\text { Australia } \\
\end{array}$ & $1990 / 98$ & 10,200 \\
\hline $\begin{array}{l}\text { Elf Atochem Portland } \\
\text { USA }\end{array}$ & 1990 & 40,000 \\
\hline $\begin{array}{l}\text { PPG } \\
\text { Canada }\end{array}$ & 1990 & 84,000 \\
\hline $\begin{array}{l}\text { Confidential } \\
\text { USA } \\
\end{array}$ & 1991 & 2,000 \\
\hline $\begin{array}{l}\text { Ansa McAl Ltd. } \\
\text { Trinidad }\end{array}$ & 1991 & 2,500 \\
\hline $\begin{array}{l}\text { Yibin Tian Yuan } \\
\text { China }\end{array}$ & 1991 & 12,000 \\
\hline $\begin{array}{l}\text { ACC } \\
\text { Saudi Arabia } \\
\end{array}$ & $1991 / 98$ & 16,500 \\
\hline $\begin{array}{l}\text { Dong Jin } \\
\text { South Korea }\end{array}$ & 1992 & 8,000 \\
\hline $\begin{array}{l}\text { Ak-Kim } \\
\text { Turkey }\end{array}$ & $1992 / 93 / 95 / 99$ & 41,000 \\
\hline $\begin{array}{l}\text { Associated Octel } \\
\text { UK }\end{array}$ & 1992 & 48,000 \\
\hline $\begin{array}{l}\text { TFI } \\
\text { Thailand }\end{array}$ & $1993 / 94$ & 14,300 \\
\hline $\begin{array}{l}\text { Jiang Han } \\
\text { China }\end{array}$ & $1994 / 96$ & 37,000 \\
\hline $\begin{array}{l}\text { Phoenix Pulp \& Paper } \\
\text { Thailand }\end{array}$ & 1994 & 11,000 \\
\hline $\begin{array}{l}\text { RIAU } \\
\text { Indonesia }\end{array}$ & 1995 & 43,500 \\
\hline $\begin{array}{l}\text { Shandong Pesticide } \\
\text { China }\end{array}$ & 1996 & 30,000 \\
\hline $\begin{array}{l}\text { Pioneer } \\
\text { Canada } \\
\end{array}$ & 1997 & 60,000 \\
\hline Confidential & 1997 & 14,000 \\
\hline
\end{tabular}




\begin{tabular}{|l|c|c|}
\hline Indonesia & & \\
\hline $\begin{array}{l}\text { Ya'an Pulp \& Paper } \\
\text { China }\end{array}$ & 1998 & 4,000 \\
\hline $\begin{array}{l}\text { Confidential } \\
\text { Iran }\end{array}$ & 1998 & 950 \\
\hline $\begin{array}{l}\text { Shandong Ganglu } \\
\text { China }\end{array}$ & 1998 & 30,000 \\
\hline $\begin{array}{l}\text { Confidential } \\
\text { North America }\end{array}$ & 1998 & 20,000 \\
\hline $\begin{array}{l}\text { Shriram } \\
\text { India }\end{array}$ & 1998 & 91,000 \\
\hline \multicolumn{1}{|c|}{ Total } & - & $8,823,810$ \\
\hline
\end{tabular}

Test plants and pilot plants are excluded from the table.

Source: Imperial Chemical Industries (1999).

Table 5-29 Supply List of the Ion Exchange Membrane Process by Uhde

\begin{tabular}{|l|c|c|}
\hline \multicolumn{1}{|c|}{ Plant Site } & Start-up & \multicolumn{1}{c|}{$\begin{array}{c}\text { Capacity } \\
\text { (t NaOH/y) }\end{array}$} \\
\hline $\begin{array}{l}\text { Roche Products } \\
\text { Dalry, UK }\end{array}$ & $1984 / 89 / 91$ & 24,000 \\
\cline { 3 - 3 } & & 1,800 \\
\hline $\begin{array}{l}\text { Tofte Industries } \\
\text { Norway }\end{array}$ & $1984 / 87$ & $+7 \%$ \\
\hline $\begin{array}{l}\text { Potasse et Produits Chimiques } \\
\text { France }\end{array}$ & 1984 & $+10 \%$ \\
\hline $\begin{array}{l}\text { P. N. Kertas Letjes } \\
\text { Indonesia }\end{array}$ & 1986 & $\begin{array}{c}700 \\
(\mathrm{KOH})\end{array}$ \\
\hline $\begin{array}{l}\text { General Electric Plastics } \\
\text { The Netherlands }\end{array}$ & $1987 / 90 / 94$ & 2,500 \\
\cline { 3 - 3 } & & Confidential \\
\hline $\begin{array}{l}\text { Bela Chemical Industries } \\
\text { Pakistan }\end{array}$ & 1988 & $+30 \%$ \\
\hline $\begin{array}{l}\text { Hoechst } \\
\text { Germany }\end{array}$ & 1988 & 5,950 \\
\hline $\begin{array}{l}\text { AECl Limited/POLIFIN } \\
\text { South Africa }\end{array}$ & 16,000 \\
\hline $\begin{array}{l}\text { Gujarat Alkalies and Chemicals I } \\
\text { India }\end{array}$ & 1989 & 12,500 \\
\hline $\begin{array}{l}\text { Gujarat Alkalies and Chemicals II } \\
\text { India }\end{array}$ & 1994 & 23,000 \\
\hline $\begin{array}{l}\text { Formosa Plastics } \\
\text { Taiwan }\end{array}$ & $1989 / 94$ & 70,000 \\
\hline $\begin{array}{l}\text { Bayer } \\
\text { Leverkusen, Germany }\end{array}$ & 1989 & $\begin{array}{l}17,500 \\
(\mathrm{KOH})\end{array}$ \\
\hline
\end{tabular}




\begin{tabular}{|c|c|c|}
\hline $\begin{array}{l}\text { Paik Kwang Corp. } \\
\text { Seoul, South Korea }\end{array}$ & 1989 & 12,600 \\
\hline $\begin{array}{l}\text { Ministry of Industry and Minerals } \\
\text { Faluja, Iraq }\end{array}$ & 1990 & 11,800 \\
\hline $\begin{array}{l}\text { Cellulose Attisholz } \\
\text { Switzerland }\end{array}$ & 1990 & 9,500 \\
\hline \multirow{3}{*}{$\begin{array}{l}\text { Paik Kwang Corp. I } \\
\text { Kunsan, South Korea }\end{array}$} & \multirow[t]{3}{*}{$1990 / 93 / 95$} & 17,800 \\
\hline & & 17,800 \\
\hline & & 17,800 \\
\hline $\begin{array}{l}\text { Aracruz Celulose } \\
\text { Brazil }\end{array}$ & 1991 & 36,400 \\
\hline $\begin{array}{l}\text { Riocell } \\
\text { Brazil }\end{array}$ & 1992 & 19,600 \\
\hline \multirow{2}{*}{$\begin{array}{l}\text { Standard Alkali } \\
\text { India }\end{array}$} & 1992 & 68,200 \\
\hline & 1995 & 5,700 \\
\hline \multirow{2}{*}{$\begin{array}{l}\text { EIASA/Aragonesas } \\
\text { Spain }\end{array}$} & \multirow[t]{2}{*}{$1992 / 97$} & 35,000 \\
\hline & & 10,600 \\
\hline $\begin{array}{l}\text { Compania Manufacturera de Papeles } \\
\text { y Cartones, Chile }\end{array}$ & 1992 & 15,000 \\
\hline $\begin{array}{l}\text { CQR Salgema } \\
\text { Brazil }\end{array}$ & 1994 & 275,000 \\
\hline \multirow{2}{*}{$\begin{array}{l}\text { Grasim Industries I } \\
\text { India }\end{array}$} & \multirow[t]{2}{*}{$1994 / 95$} & 91,000 \\
\hline & & 11,800 \\
\hline \multirow{2}{*}{$\begin{array}{l}\text { Chemfab Alkalies } \\
\text { India }\end{array}$} & \multirow[t]{2}{*}{$1994 / 97$} & 10,000 \\
\hline & & 10,000 \\
\hline $\begin{array}{l}\text { Quimica del Norte/CLOROX } \\
\text { Argentina. }\end{array}$ & 1994 & 15,000 \\
\hline $\begin{array}{l}\text { Hanwha Chemical Corp. } \\
\text { Yeochun, South Korea }\end{array}$ & 1995 & 60,000 \\
\hline $\begin{array}{l}\text { National Chlorine Industries } \\
\text { Jordan }\end{array}$ & 1995 & 7,200 \\
\hline $\begin{array}{l}\text { Punjab Alkalies Chemicals } \\
\text { India }\end{array}$ & 1995 & 36,000 \\
\hline $\begin{array}{l}\text { Chimcomplex S.A. Borzesti } \\
\text { Romania }\end{array}$ & 1996 & 122,000 \\
\hline $\begin{array}{l}\text { Saudi Petrochemical Company } \\
\text { Saudi Arabia }\end{array}$ & 1996 & 250,000 \\
\hline $\begin{array}{l}\text { United Phosphorus I } \\
\text { India }\end{array}$ & 1996 & 20,000 \\
\hline $\begin{array}{l}\text { Misr Chemical Industries } \\
\text { Egypt }\end{array}$ & 1996 & 59,500 \\
\hline $\begin{array}{l}\text { United Phosphorus II } \\
\text { India }\end{array}$ & 1996 & 35,000 \\
\hline $\begin{array}{l}\text { S. C. Chimcomplex S.A. Borzesti } \\
\text { Romania }\end{array}$ & 1996 & 122,000 \\
\hline
\end{tabular}




\begin{tabular}{|l|c|c|}
\hline $\begin{array}{l}\text { Indian Petrochemicals } \\
\text { India }\end{array}$ & 1997 & 148,000 \\
\hline $\begin{array}{l}\text { La Société National de Cellulose et de } \\
\text { Papier Alfa, Tunisia }\end{array}$ & 1997 & 7,500 \\
\hline $\begin{array}{l}\text { Indian Rayon } \\
\text { India }\end{array}$ & 1997 & 35,000 \\
\hline $\begin{array}{l}\text { Gujarat Alkalies and Chemicals } \\
\text { India }\end{array}$ & 1997 & 105,000 \\
\hline $\begin{array}{l}\text { Kothari Sugars and Chemicals Ltd. } \\
\text { India }\end{array}$ & 1997 & 20,000 \\
\hline $\begin{array}{l}\text { Olin Corporation } \\
\text { USA }\end{array}$ & 1997 & 255,700 \\
\hline $\begin{array}{l}\text { Bayer } \\
\text { Uerdingen, Germany }\end{array}$ & 1997 & 125,000 \\
\hline $\begin{array}{l}\text { Polifin } \\
\text { South Africa }\end{array}$ & 1997 & 36,700 \\
\hline $\begin{array}{l}\text { Ravi Chemicals } \\
\text { Pakistan }\end{array}$ & 1998 & 10,000 \\
\hline $\begin{array}{l}\text { Oltchim } \\
\text { Romania }\end{array}$ & 1998 & 122,000 \\
\hline $\begin{array}{l}\text { Hanwa Chemical } \\
\text { South Korea }\end{array}$ & 1998 & 140,000 \\
\hline $\begin{array}{l}\text { Punjab Alkallies Chemicals II } \\
\text { India }\end{array}$ & 1998 & 70,000 \\
\hline $\begin{array}{l}\text { Micro Bio } \\
\text { Ireland }\end{array}$ & - & $23,819,340$ \\
\hline & & \\
\hline
\end{tabular}

Test plants and pilot plants are excluded from the table.

Source: Krupp Uhde (1998).

Table 5-30 Supply List of the Ion Exchange Membrane Process by De Nora

\begin{tabular}{|l|c|c|}
\hline \multicolumn{1}{|c|}{ Plant Site } & Start-up & \multicolumn{1}{c|}{$\begin{array}{c}\text { Capacity } \\
(\mathrm{t} \mathrm{Cl} / \mathrm{y})\end{array}$} \\
\hline $\begin{array}{l}\text { P.T. Kertas Letjes } \\
\text { Probolinggo, Indonesia }\end{array}$ & 1983 & 6,600 \\
\hline $\begin{array}{l}\text { Basic Chemical Industries } \\
\text { Dammam, Saudi Arabia }\end{array}$ & 1983 & 7,700 \\
\hline $\begin{array}{l}\text { EniChem Polimeri } \\
\text { Cagliari, Italy }\end{array}$ & $1986 / 90$ & 77,700 \\
\hline $\begin{array}{l}\text { Sree Rayalaseema } \\
\text { Andhra Pradesh } \\
\text { India }\end{array}$ & $1987 / 89 / 96$ & 73,130 \\
\hline $\begin{array}{l}\text { EiASA } \\
\text { Sabinanigo, Spain }\end{array}$ & & 22,200 \\
\cline { 2 - 3 } & & 8,800 \\
\hline
\end{tabular}




\begin{tabular}{|c|c|c|}
\hline $\begin{array}{l}\text { Sitara Chemical Industries } \\
\text { Faisalabad, Pakistan }\end{array}$ & 1989 & 13,300 \\
\hline $\begin{array}{l}\text { Ballarpur Ind: } \\
\text { Ballarpur, India }\end{array}$ & $\begin{array}{r}1991 \\
\quad \\
\end{array}$ & 13,300 \\
\hline $\begin{array}{l}\text { Ballarpur Ind. } \\
\text { Yamunanagar, India }\end{array}$ & 1991 & 13,300 \\
\hline \multirow{2}{*}{$\begin{array}{l}\text { Malay-Sino Chemicals } \\
\text { Ipoh, Malaysia }\end{array}$} & \multirow[t]{2}{*}{$1991 / 96$} & 13,300 \\
\hline & & 15,000 \\
\hline $\begin{array}{l}\text { Century Rayon } \\
\text { Kallyan, India. }\end{array}$ & 1992 & 14,200 \\
\hline $\begin{array}{l}\text { Atochen } \\
\text { Fos-sur-Mer, France }\end{array}$ & 1992 & 120,000 \\
\hline $\begin{array}{l}\text { Sitara Chemical Industries } \\
\text { Faisalabad, Pakistan }\end{array}$ & 1993 & 42,200 \\
\hline $\begin{array}{l}\text { Basic Chemical Industries } \\
\text { Dammam, Saudi Arabia }\end{array}$ & 1993 & 10,650 \\
\hline $\begin{array}{l}\text { National Rayon } \\
\text { Mohone, India }\end{array}$ & 1994 & 24,800 \\
\hline $\begin{array}{l}\text { Novel \& Shenyang Chemical Plant } \\
\text { Shenyang, China }\end{array}$ & 1994 & 50,000 \\
\hline $\begin{array}{l}\text { Sree Rayalaseema } \\
\text { Andhra Pradesh, India }\end{array}$ & 1994 & 17,000 \\
\hline $\begin{array}{l}\text { Chloran Chemical Production } \\
\text { Semnan, Iran }\end{array}$ & 1994 & 3,500 \\
\hline $\begin{array}{l}\text { Tecnimont } \\
\text { Moshi, Tanzania }\end{array}$ & 1994 & 3,500 \\
\hline $\begin{array}{l}\text { Elf Atochem Colombia } \\
\text { Santafe, Colombia }\end{array}$ & 1994 & 2,000 \\
\hline $\begin{array}{l}\text { Chlor-Pars } \\
\text { Tabriz, Iran }\end{array}$ & 1995 & 6,700 \\
\hline $\begin{array}{l}\text { Nirouchlor } \\
\text { Isfahan, Iran }\end{array}$ & 1.995 & 6,700 \\
\hline \multirow{2}{*}{$\begin{array}{l}\text { Hangzhou Electiochem. Factory } \\
\text { Hangzhou, China }\end{array}$} & \multirow[t]{2}{*}{$1995 / 97$} & 12,000 \\
\hline & & 8,000 \\
\hline $\begin{array}{l}\text { TKI Hrastnik } \\
\text { Hrastnik, Slovenia }\end{array}$ & 1995 & 13,500 \\
\hline $\begin{array}{l}\text { Tata Chemicals } \\
\text { Mithapur, India } \\
\end{array}$ & 1995 & 35,000 \\
\hline $\begin{array}{l}\text { Siping Chemical Complex } \\
\text { Siping, China }\end{array}$ & 1995 & 20,000 \\
\hline $\begin{array}{l}\text { South Vietnam Basic Chemical } \\
\text { Bien Hoa, Vietnam }\end{array}$ & 1996 & 2,000 \\
\hline $\begin{array}{l}\text { Qingdao Chemical Works } \\
\text { Qingdao, China }\end{array}$ & 1996 & 60,000 \\
\hline \multirow{2}{*}{$\begin{array}{l}\text { Beijing No. } 2 \text { Chemical Works } \\
\text { Beijing, China }\end{array}$} & \multirow[t]{2}{*}{$1996 / 97$} & 40,000 \\
\hline & & 80,000 \\
\hline
\end{tabular}




\begin{tabular}{|l|c|c|}
\hline Confidential & & 10,000 \\
\hline $\begin{array}{l}\text { Mardia Chemicals } \\
\text { Gujarat, India }\end{array}$ & 1996 & 105,000 \\
\hline $\begin{array}{l}\text { The Andina Sugars } \\
\text { Kovwur, India }\end{array}$ & 1996 & 30,000 \\
\hline $\begin{array}{l}\text { Taiko Occidental Chem. } \\
\text { Kemaman, Malaysia }\end{array}$ & 1997 & 20,000 \\
\hline $\begin{array}{l}\text { S.N.F,P. } \\
\text { Mohammedia, Morocco }\end{array}$ & 1997 & 16,000 \\
\hline $\begin{array}{l}\text { Chemical Industries } \\
\text { Singapore }\end{array}$ & 1998 & 20,000 \\
\hline $\begin{array}{l}\text { Qilu Petrochemical Corporation } \\
\text { Qilu, China }\end{array}$ & 1998 & 50,000 \\
\hline $\begin{array}{l}\text { P.T. Pindo Deli Pulp \& Paper Mill } \\
\text { Indonesia }\end{array}$ & 1998 & 45,000 \\
\hline \multicolumn{1}{c|}{ Total } & - & 935,950 \\
\hline
\end{tabular}

Somce: De Nora (1999).

Table 5-31 Number of Cell Elements of Electrolyzers

\begin{tabular}{|l|c|c|c|c|c|}
\hline Company & Astahi Chemical & Asahi Glass & CEC & De Nora & Krupp Uhde \\
\hline Cell type & ML 32 & AZEC-B1 & BiTAC 800 & DN 350 & BM 2.7 \\
\hline $\begin{array}{l}\text { Max. No. of } \\
\text { cell elements }\end{array}$ & 150 & 80 & 80 & 90 & 160 \\
\hline
\end{tabular}

* bipolar electrolyzers

Source: Luke (2000).

Table 5-32 Cost Saving from the Conversion of the Mercury Process to the Ion Exchange Membrane Process in Western Europe

\begin{tabular}{|c|c|c|c|}
\hline Year & $\begin{array}{c}\text { Energy Savings } \\
(\mathrm{kWh} / \mathrm{NaOH})\end{array}$ & $\begin{array}{c}\text { Electricity Price } \\
\text { (US } \$ / \mathrm{kWh})\end{array}$ & $\begin{array}{c}\text { Cost Saving } \\
\text { US } \$ / \mathrm{t} \text { NaOH })\end{array}$ \\
\hline 1970 & $-1,250$ & 0.039 & -49 \\
\hline 1971 & $-1,150$ & 0.039 & -45 \\
\hline 1972 & $-1,050$ & 0.039 & -41 \\
\hline 1973 & -950 & 0.039 & -37 \\
\hline 1974 & -850 & 0.039 & -33 \\
\hline 1975 & -750 & 0.039 & -29 \\
\hline 1976 & 50 & 0.039 & 2 \\
\hline 1977 & 130 & 0.039 & 5 \\
\hline 1978 & 180 & 0.039 & 7 \\
\hline 1979 & 250 & 0.046 & 12 \\
\hline 1980 & 480 & 0.053 & 25 \\
\hline 1981 & 700 & 0.051 & 36 \\
\hline
\end{tabular}




\begin{tabular}{|c|c|c|c|}
\hline 1982 & 700 & 0.049 & 34 \\
\hline 1983 & 700 & 0.046 & 32 \\
\hline 1984 & 800 & 0.043 & 34 \\
\hline 1985 & 800 & 0.041 & 33 \\
\hline 1986 & 800 & 0.055 & 44 \\
\hline 1987 & 800 & 0.063 & 50 \\
\hline 1988 & 800 & 0.065 & 52 \\
\hline 1989 & 800 & 0.061 & 49 \\
\hline 1990 & 800 & 0.076 & 61 \\
\hline 1991 & 800 & 0.078 & 62 \\
\hline 1992 & 800 & 0.075 & 60 \\
\hline 1993 & 800 & 0.072 & 58 \\
\hline 1994 & 800 & 0.071 & 57 \\
\hline 1995 & 800 & 0.077 & 62 \\
\hline 1996 & 800 & 0.074 & 59 \\
\hline 1997 & 800 & 0.065 & 52 \\
\hline
\end{tabular}

The improvement in the energy consumption from 1970 to 1975 is assumed to be linear.

Source:

Electricity price: International Energy Agency (1992; 1993; 1999). For 1970 10 1977, the price of 1978; for 1979, the average of the prices of 1978 and 1980; for 1981 the average of the prices of 1980 and 1982; for 1983, the average of the prices of 1982 and 1984; for 1992, the average of the prices of 1991 and 1993.

Table 5-33 Start-up Year of the Mercury Process and the Ion Exchange Membrane Process in Western Europe

\begin{tabular}{|c|l|c|c|c|}
\hline $\begin{array}{c}\text { Plant } \\
\#^{\mathrm{a}}\end{array}$ & \multicolumn{1}{|c|}{ Plant Site } & $\begin{array}{c}\text { Start-up Year } \\
\text { of Mercury } \\
\text { Process }\end{array}$ & $\begin{array}{c}\text { Start-up Year of } \\
\text { Ion Exchange } \\
\text { Membrane Process }\end{array}$ & $\begin{array}{c}\text { Operating Years } \\
\text { of Mercury } \\
\text { Process }\end{array}$ \\
\hline- & $\begin{array}{l}\text { Akzo Nobel } \\
\text { Botlek, Netherlands }\end{array}$ & - & $1983^{\mathrm{b}}$ & - \\
\hline 1 & $\begin{array}{l}\text { Akzo Nobel } \\
\text { Skoghall, Sweden }\end{array}$ & 1918 & 1983 & 65 \\
\hline- & $\begin{array}{l}\text { Elkem Bremanger } \\
\text { Svelgen, Norway }\end{array}$ & - & $1984^{\mathrm{b}}$ & - \\
\hline- & $\begin{array}{l}\text { Tofte Industries } \\
\text { Tofte, Norway }\end{array}$ & - & $1984^{\mathrm{b}}$ & - \\
\hline- & $\begin{array}{l}\text { Finnish Chemicals } \\
\text { Joutseno, Finland }\end{array}$ & - & $1984^{\mathrm{b}}$ & - \\
\hline- & $\begin{array}{l}\text { Micro-Bio } \\
\text { Fermoy, Ireland }\end{array}$ & - & $1984^{\mathrm{h}}$ & - \\
\hline- & $\begin{array}{l}\text { General Electric Plastics } \\
\text { Bergen op Zoom, NL }\end{array}$ & - & $1987^{\mathrm{b}}$ & - \\
\hline 2 & $\begin{array}{l}\text { ICI (KOH) } \\
\text { Runcorn, UK }\end{array}$ & 1930 & 1989 & 59 \\
\hline
\end{tabular}




\begin{tabular}{|c|c|c|c|c|}
\hline 3 & $\begin{array}{l}\text { Solvay } \\
\text { Povoa, Portugal }\end{array}$ & 1938 & 1990 & 52 \\
\hline 4 & $\begin{array}{l}\text { Solvay } \\
\text { Tavaux, france }\end{array}$ & 1930 & 1991 & 61 \\
\hline 5 & $\begin{array}{l}\text { Associated Octel } \\
\text { Ellesmere Port } \text { UK }\end{array}$ & 1956 & 1992 & 36 \\
\hline 6 & $\begin{array}{l}\text { Solvay } \\
\text { Jemeppe, Belgrum }\end{array}$ & 1951 & 1992 & 41 \\
\hline 7 & $\begin{array}{l}\text { Uniteca } \\
\text { Estarreja, Portugal }\end{array}$ & 1944 & 1992 & 48 \\
\hline 8 & $\begin{array}{l}\text { EIASA/Aragonersas } \\
\text { Villaseca, Spain }\end{array}$ & 1951 & 1992 & 41 \\
\hline 9 & $\begin{array}{l}\text { Bayer } \\
\text { Uerdingen, Germany }\end{array}$ & 1955 & 1997 & 42 \\
\hline 10 & $\begin{array}{l}\text { Bayer } \\
\text { Dormagen, Germany }\end{array}$ & 1966 & 1999 & 33 \\
\hline 11 & $\begin{array}{l}\text { Donau Chemia } \\
\text { Brifckl, Austria }\end{array}$ & 1943 & 1999 & 56 \\
\hline 12 & $\begin{array}{l}\text { ECI } \\
\text { Bitterfeld, Germany }\end{array}$ & 1936 & 1999 & 63 \\
\hline 13 & $\begin{array}{l}\text { Vestolit } \\
\text { Marl, Germany } \\
\end{array}$ & 1939 & 1999 & 60 \\
\hline 14 & $\begin{array}{l}\text { Clariant } \\
\text { Gersthofen, Germany }\end{array}$ & 1940 & 2000 & 60 \\
\hline 15 & $\begin{array}{l}\text { Wacker } \\
\text { Burghausen, Germany }\end{array}$ & 1944 & 2000 & 56 \\
\hline- & Average & - & - & 991 \\
\hline
\end{tabular}

a: Plant in Figure 5-10.

b: Newly constructed plant based on the ion exchange membrane process.

Sounces:

Year of the set-up of the mencury process:

Akzo Nobal, Botlek: Sraasheijm (1999). Akzo Nobel, Skoghall: Cederhund (1999). Elkem Bremanger, Svelgen: Bosterud (2000). Tofte Industries, Tofte: Thun (1999). Finnish Chemicals, Joutseno: Cowell and Jackson (1986). Micro-Bio, Fermoy: O'Brien (2001). General Electric Plastics, Bergen op Zoom: Vos (1999). ICl, Runcorn: Ingleby, Cury, and Broom (1999). Solway, Povoa: Chlorine Institute (1972). Solvay, Tavaux. Chlorine Institute (1972). Solvay, Jemeppe: Chlorine Institute (1997). Uniteca, Estarreja: Chlorine Institute (1972). ElASA/Aragonesas, Villaseca: Grupo Aragonesas (1999). Associated Octel. Elleswere Port: Lott (1995). Borregaard Industries, Sarpsborg: De Flon (1998). Bayer, Uerdingen: Schubert (1999). Bayer. Dormagen: Schubert (1999). Donau Chemie, Brinckl: Donaw Chemie (2000). ECI, Bitterfeld: Herold (2000). Vestolit, Marl: Chlorine Instifute (1972). Clanian, Gersthofen: Teufel (2000). Wacker, Burghausen: Chlorine Institute (1972).

Year of the comersion to the ion exchange membrane process:

Asahi Chemical Industry (1998), Asahi Glass (1999), Chlorine Engineer Corp. (2000), Krupp-Uhde (1998), Imperial Chemical Industries (1999), De Nora (1999), and Eltech Sysrems (2001). 
Table 5-34 Operating Years of the Existing Chlor-Alkali Plants based on the Mercury Process in Western Europe

\begin{tabular}{|c|c|c|c|}
\hline Plant & Plant Site & $\begin{array}{l}\text { Year of Start-up of } \\
\text { Mercury Process } \\
\end{array}$ & Operating Years \\
\hline 1 & $\begin{array}{l}\text { Electroq. de Hernani } \\
\text { Hernani, Spain } \\
\end{array}$ & 1949 & 51 \\
\hline 2 & $\begin{array}{l}\text { Solvay } \\
\text { Zurzach, Switzerland }\end{array}$ & 1949 & $5 \pi$ \\
\hline 3 & \begin{tabular}{|l|} 
Hüls \\
Luillsdorf, Germany \\
\end{tabular} & 1950 & 50 \\
\hline 4 & $\begin{array}{l}\text { Hays } \\
\text { Sandbach, UK }\end{array}$ & 1956 & 44 \\
\hline 5 & $\begin{array}{l}\text { Akzo Nobel } \\
\text { Oulu, Finland } \\
\end{array}$ & 1957 & $\overline{43}$ \\
\hline 6 & $\begin{array}{l}\text { Solvay } \\
\text { Rosignano, Italy } \\
\end{array}$ & 1957 & 43 \\
\hline 7 & $\begin{array}{l}\text { BASF } \\
\text { Ludwigshafen, Germany }\end{array}$ & 1958 & 42 \\
\hline 8 & $\begin{array}{l}\text { Solvay } \\
\text { Tavaux, France }\end{array}$ & 1959 & 41 \\
\hline 9 & $\begin{array}{l}\text { Bayer } \\
\text { Leverkusen, Germany }\end{array}$ & 1960 & 40 \\
\hline 10 & $\begin{array}{l}\text { Altair Chimica } \\
\text { Volterra, Italy } \\
\end{array}$ & 1960 & 40 \\
\hline 11 & $\begin{array}{l}\text { EniChem } \\
\text { Priolo, Italy }\end{array}$ & 1960 & 40 \\
\hline 12 & $\begin{array}{l}\text { Celanese } \\
\text { Knapsack, Germany }\end{array}$ & 1962 & 38 \\
\hline 13 & $\begin{array}{l}\text { ECI } \\
\text { Ibbenbüren, Germany }\end{array}$ & 1963 & 37 \\
\hline 14 & $\begin{array}{l}\text { Hellenic Petroleum } \\
\text { Thessaloniki, Greece }\end{array}$ & 1963 & 37 \\
\hline 15 & $\begin{array}{l}\text { Solvay } \\
\text { Jemeppe, Belgium }\end{array}$ & 1964 & 36 \\
\hline 16 & $\begin{array}{l}\text { Eredi Zarelli } \\
\text { Picinisco, ltaly }\end{array}$ & 1964 & 36 \\
\hline 17 & $\begin{array}{l}\text { Elf Atochem } \\
\text { Saint Auban, France }\end{array}$ & 1965 & 35 \\
\hline 18 & $\begin{array}{l}\text { Caffarro } \\
\text { Toreviscosa, Italy } \\
\end{array}$ & 1965 & 35 \\
\hline 19 & $\begin{array}{l}\text { Solvay } \\
\text { Torrelavega, Spain }\end{array}$ & 1965 & 35 \\
\hline 20 & $\begin{array}{l}\text { BASF } \\
\text { Antwerp, Belgüum }\end{array}$ & 1966 & 34 \\
\hline 21 & $\begin{array}{l}\text { ICl } \\
\text { Runcorn, UK }\end{array}$ & 1966 & 34 \\
\hline
\end{tabular}




\begin{tabular}{|c|c|c|c|}
\hline 22 & $\begin{array}{l}\text { Rhodia } \\
\text { Staveley, UK }\end{array}$ & 1966 & 34 \\
\hline 23 & $\begin{array}{l}\text { Elf Alochem } \\
\text { Lavera, France }\end{array}$ & 1968 & 32 \\
\hline 24 & $\begin{array}{l}\text { Quimica del Cinca } \\
\text { Monzon, Spain }\end{array}$ & 1969 & 31 \\
\hline 25 & $\begin{array}{l}\text { Norsk Hydro } \\
\text { Stenungsund, Sweden }\end{array}$ & 1969 & 31 \\
\hline 26 & $\begin{array}{l}\text { Solvay } \\
\text { Antwerp, Belgium }\end{array}$ & 1970 & 30 \\
\hline 27 & $\begin{array}{l}\text { LIII Europe } \\
\text { Frankfurt, Germany }\end{array}$ & 1970 & 30 \\
\hline 28 & $\begin{array}{l}\text { Akzo Nobel } \\
\text { Hengelo, Netherlands }\end{array}$ & 1970 & 30 \\
\hline 29 & $\begin{array}{l}\text { Akzo Nobel } \\
\text { Bohus, Sweden }\end{array}$ & 1970 & 30 \\
\hline 30 & $\begin{array}{l}\text { Albemarle } \\
\text { Thann, France }\end{array}$ & 1971 & 29 \\
\hline 31 & $\begin{array}{l}\text { Elf Atochem } \\
\text { Jarrie, France }\end{array}$ & 1971 & 29 \\
\hline 32 & $\begin{array}{l}\text { EniChem } \\
\text { Porto Marghera, Italy }\end{array}$ & 1971 & 29 \\
\hline 33 & $\begin{array}{l}\text { ICI } \\
\text { Wilhelmshaven, Germany }\end{array}$ & 1972 & 28 \\
\hline 34 & $\begin{array}{l}\text { Vinnolit } \\
\text { Giendorf, Germany }\end{array}$ & 1972 & 28 \\
\hline 35 & $\begin{array}{l}\text { Tessenderlo Chemie } \\
\text { Pieve Vergonte, Italy }\end{array}$ & 1972 & 28 \\
\hline 36 & $\begin{array}{l}\text { EIASA/Aragonesas } \\
\text { Villaseca, Spain } \\
\end{array}$ & 1972 & 28 \\
\hline 37 & $\begin{array}{l}\text { Solvay } \\
\text { Martorell, Spain }\end{array}$ & 1972 & 28 \\
\hline 38 & $\begin{array}{l}\text { Novartis } \\
\text { Monthey, Switzerland }\end{array}$ & 1972 & 28 \\
\hline 39 & $\begin{array}{l}\text { Saulrefabrik Schweizerhall } \\
\text { Pratteln, Switzerland }\end{array}$ & 1972 & 28 \\
\hline 40 & $\begin{array}{l}\text { EIASA/Aragonesas } \\
\text { Huelva, Spain } \\
\end{array}$ & 1973 & 27 \\
\hline 41 & $\begin{array}{l}\text { Dow } \\
\text { Schkopau, Germany }\end{array}$ & 1974 & 26 \\
\hline 42 & $\begin{array}{l}\text { Tessenderlo Chemie } \\
\text { Loos, France }\end{array}$ & 1974 & 26 \\
\hline 43 & $\begin{array}{l}\text { EniChem } \\
\text { Porto Torres, Italy }\end{array}$ & 1974 & 26 \\
\hline 44 & $\begin{array}{l}\text { Prod. Chimiques d'Harbonnières } \\
\text { Harbonnières, France }\end{array}$ & 1975 & 25 \\
\hline
\end{tabular}




\begin{tabular}{|c|c|c|c|}
\hline 45 & $\begin{array}{l}\text { Erkimia } \\
\text { Flix, Spain }\end{array}$ & 1975 & 25 \\
\hline 46 & $\begin{array}{l}\text { AusimontMontedison } \\
\text { Bussi, Italy }\end{array}$ & 1976 & 24 \\
\hline 47 & $\begin{array}{l}\text { Bayer } \\
\text { Uerdingen, Germany }\end{array}$ & 1977 & 23 \\
\hline 48 & $\begin{array}{l}\text { Tessenderlo Chemie } \\
\text { Tessenderlo, Belgium }\end{array}$ & 1977 & 23 \\
\hline 49 & $\begin{array}{l}\text { ELASA/Aragonesas } \\
\text { Sabinanigo, Spain }\end{array}$ & 1977 & 23 \\
\hline 50 & $\begin{array}{l}\text { Elnosa } \\
\text { Lourizan, Spain }\end{array}$ & 1977 & 23 \\
\hline 51 & $\begin{array}{l}\text { Uniteca } \\
\text { Estarreja, Portugall }\end{array}$ & 1981 & 19 \\
\hline- & Average & - & 1967.4 \\
\hline
\end{tabular}

a: Plant in Figure 5-11.

b: In cases where mercury processes were introduced in multiple times, the year when the first introduction took place is used.

c: Operating years as of 2000.

Sources: Euro Chlor (1998a), Chlorine Instinute (1997; 1998a; 1999a).

Table 5-35 Installation of the Mercury, Diaphragm, and Ion Exchange Membrane Processes in the World

\begin{tabular}{|c|c|c|c|}
\hline Year & Mercury Process & Diaphragm Process & $\begin{array}{c}\text { Ion Exchange Membrane } \\
\text { Process }\end{array}$ \\
\hline 1970 & 13 & 0 & 0 \\
\hline 1971 & 16 & 1 & 0 \\
\hline 1972 & 13 & 1 & 0 \\
\hline 1973 & 6 & 0 & 0 \\
\hline 1974 & 9 & 6 & 0 \\
\hline 1975 & 14 & 8 & 2 \\
\hline 1976 & 14 & 5 & 1 \\
\hline 1977 & 14 & 8 & 1 \\
\hline 1978 & 3 & 3 & 3 \\
\hline 1979 & 7 & 4 & 1 \\
\hline 1980 & 7 & 6 & 5 \\
\hline 1981 & 8 & 4 & 7 \\
\hline 1982 & 1 & 2 & 7 \\
\hline 1983 & 5 & 1 & 13 \\
\hline 1984 & 1 & 1 & 17 \\
\hline 1985 & 1 & 1 & 22 \\
\hline 1986 & 1 & 1 & 17 \\
\hline 1987 & 2 & 1 & 21 \\
\hline 1988 & 1 & 2 & 25 \\
\hline
\end{tabular}




\begin{tabular}{|c|c|c|c|}
\hline 1989 & 0 & 1 & 38 \\
\hline 1990 & 3 & 1 & 30 \\
\hline 1991 & 1 & 0 & 22 \\
\hline 1992 & 0 & 0 & 15 \\
\hline 1993 & 0 & 0 & 9 \\
\hline 1994 & 0 & 0 & 18 \\
\hline 1995 & 0 & 4 & 20 \\
\hline 1996 & 1 & 4 & 24 \\
\hline 1997 & 0 & 0 & 25 \\
\hline Total & 1128 & 520 & 2744 \\
\hline
\end{tabular}

Source: Calculation based on Chlorine Institute (1998a; 1998b).

Table 5-36 Shares of the Mercury, Diaphragm, and Ion Exchange Membrane Processes in the World

\begin{tabular}{|l|c|c|c|}
\hline & 1980 & 1990 & 1999 \\
\hline Mercury Process & 45 & 39 & 25 \\
\hline Diaphragm Process & 53 & 45 & 34 \\
\hline Ion Exchange Membrane Process & 2 & 16 & 30 \\
\hline
\end{tabular}

Figures are expressed in percentage.

Sources: 1980 and 1990: Miller (1993). I999: TECNON (1999) 


\section{Summary and Conclusion}

In this research, we examined the effects of envirommental regulation on technological change: A particular emphasis was placed on the distinction between the end-of-pipe technology and the clean technology, with its implications for diverging impacts of environmental regulations on innovation. We first reviewed theoretical and empirical research which has been conducted on this issue in the past. Previous theoretical models basically suggest that economic instruments, including emission tax and tradable emission permits, are generally superior to command-and-control regulation in encouraging technological change for pollution abatement. Comparing relative scales of incentives under different policy instruments, they claim that economic measures generally give a greater spur to innovate in pollution control than direct controls.

These arguments, however, are based on several very restricted assumptions concerning the nature and characteristics of technological change. Among them is that these theoretical studies pay almost exclusive attention to end-of-pipe technologies as their measures for emission reduction. They basically ignore the possibility of a different type of technological change, namely, clean technologies, which will eliminate the formation of pollutants from within the production processes. Some of these studies assume that there is a tradeoff in R\&D between improvement in output production technology and improvement in pollution abatement techmology. In this approach, the technologies considered for pollution abatement are basically those of the end-of-pipe type, and the possibility of developing clean technologies is not taken into account. Since clean technologies do not require any measures for pollution abatement, it is not necessary to conduct R\&D on end-of-pipe technologies. Thus it could become possible to achieve improvement in both output production and pollution abatement at the same time, and as a result the tradeoff between the two types of improvement would disappear. What would be of critical importance then is to make an appropriate choice between the end-of-pipe technology and the clean technology as the target of $R \& D$, rather than to find the optimal combination of R\&D efforts between those for pollution abatement and for output production.

In other theoretical models, marginal cost curves have been typically used for pollution abatement, with an assumption that the marginal cost of pollution abatement increases as emissions are reduced. And the scope for innovation is limited to technologies with which marginal abatement costs are lowered. In other words, marginal abatement costs are 
continuous and strictly increasing over a relevant region of emission reduction, and technological change is modeled simply as a decline in marginal abatement costs. Effectively, these assumptions mean that pollution abatement is implemented only through adoption of end-of-pipe technologies. The other type of technologies for dealing with emissions from the production process, that is, clean technologies, has been mostly ignored. Since clean technologies eliminate the creation of pollutants from within the production process by altering the chemical reactions producing the main products, there is no pollution emission in the first place, and thus marginal cost curves for pollution abatement become inappropriate for the analysis of clean technologies.

Empirical studies conducted previously produced mixed results concerning the effects of environmental regulation on technological change. One of the crucial issues affecting the results of these studies is what kinds of technology are included in the category of innovation. As the range of clean technologies can hardlly be identified clearly in general terms without regard to details of specific production processes, earlier empirical studies either exclusively focused on technologies of the end-of-pipe type or included all innovations observed in each case. While consideration of only end-of-pipe technologies limits the scope of technological change for pollution abatement too narrowly and excludes clean technologies, the group of all innovations contains technologies that have little relevance to environmental aspects and is too broad to be appropriately used for the analysis of the impacts of environmental regulation on technological change. Previous empirical as well as theoretical studies have looked at only end-of-pipe technologies as technological measures for pollution abatement, and the existence of clean technologies has not been taken into account properly. It is thus of critical importance to incorporate into analysis the possibility of pollution elimination with clean technologies, in contrast to pollution reduction with end-of-pipe technologies.

A detailed analysis of the end-of-pipe technology and the clean technology based on chemical reaction equations clarifies the qualitative differences between the two types of technological change. Basically, the end-of-pipe technology is designed to be installed at the end of manufacturing plants and will not affect the manufacturing process producing the main products. Its pollution abatement cost is relatively small when the level of emission reduction is low and normally starts to rise as the emission standard becomes more stringent. While innovations on the end-of-pipe technology will reduce the cost of complying with any fixed level of the emission standard, the total cost of manufacturing with the use of the end-of-pipe technology will not become smaller than the original output production cost. The cost of 
output production will remain unchanged as the end-of-pipe techrology does not affect the main production process, whereas the cost of pollution abatement, which will not becone zerro by whatever innovation, is added to the output production cost.

The clean technology, in contrast, eliminates the formation of pollution from within the production process by altering the whole chemical reactions. Thus the use of the marginal pollution abatement cost curve becomes inappropriate for the analysis of the clean technology, which does not produce any pollutant emission in the first place. As the clean technology is a radical innovation involving the whole production facilities, the capital investment for its installation is normally large and its cost of output production will be larger, at least initially, than that using the end-of-pipe technology. It is possible that the output production cost with the clean technology will later become smaller than that with the original production cost as the performance of the clean technology improves significantly through $R \& D$ and learning. On the other hand, there are usually more than one options of the clean technology replacing the original production technology, and the uncertainty concerning future progress in the performance of the multiple alternatives will be large.

Based on the distinctive characters of the end-of-pipe technology and the clean technology, our analytical framework is established for the effects of environmental regulation on technological change (Figure 2-11): When an environmental issue occurs, normally there is a large degree of uncertainty concerning where the sources of pollutant emissions are located, what mechanisms of physical, chemical, and biological transformation of the pollutants are involved, and how much damage has been or is expected to be made on the human body and other living organisms. Given the existence of these various types of uncertainty, it would be rare that scientific arguments can exclusively determine environmental regulations, and other factors, including historical, political, and social backgrounds, will inevitably influence the outcome of policy discussions. Reflecting the diversity of the surrounding conditions, different regulations could be umposed in relation to the same environmental issue.

When the regulations are so stringent as to effectively require the abolishment of the existing production technology, firms will be prompted to find new clean technologies. There are normally multiple alternatives, and a large degree of uncertainty exists concenning which technology will progress to become the most efficient in the long run. Thus, to the extent that the stringent regulations are implemented with a rigidly fixed schedule, it is possible that insufficient time and opportunities allowed for R\&D and learning will lead to a technological 
choice that is not the most efficient. Yet this will only become apparent ex ante, after it has been adopted widely and used for a certain period of time. Only when the regulations maintain some flexilbility in schedule and timing, will there be time to test and experiment with various types of the clean technology, and the chance will be high that the most efficient clean technology will be picked up for development and adoption.

When the envirommental regulation is relatively weak, in contrast, firms will be induced to choose end-of-pipe technologies because it is less expensive, at least initially, to reduce emissions by using then than by adopting clean technologies that involve radical changes in the whole production process. R\&D efforts will be directed toward improving the performance of end-of-pipe technologies, and as long as these technologies work successfully to comply with the target of emission reduction, companies will continue to rely on the original, pollution-laden production technology. By the time when the most efficient clean technology becomes available from a region where more stringent regulations were implemented, more plants have already been established utilizing the present production technology. Unless the saving in the operating cost from the conversion to the clean technology is sufficiently larger than the capital investment necessary to install it, the operators of the relatively new plants will have strong incentives to continue to use the existing production technology, equipped with end-of-pipe technologies for pollution abatement, until the end of the physical life time of their plants, inhibiting the diffusion of the most efficient clean technology.

Figure 6-1 shows in this analytical framework the effects of environmental regulation on technological change in the chlor-alkali industry in Japan and Western Europe. Mercury emissions from chlor-alkali production plants have been subject to intensive environmental regulations in the two regions since the $1970 \mathrm{~s}$. Under the influence of different regulatory approaches to mercury emissions, diverging courses of technological change have been observed between the two regions. 


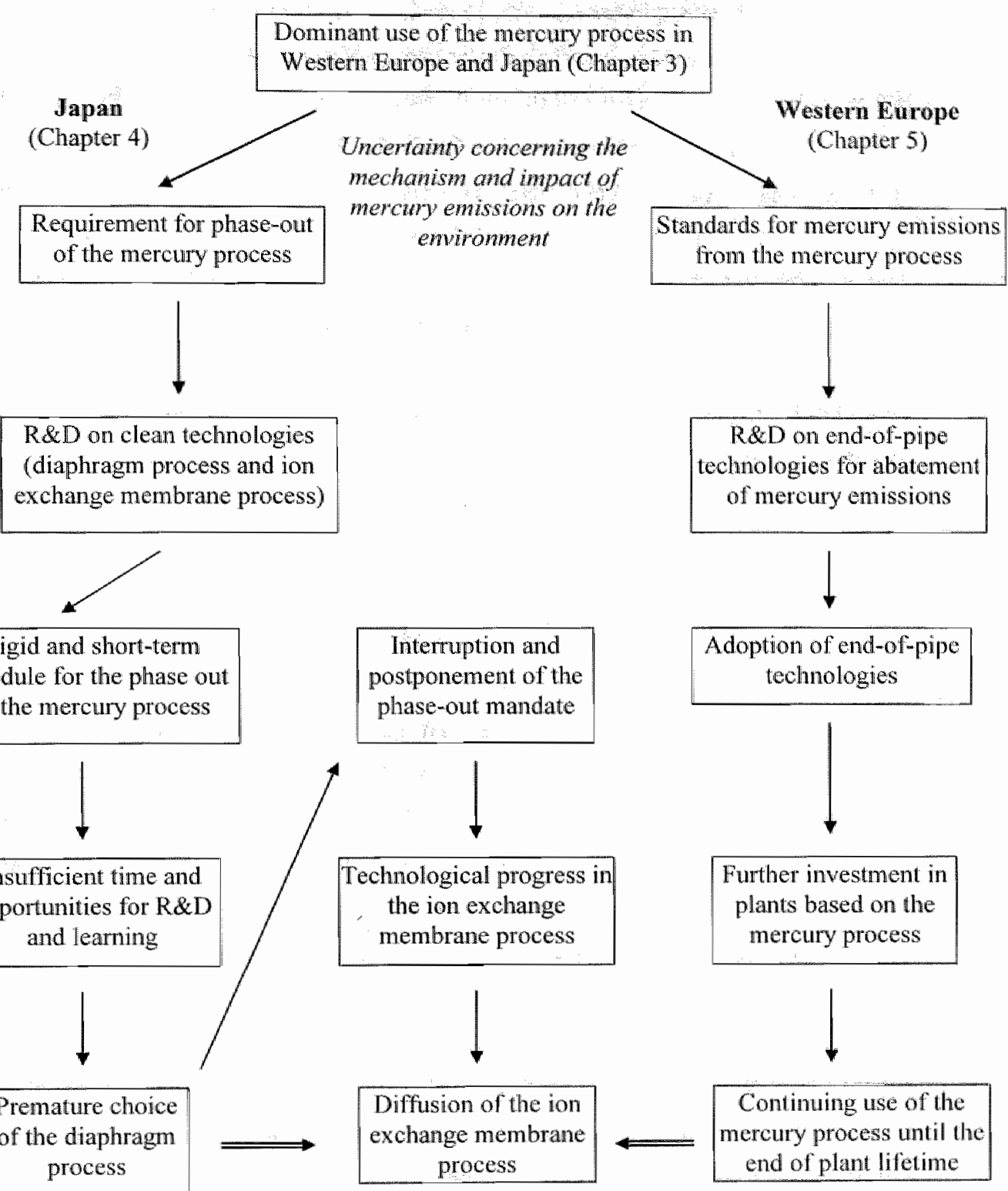

Costly shifi

Slow shift

Figure 6-1 Diverging Impacts of Environmental Regulations on Technological Change in the Chlor-Alkali Industry in Japan and Western Europe 
There are basically three types of technologies used for commercial production of chloralkali prodwets: the mercury process, the diaphragm process, and the ion exchange membrane process. The mercury proeess and the diaphragm process were invented at the end of the 19 th century. In Europe and later in Japan, technologies for the mercury process were improved. further through leaming and knowledge accumulation based on increased use in the industry, and more chlor-alkalli producers adopted the mercury process. By the end of the 1960s, the mercury process had come to dominate the chlor-alkali industry in both Western Europe and Japan. In each region, there were several innovative companies which made successful technological developments for the mercury process. In Western Europe these included De Nord, Uhde, Krebs, Solvay, and ICI whereas in Japan these were Osaka Soda, Kureha Chemical Industry, Asahi Glass, Tokuyama Soda, Asahi Chemical Industry, and Mitsui Engineering and Shipbuilding. In the early 1970 s, just before regulations started to be introduced to reduce mercury emissions into the environment, these companies in the two regions were equally innovative on the mercury process technologies. That means that the initial technological conditions in the chlor-alkali industry were similar between Western Europe and Japan prior to any regulatory influence.

Japan had a tragic experience of the Minamata disease in the $1950 \mathrm{~s}$ and 1960s. The disease caused damages on the nerve system of those people who ate fish poisoned with dimethyl mercury, a chemical substance which belongs to the category of organic mercury. It had been contained in the waste water emitted to the sea by a chemical plant producing acetaldehyde nearby. As most of the chlor-alkali plants at that time were based on the mercury process, concerns rose among the general public on the environmental effects of their emissions. What was discharged from mercury-based chlor-alkali plants, however, was actually inorganic mercury, a substance whose chemical characteristics are distinctively different from those of organic mercury, and there was no confirmed incident or scientific evidence showing that the inorganic mercury emitted from chlor-alkali plants caused any symptoms of the Minamata disease. Nevertheless, the public pressure was very intense, and several chlor-alkali plants were forced to suspend their operation because of mass demonstrations.

The increasing public pressure pushed the Japanese government to take a tough stance on mercuy emissions from chlor-alkali plants. That resulted in such as stringent regulation set by the government as to demand chlor-alkali producers to completely abolish the mercury process in just a few years, despite the chlor-industry's strong oppositions. While financial 
support was given for the adoption of clean techologies through preferential tax treatment and low-interest public loans, the government did not provide any subsidies for R\&D on clean technologies. On the other hand, the stringeta policy to abandon the mercury process created a large, secured demand for mereury-free technologies, in stead of end-of-pipe technologies aimed at reducing mercury emissions from the mercury process, and thus provided strong incentives for innovative companies to work on new clean technologies and to supply them to other chlor-alkali producers.

As the original process conversion program was implemented in a tight, inflexible schedule, many of the leading companies in developing chlor-alkali production technologies initially chose the diaphragm process as the alternative clean technology, because its technological performance and reliability was considered to be superior to that of the ion exchange membrane process at that time. Mitsui Shipbuilding and Engineering established a specialized company, CEC, to introduce the diaphragm process developed by foreign companies and provided it to chlor-alkali manufacturers. Kureha Chemical Industry also chose the diaphragm process to replace the mercury process and subsequently developed its own technology. Those companies which had been innovative on the diaphragm process, that is, Nippon Soda, Tsurumi Soda, and Showa Denko, expanded their production capacities with the diaphragm process and provided their technologies to outside companies. Only those companies with less expertise on chlor-alkali production technologies, namely, Asahi Chemical Industry, Asahi Glass, and Tokuyama Soda, directed their R\&D efforts toward the ion exchange membrane process, a production process which was not yet sufficiently developed as to be utilized for industrial applications when the decision was made for the phase out of the mercury process. Relying on their earlier experiences of developing ion exchange membranes used in different fields, these companies utilized the opportunity oflered by the stringent regulation to innovate on the still infant ion exchange membrane process for chlor-alkali production.

As the regulatory schedule for the conversion of the mercury process was initially set with a rigid, short-term deadline, most of the chlor-alkali manufacturers had no choice other than to adopt the diaphragm process, which had been long established at the level of industrial applications. With the amount of time and learning limited, however, the technologies developed by the Japanese companies could not be improved sufficiently as to be used for commercial purposes. By the time that the first phase of the government conversion program was ended, two thirds of the chlor-alkali production capacities in Japan had been convertted to 
the diaphragm process, but most of the technologies adopted were those introduced from foreign companies. While the mercury process in Japan was mostly converted to the diaphragm process, the disadvantage of the diaphragm process in terms of the production cost was getting worse, as the energy price soared following the oil crisis. Moreover, it was becoming clear that the quality of caustic soda produced by the newly introduced diaphragm process was not high enough as to be used for some industrial applications.

In the meantime, the ion exchange membrane process was undergoing a rapid technological advancement. Under these circumstances, the government interrupted the implementation of the process conversion program for a while and established an expert committee consisting of academic researchers to evaluate the extent of technological progress in the emerging ion exchange membrane process. By conducting interviews and visiting companies for detailed information on on-going technologicall developments, the committee concluded that the ion exchange membrane process had reached a stage ready for industrial applications. Following the technological assessment of the expert committee, the government modified the original schedule for process conversion and postponed the deadline for complete abolishment of the mercury process. This adjustment of the regulatory schedule allowed more time for innovative companies to undertake R\&D activities on the ion exchange membrane process and to gain learning experiences through actual operations of chlor-alkali plants, promoting further progress in the promising, but not yet fully established technology. The ion exchange membrane process had advanced to become the best technology in the end among the three chlor-alkali processes economically as well as environmentally, and subsequently the remaining mercury-based plants were all converted to this process. Currently the majority of chlor-alkali plants located in Japan are relying on the ion exchange membrane process, and its technologies are increasingly adopted by chlor-alkali producers in other countries.

On the other hand, those mercury-based plants which had been converted to the diaphragm process immediately following the government decision on the phase out of the mercury process were later converted again to the fon exchange membrane process. The operating period of these plants based on the diaphragm process turned out to be significantly shorter than that of plants operated in nomal conditions. This implies that the substantial amount of capital investment made to introduce the diaphragm process was not utilized to the full extent until the end of the plant lifetime and thus effectively ended up wasted. Although the evaluation of technological development on the ion exchange membrane process by 
independent experts finally made it possible to change the regulatory schedule, the transition was costly, going through the conversion of the mercury process initially to the diaphragm process and then to the ion exchange membrane process. In retrospect, the large-scale shift from the mercury process to the diaphragm process could have been avoided if the initial government policy for the phase out of the mercury process had maintained a certain degree of flexibility in the regulatory schedule, taking into account possibilities of future progress in altemative clean technologies. As radical breakthroughs on the ion exchange membrane process were perceived to be on the horizon by several innovative companies at the time of the government decision, if the deadline for the phase out of the mercury process had been set on a later period from the beginning, there could have been more time for detailed experiments and evaluations of multiple choices of clean technologies, and most of the existing mercury-based plants could have been converted directly to the ion exchange membrane process, without devoting large investments in the diaphragm process.

In Westem Europe, unlike the Japanese case, there was no reported incident in which human bodies were seriously affected by the intake of mercury, and a less stringent approach was taken to the regulation of mercury released into the environment. Rather than imposing a mandate for complete abolishment of the mercury process, the public authorities specified standards for mercury emissions from chlor-alkali plants, and their levels were gradually tightened in the subsequent periods. As required by the enission standards, companies were encouraged to develop technological measures for pollution abatement. Most of the innovative companies in Western Europe, including ICI, Hoechst-Uhde, De Nora, Solvay, and Krebs, directed their $R \& D$ activities to end-of-pipe technologies for the reduction of mercury emissions, rather than to clean technologies which would eliminate the use of any mercury within the production process. Various types of end-of-pipe technologies were successfully developed, and they worked adequately to such an extent that they could meet the imposed emission standards. With a remarkable reduction in mercury emission by using end-of-pipe technologies, chlor-alkali producers in Westen Europe mostly have continued to use the mercury process. Although several companies had previously been engaged in R\&D on the ion exchange membrane process, the relatively weak regulatory regulations on mercury emissions did not encourage further innovative efforts to develop the clean technology which does not involve any use of mercury.

In the same period, the ion exchange membrane process was under rapid technological progress in Japan, promoted by the strong regulation for the phase out of the mercury process, 
and was on a way to become the most efficient technology among the three production technologies. Observing this, the innovative companies in Western Europe started to intensify their R\&D activities on the lon exchange membranie process. As advanced types of ion exchange membranes had been already developed by the lapanese companies, however, the focus of R\&D activities was placed on electrolytic cells for use in the new process. Relying on ion exchange membranes introduced from outside, the Western European companies began to industrialize the ion exchange membrane process much later.

Although the ion exchange membrane process has become the best clean technology economically as well as enwironmentally, its diffusion in Western Europe has been slow and limited. There are basically two factors that theoretically could affect the diffusion of a new technology, that is, the availability of information on the new technology and the profitability of replacing the existing technology with the new one. In terms of the amount of information on the ion exchange membrane process, there have been ample opportunities for chlor-alkali producers to obtain detailed and reliable data on its technological performance through presentations made at industry conferences and papers published on technical and trade joumals. Thus lack of information could not be a major factor inhibiting a wide diffusion of the ion exchange membrane process in Western Europe. With regard to the profitability of replacing the mercury process with the ion exchange membrane process, the investment cost of adopting the ion exchange membrane process has been much larger than the cost necessary for the installation of end-of-pipe technologies to reduce mercury emissions, whereas the operating cost of the ion exchange membrane process has become lower than that of the mercury process. The scale of the cost saving by switching from the mercury process to the ton exchange membrane process, however, has not yet been sufficient to justify the imitial investment necessary for the process conversion, although it is already economical to adopt. the ion exchange membrane process for new chlor-alkali plants.

What has been the critical factor influencing the diffusion of the ion exchange membrane process in Western Europe is then the age of the existing chlor-alkali plants based on the mercury process. Compared with chlor-alkali plants which had been constructed previously, the operating period is still considerably short for most of the present mercuryprocess plants, and that suggests that these plants have not yet reached the end of their physical lifetime. Whille complying successfully with the emission standards through end-ofpipe technologies, the operators of mercury-process plants have strong incentives to continue to use them as long as they work physically. Particularly during the 1970s, after regulations 
were datroduced to limit mercury emissions into the environment; chlor-alkali plants continued to be constructed using the mercury proeess. By the time that the ion exchange nembrane process with efficient and reliable performance became available to chlor-alkali producers, many mercury-based plants had been already established. It will still take a long period of time before these relatively new plants reach the end of their lifetime. Althongh the regulators have recently recommended that the existing mercury-based plants be completely discarded by 2010 , the mercury process is still the dominant production tedmology in Western Europe. The envirommental regulations aimed at limiting mercury released to the enviromment did encourage the development and adoption of end-of-pipe technologies, which indeed worked relatively well in reducing mercury emissions. This success, however, effectively helped to prolong the lifetime of the mercury process, which actually has been in a process of technological obsolescence.

Indeed, the use of the mercury process has been increasingly avoided in the chlor-alkali industry in other parts of the world, including many developing countries. In the past there have been intense debates on the so-called pollution haven hypothesis, which basically claims that developing countries will lower the level of their environmental regulations to attract foreign direct investment by companies in pollution-intensive industries located in developed countries to avoid stringent enwironmental regulations. The case of the chlor-alkali industry shows that developing countries have been increasingly constructing new plants by adopting the clean ion exchange membrane process, rather than the mercury process equipped with end-of-pipe technologies aimed at reducing mercury emissions, as the ion exchange membrane process has become more efficient without any use of mercury than the pollutionladen mercury process. The case of technological change in the chlor-alkali industry suggests What, given the existence of the two types of technological change to deal with pollutant emissions, pollution haven may not necessarily be an unavoidable fate for developing countries; which instead could leapfrog to the most efficient clean technology.

The case of technological change in the chlor-alkali industry has important implications for analyzing the impacts of environmental regulation on industrial competiriveness. There have been intensive debates between two opposite positions on this issue. On the one hand, concerns have been raised about the negative effects of increasingly stringent regulations on industries. That is, stringent environmental regulations will force firms to invest a considerable amount of financial resources for compliance, and consequently their competitiveness will be lost against those in countries with lax environmental regulations. 
Environmental regulations impose significant costs, slow productivity, and thereby hinder the ability of companies to compete in international markets by requiring firms to sperd additional resources for pollution abatement and control without increasing the output of main products. On the other hand, the so-called Porter hypothesis claims that stringent environmental regulations will actually enhance the competitive position of frnm by encouraging them to undertake more R\&D activities and consequently to produce better innovations in the long run. In other words, the mecessity to comply with increasingly stringent environmental regulations will prompt companies to re-examine their products and production processes carefully and will ultimately lead to technological improvements. Spurred by strong regulations, companies will go beyond mere compliance and could succeed in creating radically new technologies which have not been realized previously.

Our analysis shows that what is critical in addressing this issue is to ask what kinds of technological change would be promoted by environmental regulations. Since end-of-pipe technologies are designed to be installed at the end of production processes, the costs necessary for their adoption and operation are added to the original production costs, which will only increase the total costs of manufacturing. Thus, we could say that those who argue that environmental regulations decrease industrial competitiveness basically have end-of-pipe technologies in mind. Clean technologies in contrast have the potential to achieve a better performance than present technologies. Then an important question is how to encourage companies to make innovations on a clean technology which will only be known to be the best in the long run. When an environmental regulation is introduced, unless it is so stringent as to require the existing production technologies be abolished, manufacturing companies have two technological choices, that is, end-of-pipe technologies and cllean technologies. With the regulation fixed on a short-term schedule, companies will have incentives to comply with the requirement of emission reduction with end-of-pipe technologies, an option which is relatively easy and less costly to develop and adopt than clean technologies. As a result, the present pollution-laden technologies, with emissions reduced through end-of-pipe technologies, will continue to be used, whereas innovative activities will not be activelly pursued on clean technologies under the existence of uncertainty concerning the potential for a better performance from a long term perspective.

This situation could be discussed in terms of what Clayton Christensen calls "innovator's dilemma" (Christensen, 1997). The concept basically says that a sound business practice of focusing investments on technologies which meets the current demand of 
customers profitably, which are defined as sustaining technologies, can ultimately weaken a good company. Breakthrough innowations, or distuptive technologies, are initially rejected by customers because of the lack of sufficient technological perfornance. That will lead frins with strong focus on the current market demand to allow innovations which would be strategically important in the future to languish. In a similar manner, we could argue that the strategy of focusing investments on the most efficient measures for pollution abatement, that is, end-of-pipe technologies, to meet the current demand of environmental regulations would function to miss the opportunity of making radical innovations on technologies of critical importance in the long rum, that is, clean technologies. That is the case of the Western European companies which had been previously innovative on the mencury process. These: companies initially focused on end-of-pipe technologies to reduce mercury enissions, and their technological success in meeting the regulatory requirement effectively led to sustaining the mercury process. The opportunity of inventing new ion exchange membranes was missed, however, inhibiting subsequent technological developments on the ion exchange membrane process, a truly disruptive technology for chlor-alkali production.

We could draw some policy implications from the experience in the chlor-alkali industry. Environmental regulations should seek to encourage innovations on clean technologies, which have the possibility of achieving economic and environmental objectives at the same time, rather than innowations on end-of-pipe technologies, which will only lead to incurring additional costs. At the same time, they need to avoid inducing wrong technological choices prematurely in the presence of uncertainty, diversity, and rigidity inherent in the process of technological change. Therefore, stringent regulations will be effective to create strong and secured demands for clean technologies, shifting away from end-of pipe technologies which would only sustain the trajectory of the traditional, pollution-laden production processes, but they should be implemented in a long-term framework to allow sufficient time for experience and experiment on alternative clean technologies. To do that, it would be necessary that regulations accommodate a certain degree of flexibility in schedule to reflect accurate and up-to-date information on the state of technological developments undergoing in industry. What would be important is that institutional mechanisms are sef up for appropriate information collection and assessment concerning clean technologies, which involve a much larger level of uncertainty than end-of-pipe technologies, particularly in cases where the speed of technological change is high and the uncertainty concerning furute progress is large. 
We could argue that the Japanese government made a mistake in initially prompting the companies to choose the diaphragm process effectively by implementing excessively stringent regulations, especially given that there was no confimed incident of Minamata-like disease caused by inorganic mercury emissions from chlor-alkali plants. This occurred because of the unusually strong public pressure, which allowed little time for careful consideration on the potential of alternative clean technologies. At a later stage, only by acquiring and evaluating accurate and up-to-date information on the rapid technological progress through andependent expert committee consisting of researchers in academia, the government could modify the regulatory schedule to accommodate further improvement on the ion exchange membrane process and its subsequent adoption by chlor-alkali producers. Since it is normally difficult for policy makers to closely keep up with the rapidly changing state of technological development in industry, direct support to R\&D activities focusing on a specific clean technology would not be appropriate, as a wrong technology could be picked up, given the existence of large uncertainty concerning the extent of technological progress in the future. Rather, it would be more desirable to create and maintain demands for clean technologies through regulatory incentives. When innovative companies are convinced that there will be large and stable demands for clean technologies, they will be encouraged to make imovative efforts on these technologies, as the Japanese companies did, even without receiving any direct support to their $R \& D$ activities. What is important is to maintain the diversity of options for clean technologies, avoiding a particular technological target at an initial stage.

One caveat needs to be mentioned here regarding the technological impact of stringent regulations. Stringent regulations do not necessarily promote totally new technologies which have never been imagined. In the case of the ion exchange membrane process, ion exchange membranes liad been used for other purposes previously, and the idea of applying them for chlor-alkali production had existed for a long time. The strong regulation for the phase out of the mercury process, giving an assurance of a large market for clean technologies by eliminating the possibility of end-of-pipe solutions, provided confidence sufficient to overcome the barrier of uncertainty concerning potential progress in the ion exchange membrane process which could be seen on the horizon. Thus what would be crucial is that detailed information and knowledge on the state of technological development currently occurring in industries is utilized appropriately in the process of policy making. 
In acquiring accurate and delicate information on and making proper assessment of evolving technologies, the way which communication and information exchange are practiced anong policy makers and experts in industry and academia will be particularly important. In this context, the recent emergence of voluntary agreements between industry and government in industrialized countries is an interesting phenomenon deserving careful examinations $^{113}$. Our analysis suggests that voluntary approaches could have potential to make it possible to utilize knowledge and information effectively and to adjust investment schedules efficiently. At the same time, on the other hand, they need to maintain objectively and transparency in setting the targets and monitoring the results through independent actors, avoiding the problem of regulatory capture. As each country has its own peculiarify in the relationship between government, industry, and academia, instifutional mechanisms in which information on the situation of technological development is acquired and assessed would be different $^{114}$. Accordingly, the appropriate mode of information acquisition and assessment to encourage innovations on clean technologies could be diverse, depending on the distinct institutional structure ${ }^{15}$. In other words, the structural coherence of the institutional arrangements could prove increasingly central to the emergence of the most appropriate clean technologies. Further research on international comparative analysis of institutional arrangements will be invaluable to deepen our understanding of the effects of environmental regulation on technological change ${ }^{116}$. We hope that this will help us ultimately to make a step toward sustainable development through a transition from end-of-pipe technology to clean technology.

\footnotetext{
${ }^{113}$ See , for example, Carraro and Leveque (1999) for theoretical and empirical analyses on? voluntary approachess in environmental policy.

${ }^{\text {Ins }}$ For an interesting approach to the analys of the role of information in institutonal evolution and diversity. see Aaki (2000; 2001).

115 Various types of voluntary agreements have been already observed in the chemical industry in the United States, Europe, and Japan, which could be considered to reflect institutional differences between these regions (Baba and Yarime, 2000).

${ }^{116}$ Vogel (1986) argues that there are "national styles" of regulation by examining environmental regulations in Great Britain and the United States. A recent study by Wallace (1.995) is an attempt to analyze the relationship between environmental policy and industrial innovation in Europe, Japan, and the United States in a comparative framework.
} 


\section{Appendix. Effects of Environmental Regulation on Technological Change of the Chemical Processes for Chlor-Alkali Production}

In the evolution of production technologies in the chlor-alkali industry, there was another opportunity in which divergent courses of technological trajectory were observed. That happened between the Leblanc process and the ammonia process, both of which belonged to the chemical process of chlor-alkali production. In this Appendix, we examine in a preliminary way how environmental regulations influenced the divergent courses of technological changes between the two processes by paying a particular attention to the chloralkali industry in Britain in the 19 th centary.

\section{A. 1 Leblanc Process}

The Leblanc process, invented by Nicolas Leblanc in France in 1787, was the first process for the soda production which worked satisfactorily on an industrial scale ${ }^{117}$. In Britain its first operation started in 1822. The Leblanc process had two distinct stages. The first step involved the decomposition of common salt (sodium chloride, $\mathrm{NaCl}$ ) with sulfuric acid $\left(\mathrm{H}_{2} \mathrm{SO}_{4}\right)$ to produce salt cake (sodium sulfate, $\mathrm{Na}_{2} \mathrm{SO}_{4}$ ):

$$
2 \mathrm{NaCl}+\mathrm{H}_{2} \mathrm{SO}_{4} \rightarrow \mathrm{Na}_{2} \mathrm{SO}_{4}+2 \mathrm{HCl}^{*} \text {. }
$$

The sodium sulfate was used directly for the glass manufacturer, in its purified form, sold as the purgative Glauber's salts. The vigorous reaction involved also produced large quantities of hydrochloric acid gas ( $\mathrm{HCl}$ ), which had been simply emitted to the atmosphere as waste.

In the second step, the salt cake is fluxed with limestone (calcium carbonate, $\mathrm{CaCO}_{3}$ ) and charcoal or coal (carbon, C) to produce black ash, a mixture of sodium carbonate $\left(\mathrm{Na}_{2} \mathrm{CO}_{3}\right)$ and calcium sulfide (Cas), together with a number of other impurities:

$$
\mathrm{Na}_{2} \mathrm{SO}_{4}+\mathrm{CaCO}_{3}+2 \mathrm{C}>\mathrm{NaCO}_{2}+\mathrm{CaS}+2 \mathrm{CO}_{2} \text {. }
$$

The black ash is dissolved by water and then concentrated by evaporation to produce conmercially pure soda ash.

Prior to 1850 , caustic soda (sodium hydroxide, $\mathrm{NaOH}$ ) was not available commercially. Processes such as soap making and paper making which required caustic soda had to obtain

\footnotetext{
${ }^{117}$ For detated trestments of the history of the Leblanc process and the sumumoniamesoda process, see Derry and Willians (1960) and Clow and Clow (1992).
} 
this by causticizing a solution of purchased soda ash with slacked lime calcium hydroxide, $\left.\mathrm{Ca}(\mathrm{OH})_{2}\right)$ in the causticization or lime soda process:

$$
\mathrm{Na}_{2} \mathrm{CO}_{3}+\mathrm{Ca}(\mathrm{OH})_{2} \rightarrow 2 \mathrm{NaOH}+\mathrm{CaCO}_{3}
$$

The flow diaphragn of the whole integration of the Leblane and other related processes is given in Figure A-1. As the Leblanc process developed and got more integrated, it became the source of many other bulk inorganic materials and laid the foundations of the chemical industry for more than a century afterwards. As Hardie and Pratt (1966) put, "during the first half of the nineteenth century, and even later, the alkali industry was the chemical industry." 


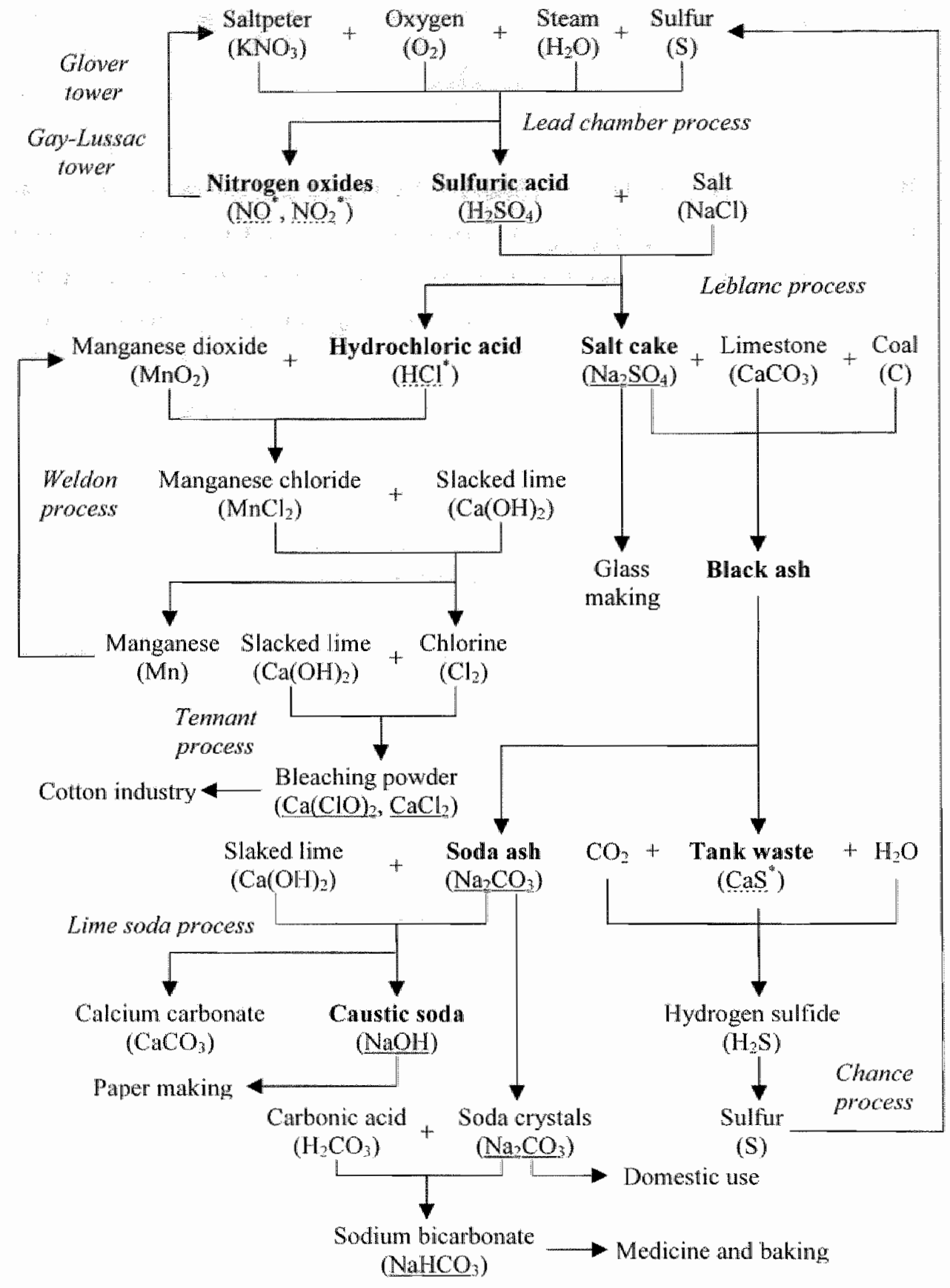

Figure A-1 Flow Diagram of the Leblanc Process

Based on Clow and Clow (1992). 


\section{A.1.1 Hydrogen Chloride Emissions}

While caustic soda was produced in this way until the advent of electrolytic methods at the end of the century, the Leblanc process was very inefficient and produced large amounts of various wastes, which were initially dumped to air and water in the surrounding environment: The overwhelming waste products littered landscapes that had once been productive agriculturally and fouled the air with noxious gases. Among the most serious problems of the Leblanc process was the hydrogen chloride (HCl) gas. For each ton of sodium carbonate produced, about $3 / 4$ of a ton of hydrogen chloride was discharged. Initially, the hydrogen gas was passed directly up factory flues and into the atmosphere. In the presence of moisture, it was converted into rapidly into droplets of hydrochloric acid. These "noxious vapours" damaged agricultural property as well as posed a health hazard, and, because of their impact; the airborne emissions from alkali manufacture were called "the monster nuisance of all" In Britain, the effects of the growing alkali industry were so offensive, to the smell as well as to the sight, that the protection of the neighboring communities became a matter of urgent attention. Some of the major technological measures are given in Table A-1.

Table A-1 Regulation and Technological Development for the Treatment of Hydrogen Chloride Emissions from the Leblanc Process

\begin{tabular}{|c|c|}
\hline Year & Regulatory and Technological Development \\
\hline 1787 & Invention of the Leblanc process in France \\
\hline 1.822 & Start of the operation of the Leblanc process in Britain \\
\hline 1836 & Invention of the Gossage tower to absorb hydrogen chloride \\
\hline 1863 & $\begin{array}{l}\text { Enactment of the Alkali Act, which required } 95 \% \text { reduction of the hydrogen } \\
\text { chloride emission }\end{array}$ \\
\hline 1866 & Development of the Weldon process for recovering manganese \\
\hline 1868 & $\begin{array}{l}\text { Development of the Deacon process for producing chlorine directly from } \\
\text { hydrochloric acid with catalyst }\end{array}$ \\
\hline 1874 & $\begin{array}{l}\text { Amendment of the Alkali Act to impose an absolute emission standard of } 0.2 \mathrm{~g} \\
\mathrm{HCl} / \mathrm{ft} \text { and to cover other gases }\end{array}$ \\
\hline
\end{tabular}

In 1836 the so-called Gossage tower was invented to prevent the escape of hydrogen chloride. When the hydrogen chloride gas was passed down through the tower, it was absorbed by a descending stream of water and converted into hydrochloric acid. By using coke or other porous material, the Gossage tower was significantly improved to such an extent that emissions of the hydrogen chloride gas could be significantly reduced if it was used properly. While hydrochloric acid began to be used for making bleaching powder and 
for other purposes, in was made in such quantities that the supply of hydrochloric acid far outstripped demand. Moreover, since it was difficult and costly to transport the hydrochlorie acid, its market was highly localized. Production costs were increased to condense the gaseous wastes, but the resultant liquid wastes still had to be disposed of in some way. Thus the economic incentive for alkali manufacturers to condense the hydrogen ehloride gas effectively was very limited (Dingle, 1982). Although some manufactures had begun to condense the hydrogen chloride gas since the $1830 \mathrm{ss}$, others were still not doing so even in the late 1850s.

As the damage to vegetation was considerable while the abatement of fumes from alkali works came to be considered as practicable, the government introduced a bill in 1863 , and the Act for the more effectual Condensation of Muriatic Acid Gas in Alkali Works came into force on 1 January next year for a trial period of five years. The act provided that alkali works were to condense 95 per cent of their hydrochloric acid gas by whatever method they preferred. A substantial decrease in pollution from hydrochloric acid was achieved rather quickly; by the end of 1964 the average escape of hydrogen chloride was reduced to 1.28 per cent, which was well within the legally permissible value of 5 per cent (Reed, 1998). This meant a reduction in the weekly escape of gas from roughly 4,000 tons in 1863 to 43 tons by the end of 1864 .

Then the Alkali Act was made perpetual in 1868, and its scope was enlarged later. The Alkali Act of 1874 set a volumetric standard of $0.2 \mathrm{~g}$ of hydrochloric acid per cubic foot, and extended the definition of noxious gases to cover fumes from sulfuric, sulfurous, and nitric acids, hydrogen sulfide, and chlorine. All alkali manufacturers were required to use the "best practicable means" to prevent their discharges into the atmosphere or render them harmless when discharged (Reed, 1998). At that time 99 per cent recovery rates were common. By 1887 hydrochloric acid gas liberated into the atmosphere amounted to no more than 0.1 per cent of the total gas produced (Warren, 1980). Subsequently, the Alkali, etc. Works Regulation Act of 1881 set fixed standards for sulfur and nitrogen acid gases and included prohibition on deposit and drainage of all alkali sulfur waste ${ }^{118}$.

\footnotetext{
ins 1892 another Alkali Act extended the provisions of previous acts not only to all branches of the chemical industry, but also to a great number of other industrics. Finaly, a bill repealing previous alkali acts and replacing them by angle consolidated act was introduced in 1894 and passed two years later (Haber, 1958).
} 
Table A-2 Emissions of Hydrogen Chloride from the Leblanc Plants in Britain

\begin{tabular}{|c|c|c|c|c|}
\hline Year & 1863 & 1864 & 1874 & 1887 \\
\hline Regulation & $5 \%$ & - & $0.2 \mathrm{~g} \mathrm{HCl} \mathrm{ft}^{3}$ & - \\
\hline Actual emissions & - & $1.28 \%$ & $1 \%$ & $>0.1 \%$ \\
\hline
\end{tabular}

These introductions of regulations on emissions of hydrogen chloride made available a large amount of hydrochloric acid recovered from the Leblanc process. That encouraged technological developments for turning it into chlorine, which could be used directly for preparing bleach. The method used to manufacture chlorine was to oxidize hydrochloric acid by the use of manganese dioxide $\left(\mathrm{MnO}_{2}\right)$ :

$$
\mathrm{MnO}_{2}+4 \mathrm{HCl} \rightarrow \mathrm{MnCl}_{2}+\underline{\mathrm{Cl}_{2}}+2 \mathrm{H}_{2} \mathrm{O}
$$

This process, however, was wasteful and costly, because all the manganese as well as much of the chlorine as manganese chloride $\left(\mathrm{MnCl}_{2}\right)$ was lost. While the profitability of bleaching manufacture depended on the recovery of manganese and the maximization of the yield of chlorine, the residual liquid, which contained both hydrochloric acid and chlorine, caused great nuisance in watercourses and drains.

Whille manganese chloride could be neutralized with lime in the middle of the $1850 \mathrm{~s}$, a more efficient process was invented in 1866 . The essential feature of the Weldon process was the use of excess lime, precipitating a mixture which contains manganese dioxide:

$$
\begin{aligned}
& \mathrm{MnCl}_{2}+\mathrm{Ca}(\mathrm{OH})_{2}>\mathrm{Mn}(\mathrm{OH})_{2}+\mathrm{CaCl}_{2} \\
& \mathrm{Mn}(\mathrm{OH})_{2}+1 / 2 \mathrm{O}_{2} \rightarrow \mathrm{MnO}_{2} \text { (recycled) }+\mathrm{H}_{2} \mathrm{O} .
\end{aligned}
$$

By constantly recirculating the slurry of manganese, the so-called Weldon mud, losses were kept within 4 to 10 per cent. For manufacturing one ton $(1,016 \mathrm{~kg})$ of bleaching powder, Weldon's process reduced the use of manganese from $16 \mathrm{cwt}$. $(813 \mathrm{~kg}$ ) to about $30 \mathrm{lb} .(1.4 \mathrm{~kg}$ ) by the late 1880s (Warren, 1980). While most of the manganese dioxide was recovered in this way, only one third of the available chlorine was liberated. Although it became possible to make a ton of bleaching powder from 45 to $50 \mathrm{cwt}$. of salt, instead of $60 \mathrm{cwt}$. as hitherto, much of the chlorine was still lost as the solid waste calcium chloride $\left(\mathrm{CaCl}_{2}\right)$.

A direct process for recovering manganese was developed in 1868. The Deacon process produced chlorine and water directly by passing hydrochloric acid gas and air over hot brickwork impregnated with a catalyst of copper chloride $\left(\mathrm{CuCl}_{2}\right)$.

$$
4 \mathrm{HCl}+\mathrm{O}_{2} \text { (air) }-\left(450-460^{\circ} \mathrm{C}, \mathrm{CuCl}_{2}\right)>2 \mathrm{Cl}_{2}+2 \mathrm{H}_{2} \mathrm{O}
$$


The Deacon process used salt more efficiently, as a ton of bleach could be made from 32 to 40 cwt. of salt. This process, however, had the disadvantage of requiring much more costly and complicated equipment than the Weldon process; a plant with a capacity of 100 tons of bleaching powder a week cost $£ 13,000$ whereas a comparable Weldon plant required $£ 12,000$ (Warren, 1980). As a result, despite its deficiencies, the Weldon process was adopted for most of the world's chlorine production up to the early year of the twentieth century.

Other countries took different approaches to legislation against atmospheric pollution by chemical and allied works, without specifying any mission standards (Haber, 1958). In France, an Imperial decree issued in 1810 empowered the prefect to control the building of certain works and to prescribe their layout. Industries were classified according to the impact they made on their surroundings, and the most noxious ones were banished to areas where they could do least harm. Chemical plants hence could not be built alongside dwellings, and the police had orders to enforce the decree. In the 1850 s they were assisted by "Conseils d'Hygiène," which could investigate abuses and submit recommendations as to their removal to the Ministry of the Interior. In Belgium a royal decree laid down that official permission had to be granted before the building of a works emitting smoke and fumes could be started. As far as is known, however, no action was taken to implement it. Prussia had no regulations of any kind, but from 1861 onwards the public were entitled to state their objections to any new project threatening the amenities. In Basle, 1853, certain types of works, including those preparing chemicals, could not be established without the prior consent of the municipality. The city's sanitary inspector took energetic action against those found guilty of polluting. streams and emitting gases and, if the need arouse, called in outside experts to investigate and offer advice.

\section{A.1.2 Tank Waste}

Another major waste produced in the Leblanc process was tank waste or alkali waste, of which the main constituent was calcium sulfide (CaS). Every ton of Leblanc soda ash was accompanied with about 1.4 tons of tank waste, an insoluble residue which remained after the sodia ash had been extracted from the black ash. This smelly waste was dumped around the works, causing a great loss of space and polluted air and water. The Alkali Inspector estimated in the early $1880 \mathrm{~s}$ that there were nearly 4.5 million tons of alkali waste in Lancashire alone and that it was increasing at the rate of 1,000 tons a day (Haber, 1958). In Widnes tips began to appear after 1865 , and by 1888 it was estimated that 680 acres of land 
had been covered with waste to a depth of from 8 to 25 feet, anounting to 9 million tons (Warren, 1980). The loss of sulfur, which consisted of 20 to 25 per cent of the tank waste, was considerable; indeed, it was well known that all the sulfur, in the form of sulfuric acid, cmployed in the production of Leblane soda was lost. As sulfur was a substance that was expensively imported to make sulfuric acid, there was a great incentive to recover sulfur from the solid waste.

Attempts were made as early as in the 1830 s to liberate hydrogen sulfide from calcium sulfide and to convert this gas to sulfurous acid (Table A-3). Other similar investigations in the 1860 s achieved a measure of success. They converted calcium sulfide to hyposulfite and then precipitated sulfur by treatment with excess hydrochloric acid. It was clamed that 50 to 60 per cent of the available sulfur could be recovered, but in practice it was not possible to obtain more than 40 per cent. The process was expensive and troublesome and therefore was only in limited use (Haber, 1958).

Table A-3 Technological Developments for the Treatment of Tank Waste form the Leblanc Process

\begin{tabular}{|c|c|}
\hline Year & Technological Development \\
\hline 1837 & Gossage's attempts to recover sulfur from calcium sulfide \\
\hline 1862 & Mond's and Schaffner's attempts to recover sulfur from calcium sulfide \\
\hline 1882 & Invention of the Claus kiln \\
\hline 1888 & $\begin{array}{l}\text { Development of the Chance process for recovering sulfur from the waste of } \\
\text { calcium sulfide }\end{array}$ \\
\hline
\end{tabular}

The decisive breakthrough came only in the 1880 s. About forty years earlier it had been already realized that an excess of carbonic acid was necessary to liberate hydrogen sulfide from tank waste, but suitable equipment to accomplish this purpose was not successfully devised. Owing to the availability of improved machinery and appliances, an efficient apparatus was invented by Chance in 1888 . In the Chance process, tank waste was made into slurry and passed through an arrangement of cylinders, "carbonators", where it came into contact with the gas containing carbon dioxide. Hydrogen sulfide $\left(\mathrm{H}_{2} \mathrm{~S}\right)$ of the desired concentration was evolved in the last cylinder:

$$
\begin{aligned}
& 2 \mathrm{CaS}+\mathrm{H}_{2} \mathrm{O}+\mathrm{CO}_{2}>\mathrm{Ca}(\mathrm{SH})_{2}+\mathrm{CaCO}_{3} \\
& \mathrm{Ca}(\mathrm{SH})_{2}+\mathrm{H}_{2} \mathrm{O}+\mathrm{CO}_{2}>\mathrm{CaCO}_{3}+2 \mathrm{H}_{2} \mathrm{~S} .
\end{aligned}
$$

The hydrogen sulfide was then transferred to a kiln, which was invented by Claus in 1882 , in which the catalytic action of ferric oxide liberated sulfur (S): 
ash with ferric oxide ${ }^{119}$ and separating the resulting sodium ferrite, by leaching with water, into caustic soda and ferric oxide ${ }^{120}$, which was reused in the process (Warren, 1980).

The ammonia soda process was to a high degree self-contained, and the raw materials of brine and ammonia were readily available. Less fuel was used than in the Leblanc process, and no sulfur or nitre was involved. The ammonia soda process hence had enormous advantages over the Leblanc process. A comparison of costs between the Leblanc and the ammonia soda processes in 1872 is given in Table A-7.

Table A-7 Production Costs of the Leblanc and Ammonia Soda Processes in 1872

\begin{tabular}{|c|c|c|c|c|}
\hline & \multicolumn{2}{|c|}{ Leblane process ${ }^{\mathrm{a}}$} & \multicolumn{2}{|c|}{ Ammonia soda process } \\
\hline $\begin{array}{c}\text { Materials and } \\
\text { overheads }\end{array}$ & Quantity per ton & $\begin{array}{c}\text { Cost per ton } \\
\& \quad \text { s. d. }\end{array}$ & Quantity perton & $\begin{array}{l}\text { Cost per ton } \\
\qquad \mathrm{s} . \mathrm{d} .\end{array}$ \\
\hline Pyrites & 17.5 cwt. $^{\circ}$ & 1108 & - & - \\
\hline Saltpeter & $56 \mathrm{lb}$ & 70 & - & - \\
\hline Salt & $29 \mathrm{cwt}$. & 124 & 40 cwt. (brine) & 16 \\
\hline Limestone & $35 \mathrm{cwt}$. & 114 & 44 cwt. & 144 \\
\hline Coall (slack) & $88 \mathrm{cwt}$. & 1152 & 39 cwt. & 173 \\
\hline Coke & - & - & $5.5 \mathrm{cwt}$ & 50 \\
\hline Ammonia sulfate & - & - & $202 \mathrm{lb}$. & 1160 \\
\hline Total material costs & - & 4166 & - & 3141 \\
\hline Wages & - & 1120 & - & 150 \\
\hline Salaries, rents, rates & - & 150 & - & 148 \\
\hline Insurance & $=$ & 140 & - & 110 \\
\hline Packages & - & 180 & - & 120 \\
\hline Freight to Liverpool & - & 20 & - & 36 \\
\hline Royalty & - & - & - & 80 \\
\hline Grand total & - & 970 & - & 783 \\
\hline
\end{tabular}

( $55 \% \mathrm{Na} \mathrm{O}$ equivalent)

a: a plant at Widnes

b: a projected plant at Winsford

c: 1 hundredweight $(\mathrm{cwt})=$.112 pounds $($ lbs. $)=50.8 \mathrm{~kg}$

Source: Cohen (1956).

He drew on his experience with Hutchinson at Widnes for the Leblanc figures and on Solvay and Mond for the ammonia soda estimates. The table shows that there was a difference of nearly $£ 2$ per ton in favor of the ammonia soda process. As regards the capital investment, it was estimated that an ammonia soda plant with a weekly output of 60 tons cost

${ }_{13} \mathrm{Na}_{2} \mathrm{CO}_{3}+\mathrm{Fe}_{2} \mathrm{O}_{3}>2 \mathrm{NaFeO}_{3}+\mathrm{CO}_{2}$ 


$$
2 \mathrm{H}_{2} \mathrm{~S}+\mathrm{O}_{2}-2 \mathrm{~S} \text { (recyeled) }+2 \mathrm{H}_{2} \mathrm{O} \text {. }
$$

About 65 to 80 per cent of the sulfur in tank waste could be recovered by this process, with its purity very high. In 1893 the Chance-Claus process was worked in Britain on a scale sufficient to yield 35,000 tons of sulfur annually, which found a market for the manufacture of sulfuric acid.

\section{A. 1.3 Nitrogen Oxides Emissions}

The production of sulfuric acid $\left(\mathrm{H}_{2} \mathrm{SO}_{4}\right)$, which was an essential input for the Leblanc process, also created wastes. Since a considerable amount of sulfuric acid, which was difficult to transport, was required, most alkali manufacturers produced it by themselves. The sulfuric acid was originally prepared by heating sulfates such as alum and copperas and condensing the products of distillation. In 1737 sulfurio acid began to be produced by the Bell Chamber method, in which a mixture of sulfur and nitre (saltpeter, $\mathrm{KNO}_{3}$ ) was burned in the necks of large glass vessels containing a little water. In 1746, based on essentially the same process, operations on an even larger scale started by replacing the glass vessels with lead boxes, the so-called lead chambers (Table A-4).

Table A-4 Technological Developments of the Treatment of Nitrogen Oxides Emissions from the Leblanc Process

\begin{tabular}{|c|l|}
\hline Year & \multicolumn{1}{|c|}{ Technological Development } \\
\hline 1746 & Development of the Lead Chamber process \\
\hline 1827 & Invention of the Gay-Lussac tower for recovering nitrogen oxides \\
\hline 1860 & Invention of the Glover tower for recovering nitrogen oxides \\
\hline
\end{tabular}

The Lead Chamber method, however, was not a continuous process and wastefully emitted vollumes of foul gases, as demonstrated in the following reactions:

$$
\begin{aligned}
& \mathrm{SO}_{2}+\mathrm{NO}_{2}+\mathrm{H}_{2} \mathrm{O}>\mathrm{H}_{2} \mathrm{SO}_{4}+\mathrm{NO}^{*} \\
& \mathrm{NO}+1 / 2 \mathrm{O}_{2}>\mathrm{NO}_{2} .
\end{aligned}
$$

Successful operation of this process required that the waste gases of nitrogen oxides, i.e. nitric oxide ( $\mathrm{NO}$ ) and nitrogen dioxide $\left(\mathrm{NO}_{2}\right)$, which were originally carried away to the atmosphere, should be recovered. The process was greatly improved after the addition of the Gay-Lussac and the Glover towers, which made it possible to recycle these waste gases and thus to reduce the amount of saltpeter used in the catalyzing the reaction. 
In 1827 Gay-Lussac developed the absorption tower that then made it possible to capture nitrogen oxides from the sulfuric acid chambers to produce nitrosyl sulfuric acid (ONOSO $3 \mathrm{H}$ ), so-called "mitrous vitriol":

$$
\mathrm{NO}+\mathrm{NO}_{2}+2 \mathrm{H}_{2} \mathrm{SO}_{4} \rightarrow 2 \mathrm{ONOSO}_{3} \mathrm{H}+\mathrm{H}_{2} \mathrm{O}
$$

This improved not only the envirommental but also the economic aspects of the process, as more than 50 per cent of the saltpeter used could be saved. However, it was not easy to return. the active nitrogen oxides to the working chambers without diluting the solution of nitrosyl sulfuric acid in sulfuric acid with water. Because of the high cost of reconcentrating the diluted acid to commercial strength after the release of nitrogen oxides, most producers did not put the Gay-Lussac's invention into practice (Hocking, 1998). With nitrate of soda at 12 a ton in the early $1860 \mathrm{~s}$, it did not pay to collect and absorb the waste oxides of nitrogen (Warren, 1980).

The development of the Glover tower in 1860 allowed, in the same unit, both the release of nitrogen oxides by water dilution and the reconcentration of the acid via the hot gases generated from sulfur combustion:

$$
\mathrm{ONOSO}_{3} \mathrm{H}+\mathrm{H}_{2} \mathrm{O} \rightarrow \mathrm{H}_{2} \mathrm{SO}_{4}+\mathrm{HNO}_{3} \text { (recycled). }
$$

This additional innovation made the combination of the two towers more attractive to sulfuric acid producers: the Glover tower at the front-end unit, as a generator-concentrator, and the Gay-Lussac tower at the tail gas recovery unit. A rise in sallpeter prices between 1868 and 1870 led to the widespread adoption of the Glover-Gay-Lussac system in Britain (Haber, 1958).

\section{A.1.4 Improvement of the Leblanc Process through End-of-Pipe Technologies}

The years between 1860 and 1880 have been called the golden years of the Leblanc soda industry. The problems of waste and pollution were overcone gradually by technological improvements, which were basically end-of-pipe equipment. That also brought about great savings in raw materials at the same time. The Leblane process had reached a modicum of efficiency as a selli-contained series of interlocking processes by the $1880 \mathrm{~s}$. By the end of the 19 th century, the cost of raw materials required to make a ton of soda ash had fallen to less than $\mathfrak{E 2}$, as shown by the trends in the consumption of materials for the Leblano process in Table $\mathrm{A}-5$. 
Table $A-5$ Consumption and Cost of Raw Materials for the Unit Production of Soda Ash in the Leblane Process

\begin{tabular}{|c|c|c|c|c|c|c|c|c|}
\hline & \multicolumn{2}{|c|}{1861} & \multicolumn{2}{|c|}{1876} & \multicolumn{2}{|c|}{1886} & \multicolumn{2}{|c|}{1894} \\
\hline & guant. & fs.d. & quant. & Es.d. & quant. & Es.d. & quant. & $f$ s. d, \\
\hline Pyrites & $24 \mathrm{cwt}$ & 1150 & $17 \mathrm{cwt}$. & 154 & $13.5 \mathrm{cwt}$ & 93 & - & - \\
\hline Siallpeter & $1121 \mathrm{~b}$ & 120 & $32 \mathrm{lb}$ & 34 & $23 \mathrm{lb}$ & 20 & - & - \\
\hline Salt & $25 \mathrm{cwit}$ & 100 & 25 cwt. & 100 & $25 \mathrm{cwt}$ & 100 & - & - \\
\hline Saltcake & - & - & - & $=$ & $=$ & - & $33 \mathrm{cwt}$. & 168 \\
\hline Eimestone & $30 \mathrm{cw}$. & 100 & $32 \mathrm{cwl}$. & 44 & $26 \mathrm{cwt}$ & 66 & $n d a$ & $\begin{array}{ll}66 \\
\end{array}$ \\
\hline $\begin{array}{l}\text { Coal } \\
\text { (slack) }\end{array}$ & $70 \mathrm{cwt}$. & 140 & $60 \mathrm{cwt}$. & 166 & $55 \mathrm{cwt}$. & 126 & $\mathrm{n} / \mathrm{a}$ & 139 \\
\hline Total & - & 480 & - & 2196 & - & 203 & - & 11611 \\
\hline
\end{tabular}

1861 and 1886: the costs are for a works in Lancashire.

1876: the costs are for a medium-sized business in Tyneside.

Source." Haber (1958).

\section{A.2 Ammonia Soda Process}

On the other hand, it was shown theoretically as early as 1811 that ammonium salts could be used to generate soda in the so-called ammonia soda process (Table A-6). Although the apparent simplicity of the process was quite attractive, for many years the complexity of the equipment and the problem of the loss of ammonia defeated attempts to develop it on an industrial scalle.

Table A-6 Technological Developments of the Ammonia Sada Process

\begin{tabular}{|c|l|}
\hline Year & \multicolumn{1}{|c|}{ Technological Development } \\
\hline 1811 & Theoretical investigation on the ammonia soda process by Fresnel \\
\hline 1861 & Invention of the Solvay tower for the recovery of ammonia \\
\hline 1864 & Operation of the first ammonia soda plant by Solvay \\
\hline 1872 & Operation of the first ammonia soda plant in Britain \\
\hline 1880 & Operation of the first ammonia soda plant in Germany \\
\hline 1884 & Operation of the first ammonia soda plant in the United States \\
\hline
\end{tabular}

The flow diagram of the ammonia soda process is given in Figure A2-2. First, calcium carbonate $\left(\mathrm{CaCO}_{3}\right)$ is heated to give calcitum oxide $(\mathrm{CaO})$ and carbon dioxide $\left(\mathrm{CO}_{2}\right)$ :

$$
\mathrm{CaCO}_{3}>\mathrm{CaO}+\mathrm{CO}_{2} \text {. }
$$

The carbon dioxide is then bubbled into a solution of sodium chloride ( $\mathrm{NaCl}$ ) in ammonia $\left(\mathrm{NH}_{3}\right.$ ), and sodium bicarbonate (sodium bicarbonate, $\mathrm{NaHCO}_{3}$ ) is precipitated:

$$
\mathrm{NaCl}+\mathrm{NH}_{3}+\mathrm{CO}_{2}+\mathrm{H}_{2} \mathrm{O} \rightarrow \mathrm{NaHCO}_{3}+\mathrm{NH}_{4} \mathrm{Cl}
$$


The sodium bicarbonate is converted into soda ash (sodium carbonate, $\mathrm{Na}_{2} \mathrm{CO}_{3}$ ) by the application of heat:

$$
2 \mathrm{NaHCO}_{3}>\mathrm{Na}_{2} \mathrm{CO}_{3}+\mathrm{CO}_{2}+\mathrm{H}_{2} \mathrm{O}
$$

The ammonium chloride ( $\mathrm{NH}_{4} \mathrm{Cl}$ ) is heated with calcium oxide, which is obtained from the first stage of the process, to regenerate the ammonia:

$$
2 \mathrm{NH}_{4} \mathrm{Cl}+\mathrm{CaO}-(\text { heat })>\mathrm{CaCl}_{2}+2 \mathrm{NH}_{3} \text { (reuse) }+\mathrm{H}_{2} \mathrm{O} \text {. }
$$

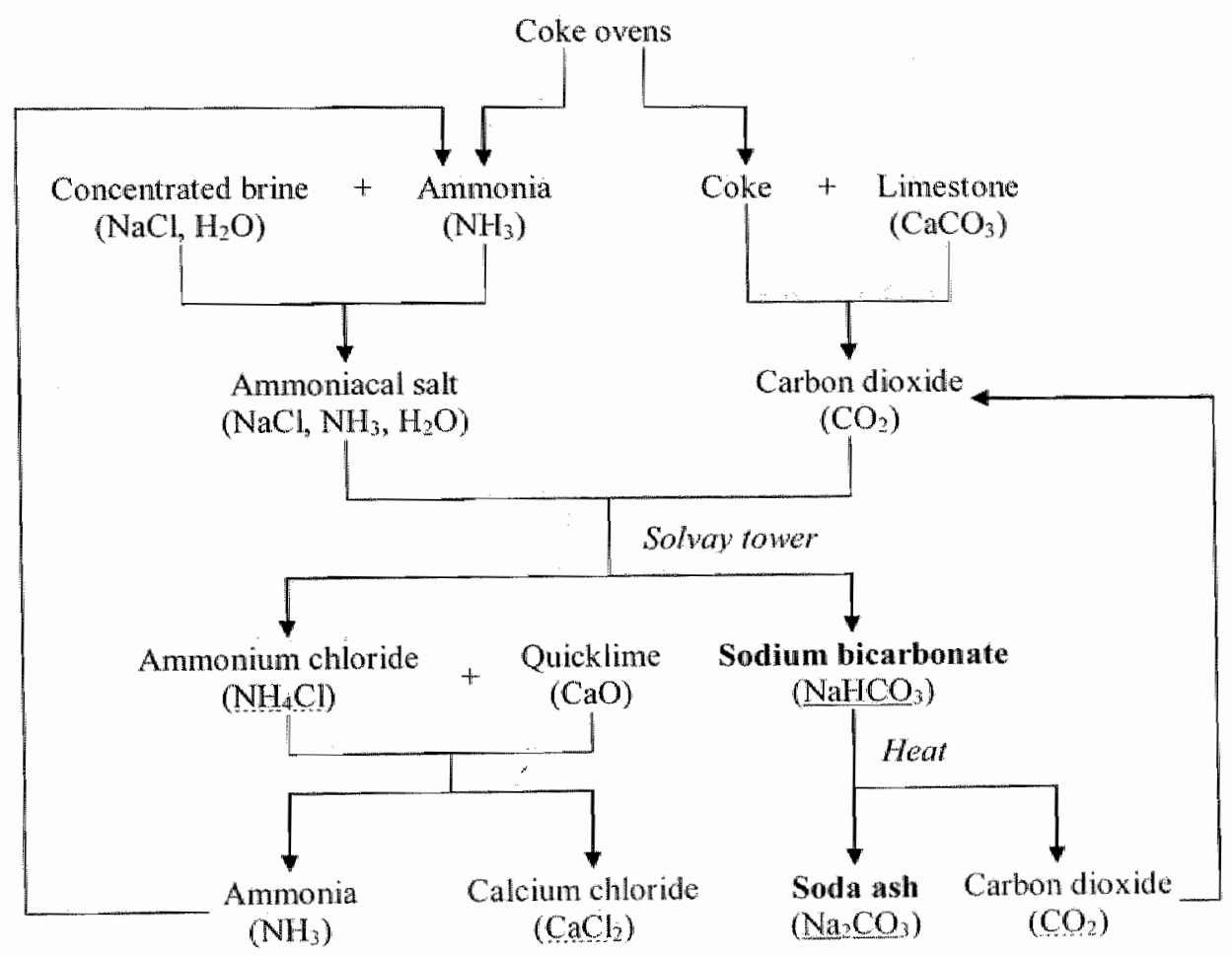

\section{Figure A-2 Flow Diagram of the Ammonia-Soda Process}

Based on Warren (1980).

A similar process was patented in Britain in 1838 and was practiced subsequently. A number of other chemical manufacturers in Britain, France, and Germany attempted to manufacture soda by this ammonia soda method, on which at least eight patents were granted between 1838 and the early 1860 s (Warren, 1980). All the efforts, however, proved to be commercial failues, because of practical difficulties, namely, imperfect conversion of the salt 
and, more importantly, the loss of ammonia, a light and volatile gas; which was relatively cosilly to manufacture.

In 1861 the Belgian chemist, Enst Solvay designed a tower to recover ammonia successfully. In the so-called Solvay tower, a solution of ammoniacal salt was met by an up current of carbon dioxide. By periodic withdrawal of part of the solution from the Solvay tower and its replacement by a fresh solution of ammoniacal salt, the process was made continuous. Ammonia was initially provided from gasworks, but the supply was later increased by installation of by-product coke ovens. Solvay's work on this involved the scrubbing of by-product gases and led to the development of the Semet-Solvay oven design. His other developments included improvements in the kilns for liberating carbon dioxide from limestone and for calcining the sodium bicarbonate. Solvay formed a company in Belgium to work the process, and the first works was built in 1863. It was four years before the Solvay process was finally working satisfactorilly.

The ammonia socla process was licensed and introduced into Britain in 1873, and the soda production started one year later. The initial failure of the ammonia soda process was. due to the lack of an efficient method of recovering ammonia from the mother liquor and the inability to minimize ammonia losses during operation. Since ammonia was a comparatively expensive commodity, the heavy losses of ammonia in the cycle made it impossible for the process to compete with the Leblanc process. A column distiller designed by Mond and built in 1883 made the recovery of ammonia possible by reacting ammonium chloride with quicklime, leaving calcium chloride as waste material (Hou, 1942). As a result, the loss of ammonia in the ammonia soda process was almost halved between 1862 and 1887 (Warren, 1980).

The ammonia soda process, however, had a weakness that the chlorine used in the salt rentained locked up in the calcium chloride $\left(\mathrm{CaCl}_{2}\right)$, It had to be dumped as solid waste, although on a very much smaller scale than that of the tank waste of the Leblanc process. In 1886 Mond developed a method to make it possible to recover the chlorine by passing calcium chloride over a nickel oxide catalyst. In practice, his method was still ineffective and was superseded by Carl Höpfner's process, in which the chlorine was recovered as zinc chloride and then decomposed electrolytically, making it possible to produce bleaching powder. In 1895 the Löwig process was adopted for making caustic soda by furnacing soda 
ash with ferric oxide ${ }^{119}$ and separating the resulting sodium ferrite, by leaching with water, into caustic soda and ferric oxide ${ }^{120}$, which was reused in the process (Warren, 1980).

The ammonia soda process was to a high degree self-eontained, and the raw materiats of brine and ammonia were readily available. Less fuel was used than in the Leblanc process, and no sulfur or nitre was involved. The ammonia soda process hence had enomous advantages over the Leblano process. A comparison of costs between the Leblane and the ammonia soda processes in 1872 is given in Table A-7.

Table A-7 Production Costs of the Leblanc and Ammonia Soda Processes in 1872

\begin{tabular}{|c|c|c|c|c|}
\hline & \multicolumn{2}{|c|}{ Leblanc process ${ }^{a}$} & \multicolumn{2}{|c|}{ Ammonia soda process } \\
\hline $\begin{array}{c}\text { Materials and } \\
\text { overheads }\end{array}$ & Quantity per ton & $\begin{array}{r}\text { Cost per ton } \\
\pm \quad \text { s.d. }\end{array}$ & Quantity per ton & $\begin{array}{l}\text { Cost per ton } \\
\mathrm{e} \text { s. d. }\end{array}$ \\
\hline Pyrites & 17.5 cwt. $^{\circ}$ & 1108 & $=$ & - \\
\hline Saltpeter & $56 \mathrm{lb}$. & 70 & $=$ & $=$ \\
\hline Salt & 29 cwt. & 124 & 40 cwt: (brine) & 16 \\
\hline Limestone & $35 \mathrm{cwt}$. & 114 & 44 cwl. & 144 \\
\hline Coal (slack) & $88 \mathrm{cwt}$. & 1152 & $39 \mathrm{cwt}$. & 173 \\
\hline Coke & - & - & 5.5 cwt. & 50 \\
\hline Ammonia sulfate & - & - & $202 \mathrm{Ib}$ & 1160 \\
\hline Total material costs & $=$ & 4166 & - & 3141 \\
\hline Wages & z & 1120 & - & 150 \\
\hline Salaries, rents, rates & - & 150 & - & 148 \\
\hline Insurance & - & 140 & - & 110 \\
\hline Packages & - & 180 & - & 120 \\
\hline Freight to Liverpool & $=$ & 20 & - & 36 \\
\hline Royalty & $=$ & - & - & 80 \\
\hline Grand total & - & 970 & - & 783 \\
\hline
\end{tabular}

( $55 \% \mathrm{Na}_{2} \mathrm{O}$ equivalent)

a: a plant at Widnes

b: a projected plant at Winsford

c: 1 hundredweight (cwt.) $=112$ pounds $(\mathrm{lbs})=.50.8 \mathrm{~kg}$

Source: Cohen (1956).

He drew on his experience with Hutchinson at Widnes for the Leblanc ligures and on Solvay and Mond for the ammonia soda estimates. The table shows that there was a

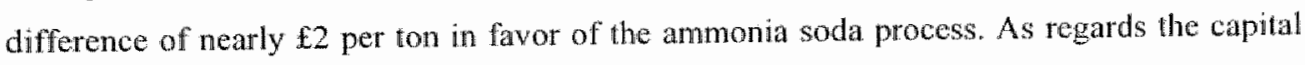
investment, it was estimated that an ammonia soda plant with a weekly output of 60 tons cost

\footnotetext{
$119 \mathrm{Na}_{2} \mathrm{CO}_{3}=\mathrm{Fe}_{7} \mathrm{O}_{3}>2 \mathrm{NaPaO}_{3}+\mathrm{CO}_{2}$

$2 \mathrm{NaFeO}_{2}+\mathrm{H}_{2} \mathrm{O} \rightarrow 2 \mathrm{NaOH}+\mathrm{Fe}_{2}$
} 
113,500 and a Leblame installation of the same capacity, $\mathfrak{E} 10,000$ (Haber, 1958). Assuming plants were operated for 50 weeks a year, their annual output was

60 tons/week $x 50$ weeks/year $=3,000$ tons/year.

Hence the annual saving in operating cost was

$$
£ 2 / \text { ton } \times 3,000 \text { tons/year }=£ 6,000 / \text { year. }
$$

On the other hand, the difference in capital investment between the ammonia soda and the Leblanc processes was

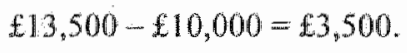

Thus, it did: not take one year to recover the initial excess investment in the ammonia process.

As another cost estimation made in 1894 shows in Table A-8, the difference in operating costs between the two processes remained significantly wide and, as far as the Leblanc process was concerned, irreducible. Accordingly, the Leblanc process started to experience severe competition from the ammonia soda process.

\begin{tabular}{|c|c|c|}
\hline & Leblanc process & Ammonia soda process ${ }^{b}$ \\
\hline$\because$ & E s. d. & s s.d. \\
\hline Raw materials & $116 \quad 11$ & 16 \\
\hline Saltcake & $16 \quad 8$ & - \\
\hline Brine and pumping charges & - & 9 \\
\hline Limestone & $\begin{array}{ll}6 & 6 \\
\end{array}$ & 46 \\
\hline Slack & 139 & 90 \\
\hline Coke & - & \\
\hline Loss of ammonia & - & 60 \\
\hline Wages & $14 \quad 0$ & 143 \\
\hline Management, laboratory, and office expenses. & 20 & 36 \\
\hline Repairs, wages, and materials & 4.6 & 56 \\
\hline Gencral oharges & 46 & 140 \\
\hline Total & $£ 3111$ & $\mathfrak{1 2} 18 \quad 9$ \\
\hline
\end{tabular}

Table A-8 Production Costs of the Leblane and Ammonia Soda Processes in 1894

a: $55 \%$ Nas $\mathrm{O}$ equivalent

b: $58 \%$ NarO equivalent

Sowre: Worpen (1980).

Significantly, however, many alkali producers in Britain continued to use the Leblanc process. The British Leblanc soda production increased throughout the 1870 s, with the highest point acheved in 1880 (Table A-9). Thereafter, the Leblanc process maintained its position as the dominant technology for the British chlor-alkali industry, although its 
production shrank by 10 per cent from 1884 to 1994 , from 380,000 tons to 340,000 tons in 1894.

Table A-9 Soda Productions by the Leblanc and the Ammonia Sodn Processes in Britain

\begin{tabular}{|c|c|c|c|c|}
\hline \multirow{2}{*}{ Year } & \multicolumn{3}{|c|}{ Leblanc process } & Ammonia soda process \\
\cline { 2 - 5 } & Soda ash & Caustic soda & Total & \\
\hline 1874 & - & - & - & 800 \\
\hline 1875 & - & - & - & 2,400 \\
\hline 1878 & 196,900 & $100,800^{\mathrm{b}}$ & 330,460 & 11,100 \\
\hline 1880 & 266,100 & 106,400 & 407,080 & 18,800 \\
\hline 1882 & 233,200 & 116,900 & 388,093 & - \\
\hline 1884 & 204,100 & 141,600 & 391,720 & - \\
\hline 1885 & - & - & - & 77,500 \\
\hline 1886 & 165,900 & 153,900 & 369,818 & - \\
\hline 1890 & - & - & - & 179,700 \\
\hline 1894 & - & - & 340,000 & 181,000 \\
\hline 1898 & - & - & - & 181,000 \\
\hline 1903 & - & - & - & 240,000 \\
\hline
\end{tabular}

Figures are expressed in British tons.

a: as $48 \% \mathrm{Na}_{2} \mathrm{O}$

b: Including production by non-members of the Alkali Association. (Later statistics of the Leblane soda industry have not been published.)

c: Total production of the Leblanc process was calculated as equivalent to soda $\operatorname{ash}^{121}$. d: Production figures of the ammonia soda process are those of Brumer, Mond \& $\mathrm{Co}$.

Sownes: 1894: Warren (1980). All other years: Haber (1958).

Operators of the Leblanc process made heavy capital investments in plants and had strong incentives to continuing to use it. Over 90 per cent of the British Leblanc manufacturers combined forces to form the United Alkali Company (UAC) in 1890 and began to modernize their obsolescent plants. The new company established a Central Rescarch Laboratory in 1891 , which was unusual in any chemical company at that time except for the German dyestuffs industry ${ }^{122}$, to conduct a research program to improve the efliciency of the Leblane process. Hence for a limited period of time UAC could remain viable and increasingly effictent by reducing its output of soda ash and maximizing its output of sulfuric acid, bleach and caustic soda, and the Leblanc process was still the dominant technology at the end of the 19 th century.

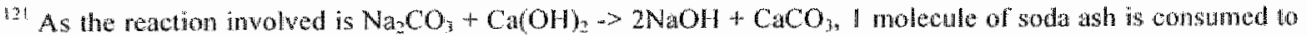
produce 2 molecules of canstic soda. Since the molectlar weight of soda ash. Na $\mathrm{CO}_{3}$, is 106 and thest of caustic soda, $\mathrm{NaOH}$, is 40 , I won of caustic soda is equivalent $10 \mathrm{l}$. $66 /(40 \times 2)=1.325$ tons of soda ash.
} 
In contrast, the nanufacture of soda in France was transformed by the introduction of the ammona soda process, as shown in Table A-10. White 30 to 40 Leblanc plants produced about 50,000 to 60,000 tonnes of alkali at around the time of 1870 , only three plants operated in 1899, whose combined output had declined significantly to 20,000 tonnes. On the other hand, soda production by the ammonia-soda process inereased rapidly. Its share in soda production in France surpassed that of the Leblanc process in the middle of the 1880 s and had. reached more than $80 \%$ by 1993 . Solway, in particular, quickly obtained a dominant position in operating the ammonia soda process; by the end of the century, the company had accounted for over four fifths of the French ammonia soda production.

Table A-10 Soda Productions by the Leblanc and the Ammonia Soda Processes in France

\begin{tabular}{|c|c|c|c|}
\hline Year & Leblanc process & Ammonia soda process & Total \\
\hline 1874 & $56,000(77 \%)$ & $17,000(23 \%)$ & 73,000 \\
\hline 1880 & $55,000(56 \%)$ & $44,000(44 \%)$ & 99,000 \\
\hline 1883 & $50,000(53 \%)$ & $44,000(47 \%)$ & 94,000 \\
\hline 1888 & $32,000(25 \%)$ & $97,000(75 \%)$ & 129,000 \\
\hline 1893 & $27,000(18 \%)$ & $120,000(82 \%)$ & 147,000 \\
\hline 1896 & $22,000(12 \%)$ & $168,000(88 \%)$ & 190,000 \\
\hline 1899 & $20,000(9 \%)$ & $195,000(91 \%)$ & $215,000^{\mathrm{n}}$ \\
\hline 1902 & $15,000(7 \%)$ & $215,000(93 \%)$ & 230,000 \\
\hline 1905 & $6,000(2 \%)$ & $270,000(98 \%)$ & $276,000^{\mathrm{h}}$ \\
\hline
\end{tabular}

Figures are expressed in metric tonnes.

a: 2,000 tonnes of electrolytic allkali were made in addition.

b: 4,000 tonnes of electrolytic alkali were made in addition.

Sowces: Ogbum and Jaffe (1929), Haber (1958).

Table A-1 II shows the world trends in soda production by the Leblanc and the ammonia soda processes from the middle of the 19 th century to 1940 . From the early 19 th century, the alkali industry was a growth industry in the world. In 1863 soda ash production reached an estimated 300,000 tons, all of which were produced by the Leblanc process. The world production had passed I million tons by 1890 , by which time the ammonia soda process had stolen the edge over the Leblanc process in output. In 1900, of the world total production of $1,500,000$ tons, only 200,000 tons were produced by the Leblanc process. In 1920 the last Leblanc plant in Britain was closed whereas by that time the production by the ammonia soda process had already surpassed three million tons.

Meyer-Thurow (1982) discusses the decisive tole that scientitic research played in the development of the 
Table A-11 World Soda Production by the Leblanc and the Ammonia Soda Processes

\begin{tabular}{|c|c|c|c|}
\hline Year & Leblanc Process & Ammonia Soda Process & fotal \\
\hline 1850 & $150,000(100 \%)$ & 0 & 150,000 \\
\hline 1863 & $300,000(100 \%)$ & 0 & 300,000 \\
\hline 1865 & $374,000(100 \%)$ & $300(-)$ & 375,000 \\
\hline 1870 & $447,000(99 \%)$ & $2,600(1 \%)$ & 450,000 \\
\hline 1875 & $495,000(94 \%)$ & $30,000(6 \%)$ & 525,000 \\
\hline 1880 & $545,000(80 \%)$ & $136,000(20 \%)$ & 681,000 \\
\hline 1885 & $435,000(54 \%)$ & $365,000(46 \%)$ & 800,000 \\
\hline 1890 & $390,000(38 \%)$ & $633,000(62 \%)$ & $1,023,000$ \\
\hline 1895 & $265,000(21 \%)$ & $985,000(79 \%)$ & $1,250,000$ \\
\hline 1990 & $200,000(13 \%)$ & $1,300,000(87 \%)$ & $1,500,000$ \\
\hline 1902 & $150,000(9 \%)$ & $1,610,000(91 \%)$ & $1,760,000$ \\
\hline 1905 & $150,000(8 \%)$ & $1,750,000(92 \%)$ & $1,900,000$ \\
\hline 1911 & $130,000(6 \%)$ & $1,900,000(94 \%)$ & $2,030,000$ \\
\hline 1913 & $50,000(2 \%)$ & $2,800,000(98 \%)$ & $2,850,000$ \\
\hline 1916 & negligible & $3,000,000(100 \%)$ & $3,000,000$ \\
\hline 1923 & 0 & $3,500,000(100 \%)$ & $3,500,000$ \\
\hline 1927 & 0 & $4,100,000(100 \%)$ & $4,100,000$ \\
\hline 1932 & 0 & $5,000,000(100 \%)$ & $5,000,000$ \\
\hline 1940 & 0 & $7,000,000(100 \%)$ & $7,000,000$ \\
\hline
\end{tabular}

Figures are expressed in US tons.

Source: Hon (1942).

\section{A.3 Concluding Remark}

In this Appendix, we made a preliminary analysis of different courses of technological change between the British and the French chlor-alkali industries in the late 19 th century. In Britain, the Leblanc process had become the dominant technology for alkali production by the middle of the 19th century. Following the introduction of the Alkali Act in 1863, various types of technological measures were developed to reduce pollutant emissions and wastes, such as hydrogen chloride, tank waste, and nitrogen oxides. Without changing the chemical reactions involving the main products, these technological measures were basically those of the end-ofpipe type. The performance of these technologies was improved gradually, and eventually the Leblanc process was made more efficient, as fewer inputs were consumed and more wastes were recycled. Thus the Leblanc process continued to be the dominant production technology in Britain, even after the successful industrial operation of a new production process, that is, 
the anmonia soda process. Following its successful invention in the 1860 s, the new ammonia soda process became more efficient than the Leblanc process as early as the 1870 s and cane to dominate the chlor-alkali industry. In other countries such as France, the Leblanc process was replaced with the ammonia soda process rather quickly while the Leblanc process remained as a major production technology in the British alkali industry for a long time.

Although this case of technological change needs more detailed and careful analysis, it suggests the possibility that environmental regulations on pollutant emissions in Britain induced alkali producers to develop end-of-pipe technologies for pollution reduction, which in effect delayed the diffusion of the newly developed, more efficient ammonia soda process. The chemical processes, however, were only to be superseded by the electrolytic routes, including the mercury process and the diaphragm process, which at that time were rapidly becoming established, concomitant with the development of the large-scale methods for the production and distribution of electricity. 


\section{References}

Adar, Zvi and James M. Griffin. 1976. "Uncertainty and the Choice of Pollution Control Instruments." Journal of Environmental Economics and Management, 3, 178-188. Aftalion, Fred. 1991. A History of the International Chemical Indusiry. Philadelphia: University of Philadeiphia Press.

Ahlqvist, Harald. 1936. "Alkali Industries Girdle the Globe." Chemical \& Metallurgicat Engineering, 43 (5), 278-281.

Aikawa, Hiroaki. 1998. "Kagaku Kogyo ni okenu Enso no Yakuwari: Iwarenaki 'Kankyo Osen no Genkyo'-setsu ni taishite (The Role of Chlorine in the Chemical Industry: Against the Unfounded Theory of 'The Cause of Environmental Pollution')." Soda to Enso, (10), 18-22.

Alperowicz, Natasha, Esther D'Amico, and Robert Westervelt. 2001. "Engineering \& construction: Still a buyers' market." Chemical Week, 163 (21), 23-26.

Anastas, Paul T. and John C. Warner, 1998. Green Chemistry: Theory and Practice. New York: Oxford University Press.

Aoki, Masahiko. 2000. Information, Corporate Governance, and Instifutional Diversity:

Competitiveness in Japan, the USA, and the Transitional Economies. New York: Oxford University Press.

Aoki, Masaluiko. 2001. Toward a Comparative Institutional Analysis. Cambridge, Massachusetts: MIT Press.

Arora, Ashish. 1997. "Patents, licensing, and market structure in the chemical industry." Research Policy, 26, 391-403. 
Arrow, Kenneth J. 1962. "The Economic Implications of Learning by Doing." Review of Economic Studies, $29,155-173$.

Arthur, W. Brian. 1989. "Competing Technologies, Increasing Returns, and Lock-in by Historical Small Events." Economic Jownal, 99, 116-131.

Asahi Chemical Industry. 1998. "Chlor-Alkali PJant Capacity Employing Asahi Chemical Bipolar Process." Asahi Chemical Industry.

Asahi Class. 1999. "AZEC Electrolyzer Supply Record." Asahi Glass.

Asahi Shinbun. 1973a. "Ariake-kai ni 'Daisan Minamata-byo' ('The Third Minamata Disease' in the Ariake Sea)." Asahi Shinbun, May 22.

Asahi Shnbun. 1973b. "Tokuyama-wan Engan, Jumin ni Minamata-byo no Utagai (An Allegation of the Minamata Disease in the Tokuyama Bay area)." Asahi Shinbun, June 11 .

Austin, John H. and Manuel Esayian. 1984. "Membrane Technology for Existing Chloralkali Plants." in Milton M. Silver and Everett M. Spore eds. Proceedings of the Symposizm on Advances in the Chlor-Alkali and Chlorate Industry. Pennington, NJ: Electrochemical Society.

Avery, Ruth Butler, Mary Lou Conant, and Helen F. Wiessenborn. 1959. "Selected Annotated Bibliography of Asbestos Resources in the United States and Canada," in United States Geological Survey ed. Contribution to Bibliography of Mineral Resources 1955-59. Washington, D.C.: United States Government Printing Office.

Baba, Yasunori and Masaru Yarime. 2000. "Bringing forth Green Innovation: Role of Industry's Voluntary Actions." in. Proceedings of the International Symposium 'The 21st Century: How Can the Circulatory Society be Achieved?" Graduate School of Agricultural and Life Sciences, University of Tokyo. 
Baba, Yasunori, Masaru Yarime, and Hiroyuki Hatashima. 1997. "Realising the Shift towards Closed-loop Recycling: Strategies of the Japanese Fims." Innewational Jowmal of Inwovation Management, 1 (1), 89-110.

Balmann, Alfons, Martin Odening, Hans-Peter Weikard, and Wilhelm Brandes. 1996. "Pathdependence without increasing returns to scale and network externalities." Jowmal of Economic Behavior and Organization, 29, 159-172.

Bartzokas, Anthony and Masaru Yarime. 1997. "Technology Trends in Pollution Intensive Industries: A Review of Sectoral Trends." Discussion Paper. 9706. United Nations University Institute for New Technologies:

Baumol, William and Wallace Oates. 1988. The Theory of Environmental Policy, Second ed. Cambridge, UK: Cambridge University Press.

Bellas, Allen S. 1998. "Empirical evidence of advances in scrubber technology." Resowrce and Energy Economics, 20, 327-343.

Bergner, Dieter. 1977. "Elektrolytische Chlorerzeugung nach dem Membranverfahren." Chemiker-Zeitung, 101 (10), 433-447.

Bergner, Dieter. 1982. "Membrane cells for chlor-alkali electrolysis." Journal of Applied Electrochemistry, 12, 631-644.

Bhanagar, Smita B. and Mark A. Cohen. 1999. "The Impact of Environmental Regulation on Innovation: A Panel Data Study." Working Paper. Vanderbilt Center for Enwironmental Management Studies, Vanderbilt University.

Bird, R. Byron, Warren E. Stewart, and Edwin N. Lightfoot. 1960. Transport Phenomena. New York: John Willey. 
Block, Jacob, Leonard E. Dolhert, Leonidas Petrakis, and Ronald P. Webster. 2000 .

"Eliminating asbestos from fireproofing materials:" Chemical Innovation, 30 (6), 21 29.

Bordoni, Valter 2000 . "Technological change in the chlor-alkali industry - your e-mail dated March 6, 2000: E-mail to the author. Proposal Manager, De Nora S.p.A., Millan, Italy, March 30.

Borregaard. 1998. "Conversion of Borregaard Chlor-Alkali Plant." Information paper submitted to European IPPC Bureau. Borregaard.

Bosterud, Ola. 2000. "Re: Chlor-Alkali Plant." E-mail to the author. Elkem, Bremanger, Norway, February 28.

Bouveng, H. O. 1972. "Control of Mercury in Effluents from Chlorine Plants." Pure and Applied Chemistry, 29, 75-91.

Brickman, Ronald, Sheila Jasanoff, and Thomas IIgen. 1985. Controlling Chemicals: The Politics of Regulation in Europe and the United States. Ithaca, NY: Comell University Press.

Brooks, J. David. 1988. "Membrane Technology: A Revolution in Chloralkali." in Fumio Hine, W. Bruce Darlington, Robert E. White and Richard D. Varjian eds. Proceedings of the Sympositum on Electrochenical Engmeering in the Chlor-Alkali and Chlorate Industries. Pennington, NJ: Electrochemical Society.

Brooks, Kenneth (with Anne Watzman). 1986. "New entries vie in chlorine technology." Chemical Week, 22-23.

Bruni, L. 1964. "Internal Economies of Scale with a Given Technique." Journal of Industrial Economics, 12, 175-190.

Buchanan, James M. and Gordon Tullock. 1975. "Polluters' Profits and Politicall Response: Direct Controls Versus Taxes." American Economic Review, 65 (1), 139-147. 
Carraro, Carlo and Francois Leveque eds. 1999. Woluntay Approaches in Emironmental Policy. Dordrecht: Kluwer Academic Publishers.

Cederlund, Peo. 1999. "Question about Chlor-Alkali Plant -Svar." E-mail to the author. Base Chemicals, Bohus, Sweden, December 20.

Chatterjee, S. N. 1984. "Design and Development of Electrochemical Chlor-Alkali Cells," in Ralph E. White ed. Electrochemical Cell Design. New York: Plenum Press.

Chemical Week. 2001. "Krupp Uhde, De Nora Form Chlor-Alkali JV:" Chemical Week, 163 $(6), 5$.

Chlorine Engineers Corp. 1998. "Chlorine Engineers Corp., Lid." Chlorine Engineers Corp. Chlorine Engineers Corp. 1999a. "CME Supply Record." Chlorine Engineers Corp. Chlorine Engineers Corp. 1999b. "Diaphragm Cell Supply Record." Chlorine Engineers Corp. Chlorine Engineers Corp. 1999c. "MBC Supply Record." Chlorine Engineers Corp. Chlorine Engineers Corp. 2000. "Supply Record of CEC's IEM Electrolyzer." Chlorine Engineers Corp.

Chlorine Institute. 1972. "Chlor-Alkali Producers outside North America." Chlorine Institute. Chlorine Institute. 1995. "Guidelines: Asbestos Handling for the Chlor-Alkali Industry, Edition 3." Chlorine Institute.

Chlorine Institute. 1997. "Chlor-Alkali Plants Outside North America." Chlorine Institute. Chlorine Institute. 1998a. "Chlor-Alkali Plants Outside North America." Chlorine Institute. Chlorine Institute. 1998b. "North American Chlor-Alkali Industry Plants and Production Data Report - 1997." Chlorine Institute.

Chlorine Institute. 1999a. "Chlor-Alkali Plants Outside North America." Chlorine Institute.

Chlorine Institute. 1999b. "North American Chlor-Alkali Industry Plants and Production Data Report - 1998." Chlorine Institute. 
Christensen, Clayton M. 1997. The Imovafor" Dillemma: When New Technologies Canse

Great Firms to Fail. Boston: Harvard Business School Press.

Clow, Archibald and Wan L. Clow. 1992. The Chemical Revolution: A Contribution to Soctal Technology. Philadelphia: Gordon and Breach Science Publishers:

Coase, Ronald H. 1960. "The Problem of Social Cost." Journal of Law and Economics, 3, 144.

Cohen, J. M. 1956. The Life of Ludwig Mond. London: Methuen.

Cole, Daniell H. and Peter Z. Grossman. 1999. "When is Command-and-Control Efficient?:

Institutions, Technology, and the Comparative Efficiency of Alternative Regulatory Regimes for Environmental Protection." Wisconsin Law Review, 887-938.

Cöllins, J. H. and J. H. Entwisle. 1980. "The Development and Operation of High Current Density Mercury Cells," in M. O. Coulter ed. Modern Chlor-Alkali Technology. Chichester: Ellis Horwood.

Committee for the Promotion of Process Conversions in the Soda Industry. 1973. "Soda Kogyo Seiho Tenkan Suishin Taisaku linkai Hokoku (Kinyu, Zeisei ni tsuite) (Report of the Committee for the Promotion of Process Conversion in the Soda Industry (On Finance and Tax)y." Committee for the Promotion of Process Conversions in the Sodta Industry.

Convention for the Prevention of Marine Pollution from Land-Based Sources. 1974.

"Convention for the Prevention of Marine Pollution from Land-Based Sources (Paris Convention)."

Convention for the Protection of the Marine Environment of the North-East Atlantic. 1992.

"Convention for the Protection of the Marine Environment of the North-East Atlantic (OSPAR Convention)." 
Coulter, M. O. ed. 1980. Modern Chor-Alkali Techrology (Proceedings of the Intermational

Chlorine Symposium, London, June 1979). Chichester: Ellis Horwood.

Council for the Promotion of Countermeasures against Mercury Pollution: 1973. "Dai 3-kai

Suigin-to Osen Taisaku Suishin Kaigi Giji Yoshi (Abstract of the Note of the 3rd

Meeting of the Council for the Promotion of Countemeasures against Mercury

Pollution)." Council for the Promotion of Countermeasures against Mercury Pollution.

Council for the Promotion of Countermeasures agaimst Mercury Pollution. 1977. "Dai 4-kai

Suigin-to Osen Taisaku Suishin Kaigi Kettei (Decisions of the 4th Meeting of the

Councill for the Promotion of Countermeasures against Mercury Pollution)." Council

for the Promotion of Countermeasures against Mereury Pollution.

Council for the Promotion of Countermeasures against Mercury Pollution. 1979. "Dai 5-kai

Suigin-to Osen Taisaku Suishin Kaigi Kettei (Decisions of the 5th Meeting of the

Council for the Promotion of Countermeasures against Mercury Pollution)." Council

for the Promotion of Countermeasures against Mercury Pollution.

Council for the Promotion of Countermeasures against Mercury Pollution. 1980. "Dai 6-kai

Suigin-to Osen Taisaku Suishin Kaigi Kettei (Decisions of the 6th Meeting of the

Council for the Promotion of Countermeasures against Mercury Pollution)." Council

for the Promotion of Countermeasures against Mercury Pollution.

Council for the Promotion of Countermeasures against Mercury Pollution. 1981. "Dai 7-kai

Suigin-to Osen Taisaku Suishin Kaigi ni tsuite (On the 7th Meeting of the Council for the Promotion of Countermeasures against Mercury Pollution)." Council for the

Promotion of Countermeasures against Mercury Pollution.

Council for the Promotion of Countermeasures against Mercury Pollution. 1982. "Dai 8-kai.

Suigin-to Osen Taisaku Suishin Kaigi ni tsuite (On the 8th Meeting of the Council for 
the Promotion of Countermeasures against Mercury Pollution). ${ }^{\text {" Council for the }}$ Promotion of Countermeasures agdinst Mercury Pollution.

Coundil for the Promotion of Countermeasures against Mercury Pollution. 1983. "Dai 9-kai Sugin-to Osen Taisaku Suishin Kaigi ni tsuite (On the 9 th Meeting of the Council for the Promotion of Countermeasures against Mercury Pollution)." Council for the Promotion of Counitermeasures against Mercury Pollution.

Council of the European Communities. 1973. "Environmental Action Programme." Official Jownal of the European Communities, $\mathrm{C}$ (112).

Council of the European Communities. 1976. "Council Directive 76/464/EEC of 4 May 1976 on pollution caused by certain dangerous substances discharged into the aquatic environment of the Community." Official Journal of the European Communities, $\mathbf{L}$ $(129), 23-$

Council of the European Communities. 1982. "Council Directive of 22 March 1982 on limit values and quality objectives for mercury discharged by the chlor-alkali electrolysis industry (82/176/EEC)." Official Journal of the European Communities, L (81), 29-34. Council of the European Communities. 1983. "Council Directive of 26 September 1983 on limit values and quality objectives for cadmium discharges $(83 / 513 / \mathrm{EEC})$." Official Jomnal of the European Conmunities, L (291).

Couneil of the Eurapean Communities. 1984a. "Council Directive of 8 March 1984 on limit values and quality objectives for mercury discharges by sectors other than the chloralkali electrolysis industry (84//56/EEC)." Official Joumal of the European Commmities, L (74). 
Council of the European Conmunities. 1984b. "Council Directive of 9 October 1984 on limit values and quality objectives for discharges of hexachlorocyclohexane (84/491/EEC)." Official Jowrnal of the European Communities, L (274).

Cowan, Robin and Philip Gunby. 1996. "Sprayed to Death: Path Dependence, Lock-in and Pest Control Strategies." Economic Joumal, 106 (436), $521-542$.

Cowan, Robin and Staffan Hulten. 1996. "Escaping Lock-in: "The Case of the Electric Vehicle." Techological Forecasting and Social Change, 53, 61-79.

Cowell, G. W. and C. Jackson. 1986. "Operating experience with the ICI FM21 Electrolyzer," in K. Wall ed. Modern Chlor-Alkali Technology, Volume 3. Chichester: Ellis Horwood. Craig, Paul and Graime de Burca. 1995. EC Law: Text, Cases, and Materials. Oxford: Clarendon Press.

Curlin, Calvert L., Tilak V. Bommaraju, and Constance B. Hansson. 1991. "Alkali and Chlorine Products: Chlorine and Sodium Hydroxide." Kirk-Orhmer Encyclopedia of Chemical Technology, Fourth ed, vol. 1. New York: Jolm Wiley.

Curlin, Calvert L., Thomas F. Florkiewicz, Benno Luke, Hans-Rudolf Minz, and Peter Schmittinger. 2000. "Comparison of the Processes," in Peter Schmittinger ed. Chlorine: Principles and Industrial Practice. Weinheim: Wiley-VCH.

Currey, J. E. and J. W. Ahern. 1974. "Hooker's Membrane Cell at Reed Paper Ldd."s Dryden, Ontario Plant." in. Proceedings of the Nineteenth Meeting of Chlorine Plant Managers Seminar. Washington, D.C.: Chlorine Institute.

Curry, R. W. ed. 1995. Moden Chor-Alkali Technology, vol. 6. Cambridge, UK: Royal Society of Chemistry.

David, Paul A. 1975. Technical Choice, Mnovation and Ecanomic Gromth: Essays on American and British Experience in the Nineteenth Century. Cambridge, UK: Cambridge University Press. 
David, Paul A. 1985. "Clo and the Economics of QWERTY."AEA Papers and Proceedings. $75(2), 332-337$

De Flon, R. 1998. "Conversion of Borregaard Chlor-alkali Plant." mimeo.

De Nora. 1999. "Chlor-Alkali Plants Contracted by De Nora in the Latest Decades." De Nora. Dean, Thomas J. and Robert L. Brown. 1995. "Pollution. Regulation as a Barrier to New Firm Entry: Initial Evidence and Implications for Future Research." Academy of Management Journal, 38 (1), $288-303$.

Derry, T. K. and Trevor I. Williams. 1960. A Short History of Technology: From The Earliest Times to A.D. 1900. Oxford: Oxford University Press.

Dia Sait. 2001. "History." Dia Salt.

Diamond, Peter A. and Jerry A. Hausman. 1994. "Contingent Valuation: Is Some Number Better than No Number?" Journal of Environmental Perspectives, 8 (4), 45-64.

Dingle, A. E. 1982. "The Monster Nuisance of All: Landowners, Alkali Manufacturers, and Air Pollution, 1828-64:" Economic History Review, 35, 529-548.

Donau Chemie AG. 2000 . Fax message to the author. Bruckl, Austria, April 21.

Dorfiner, Konrad. 1990. "Introduction to Ion Exchange and Ion Exchangers," in Konrad Dorfner ed. Lon Exchangers. Berlin: Walter de Gruyter.

Downing, Pau॥ B. and Lawrence J. White. 1986. "Innovation in Pollution Control." Journal of Enironmental Economics and Management, 13, 18-29.

Edwards, Perter. 1979. "Nafion' Seihin no Genkyo to Shorai" (The Present and Future of 'Nafion' Products)." Soda vo Emso, (2), 1-11.

Ehlers, Peter. 1990. "The History of the International North Sea Conferences." Intermational Journal of Coastal and Estuarine Law, 5 (1-3), 3-14.

Eltech Systems. 2001. "Membrane Cell Projects Licensed by ELTECH." Eltech Systems. 
Engelhardt, Jr., H. Tristram, and Arthur L. Caplan eds. 1987. Stemific Conwoversies: Case Sindies in the Resolntion and Closure of Disputes m Science and Technology. Cambridge, UK: Cambridge University Press.

EniChem. 2001. "Profile - Our History." Enichem.

Euro Chlor. 1993. "Memorandum on Mercury Emissions to Atmosphere from Chloralkali Cell Room Ventilation Air, 2nd edition." Euro Chlor.

Euro Chlor. 1996. "Chlor-Alkali Mercury Cells: Economics and the Enwiromment, 2nd Edition." Euro Chlor.

Euro Chlor. 1997. "Chlorine Industry Review 1996-1997." Euro Chlor.

Euro Chlor. 1998a. "Chlorine Industry Review 1997-1998:" Euro Chlor.

Euro Chlor. 1998b. "Mercury Process for Making Chlorine." Euro Chlor.

Euro Chlor. 1998c. "Reduction of Mercury Emissions from the West European Chlor Alkali Industry, 2nd Edition." Euro Chlor.

Euro Chlor. 1999a. "Chlorine Industry Review 1998-1999." Euro Chlor.

Euro Chlor. 1999b. "Decommissioning of Mercury Chlor-Alkali Plants, 2nd Edition." Euro Chlor.

Euro Chlor. 1999c. "Voluntary Commitments by each Western European Chlor-Alkali Producer (Mercury cells)." Euro Chlor.

European Chemical News. 1972. "Uhde details chlorine cell mercury recovery processes." Ezropean Chemical News, 22.

European Chemical News. 1974. "Electrolytic Chlor-Alkali Plants in Japan Licensed by Hooker. "European Chemical News.

European Fertilizers Manufacturers" Association. 1995. "Best Available Techniques for Pollution Prevention and Control in the European Fertilizer Industry - Booklet No.2 of 8: Production of Nitric Acid." European Fertilizers Manufacturers' Association. 
European IPPC Bureau. 1999. "Integrated Pollution Prevention and Control (IPPC): Best Available Techniques Reference Document on the Chllor-Alkali Industry (Draft)." European IPPC Bureau.

European IPPC Bureau. 2000. "Integrated Pollution Prevention and Control (IPPC):

Reference Document on Best Available Techniques in the Chlor-Alkali

Manufacturing Industry." European IPPC Bureau:

European Patent Office. 2000. "Facts and Figures 2000." European Patent Office.

Expert Committee for Examination of the Closed System. 1977. "Suigin-ho Denkai Kojo no Kurozudo-Shisutemu no Anzen-sei ni kansuru Chosa Kekka (Bassui) (Results of the Examination of the Safety of the Closed System in Ellectrolytic Plants Based on the Mercury Process (Excerpt))."

Expert Committee for Examination of the Closed System. 1979. "Suigin-ho Denkai Kojo no Kurozudo-Shisutemu no Anzen-sei ni kansuru Hyoka Kekka (Yoshi) (Results of the Evaluation of the Safety of Closed System in Electrolytic Plants Based on the Mercury Process (Abstract)):"

Expert Committee for Technical Evaluation of the Ion Exchange Membrane Process. 1977. "Ion Kokanmaku-ho Gijutsu Hyoka Kekka (Results of Technical Evaluation of the lon Exchange Membrane Process)." Committee for the Promotion of Process Conversions in the Soda Industry.

Expert Committee for Technical Evaluation of the Ion Exchange Membrane Process. 1979. "Ion Kokanmaku-ho Gijutsu Hyoka Kekka (Results of the Technical Evaluation of the Ion Exchange Membrane Process)." Committee for the Promotion of Process Conversions in the Soda Industry.

Faita, Guuseppe and Marco Tenconi. 1999. Personal Interview. De Nora, Milan, September 28. 
Farrell, Joseph. 1987. "Information and the Coase Theorem." Jownal of Economo Perspectives, 1 (2), 113-129.

Fischer, Carolyn, Ian W. H. Parry, and William A. Pizer. 1998. "Instrument Choice for Environmental Protection When Technological Innovation is Endogenous," Discussion Paper. 99-04. Resources for the Future:

Fishelson, Gideon. 1976. "Emission Control Policies under Uncertainty." Journal of" Environmental Economics and Management, 3, 189-197.

Flagan, Richard C. and John H. Seinfeld. 1988. Fundamentals of Air Pollution Engineering. Englewood Cliffs, NJ: Prentice Hall.

Florkiewicz, Thomas F. 1998. "The Future of Diaphragm Cell Technology." in. Proceedings of the 41 st Chlor-Alkall Plant Operations Seminar. Washington, D.C.: Chlorine Institute.

Foray, Dominique and Arnulf Grubler. 1990. "Morphological Analysis, Diffusion and Lockout of Technologies: Ferrous Casting in France and the FRG." Research Policy, 19, 535-550.

Foreman-Peck, James. 1996. "Technological Lock-In' and the Power Source for the Motor Car." Discussion Paper in Economic and Social History. 7. University of Oxford. Frankel, Marvin. 1955. "Obsolescence and Technological Change in a Maturing Economy," American Economic Review, 45, 296-319.

Freeman, Christopher. 1982. The Economics of Industrial Jmovation, Second ed. London: Pinter.

Freeman, Christopher. 1994. "The economics of technical change." Cambridge Journal of Econowics, 18, 463-514. 
Gardiner, Willam C. 1978. "Advanees in Electrolytic Production of Industral Chemicals from 1952 to $1977 . "$ Jownal of Electrochemical Society, 125 (1), 22C-29C.

Gates, Bruce C. 1992. Catalytic Chemistry. New York: John Wiley.

Goldwater Leonard 1. 1972. Mercuy: A History of Quicksilver. Baltimore". York Press.

Gray, Wayne B. and Ronald J. Shadbegian. 1993. "Enwironmental Regulation and

Manufacturing Productivity at the Plant Level." Working Paper. 4321. National Bureau of Economic Research.

Gray, Wayine B. and Ronald J. Shadbegian. 1995. "Pollution Abatement Costs, Regulation, and Plant-Level Productivity." Working Paper. 4994. National Bureau of Economic Research.

Gray, Wayne B. and Ronald J. Shadbegian. 1998. "Environmental Regulation, Investment Timing, and Technological Change." Joumal of Industrial Economics, XLVI (2), $235-256$.

Green, Kenneth and Alan Irwin. 1996. "Clean Technologies," in Peter Groenewegen, Kurt Fischer, Edith G. Jenkins and Johan Schot eds. The Greening of Industry Resource Guide and Bibliography. Washington, D.C.: Island Press.

Griliches, Zvi. 1957. "Hybrid Corn: An Exploration in the Economics of Technological Change." Econometrica, 25 (4), 501-522.

Griliches, Zvi. 1990. "Patent Statistics as Economic Indicators: A Survey." Joumal of Economic Literature, 28, 1661-1707.

Grot, Walther G. F. 1986. "NAFION as a Separator in Electrolytic Cells." in John W. Van Zee, Ralph E. White, Kim Kinoshita and Harry S. Burney eds. Proceedings of the Symposium on Diaphragms, Separators, and Lon-Exchange Membranes. Pennington, NI: Electrochemical Society. 
Grubler, Amulf. 1998. Techology and Global Change. Cambridge, UK: Cambridge University Press.

Grupo Aragonesas. 1999. "Productos: Cloro/ Sosa Caustica."

Haas, Peter M. 1993. "Protecting the Baltic and North Seas," in Peter M. Haas, Robert O.

Keohane and Marc A. Levy eds. Institutions for the Earth. Sources of Effective International Envirommental Protection. Cambridge, MA: MIT Press.

Haber, L. F. 1958. The Chemical Industry During the Nineteenth Century: A Study of the Economic Aspect of Applied Chemistry in Europe and Nonth America. Oxford: Clarendon Press.

Haber, L. F. 1971. The Chemical Industry 1900-1930: International Growth and Technolagical Change. Oxford. Clarendon Press.

Hahn, Robert W. 1990. "The political economy of environmental regulation: Towards a unifying framework." Public Choice, 65, 21-47.

Haigh, Nigel. 1987. EEC Envirammental Policy and Britain, 2nd ed. Essex: Longman. Hain, Stefan. 1999. Personal interview. OSPAR Commission, London, October 11. Hamada, Masao, 2000. "Chlor-Alkali Technology." E-mail to the author. Asahi Chemical Industry, April 4.

Hanafusa, Fumiyuki. 1998. "Ion Kokanmaku-ho heno Seiho Tenkan no Omoide (Memory of the Process Conversion to the Ion Exchange Membrane Process)," in Research Group on the Japanese Salt Industry ed. Research on the Japanese Salt Industry. Tokyo: Japan Salt Industry Association.

Hanemann, W. Michael. 1994. "Valuing the Environment Through Contingent Valuation." Journal af Economic Perspectives, $8(4), 19-43$.

Hanmer, Rebecca. 1997. "Policy Approaches for Promoting Cleaner Production and Waste Minimisation in OECD Member Countries." Cleaner Production and Waste 
Minimisarion in OECD and Dynamic Non-Member Economies. Paris: Organisation for Economic Coroperation and Development.

Hardic, D. W. F. and J. Davidson Pratt. 1966. A History of we Modern British Chemical Industry. Oxford: Pergamon Press.

Harris, Florence E. 1960. "Economics of the Salt Industry," in Dale W. Kaufmann ed. Sodium Chloride. The Production and Properties of Salt and Brine. New York: Reinhold. Heaton, Alan. 1996. "Research and Development," in Alan Heaton ed. An Introduction fo Industrial Chemistry, Third ed. Glasgow: Blackie Academic \& Professional.

Henson, David. 1997. Letter to Sara Stenhammar, Swedish Environmental Protection Agency, Industry and Ecocycles Department, Stockholm. February 13.

Herold, W. 2000. "Antwort: RE: Question about the Chlor-Alkali Plants." E-mail to the atthor. ECL, Germany, January 28.

Hettige, Hemamala, Paul Martin, Manjula Singh, and David Wheeler. 1994. "IPPS: The Industrial Pollution Projection System." Policy Research Working Paper. 1431. World Bank.

Hocking, Martin B. 1998. Handbook of Chemical Techmology and Pollution Control. San Diego: Academic Press.

Hon, Te-Pang. 1942. Manufacture of Soda with Special Reference to the Ammonia Process: A Practical Treatise. New York: Reinhold Publishing.

Houghton, J. T., X. Ding, D. J. Griggs, M. Noguer, P. J. van der Linden, X. Dai, K. Maskell., and C. A. Johnson eds. 2001. Climate Change 2001: The Scientific Basis. Cambridge, UK: Cambridge University Press.

Houghton, J. T., L. G. Meira Filho, B. A. Callander, N. Harris, A. Kattenberg, and K. Maskell eds. 1996. Climate Change 1995: The Science of Climate Change. Cambridge, UK: Cambridge University Press. 
Hutcheson, P., A. W. Pearson, and D. F. Ball. 1996. "Sources of teclmieal innevation in the network of companies providing chemical process plant and equipment ${ }^{\text {it }}$ Research Policy, 25, 25-41.

Jijma, Takashi. 1990a. "Wagakuni no Asechiren-ho Asetoarudehido Seizou Gijutsu no Hatten, Sono 1 (The Development of Acetaldehyde Manufacturing Technology in Japan, Part 1)." Kagaku-shi Kenkyu, 17, 61-79.

lijima, Takashi. 1990b. "Wagakuni no Asechiren-ho Asetoarudehido Seizou Gijutsu no Hatten, Sono 3 (The Development of Acetaldehyde Manufacturing Technology in Japan, Part 3)." Kagaku-shi Kenkyu, 17, 151-172.

Ikeda, Minoru, Takashi Tokutomi, and Yasutaka Nakajima. 1998. "Methyl Methacrylate," in Society of Chemical Engineers of Japan ed. Kagaku Purosesu: Kiso kara Gijutsu Kaihatsu made (Chemical Processes: From Fundamentals to Technological Developments). Tokyo: Tokyo Kagaku Dojin.

Imperial Chemical Industries. 1999. "Supply Record." Imperial Chemical Industries. Industrial Structure Council. 1972. "Report of the Soda Group of the Chemical Industry Section." Industrial Structure Council.

Information Centre for Environmental Licensing. 1998. "Dutel Notes on BAT for the ChlorAlkali Industry." Final Report. Dutch Ministry of Housing, Spatial Planning and the Environment, Directorate for Air and Energy, Department of Industry; and Dutch Ministry of Transport, Public Works and Water Management, Institute for Inland Water Management and Waste Water Treatment RIZA.

Ingleby, Steve, R. W. Curry, and Cliff Broom. 1999. Personal interview. ICI, Runcorn, October 8 .

International Energy Agency. 1992. "Electricity Information 1992." Organisation for Economic Co-operation and Development / International Energy Agency. 
International Energy Agency. 1993. "Electricity Information 1992."' Organisation for

Economic Co-operation and Development/International Energy Agency.

International Energy Agency. 1999. "Electricity Information 1998." Organisation for

Economic Co-operation and Development/ International Energy Agency.

Irukayama, Katsuro. 1977. "Countermeasures and Unresolved Problems," in Tadao Tsubaki and Katsuro Irukayama eds. Minamata Disease: Methylmercury Poisoning in Minamata and Niigata, Japan. Tokyo: Kodansha.

Jackson, C. ed. 1983. Modern Chlor-Alkali Technology, vol. 2. Chichester: Ellis Horwood. Jackson, C., B. A. Cooke, and B. J. Woodhall. 1971. "Diaphragms and Electrolytes," in A. T. Kuhn ed. Industrial Electrochemical Processes. Amsterdam: Elsevier Publishing. Jackson, Colin and Stephen F. Kelham. 1984. "Developments and trends in the chlor-alkali industry." Chemistry and Industry, 397-402.

Jackson, T. 1994. "Principles of Clean Production - developing an operational approach to the preventive paradigm," in T. Jackson ed. Clean Production Strategies: Developing Preventive Environmental Management in the Industrial Economy. Boca Raton, FL: Lewis Publishers.

Jaffe, Adlam B., Richard G. Newell, and Robert N. Stavins. 1999. "Energy-Efficient

Technologies and Climate Change Policies: Issues and Evidence." Climate Issue Brief.

19. Resources for the Future.

Jaffe, Adam B. and Karen Palmer. 1997. "Environmental Regulation and Innovation: A Panel Data Study." Review of Economics and Statistics, 79 (4), 610-619.

Jaffe, Adam B., Steven R. Peterson, Paul R. Portney, and Robert N. Stavins. 1995.

"Environmental Regulation and the Competitiveness of U.S. Manufacturing: What Does the Evidence Tell Us?" Journat of Economic Literature, 33, 132-163.

Japan Salt Industry Association. 2001. "The Japanese Salt." Japan Salt Industry Association. 
Japan Soda Industry Association. 1952. Zoku Nihon Soda Kogyo-sh (A Sequel to the History of the Japamese Soda Industry). Tokyo: Japan Sodia Industry Association.

Japan Soda Industry Association. 1973a. "Denkai Soda Kogyo no Jitsujo (Real Situation of the Electrolytic Soda Industry)." Statement. Japan Soda Industry Association.

Japan Soda Industry Association. 1973b. "Request to the Minister of the Environmental Agency Regarding the Real Situation of the Soda Industry." Japan Soda Industry Association.

Japan Soda Industry Association. 1974a. "Seiho Tenkan ni kansuru Sho-Mondai ni tsuite (Various Issues on the Process Conversion). "Soda to Enso, (2), 1-13.

Japan Soda Industry Association. 1974b. "Seiho "Tenkan no Sho-Mondai ni tsuite (On Various Issues Related to the Process Conversion)." Soda to Enso, (10), 1-8.

Japan Soda Industry Association. 1974c. "Soda Kogyo Seiho Tenkan Setsubi Shikin Kakuho ni kansuru Chinjo (Request Regarding Financial Resources for the Process Conversion in the Soda Industry)." Japan Soda Industry Association.

Japan Soda Industry Association. 1975. Soda Handobukku (Soda Handbook). Tokyo: Japan Soda Industry Association.

Japan Soda Industry Association. 1976. "Tokkyo kara mita Shokwen Denkai ni okeru Kinzoku Yokyoku/Ion Kokanmaku-ho Kanren Gijutsu no Genjo, Bessatsu 2: Tokkyo Gaiyo Ichiran-hyo (Current Situation of Technologies Related to the Metal Electrode and the Ion Exchange Membrane Process for Brine Electrolysis In Terms of Patents, Supplement Volume 2: Lists of Patent Abstracts)." Technology Examination Document. 351. Japan Soda Industry Association.

Japan Soda Industry Association. 1977. "Shokuen Denkai ni okeru Kinzoku Yokyoku/Ion Kokanmaku-ho Kanren Tokkyo no Genjo, Tsuiroku-ban I: Showa 57.7-12 Kokoku/Kokai-bun (Current Situation of Patents Related to the Metal Electrode and 
the Ion Exchange Membrane Process for Brine Electrolysis; Sequel Edition I:

Publications from July 1976 to December (976)." Technology Examination Document.

361. Japan Soda Industry Association.

Japan Soda Industry Association. 1978a, "Shokuen Denkai ni okeru Ion Kokanmaku-ho narabini Kakumakti-ho Kanren Tokkyo no Genjo, Tsuiroku-ban III: Showa 52.1-12 Kokoku, Kokat-bun (Current Situation of Patents Related to the Ion Exchange Membrane Process and the Diaphragm Process for Brine Electrolysis, Sequel Edition III: Publications from January 1977 to December 1977)." Technology Examination Document. 383. Japan Soda Industry Association.

Japan Soda Industry Association. 1978b. "Shokuen Denkai ni okeru Kakumaku-ho Kanren Tokkyo no Genjo, Tsuiroku-ban II: Showa 30-5I nen Kokoku/Kokai-bun (Current Situation of Patents Related to the Diaphragm Process for Brine Electrolysis, Sequel Edition II: Publications from 1955 to 1976)." Technology Examination Document. 373. Japan Soda Industry Association.

Japan Soda Industry Association. 1979a. "Dai-2-ki Seiho Tenkan Shisaku ni taisuru Yobo (Request Regarding Policies for the Second Phase of the Process Conversion)." Japan Soda Fridirstry Association.

Japan Soda Industry Association. 1979b. "Shokuen Denkai ni okeru Ion Kokanmaku-ho narabini Kakumaku-ho Kanren Tokkyo no Genjo, Tsuiroku-ban V: Showa 53.1-12 Kokoku, Kokai-bun (Current Situation of Patents Related to the Ion Exchange Membrane Process and the Diaphragm Process for Brine Electrolysis, Sequel Edition V: Publications from January 1978 to December 1978)." Technology Examination Document. 397. Japan Soda Industry Association.

Japan Soda Industry Association. 1980a. "Dai-2-ki Seiho Tenkan Mondai no Shuhen (Around the Issue of the Second Phase of the Process Conversion)." Soda to Enso, (8), 17-29. 
Japan Soda Industry Association, 1980b. Dai-2-ki Seiho Tenkan mi kanswru Yobosho

(Request Regarding the Second Phase of the Process Conversion). "Japan Soda Industry Association.

Japan Soda Industry Association. 1982. Nihon Sada Kogyo Hyakumensh (Centemial Histony of the Japanese Soda Industry). Tokyo: Japan Soda Industry Association.

Japan Soda Industry Association. 1985. "Soda Kogyo Kankei no Kinyu oyobi Zeisei Sochi ni tsuite (On the Financial and Tax Measures Related to the Soda Industry). so Soda to $E_{n s o}(1), 20-25$.

Japan Soda Industry Association. 1988. "Denryoku (Electric Power)." Soda to Enso, (5), 4655 .

Japan Soda Industry Association. 1991a. "Shokuen Denkai ni okeru Ion Kokanmaku-ho Kanren Tokkyo no Genjo, Tsuiroku-ban VI: Showa 54 - 63 nen Kokoku/Koka-bun, Dai 1 Bunsatsu: Denkai Hoho oyobi Kanren Gijutsu, C-1 Sotai Kozo (Current Situation of Patents Related to the Ion Exchange Membrane Process for Brine: Electrolysis, Sequel Edition VI: Publications from 1979 to 1988 , Volume 1:

Electrolytic Methods and Related Technologies, C-1 Cell Structure)." Technology Examination Document. 558. Japan Soda Industry Association.

Japar Soda Industry Association. 1991 b. "Shoknen Denkai ni okeru Ion Kokanmaku-ho Kanren Tokkyo no Genjo, Tsuiroku-ban V1: Showa 54 - 63 nen Kokoku/Kokai-bum. Dai 2 Bunsatsu: Denkai Hoho oyobi Kanren Gijutsu, C-2 Denkai Hoho, C-3 Sonota. (Current Situation of Patents Related to the Ion Exchange Membrane Process for Brine Electrolysis, Sequel Edition VI: Publications from 1979 to 1988 , Volume 2: Electrolytic Methods and Related Technologies, C-2 Electrolytic Methods, $\mathrm{C}-3$ Other)." Technology Examination Document. 559. Japan Soda Industry Association. 
Japan Soda Industry Association. 1992a. "Shokuen Denkai ni okeru Ion Kokanmaku-ho Kanren Tokkyo no Genjo, Tsuiroku-ban VI: Showa 54 - 63 nen Kokoku/Kokai-bun, Dai 3 Bunsatsu: Ion Kokanmaku, M (Current Situation of Patents Related to the Ion Exchange Membrane Process for Brine Electrolysis, Sequel Edition VI: Publications from 1979 to 1988, Volume 3: Ion Exchange Membranes, M)." Technology Examination Document. 572. Japan Soda Industry Association.

Japan Soda Industry Association. 1992b. "Shokuen Denkai ni okeru Ion Kokanmaku-ho Kanren Tokkyo no Genjo, Tsuiroku-ban VI: Showa 54 - 63 nen Kokoku/Kokai-bun, Dai 4 Bunsatsu: Denkyoku (E), Ensui Seisei (B), Sono-ta (T) oyobi Kakumaku (D) (Current Situation of Patents Related to the Ion Exchange Membrane Process for Brine Electrolysis, Sequel Edition VI: Publications from 1979 to 1988, Volume 4: Electrodes (E), Brine Purification (B), Other (T), and Diaphragms (D))." Technology Examination Document. 573. Japan Soda Industry Association.

Japan Soda Industry Association. 1995. "Soda Now '95: Nihon no Soda Kogyo (Japan's Soda Industry)." Japan Soda Industry Association.

Japan Soda Industry Association. 1998a. "Denryoku (Electric Power)." Soda to Enso, (12), $42-48$.

Japan Soda Industry Assaciation. 1998b. Soda Handobukku 1998 (Soda Handbook 1998). Tokyo: Japan Soda Industry Association.

Japan Soda Industry Association. 1999a. "Soda Kogyo no Genjo (Current Situation of the Soda [ndustry)." Japan Soda Industry Association.

Japan Soda Industry Association. 1999b. "Soda Now: Nihon no Soda Kogyo (Japan's Soda Industry)." Japan Soda Industry Association.

Japanese Ministry of International Trade and Industry. 1973. "Soda Kogyo ni okeru Suigin-ho kara Kakumaku-ho eno Tenkan Kijun (Criteria for the Conversion from the Mercury 
Process to the Diaphragm Process in the Soda Industry). "Ministry of Intemational Trade and Industry.

Japanese Ministry of International Trade and Industry. 1974. "Suigin-ho Denkai Soda Setsubi oyobi Suigin no Yushutsu ni tsuite (On Exporting Mereury Process Facilities tor Electrolytic Soda and Mercury)." Division of Basic Chemicals, Bureau of Basic Industries, Ministry of International Trade and Industry.

Japanese Ministry of International Trade and Industry. 1975a. "Kasei Soda Seiho Tenkan no Genjo to Kongo no Susume-kata ni tsuite (On the Current Situation of the Caustic Soda Process Conversion and the Procedure in the Future)." Ministry of International Trade and Industry.

Japanese Ministry of International Trade and Industry. 1975b. "Kasei Soda Yuzu Jisshi Yoko (Outline for the Implementation of Barter Trades of Caustic Soda)." Division of Basic Chemicals, Bureau of Basic Industries, Ministry of International Trade and Industry. Japanese Ministry of International Trade and Industry. 1979. "Kasei Soda Kogyo Seiho Tenkan Kankei Shiryo (Documents on Process Conversions in the Caustic Soda Industry)." Division of Basic Chemicals, Bureau of Basic Industries, Ministry of International Trade and Industry.

Japanese Ministry of International Trade and Industry. 1985. "Kasei Soda Kogyo no Genjo (Current Situation of the Caustic Soda Industry)." Division of Basic Chemicals, Bureau of Basic Industries, Ministry of International Trade and Industry. Japanese Ministry of International Trade and Industry. 1989." "Soda Kogyo no Genjo to Kadai (Current Situation and Problems in the Soda Industry)." Division of Basic Chemicals, Bureau of Basic Industries, Ministry of International Trade and Industry. 
Japanese Ministry of htemational Trade and Industry. 1990. "Soda Kogyo no Genjo (Cument Situation of Soda Industry)." Division of Basic Chemicals, Bureau of Basic Industries, Ministry of Intemational Trade and lindustry.

Jensen, S. and A. Jemelov. 1969: "Biological Methylation of Mercury in Aquatic Organisms." Nature, 223, 753 .

Juda, W. and W. A. McRae. 1950. "Coherent ion exchange gels and membranes." Journal of American Chemical Saciety, $72,1044$.

Jung, Chulho, Kerry Krutilla; and Roy Boyd. 1996. "Incentives for Advanced Pollution Abatement Technology at the Industry Level: An Evaluation of Policy Alternatives." Jownal of Emironmental Economics and Management, 30, 95-111.

Kanto Denka Kogyo. 1998. Kanto Denka Kogyo Rokuju-Nenshi (Sixty-Year History af Kanto Denka Kogyo). Toyo: Kanto Denka Kogyo.

Karshenas, Massound and Paul Stoneman. 1995. "Technological Diffusion," in Paul Stoneman ed. Handbook of the Economics of Innovation and Technological Change. Oxford: Blackwell.

Katsumura, Tatsuo. 1979. "Soda Seiho Tenkan o Isoguna (Do not rush into process conversions for the soda production)." Asahi Shimbun, July 30.

Kawate, Hideo, Kazuo Tsuzura, and Hiroshi Shimizu. 1990. "Ion Exchange Membranes," in Kourad Dorfner ed. Ion Exchangers. Berlin: Walter de Gruyter.

Kelham, Steve. 1996. "Chlor-alkali Products," in Alan Heaton ed. An Introduction to Industrial Chemistry, Third ed. Glasgow: Blackie Academic \& Professional. Kemp, Rene. 1995. "Environmental Policy and Technical Change: A Comparison of the Technological Impact of Policy Instruments." Ph.D. Dissertation. Department of Economics and Business Administration, University of Maastricht. 
Kemp, Rene. 1998. "The Diffusion of Biological Waste-Water Treatment Plants in the Duteh Food and Beverage Industry." Enviromnental and Resowre Ecomomics, 12, 113-136. Keohame, Nathaniel O., Richard L. Revesz, and Robert N. Stavins. 1998. "The Choice of Regulatory Instruments in Environmental Policy." Harkard Enwiromental Law Review, 22, 313-367.

Kircher, Morton S. 1962. "Electrolysis of Brines in Diaphragm Cells," in J. S. Sconce ed. Chlorine: Its Manwacture, Properties and Uses. New York: Robert E. Krieger.

Kleijn, Rene, Arnold Tukker, and Ester van der Voet. 1997. "Chlorine in the Netherlands, Part 1: An Overview:" Journal of Industrial Ecology, 1 (1), 95-116.

Kline, Stephen J. and Nathan Rosenberg. 1986. "An overview of innovation," in Ralph Landau and Nathan Rosenberg eds. The Positive Sum Strategy. Washington, D.C:: National Academy Press.

Koch, T. A., K. R. Krause, L. E. Manzer, M. Mehdizadeh, J. M. Odom, and S. K. Sengupta. 1996. "Environmental Challenges Facing the Chemical Industry." New Joumal of Chemistry, 20,163-173.

Kopp, Raymond I., Paul Portney, and Dianne E. DeWitt. 1990. "International Comparison of Envirommental Regulation." Discussion Paper. QE90-22-REV. Resources for the Future.

Koyama, Jiro. 1972. "Kaigai Denkai Soda Kogyo Jittai Chosa-dan Hokoku-sho (Report of the Fact-Finding Mission on Foreign Electrolytic Chlor-Alkali Irrdustries)"

Kramer, W. and B. Luke. 1990. "Hoechst-Uhde Single Element Membrane Electrolyzer: Concept-Experiences-Applications," in N. M. Prout and J. S. Moorhouse eds. Modern Chlor-Alkali Technology, vol. 4. London: Elsevier Applied Science.

Krebs Swiss. 1997. "Chlorine Production: PT. Industri Soda Employs Asahi Glass's Bipolar Membrane Cell Technology." News Release. Krebs Swiss. 
Krebs Swiss. 2001. "Reference List" Krebs Swiss.

Krupp Uhde. 2001: "Krupp Uhde - a company overwiew." Krupp Uhde.

Krupp-Uhde. 1998. "References: Membrane-cell: electrolysis plants." Krupp Uhde.

Kuhn, A. T. 1971. "The Chlor-Alkali Industry" in A. T. Kuhn ed. Industrial Elecrochemical Processes. Amsterdam: Elsevier.

Lanjouw, Jean Olson and Ashoka Mody. 1996. "Innovation and the International Diffusion of Environmentally Responsive Technology." Research Policy, 25, 549-571.

Leonard, H. Jeffrey. 1988. Pollution and the Striggle for the World Product: Mulrinationat Corporations, Environment, and International Comparative Advantage. Cambridge, UK: Cambridge University Press.

Levenspiel, Octave. 1962. Chemical Reaction Engineering. New York: Wiley.

Levin, Richard C., Alvin K. Klevorick, Richard R. Nellson, and Sidney G. Winter. 1987.

"Appropriating the Returns from Industrial Research and Development." Brookingss Papens on Economic Activity, 3, 783-820.

Levinson, Arik. 1996. "Environmental regulations and manufacturers' location choices:

Evidence from the Census of Manufacturers." Joumal of Public Economics, 62, 5-29.

Liebowitz, S. J. and Stephen E. Margolis. 1990. "The Fable of the Keys." Journal of Law and Economics, 33 (April), 1-25.

Liebowitz, S. I. and Stephen E. Margolis. 1995. "Path Dependence, Lock-in, and Fistory." Jourial of Law, Economics, \& Organization, 11 (1), $205-226$.

Lindley, Andrew A. 1997. "An Economic and Environmental Analysis of the Chlor-Alkali Production Process: Mercury Cells and Alternative Technologies." Final Report prepared for the European Commission (DG III C-4, Chemicals, plastics, rubber). 
Lott, Brian. 1995. "Practical Experiences on the Conversion of Mercury Cells to Membrane

Technology," in R. W. Curry ed. Modern Chlor-Alkal Technology, vol. 6. London:

Society of Chemical Industry.

Low "Patrick and Alexander Yeats. 1992. "Do Dirty Industries Migrate?," in Patrick Low ed.

International Trade and the Emviromment. Washington, D.C.: World Bank.

Luke, Benno. 1989. "Die spezifischen Kosten sinken." Chemische Industrie, 8, 56-60.

Luke, Benno. 2000. "Membrane Process," in Peter Schmittinger ed. Chlorine: Principles and Industrial Practice. Weinheim, Germany: Wiley-VCH.

Luke, Benno and Roland Beckmann. 1999. Personal interview, Krupp-Uhde, Dortmund, 31 August.

MacMullin, R. B. 1962. "Electrolysis of Brines in Mercury Cells," in J. S. Sconce ed.

Chlorine: Its Mamufachne, Properties and Uses. Litton Educational Pub.

MacMullin, Robert B. 1947. "A CI Report on Diaphragm vs. Amalgam Cells for Chlorine-

Caustic Production." Chemical Industries, (July); 41-50.

Magat, Wesley A. 1978. "Pollution Control and Technological Advance: A Dynamic Model of the Firm." Journal of Environmental Economics and Management, 5, 1-25.

Manzer, L. E. and V. N. M. Rao. 1993. "Catalytic Synthesis of Chlorofluorocarbon Alternatives." Advances in Catalysis, 39, 329-350.

Marin, Alan. 1991. "Firm Incentives to Promote Technological Change in Pollution Control: Comment." Journal of Envirowmental Economics and Management, 21, 297-300.

Martin, R. P. and G. J. Martens. 1996. "IUPAC White Book on Chlorine: A Contribution to the Debate on the Effect of Chlorine and Chlorine-containing Compounds on the Environment." Pure and Applied Chemistry, $68(9)$.

Matsuura, Shunji. 2002. Personal Interview. Tokuyama, Tokyo, February 19. 
MeKelvey, Maureen. 1996. Evolutionary Mnowations: The Business of Biotechnology. Oxford: Oxford University Press.

McMeekin, Andrew and Ken Green. 1995. "Defining Clean Technology." Fufures, 1.

MeRae, W. A. 1974. Won Kokan-maku Clor-Alkali Denkai-so no Genjo (Current Situation of Chlor-Alkali Cells with lon Exchange Membranes):" Soda to Enso, (3), 10-14.

Means, R. E. and T. R. Beck. 1984. "A techino/economic review of chlor-alkali technology." Chemical Engineering, $91(22), 46-51$.

Mellish, S. F. 1977. "Membrane Cells - Where Are We Now?," in Society of Chemical Industry ed. Diaphragm cells for chlorine production. London: Society of Chemical Industry.

Mendelsoln, Robert. 1984. "Endogenous Technical Change and Environmental Regulation." Joumal of Environmental Economics and Management, 11, 202-207.

Meyel-Thurow, Georg. 1982. "The Industrialization of Invention: A Case Study From the German Chemical Industry." Isiss, 73, 363-381.

Milliman, Scott R and Raymond Prince. 1989. "Firm Incentives to Promote Technological Change in Pollution Control." Joumal of Envirommental Economics and Management, $17,247-265$.

Milliman, Scott R. and Raymond Prince. 1992. "Firm Incentives to Promote Technological Change in Polluting Contirol: Reply." Joumal of Enviromental Economics and Management, 22, 292-296.

Mitsubishi Chemical. 2001. "Enkaku (Chronology)." Mitsubishi Chemical. Mitsubishi Chemical MKV. 2001. "Enkaku (Chronology)." Mitsubishi Chemical MKV. Mitsubishi Gas Chemical. 2001. "Rekishi - Kojo to Seihin no Enkaku (History - Chronology of the Plants and Products)." Mitsubishi Gas Chemical. 
Mizsey, Peter. 1994. "Waste Reduction in the Chemicall Industry: A Two Level Problem:" Journal of Hazardous Materials, 37, 1-13.

Morris, Gregory J. 1990. "Improving Membrane Cell Operation," in N. M. Prout and J. S. Moorhouse eds. Modern Chlor-Alkait Technology; vol. 4. London: Elsevier Applied Science.

Motani, K. and T. Sata. 1980. "The Tokuyama Soda menbrane - caustic-chlorine process," in M. O. Coulter ed. Modern Chlor-Alkali Technology. Chichester: Ellis Horwood. Motani, Kensuke. 1982. "Tokuyama Soda Ion Kokanmaku-ho Shokuen Denkai Purosesu ni tsuite (On the Ion Exchange Membrane Process for Brine Electrolysis of Tokuyama Soda)." in. Proceedings of the 8th Seminar on the Current Situation of the Ion Exchange Membrane Process. Association for the Promotion of Installations of the Diaphragm Process Facilities.

Muller, W. D. 1993. "General Technology Overview." in. Proceedings of the Third Euro Chlor Technical Seminar: Responsible Care in Practice. Paris: Euro Chlor. Murray, R. L. 1949. "The Chlor Alkali Industry in the United States." Industrial and Engineering Chemistry, 41 (10), 2155-2164.

Nagamura, Masao, Hiroshi Ukihashi, and Osamu Shiragami. 1980. "Chlor-alkali process with Flemion," in M. O. Coulter ed. Modern Chlor-Alkali Technology. Chichester: Bllis Horwood.

Nagamura, Masao, Hiroshi Ukihashi, and Osamu Shiragami. 1983. "AZEC System - New Ion-exchange Membrane Chlor-alkali Process," in C. Jackson ed. Modern ChlorAlkali Technology, vol. 2. Chichester: Ellis Horwood.

Nakanishi, Junko. 1993. "Gijutsu-ya no Kankyo Seisaku Iron: Nihon no Kankyo Tokusei (A Different View on Environmental Policy of a Technologist). "Sekal, (1), 312-321. 
Nakao, M. and H. Miyake. 1995. "Advaneed Cell Operation with Flemion Membranes," in R.

W. Curry ed. Moderk Chlor-Alkali Technology, wol. 6. Cambridge, UK: Royal Society of Chemistry.

Nakao, M., T. Shimohira, and Y. Takechi, 1998. "High Performance Operation with Flemion Membranes and the AZEC-B I Electrolyzer," in S. Sealey ed. Modern Chlor-Alkali Technology, vol. 7. Cambridge, UK: Royal Society of Chemistry.

Nelkin, Dorothy ed. 1992. Controversy: Politics of Technical Decisions, Third ed. Newbury Park, CA: SAGE.

Nihon Keizai Shinbun. 1982. "Nissan Kagaku ga Genryo Seisan Itaku - Soda/Enso ha Asahi Garasu, Nisanka Echiren ha Toyo Soda ni (Nissan Chemical Transfer Raw Material Production - Soda and Chlorine to Astahi Glass, Ethylene Dichloride to Toyo Soda)." Nihon Keizai Shinbun, March 27.

Nikkei Kinyu Shinbun. 1987. "Nissoda, 3-nen-buri Keijo Kuroji ni - Gorika to Shikyo Kaifuku ga Kiyo (Nippon Soda, Operating Profit First in 3 Years - Due to Rationalization and Strong Market Demand)." Nikkei Kinyu Shinbun, December 8.

Nikkei Sangyo Shimbun. 1975a. "Shoden Kawasaki Kojo no Kakumaku-ho niyoru Kasei Soda Sejzo Setsubi Kansei - Jisha Gijutsu de Seisan Kaishi (Showa Denko Completes Construction of Caustic Soda Production Facilities with Diaphragm Process - Start of Production with Own Technology)." Nikkei Sangyo Shinbum, June 19.

Nikkei Sangyo Shimbun. 1975b. "Tsurumi Soda, Soda Setsubi wo Isshin, Noryoku 20\% Appu (Tsurumi Soda Renews Soda Facilities, 20\% Increase in Capacity)." Nikkei Sangyo Shimbun, December 2.

Nikkei Sangyo Shinbun. 1976. "Shoden/Hitachi-zo, Kasei Soda no Asubesuto Kakumaku-ho de Makikaeshi (Showa Denko and Hitachi Engineering and Shipbuilding Return with 
Asbestos Diaphragm Process to Caustic Sada Production)." Nikke Sangyo Shmban. May 13.

Nippon Paper Industries. 2001. "Nippon Seishi (kabu) Shareki (Corporate History of Nippon Paper Industries):" Nippon Paper Industries.

Nippon Soda. 2001. "Enkaku (Chronology)." Nippon Soda.

Nishimura, Hajime and Tatsuaki Okamura. 2001. Minamata-byo no Kagaku (The Science of the Minamaia Disease). Tokyo: Nihon Hyoron-sha.

Nishino, Hiroshi. 1998. "Sakusan (Acetic Acid)," in Japan Society of Chemical Engineers ed. Kagaku Purosesu: Kiso kara Gijutsu Kaihatsu made (Chenical Processes: From Fundamenals to Technological Developments). Tokyo: Tokyo Kagaku Dojin.

Nriagu, Jerome. 1994. "Industrial Activity and Metal Emissions," in R. Socolow; C. Andrews, F. Berkhout and V. Thomas eds. Industrial Ecology and Global Change. Cambridge, UK: Cambridge University Press.

Nriagu, Jerome O. 1979. "Global inventory of natural and anthropogenic emissions of trace metals to the atmosphere." Nature, 279, 409-411.

O'Brien, Denis. 2001. Fax message to the author. Technical \& QA Manager, Micro-Bio, Fermoy, Ireland, January 29.

Occupational Safety and Health Administration. 1993. "Better Production Against Asbestos in the Workplace." OSHA Fact Sheet. 93-66. U.S. Department of Labor.

Ogburn, William F. and William Jaffe. 1929. The Economic Developmen of Post-Wor France: A Survey of Production. New York: Columbia University Press.

Oh-hama, Miroshi, Masato Hamada, and Mitsuo Yoshida. 1998. Personal interview. Asahi Chemical Industries, Tokyo, June 12. 
ir Economic Co-operation and Development. 1974. "Mercury and the ment: Studies of Mercury Use, Emission, Biological Impact and ControL." Sation for Economic Co-operation and Development. Ir Economic Co-operation and Development. 1981: "Measures to Reduce All ade Emissions of Mercury to the Environment: Summary Report of stion Exchange for the Years 1973, 1974, 1975 and 1976." Organisation for aic Co-operation and Development.

ir Economic Co-operation and Development. 1994. "Managing the ument: The Role of Economic Instruments." Organisation for Economic Com and Development.

or Economic Co-operation and Development. 1997. "Cleaner Production and Minimization in OECD and Dynamic Non-Member Economies." Organisation momic Co-operation and Development.

76. "Incentive for Innovation as the Basis for Effluent Charge." American nic Review, 66 (2), 441-447.

Commissions. 1984. "The First Decade: International Co-operation in ing Our Marine Environment." Oslo and Paris Commissions.

, Commissions. 1997. "Report on Mercury Losses from the Chlor-Alkali y (1982-1995)." Oslo and Paris Commissions.

nission. 1999a. "Assessment of Implementation of PARCOM Decision 90/3 on ing Atmospheric Emissions from Existing Chlor-Alkali Plants." Implementation Dec. 90/3. OSPAR Commission.

nission. 1999b. "Note of Proceedings of the OSPAR Workshop on the ChlorIndustry, Madrid, 27-29 September." OSPAR Commission. 
OSPAR Commission. 1999c. "Repont on Mercury Losses from the Chlor-Alkall lisdustry (1982-1997)." OSPAR Commission.

OSPAR Commission. 2001. "Mercury Losses firom the Chlor-Akali lindustry in $1999^{\text {" }}$ OSPAR Commission.

Palmer, Karen, Wallace E. Oates, and Paul R. Portney. 1995. "Tightening Environmental Standards: The Benefit-Cost or the No-Cost Paradigm?" Joumal of Economic Perspectives, 9 (4), 119-132.

Paris Commission. 1977. "Summary Record of the Fifth Meeting of the Technical Working Group, Stockholm, 21-23 September." Paris Commission.

Paris Commission. 1978a. "Environmental Quality Objectives and Uniform Emission Standards Approaches in Relation to Mercury." Report presented at the First Meeting of the Commission, Convention for the Prevention of Marine Pollution from LandBased Sources, The Hague, 27-30 November. Paris Commission.

Paris Commission. 1978b. "No New Waste Brine Plants be Built." PARCOM Recommendation 78/1, The Hague. OSPAR Commission.

Paris Commission. 1980a. "Adoption of a 'standstill principle" for mercury concentrations in water." Agreement 1980-03, Stockholm. OSPAR Commission.

Paris Commission. 1980b. "Environmental Quality Standard for Mercury in Organisms," PARCOM Decision 80/1, Stockholm. OSPAR Commission.

Paris Commission. 1980c. "Limit Values for Mercury Emissions in Water from Existing and New Brine Recirculation Chloralkali Plants (exit of the purification plant). PARCOM Decision 80/2, Stockholm. OSPAR Commission.

Paris Commission. 1981 a " Limit Values for Existing Brine Recirculation Chlor-Alkali Plants (exit of the factory site)." PARCOM Decision 81/2, Brussels. OSPAR Commission. 
Paris Commission. $1981 \mathrm{~b}$. "Limit Values for Existing Waste Brine Chlor-Alkali Plants." PARCOM Decision 81/1, Brussels. OSPAR Commission.

Paris Cormmission. 1982. "New Chloralkali Plants using Mercury Cells." PARCOM Decision 82/1, Copentagen OSPAR Commission.

Paris Commission. 1983a. "Mercury in the Paris Convention Area." Paris Commission.

Paris Commission. 1983b. "Third Annual Report on the Activities of the Paris Commission." Paris Commission.

Paris Commission. 1984. "Fourth and Fifth Annual Reports on the Activities of the Paris Commission." Paris Commission.

Paris Commission. 1985a. "First and Second Annual Reports on the Activities of the Paris Commission." Paris Commission.

Paris Commission. 1985b. "Limit Values for Mercury Emissions in Water from Existing Brine Recirculation Chlor-Alkali Plants (exit of factory site)." PARCOM Recommendation 85/1, Brussels. OSPAR Commission.

Paris Commission. 1985c. "Seventh Annual Report on the Activities of the Paris Commission." Paris Commission.

Paris Commission. 1989. "Tenth Annual Report on the Activities of the Paris Commission." Paris Commission:

Paris Commission. 1990. "Reducing Atmospheric Emissions from Existing Chlor-Alkali Plants." PARCOM Decision 90/3, Reykjavik. OSPAR Commission.

Patel, Pari and Keith. Pavitt. 1995. "Patterns of Technological Activity: Their Measurement and Interpretation, ${ }^{\prime \prime}$ in Paul Stoneman ed. Handbook of the Economics of Innovation and Technological Change. Oxford: Basil Blackwell. 
Pauli, Gunter. 1995. "Industrial Chusters of the Twenty-frst Century," in Fritjof Capra and Gunter Pauli eds. Steering Busimess Toward Sustamability. Tokyo: United Nations University Press.

Porter, Michael and Claas van der Linde. 1995a. "Green and Competitive: Ending the Stalemate." Harvard Business Review, (September-October), 120-134.

Porter, Michael and Claas van der Linde. 1995b. "Toward a New Conception of the Environment-Competitiveness Relationship." Joumal of Economic Perspechnes, 9 (4), $97-118$

Portney, Paul R. 1994. "The Contingent Valuation Debate: Why Economists Should Care:" Journal of Economic Perspectives, 8 (4), 3-17.

PPG Industries. 1981. "Cl2: Chlorine." PPG Industries.

Prout, N. M. and J. S. Moorhouse eds. 1990. Modern Chlor-Alkali Technology, vol. 4. London: EIsevier Applied Science.

Ratnayake, Ravi. 1999. "Does Environmental Regulation Stimulate Innovative Responses? Evidence from U.S. Manufacturing." Working Paper Series. 188. Department of Economics, University of Auckland.

Reed, Peter. 1998. "Robert Angus Smith and the Alkali Inspectorate," in Ernst Homburg, Anthony S. Travis and Harm G. Schroter eds. The Chemical Indusry in Europe. 18501914: Industrial Growth. Pollution, and Professionalization. Dordrecht: K luwer Academic Publishers.

Rekers, C. J. N. 1973. "Some New Developments in the Field of Mercury Pollution Abatement by Akzo." in. Proceedings of the 16th Meering of Chlorine Plant Managers. Washington, D.C.: Chlorine Institute.

Richter, Steffi. 2000. "AW: Claloro-Alkali- Industry." E-mail to the author. German Federal Envirommental Agency, March 10. 
Roberts, Marc I. and Michael Spenee. 1976. "Effluent Charges and Licenses under

Uncertainty." Journal of Public Economies, $5,193-208$.

Robinson, H. David. 1985. "Who Pays for Industrial Pollution Abatement?" Review" of Economics and Statistics, $67,702-706$.

Rosenberg, Wathan. 1982. Inside the Black Box: Technology and Economics. Cambridge, UK: Cambridge University Press:

Ruttan, Vemon W. 2001. Technology, Growth, and Development: An Induced Innovation Perspective. New York: Oxford University Press.

Sakota, Masaaki. 1977. "Reyon Kogyo no Genkyo to Kongo no Mitoshi (Current Situation and Future Prospect of the Rayon Industry)." Soda to Enso, (3), 18-24.

Sata, T., K. Motani, and Y. Ohashi. 1983. "Perfluorinated Ion Exchange Membrane, Neosepta-F and Its Properties," in D. S. Flett ed. Ion Exchange Membranes. Chichester: Ellis Horwood.

Sata, Toshikatsu. 2002. Personal Interview. Tokuyama Soda, Tokuyama, February 8. Sato, Kimihiko. 1998. Personal interview. Asahi Glass, Tokyo, June 16.

Schmalensee, Richard. 1994. "The Cost of Environmental Protection." Balancing Economic Growth \& Environmental Goals. Washington, D.C.: American Council for Capital Formation Center for Policy Research.

Schmittinger, Peter. 2000. "Mercury Cell Process," in Peter Schmitinger ed. Chlorine: Principles and Industrial Practice. Weinheim: Wiley-VCH.

Schmittinger, Peter, L. Calvert Curlin, Tatsuro Asawa, Stephan Kotowski, Henri Bernhard Beer, Arthur M. Greenberg, Erich Zelfel, and Rolf Breitstadt. 1986. "Chlorine," in Wolfgang Gerhartz ed. Ulinam's Encyclopedia of Industrial Chemistry, Fifth, Completely Revised ed., vol. Volume A6: Ceramies to Chlorohydrins. Weinheim: VCH. 
Schneiders, K. and B. Luke. 1992. "Safety and Economy of Membiane Cell Electrolyzers," in T. C. Wellington ed. Modern Chlor-Alkali Techology, wol. 5: London: Elsevier Apphied Science.

Schubert, Hermann. 1999. Personal interview. Bayer, Leverkusen, September 21.

Sealey, S. ed. 1998. Modern Chlor-Alkali Technology, vol. 7. Cambridge, UK: Royal Society of Chemistry.

Seko, M., A. Yomiyama, and S. Ogawa. 1983. "Chlor-alkali Electrolysis using Perfluorocarboxylic Acid Membrane," in D. S. Flett ed. Ion Exchange Mambranes. Chichester, UK: Ellis Horwood.

Seko, Maomi. 1976. "The Ion-Exchange Membrane, Chlor-Alkali Process." Industrial and Engineering Chemistry, Product Research and Development, 15 (4), 286-292.

Seko, Maomi. 1980. "New Development of the Asahi Chemical membrane chlor-alkali process," in M. O. Coulter ed. Modern Chlor-Alkali Technology. Chichester: Ellis Horwood.

Seko, Maomi, Shinsaku Ogawa, Hiroshi Ono, and Osamu Suzuki. 1984. "Important Aspects of Membrane Chlor-Alkali Process." in Milton M. Silver and Everett M. Spore eds. Proceedings of the Symposium on Advances in the Chlor-Alkali and Chlorate Industry. 84-11. Pennington, NJ: Electrochemical Society.

Seko, Maomi, Jukichi Omura, and Mitsuo Yoshida. 1986. "Recent developments in ion exchange membranes for chlor-alkali electrolysis," in K. Wall ed. Moderw ChlorAlkali Technology, voll. 3, Chichester, UK: Ellis Horwood.

Seko, Maomi, Akira Yomiyama, Shinsaku Ogawa, and Hiroshi Ono. 1983. "Devellopment of Asahi Chemical Chlor-alkali Technology," in C. Jackson ed. Modem Chlor-Alkali Technology, vol. 2. Chichester: Ellis Horwood. 
Shibata, Hiroshi, Y. Kokubu, and I. Okazaki. 1977. "The Nobel Diaphragm Cell: A Flexible Design for High Currents and Its Performance Characteristics at $330 \mathrm{kA} . "$ in.

Procecdings of the Symposizm on Diaphragn Cells for Chlorine Production. London: Society of Chemical Industry.

Shimizu, Hiroshi: 1992. "Whon ni okeru lon Kokan Gijutsu no Hatten ni tsuite, Sono 1 (On the Development of Ion Exchange Membranes in Japan, Part 1)." Jownal of Ion Exchange, $3(2), 40-50$.

Shimiza, Hiroshi, 1993. "Wihon ni okeru Ion Kokan Gijutsu no Hatten ni tsuite, Sono 2 (On the Development of Ion Exchange Membranes in Japan, Part 2)." Journal of Ion Exchange, 4 (1), 2-22.

Shimohira, Tetsuji, Yoshihiko Saito, Kazuhiko Saito, and Haruhisa Miyake. 1993. "A Membrane for Production of 50\% Caustic Soda," in T. C. Jeffery, K. Ota, J. Fenton and H. Kawamoto eds. Proceedings of the Symposinm on Chlor-Alkali and Chlorate Production and New Mathematical and Computational Methods in Electrochemical Engineering. 93-14. Pennington, NJ: Electrochemical Society.

Shin-Nihon Salt. 2001. "Shio Jigyo Bumon (Salt Business Division)." Shin-Nihon Salt. Shiroki, Hiroyuki. 1994. "Rondon Kokusai Enso Shinpojiumu nì Sanka shite (Having Attended the London International Chlorine Symposium)." Soda to Enso, 11 (16-21). Showa Chemical. 2001. "Nenpu (Chronology)." Showa Chemical.

Siddiqu, Abdul-Rauf. 1994. "Chloralkali plant in Pakistan arouses environmentalists" ire." Chemical Engineering, (December), 46-48.

Skjarseth, Jon Birger. 1998. "The Making and Implementation of North Sea Commitments: The Politics of Environmental Participation," in David G. Victor, Kal Raustiala and Eugene B. Skolnikoff eds. The Implennentation and Effectiveness of International Envirommental Commitments: Theory and Practice Cambridge, MA: MIT Press. 
Smith, J. M. and H. C. Van Ness. 1959. Imroduction to Chemical Engmeering

Thermodynamics. New York: McGraw-Hill.

Smith, W. Watson. 1968. "Comparison of Modern Mercury and Diaphragm Type Chlorine Cells." Chemical Engimeer, (March), CE54-CE57.

Smith, W. Watson. 1975. "Electrolytic Manufacture of Chemicals from Salt, Second Edition." Chlorine Institute.

Society of Chemical Engineers of Japan. 1998. Kagaku Puposesu. Kiso kana Gijutsu Kaihatsw made (Chemical Processes: From Fundamentals to Techmological Development). Tokyo: Tokyo Kagaku Dojin.

Society of Chemical Industry ed. 1977. Diaphragm cells for chlorine production. London: Society of Chemical Industry.

Society of Chemical Industry. 2000. "The 2000 London International Chlorine Symposium, Final Circular and Registration Form." SCI Electrochemical Technology Group. Society of Environmental Toxicology and Chemistry. 1991. "A Technical Framework for Life-Cycle Assessment." Society of Envirommental Toxicology and Chemistry. Sommers, H. A. 1957a. "Chlorine Caustic Cell Development in Europe and the United States." Chemical Engineering Progress, 53 (9), 409-417.

Sommers, H. A. 1957b. "Chlorine Caustic Cell Development in Europe and the United States." Chemical Engineering Progress, $53(10), 506-510$.

Sommers, H. A. 1965. "The chlor-alkali industry." Chemical Engineering Progress, 61 (3), 94-109.

Sommers, Howard A. 1967. "The Design of Large Mercury Cells." Electrochemical Technology, 5 (3-4), 108-124.

SRI. 1996. "Chlorine/Sodium Hydroxide." CEH Marketing Research Report. SRI. 
Stadig. Willam. 1993. "Chlor-alkall producers evaluate safer alternatives to asbestos." Chemical Processing, (March), 41-46.

Stavins; Robert N. 1995. "Transaction Costs and Tradeable Permits." Joumal of Enwhommenal Economics and Management, 29, 133-148.

Stavins, Robert N. 2000. "Experience with Market-Based Environmental Policy Instruments," in Karl-Gonan Maler and Jeffrey Vincent eds. The Handtook of Enwironmental Economics. Amsterdam: North-Holland/Elsevier Science.

Stinson, Stephen C. 1982. "Electrolytic cell membrane development surges." Chemical and Engineering News, 22-25.

Stokes, Donald 19. 1997. Pasteur's Quadrant: Basic Science and Technological Innovation. Washington, D.C.: Brookings Institution.

Stoneman, Paul L. and Paul A. David. 1986. "Adoption Subsidies vs. Information Provision as Instruments of Technology Policy." Economic Jourmal, 96 (Supplement), 142-150.

Straasheijm, Fred G. 1999. Personal interview. Akzo Nobel, Amersfoort, September 24.

Straasheijm, Fred G. 2000: "Chlor-Alkali Plant in Rotterdam." E-mail to the author. Akzo Nobel, Amersfoort, The Netherlands, March 27.

Suckling, C. I. 1994, "Clean Synthesis," in R. C. Kirkwood and A. J. Longley eds. Clean Technology and the Environment. Glasgow: Blackie Academic \& Professional. Sugino, Tosbiyuki. 1991. "PB Repoto to Suigin-ho no Kindai-ka (PB Report and the Modernization of the Mercury Process)." Soda to Enso, (6), 10-21.

Sumitomo Chemical. 1998. "Enka Biniru Monoma Kanren Jigyo no Saikochiku ni tsuite (On the Restructuring of the Business Related to Vinyl Chloride Monomer)." Press Release. Sumitomo Chemical.

Tajima, Keizo. 1997. Personal interview. Ministry of International Trade and Industry, Tokyo, November 25 . 
Takeshita, Tetsuo. 1990. "Showa Denko Diaphragm Chlor-Alkall Technology." in.

Procedings of the 33 rd Chlorine Plant Operations Sewinat amd Workhop Seswions.

Washington, D.C.: Chlorine Institute:

Teufel, Hermann 2000. "Further question about the Chlor-Alkali plant at Gersthofen." E-mail

to the author. Plant Manager, Clariant, Gersthofen, Germany, February 2.

Third International Conference on the Protection of the North Sea. 1990. "Ministerial

Declaration." Third International Conferenee on the Protection of the North Sea, The

Hague, The Netherlands, 8 March.

Thornton, Joe. 2000. Pandora's Poison: Chlowine, Health, and a New Environmental Strategy.

Cambridge, MA: MIT Press.

Thun, Ivar. 1999. "Ad: Question about Chlorine Plant at Tofte." E-mail to the author. Head of Education and Information, Norske Skog, Tofte, Norway, November 25.

Tobey, James A. 1990. "The Effects of Domestic Environmental Policies on Patterns of

World Trade: An Empirical Test." Kyklos, 43 (2), 191-209.

Tokuyama. 2002. "Research and Development Themes and Electrolytic Plants at Tokuyana."

Tokuyama.

Tosoh. 2001. "Enkaku (Chronology)." Tosoh.

Trettin, Peter. 1997. "Asbestos - Availability \& Safety: A Supplier's Perspective." in.

Proceedings of the 40th Chlor-Alkali Plant Operations Seminar Meering. Washington.

D.C.: Chlorine Institute.

Tsubaki, Tadao and Katsuro Irukayama eds. 1977. Minamata Disease: Methylmercwy poisoning in Minamata and Nirgata, Japan. Tokyo: Kodansha.

Tsurumi Soda. 2001. "Kaisha Enkaku (Corporate Chronology)." Tsurumi Soda. 
Ukihash, H, T. Asawa, and H. Myyake. 1983. "The Progress of Membrane Technology for Chlor allkall Production," in D. S. Flett ed. Ion Exchange Membranes. Chichester: Ellis Horwood.

Gkihash, Hiroshi and Kimihiko Sato. 1986. "Operational cell technology;" in K. Wall ed. Modern Chlow-Alkall Technology, vol. 3. Chichester: Ellis Horwood.

Ulph, David: 1997. "Environmental Policy and Technological Innovation," in Carlo Carraro and Domenico Siniscalco eds. New Directions in the Economic Theory of the Environment. Cambridge, UK: Cambridge University Press.

United States Department of the Interior, Bureau of Mines. 1968. Minerals Yearbook 1967. Washington, D.C.: United States Government Printing Office.

United States Environmental Protection Agency. 2000. "Asbestos Worker Protection: Final Rule." Federal Register. 40 CFR Part 763. United States National Archives and Records Administration.

United States Environmental Protection Agency, National Center for Environmental Economics, Office of Policy, Economics, and Innovation, Office of the Administrator. 2001. "The United States Experience with Economic Incentives for Protection the Environment." Report: EPA-240-R-01-001. United States Environmental Protection Agency.

United States Tariff Commission. 1951. "Asbestos: A Summary of Information on Uses, Production, Trade, and Supply." Industrial Material Series Report. M-3. van Beers, Cees and Jeroen C. J. M. van den Bergh. 1997. "An Empirical Multi-Country Analysis of the Impact of Environmental Regulations on Foreign Trade Flows." Kyklos, $50(1), 29-46$.

Vogel, David. 1986. National Styles of Regulation: Environmental Policy in Great Britain and the United States. Ithaca: Cornell University Press. 
Vos, Ad. 1999. "FW: Question about Chlor-Alkali Plant." E-mail to the author. GE Plastics, Bergen op Zoom, The Netherlands, November 30.

Wall, K. ed. 1986. Modem Chlor-Alkali Technology, vol. 3. Chichester: Ellis Horwood.

Wallace, David. 1995. Environmental Policy and Industrial Innowation: Strategies in Europe, the US and Japaw. London: Royal Institute of International Affairs:

Warren, Kenneth. 1980. Chemical Foundations: The Alkali Industry in Britain to 1926. Oxford: Clarendon Press.

Watanabe, Chihiro. 1995. "The Feedback Loop between Technology and Economic Development: An Examination of Japanese Industry." Technological Forecasting and Social Change, 49, 127-145.

Weitzman, Martin L. 1974. "Prices vs. Quantities." Review of Economic Studies, 41 (4), 477491.

Wellington, T. C. ed. 1992. Modern Chlor-Alkali Technology, vol. 5. London: Elsevier Applied Science.

Wenders, John T. 1975. "Methods of Pollution Control and the Rate of Change in Pollution Abatement Technology." Water Resources Research, 11 (3), 393-396.

Wheeler, David. 2000. "Racing to the Bottom?: Foreign Imvestment and Air Quality in Developing Countries." Working Paper. Development Research Group, World Bank.

World Commission on Environmental and Development. 1987. Our Common Furure. Oxford: Oxford University Press.

Xing, Yuquing and Charles D. Kolstad. 1995. "Do Lax Environmental Regulations Attract Foreign Investment?" Working Paper in Economics. 6-95. Department of Economics, University of California, Santa Barbara.

Yamaguchi, Kenzo. 1999a. Personal interview. Chlorine Engineers Corp., Tokyo, December 8. 
Yamaguchi, Kenzo. 1999b. "Chlor-Alkali Electrolysis Technologies Applied in Japan." in

Electrochemical Society ed. Proceedings of the Joint International Meeting. Honolulu, Hawaii.

Yamaguchi, Kenzo and Isao Kumagai: 1990. "Development of Large Monopolar Type Membrane Electrolyzers," in N. M. Prout and J. S. Moorhouse eds. Modern ChlorAlkali Technology, vol. 4. London: Elsevier Applied Science.

Yanagioka, Hiroshi. 1993. "Kankyo Mondai ni okeru Gijutsu no Keizai-sei: Nihon-gata Taisaku ni Saiteki-ka Hyoka wo (Economics of Technologies in Environmental Issues: For Optimality Evaluation of the Japanese Countermeasures)." Kagaku Keizai, (3), $1-5$.

Yarime, Masaru. 1999. "Uncertainty and Lock-in in Technological Dynamics: Some Implications for Zero Emissions," in K. Iiyama J. Gravitis and A. Sakoda eds. Targeting Zero Enissions for the Utilization of Renewable Resources (Biorefinery, Chemical Risk Reduction, Lignocellulosics Economy). Tokyo: Asian Natural Environmental Sciences Center, University of Tokyo.

Yelle, Louis E. 1979. "The Learning Curve: Historical Review and Comprehensive Survey." Decision Sciences, 10, 302-328.

Yomiyama, Akira. 1982. "On the Current Situation of the Technological Development of lon Exchange Membrane Process for Brine Electrolysis of Asahi Chemical." in. Proceedings of the 8th Seminar on the Current Situation of the lon Exchange Membrane Process. Tokyo: Association for the Promotion of Installations of the Diaphragm Process Facilities.

Zerbe, Richard O. 1970. "Theoretical Efficiency in Pollution Control." Western Economic Jourvial, 8, 364-376. 
Zirmmermann, Albert. 2000. "Your e-mail from 6.3.2000." E-mail to the author, EL-PR, Krupp-Uhde, Dortmund, Germany, March 30. 


\section{Samenvatting}

Dit proefschrift gaat over de invloed van milieureguleringen op technologische verandering in de chloor-en alkali-industrie in Japan en West-Europa.

In hoofdstuk 2 wordt een overzichr gegeven wan eerder uitgevoerd theoretisch en empirisch onderzoek natar de effecten van milieureguleringen op technologische verandering. De kritiek in dit proefschrift spitst zich toe op de manier waarop deze studies technologische verandering behandelen waar het gaat om het terugdringen van milieuvervuiling. Bij de analyse van de teclmologische invloed van milieuregulereingen werd in eerdere publicaties onder andere onvoldoende aandacht besteed aan een cruciaal onderscheid tussen end-of-pipe technologieën en schone technologieën. De meeste theoretische modellen gaan uit van technologieën die zijn gericht op incrementele emissievermindering bij stijgende kosten van marginale vervuilingsbestrijding. Effectief betekent dit dat de technologieën die in de modellen worden gebruikt, eigenlijk end-of-pipe technologieèn zijn. Anderzijds is in vrijwel geen enkele studie alandacht besteed aan de mogelijkheid om emissies tegen te gaan vanuit het productieproces door het gebruik van schone technologieën. Bij het gebruik van schone technologieën komen geen emissies vrij. De marginale analyse van de kostencurve van vervuilingsbestrijding, die veelvuldig wordt toegepast in theoretische modellen, is daarom ongeschikt als we uitgaan van het bestaan van schone technologieën.

Ook hebben de meeste empirische studies geen aandacht besteed aan het onderscheid tussen de verschillende soorten technologieën bij het bestuderen van de effecten van milieureguleringen op technologische verandering. Een groot aantal van deze studies kijken naar patenten als indicator van innovaties op een hoog aggregatieniveau en zijn dan ook vooral gericht op end-of-pipe technologieün, zoals emissiebehandelingstechnieken en filters, of op alle soorten innovaties die de onderzoekers waren tegengekomen. Zonder gedetailleerde informatie over specifieke productieprocessen is het namelijk erg moeilijk om een duidelijk beeld te krijgen van de verscheidenheid aan schone technologieën. Door schone technologieën buiten beschouwing te laten, wordt de verscheidenheid aan technologische veranderingen t.b.v. vervuilingsbestrijding te sterk beperkt tot de groep van end-of-pipe technologieën. Aan de andere kant zal, als we alle soorten innovaties in aanmerking nemen, de groep ook technologieën onvatten die weinig te maken hebben met ecologische aspecten en te breed zijn om te kumnen worden aangeduid als 'groene' innovaties. Naar onze mening is 
een gedetailleerde studie van de aard en het karakter van tochnologiekn belangrijk voor een. gedegen analyse van groene immovatie.

Daarna tonen we aan dat er in principe twee somten technologie ziju voor de vermindering van emissies als gevolg van bedrijfsactivitedten: end-of-pipe techologiedn en schone technologieën. End-of-pipe technologieën zijn gericht op emissiereductie aan het eind van de productiefaciliteiten, en hebben geen invloed op de reacties waarbij het hoofdprodukt wordt geproduceerd. Bij schone technologieèn worden de belangrifkste procesteacties vervangen door andere reacties, en worden ongewenste bijprodukten die vrijkomen tijdens het productieproces, op effectieve wijze teniet gedaan. In het verleden zin veelal end-of-pipe technologieën ontwikkeld om emissies van industriële processen te redweeren. Deze technologieën behandelen milieuverontreinigende stoffen aan het eind van de emissiepijp zonder het productieproces te beïnloeden, en zijn relatief eenvoudig te installeren en te gebruiken; er zijn dan ook vele soorten end-of-pipe technologieën in de industrie. End-of-pipe technologieën maken de productie duurder vanwege de extra kosten die nodig zijn on ze te installeren aan het eind van de productiefaciliteiten. Dit in tegenstelling tot schone technologieën, die de vorming van milieuverontreinigende stoffen vanaf het begin voorkomen door alle faciliteiten te veranderen en zo het productieproces kunnen verbeteren en op termin de productiekosten kunnen verlagen.

In het analytisch raamwerk dat wij hebben ontwikkeld om de effecten van milieureguleringen op technologische veranderen te bestuderen, wordt dit onderscheid tussen end-of-pipe en schone technologie wel gemaakt. Op basis van onze bevindingen stellen wij dat verschillende millieureguleringen kunnen leiden tot uiteenlopende soorten technologische verandering. Bij relatief soepele milieureguleringen zullen bedrijven sneller overgaan op endof-pipe technologieën, die - aanvankelijk althans - waarschijnlijk minder duur zullen uitvallen dan schone technologieën. Dit zal weer leiden tot meer investeringen in de bestaande productietechnologie, waarbij de emissies naar verwachting worden gereduceerd door de installatie van end-of-pipe technologieën. Bedrijven zullen hierdoor niet snel overgaan op schone technologieën, zelfs wanneer later blijk dat schone technologieẻn efficiënter zijn in de productie; bedrijven zullen geneigd zijn deze bestaande fabrieken te laten voortbestaan tot het eind van hun levensduur temzij de schone technologieën extreem efficiënt blijken te zijn.

Anderzijds kunnen bedrijven niet voldoen aam strenge reguleringen door uitsluitend end-of-pipe technologieën te installeren. Ze zullen dus bestaande productietechnologieën 
moeten vervangen on investeren in R\&D $1,6 . \%$. innovaties gerich op schone technologieen. Hoewel er doorgaans diverse schone technologieën voorhanden zïn, zullen bedrijven bij strenge regels waraan ze op korte termijn moeten voldoen, echter worden 'gedwongen' vroegtijdig beslissingen te nemen over alternatieve technologieèn, die op de langere termign misschien niet de meest geschikte blijken te zijn. Het wervangen van deze technologieèn door een betere technologie later betekent extra kosten.

We gebruiken dit analytische ramwerk in onze empirische studie van de chlooralkaliindustrie. In hoofdstuk 3 gaan we meer dan honderd jaar terug in de geschiedenis van de technologische evolutie in de chloor-en alkali-industrie. Sinds het begin van de negentiende eeuw hebben zich bij de productietechnologieèn die werden gebruikt in de chloor- en alkaliindustrie en aantal grote innovaties voorgedaan in de vorm van chemische en electrolytische processen. Wat betreft de laatste zien we dat aan het begin van de jaren zeventig de kwiktechnologie het meest werd gebruikt in West-Europa en Japan, voordat hier voor het eerst sprake was van milieureguleringen voor kwikemissies. Diverse bedrijven in WestEuropa en Japan hadden hoogwaardige technologieën ontwikkeld voor deze kwiktechnologie, die in de meeste chloor-alkali-fabrieken werd gebruikt. In beide gebieden waren dus bedrijven actief die vóor de introductie van milieureguleringen even innovatief waren wat betreft chloor-alkali productietechnologieën. Dit wijst erop dat de technologische omstandigheden in deze industrie in West-Europa en Japan, aanvankelijk vergelijkbaar waren.

Sinds de milieureguleringen voor het verminderen van kwikemissies afkomstig van chlloor-alkali-fabrieken in het begin wan de jaren zeventig lopen de technologische veranderingspaden in Japan en West-Europa echter uiteen. In de overige hoofdstukken van dit proefschrift zien we hoe een verschillend milieubeleid heef bijgedragen tot de verschillende technologische situaties in de twee gebieden. In hoofstuk 4 kijken we naar Japan, waar de regering de chloor- en alkali-industrie via strikte regelgeving dwong over te schakelen op andere processen, waandoor innovatieve bedrijven werden aangespoord alternatieve schone technologieèn te ontwikkelen. Deze strenge regelgeving, aanvankelijk vastgelegd in een strak tijdsschema, leidde ertoe dat een groot aantal producenten van chloor-alkali overging op het diafragmaproces, dat in die tijd relatief goed bleek te functioneren vergeleken met het ionwisselingsmembraanproces, dat toen nog in de kinderschoenen stond. Later bleek het diafragmaproces echter een zeer inefficiënte technologie, minder efficiënt dan het membraanproces dat in rap tempo werd verbeterd. Op basis van nieuwe informatie over deze technologische ontwikkelingen vanuit de industrie onderbraken de Japanse autoriteiten 
tijdelijk de implementatio van de oorspronkelijke regulering in afwachting van vordere ontwikkelingen in het membraanproces. Na een evaluatie door experts van de halbaameid van thet membraanproces in de industrie werd bedrijwen meer tijd gegeven hun processen ahn te passen. Door deze wijziging in de regelgeving kregen de overgebleven kwikprocesfabrieken de gelegenheid direct over te schakelen op het nembraanproces, die zich sindsdien zowel economisch als ecologisch heeft ontwikkeld tot de beste technologie. De kwikprocesfitbrieken die eerder waren overgegaan op het diafragmaproces, moesten echter weer overschakelen op het membraanproces. Dit leidde tot aanzienlijke investeringen in fabrieken waarbij bestaande processen ruim voor het einde van hun eigenlijke levensduur buiten werking warden gesteld.

In hoofdstuk 5 komen de technologische veranderingen in de chloor- en alkall-industrie in West-Europa aan de orde. Hier werden minder strenge reguleringen in de vorm van emissiestandaarden opgelegd aan chloor-alkali fabrieken die hun kwikemissies moesten verminderen. De meeste bedrijven in deze industrie kozen voor end-of-pipe technologieën, die veel goedkoper waren en meer zekerheid boden dan nieuwe, kostbare schone technologieën waarvan het effect niet duidelijk was. Het grotendeel van de kwikprocesbedrijven ging over op de ontwikkeling en installatie van end-of-pipe technologieèn teneinde te voldoen aan de regels voor de reductie van kwikemissies. Er werden veel chloor-alkalifabrieken gebouwd die functioneerden op basis van kwikprocessen en waren uitgerust met end-of-pipe technologieèn om vervuiling tegen $t e$ gaan. Deze fabrieken hebben het eind van hum fysieke levensduur, die normaal gesproken zo'n 40 jaar of langer is, nog niet bereikt. Daarom zijn de chloor-alkali producenten in WestEuropa ook nu nog sterk geneigd deze kwikfabricken te blijuen gebruiken, hoewel het membraanproces de meost efficięnte productietechnologie is gebleken en in andere landen wordt toegepast, ook in veel industrialiserende landen. Kortom, de betrekkelijk soepele milieureguleringen in WestEuropa hebben geleid tot aanzienlijke vooruitgang in end-of-pipe technologieèn om kwikemissies te reduceren, maar hebben ook de ontwikkeling van het membraanproces ontmoedigd, een voorbeeld bij uitstek van een schone technologie, ook al waren er een aantal innovatieve bedrijven die zich richtten op chloor-alkali productietechnologieèn. Omdat veel chloor-alkali fabrieken, uitgerust met end-of-pipe technologieèn om kwikemissies te reduceren, het kwikproces zijn blijven gebruiken, is de diffusie van het efficiënte membraanproces langzaam en beperkt geweest. 
Tenslotte worden in hoofdstuk 6 een samenvating en de conclusies van ons onderzoek gepresenteerd. Relatief soepele milieureguleringen gericht op betere vervulingsbestrijding van industriele activiteiten, bevorderen innovaties van end-of-pipe technologieen. In feite zou dit de levensduur wan bestaande, acherhaalde productieprocessen kunnen verlengen. Strenge regelgeving bevordert weliswaar innovatieve activiteiten ten behoeve van schone technologieèn maar kimnen tevens leiden tot een vroegtijdig keuze voor ongeschikte technologieèn. Alleen wanneer in geval van strenge regelgeving de implementatietijd flexibel wordt gehanteerd en numte wordt geboden voor technologisehe experimenten, kunnen bedrijwen op efficiënte wijze schone technologieën ontwikkelen en breed toepassen. Op basis van onze bewinding m.b.t. de uiteenlopende effecten van milieureguleringen op technologische verandering gaat dit proefschrift ook in op implicaties voor bedrijfsstrategieën, besluityorming, en beleidsarrangementen die bedrijven helpen over te schakelen van end-ofpipe op schone technologieẽn. 


\section{Curriculum Vitae}

Masara Yarime was born in Akita, Japan on 3 October 1969. He received his Bachelor of Science in Chemical Engineering from the University of Tokyo, Tokyo, Japan in 1993 and Master of Science in Chemical Engineering from the California Institute of Technology, Pasadena, California, the United States in 1995. He is currently a Research Associate of the Research Center for Advanced Economic Engineering of the University of Tokyo. His research interests include Economics of Technological Change, Environmental Economics, Science and Technology Policy, and University-Industry Collaboration. 